\title{
Technologies to Enhance Operation of the Existing Natural Gas Compression Infrastructure
}

\author{
Topical Report \\ Reporting Period Start Date: 10/01/02 \\ Reporting Period End Date: 06/30/04
}

\author{
Principal Authors: \\ Anthony J. Smalley \\ Ralph E. Harris \\ Gary D. Bourn
}

August 2004

DOE Award No. DE-FC26-02NT41646

SwRI Project No. 18.06223

Submitting Organization:

Southwest Research Institute ${ }^{\circledR}$

6220 Culebra Road

San Antonio, TX 78238-5166 


\title{
Technologies to Enhance Operation of the Existing Natural Gas Compression Infrastructure
}

\author{
Topical Report \\ Reporting Period Start Oate: 1000102 \\ Reporing Period End Date: 06raol
}

Primcipal Authors:

Arthony S. Smalley

Raiph E. Marti:

cary D. 8oury

August 2004

DOE Award No. DE-FC26-02NT4 646 SwRI Project No. 18.06223

Submitting Organization:

Southwest Research institute:

6220 CHobra Road

San Antonio, TX 78238.\$166

Aprover:

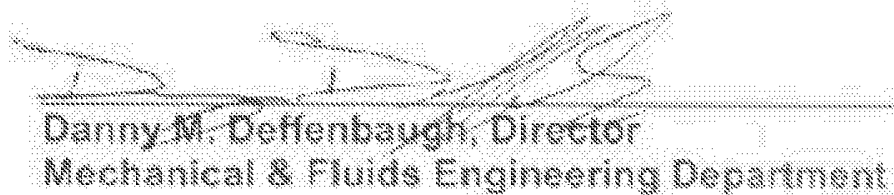




\section{DISCLAIMER}

"This report was prepared as an account of work sponsored by an agency of the United States Government. Neither the United States Government nor any agency thereof, nor any of their employees, makes an warranty, express or implied, or assumes any legal liability or responsibility for the accuracy, completeness, or usefulness of any information, apparatus, product, or process disclosed, or represents that its use would not infringe privately owned rights. Reference herein to any specific commercial product, process, or service by trade name, trademark, manufacturer, or otherwise does not necessarily constitute or imply its endorsement, recommendation, or favoring by the United States Government or any agency thereof. The views and opinions of authors expressed herein do not necessarily state or reflect those of the United States Government or any agency thereof." 


\section{ABSTRACT}

This report documents work performed in Phase I of the project entitled: Technologies to Enhance Operation of the Existing Natural Gas Compression Infrastructure. The project objective is to develop and substantiate methods for operating integral engine/compressors in gas pipeline service, which reduce fuel consumption, increase capacity, and enhance mechanical integrity. The report describes a number of potential enhancements to the existing natural gas compression infrastructure that have been identified and tested on four different integral engine/compressors in natural gas transmission service. 


\section{TABLE OF CONTENTS}

Page

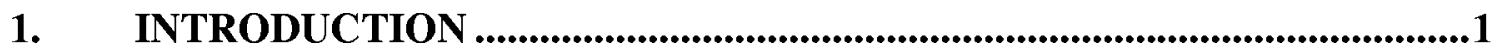

2. EXECUTIVE SUMMARY.......................................................................................8

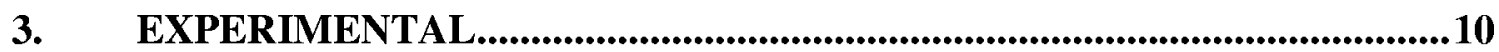

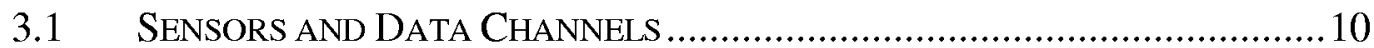

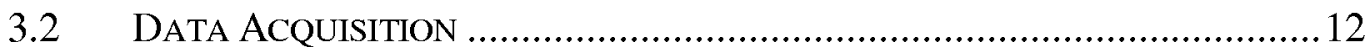

3.3 TRANSDUCER INSTALLATION ………………....................................14

$3.4 \quad$ SELECTION OF TEST ENGINE MODELS.......................................................23

4. RESULTS AND DISCUSSION: FIRST TEST ON AN HBA-6T .................25

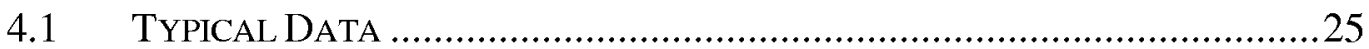

4.2 SUPPLEMENTARY ANALYSIS OF DATA FROM HBA-6T, TEST \#1 .................31

4.2.1 Relating Crankshaft Strain Characteristics to Life.......................31

4.2.2 Relating Crankshaft Integrity to Combustion Balance..................33

4.2.3 Relating Operational Severity to Torsional and Lateral

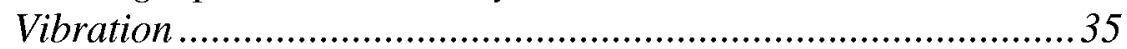

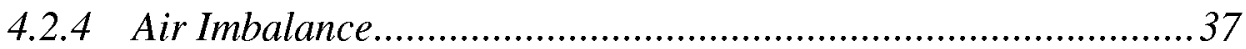

4.2.5 Relating Air Imbalance to Manifold Flow Dynamics....................39

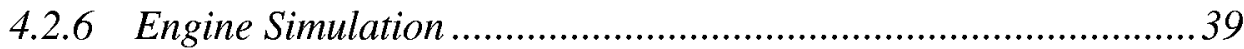

4.2.7 Using the Engine Simulation Model to Relate Combustion Balancing to Engine Performance with Air Imbalance.................41

4.2.8 Relating Combustion Balancing to Trapped Air Fuel Ratio ........43

4.2.9 Relating System Mechanical Efficiency to Oil Temperature

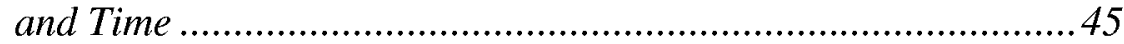

4.2.10 Relating Engine-Compressor Efficiency Definitions to each Other and to the Data from the First HBA-6T Test .....................49

4.2.11 Relating DIP-Based Efficiency to Enthalpy-Based

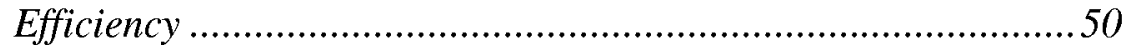

4.2.12 Relating Performance to Timing...............................................51

4.2.13 Relating Compressor Efficiency to Available Industry

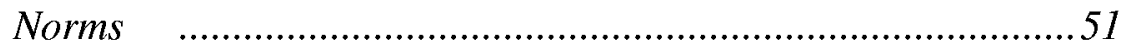

4.2.14 Variation of Equivalence Ratio..................................................52

5. RESULTS AND DISCUSSION: TEST ON A GMW10 MODIFIED FOR HIGH-PRESSURE FUEL AND TURBOCHARGER ............................54

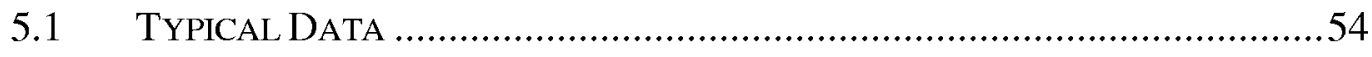




\section{TABLE OF CONTENTS (CONT'D)}

Page

5.2 SUPPLEMENTARY ANALYSIS OF DATA FROM GMW10 TEST $1 \ldots \ldots \ldots \ldots \ldots \ldots . . .74$

5.2.1 Relating Heat Rate, Efficiency, and NOx Emissions to Timing and Air Manifold Pressure .............................................. 74

5.2.2 Relating Rod Load Monitor Output to Cylinder-Indicated

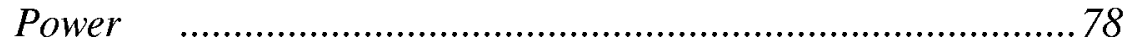

5.2.3 Influence of Load and Load Step (Williams Station 40)..............81

6. RESULTS AND DISCUSSION: SECOND TEST ON A GMW10...............86

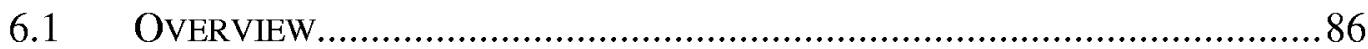

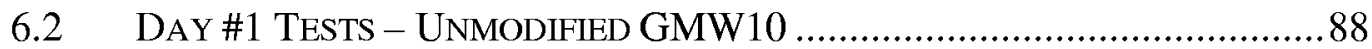

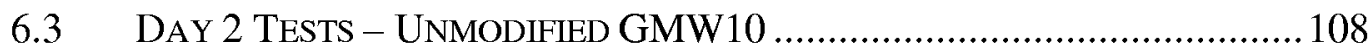

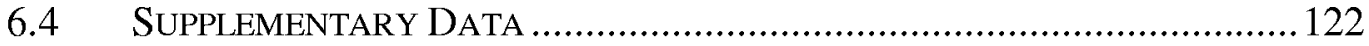

6.4.1 Emission Equivalence Ratio and Normalized NOx

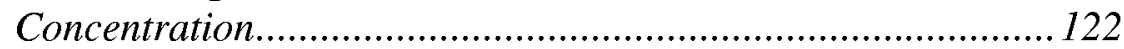

6.4.2 Air Manifold Pressure ........................................................... 123

6.4.3 Knock Detection ..................................................................... 124

6.4.4 Comparison of Indicated Power and Station Power.................. 125

6.4.5 Performance Summary ......................................................... 126

6.4.6 Comparison of Pressures and Strains ..................................... 128

7. RESULTS AND DISCUSSION: SECOND TEST OF HBA-6T ..................129

7.1 INSTALLATION PHOTOGRAPHS.............................................................. 129

7.2 DATA From PERMANENTLY INSTALLED STATION INSTRUMENTS -

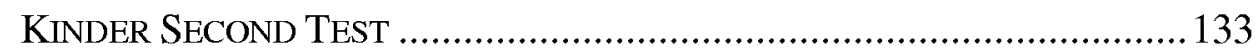

7.3 DATA FROM TEMPORARILY INSTALLED TEST INSTRUMENTATION -

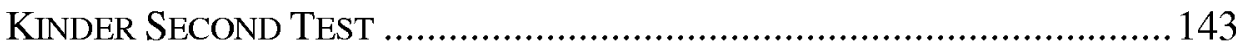

7.4 Data From the StRain Data CAPTURE Module (SDCM) -

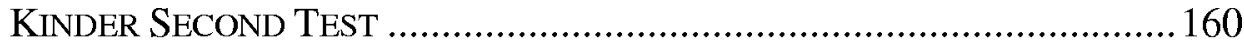

7.5 HeAt RATE SUMMARIES - KINDER SECOND TEST...................................166

7.6 ANALYsis OF Heat Rate as a FunCtION OF LOAD - Kinder

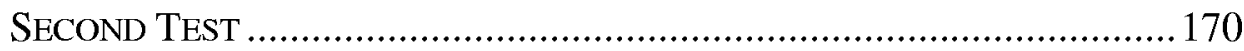

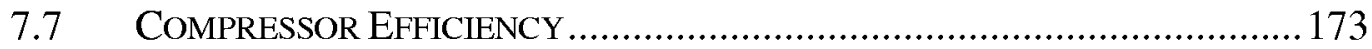

7.8 Rod LOAd MONITOR EVALUATION - KINDER SECOND TEST ...................175

7.9 EQUIVALENCE RATIO CONTROL EVALUATION ........................................178

7.10 KNOCK DETECTION - KINDER SECOND TEST ........................................180

7.11 POTENTIAL INTEGRITY INDICATORS BASED ON INSTANTANEOUS Rotational Velocity - Kinder SECOND TeST ...................................182

7.12 SYSTEM AND COMPONENT THERMAL EFFICIENCY DISPLAY -

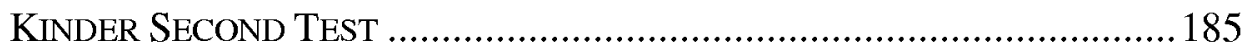

7.13 REFINEMENT AND DEMONSTRATION OF COMBUSTION PRESSURE RATIO BALANCING - KindER SECOND TEST. 


\section{TABLE OF CONTENTS (CONT'D)}

\section{Page}

7.14 COMPARISON OF STATION BHP TO BHP FROM CYLINDER

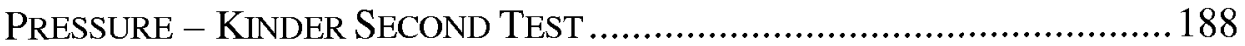

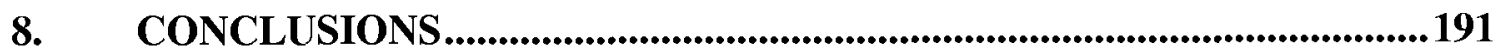

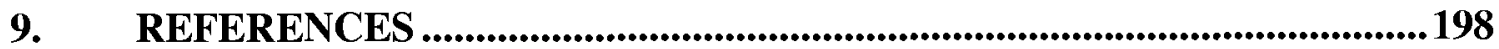

10. LIST OF ACRONYMS AND ABBREVIATIONS.....................................199 


\section{LIST OF FIGURES}

Page

Figure 1-1. TLA6 (2000 HP) AND GMW10 (2500 HP) IN PiPELINE

SERVICE 1

Figure 1-2. Install Dates: OVer 50\% OF Pipeline COMPRESSORS

EXCEED 40 YEARS OLD 2

Figure 1-3. Industry Fuel CONSUMPTION ( 7.7 MCF/HP-Hr. +/-20\% -

NEED TO LOWER THE High VALUES)..................................................... 3

FigURE 1-4. COMPRESSOR THERMAL EFFICIENCY HISTOGRAM BASED ON

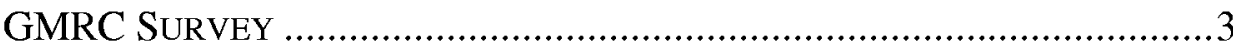

Figure 1-5. InTEGRITY: CRANKSHAFt FaILURE EXAMPLeS - NEED

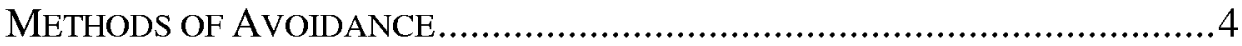

Figure 1-6. AgE (1000 Hours) Histogram OF CRANKSHAFt FAILURES

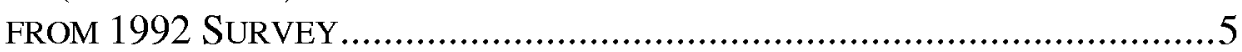

FiguRE 3-1. FRONT VIEW OF DATA ACQUISITION SYSTEM (DAS) .................................... 13

Figure 3-2. REAR VIEW OF DATA ACQUISITION SYSTEM (DAS) ................................... 13

Figure 3-3. COMPRESSOR CYLINDER AND PRESSURE TRANSDUCERS ON EaCH END (Williams Station 40; August 2003) ................................14

Figure 3-4. Details of PoWer Cylinder Pressure Transducer

INSTALLATION (WILLIAMS STATION 40; AUGUST 2003) ...........................15

Figure 3-5. Initial Site Test (HBA-6T; TGP Kinder Station; APRIL 2003)

Figure 3-6. Pressure Transducer in Air InTAKe Manifold (GMW10;

WiLliaMs SOUR LAKE STATION; AUGUST 2003) .....................................16

Figure 3-7. Pressure Transducer in Exhaust Manifold (GMW10;

WiLLIAMS SOUR LAKE Station; AUgUST 2003) .....................................16

FiguRE 3-8. ENCODER, OUTBOARD OF FLYWHEEL ON MOUNTING TRIPOD

(GMW10; Williams Sour LaKe Station; August 2003) ....................17

Figure 3-9. DETAILED VIEW OF ENCODER AND CONNECTION TO

FLYWHEEL (GMW10; WILLIAMS SOUR LAKE STATION;

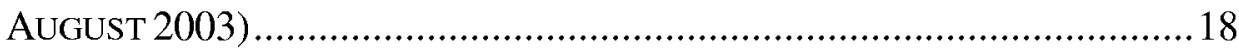

Figure 3-10. Accelerometer Mounted on Frame (GMW10;

Williams Sour Lake Station; August 2003) ..................................... 18

Figure 3-11. Strain Data Capture Module InStalled (GMW10;

Williams' STATION 40 (SouR LAKe); August 2003) ............................19

FiguRE 3-12. SDCM INSTALLATION FOR CRANKSHAFT STRAIN

MEASUREMENTS (HBA-6T; El Paso Kinder STATION;

APRIL 2003)

Figure 3-13. $\mathrm{O}_{2}$ /NOX SENSOR AND CONNECTION TO LiNE FROM STACK

(GMW10; Williams Sour LaKe Station; August 2003) .....................20

FigURE 3-14. INSTALLATIONS OF THE RLM ON HBA-6T (APRIL 2003)

AND GMW10 (AUGUST 2003) 21 


\section{LIST OF FIGURES (CONT'D)}

Page

Figure 3-15. CABLE From RLM ANTENNA (GMW10; Williams Sour

LaKe Station; August 2003) 21

FIGURE 3-16. SELF-POWERED ROD LOAD MONITOR (RLM).

Figure 3-17. FuEl Flow MEASUREMENT USING EMERSON Flobas 103

TRANSMITTER (HBA-6T; El PASO KINDER STATION; APRIL 2004) .23

Figure 4-1. Typical Data SETs; HBA-6T; Test \#1 (El Paso Station

823 (KINDER); APRIL 2003).

FIgURE 4-2. TYPICAL AMP AND IRV DATA SETS; HBA-6T; TEST \#1 (EL

PASO STATION 823 (KINDER); APRIL 2003) .26

FIGURE 4-3. AMP VARIATION SUMMARY; HBA-6T; TEST \#1 (El PASO

STATION 823 (KINDER); APRIL 2003).

Figure 4-4. COMPRESSOR PERFormance Data; HBA-6T; TeST \#1

(HEAD AND CRANK END DIP); (EL PASO STATION 823

(KINDER); APRIL 2003).

FIGURE 4-5. COMPRESSOR EFFICIENCY DATA; HBA-6T; TEST \#1; (EL

PASO STATION 823 (KINDER); APRIL 2003).

FIGURE 4-6. TYPICAL SDCM WAVEFORM; HBA-6T; TEST \#1; (EL PASO

STATION 823 (KINDER); APRIL 2003).

Figure 4-7. Overall PeaK-To-Peak Strain Summary; HBA-6T; Test

\#1 (El PASO STATION 823 (KINDER); APRIL 2003).

Figure 4-8. RASTER Plots of SDCM DATA; HBA-6T; Test\#1; (EL

PASO STATION 823 (KINDER); APRIL 2003).

Figure 4-9. ORdER SUMMARY OF SDCM DATA; HBA-6T; TEST \#1; (EL

PASO STATION 823 (KINDER); APRIL 2003).

Figure 4-10. SAMPLE Histogram OF StREss ReVERsals (2-SECOND

INTERVAL); (El PASO STATION 823 (KINDER); APRIL 2003).

Figure 4-11. Comparative Life Estimate; HBA-6T; Test \#1; (El Paso

STATION 823 (KINDER); APRIL 2003).

Figure 4-12. Unit PeAK-FIRING SPREAd Test Characteristics; HBA-

6T; Test \#1; (El Paso Station 823 (Kinder); April

2003)

FIGURE 4-13. COMPARISON OF KEY PFP STATISTICS (INSTANTANEOUS

SPEED - AVERAGE SPREAD); AND TIME FROM LAST 70+

Microstrain EVEnT; HBA-6T; TEST \#1; (El PASO

STATION 823 (KINDER); APRIL 2003).

Figure 4-14. Vibration BeARING CENTERLine (Throw 1); (El PASO

STATION 823 (KINDER); APRIL 2003). .35

FIGURE 4-15. VIBRATION BEARING CENTERLINE (THROW 6); HBA-6T;

Test \#1; (El Paso Station 823 (Kinder); APRIL 2003). 36

Figure 4-16. Summary Crankshaft Rotational Velocity; (El Paso

STATION 823 (KINDER); APRIL 2003) .............................................. 37

Topical Report

(Reporting Period 01/01/04 - 06/30/04)

DOE Award No. DE-FC26-02NT41646 - SwRI Project 18.06223 


\section{LIST OF FIGURES (CONT'D)}

Page

Figure 4-17. Sample HBA-6T Cylinder Pressure Data; (El Paso

STATION 823 (KINDER); APRIL 2003) ..................................................

Figure 4-18. HBA-6T Test Data, Cylinder Pressure 20 DegreEs

BEFORE TDC (COMPRESSION PRESSURE); (EL PASO

STATION 823 (KINDER); APRIL 2003)

Figure 4-19. Unbalanced Engine Simulation - SPREAd in

COMPRESSION PRESSURE INDUCED BY EVEN INCREMENT

SPREAD IN AMP - 15\% RANDOM SPREAD IN A/F RATIO

Figure 4-20. Predicted Cylinder PRESSURes - Simulation with

EVENLY DISTRIBUTED VARIATION OF AIR MANIFOLD

PRESSURE.

Figure 4-21. PREDicted VARIATION OF A/F Ratio aCROSS CYLINDERS

to Achieve Balanced Peak-Firing Pressure with

SPREAD IN COMPRESSION PRESSURE

Figure 4-22. Typical Lean-Burn Spark-Ignited Gas Engine

OPERATING BOUNDARIES.

Figure 4-23. Engine Simulation - Pressures for Constant

EQUIVALENCE RATIO WITH SPREAD IN COMPRESSION

PRESSURE.

Figure 4-24. Ratio of PFP to COMPRESSION PRESSURE FOR THREE

DiFFERENT BALANCING SITUATIONS

Figure 4-25. ENGine HP, COMPRESSOR HP, AND INFERRED MECHANICAL

EFFICIENCY; (El Paso Station 823 (Kinder); Test 1;

APRIL 2003) 46

Figure 4-26. BTU/HP-Hr. DATA From Station ReCORDS; (El PASo

STATION 823 (KINDER); TEST 1; APRIL 2003) ......................................4 4

Figure 4-27. HBA8 SuMP TEMPERATURE DATA (1984) 48

Figure 4-28. Oil OUtLET TeMPERATURE VERSUS TIME FROM STATION

RECORDS (NOTE INCREASE OVER 5 HOURS MATCHES

MECHANICAL EFFiCIENCY TREND); (El PASO STATION 823

(KINDER); TEST 1; APRIL 2003) .48

Figure 4-29. COMPRESSOR PERFORMANCE DATA FOR DIPs (HBA-6T);

(El Paso STATION 823 (Kinder); Test 1; APRIL 2003).

FIGURE 4-30. COMPRESSOR EFFICIENCY VERSUS INDUSTRY DISTRIBUTION ....................52

Figure 4-31. Kinder TeSt 1, APRIL 2003 - VARIATION IN EQUIVALENCE

RATIO. 53

Figure 5-1. Williams SOUR LaKe STATION; Unit 6; AUguST 2003 ............................54

Figure 5-2. Power Cylinder, LefT BanK; (Williams Station 40

(SOUR LAKE); AUGUST 2004) ............................................................55

Figure 5-3. SNAPShot OF ON-Site Real-Time Calculations;

(Williams STATION 40 (SOUR LaKe); August 2004) .56 


\section{LIST OF FIGURES (CONT'D)}

Page

Figure 5-4. TyPiCAL POWER Cylinder Pressure Data; (Williams

STATION 40 (SOUR LAKE); AUGUST 2004) .........................................57

FIGURE 5-5. TYPICAL COMPRESSOR CYLINDER PRESSURE DATA;

(Williams STATION 40 (SOUR LAKE); AUgust 2004) .......................58

FIGURE 5-6. TyPICAL INLET MANIFOLD PRESSURE TRACE AND ORDER

SPECTRum; (Williams STATion 40 (SOUR LAKE); August

2004)

Figure 5-7. EXHAUST MANIFOLd PRESSURE TRACE AND ORDER

SPECTRUM; (Williams StaTion 40 (SOUR LAKE); AUgust

2004)

FIGURE 5-8. VARIATION IN INLET AND EXHAUST PRESSURES AT POINT OF

MEAsurement; (Williams Station 40 (SOUR LaKe);

AuguST 2004).

FIGURE 5-9. TyPICAL ROD LOAD VARIATION OVER ONE REVOLUTION;

(Williams Station 40 (SOUR LaKe); August 2004) ........................62

Figure 5-10. INDICATED HP OVER TEST DAY; (WILLIAMS STATION 40

(SOUR LAKE); AUGUST 2004)

FIGURE 5-11. RATIO OF INDICATED COMPRESSOR HP TO ENGINE HP

DURING TEST DAY; (Williams STATION 40 (SOUR LAKE);

AugusT 2004).

FIgure 5-12. POWER Cylinder COMPRESSION PRESSURE; (WILliaMs

Station 40 (Sour LaKe); August 2004)

Figure 5-13. COMPRESSOR EFFICIENCY; (Williams Station 40 (SOUR

LAKE); AUGUST 2004).

Figure 5-14. TyPICAL WAVEFORM (PC34); (Williams Station 40

(SOUR LAKE); AUGUST 2004)

Figure 5-15. PEAK-TO-PEAK VARIATION IN CRANKSHAFT WEB BENDing

STREAM (PC34); (Williams STATION 40 (SOUR LAKE);

August 2004).

Figure 5-16. TyPICAL 20 SuCCESSIVE CYCleS - PoWER CyLINDER \#2;

(Williams Station 40 (Sour Lake); August 2004).... .68

Figure 5-17. Average Standard Deviation in Peak-Firing Pressure

over Time; (Williams Station 40 (SOUR Lake); AUgust

2004) .68

Figure 5-18. Engine Fuel Flow; (Williams Station 40 (Sour LaKe);

August 2004).

FIguRE 5-19. NORMALIZED NOX CONCENTRATION AND EQUIVALENCE

Ratio; (Williams Station 40 (SOUR LaKe); August

2004) .70

Figure 5-20. ENGine PFP SPREAd; (Williams Station 40 (SOUR LAKE);

AUGUST 2004). 71

Topical Report

(Reporting Period 01/01/04 - 06/30/04)

DOE Award No. DE-FC26-02NT41646 - SwRI Project 18.06223 


\section{LIST OF FIGURES (CONT'D)}

Page

Figure 5-21. CPR BALANCING FEASIBILITy DEMONSTRATION; (WILliams

STATION 40 (SOUR LAKE); AUGUST 2004) ..........................................72

FIGURE 5-22. RATIO OF PFP TO COMPRESSION PRESSURE - AVERAGE AND

COV; (Williams Station 40 (Sour LaKe); August

2004)

Figure 5-23. System Performance; (Williams Station 40 (SOUR

LAKE); AUgusT 2004).

Figure 5-24. HEAT RATE AND SYSTEM EFFICIENCY AS A FUNCTION OF

TIMING (USE FOR RELATIVE ANALYSIS ONLY); (WILLIAMS

STATION 40 (SOUR LAKE); AUGUST 2004)...

Figure 5-25. HEAT RATE AND SySTEM EFFICIENCY AS A FunCTION OF AIR

MANifOLd PRESSURE; (Williams Station 40 (SOUR

LAKE); AUGUST 2004).

Figure 5-26. Change in NOX as a Function of Timing; (Williams

Station 40 (Sour LaKe); August 2004) .76

Figure 5-27. Change in NOX as a FunCtion OF Air MANifOld

Pressure; (Williams Station 40 (SOUR LAKE); August

2004)

Figure 5-28. TRADE-OFF BETWEEN HEAd RATE AND NOX (RELATIVE

ANALYSIS ONLY); (WiLliams STATION 40 (SOUR LAKE);

AugusT 2004).

Figure 5-29. Post Test RLM TEMPERATURE SENSITIVITY

MEASUREMENTS WITH SUBSEQUENTLY REPLACED

COMPONENT .78

FIGURE 5-30. VARIATION OF OIL INLET AND OUTLET TEMPERATURES;

(Williams Station 40 (SOUR LAKE); August 2004). .79

FIgURE 5-31. COMPRESSOR IHP AND RLM HP; (WILlIAMS STATION 40

(SOUR LAKE); AUGUST 2004)

FIGURE 5-32. RESIDUAL RATIO COMPRESSOR IHP TO RLM HP;

(Williams Station 40 (SOUR LAKE); AUgust 2004)

Figure 5-33. VARiation in Power during Second Day's Testing;

(Williams Station 40 (SOUR LAKE); AUgust 2004) .

FIGURE 5-34. COMPRESSION PRESSURE FOR 10 POWER CYLINDERS DURING

SECOND DAY's TESTING; (WILLIAMS STATION 40 (SOUR

LAKE); AUGUST 2004).

Figure 5-35. Compression Pressure Relative to Cylinder \#1 FOR

SECOND DAY's TESTING; (Williams STATION 40 (SouR

LAKE); AUGUST 2004).

FIGURE 5-36. CYLINDER INDICATED HP AND RATIO OF IHP TO ROD LOAD

HP (WITHOUT TEMPERATURE CORRECTION); (WILLIAMS

Station 40 (SOUR LaKe); August 2004) .85 


\section{LIST OF FIGURES (CONT'D)}

Page

Figure 6-1. GMW10 COMPRESSOR CyLINDERS WITH PRESSURE

TRANSDUCER INSTALLED (WILLIAMS STATION 60;

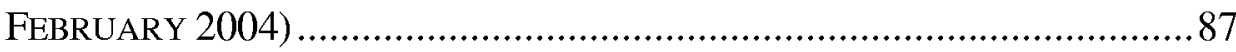

Figure 6-2. GMW10 POWER CYLINDER WITH PRESSURE TRANSDUCERS

INSTALLED (WILLIAMS STATION 60; FEBRUARY 2004)

Figure 6-3. Strain Data Capture Module and Combined Power and

COMPRESSOR THROW (Williams STATION 60; FEBRUARY

2004)

Figure 6-4. SPEEd IN RPM Throughout TeSt PROGRAM From 10.08

THROUGH 15.14, FEBRUARY 25, 2004; DAY 1; WILLIAMS

STATION 60 (LOSS IN SPEED SIGNAL FROM 1.42 THROUGH

1.57 SHOULD BE IGNORED.)

Figure 6-5. Torque, Percent From 10.04 through 15.21, Day 1;

WILLIAMS STATION 60

Figure 6-6. SUCTION AND DischaRge PRESSURE FROM 10.04 THROUGH

15.21; DAY 1; WILLIAMS STATION 60

Figure 6-7. RATIO OF COMPRESSION DURING DAY 1; Williams STATION 60.

FigURE 6-8. LOAD STEP DURING DAY 1; WiLLIAMS STATION 60. 91

Figure 6-9. TEMPERATURES DURING DAY 1 FOR SUCTION GAS,

Discharge Gas, Air Manifold, Lube Oil CoOling

WATER INLET, LUBE OIL OUTLET, JACKET WATER INLET,

AND JACKET WATER OUTLET; WILLIAMS STATION 60

Figure 6-10. TEST CONDITIONS OVERVIEW SUPERIMPOSED ON SPREAD IN

Peak-Firing Pressure as Percent; Day 1; Williams

STATION 60; FEBRUARY 2004

FiguRE 6-11. CYLINDER-TO-CYLINDER VARIATION IN COMBUSTION

Pressure Ratio (CPR); Day 1; Williams Station 60;

FEBRUARY 2004

Figure 6-12. CYLINDER-TO-CYLINDER VARIATION IN COMBUSTION

PRESSURE RATIO AFTER CPR BALANCING; WILLIAMS

STATION 60; FEBRUARY 2004

Figure 6-13. ENGine Fuel Flow IN MCFD DURING DAY 1 TESTING;

WiLliams STATION 60; FEBRUARY 2004

Figure 6-14. Heat Rate During Day 1 Tests; Williams Station 60;

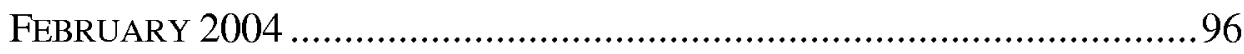

Figure 6-15. COMPRESSOR EFFICIENCY; WILLIAMS STATION 60; DAY 1;

FEBRUARY 2004 .97

FIGURE 6-16. OVERALL ENGINE-COMPRESSOR SYSTEM EFFICIENCY;

WILLIAMS STATION 60; DAY 1; FEBRUARY 2004. .98 


\section{LIST OF FIGURES (CONT'D)}

Page

Figure 6-17. Ratio of ENGine to COMPRESSOR IndiCATED Power;

Williams Station 60; DAy 1; February 2004

Figure 6-18. Peak-Firing Pressure and Compression Pressure $\left(20^{\circ}\right.$

BTDC); DAy 1; Williams STATION 60; FEBRUARY 2004

Figure 6-19. Engine Average CyCle-To-Cycle Standard Deviation

Estimate; Ratio of PeAK-Firing PRessure to

COMPRESSION PRESSURE (CPR); DAY 1; WILLIAMS

STATION 60; FEBRUARY 2004

Figure 6-20. MEAN AND STANDARd DEVIATION FOR P20 (PRESSURe 20

DBTDC) AS A FUNCTION OF CYLINDER; DAY 1; WILLIAMS

STATION 60; FEBRUARY 2004

Figure 6-21. Average and Instantaneous Spread in Peak-Firing

Pressure; Day 1; Williams STATION 60; FEBRUary 2004

Figure 6-22. COEFFICIENT OF VARIATION FOR CPR (STANDARD

DEVIATION/MEAN); Day 1; Williams Station 60;

FEBRUARY 2004

Figure 6-23. VARIATION OF COMPRESSION PRESSURe (P20) FOR ALL 10

Cylinders; DAY 1; Williams STATION 60; February 2004

Figure 6-24. Average Location of Peak-Firing Pressure in Degrees

AFTER TDC; DAy 1; Williams Station 60; FEbRUARY

2004

Figure 6-25. Vibration at Two Locations on Frame; InCHes Per

SeCond; PeaK-TO-PEaK; Day 1; Williams Station 60;

FEBRUARY 2004 105

Figure 6-26. Vibration Waterfall Plot; Day 1; Williams Station

60; FEBRUARY 2004 105

Figure 6-27. TYPICAL WAVEFORM FOR CRANKSHAFt StRAiN VARIATION;

Day 1; Williams STATION 60; February 2004. 106

Figure 6-28. Waterfall Plot For Crankshaft Strain; Day 1;

Williams STATION 60; FEbRUaRy 2004 107

Figure 6-29. VARIATION IN PEAK-TO-PEAK CRANKSHAFt STRAIN;

Williams STATION 60; FebrUaRY 2004; Day 1.

Figure 6-30. Speed Variation; Day 2; Williams Station 60;

FEBRUARY 2004

Figure 6-31. TORQUE From Station Data; DAy 2; Williams STATION

60; FEBRUARY 2004

Figure 6-32. Suction AND Discharge PRESSURe; Day 2; Williams

STATION 60; FEBRUARY 2004

Figure 6-33. Ratio of Compression; Day 2; Williams Station 60;

FEBRUARY 2004 110

Topical Report

(Reporting Period 01/01/04 - 06/30/04)

DOE Award No. DE-FC26-02NT41646 - SwRI Project 18.06223

August 2004 


\section{LIST OF FIGURES (CONT'D)}

Page

Figure 6-34. LoAd StEP; DAy 2; Williams Station 60; FEBRUARY 2004 111

FIGURE 6-35. TEMPERATURES DURING DAY 2 FOR SUCTION GAS, Discharge Gas, Air Manifold, Lube Oil CoOling

WATER INLET, LUBE OIL OUTLET, JACKET WATER INLET, AND JACKET WATER OUTLET; WiLliams STATION 60; FEBRUARY 2004

Figure 6-36. SPREAd In PEAK-FIRING PREssure as a PERCENTAGE With

TIMING OF TEST CONDITIONS; WILLIAMS STATION 60;

FEBRUARY 2004; DAY 2

Figure 6-37. ENGine Fuel Flow; Day 2; Williams Station 60;

FEBRUARY 2004

Figure 6-38. Heat Rate; Day 2; Williams Station 60; February

2004

Figure 6-39. OVERALL SySTEM EFFICIENCY; DAy 2; WILLIAMS STATION

60; FEBRUARY 2004

FIGURE 6-40. RATIO OF ENGINE TO COMPRESSOR POWER; WILLIAMS

STATION 60; FEBRUARY 2004; DAY 2

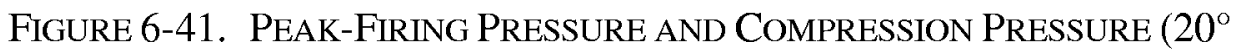

BTDC); DAY 2; WILLIAMS STATION 60; FEBRUARY 2004

FIgURE 6-42. INDIVIDUAL CYLINDER COMPRESSION PRESSURE; DAY 2;

WiLliams STATION 60; FEBRUARY 2004

Figure 6-43. ENGine Average CyCLE-TO-CyCLE StANDARd DEVIATION

Estimate; Ratio of PEAK-FIRING PRESSURe to

COMPRESSION PRESSURE (CPR); DAY 2; WILLIAMS

STATION 60; FEBRUARY 2004

Figure 6-44. MEAN AND Standard DEVIATION FOR P20 (PRESSURE 20

DBTDC) AS A FUNCTION OF CYLINDER; WILLIAMS

STATION 60; FEBRUARY 2004; DAY 2

Figure 6-45. Average and Instantaneous SPREAd IN PEAK-Firing

Pressure; Day 2; Williams Station 60; February 2004

FIGURE 6-46. ESTIMATE FOR COEFFICIENT OF VARIATION IN CPR; DAY 2;

WILLIAMS STATION 60; FEBRUARY 2004

Figure 6-47. Average LoCation of PEAK-Firing Pressure in DegreEs

AFTER TDC; DAY 2; WILLIAMS STATION 60; FEBRUARY

2004

Figure 6-48. WATERFALl Plot OF CRANKSHAFt STRAin; Williams

STATION 60; FEBRUARY 2004; DAY 2

Figure 6-49. CRANKSHAFt PEAK-TO-PEAK StRain; DAy 2; Williams

STATION 60; FEBRUARY 2004

FIGURE 6-50. NORMALIZED NOX CONCENTRATION AND EQUIVALENCE

RATIO; DAy 1; Williams Station 60; FEBRUARy 2004..................... 122 


\section{LIST OF FIGURES (CONT'D)}

Page

FIGURE 6-51. NORMALIZED NOX CONCENTRATION AND EQUIVALENCE RATIO; DAY 2; Williams STATION 60; FEBRUARY 2004

Figure 6-52. InLET MANIFOLD PRESSURE; TIME WAVE AND ORDER SPECTRUM; Williams STATION 60; FEBRUARY 2004; DAY 2

FIgURE 6-53. KNOCK DETECTOR OUTPUT ON CYLINDER \#4L; WILLIAMS

STATION 60; FEBRUARY 2004; DAY 2

Figure 6-54. PRESSURE-BASED BHP versus Station DATA - WiLliams

STATION 60

FIgURE 6-55. RATIO OF PERFORMANCE FOR MODIFIED GMW10 (TURBO +

High-PRESSURE FuEL) TO ANOTHER UNMODIFIED GMW10;

$8^{\circ}$ BTDC TIMING.

Figure 6-56. CRankshaft Strain, Mean Compression Pressure,

Combustion Pressure Ratio, and Peak Pressure;

RATIO OF TYPICAL VALUES FOR GMW10 MODIFIED FOR

High-PRESSURE FUEL + TURBOCHARGER COMPARED TO

UNMODIFIED GMW10 .

FIgure 7-1. COMPRESSOR Cylinders; HBA-6T AT El PASO Station

823; APRIL 2004

Figure 7-2. Power Cylinders; HBA-6T at El Paso Station 823;

APRIL 2004.

Figure 7-3. Back View of Engine; HBA-6T at El Paso's Station 823;

APRIL 2004

Figure 7-4. COMPRESSOR CYLINDER WITH PRESSURE TRANSDUCERS

INSTALLED ON HEAD AND CRANK ENDS; HBA-6T AT EL

PASO'S STATION 823; APRIL 2004

Figure 7-5. POWER Cylinder PRESSURE TRANSDUCER; HBA-6T AT EL

PASO'S STATION 823; APRIL 2004.

Figure 7-6. AIR MANIFOLD PRESSURE TRANSDUCER; HBA-6T AT EL

PASO'S STATION 823; APRIL 2004.

Figure 7-7. ElEMENT OF WASTEGATE CONTROL FOR EQUivalENCE

RATIO; HBA-6T at El PASO's STATION 823; APRIL 2004

Figure 7-8. Station Data TEMPERATUREs; Kinder Test 2; Day 1

(APRIL 21, 2004)....

Figure 7-9. Temperature Deg. F; DAy 2; Kinder Tests; April 22,

2004

Figure 7-10. Suction Pressure, Discharge Pressure, SPEed During

DAY 1 TEST (APRIL 21, 2004); KINDER TESTS.

Figure 7-11. Suction Pressure, Discharge Pressure, SPEed, AND

RATIO DURING DAY 2 TEST; APRIL 22, 2004; KINDER TESTS. 136 


\section{LIST OF FIGURES (CONT'D)}

Page

Figure 7-12. Station Data For BRake HP and LoAd SteP ("Fuel CURVE"); DAY 1, APRIL 21, 2004; KINDER STATION

Figure 7-13. STATION Data FOR BRAKe HP AND LOAD StEP ("Fuel

CURVE"); DAY 2; APRIL 22, 2004; Kinder STATION.

Figure 7-14. COMPRESSOR CyLinder TeMPERATURE RISE IN DEG. F; DAY 1; APRIL 21, 2004; KINDER TESTS.

Figure 7-15. Compressor CyLINDER TeMPERATURe Rise IN DEg F; DAY

2; APRIL 22, 2004; KINDER TESTS.

Figure 7-16. Cylinder Temperature Rise as a Function of Ratio

(SERIES NuMBER $=$ CYlindER NuMBER); KINDER TESTS;

DAY 1; APRIL 21, 2004

Figure 7-17. Cylinder Temperature Rise as a FunCtion OF Ratio

(SERIES NUMBER = CYLINDER NUMBER); KINDER TESTS;

DAY 2; APRIL 22, 2004

Figure 7-18. AvERAge CyLINDER Td VERSUS HEADER TD; DAys 1 AND 2............... 141

Figure 7-19. POWER CYLINDER EXHAUST TEMPERATURES; KindER

TESTS; DAY 1; APRIL 24, 2004

Figure 7-20. POWER CYLINDER EXHAUst TEMPERATURES; KINDER

TESTS; DAY 2; APRIL 22, 2004

FIgURE 7-21. UNIT SPEED; KIndER SECOND TEST; DAy 1; APRIL 21, 2004

Figure 7-22. Unit SPEEd; Kinder Second Test; Day 2; April 22, 2004

Figure 7-23. Global EQUivalence RATIO AND NoRMALIZED NOX

CONCENTRATION; Kinder SECOND TEST; DAY 1; APRIL 21, 2004

Figure 7-24. GLOBAL EQUIVALENCE RATIO AND NORMALIZED NOX

CONCENTRATION; Kinder SECOND TEST; DAY 2; APRIL 22,

2004

Figure 7-25. Fuel Flow; Kinder Second Test; DAy 1; ApriL 21, 2004

Figure 7-26. Fuel Flow; KIndER SECOND TeST; DAY 2; APRIL 22, 2004

FIgure 7-27. MEASURED IHP FOR ENGINE AND COMPRESSOR AND THEIR

RATIO; KINDER SECOND TEST; DAy 1; APRIL 21, 2004

FIGURE 7-28. MEASURED IHP FOR ENGINE, COMPRESSOR, AND THEIR

RATIO; KINDER SECOND TEST; DAY 2; APRIL 22, 2004

Figure 7-29. HeAt RATE (LHV); Kinder SECOND TEST; DAy 1; APRIL

21,2004

Figure 7-30. Heat Rate (LHV); KInder SECONd Test; DAy 2; APRIL

22, 2004

Figure 7-31. CPR AND Standard DEVIATION FOR PEAK-FIRING

PRESSURE; AVERAGED ACROSS THE SIX POWER CYLINDERS;

KINDER SECOND TEST; DAY 1; APRIL 21, 2004 


\section{LIST OF FIGURES (CONT'D)}

Page

FIGURE 7-32. CPR AND STANDARD DEVIATION FOR PEAK-FIRING

PRESSURE; AVERAGED ACROSS THE SIX POWER CYLINDERS;

KINDER SECOND TEST; DAY 2; APRIL 22, 2004.

Figure 7-33. Average AND InstantaneOUs SPREAD; KINDER SECOND

TEST; DAY 1; APRIL 21, 2004

Figure 7-34. Instantaneous and Average Spread; Kinder SEcond

TEST; DAY 2; APRIL 22, 2004

FIgure 7-35. PEAK-FIRING PREssure AND AVERAGE SPREAD

NORMALIZED BY PEAK-FIRING PRESSURE; KINDER SECOND

TEST; DAY 1; APRIL 21, 2004

FIgure 7-36. PEAK-FIRING PREsSURE AND AvERAGE SPREAD

NORMALIZED By PEAK-FIRING PRESSURE; KINDER SECOND

TEST; DAY 2, APRIL 22, 2004

Figure 7-37. POWER CYlinder PRESSURE 20 DEGREES BTDC AND

Angle of PeAK-Firing Pressure; Kinder Second Test;

DAY 1; APRIL 21, 2004

Figure 7-38. POWER CYLINDER PRESSURE 20 DEGREES BTDC AND

ANGLE OF PEAK-FIRING PRESSURE; KIndER SECOND TEST.;

DAY 2; APRIL 22, 2004

FIGURE 7-39. MAXIMUM StandaRd DEVIATION FROM All POWER

CYLINDERS; KINDER SECOND TEST; DAY 1; APRIL 21, 2004

Figure 7-40. Maximum Standard Deviation From All Power

CYLINDERS; KINDER SECOND TEST; DAY 2; APRIL 22, 2004

FIGURE 7-41. NORMALIZED STANDARD DEVIATION OF COMBUSTION

PRESSURE RATIO ACROSS All POWER CYLINDERS; KINDER

SECOND TEST; DAY 1; APRIL 21, 2004.

Figure 7-42. NORMALIZED STANDARD DEVIATION OF COMBUSTION

PRESSURE RATIO ACROSS ALL POWER CYLINDERS; KINDER

SECOND TEST; DAY 2; APRIL 22, 2004.

Figure 7-43. Overall System EFFICIENCY; KInDER SECOND TEST; DAY

1; APRIL 21, 2004.

Figure 7-44. Overall System EFFICIENCY; KIndER SECOND TeSt; DAy

2; APRIL 22, 2004

FIGURE 7-45. CRANKSHAFT SHOWN AS A FUNCTION OF TIME FROM START

OF SDCM DATA ACQUISITION; KINDER SECOND TEST; DAY

1; APRIL 1, 2004

Figure 7-46. CRANKSHAFt StRain SNAPShot; 300 RPM; KIndER TEST

2; DAY 1; APRIL 21, 2004 161

Figure 7-47. CRANKShaft StRain SNAPShot; 290 RPM; Kinder TEST

2; DAY 1; APRIL 21, 2004. 162

Figure 7-48. CRANKSHAFT STRAIN SNAPSHOT; 280 RPM; KINDER TEST

2; DAY 1; APRIL 21, 2004 162

DOE Award No. DE-FC26-02NT41646 - SwRI Project 18.06223 


\section{LIST OF FIGURES (CONT'D)}

Page

Figure 7-49. CRANKSHAFT STRAIN AS A FUnCTION OF TIME FROM START OF SDCM DATA ACQUISITION; KINDER SECOND TEST; DAY 2; APRIL 22, 2004

Figure 7-50. CRANKSHAFT StRain SNAPSHOt; 300 RPM; Kinder TEST

2; DAY 2; APRIL 22, 2004 164

Figure 7-51. Crankshaft Strain SNapshot; 290 RPM; Kinder Test

2; DAY 2; APRIL 22, 2004

Figure 7-52. CRANKSHAFT STRAIN SNAPSHOt; 280 RPM; KINDER TEST

2; DAY 2; APRIL 22, 2004 165

FIGURE 7-53. KINDER 2; DAY 1; FUEL FLOW HISTORY . 166

FIGURE 7-54. KINDER 2; DAY 1; IHP HISTORY. 167

FIGURE 7-55. KINDER 2; DAY 2; FUEL FLOW HISTORY ........................................ 168

FIGURE 7-56. KINDER 2; DAY 2; IHP HISTORY .................................................. 168

Figure 7-57. Hear Rate Calculations; Kinder 2; Day 2 .................................. 169

FIGURE 7-58. HEAT RATE FOR DAY 2 VERSUS ICHP WITHOUT CPR OR TIMING TESTS OR SPEED TESTS

FIGURE 7-59. HEAT RATE FOR DAYS 1 AND 2 VERSUS ICHP WITHOUT CPR OR TIMING TESTS OR SPEED TESTS...

Figure 7-60. HeAt RATE VERSUS ICHP; SERIES 2 ADDS IN THE CPR

BALANCING DATA, AND SERIES 3 ADDS IN THE ADVANCED

TIMING DATA; KINDER SECOND TEST; DAY 2; APRIL 22, 2004.

FIGURE 7-61. HEAT RATE FOR 280 AND 290 RPM AS A FUNCTION OF LOAD; DAY 2 AND DAY 1 (= SERIES 1 AND SERIES 2) ........................ 172

FIGURE 7-62. COMPRESSOR EFFICIENCY DURING DAY 1 TESTING ...........................173

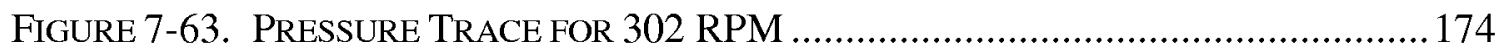

FigURE 7-64. PRESSURE TRACE FOR 278 RPM ................................................... 174

FIgURE 7-65. RAW DATA (KINDER 2) COMPARISON; CYLINDER 4; ROD

LOAD AND PRESSURE-BASED HP 176

FiguRE 7-66. "SCALE FACTOR" ADJUSTED COMPARISON; ICHP VERSUS RLM (TEST 4)

Figure 7-67. Equivalence Ratio versus SPEEd; Comparison OF OPEN-

LOOP AND CLOSED-LOOP CONTROL; KINDER TEST 2

Figure 7-68. MEAN Cylinder CyCle-TO-CyCle Standard DEVIATION VERSUS SPEED; COMPARISON OF OPEN-LOOP AND CLOSEDLOOP CONTROL OF WASTEGATE; KINDER TEST 2

Figure 7-69. Test Results; Kinder Test SERIES 2; Open- AND ClosedLOOP EQUIVALENCE RATIO CONTROL; INFLUENCE ON NORMALIZED NOX CONCENTRATION .

FIGURE 7-70. KNOCK DETECTOR OUTPUT; WILLIAMS STATION 60............................ 181

Figure 7-71. KNOCK DETECTOR OUTPUT; El PASO STATION 823 ........................... 181

FIGURE 7-72. ENGINE CYLINDER POWER OVER 20 REVOLUTIONS ............................. 182 


\section{LIST OF FIGURES (CONT'D)}

Page

Figure 7-73. COMPRESSOR CyLINDER POWER OVER 20 REVOLUTIONS .................... 183

Figure 7-74. COMBINED, TOTAL ENGINE, AND COMPREsSOR POWER Over

20 REVOLUTIONS

FIGURE 7-75. INSTANTANEOUS ROTATIONAL VELOCITY, AS A FUNCTION OF

CRANK ANGLE OVER 20 REVOLUTIONS.

Figure 7-76. DEVIATIONS IN HP AND IRV FOR SEVEN RECORDS OF 20

REVOLUTIONS EACH.

FIGURE 7-77. SYSTEM AND COMPONENT THERMAL EFFICIENCY

COMPARISON; GMW10 WITH HIGH-PRESSURE FUEL

INJECTION AND TURBOCHARGER

FIGURE 7-78. SYSTEM AND COMPONENT THERMAL EFFICIENCY

COMPARISON; UNMODIFIED GMW10. 186

FIGURE 7-79. SYSTEM AND COMPONENT THERMAL EFFICIENCY

COMPARISON; HBA-6T WITH LOW-PRESSURE FUEL 186

Figure 7-80. Combustion Pressure Ratio "Before ANd After" CPR

BALANCING (AT KINDER SECOND TEST). 188

FIGURE 7-81. COMPARISON OF STATION BHP TO BHP FROM CYLINDER

PRESSURE (USING 0.95 MECHANICAL EFFICIENCY); KINDER

TEST 2; DAY 1

Figure 7-82. COMPARISON OF STATION BHP TO BHP FROM CYLINDER

PRESSURE (USING 0.95 MECHANICAL EFFICIENCY); KINDER

TEST 2; DAY 2 


\section{LIST OF TABLES}

Page

TABle 3-1. High Count Engines in Gas Transmission - SORTED BY NUMBER (FROM 1998 COERR DATABASE) ........................................224

TABLE 3-2. High COUnT ENGINES In GAS TRANSMission - SORTED BY

HORSEPOWER (FROM 1998 COERR DATABASE).............................24

TABLE 5-1. Summary OF SOUR LaKe Data ANALYSIS RESUlTS ...............................74

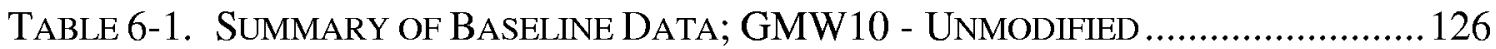

TABLE 6-2. STATIONS 60 AND 40: ADDITIONAL DATA COMPARISONS FOR

CRANKSHAFT STRAIN, COMPRESSION PRESSURE,

COMBUSTION PRESSURE RATIO, AND PEAK PRESSURE ....................... 128

Table 7-1. Crankshaft StRain Summary TABle; Kinder TeSt 2; Day

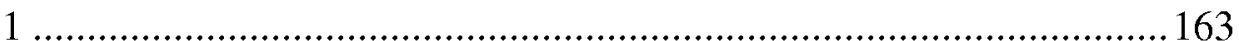

Table 7-2. CRankshaft StRain Summary Table; KInder TeSt 2; Day

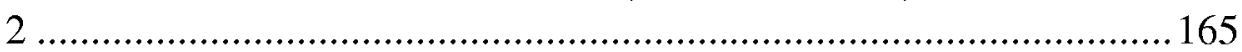

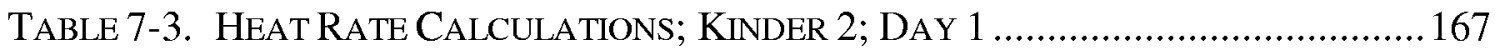

TABLE 7-4. Heat Rate SumMaries; KInder 2; DAY 2 ....................................... 169

TABLE 7-5. APPROXIMATE SYSTEM THERMAL EFFICIENCY VARIATION

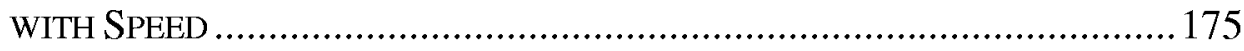




\section{INTRODUCTION}

This report presents a number of potential enhancements to the existing natural gas compression infrastructure that have been identified and quantitatively demonstrated in tests on four different integral engine compressors in natural gas transmission service.

The gas transmission industry operates over 4,000 integral engine compressors, which play a major role in pumping natural gas through the US pipeline system. Although the use of centrifugal compressors in the US pipeline industry has grown, these integral reciprocating units still represent over $70 \%$ of the fleet in numbers, and over half the installed power. These "slow-speed" integral engine compressors have been the workhorses of the industry for over 50 years, providing the reliable gas compression needed by the pipeline system. Figure 1-1 shows two such units: a 48-year old TLA6 and a 50-year old GMW10.
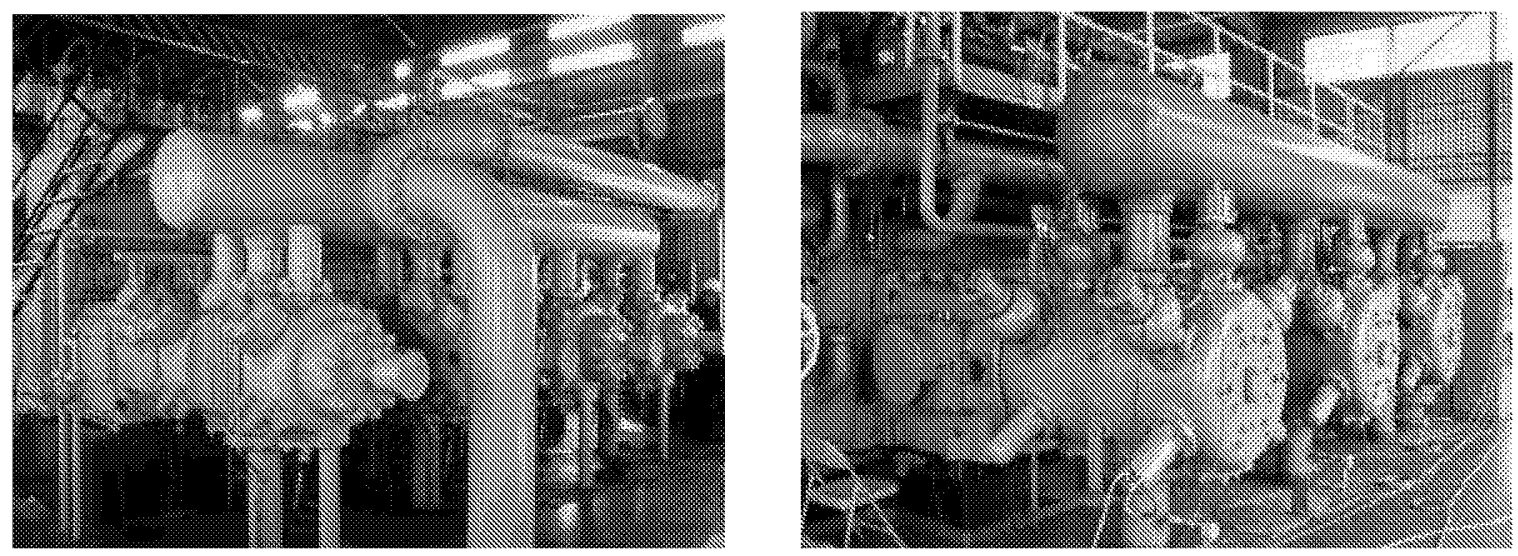

Figure 1-1. TLA6 (2000 HP) and GMW10 (2500 HP) in Pipeline Service

Figure 1-2 shows the age distribution of the current infrastructure. Over half the fleet is well over 40 years old, but replacing all these units with currently available technology would incur a huge cost and disruption to service with insufficient improvement in overall performance of the pipeline system to justify this cost and disruption. For these reasons, wholesale replacement remains unlikely (although selective replacement driven by factors such as environmental regulations can be expected). Growth to a 30-TCF-plus gas market in the US, anticipated over the next 10 to 20 years, must come on the backs of the existing compression infrastructure; it will, therefore, depend on continued integrity, enhanced capacity, and efficiency of the existing integral engine/compressors under all loads. The industry needs demonstrated technology options and operating methods, which will cost-effectively maximize the capacity of these old units, and reduce their fuel consumption, while respecting or improving their integrity. 


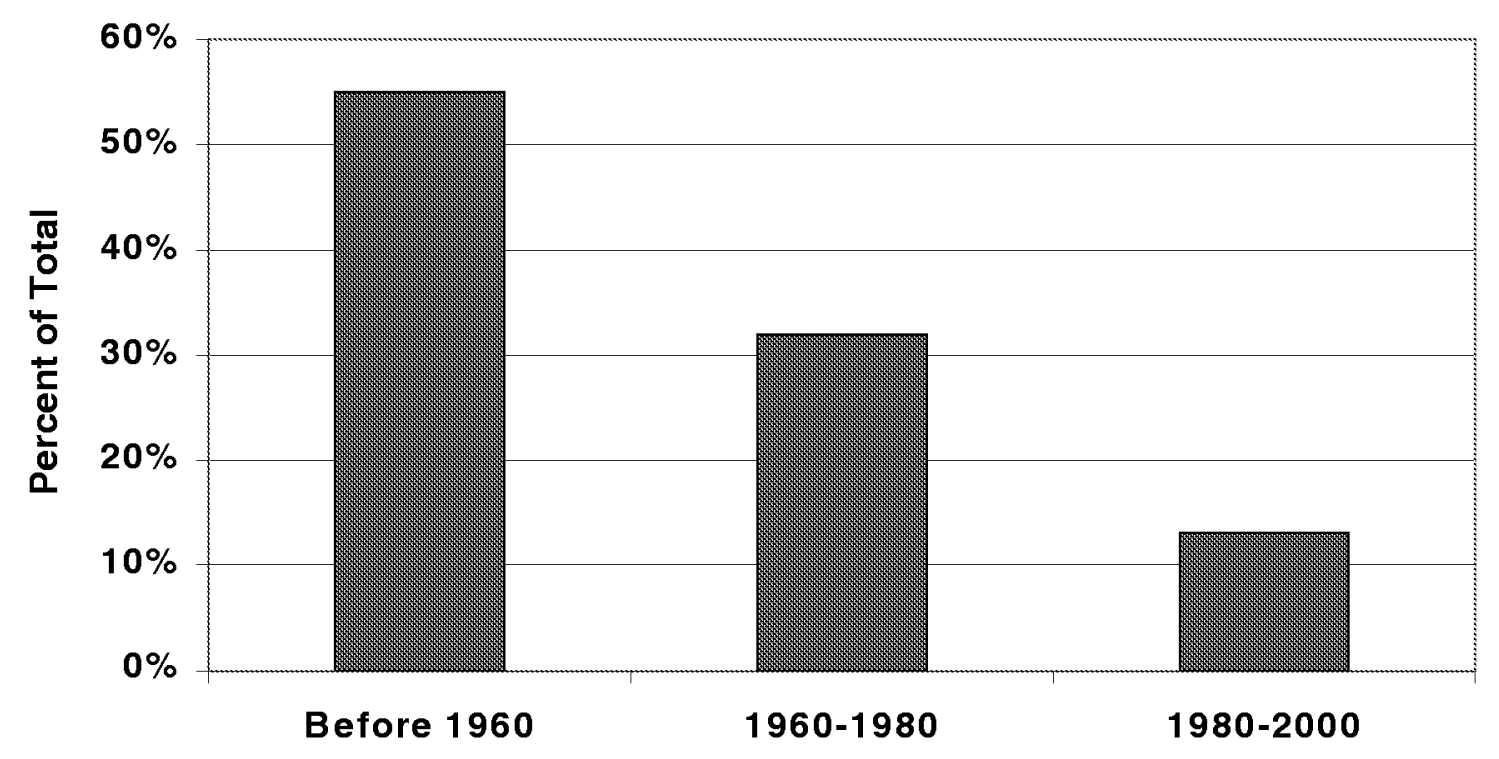

Figure 1-2. Install Dates: Over $50 \%$ of Pipeline Compressors Exceed 40 Years Old

Figure 1-3, Figure 1-4, and Figure 1-5 exemplify these needs of the existing infrastructure.

Figure 1-3 shows how annual fuel consumption at individual compressor stations in the pipeline system varies with the number of horsepower hours delivered by the engine to the compressor cylinders at that station. Points on the high side of the mean slope represent stations, which are burning more than the industry average. In addition, with a regressed slope of $7.7 \mathrm{CF} / \mathrm{BHP}-\mathrm{hr}$. for Figure 1-3, the industry burns significantly more fuel than the most efficient current technology natural gas engines (as little as $6 \mathrm{CF} / \mathrm{BHP}$ $\mathrm{hr}$.). As a slightly different performance measure for the industry, Smalley et al calculate an industry average (ratio of total fuel volume to total BHP-hrs.) of 8.25 SCF/BHP-hr.

Figure 1-4 presents a distribution of compressor thermal efficiency for the industry created by GMRC from a quantitative survey a number of years ago. This is the efficiency with which the compressors convert HP-hrs. to useful compression. The width of the range and the 12 points by which the $79 \%$ median lies below the best achieved (91 to $92 \%$ ) represents not only gas which is burnt rather than delivered, but also engine capacity which must overcome losses rather than deliver useful compression of the transported gas. 


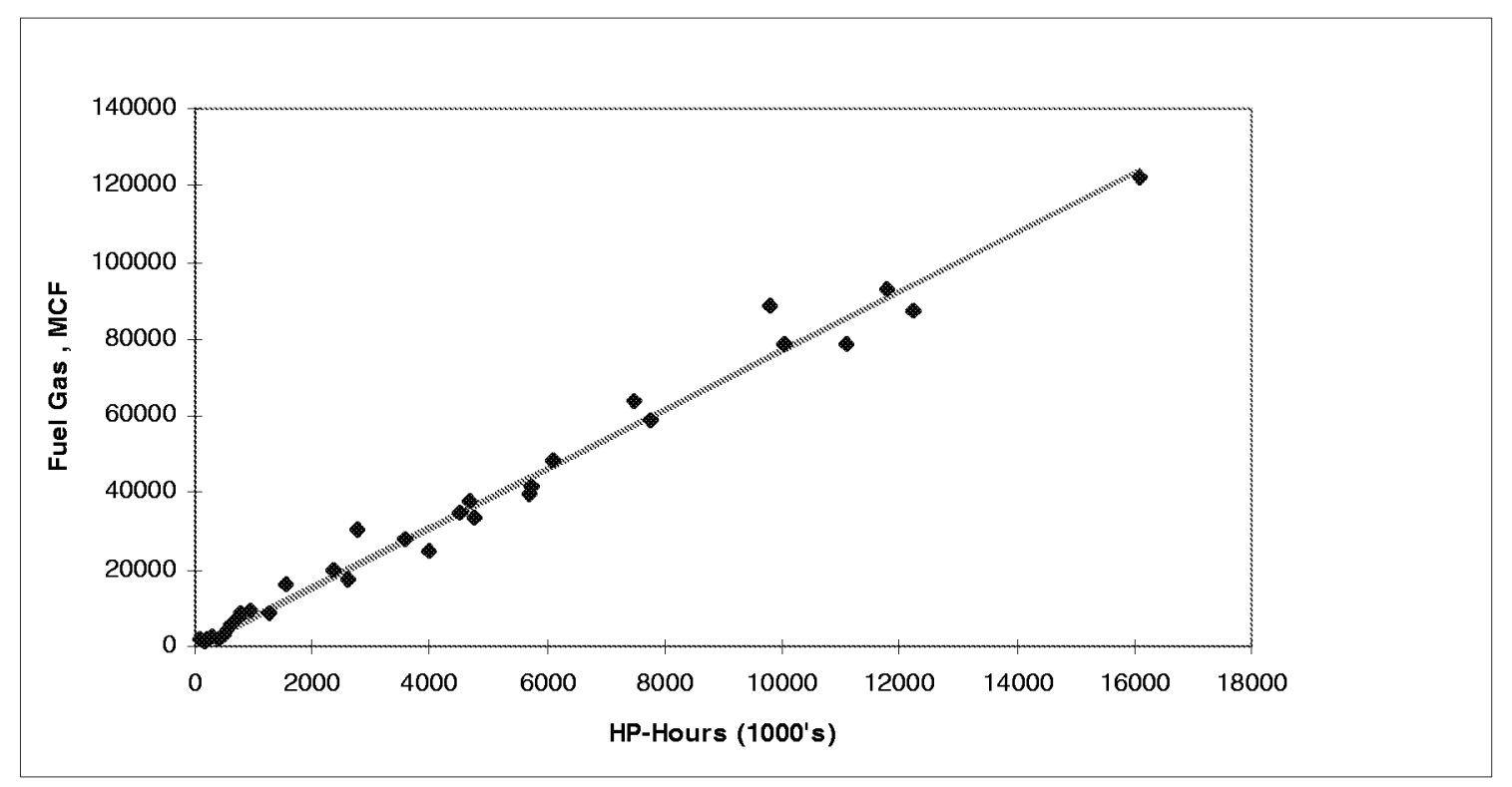

Figure 1-3. Industry Fuel Consumption ( 7.7 MCF/HP-Hr. +l-20\% - Need to Lower the High Values)

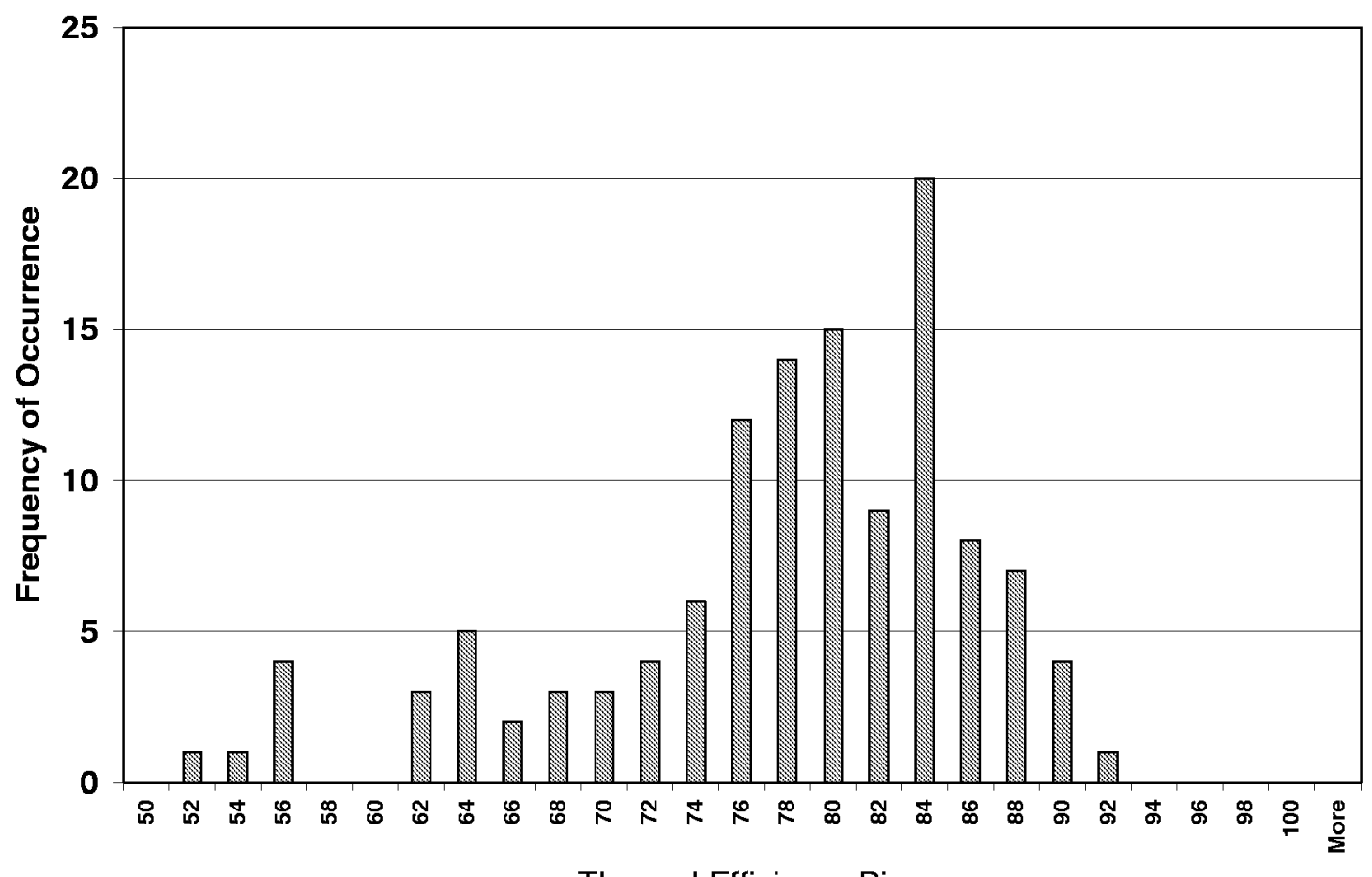

Figure 1-4. Compressor Thermal Efficiency Histogram based on GMRC Survey 
Figure 1-5 shows a number of failed crankshafts. This problem continues to occur at an undesirable rate for the pipeline industry as a whole (about one failure per thousand engines per year). This rate may not seem excessive, but for the compressor station and company which incurs such a failure, the disruption, cost, and loss of capacity at the time is significant. The chance of this rate increasing as a penalty for improved performance and increased capacity must be avoided, as well as any increase in problems such as bearing failure, or damage caused by detonation, or unintended overload. Ideally, the failure rate should be decreased.
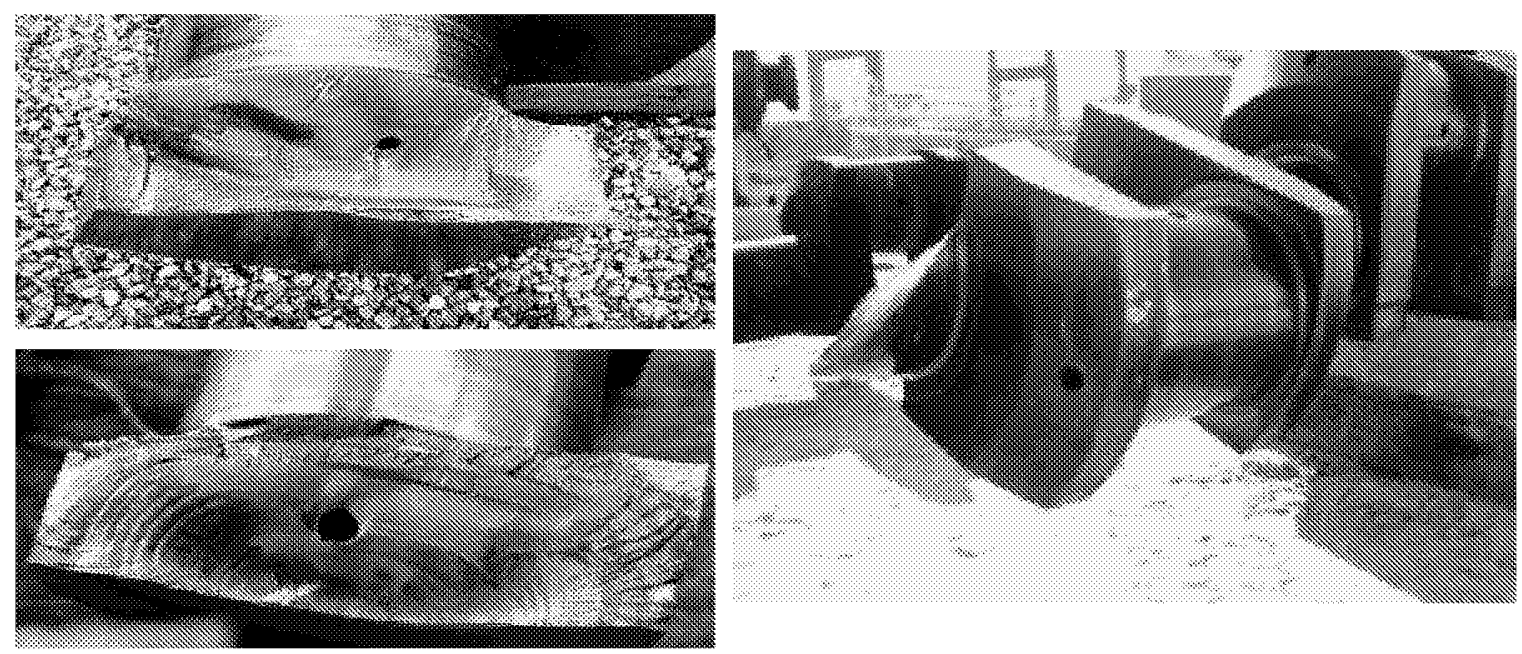

Figure 1-5. Integrity: Crankshaft Failure Examples - Need Methods of Avoidance

Figure 1-6 shows the histogram for operating life of a failed crankshaft from a 1992 survey of the gas transmission industry. It shows that of those crankshafts which had fractured, the distribution had a peak at 100,000 to 150,000 hours of life. This coupled with other data may provide operating guidance.

Three years ago, the US Department of Energy (DOE) initiated a Natural Gas Infrastructure (NGI) program, whose goals include increasing capacity of the current pipeline infrastructure $(10 \%)$, and reducing operational costs $(50 \%$ by 2010$)$. As a part of this program, SwRI is undertaking a project entitled "Technologies to Enhance the Existing Natural Gas Compression Infrastructure". The project is managed for DOE by the National Energy Technology Laboratory (NETL). The project objective is:

To develop and substantiate methods for operating integral engine/compressors in gas pipeline service which reduce fuel consumption, increase capacity, and enhance mechanical integrity. 


\section{Number of failures as a Function of Shaft Operating Life in thousands of Hours}

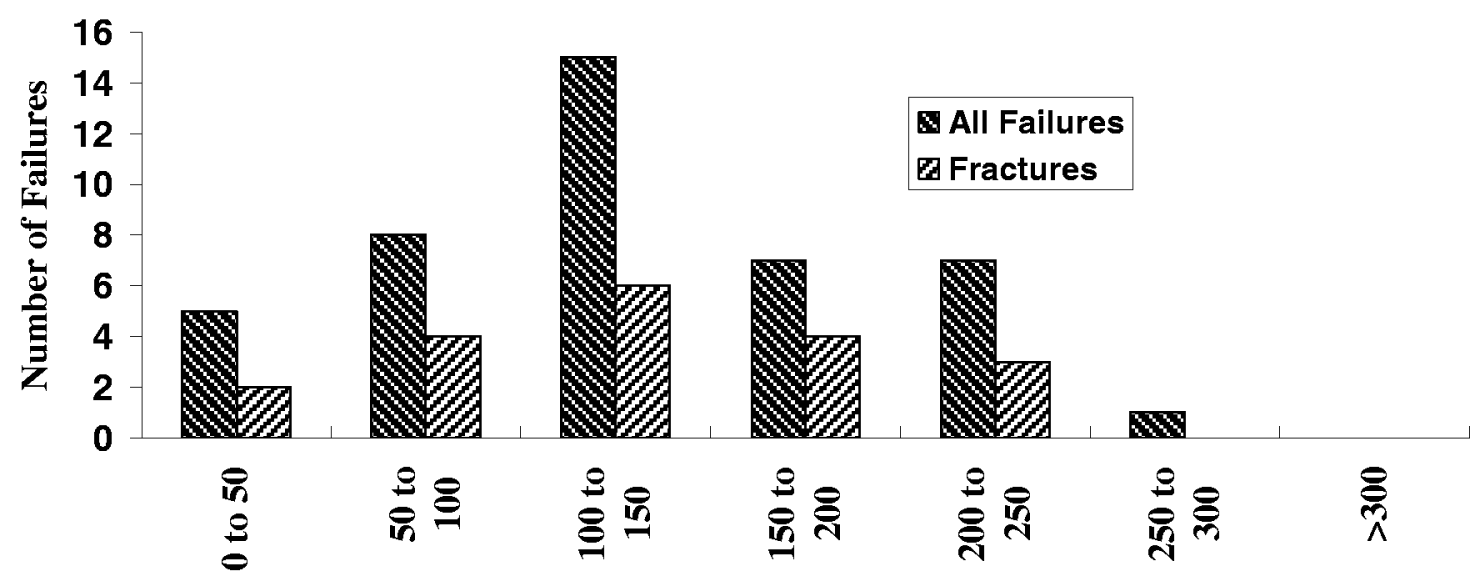

Figure 1-6. Age (1000 Hours) Histogram of Crankshaft Failures from 1992 Survey

To support this objective, SwRI has assembled a suite of instruments for measuring key performance parameters on these engine/compressors, and has integrated the data channels from these instruments into a powerful Data Acquisition System (DAS). On the widely accepted premise that effective improvement depends first on accurate measurement, the project has established the capability to concurrently measure and record a range of parameters (including cylinder pressure, fuel flow, torsional vibration, lateral vibration, crankshaft strain, manifold dynamic pressures, and global equivalence ratio). Using these measurement capabilities, the project has performed tests on a number of integral engine compressors. Data analysis capability has been added to provide operational measures such as efficiency of engine, compressor, and the system they form, cycle-to-cycle variance statistics, cylinder-to-cylinder variation in peak-firing pressure, and measures of crankshaft cumulative damage.

The general approach for the project has been to design a test program which links integrity, capacity, and efficiency to operation and balance; to acquire data by test on operational engine compressors; to analyze data and develop relationships; to apply these relationships and identify methods to optimize capacity and/or efficiency (subject to integrity constraints); and to evaluate optimization methods and benefits.

With this approach and the measurement capability described, the program has already accomplished the following:

- A new method of achieving balanced combustion across the cylinders has been invented and demonstrated. 
- The need for improved cylinder-to-cylinder air balance has been documented. An investigation to accomplish this through control of manifold dynamic flow modulations has been proposed, and baseline testing has recently been completed under a new task, which will be separately reported.

- A relationship between engine balance and crankshaft integrity has been shown.

- Knock detection capability has been evaluated and demonstrated as a means to allow advanced timing and more efficient engine operation, while protecting engine integrity.

- The use of closed-loop global air fuel ratio control has been identified and its feasibility demonstrated. This provides a means to maintain consistent engine operation as ambient and operating conditions change, subject to knock protection.

- The use of system efficiency to measure the conversion of fuel energy to useful compression of transported gas has been demonstrated and used to create benchmarks for the industry, and to identify technologies which will enable achievement of these benchmarks.

- Further benchmarks in component efficiency for engine and compressor have been documented.

- A relationship between system mechanical efficiency for transmission of engine power to compressor power and oil temperature has been observed on two engines.

- High-pressure fuel injection, in combination with turbo-charging, has been shown to allow leaner operation and to achieve both lower heat rate, lower emission of NOx, and to lower crankshaft strain for a given compression power.

- A means of directly monitoring and controlling compressor cylinder load by measurement of rod load variation has been tested and refined during the program. While still needing some final refinements and application decisions, this technology has the potential to maintain the engine at its most efficient full load condition, while protecting against overload and the associated threat to integrity.

Based on these demonstrations, the project is bringing forward technology options that promise to increase capacity, and reduce operating costs in the following ways:

- Improving efficiency of power transmission, and of the compression process, makes more of the installed engine power available for useful compression.

- Enhancing integrity increases availability and capacity by avoiding forced downtime for maintenance.

- Enhancing integrity also reduces operating costs required for maintenance. 
- Improving system efficiency reduces fuel consumption and associated fuel use costs, and makes more of the gas entering the pipeline system available to the end consumer.

Thus, project results are very consistent with DOE's goals of increasing capacity and reducing operating costs.

The tests and analyses have been performed so far on two different two-stroke engine models from two manufacturers: a Cooper GMW10 with three compressor cylinders, and a Dresser-Clark HBA-6T with four compressor cylinders. The HBA is a straight six with turbocharger. The GMW is a V-10, and has been tested both with and without the combination of a turbocharger and high-pressure fuel injection system. The engine selection was based on detailed quantitative analysis of the engine population using a database prepared for the pipeline industry, which shows both models are in the top six, measured by horsepower installed or by number of units installed. Thus, marked diversity has been achieved in the process of testing two widely deployed engine models. In testing these two different models, four different units have been tested at three different sites. 


\section{EXECUTIVE SUMMARY}

This report documents a program to enhance operation of integral engine/compressors in gas pipeline service. The project has tested two models, both two-stroke (HBA; GMW), and four distinct units. The suite of instruments, data system, and analysis have shown:

- Fuel supply, trapped air, and their ratio vary cylinder-to-cylinder. The industry widely uses fuel adjustment to balance combustion, but high cycle-to-cycle variation complicates this practice and limits the benefits of balancing. The most common method equalizes peak-firing pressures (PFP), but with unequal trapped air, unequal fuel/air ratios can result.

- A newly invented method (CPR balancing) equalizes combustion pressure ratio (CPR equal to ratio of PFP to compression pressure) across cylinders and has proven feasible, with some evidence of reduced heat rate. Implementation involves calculating CPR each cycle, then averaging over multiple cycles. Cutting fuel to high CPR cylinders flattens the CPR distribution. PFP balancing works against compression pressure variation (observed at 6 to $12 \%$ across cylinders), while CPR balancing works with this variation.

- An alternative, with similar goal, equalizes each cylinder's cycle-to-cycle standard deviation in PFP. Limited testing indicates this benefits crankshaft integrity.

- Data shows $25 \%$ to $50 \%$ dynamic variability in manifold pressures, which likely contribute to air imbalance. Separate, ongoing tasks will characterize manifold dynamics and air imbalance in a GMVH6, and optimize manifold design to reduce this imbalance.

- Global equivalence ratio can vary - and the project has shown feasibility of a low-cost means to maintain an equivalence ratio set point via turbocharger wastegate control.

- Heat rate depends strongly on load, emphasizing the need for accurate, reliable, brake power measurement. Inaccurate torque can overload engines or hurt their efficiency. Inferential methods show up to $10 \%$ discrepancy; increasing their accuracy requires extensive mapping, and errors can still result when malfunctions occur. The GMRC Rod Load Monitor (RLM) will measure power directly, optimize heat rate, and avoid overload.

- Testing the evolving RLM has guided refinements; the project has now demonstrated the first self-powered RLM with digital telemetry on a large integral engine. Indicated power provides a viable calibration basis and initial evaluation showed the result remained consistent with indicated power when speed and load varied. The RLM measures torque upstream of ring/rider band losses, and translating RLM power into engine brake torque for set point comparison will demand better knowledge of such mechanical losses. 
- The crankshaft Strain Data Capture Module (SDCM) revealed how standard deviation balancing reduced the number of high strain excursions; how reducing speed and high-pressure fuel cut strain; and how advanced timing increased strain.

- Because of sensitivity to small, natural, load variations, using heat rate directly to compare operational changes incurs uncertainty. However, the heat rate versus load chart shows promise as basis for comparison. While not conclusive, tests showed a distinct reduction in heat rate after CPR balancing ( 100 BTU/HP-hr.), when compared to the baseline heat rate/load chart.

- Similar comparison showed distinct heat rate reduction with 2 degrees HBA-6T timing advance. GMW10 timing tests showed the same or more heat rate reduction. Operators tend to limit timing advance for reduced heat rate because of the potential for detonation. A detonation detector loaned by Metrix shows promise as a sensitive and discriminating device to avoid detonation when advancing timing.

- Comparing two different GMW10's showed much leaner operation, reduced heat rate, and reduced NOx concentration for a unit modified with high-pressure fuel and turbocharger. This unit also showed lower crankshaft strains and lower peak pressure.

- Data shows system thermal efficiencies from 26.5 to $30 \%$ with "as found" timing. System thermal efficiency helps assess any complete compressor package. Attempts to assess how speed influences system efficiency emphasize the need to enhance mechanical efficiency knowledge and (ideally) avoid depending on assumed mechanical efficiency. Future rod load tests should help generate this knowledge.

- Observed compressor thermal efficiencies (84 to 91\%) have significance, because high values reduce fuel consumption and increase capacity for fixed engine power.

- Data confirms the value of monitoring discharge temperature to catch deteriorating compressor performance, and the potential role of other integrity monitoring methods using vibration and torsional velocity. 


\section{EXPERIMENTAL}

\subsection{Sensors and Data Channels}

Sensors and data acquisition capability have been assembled to record the following data on large integral engine compressors.

- Dynamic Pressure in the Compressor Cylinders - these measurements are used for compressor horsepower and flow determination. Both ends of each compressor cylinder have been instrumented for dynamic pressure in each test series. The sensors are Sensotec piezo-restrictive transducer). They are calibrated prior to each test by deadweight loading to generate known force per unit area in the test fluid applied to the sensing element.

- Dynamic Pressure in the Engine Cylinders - these measurements are used for engine horsepower determination, engine balancing, and to calculate engine statistics. All power cylinders have been instrumented for dynamic pressure in each test series. The sensors are Kistler quartz piezoelectric transducers. Being dynamic sensors, they are calibrated prior to each test by suddenly applied deadweight loading to generate known force per unit area in the test fluid applied to the sensing element.

- Dynamic Pressure in the Engine Air Intake Manifold - these measurements are used to correlate dynamic effects in the inlet manifolds, which deliver air for each cylinder with the dynamic statistics within each cylinder. They also provide the time-averaged value for air manifold pressure whose influence on engine heat rate and emissions is assessed. Air manifolds have been instrumented in each test series. The sensors are Kistler piezo-resistive pressure transducers with factory provided calibration.

- Dynamic Pressure in the Engine Exhaust Manifold - these measurements are used to determine dynamic variation of pressure in the engine manifolds, which capture hot exhaust gas from each cylinder, and to correlate these dynamic pressure variations with the dynamics within each cylinder. The sensors are Kistler piezo-resistive transducer with factory provided calibration; they are water-cooled to reduce uncertainty resulting from temperature influence on the sensor readings. It has not been possible to install these transducers on exhaust manifolds with water jackets.

- Torsional Vibrations (IRV) - This measures the dynamic variation in speed of rotation of the flywheel. The sensor is a BEI 512 pulse encoder driven through a flexible coupling by a shaft connected by a friction drive to the flywheel. The frequency of its output pulse train directly reflects instantaneous flywheel angular velocity, which varies within each cycle of the engine as a result of dynamic load variation. Rather than digitally time the variation in period between pulses (which imposes unrealistic period discrimination requirements), a frequency to voltage 
analog circuit is used to determine the continuous variation in flywheel speed. The speed variation is assessed as a surrogate for mechanical integrity. The frequency-tovoltage measurement is calibrated by supplying the analog circuitry with a pulse train of known frequency from a signal generator. The torsional vibration has been measured in this way on all tests. The torsional vibration data has been assessed as a potential indicator of engine dynamic loading severity.

- Data Acquisition Triggering - The BEI encoder signal is also used to trigger acquisition of samples from all dynamic transducers. The phasing of the pulse train to top dead center is important. A pre-established top dead center mark for power cylinder \#1 is used as a reference, and the angular setting within the DAS corresponding to cylinder \#1 TDC is adjusted, as the engine runs, until a strobe light triggered by the DAS at this angle shows the mark on the flywheel coincides with the stationary mark.

- Bearing Centerline Vibration - This measurement is assessed as an indicator of engine dynamic loading severity. The sensors are PCB velocimeters with factory provided calibration. The sensors have been located to measure lateral vibration at each end of the engine/compressor frame.

- Crankshaft Dynamic Strain - This measurement is used as a direct indicator of shaft loading, and to provide a link between engine statistical quantities and potential for crankshaft fatigue damage [1]. The strain gage is placed on the crankshaft web as close as possible to the crank pin - at the point most sensitive to opening and closing of the crank throw faces under load from engine and compressor rods. Data is acquired by the Strain Data Capture Module (SDCM), which rides on the shaft within the engine during each day of testing, and from which data is downloaded at the end of each day. This is calibrated using a calibration resistance. The SDCM has worked with complete reliability for all tests so far. Its main drawback is the need for daily download, which can cut into test time; a refinement is under consideration, which increases storage and energy capacity by a factor of ten or more.

- Engine Fuel Flow - Used to document overall engine efficiency. The sensor is an Emerson Flobas 103 transmitter which implements the AGA3 flow measurement based on a differential pressure measurement, and is factory calibrated with a certificate. This sensor is connected to taps on the already installed engine fuel flow orifice, which has been available on all engines tested so far. The fuel flow, coupled with a gas analysis, provides the basis for determining fuel energy consumed by the engine, and for determining heat rate and overall system efficiency. At the first test, the flow measurement functioned, but the flow range was not properly matched to the engine, and satisfactory data was not obtained. At subsequent tests, the fuel flow has been successfully measured and used for the intended purposes. 
- Suction Header and Discharge Header Pressures and Temperatures - These measurements are used for installation efficiency determination. Pressures are measured with Sensotec piezo-restrictive transducers. Permanently installed station sensors have been used to provide this data at some sites.

- Engine Exhaust $\mathrm{O}_{2}$ Level - This measurement is used to determine global equivalence ratio, both as an independent variable influencing engine performance, and where the loop is closed to the turbocharger wastegate for active control. The sensor used is an NGK fast-response transducer, which provides a continuous variation of voltage with exhaust oxygen level. It is calibrated against a standard.

- Engine Exhaust NOx Level - This measurement is used to provide comparative emissions data. The sensor used is an NGK fast-response transducer, which provides a continuous variation of voltage with exhaust NOx level. It is calibrated against a standard.

- Compressor Rod Load - This measurement is used for both mechanical integrity and loading optimization. The sensor uses a pair of strain gages mounted on either side of the rod, which are bridged additively to cancel bending and to produce a signal proportional to axial load on the piston rod. The signal is transmitted using RF from a moving antenna to a stationary antenna. The strain gage and signal transmission can be powered by a battery, or by a generator driven by rod motion. The battery power is adequate and simpler to set up for short-term tests, but for continuous monitoring and control self-powering is needed. Calibration issues are not fully resolved yet for this device (termed the "rod load monitor" (RLM)). So far, the horsepower measurement from the compressor cylinder, based on cylinder pressure transducer, has been used for calibration.

- Knock Detection - Evaluation of a sensor provided by Metrix, which counts occurrences of dynamic acceleration levels above a threshold.

\subsection{DATA ACQUISITION}

Figure 3-1 and Figure 3-2 show photographs of the Data Acquisition System (DAS). The system comprises an industrially hardened computer, a flat screen for display, and a separate box with connectors to which cables from individual sensors are connected. The DAS box has analog-to-digital converters of appropriate speed for over 50 different channels. 


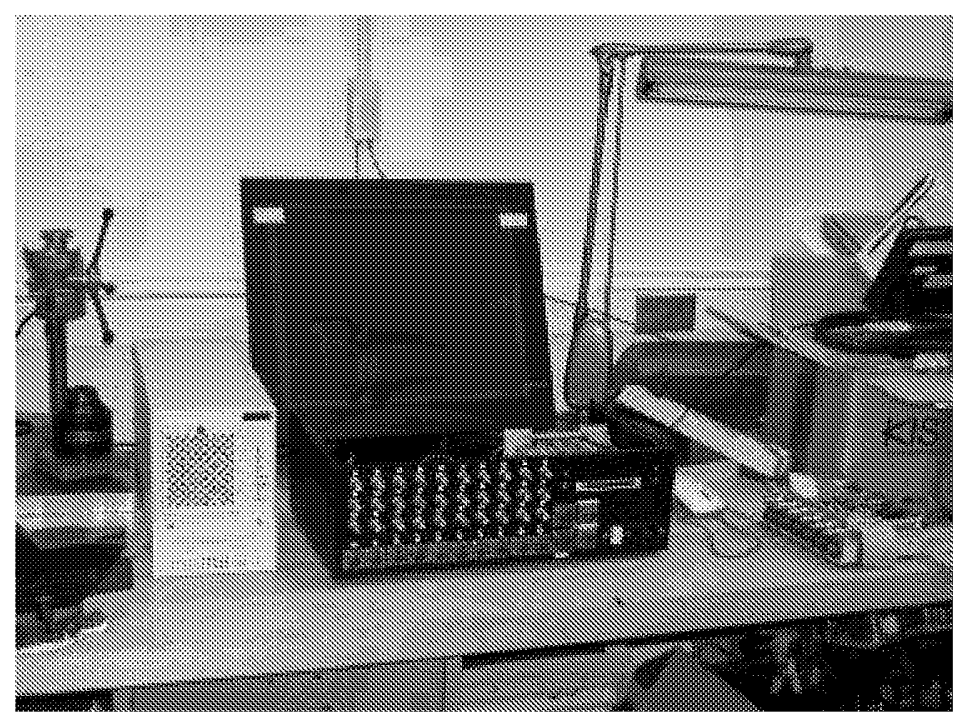

Figure 3-1. Front View of Data Acquisition System (DAS)

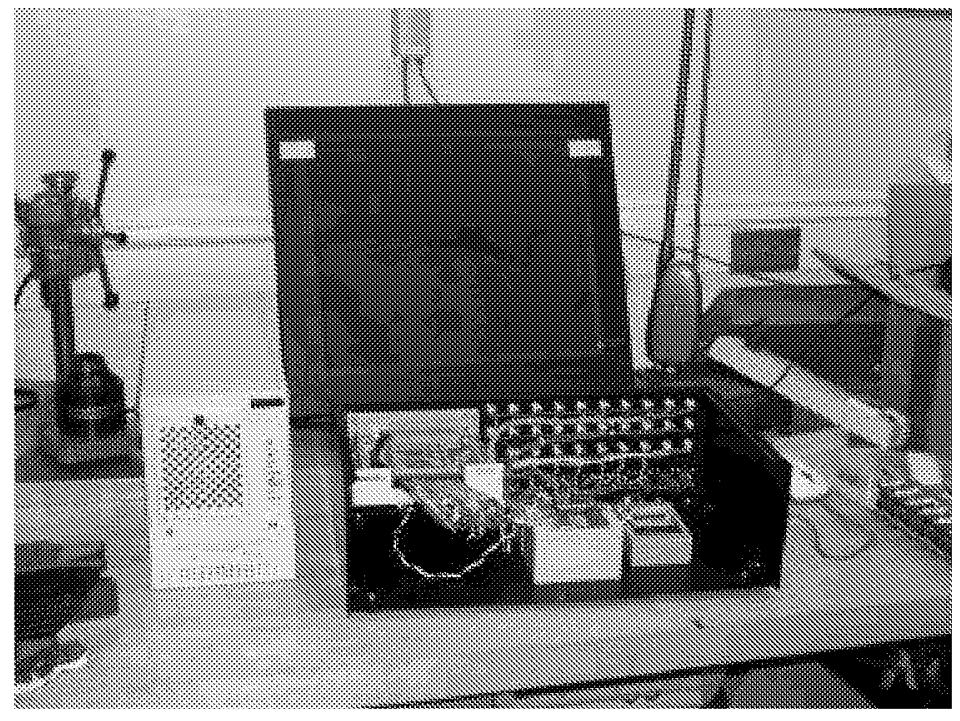

Figure 3-2. Rear View of Data Acquisition System (DAS)

The individual power cylinder transducers (up to 10) are connected to a box with connectors on the deck near the cylinders. A single cable from this box carries the signals from all the power cylinder transducers to the main data acquisition box. A similar approach is used for the compressor cylinders. In this way, the complexity of the cabling and system checkout is minimized. Signals from rod load monitors, from other system pressures, and from temperature sensors are acquired by the DAS, concurrently, and a database of the sensor values throughout each test is created by the DAS. 


\subsection{TRANSDUCER INSTALLATION}

Figure 3-3 shows a compressor cylinder with pressure transducers installed on head and crank end. As discussed above, these are Sensotec piezo-resistive sensors.

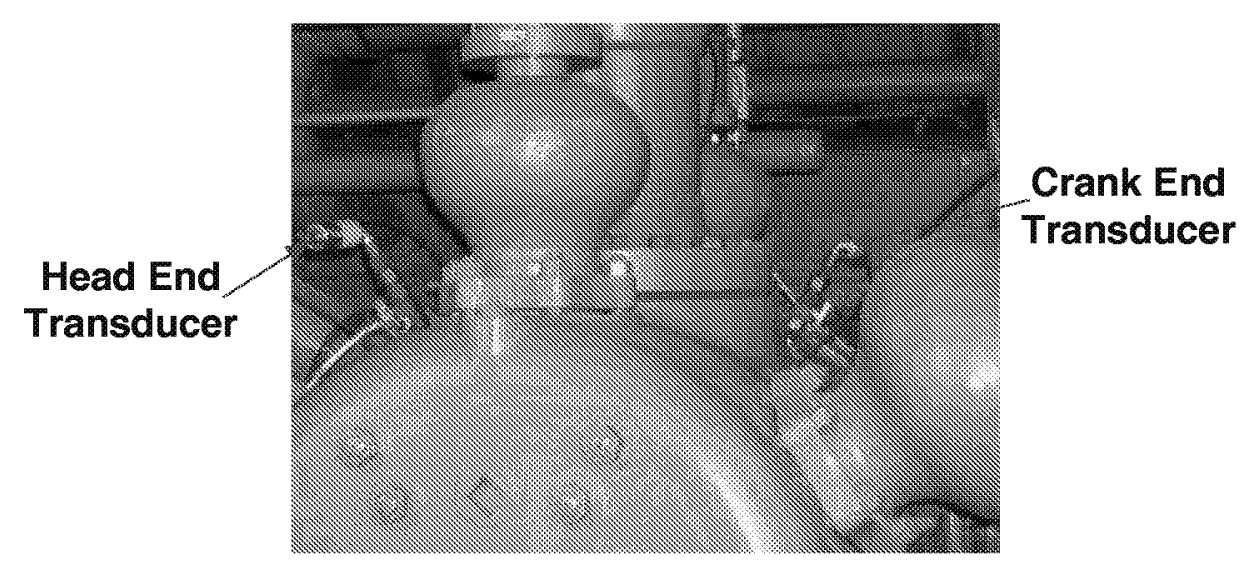

Figure 3-3. Compressor Cylinder and Pressure Transducers on each End (Williams Station 40; August 2003)

Figure 3-4 shows the details of the power cylinder pressure transducer installation on one cylinder of the first GMW10 tested. Close examination reveals two pressure transducers installed - the one nearest the cylinder was already installed at test time as part of the high-pressure fuel injection system; the one further removed from the cylinder provided the data for SwRI's test on the engine with high-pressure fuel. This separation and associated effects with loss of information in the measurement channel leads to some uncertainty in the measurement of power cylinder pressure for this test.

Figure 3-5 shows the unit tested at El Paso's Station 823. Close examination reveals the pressure transducer located in its air manifold. Figure 3-6 shows rather more clearly the pressure transducer in the air manifold for the GMW10 with high-pressure fuel injection.

Figure 3-7 shows the pressure transducer in the exhaust manifold of the GMW10 at Williams' Station 40. Close examination also shows the tubes carrying cooling water to the transducer. 


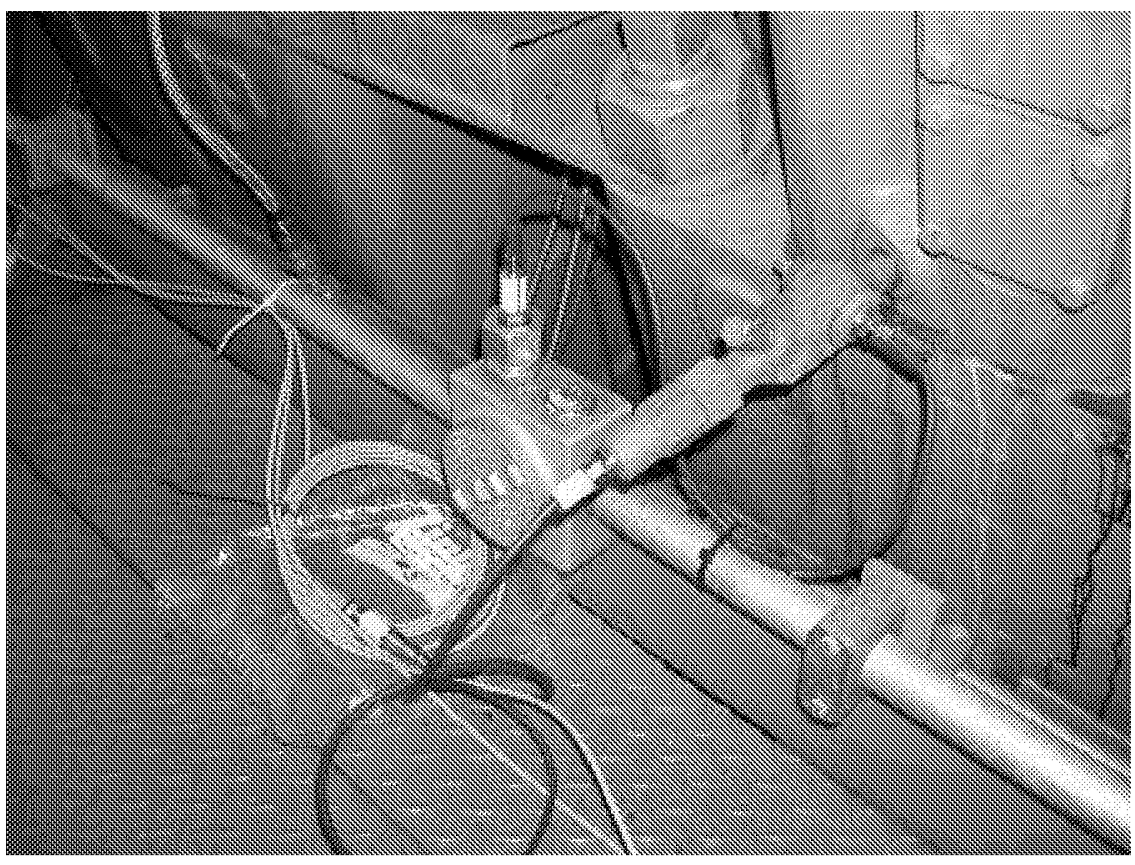

Figure 3-4. Details of Power Cylinder Pressure Transducer Installation (Williams Station 40; August 2003)

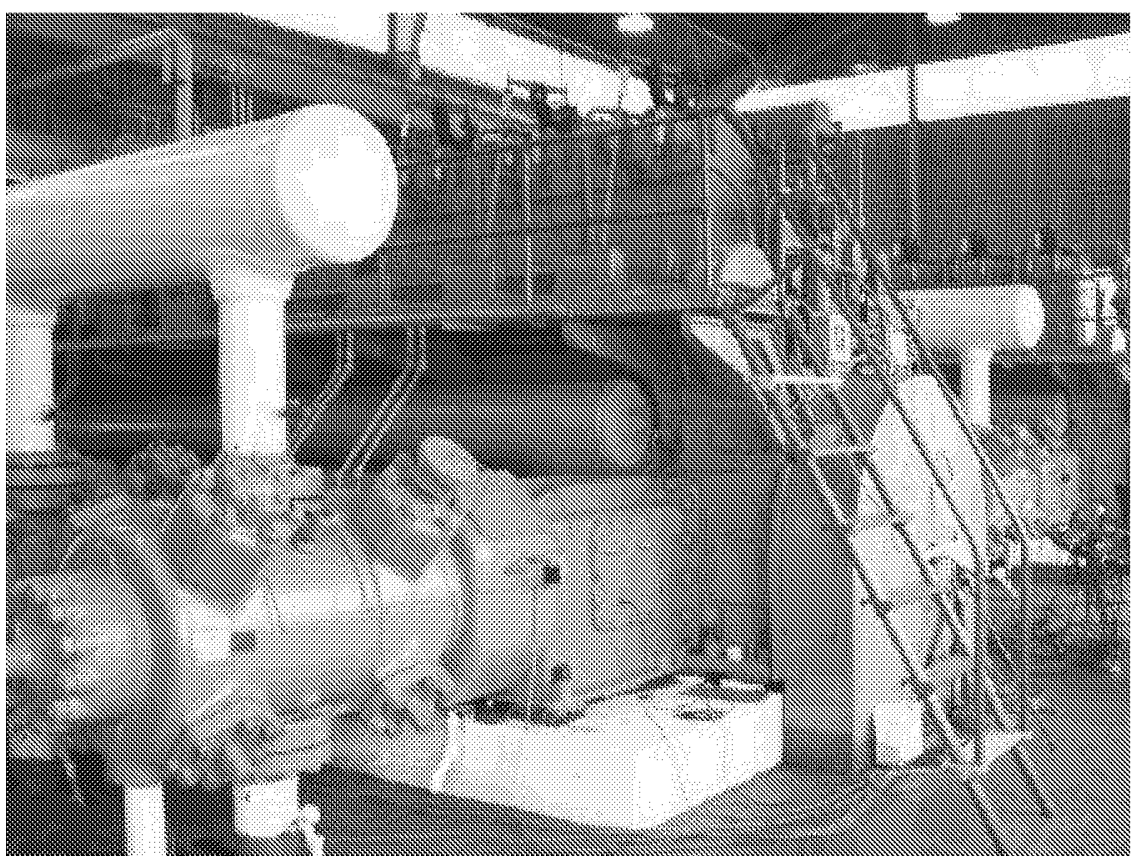

Figure 3-5. Initial Site Test

(HBA-6T; TGP Kinder Station; April 2003) 


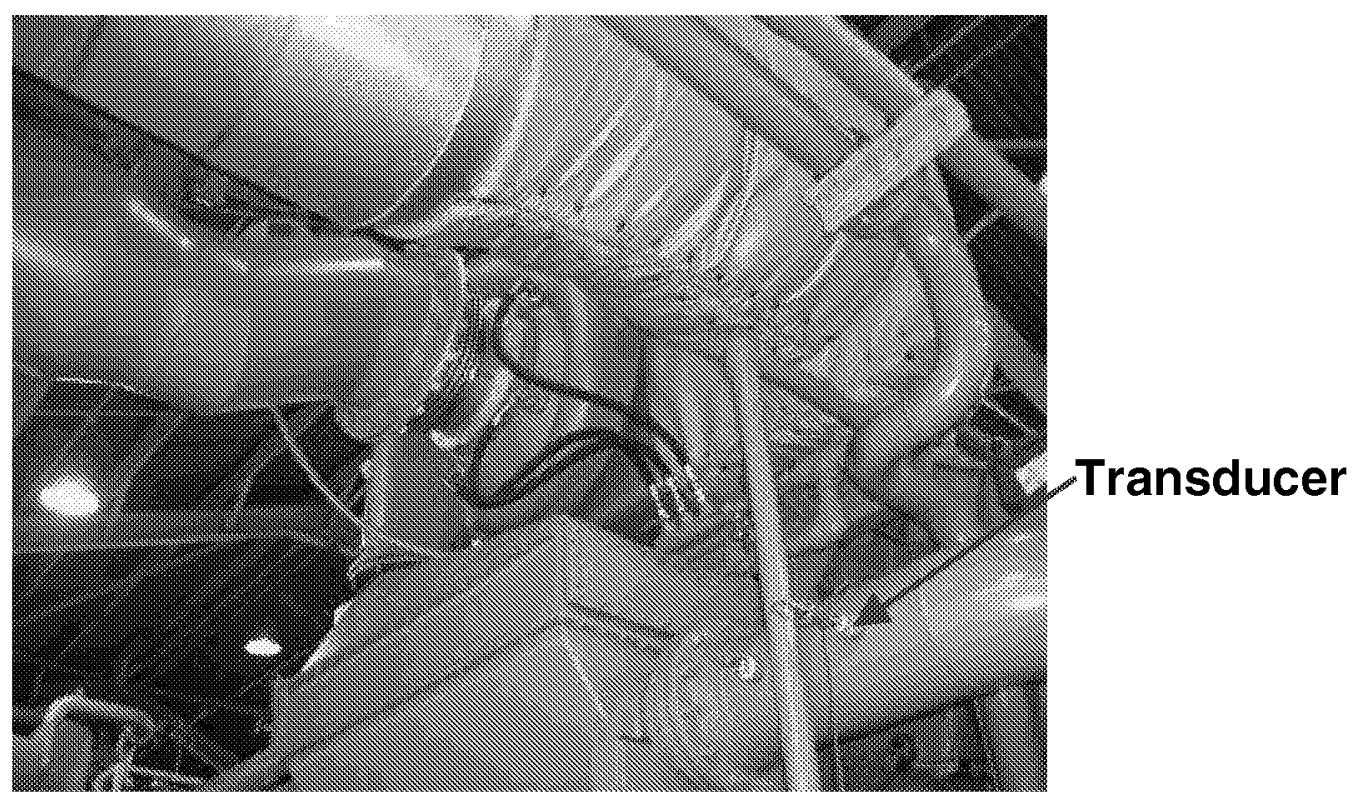

Figure 3-6. Pressure Transducer in Air Intake Manifold (GMW10; Williams Sour Lake Station; August 2003)

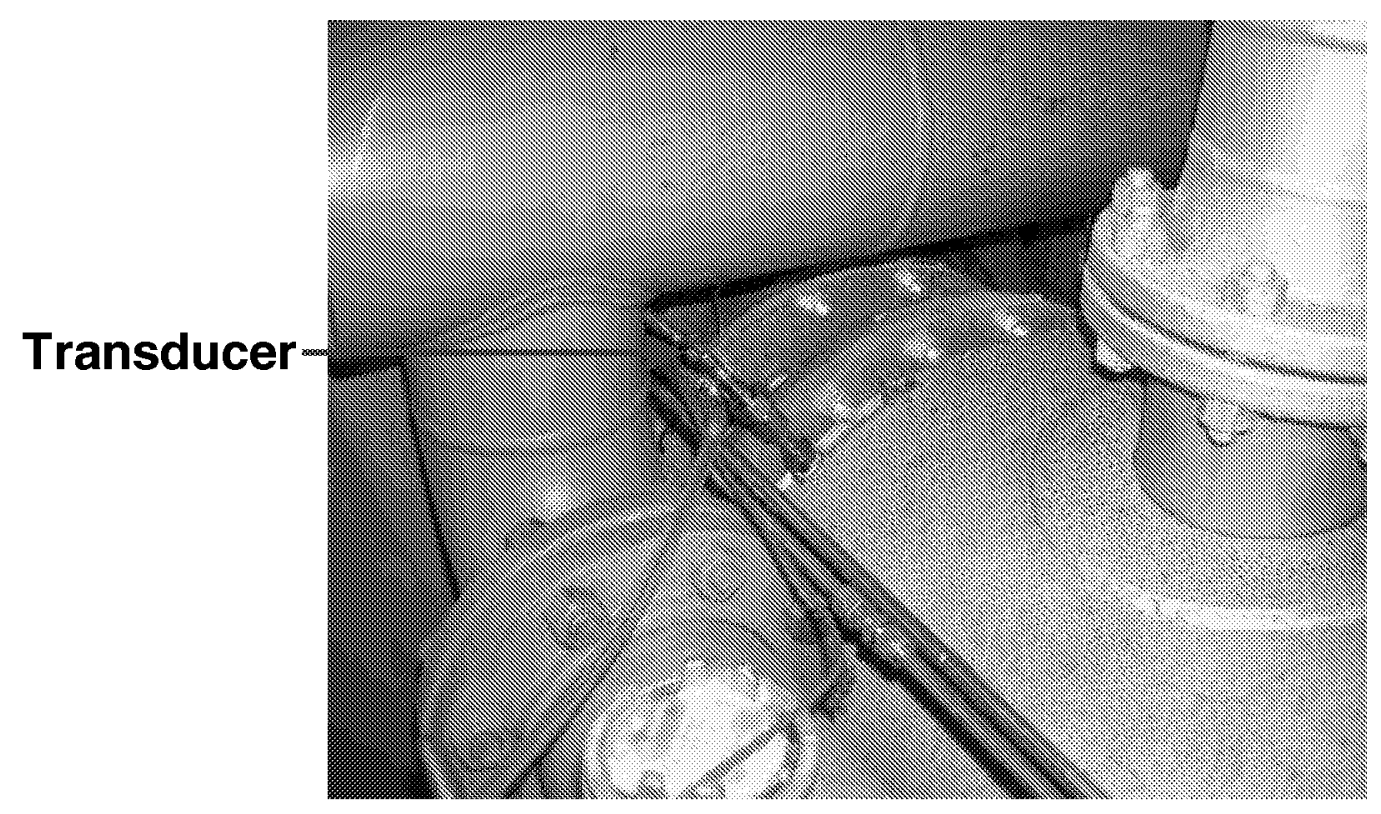

Figure 3-7. Pressure Transducer in Exhaust Manifold (GMW10; Williams Sour Lake Station; August 2003) 
Figure 3-8 and Figure 3-9 show an overview and close-up of the installation for the encoder. As discussed above, the encoder provides the multiple functions of torsional vibration measurement and triggering of data acquisition for all dynamic channels. The bracket holding the encoder is mounted on the tripod shown in Figure 3-8, and the shaft connecting the encoder to the flywheel is also apparent in both figures. The cable evident in these figures connects the encoder to the DAS.

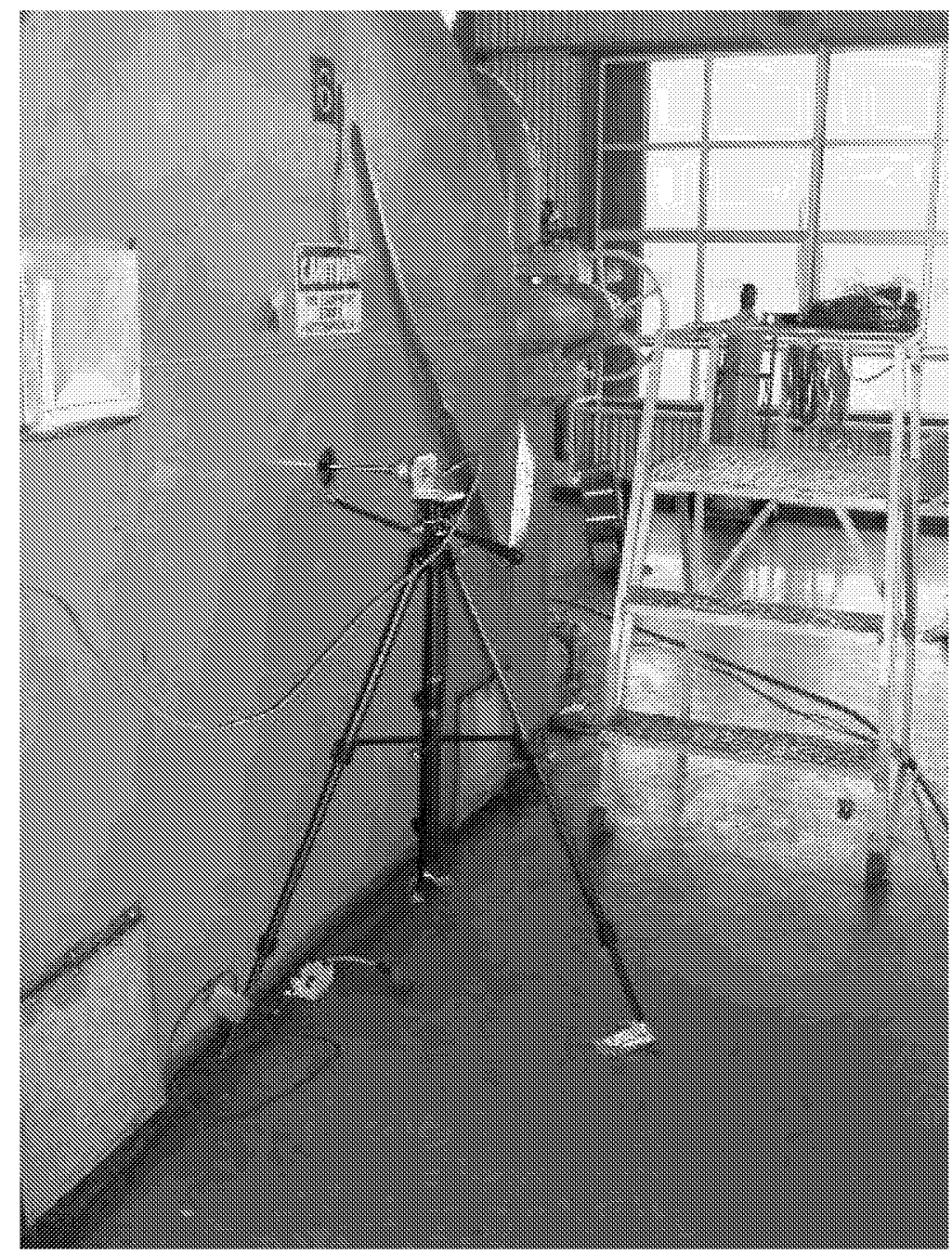

\section{Figure 3-8. Encoder, Outboard of Flywheel on Mounting Tripod (GMW10; Williams Sour Lake Station; August 2003)}

Figure 3-10 shows one of the velocity probes mounted on the back of the compressor to measure lateral vibration of the frame; there are two such installations, one at each end of the compressor. 


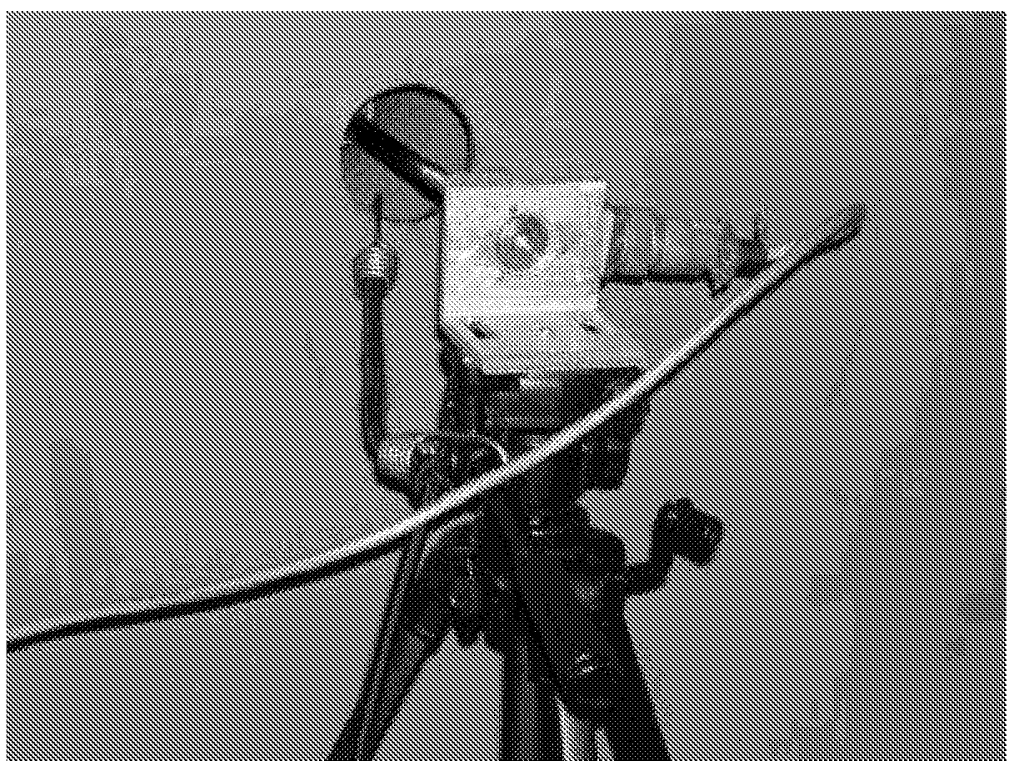

Figure 3-9. Detailed View of Encoder and Connection to Flywheel (GMW10; Williams Sour Lake Station; August 2003)

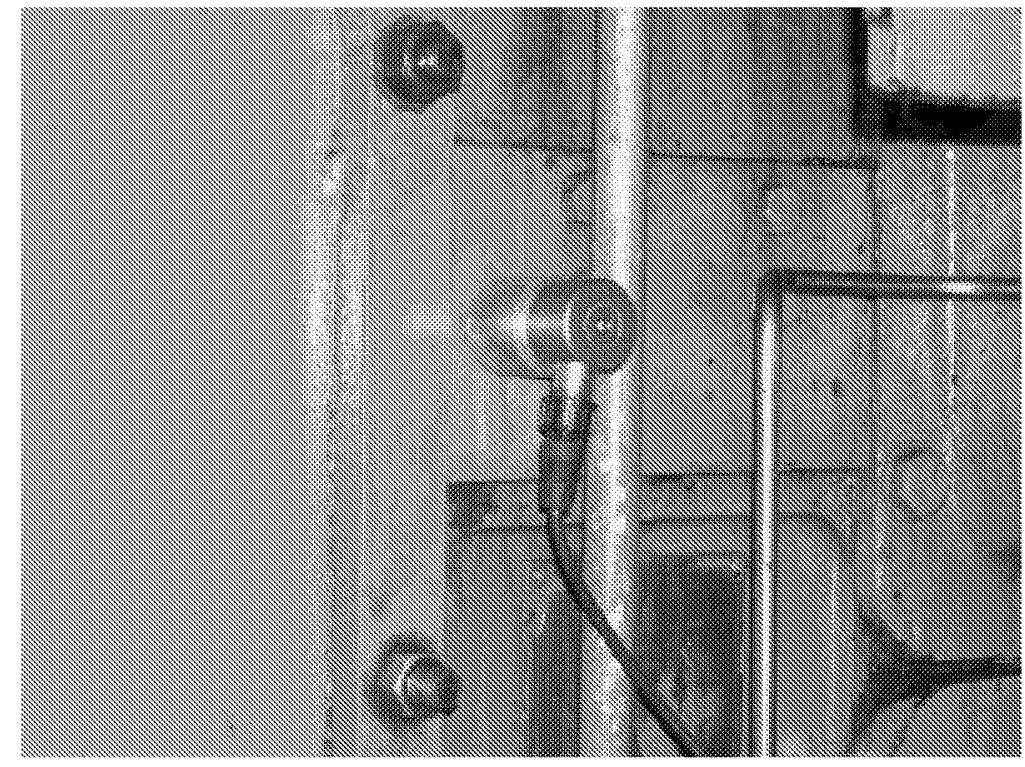

Figure 3-10. Accelerometer Mounted on Frame (GMW10; Williams Sour Lake Station; August 2003)

Figure 3-11 shows an installation of the crankshaft Strain Data Capture Module (SDCM) on a GMW10 at Williams' Station 40 (Sour Lake). The data acquisition system dedicated to one channel of crankshaft strain is seen in this figure mounted on the unstressed flat part of the crank throw. The lead from the strain gage is seen attached to the face of the crank web. The strain gage itself is hidden by the rod - since it is pushed so far up into the space between rod and web face. As previously described, the strain 
gage, cable, and single channel data acquisition system represent a standalone system with battery power which captures data unattended throughput a day of testing.

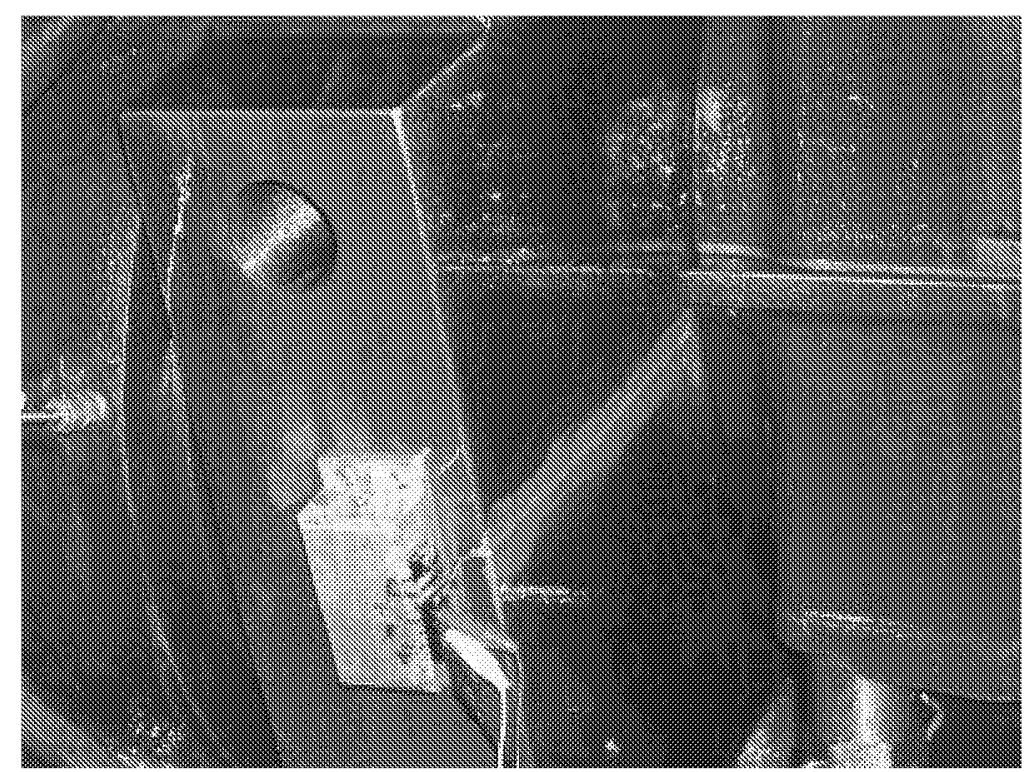

Figure 3-11. Strain Data Capture Module Installed (GMW10; Williams' Station 40 (Sour Lake); August 2003)

Figure 3-12 shows the SDCM installed on two throws at the Kinder Station (El Paso Station 823) - one throw with power rod only connected, and one throw with both power and compressor cylinders attached. Two connectors may be seen attached to the data acquisition system; this temporary condition allows the data acquired over the preceding day's testing to be downloaded to a computer for analysis, and to make the onboard memory available for another day's testing.

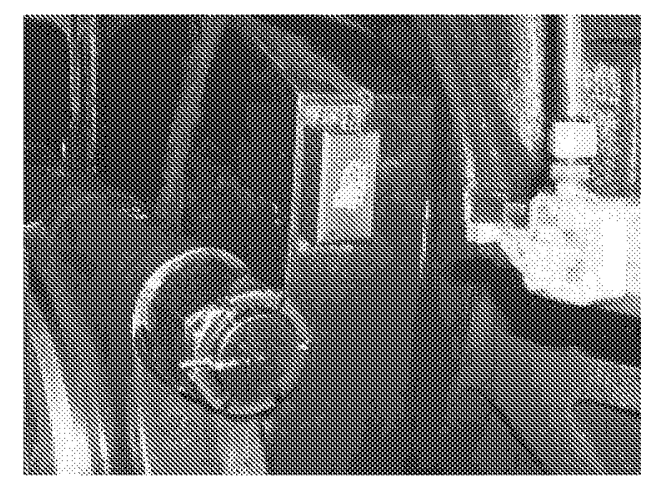

Throw 3

(Power \& Compressor)

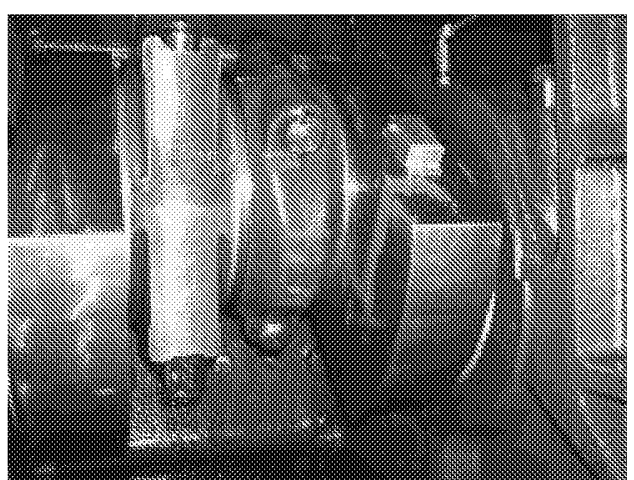

Throw 2

(Power Only)

Figure 3-12. SDCM Installation for Crankshaft Strain Measurements (HBA-6T; EI Paso Kinder Station; April 2003) 
Figure 3-13 shows the NGK combined $\mathrm{O}_{2} / \mathrm{NOx}$ sensor connected to a pipe already installed, which connects to the exhaust stack.

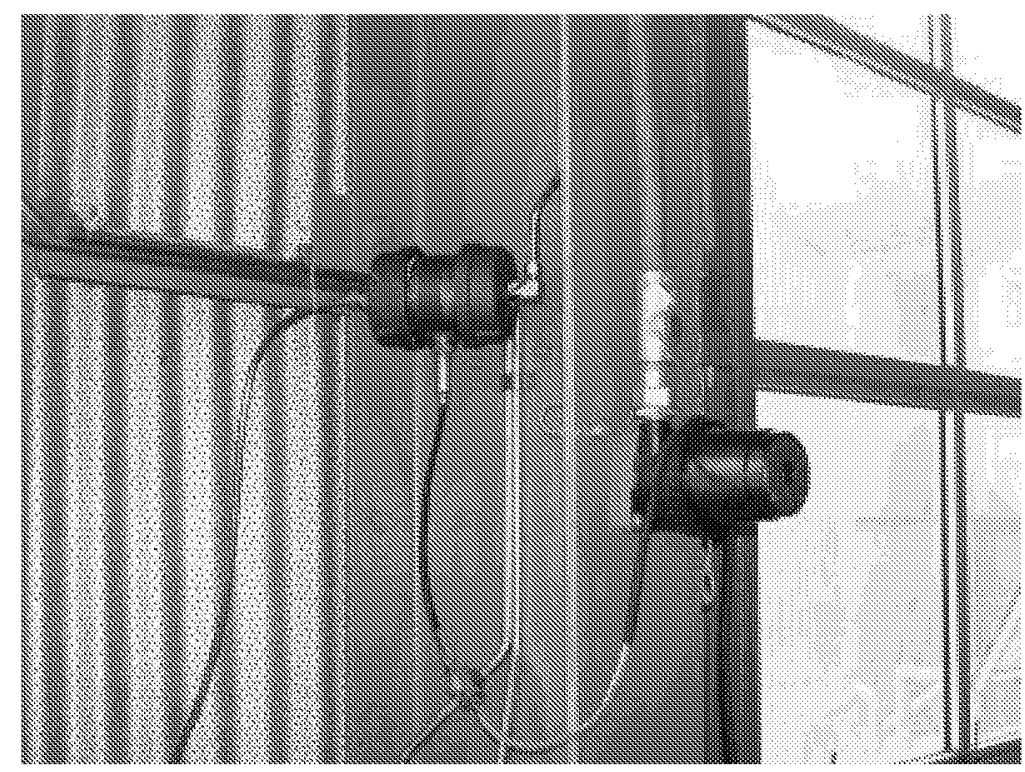

Figure 3-13. $\mathrm{O}_{2} / \mathrm{NO} \times$ Sensor and Connection to Line from Stack (GMW10; Williams Sour Lake Station; August 2003)

Figure 3-14 shows installations of the rod load monitor on the first HBA-6T tested, and on the first GMW10 tested. These installations are visible with the "dog-house" cover removed for installation. Once the installation is checked out and the cover re-installed, Figure 3-15 shows that only the antenna connection remains visible. The antenna connection is then cabled to the DAS. Both installations photographed show the rod load monitor in a battery-powered version, which is satisfactory for short term testing. As a device for long term monitoring, however, the rod load monitor must be self-powered. Figure 3-16 shows the self-powered Rod Load Monitor (RLM) installed on the second HBA-6T tested. This was the first successful operation of the RLM in self-powered data telemetry mode.

For the first test at TGP's Kinder, Louisiana station (April 15-17, 2003), the majority of these channels were successfully acquired as a coherent data set for every test condition. All channels were calibrated prior to the tests. 

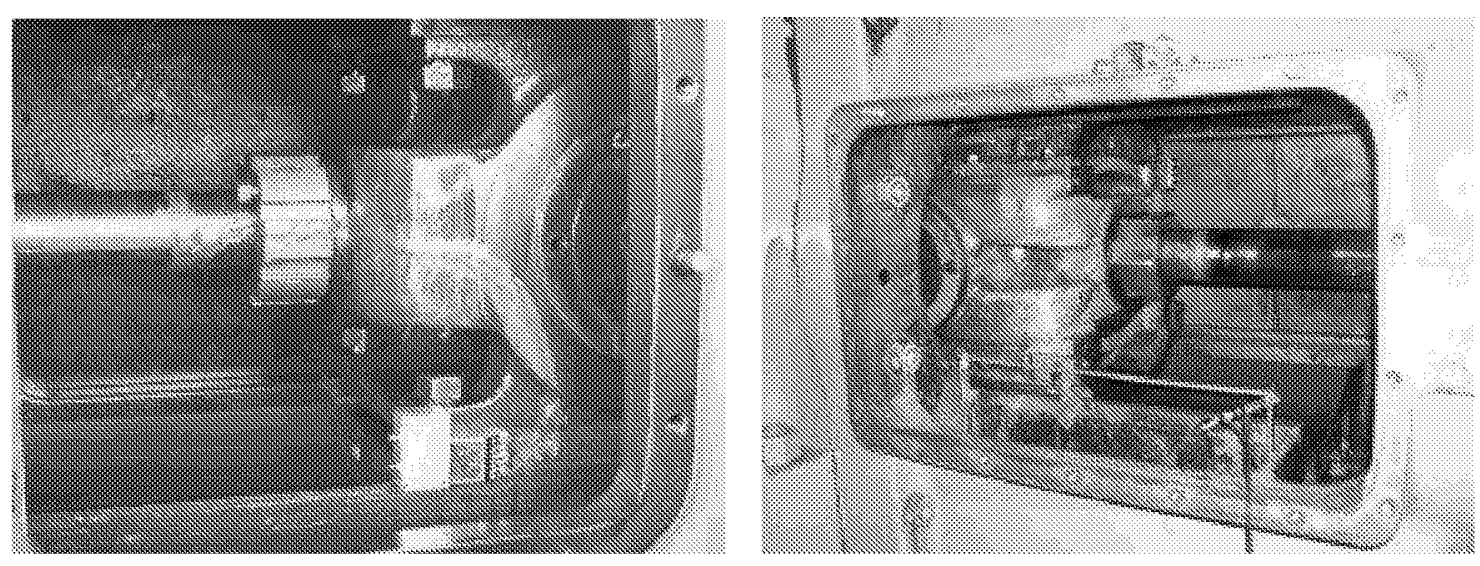

Figure 3-14. Installations of the RLM on HBA-6T (April 2003) and GMW10 (August 2003)

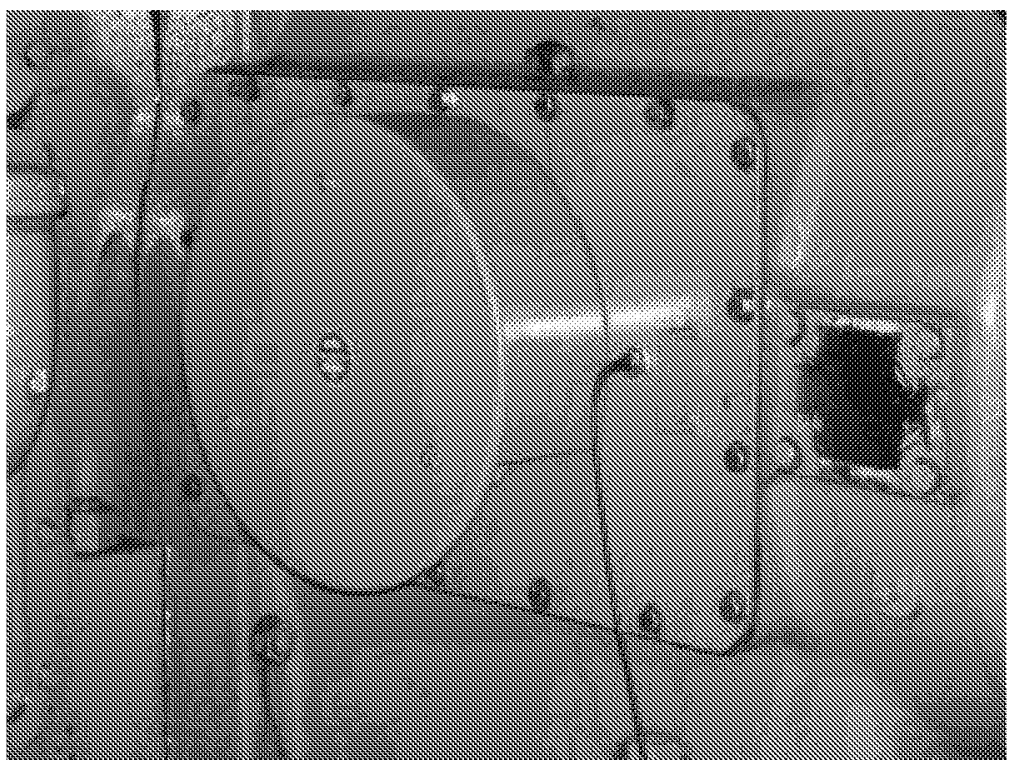

Figure 3-15. Cable from RLM Antenna (GMW10; Williams Sour Lake Station; August 2003)

However, a few of the channels listed above gave problems at the first site. The engine fuel flow meter was calibrated prior to the test, but it was discovered during the test that it was set for a much higher flow rate than was needed, and did not give useful data. The rod load monitor RF transmitter drifted too much. This is a development device and the underlying problem has now been corrected. The power cylinder \#1 pressure transducer gave suspect data, and this has proved more elusive than expected! The problem has finally been traced to an artifact of the data acquisition circuitry. The multiplexor was found to inject a charge, which most strongly influenced the power cylinder \#1 channel. Addition of a unity gain isolation amplifier was found to correct the problem. 


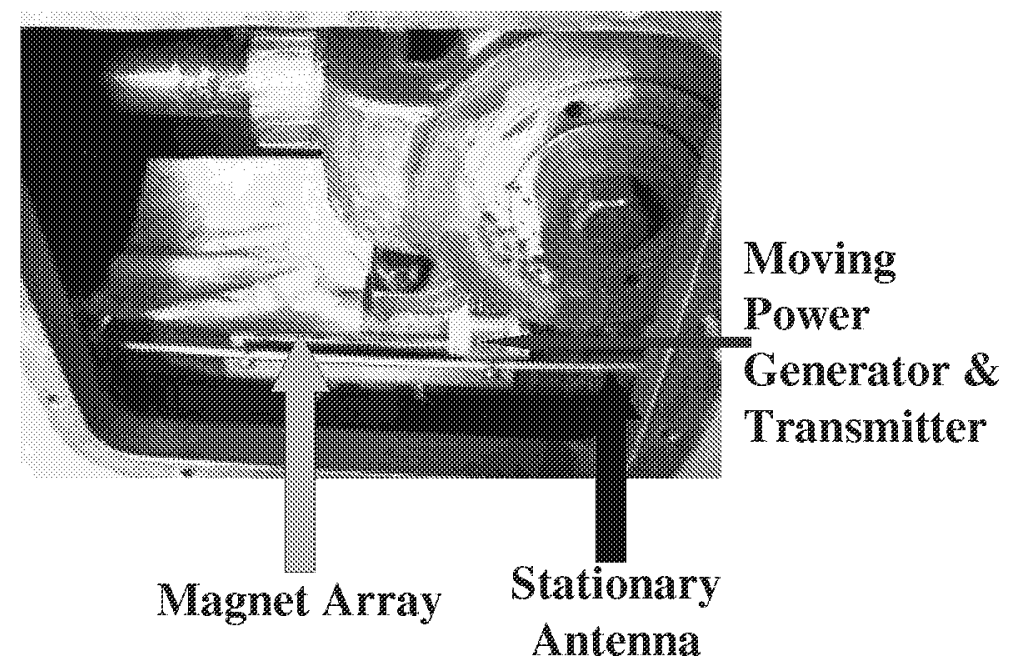

Figure 3-16. Self-Powered Rod Load Monitor (RLM)

At the second test site (Transco Station 40, Sour Lake, Texas, August 26-28, 2003), the fuel flow was successfully measured throughout the test series, and the problems obtained with fuel flow measurement at the first site should not reoccur. The rod load monitor worked successfully, although as subsequent results will show, a small amount of temperature drift was still encountered at the second test site. Exhaust manifold dynamic pressure was acquired, as well as air manifold pressure. Station records were used for suction and discharge pressure and temperature for the compressor.

Figure 3-17 shows the flow transmitter connected to the orifice taps in the fuel flow gas flow line for the second set of tests on an HBA-6T. 


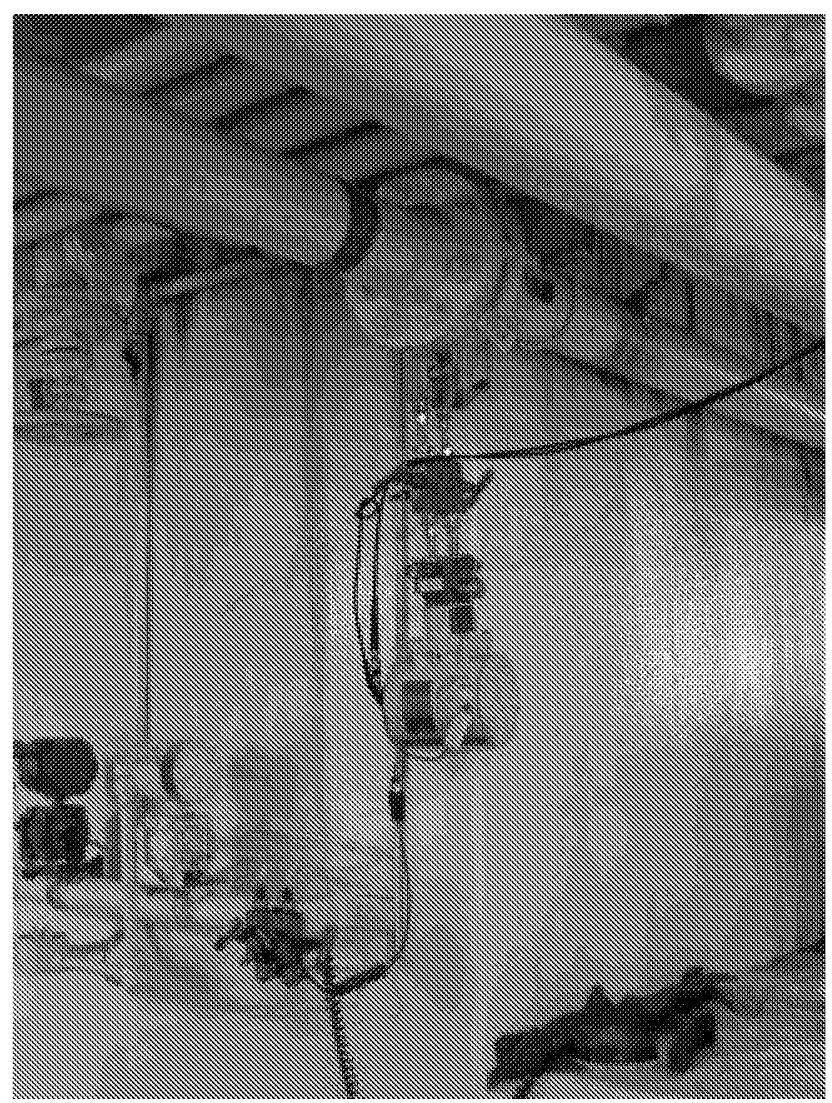

Figure 3-17. Fuel Flow Measurement using Emerson Flobas 103 Transmitter (HBA-6T; EI Paso Kinder Station; April 2004)

\subsection{Selection of Test Engine Models}

In Phase I, two different engine models were selected for testing and two different engines of each model have been tested. Data to guide this selection was obtained from an industry database of engines and compressors in gas transmission service, supported by PRCI. Table 3-1 and Table 3-2 were obtained by appropriate sorting of the database to show the top 10 engine models in terms of number installed (Table 3-1), and in terms of horsepower installed (Table 3-2). It may be seen that the GMW has the highest count (336) and the second highest installed power $(708,336 \mathrm{HP})$. The HBA is in the top six for both count $\left(6^{\text {th }}\right.$ with 223 ) and installed power $\left(5^{\text {th }}\right.$ with $\left.372,414 \mathrm{HP}\right)$. Thus, these two engines rank highly in terms of pipeline industry deployment. They also achieve diversity; one is made by Cooper, and one by Clark; one is a straight six and one is a V10. The HBA-6T is turbocharged; two different GMW units have been tested - one has a turbocharger and high-pressure fuel injection; the other has no turbocharger and standard fuel pressure. 
Table 3-1. High Count Engines in Gas Transmission - Sorted by Number (from 1998 Coerr Database)

\begin{tabular}{|c|c|c|c|c|c|c|}
\hline nodel & sum of Rated 18 & Cotrit & cumutatise & & & Connents \\
\hline GMW & 708336 & 336 & 336 & Top 6 by HP or \# & Top 10 by HP or \# & Just GMW - No GMWA GMWC \\
\hline KVG & 330918 & 296 & 632 & & Top 10 by HP or \# & \\
\hline TLA & 672085 & 280 & 912 & Top 6 by HP or \# & Top 10 by HP or \# & \\
\hline GMV & 270489 & 269 & 1181 & & Top 10 by HP or \# & Just GMV - No GMVB, GMVH \\
\hline KVS & 441455 & 233 & 1414 & Top 6 by HP or \# & Top 10 by HP or \# & \\
\hline $1 \mathrm{BBA}$ & 372414 & 223 & 1637 & Top 6 by HP or \# & Top 10 by HP or \# & \\
\hline GMVH & 302242 & 179 & 1816 & & Top 10 by HP or \# & \\
\hline Tov & 872106 & 155 & 1971 & & Top 10 by HP or \# & Includes TCV Thru TCVD \\
\hline$\llcorner-7042$ & 154528 & 150 & 2121 & & & Small High-Speed Waukesha \\
\hline $\mathrm{BA}$ & 207271 & 140 & 2261 & & & Old \& Small \\
\hline
\end{tabular}

Table 3-2. High Count Engines in Gas Transmission - Sorted by Horsepower (from 1998 Coerr Database)

\begin{tabular}{|c|c|c|c|c|c|c|}
\hline Model & Suri of Rated HP & count & curnulatrve ur & 1.68 & 2 & 4 Comnents \\
\hline TCV & 872106 & 155 & 872106 & & Top 10 by HP or \# & High HP \\
\hline GMW & 708336 & 336 & 1580442 & Top 6 by HP or \# & Top 10 by HP or \# & \\
\hline TLA & 672085 & 280 & 2252527 & Top 6 by HP or \# & Top 10 by HP or \# & \\
\hline kVs & 441455 & 233 & 2693982 & Top 6 by HP or \# & Top 10 by HP or \# & \\
\hline HBA & 372414 & 223 & 3066396 & Top 6 by HP or \# & Top 10 by HP or \# & \\
\hline$v-250$ & 335450 & 93 & 3401846 & & & \\
\hline KVG & 330918 & 296 & 3732764 & & Top 10 by HP or \# & \\
\hline w-330 & 315656 & 56 & 4048420 & & & High HP, Recent \\
\hline GMVt & 302242 & 179 & 4350662 & & Top 10 by HP or \# & \\
\hline GMV & 270489 & 269 & 4621151 & & Top 10 by HP or \# & \\
\hline
\end{tabular}




\section{RESULTS AND DISCUSSION: FIRST TEST ON AN HBA-6T}

\subsection{TyPical Data}

Figure 3-5 has already shown the HBA-6T tested at El Paso's Station 823 (Kinder, Louisiana). The next nine figures are initial data for the first HBA-6T tests and some preliminary data summaries or expressions are presented. These are followed by focused analyses aimed at developing relationships from the data.

Figure 4-1 shows a sample of pressure data from both the power cylinders (on the left of the figure) and from the compressor cylinders (on the right). There are six traces in the power cylinder plot, but the cylinder \#1 pressure transducer was suspect. These traces are averaged over 32 cycles. Even when discounting the possibly suspect trace of cylinder \#1, the spread between highest and lowest peak pressure is clear. The PFP spread in this example is 190 PSI $(1.3 \mathrm{Mpa})$. This plot simply presents representative data at some stages in the test program and represents neither highest nor lowest spread. Though not shown by this figure, the cycle-to-cycle variation for any cylinder is also significant for this two-stroke engine. Because cylinder pressure varies with time and across cylinders, it is important to distinguish how spread is expressed. Subsequent report sections will refer to the "average instantaneous spread," which is the difference between the maximum and minimum peak-firing pressure across the cylinders in one engine revolution averaged over many cycles. These sections will also refer to the average peak-firing pressure spread, which is the difference between maximum and minimum pressure as calculated from the time-averaged pressure in each cylinder.

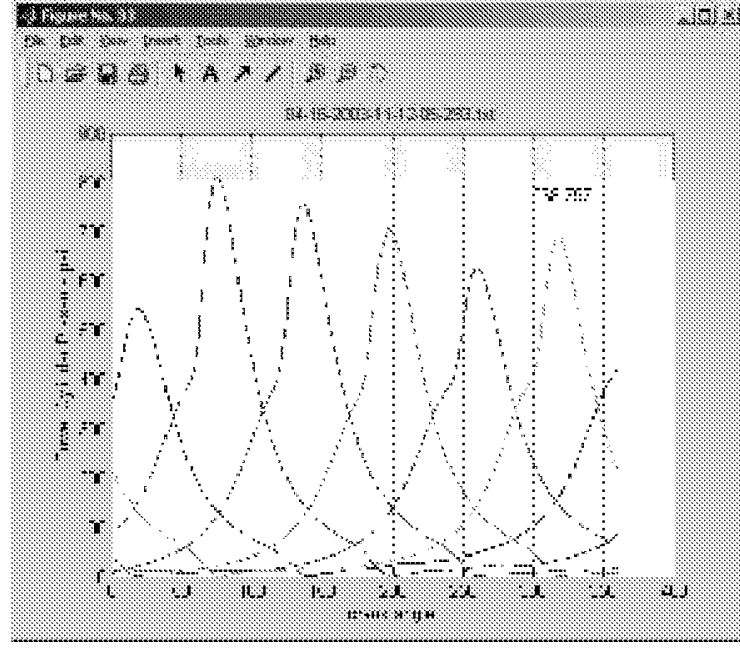

Power Cylinder Pressures

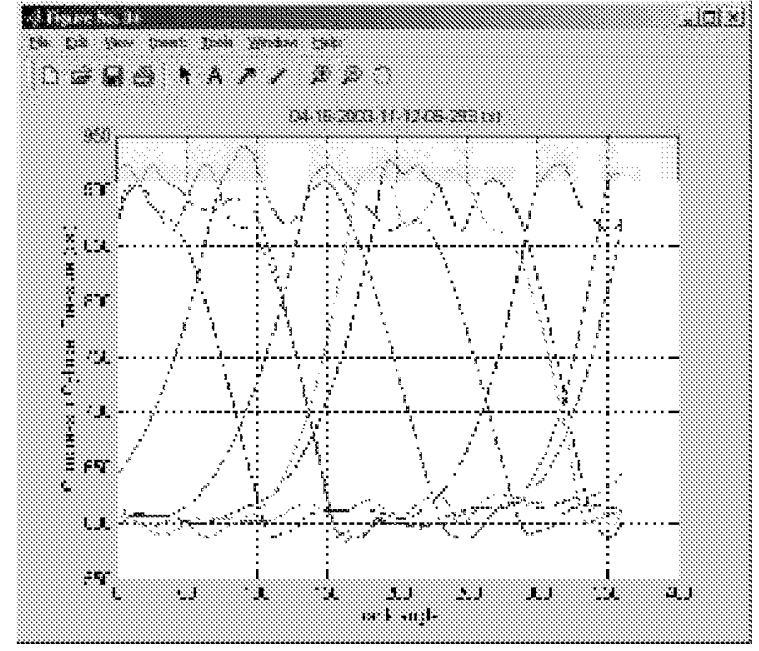

Compressor Cylinder Pressures

Figure 4-1. Typical Data Sets; HBA-6T; Test \#1 (EI Paso Station 823 (Kinder); April 2003) 
The compressor cylinders exhibit less spread between highest and lowest peak pressure. This is, in part, because discharge pressure pegs the highest cylinder pressure quite closely. Close examination shows seven compressor traces - this represents head and crank end from three cylinders and head end only for one cylinder. The crank end of one cylinder was deactivated, which is one convenient means of capacity control.

Further typical data is shown in Figure 4-2. Here, we see the inlet air manifold pressure (on the left) and the crankshaft rotational velocity (on the right). Both these quantities are presented in the upper frames as the variation with crank angle from zero to 360 degrees, and in the lower frame as a spectrum showing variation with engine order from one to one hundred. The inlet air manifold pressure clearly varies quite widely over one revolution (1.8 PSI or 12.4 Kpa peak-to-peak variation out of about 7.8 PSI or $53.8 \mathrm{Kpa}$ ). The spectrum shows significant content out to at least the $13^{\text {th }}$ order. This specific measurement was taken at the flywheel end of the air manifold (as previously shown in Figure 3-5).

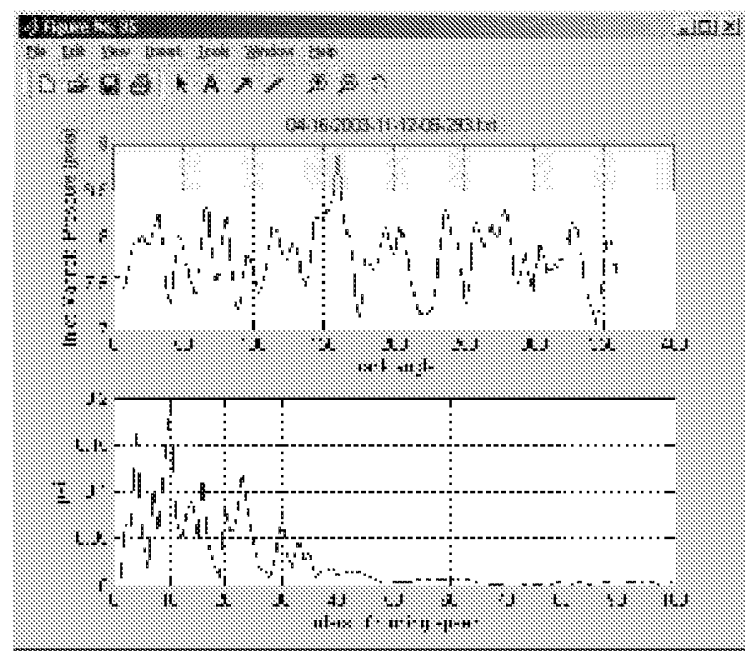

Inlet Air Manifold Pressure

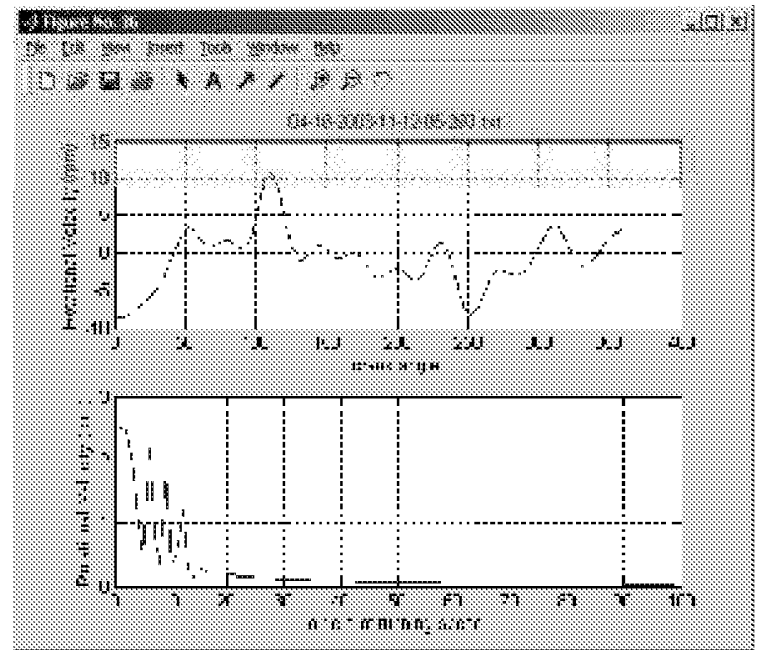

Rotational Velocity

Figure 4-2. Typical AMP and IRV Data Sets; HBA-6T; Test \#1 (EI Paso Station 823 (Kinder); April 2003)

The crankshaft velocity varies in one revolution by over 18 RPM peak-to-peak out of an average of about 300 RPM (6\% variation). The spectral content of this variation in angular velocity is mainly concentrated in the first 12 orders.

Figure 4-3 presents further quantification of air manifold pressure (AMP or MAP) variation over 36 successive data sets acquired with different engine balance conditions. The average peak-to-peak variation is about $25 \%$ of the average, and it ranges from $22.6 \%$ to $26.9 \%$. This AMP variation could be a significant contributor to imbalance or spread between cylinders, as will be subsequently discussed. 


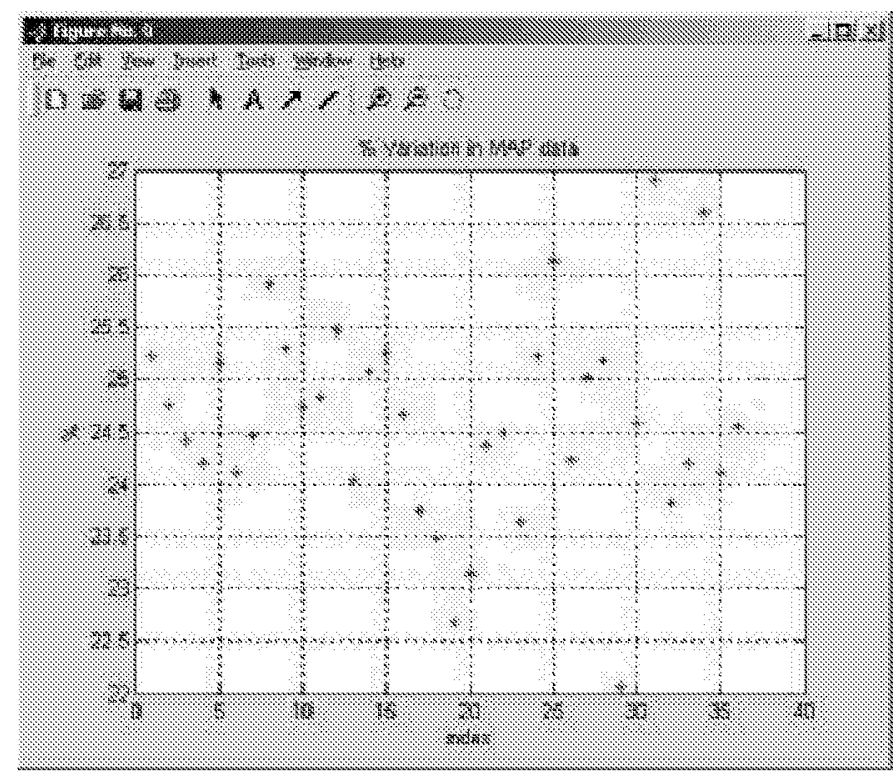

Figure 4-3. AMP Variation Summary; HBA-6T; Test \#1 (EI Paso Station 823 (Kinder); April 2003)

Figure 4-4 shows compressor Differential Indicated Power (DIP) for head and crank ends of the compressor in percent of indicated power. DIP is a measure of the cylinder power lost to flow resistance; thus, low DIP leads to high thermal efficiency, and based on these DIP values between 3.5 and $5.5 \%$, the efficiency would be expected to be high.

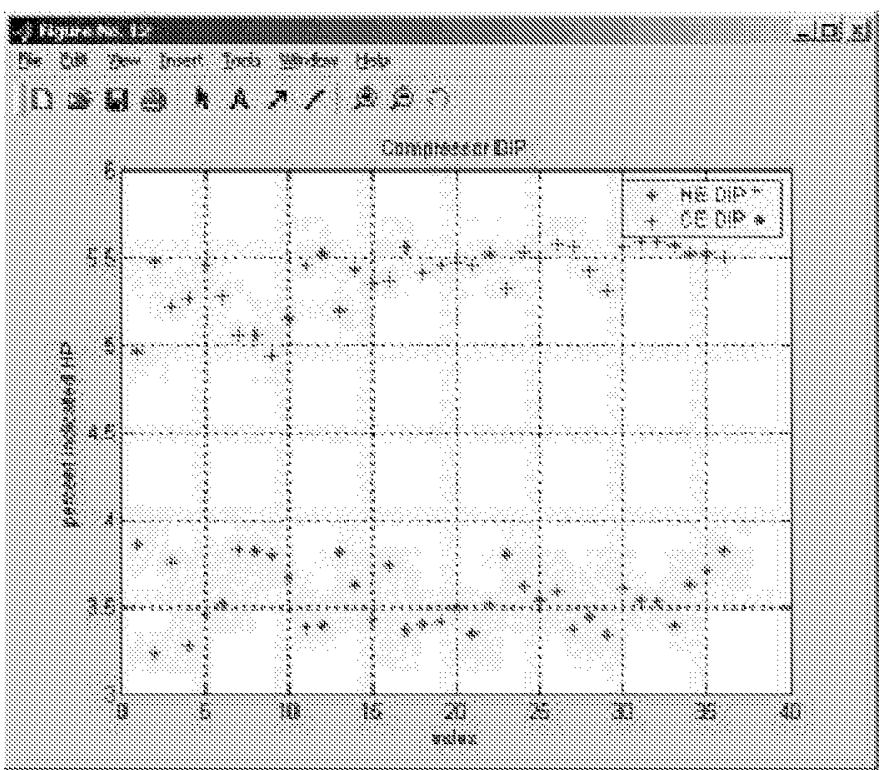

Figure 4-4. Compressor Performance Data; HBA-6T; Test \#1 (Head and Crank End DIP); (EI Paso Station 823 (Kinder); April 2003) 
Figure 4-5 confirms efficiencies across 36 data sets range from a low of $90.7 \%$ to a high of $91.5 \%$. A compressor thermal efficiency survey conducted by SwRI for GMRC a few years ago, based on measured enthalpy rise, showed that 91 or $92 \%$ was about the best achieved on any pipeline industry compressor. The median thermal efficiency for the pipeline industry, based on this survey, was about $79 \%$.

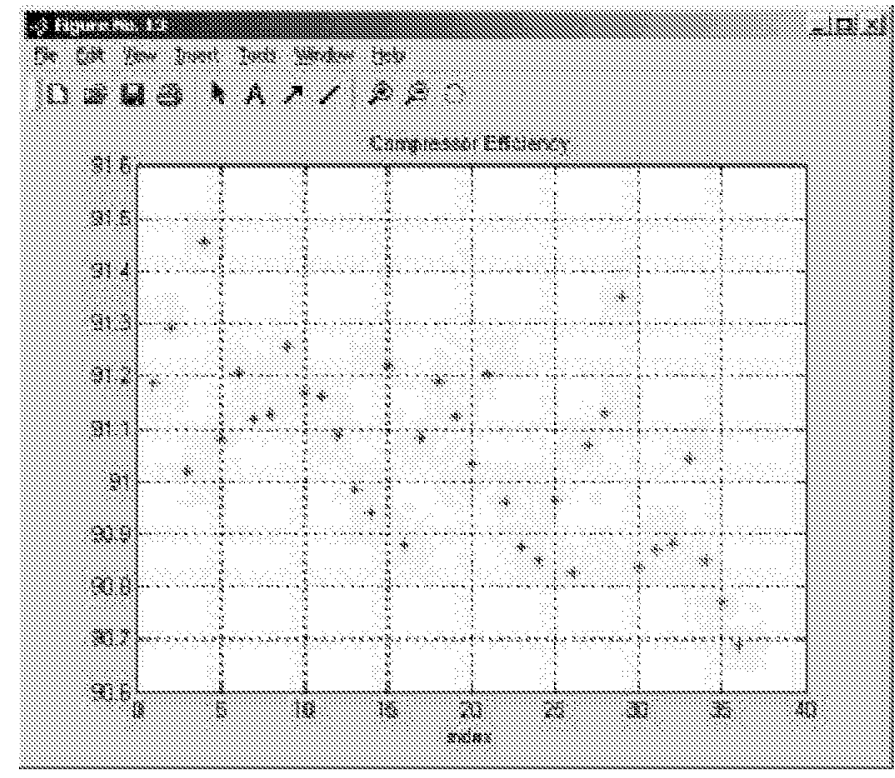

Figure 4-5. Compressor Efficiency Data; HBA-6T; Test \#1; (EI Paso Station 823 (Kinder); April 2003)

Thus, based on the cylinder pressure data and differential power, the first HBA-6T tested is operating at a high percentile efficiency for the industry. This is a significant, positive result for several reasons: 1) it represents efficient use of fuel gas; 2) it helps lower the ratio of emissions to useful compression power; 3 ) it leads to high available capacity; if at any time a compressor's capacity is limited because the load on the engine is at the safe limit for that engine, then any losses in the compressor represent engine capacity, which is unavailable as useful energy to be imparted to the transported gas. This compressor has maximized the engine capacity available for gas energy. The result is significant also because it sets a benchmark for the industry; if all compressors could consistently reach this level of compressor efficiency, a significant increase in industry-wide capacity would be achieved.

Figure 4-6 shows typical waveforms of crankshaft dynamic strain from the strain data capture module- one from a crank throw with both power and compressor cylinders acting on its crank pin, and one from a crank throw with only a power cylinder acting on its crank pin. Figure 3-12 has shown how the SDCM was installed on these two throws. The two second data snapshots in Figure 4-6 cover about 10 revolutions and show significant differences, by almost a factor of two in the magnitude of the peak-to-peak variation for the throw with both power and compressor rods attached when compared to the throw with power rod only. This represents significant nonuniformity along the 
crankshaft in the potential for fatigue damage as the crankshaft transmits power to the compressor cylinders.

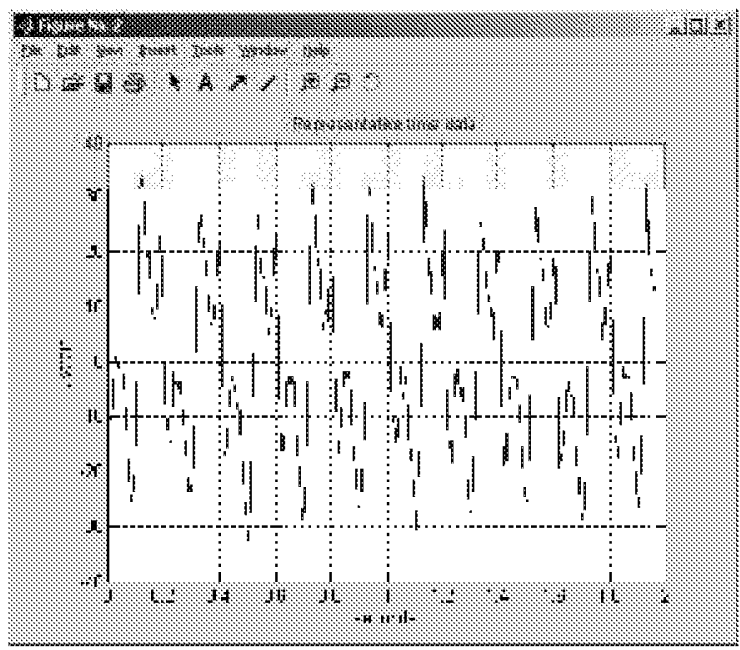

Throw 3

(Power \& Compressor)

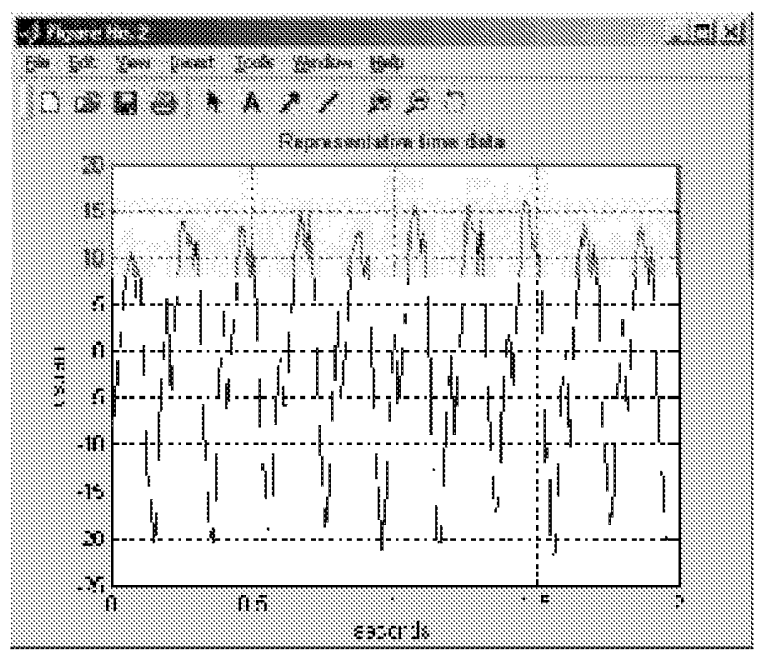

Throw 2

(Power Only)

Figure 4-6. Typical SDCM Waveform; HBA-6T; Test \#1; (EI Paso Station 823 (Kinder); April 2003)

Figure 4-7 shows the variation in peak-to-peak microstrain from the SDCMs on the same two throws over a 10-hour test period. Here, a further difference between the power and compressor throw and the power only throw becomes apparent - the throw which drives a compressor throw directly, experiences pronounced spikes in the strain, which differ in magnitude from the normal variation. The throw which carries a power cylinder connecting rod does not exhibit such distinct "spikiness".

Figure 4-8 shows the variation in strain spectra (first to eighth orders) from these two throws over the period of the test. Of primary interest, here, is the higher relative magnitude of second and third orders in the strain from the combination throw as opposed to the power only throw.

Figure 4-9 compares the first eight orders in the strain spectra from these two throws over the period of the test. Again, this figure shows higher relative magnitude of second and third orders in the strain from the combination throw when compared to the power only throw. 


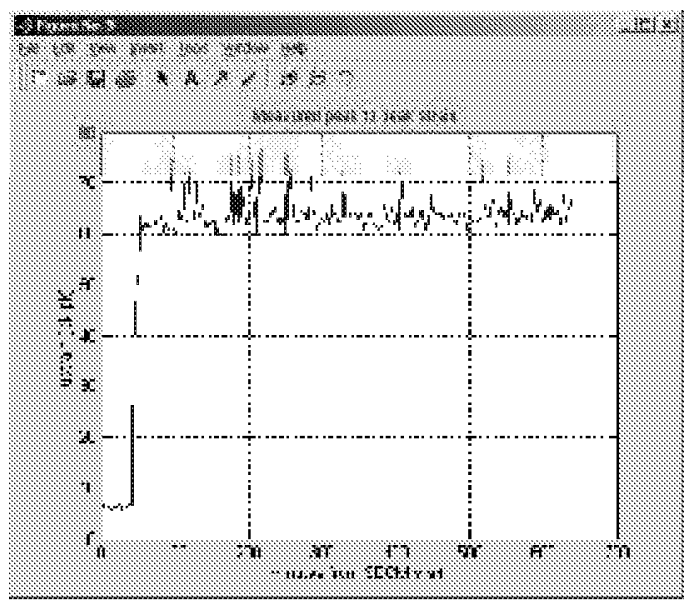

Throw 3

(Power \& Compressor)

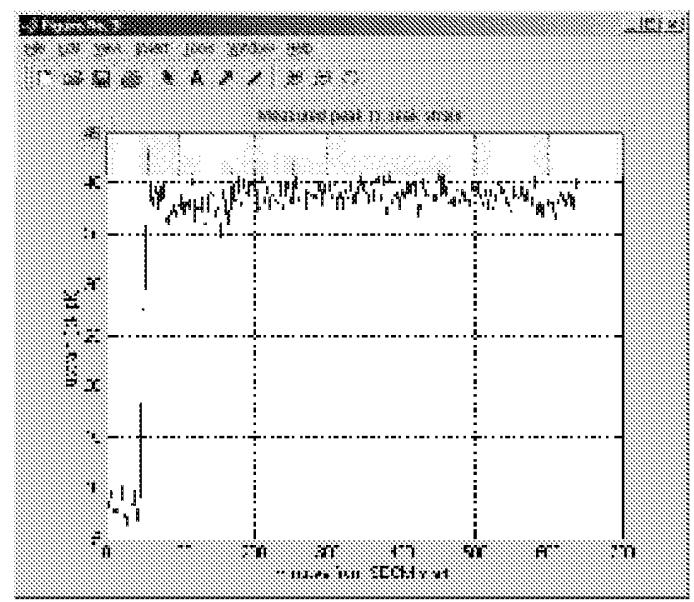

Throw 2

(Power Only)

Figure 4-7. Overall Peak-to-Peak Strain Summary; HBA-6T; Test \#1 (EI Paso Station 823 (Kinder); April 2003)

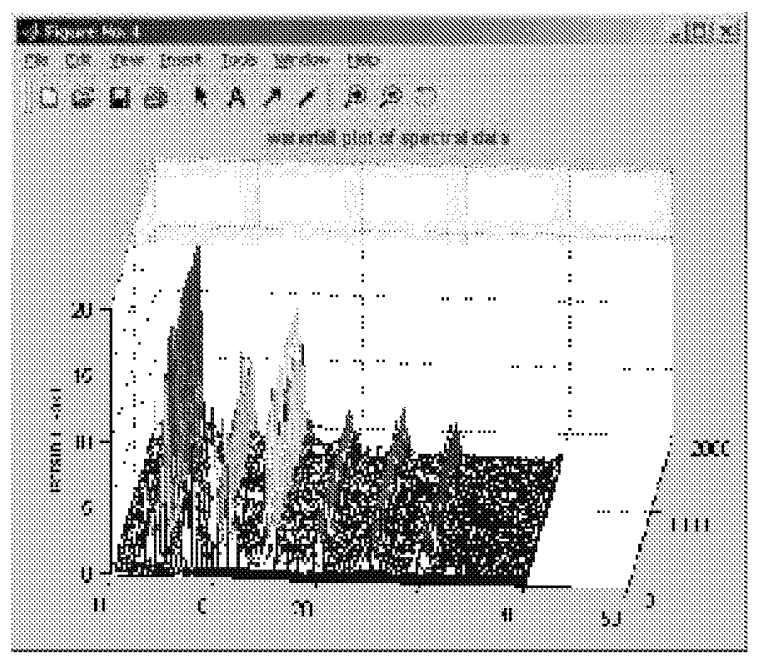

Throw 3

(Power \& Compressor)

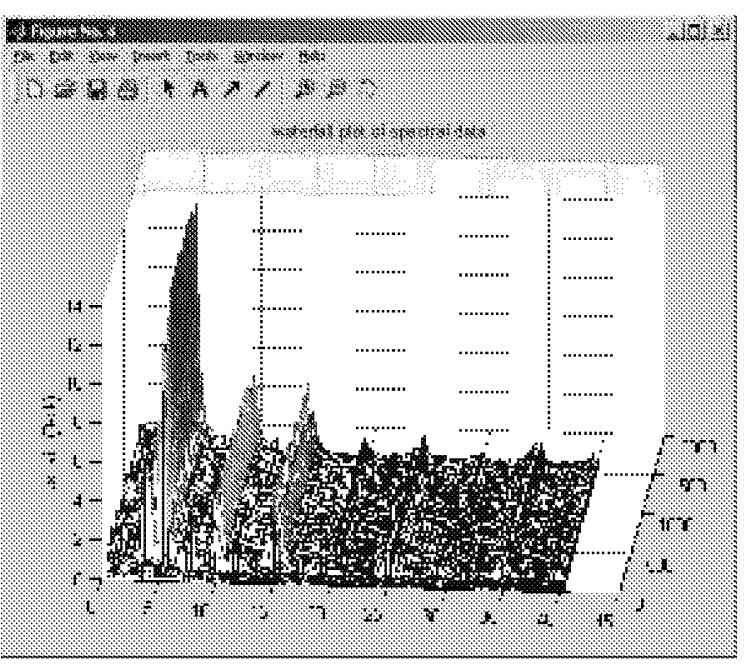

Throw 2 (Power Only)

Figure 4-8. Raster Plots of SDCM Data; HBA-6T; Test \#1; (EI Paso Station 823 (Kinder); April 2003) 


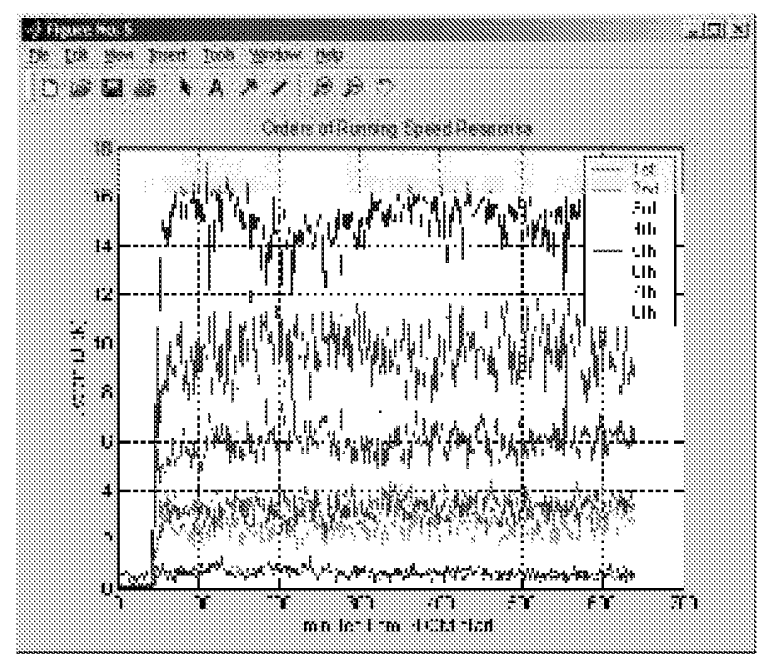

Throw 3

(Power \& Compressor)

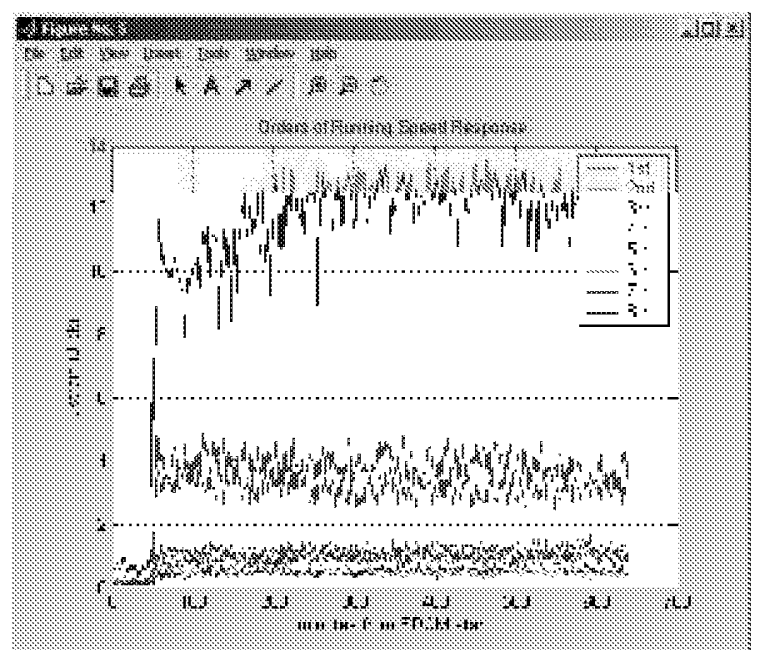

Throw 2

(Power Only)

Figure 4-9. Order Summary of SDCM Data; HBA-6T; Test \#1; (EI Paso Station 823 (Kinder); April 2003)

\subsection{SupplementaRy ANALYSIS Of DATA FROM HBA-6T, TEST \#1}

\subsubsection{Relating Crankshaft Strain Characteristics to Life}

The significance of crankshaft strain variation is difficult to define on an absolute basis, because laboratory fatigue data does not exist for crankshaft materials out anywhere close to the number of cycles to which a crankshaft is exposed over its lifetime (over $4.5 \times 10^{9}$ revolutions for a $250,000-h r$. crankshaft). In essence, the long life crankshafts are the fatigue testers! The simple assumption in classical fatigue analysis is that an endurance limit exists - according to this assumption, if dynamic strains are below the endurance limit, then the component in question will last forever. Data makes it clear for most materials that the variation of cyclic stress amplitude with cycles to failure at that amplitude (the SN diagram) becomes flatter when the number of cycles exceeds about $10^{7}$, but whether it is truly flat or just has a gradual slope is not so clear. One explanation for the observed fact that some high hour crankshafts eventually fail is the existence of a gradual slope in the $\mathrm{SN}$ diagram. If an endurance limit existed, the crankshaft should not fail unless the loads it experiences have changed, or it has accumulated damage from occasional loads substantially higher than it sees under normal operation.

To calculate possible life implications of the measured strain data, Figure 4-10 shows histograms of stress level for the two measured throws. These histograms give the frequency of occurrence, using a method called "rainflow counting" of different strain ranges in a two-second sample. The power/compressor combination throw clearly produces several stress cycles at nearly twice the highest stress level compared to the power only throw. 


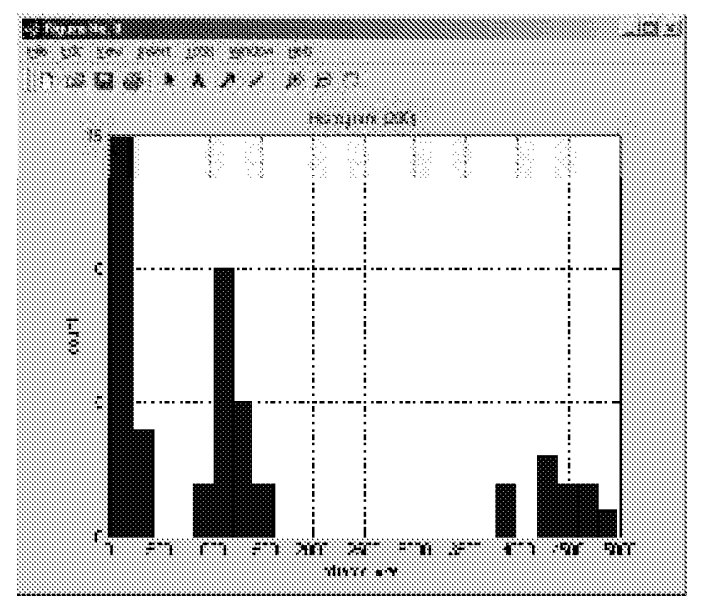

Throw 3

(Power \& Compressor)

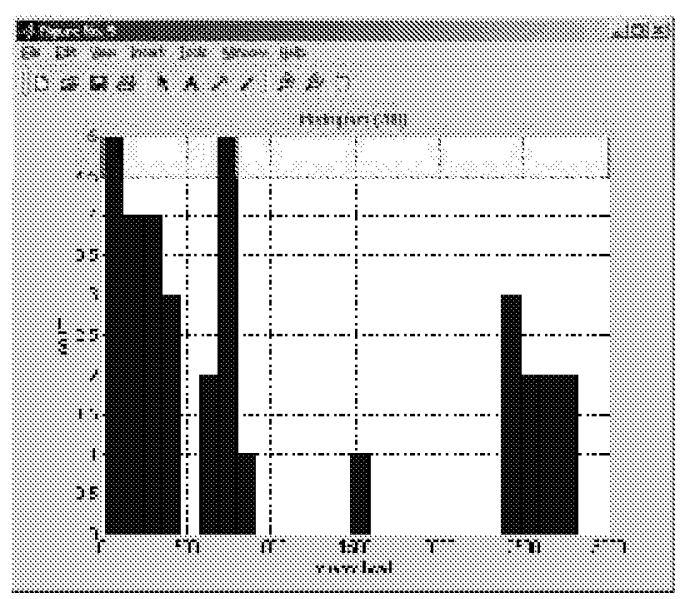

Throw 2

(Power Only)

Figure 4-10. Sample Histogram of Stress Reversals (2-Second Interval); (El Paso Station 823 (Kinder); April 2003)

Figure 4-11 seeks to show the potential implication in life of the stress level and occasional spikes from the combination throw compared to the "power only" throw. It assumes a gradual slope to the long life portion of the $\mathrm{SN}$ diagram with slope guided by experience on a few long life shafts. It is emphasized that this figure does not provide absolute information, just comparison. The hours to failure for the power-only throw are projected at least one thousand times the hours to failure for the power/compression combination. The spikes produce momentary damage accumulation, such that, if the engine were always to run under this momentary condition, life would be reduced by a factor of more than 10. Thus, the potential life implications of the observed stress levels could be significant, but are not in themselves conclusive. 


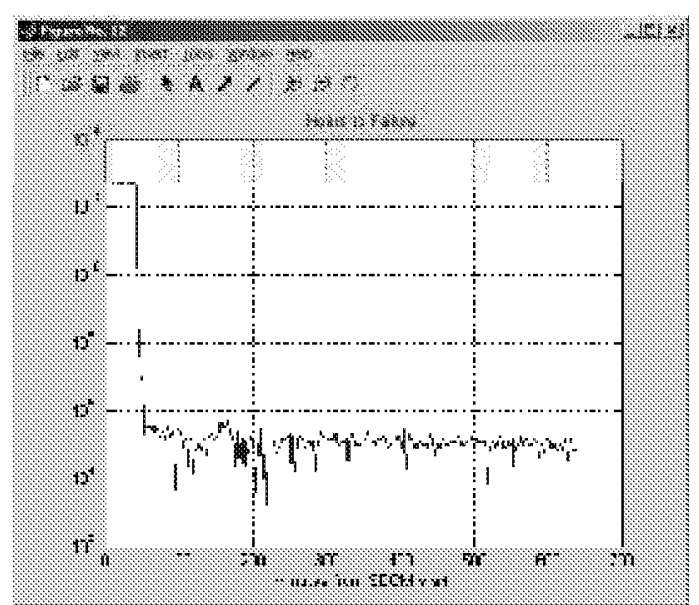

Throw 3

(Power \& Compressor)

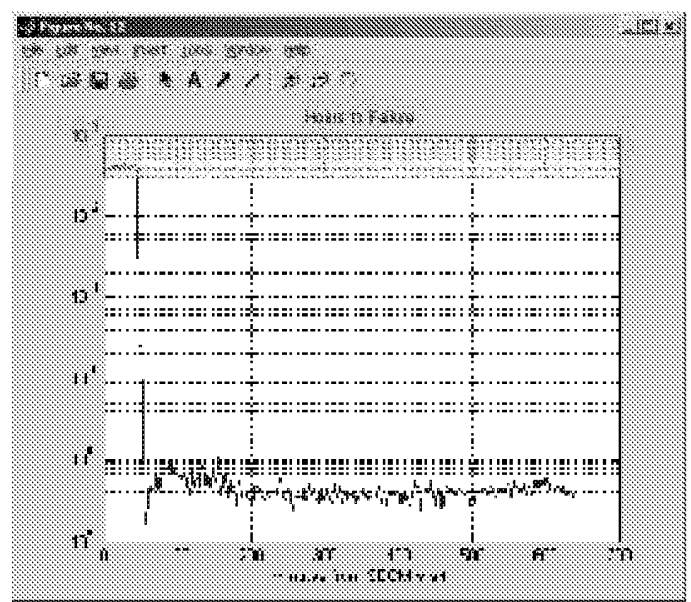

Throw 2

(Power Only)

Figure 4-11. Comparative Life Estimate; HBA-6T; Test \#1;

(EI Paso Station 823 (Kinder); April 2003)

\subsubsection{Relating Crankshaft Integrity to Combustion Balance}

This subsection explores the relationship of possible cyclic strain damage to the state of engine balance. As background, Figure 4-12 shows the changes in average peak-firing pressure spread and the variation in average instantaneous spread during a 6-hour test period in which various balancing strategies were investigated. The various timing and balancing approaches (Peak-Firing Pressure (PFP) balancing and Coefficient of Variance (COV) balancing) are noted. Conventional PFP balancing, starting just after 10:09 AM, reduces the average PFP spread almost by a factor of two, but has a smaller $(20 \%)$ relative influence on reducing the average instantaneous spread. Increasing the timing to 13 degrees BTDC enabled further reduction in average PFP spread to about 80 PSI. Turning all fuel valves open $100 \%$ increased both measures of spread to 250 and 300 PSI, respectively. PFP balancing from this condition, now with timing at 14 degrees BTDC, reduced average PFP spread to about 75 PSI. Starting at 1:14 PM, COV balancing (increasing fuel flow to the cylinders with highest COV for cycle-to-cycle variation) increased both measures of spread, but reduced the difference between them.

In Figure 4-13, a measure of the "smoothness" of the crankshaft dynamic stress variation is plotted against time. This measure, referred to as T70, equals the time in minutes since the previous crankshaft dynamic strain above 70 microstrains was observed. Also in Figure 4-13 is the difference between instantaneous and average PFP spread values, which provides an intuitive measure of the smoothness of operation. Both PFP and COV balancing lead to evidence of increased time between high strain events. 
Unit Spread Characteristics

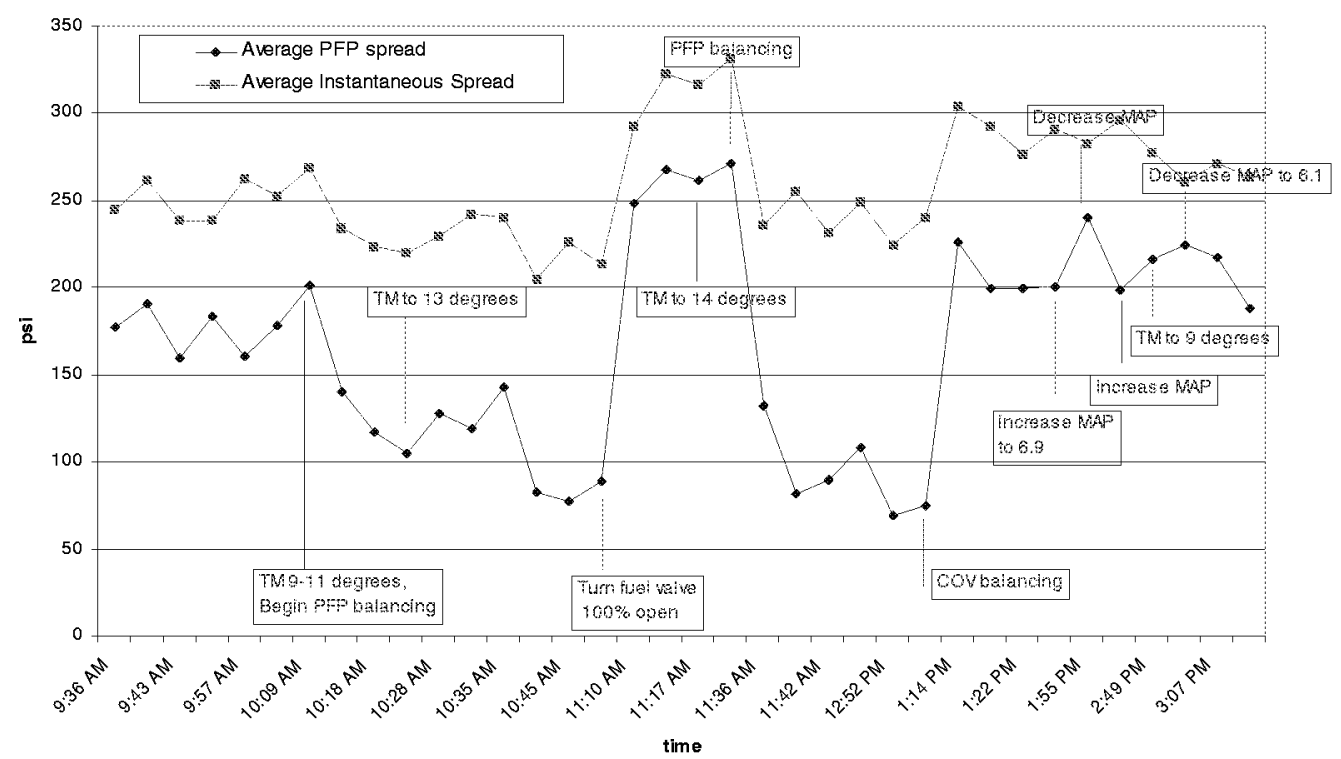

Figure 4-12. Unit Peak-Firing Spread Test Characteristics; HBA-6T; Test \#1; (EI Paso Station 823 (Kinder); April 2003)

Comparison of Key PFP Statistics with T70 data

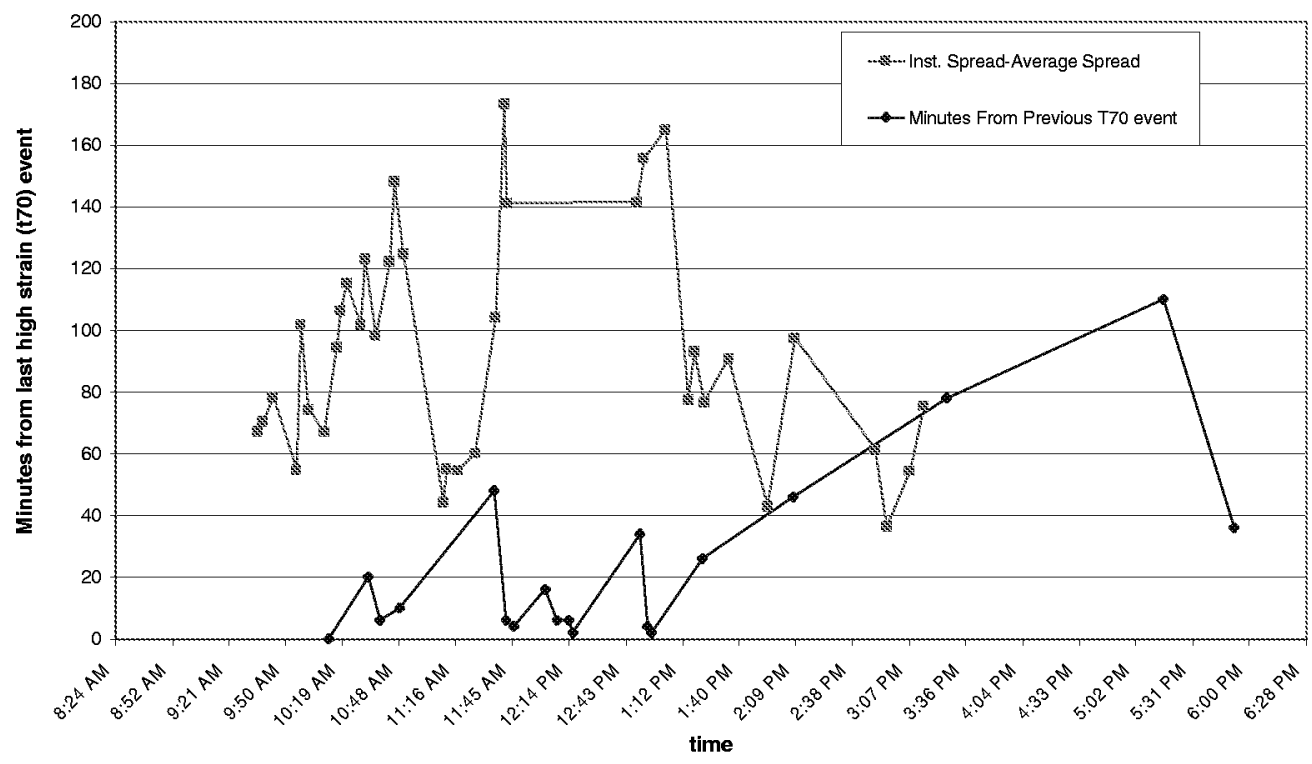

Figure 4-13. Comparison of Key PFP Statistics (Instantaneous Speed - Average Spread); and Time from Last 70+ Microstrain Event; HBA-6T; Test \#1;

(EI Paso Station 823 (Kinder); April 2003) 
COV balancing provides clear evidence of an improvement in engine smoothness. Unfortunately, the ability to pursue COV balancing was limited by the available range in fuel valve adjustments coupled with air imbalance, which will be discussed further below after vibration is discussed.

\subsubsection{Relating Operational Severity to Torsional and Lateral Vibration}

Figure 4-14 and Figure 4-15 presents bearing centerline vibration at the flywheel and oil pump ends of the unit as raster plots (throws 1 and 6). The signals stay remarkably constant during the changes in balance approach and spread discussed previously and, therefore, do not appear promising as measures of severity of operating conditions.

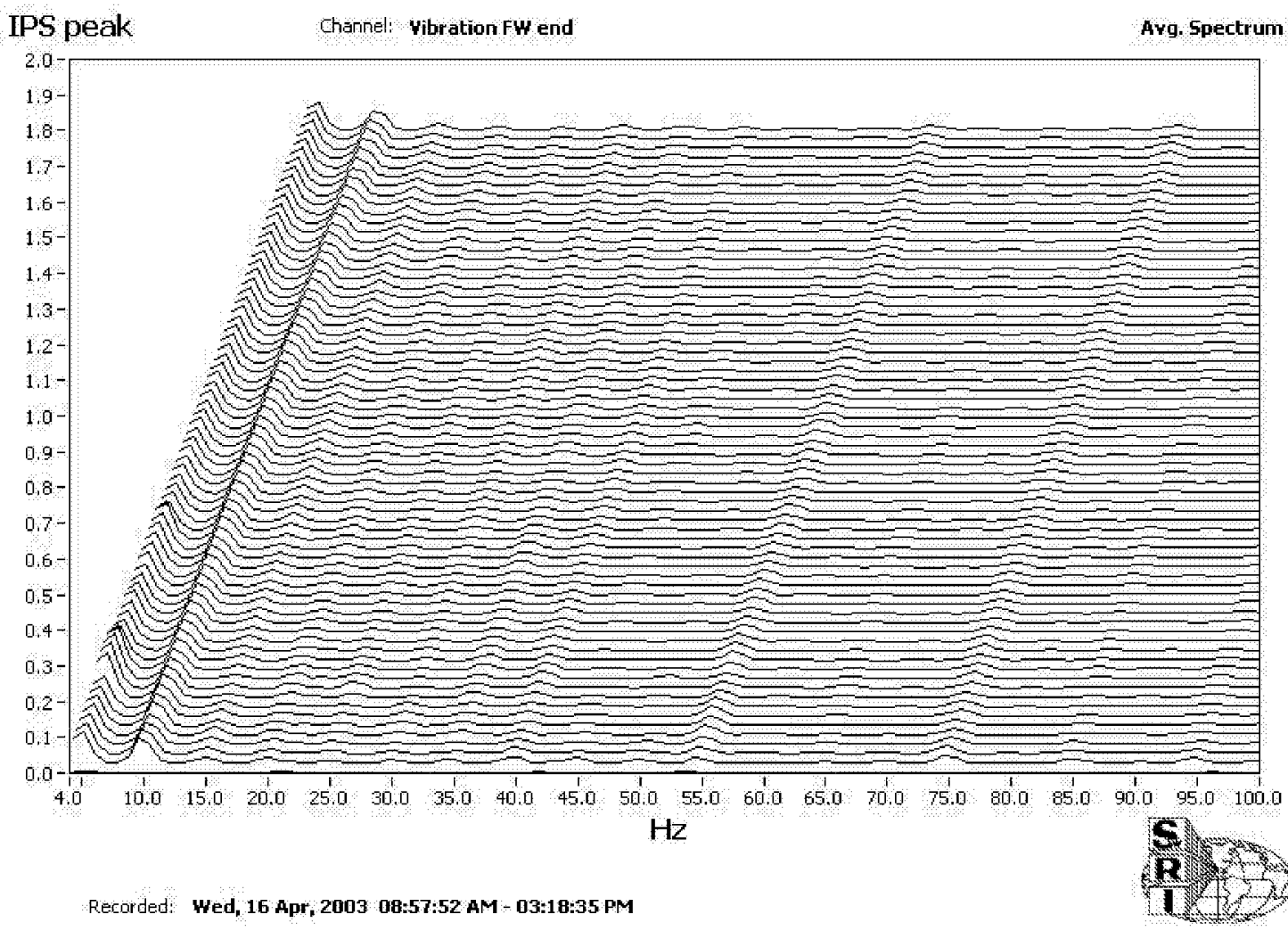

Figure 4-14. Vibration Bearing Centerline (Throw 1); (El Paso Station 823 (Kinder); April 2003) 


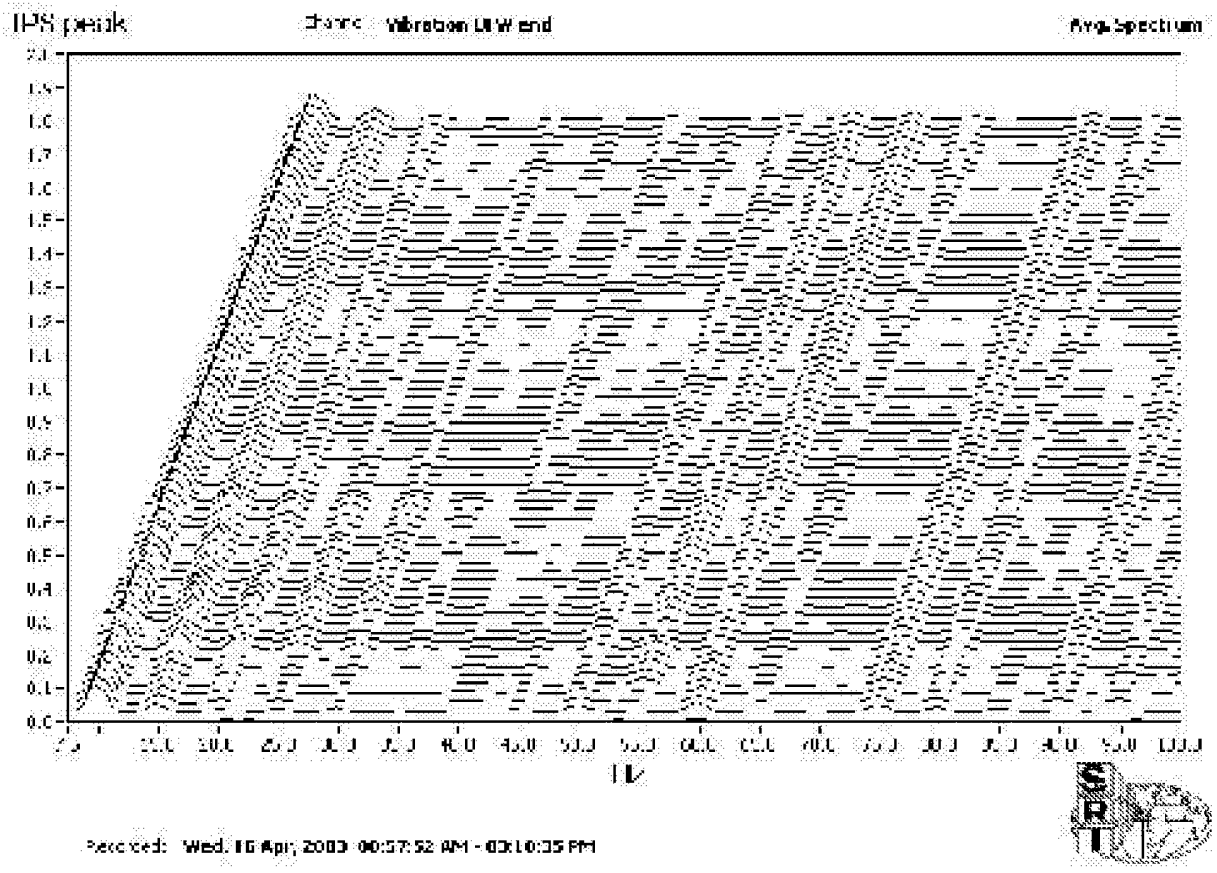

Figure 4-15. Vibration Bearing Centerline (Throw 6); HBA-6T; Test \#1; (El Paso Station 823 (Kinder); April 2003)

Figure 4-16 presents the peak-to-peak variation in crankshaft instantaneous rotational velocity (IRV) expressed in RPM during the changes in balance condition. It will be difficult to extract a distinguishing measure of severity from the peak-to-peak IRV variation.

By comparison to the vibration and IRV data, the strain data capture module results clearly provide a more sensitive measure of severity of dynamic loading and potential damage. 


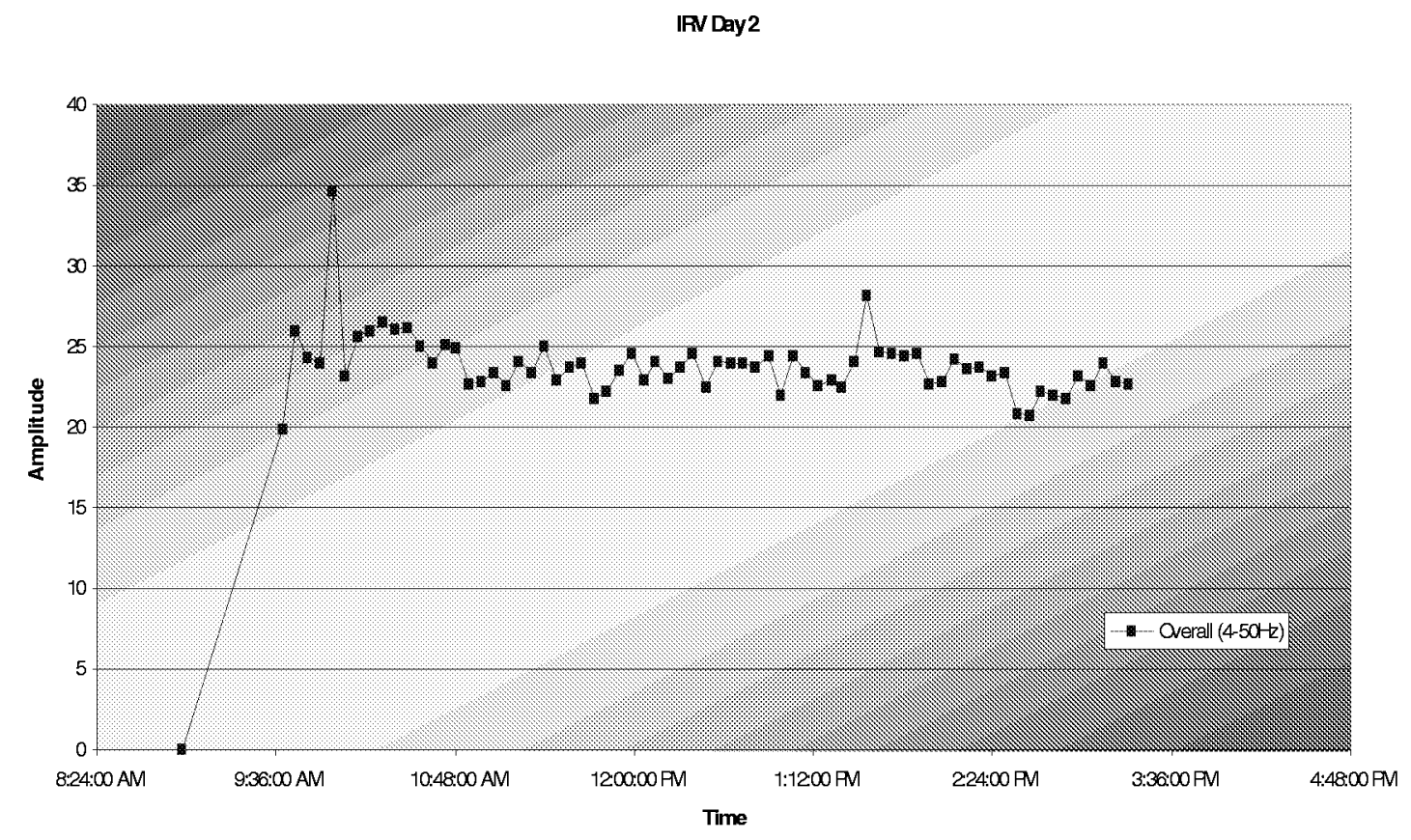

Figure 4-16. Summary Crankshaft Rotational Velocity; (El Paso Station 823 (Kinder); April 2003)

\subsubsection{Air Imbalance}

Close review of the power cylinder pressure plots during balancing revealed a spread between the "compression pressure" values. This is the pressure developed prior to ignition as a result of compression of trapped air and fuel by piston motion following port closure. A spread in this pressure implies a different mass of trapped air (air imbalance) in the power cylinder, and also represents a different point from which pressure builds as a result of heat release after ignition. Figure 4-17 shows traces from power cylinders \#2 through \#5, and makes clear the spread of $10 \%$ or more in compression pressure. Figure 4-17 also shows how the PFP spread is greater than the compression pressure spread, and how the PFP does not necessarily correlate with compression pressure.

Figure 4-18 shows the compression pressure for five power cylinders (without cylinder \#1) and its variation through 36 samples covering more than 6 hours of testing with different balance conditions. The cylinders clearly track each other closely in compression pressure. Although not explicitly shown in Figure 4-18, the data shows that compression pressure does not exhibit the cycle-to-cycle variation that the PFP shows. The compression cylinder spread is a repeatable characteristic of the engine. Balancing to achieve equal PFP has to compensate in fuel flow for these inherent differences between cylinders. 


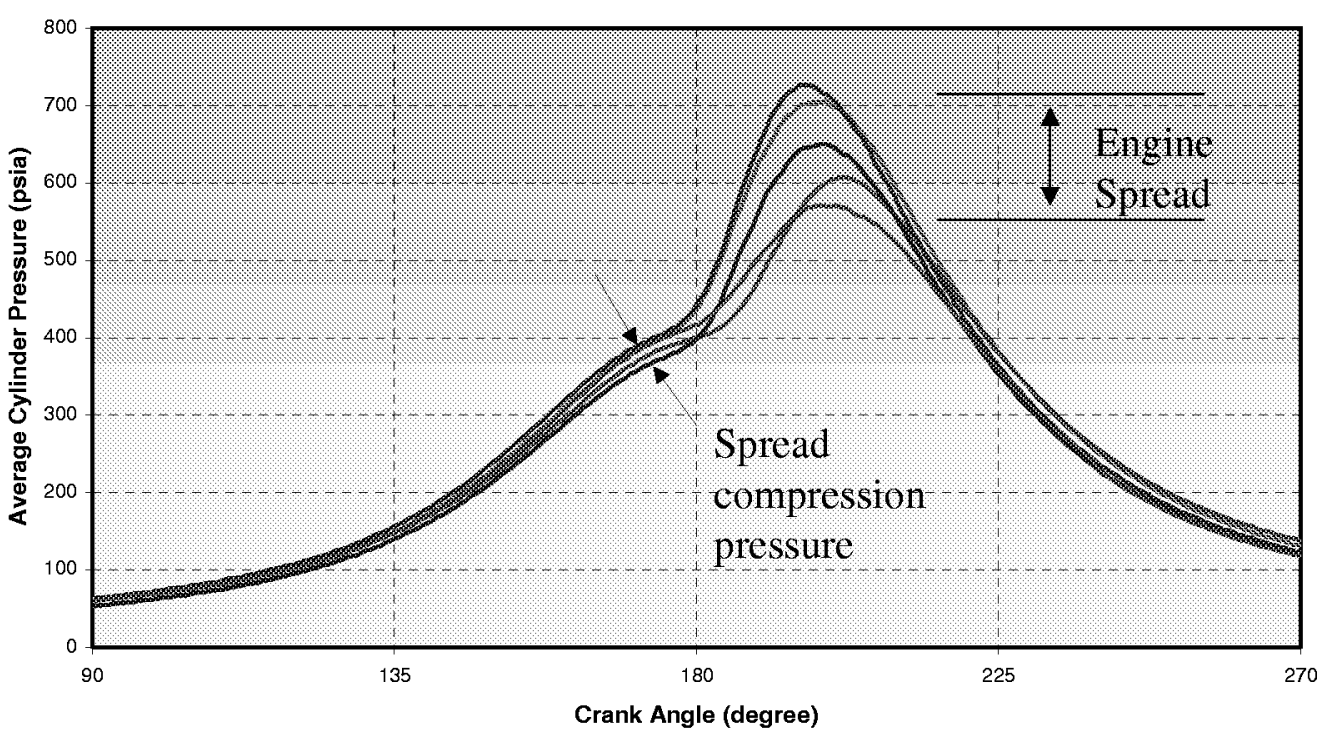

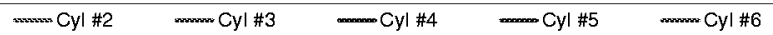

Figure 4-17. Sample HBA-6T Cylinder Pressure Data;

(El Paso Station 823 (Kinder); April 2003)

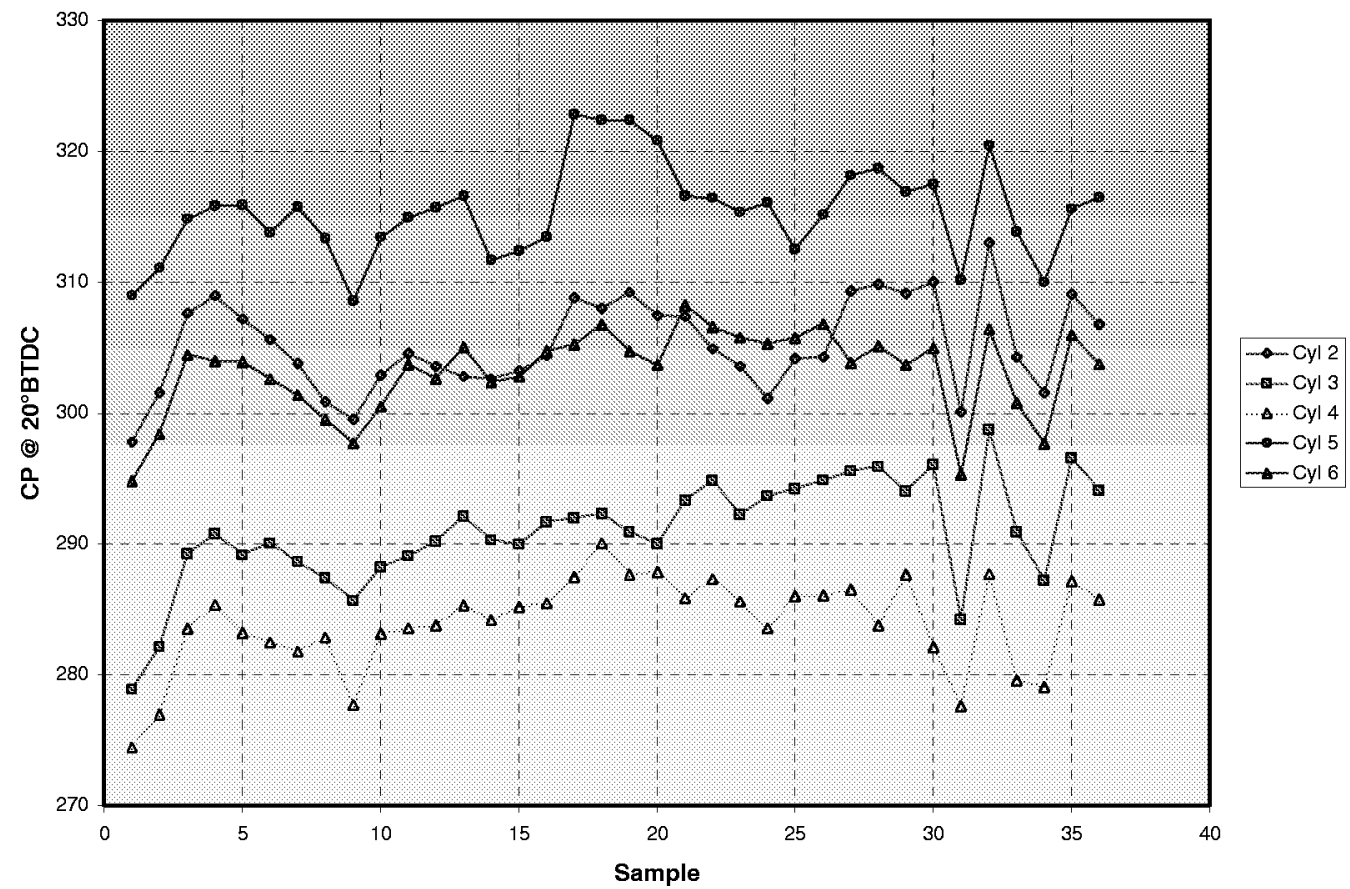

Figure 4-18. HBA-6T Test Data, Cylinder Pressure 20 Degrees before TDC (Compression Pressure); (El Paso Station 823 (Kinder); April 2003) 


\subsubsection{Relating Air Imbalance to Manifold Flow Dynamics}

The potential reasons for the cylinder-to-cylinder variation in compression pressure include:

- Manifold Dynamics

- Differences in Liner Port Flow Area or Coefficient

- Compression Ratio Variation Due to Dimensional Differences in Pistons, Heads, and Liners

- Excessive Blow-by

- Variations in Crankshaft Rotational Velocity Over the Cycle

These all need to be assessed. However, it will be recalled that air manifold pressure at the measurement location exhibited a $25 \%$ variation over each revolution, as shown in Figure 4-3. This implies a similar spatial variation in air manifold pressure. The local air manifold pressure drives airflow through the ports into the cylinder. Inevitably, airflow is a significant contributor to the cylinder-to-cylinder variability in trapped air mass, and therefore in compression pressure, so air manifold dynamics are a likely candidate for the primary cause of compression pressure difference. (Subsequent tests on a GMW10 will show over $50 \%$ modulation in exhaust manifold pressure, making this a further likely contributor to air unbalance.)

Based on this relationship, an investigation has been proposed which will seek to reduce air imbalance by redesign of the manifold (air exhaust) to reduce sensitivity to manifold flow dynamics in a laboratory engine.

\subsubsection{Engine Simulation}

To assist understanding of engine characteristics observed during the tests, a single cylinder combustion model (virtual engine) was applied to this and adjusted to fit observed burn rate characteristics of the average cylinder. The cycle simulation model utilized is based on prior models developed specifically for two-stroke spark-ignited integral engines [2].

This model was then applied to assess the sensitivity of fuel consumption and emissions to changes in trapped air in the cylinder. These changes in trapped air were achieved by changing air manifold pressure in the model. A constant pressure ratio (intake/exhaust) was assumed. While no exhaust pressure measurements were taken, previous data on another straight six indicated a closely constant pressure ratio at a constant engine speed. Empirical relationships for burn rate and combustion efficiency were based on the HBA6T data. 
The NOx model is based on a rate formation model and tuned to the HBA data. The heat transfer model is based on the correlation by Woschni, and also tuned to the HBA data. With these tuned models, the first law of thermodynamics is used to determine cylinder temperature, then pressure.

The single cylinder data was used to predict performance of a six-cylinder engine in which the air manifold pressure driving air into the cylinders was assumed to have an evenly distributed range from high to low across the six cylinders. The fuel flow (or air fuel ratio) was then adjusted to achieve constant peak-firing pressure in this engine. The performance and effects of balancing with this engine condition will be compared to the engine condition, in which the air manifold pressure and air fuel ratio are constant across all cylinders, and as result of this desirable condition, peak-firing pressure is constant across the cylinders.

As a starting point, Figure 4-19 shows the pressure distribution in which a random imbalance in air fuel ratio of about $15 \%$ is superimposed on air imbalance caused by manifold pressure spread of $10 \%$ across the engine. This air manifold spread is assumed uniformly distributed from low to high. The compressor pressure spread is 35 PSI and the peak pressure spread is 180 PSI.

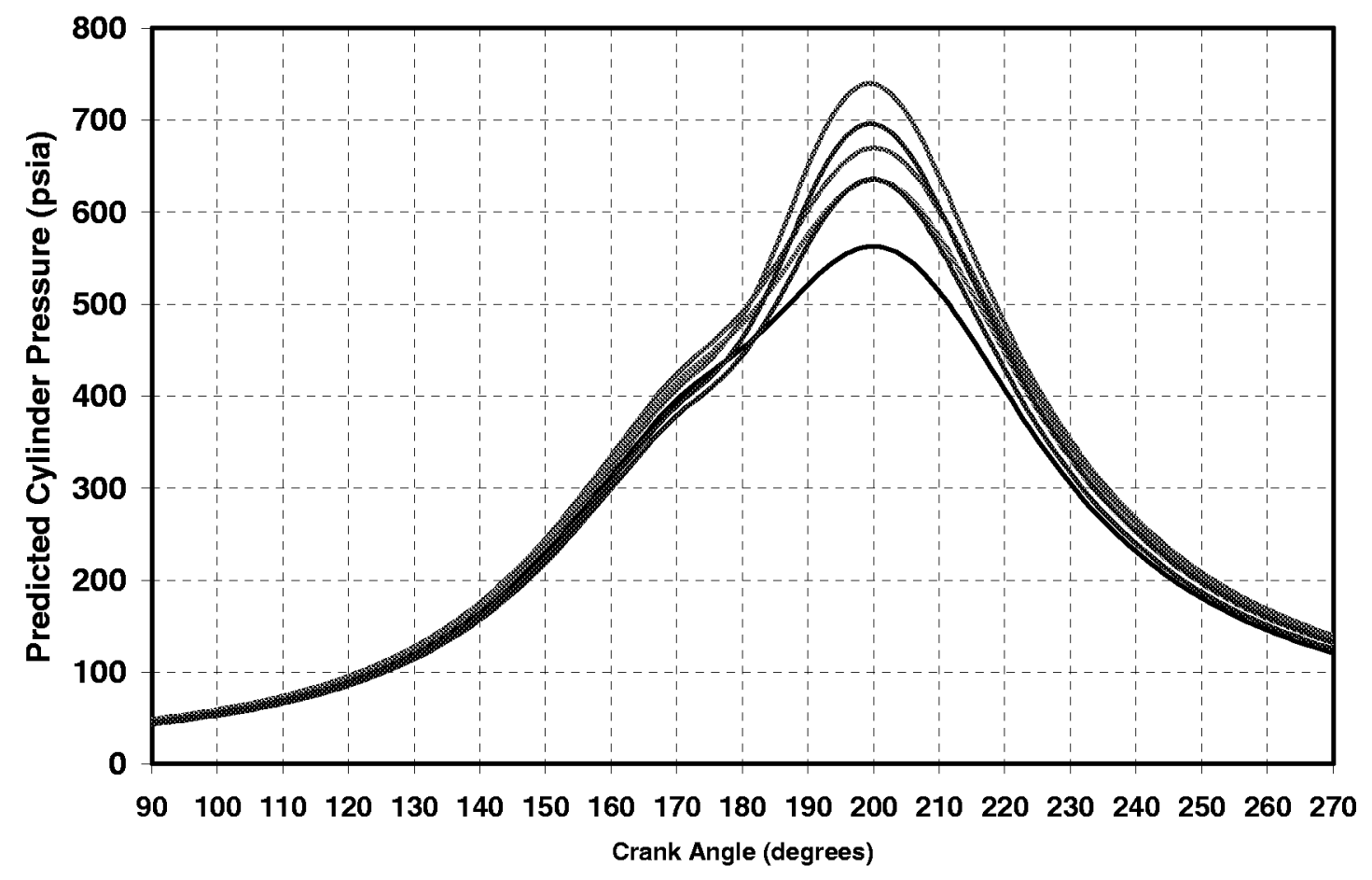

Figure 4-19. Unbalanced Engine Simulation - Spread in Compression Pressure Induced by Even Increment Spread in AMP - 15\% Random Spread in A/F Ratio 


\subsubsection{Using the Engine Simulation Model to Relate Combustion Balancing to Engine Performance with Air Imbalance}

Figure 4-20 shows the predicted cylinder pressure variation for the engine balanced to achieve equal peak-firing pressure across all six cylinders.

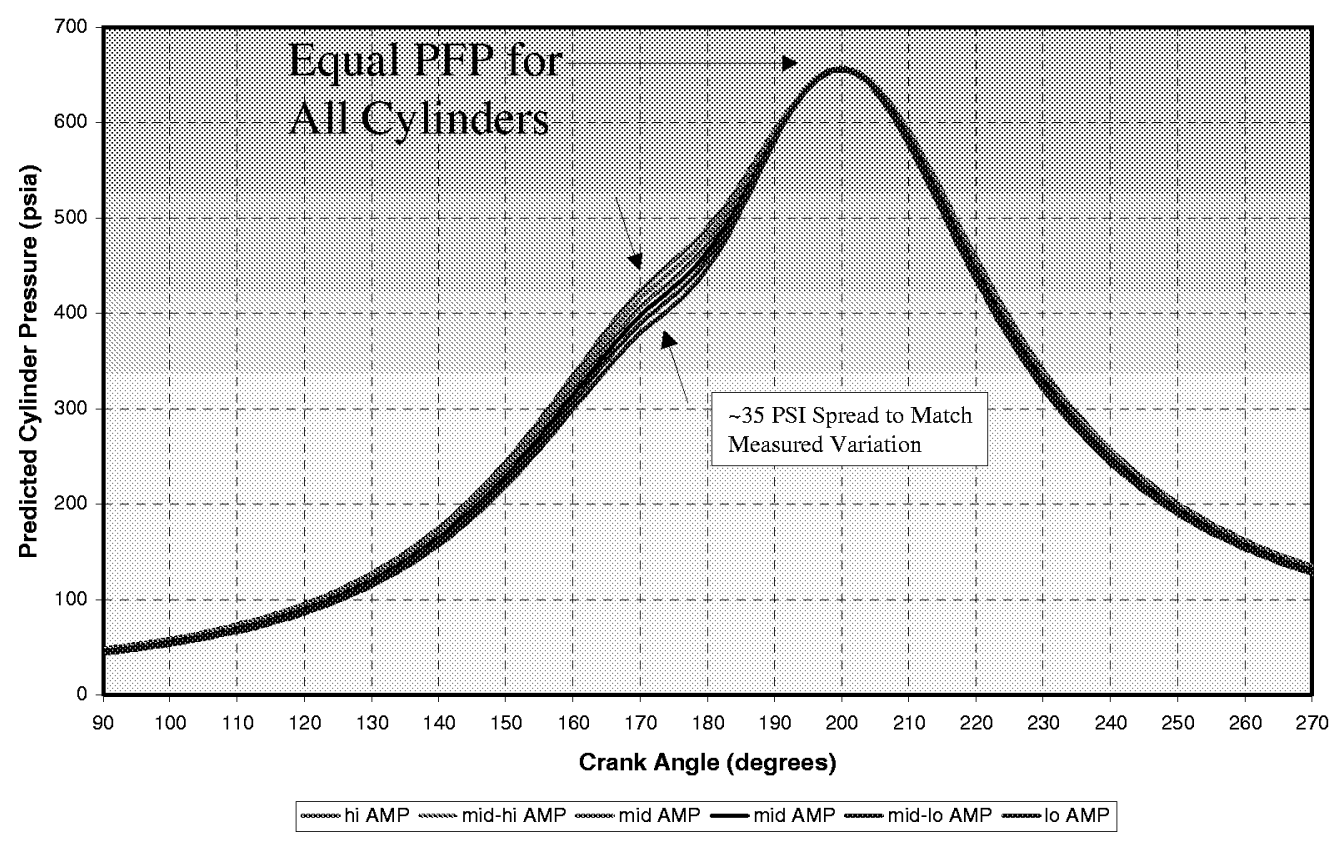

Figure 4-20. Predicted Cylinder Pressures - Simulation with Evenly Distributed Variation of Air Manifold Pressure

Figure 4-21 then shows the distribution of trapped air fuel ratios required to achieve the constant peak-firing pressure exhibited in Figure 4-20. The required trapped air fuel ratios range from 23.8 to 25.9 . 


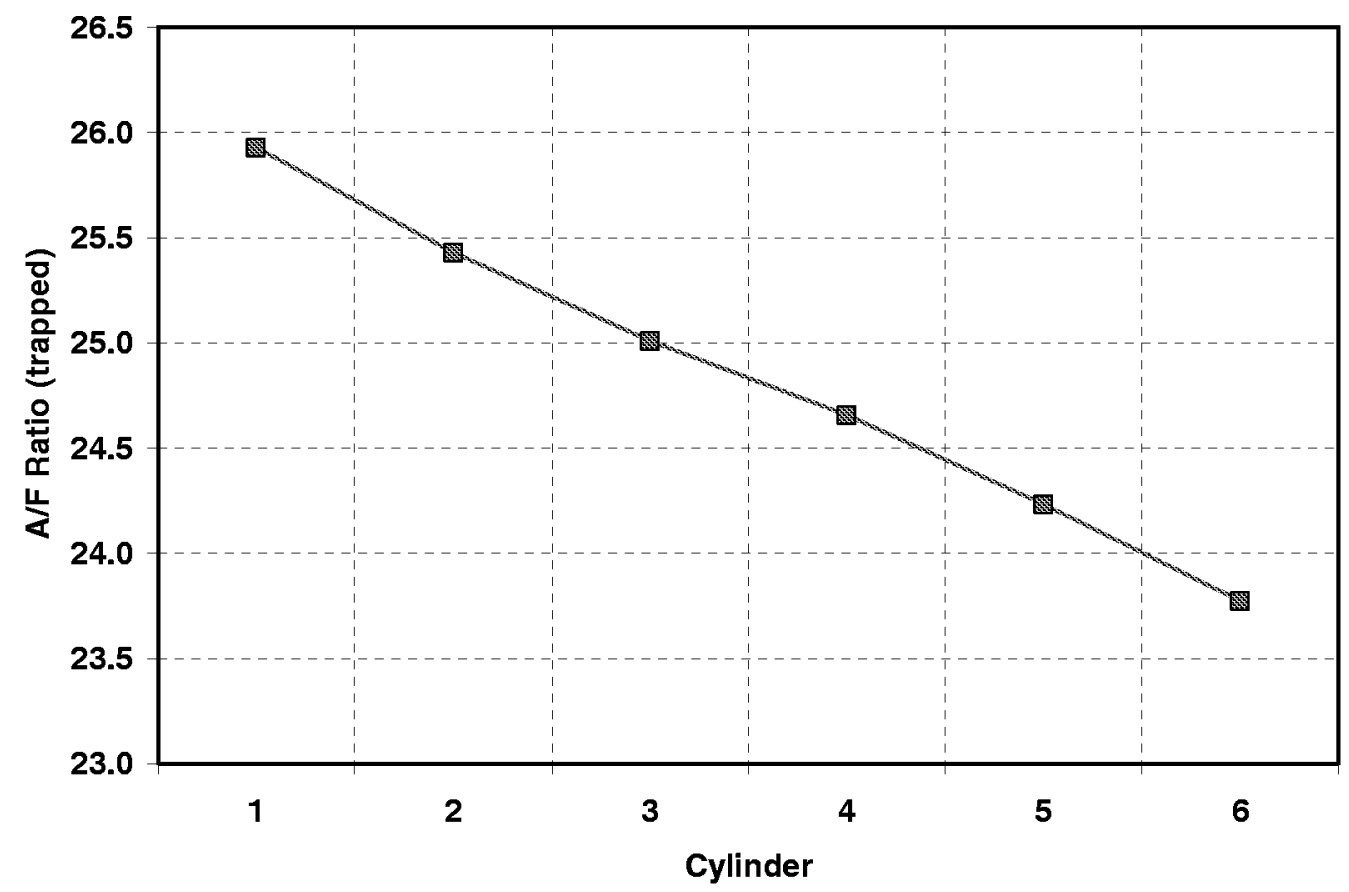

Figure 4-21. Predicted Variation of A/F Ratio across Cylinders to Achieve Balanced PeakFiring Pressure with Spread in Compression Pressure

This spread in trapped air fuel ratios will not only cause NOx emissions to be increased from that expected from the mean equivalence ratio, but also reduce the operating range of the engine. This is illustrated in Figure 4-22 below showing an operating map for a typical Lean-Burn Spark-Ignited (LBSI) gas engine. At a constant engine speed and load, the major control parameters are spark timing and equivalence ratio (fuel air ratio normalized by the Stoichiometric fuel air ratio). These can be adjusted to meet either a NOx emissions or efficiency target, or both. Limits to operation of a LBSI gas engine are the lean flammability limit and the knock (detonation) limit. A specific NOx emissions level is typically a linear function of spark timing and equivalence ratio, as illustrated in Figure 4-22. There is typically an "island" of best efficiency for a moderately lean equivalence ratio and advanced timing. Depending on the combustion chamber and engine load, this "island" will be near the knock limit or some distance below it. An optimum operating point for a given NOx emissions level will be at as lean an equivalence ratio and as advanced a timing as possible with acceptable margins from knock and lean instability. An engine with widely varying equivalence ratios per cylinder, Group A in Figure 4-22, will result in a somewhat rich mean equivalence ratio and require retarded spark timing to operate within the limits. The lean cylinder(s) will be prone to misfire and the rich cylinder(s) will be prone to knock, reducing the margins of operation. The engine-out NOx emissions will be abnormally higher, and the efficiency will not be as good for a given NOx limit. The same engine with balanced air and fuel, Group B in Figure 4-22, provides a much greater operating range that can allow adjustment for either increased efficiency at a given NOx or lower NOx for a given efficiency, with increased margins from knock and lean limits. This balanced engine will 
be less sensitive to changing ambient conditions, temperature and humidity, due to the increased margins. The ideal way to achieve such a balanced condition starts with equal air supplied to and trapped by each power cylinder. Tasks to characterize air imbalance and to investigate manifold redesign as a means to correct it have been proposed as a result of these observations and recently started. Baseline testing is already complete under these tasks and will be separately reported.

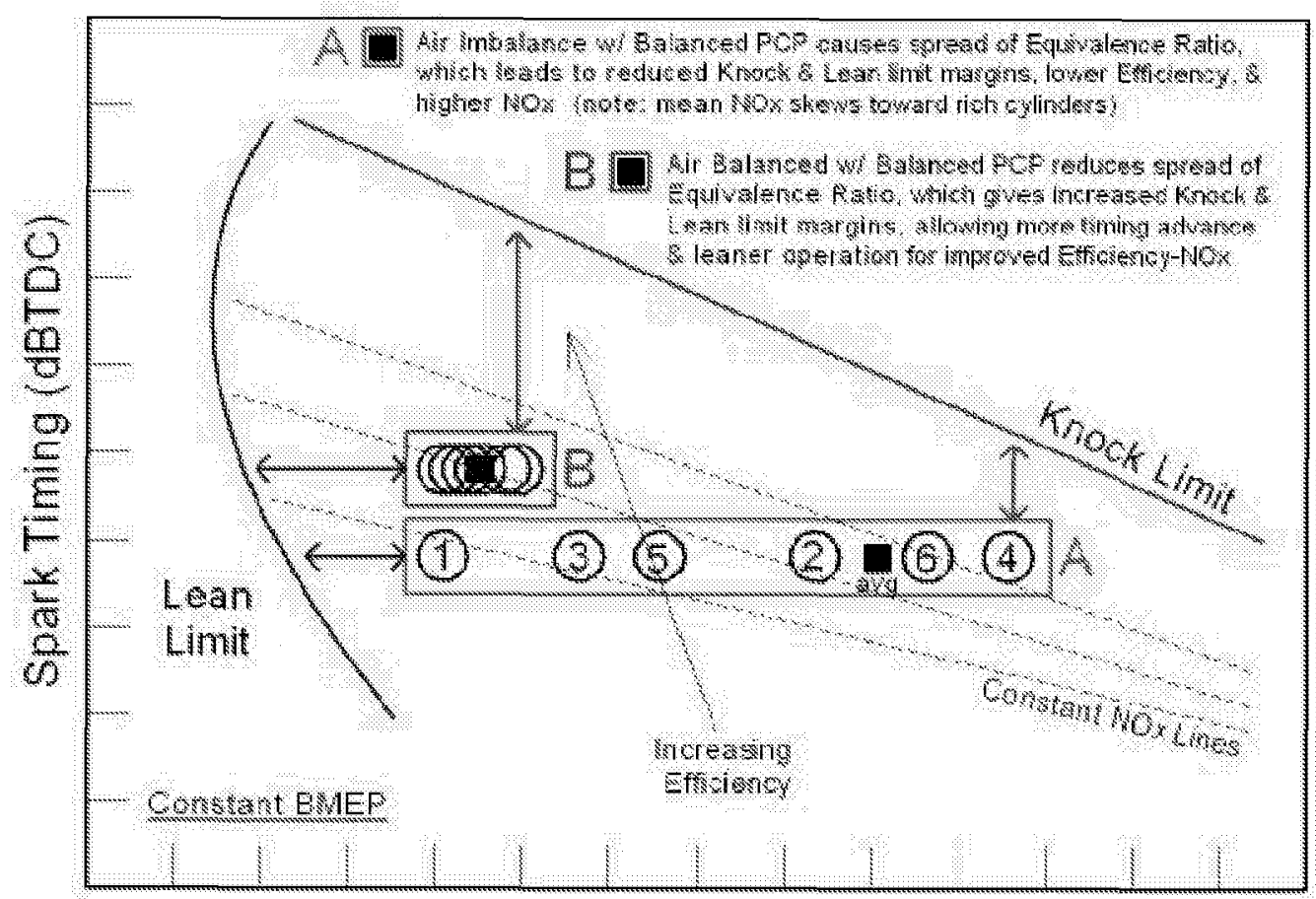

Fuel-Air Equivalence Ratio

Figure 4-22. Typical Lean-Burn Spark-Ignited Gas Engine Operating Boundaries

\subsubsection{Relating Combustion Balancing to Trapped Air Fuel Ratio}

Figure 4-23 shows the pressure distributions which result from imposing constant trapped air fuel ratio in each cylinder for the engine with $10 \%$ air manifold spread, causing 35 PSI compression pressure spread-out. The predicted NOx and fuel consumption, which this condition achieves, is the same as that with the air manifold spread eliminated. The qualification with this is that there may be insufficient fuel adjustment range on cylinders with excessively high-trapped air mass. Also, the load distribution along the crankshaft may not be optimum for crankshaft integrity. 


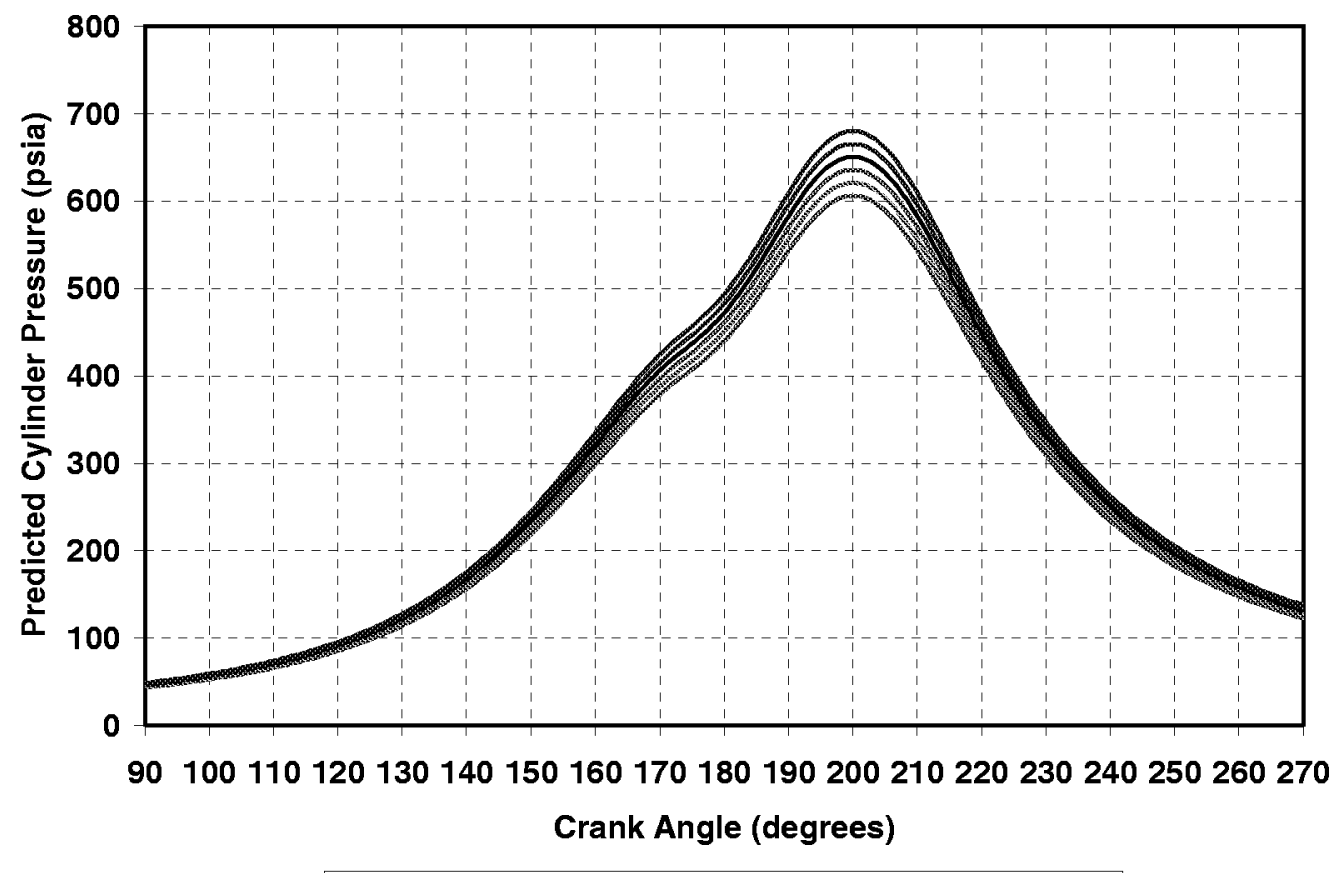

20.5 AMP $\cdots=21$ AMP $=21.5$ AMP -22 AMP -22.5 AMP -23 AMP

Figure 4-23. Engine Simulation - Pressures for Constant Equivalence Ratio with Spread in Compression Pressure

Figure 4-24 shows the distribution of peak pressure normalized with respect to pressure 20 degrees before top dead center for three conditions of an engine with $10 \%$ air manifold spread:

- Air Fuel Ratio (Equivalence Ratio) Balanced (AF Balance)

- Unbalanced

- Peak-Firing Pressure (PFP) Balanced

The results of Figure 4-24 are revealing. If we refer to the ratio of peak-firing pressure to compression pressure as Combustion Pressure Ratio (CPR), Figure 4-24 shows that only if the air fuel ratio is the same for all cylinders, is the predicted CPR equal for all cylinders of an engine with air imbalance. Peak-Firing Pressure (PFP) balancing causes the CPR to vary from cylinder-to-cylinder in proportion to the amount of air imbalance. Of course, an unbalanced engine has neither equal CPR nor equal PFP. This set of results provides, as a corollary, a new procedure with which to pursue combustion balancing. Specifically, if we compute CPR and make fuel adjustments to equalize CPR rather than PFP, we should more closely equalize air fuel ratio across the cylinders. 


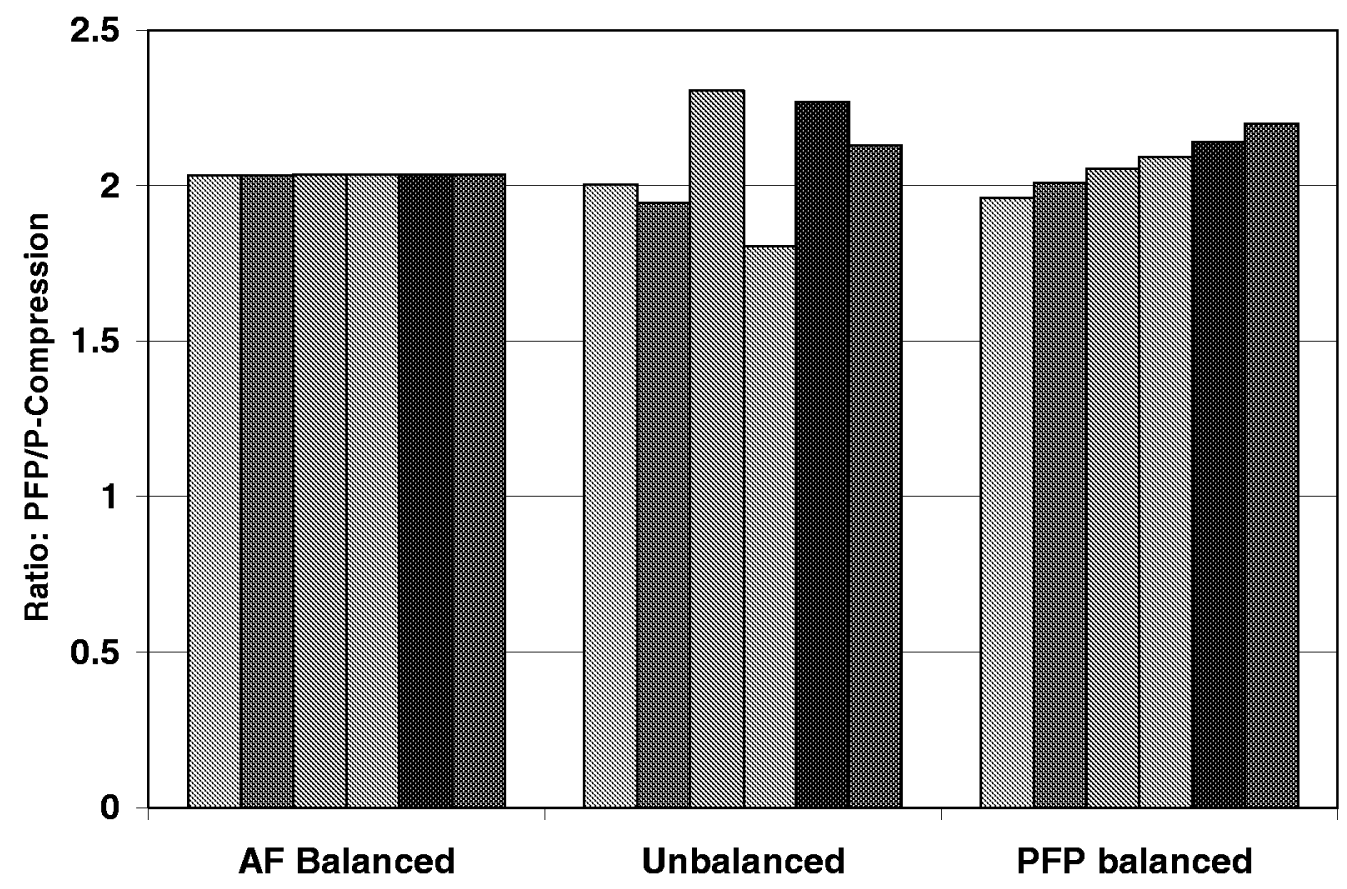

Figure 4-24. Ratio of PFP to Compression Pressure for Three Different Balancing Situations

On the basis of this result, an invention disclosure was prepared, and SwRI subsequently filed for a utility patent in early September 2003.

\subsubsection{Relating System Mechanical Efficiency to Oil Temperature and Time}

The term "system mechanical efficiency" is used in recognition that the mechanical efficiency, used as common practice by the industry for relating BHP delivered to the crosshead to power at the compressor piston face, may in concept include fewer losses than in the mechanical efficiency between power piston face and compressor piston face. Figure 4-25 shows for the HBA-6T engine tested how compressor piston power, engine piston power, and their ratio ("inferred system mechanical efficiency") varied over 6 hours of testing. The ratio of compressor piston power to engine piston power increased (with a few momentary reversals of this trend) from the start of the test series. 
Engine \& Compressor HP \& Inferred Mechanical Efficiency

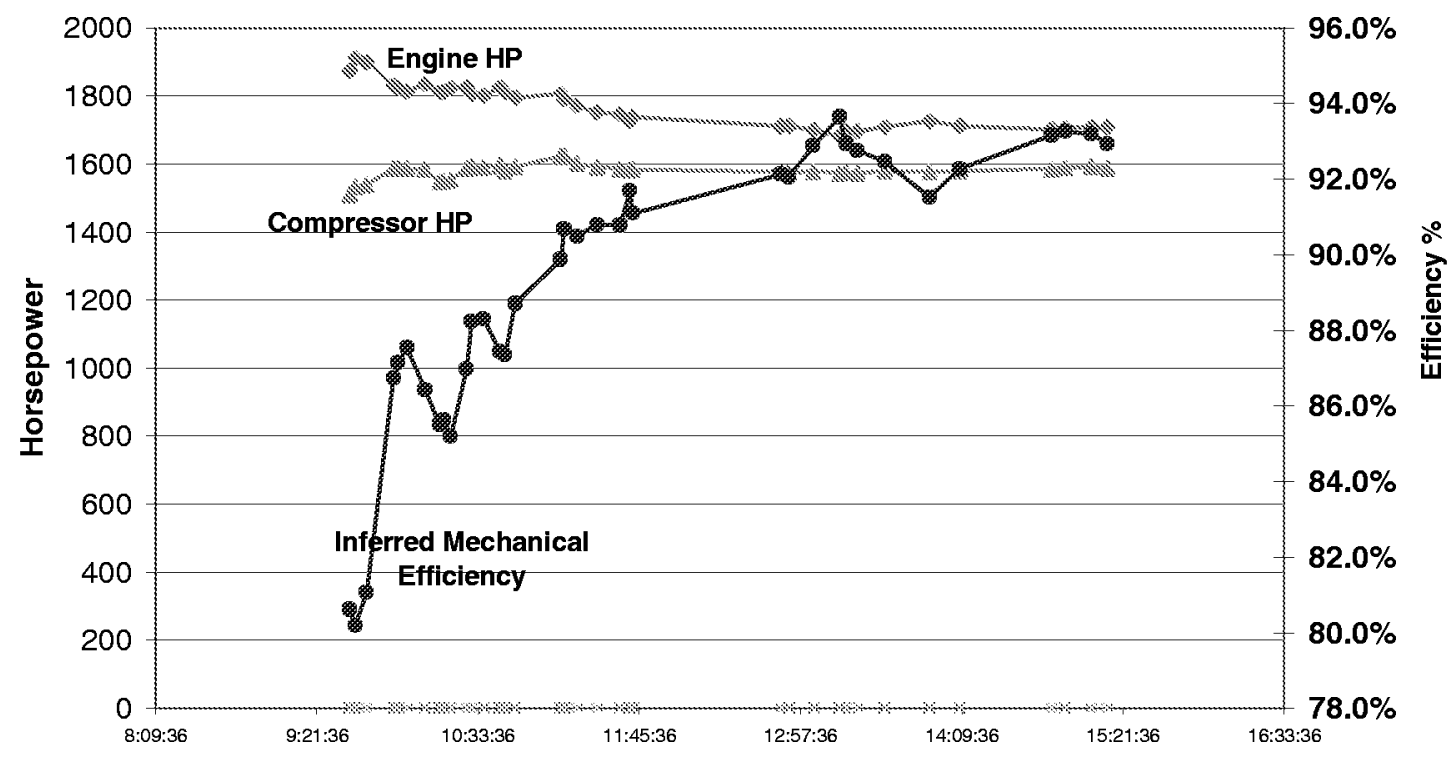

Figure 4-25. Engine HP, Compressor HP, and Inferred Mechanical Efficiency; (El Paso Station 823 (Kinder); Test 1; April 2003)

Figure 4-26 uses station records to provide some supportive evidence that the engine heat rate (BTU/HP-hr.) dropped over the same period. The change is 4 to 5\%. This is not as large as the apparent increase in system mechanical efficiency, but an effect that would partially explain this is the influence of engine load on brake thermal efficiency. This efficiency tends to reduce as engine load reduces, so reducing the impact on fuel flow in comparison to a proportional relationship. 
BTU/HP-Hour Data from Station Records

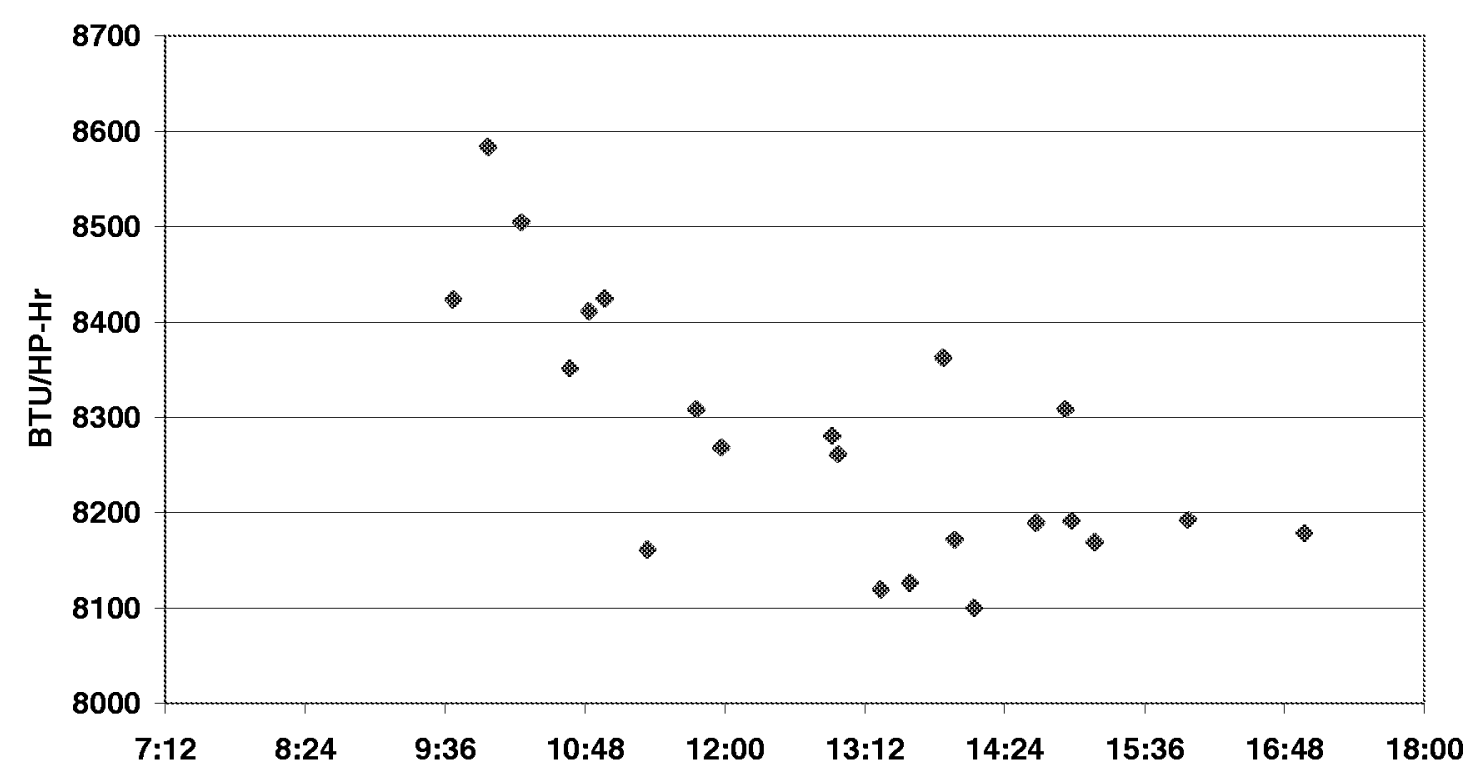

Figure 4-26. BTU/HP-Hr. Data from Station Records; (EI Paso Station 823 (Kinder); Test 1; April 2003)

The most obvious parameter which might be changing after start-up, and which would influence system mechanical efficiency is oil temperature - the period might seem long for oil temperature to stabilize, but records show that, at least for the HBA engine, oil sump temperature is surprisingly slow to reach a stable operating temperature. Data recorded in 1984 on a PRCI project [3] related to crankshaft alignment (reproduced in Figure 4-27) indicate that sump oil temperature continues to rise for as many as 5 hours after a start-up, starting at 80 to 90 degrees and reaching 145 to 150 degrees. There is a daily temperature cycle for sump oil temperature, in addition to the increase in temperature following start-up. Sump oil temperature is an indicator of the oil temperature, which reaches the crosshead bearings, main bearings and pin bearings through the crankshaft, and the temperature of oil reaching the rider bands. This temperature has a direct influence on the viscosity of the oil being sheared in the bearings, and at other close clearances between moving parts. For the recent tests, data is not available for the sump temperature, but in Figure 4-28, lube oil outlet temperature is plotted as a function of time, and clearly has a shape remarkably similar to the mechanical efficiency curve. Oil temperature, at inlet to the bearing, will be lower than this, and so there is a credible hypothesis that mechanical efficiency is a strong function of oil inlet temperature, since viscosity is also a strong function of oil temperature. 


\section{Sump Temperature Data During Startup}

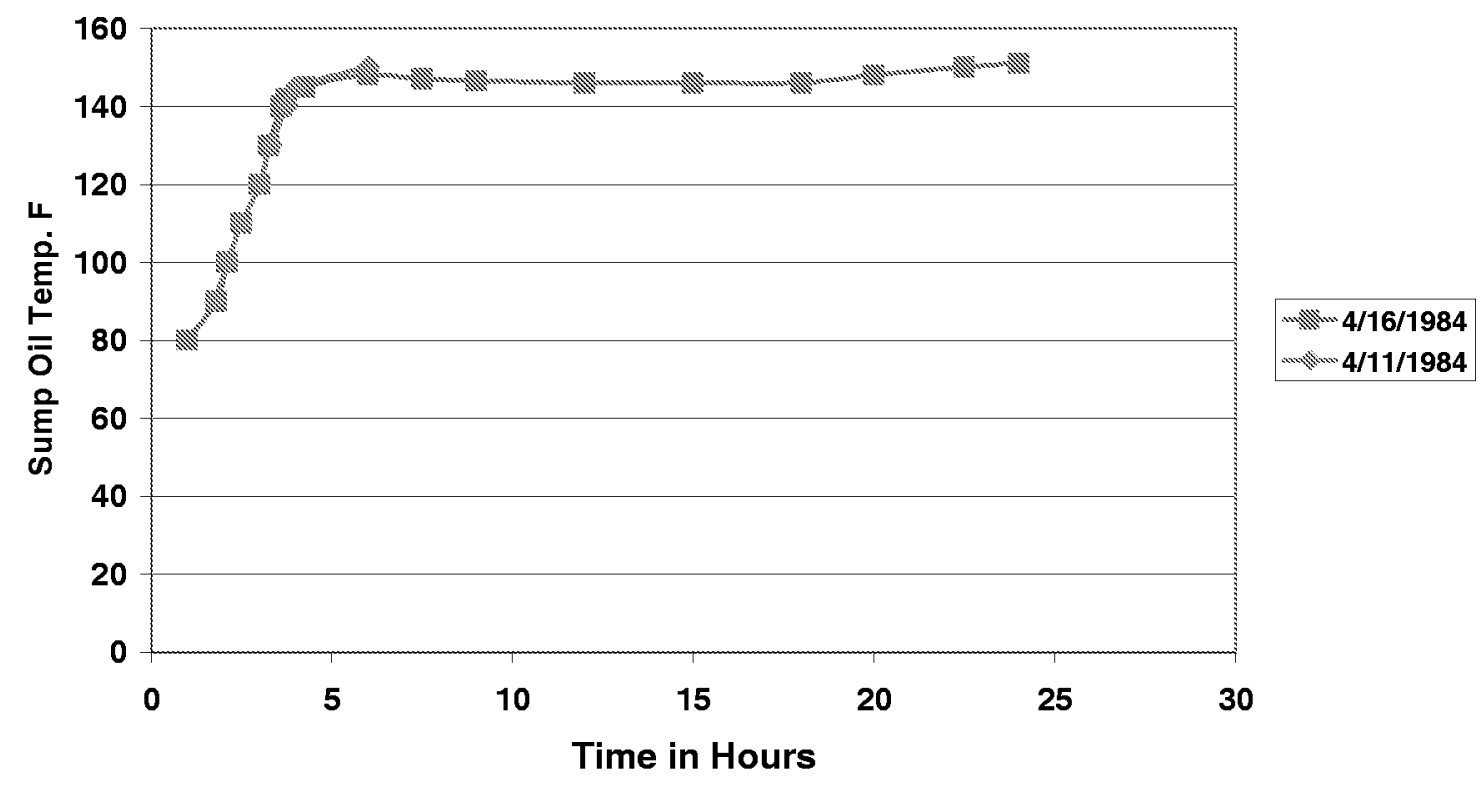

Figure 4-27. HBA8 Sump Temperature Data (1984)

\section{Lube Oil Outlet Temperature}

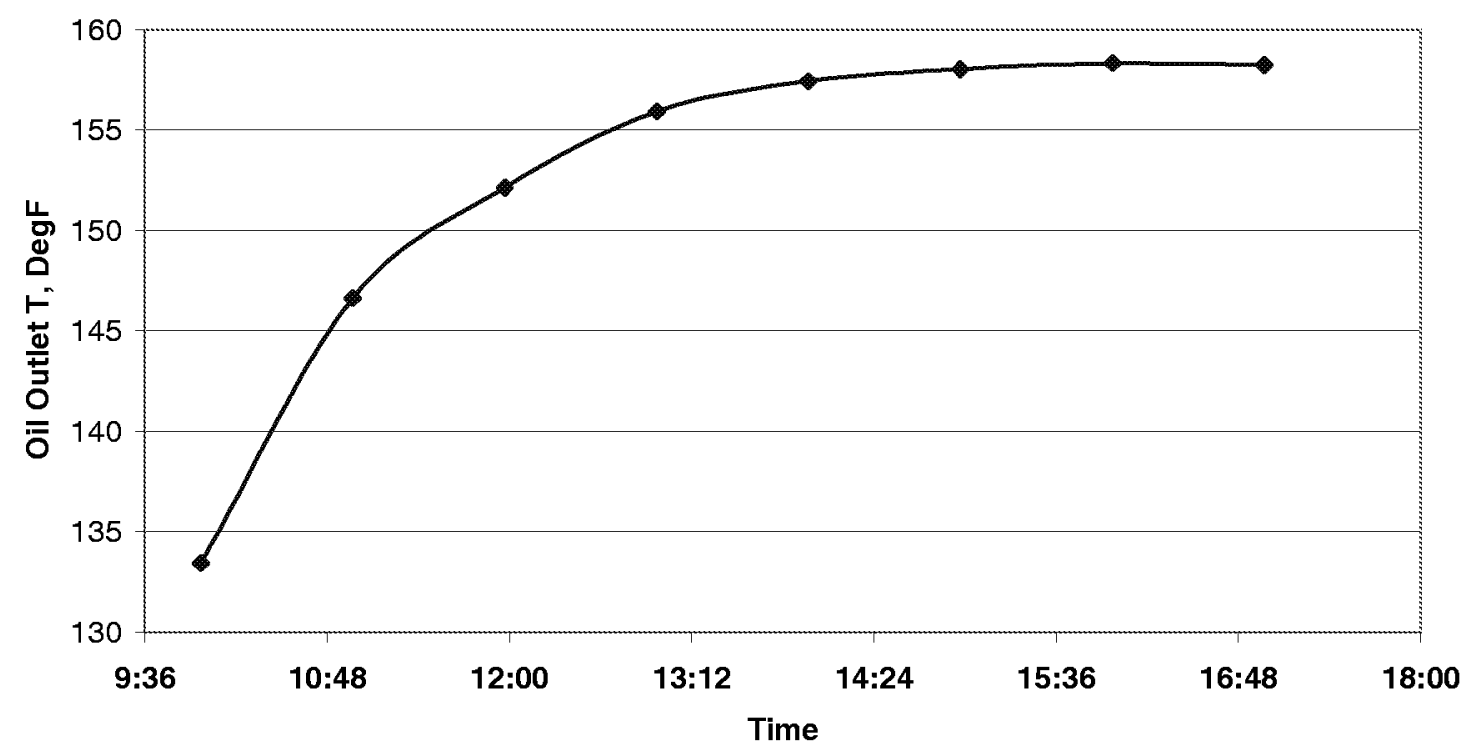

Figure 4-28. Oil Outlet Temperature versus Time from Station Records (Note Increase Over 5 Hours Matches Mechanical Efficiency Trend);

(EI Paso Station 823 (Kinder); Test 1; April 2003) 


\subsubsection{Relating Engine-Compressor Efficiency Definitions to each Other and to the Data from the First HBA-6T Test}

The Engine/Compressor System Thermal Efficiency - the purpose of introducing system thermal efficiency is to focus on the overall efficiency of fuel use in providing useful compression energy to the transported gas. This addresses the complete function of the engine/compressor and combines several measures of component efficiency commonly discussed in relation to integral engine compressors, as defined below.

The Engine Brake Thermal Efficiency - the ratio between power available to the crossheads of the compressor and power consumed as fuel gas energy by the engine.

The Compressor Mechanical Efficiency - the ratio between power available at the compressor piston faces and power available to the crossheads.

The Compressor Thermal Efficiency - the ratio between the ideal (lossless) power to raise the pressure of the gas from suction to discharge pressure, and the actual power consumed in the compressor cylinders.

Engine/compressor system thermal efficiency is the product of these three component efficiencies. Because of the incomplete measurement set at the first test site, the following discussion uses data with several inferences and assumptions in it, but is intended to provide some approximate trends, and to illustrate expectations of what may be better inferred with a more complete instrumentation set.

For this test, the only available fuel flow measurement available was from the station instrumentation. Figure 4-26 has shown that the inferred BTU/BHP-hr. from the station data dropped over 6 hours of testing from 8500 to 8200 . It should be noted that this efficiency relates power at the crosshead to fuel power. Expressed as a brake thermal efficiency, this data implies an increase over 6 hours from $29.9 \%$ to $31.0 \%$. Combined with an assumed constant compressor mechanical efficiency of $95 \%$ and compressor thermal efficiency of $91 \%$ (see Figure 4-5) the engine compressor system thermal efficiency appears to vary from $25.8 \%$ to $26.8 \%$.

The inferences and assumptions mainly apply to the BHP in the BTU/HP-hr. calculation. This is obtained from a model of the compressor gas horsepower as used by the host company. In this model, a standard compression exponent is used to calculate from suction pressure, suction temperature, and discharge pressure an ideal compressor gas horsepower. This ideal is then corrected (increased) for flow resistance losses and pulsation effects. The resultant gas horsepower is then translated to an inferred brake horsepower by dividing by a value for compressor mechanical efficiency (95\% is used in this calculation). Comparison of station BHP to the data obtained during the test indicates the station BHP numbers were 3 to $5 \%$ below those based on measured cylinder pressure. Thus, the $25.8 \%$ to $26.8 \%$ discussed above for system thermal efficiency might be corrected to record $26.8 \%$ to $27.8 \%$ based on the cylinder pressure measurements. 
Reference [4] provides a typical heat balance for a compressor station, suggesting that 26 to $29 \%$ of the fuel energy is delivered to gas discharged from the compressor. Thus, the present data is comparable to this assessment.

The limited GMRC compressor efficiency survey indicates a median of $79 \%$ rather than the $91 \%$ obtained in these tests - thus, with median thermal efficiency, the industry is also likely to exhibit lower system thermal efficiencies (as low as $23 \%$ to $24 \%$ ).

As has been discussed, the system mechanical efficiency in this test started low and increased as the oil heated up over several hours. Thus, immediately after start-up and for the next few hours, even lower system efficiencies may be expected than the range inferred above.

Limited data is available on brake thermal efficiency norms for the industry. Smalley et al [5] shows that as a global average, the industry burns 8.25 SCF per BHP-hr. At an assumed lower heating value (LHV) of $1050 \mathrm{BTU} / \mathrm{SCF}$, the implied industry brake thermal efficiency is $29.4 \%$ - just below the low end of the range for the HBA-6T engine during the tests (29.9 to $31 \%$ ). Of course, this industry average is a very coarse number and includes turbines as well as four-stroke engines - both separable and integral.

In summary, the compressor tested provides a data point indicating $26.8 \%$ to $27.8 \%$ system thermal efficiency for an integral engine compressor, once thermally stable operation is established. Industry averages for engine thermal efficiency and compressor thermal efficiency suggest that the average system thermal efficiency for the industry may be lower than this. Engine start-up transients will further lower system thermal efficiency for recently started engines.

\subsubsection{Relating DIP-Based Efficiency to Enthalpy-Based Efficiency}

Figure 4-29 shows a comparison between compressor thermal efficiency based on enthalpy rise, and that based on DIP. The close agreement is clear since the total range of Figure 4-29 is one percentage point and covers all the data from the first HBA-6T test; the enthalpy-based efficiencies are in the middle of this range. 


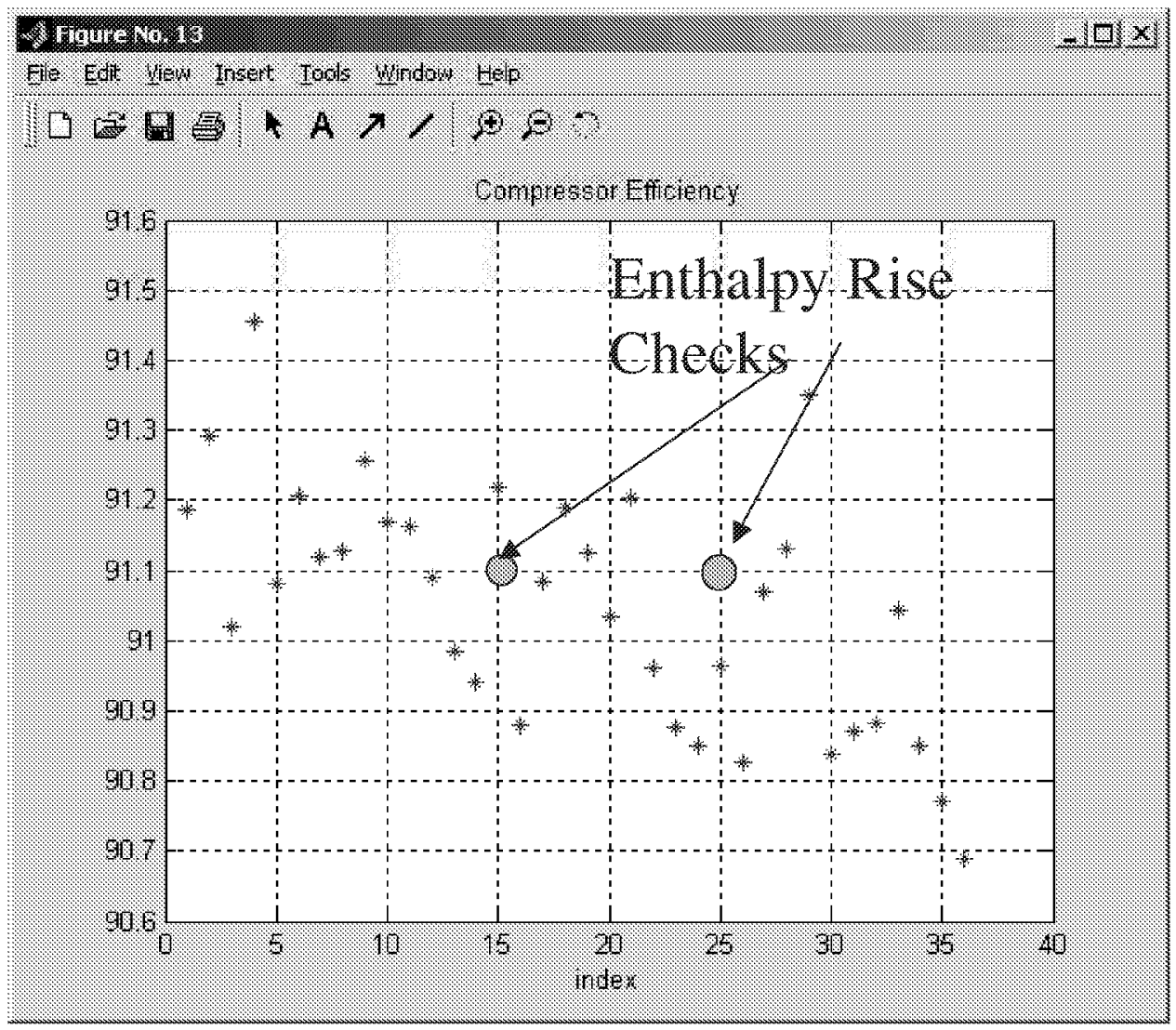

Figure 4-29. Compressor Performance Data for DIPs (HBA-6T); (El Paso Station 823 (Kinder); Test 1; April 2003)

\subsubsection{Relating Performance to Timing}

During the testing, advances in timing were investigated. Unfortunately, the fuel flow measurement was not available to measure the impact. However, it was stated that station practice tended to keep timing less advanced as a precaution against detonation. Some form of detonation detection and active protection would allow timing advance as an option.

\subsubsection{Relating Compressor Efficiency to Available Industry Norms}

Figure 4-30 shows where the HBA-6T compressor thermal efficiency lies in comparison to the survey performed by GMRC about 10 years earlier, based on about 120 individual compressor data sets. It is clear that the HBA-6T, on the day tested, was achieving a thermal efficiency at the very top end of industry standards. Informal discussions with industry representatives provides the opinion that 91 to $92 \%$ is about the highest thermal efficiency which can be expected from a reciprocating compressor. As such, it is three to four percentage points higher than the most efficient centrifugal compressor. 


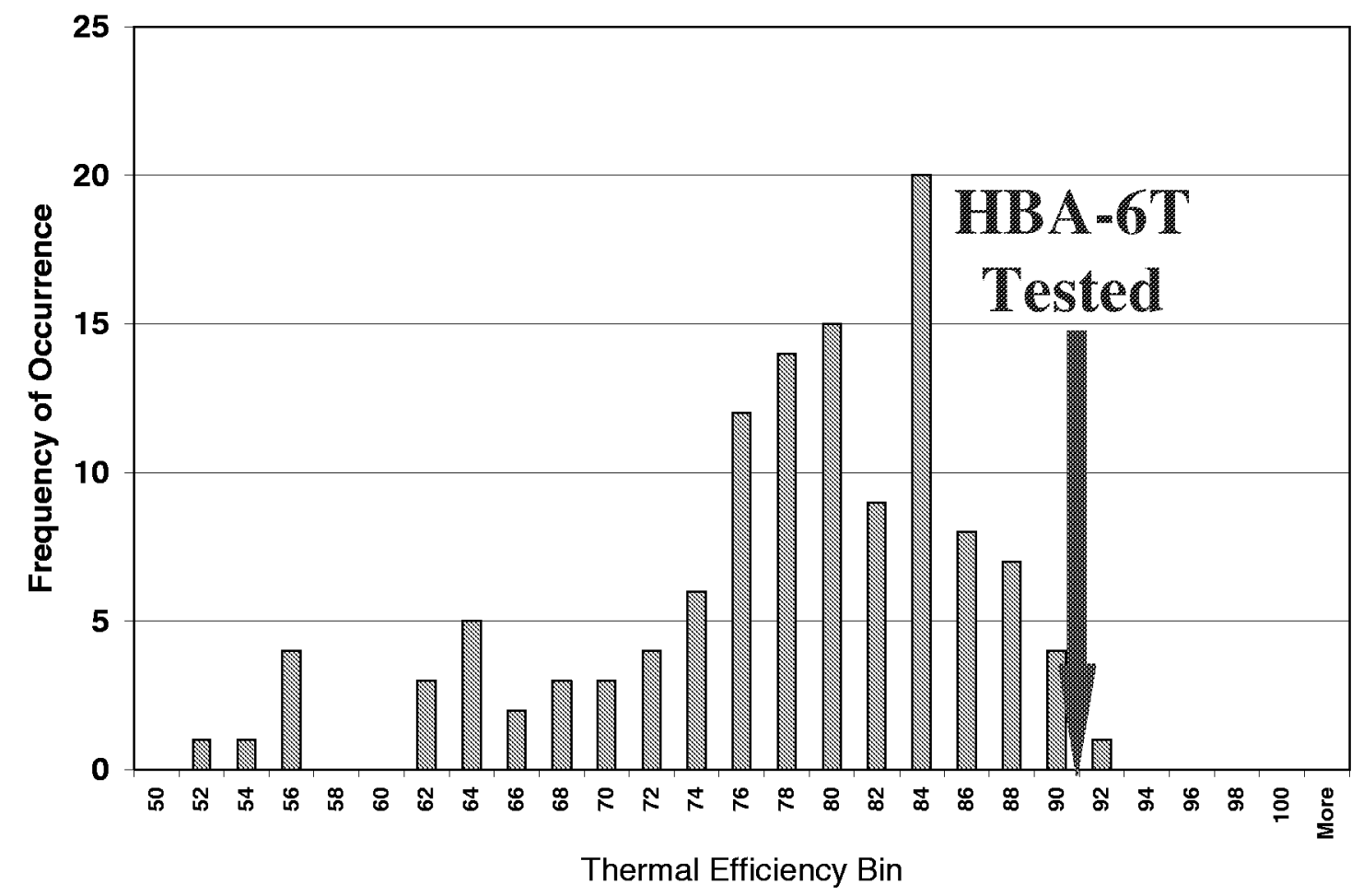

Figure 4-30. Compressor Efficiency versus Industry Distribution

\subsubsection{Variation of Equivalence Ratio}

Figure 4-31 shows the extent of variation of equivalence ratio during the first series of tests at El Paso's Kinder station. Some of the high extremes late in the day result from intentional changes in air manifold pressure. However, some significant changes result from changes in conditions not imposed by the test program. The range of 5 to $6 \%$ observed in the early part of the day's testing is significant and can influence engine operation. This data prompted the observation that for turbocharged engines, a means of controlling equivalence ratio would be valuable and should be achievable at low cost with state-of-the-art, commercially available sensors and controls. Section 6 will show the feasibility on this engine model of a closed-loop controller using the UEGO sensor in the exhaust stack (which provides an output proportional to equivalence ratio) coupled with actuation of the turbocharger's wastegate controller to maintain an equivalence ratio set point. 
EQ Ratio - El Paso Sta 823

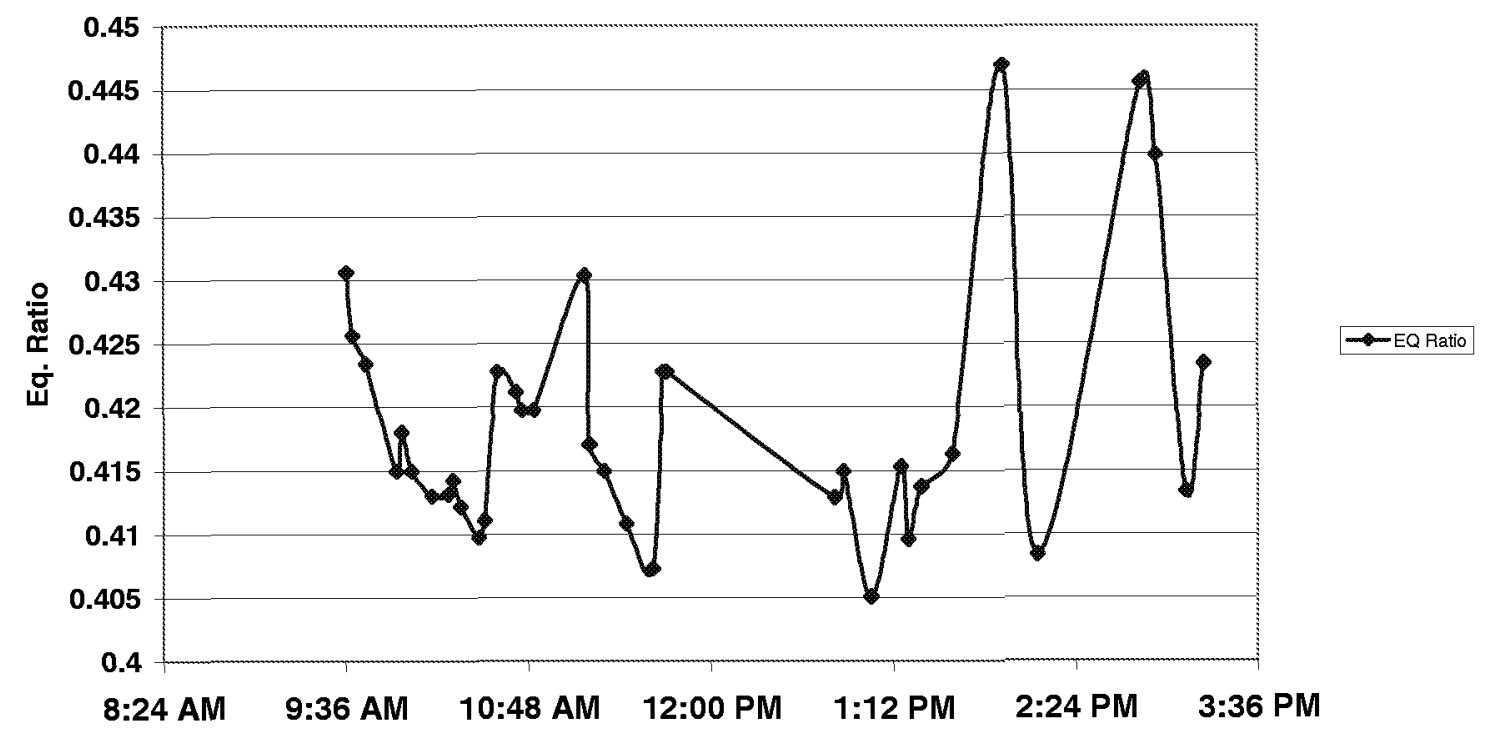

Figure 4-31. Kinder Test 1, April 2003 - Variation in Equivalence Ratio 


\section{RESULTS AND DISCUSSION: TEST ON A GMW10 MODIFIED FOR HIGH-PRESSURE FUEL AND TURBOCHARGER}

\subsection{TyPical DATA}

The first tests on a GMW10 were performed at Williams Transco Station 40, near Sour Lake, Texas. Figure 5-1 shows the three compressor cylinders. Figure 5-2 shows the power cylinders, left bank. The unit has high-pressure fuel injection installed (Enginuity's HPFI ${ }^{\mathrm{TM}}$ system) with a turbocharger. Tests were conducted August 25-28, 2003. Tests conducted included a successful demonstration of CPR balancing and a comparison of CPR balancing with PFP balancing, tests on the influence of timing and air manifold pressure on performance, and tests to evaluate the influence of load step and load on engine performance.

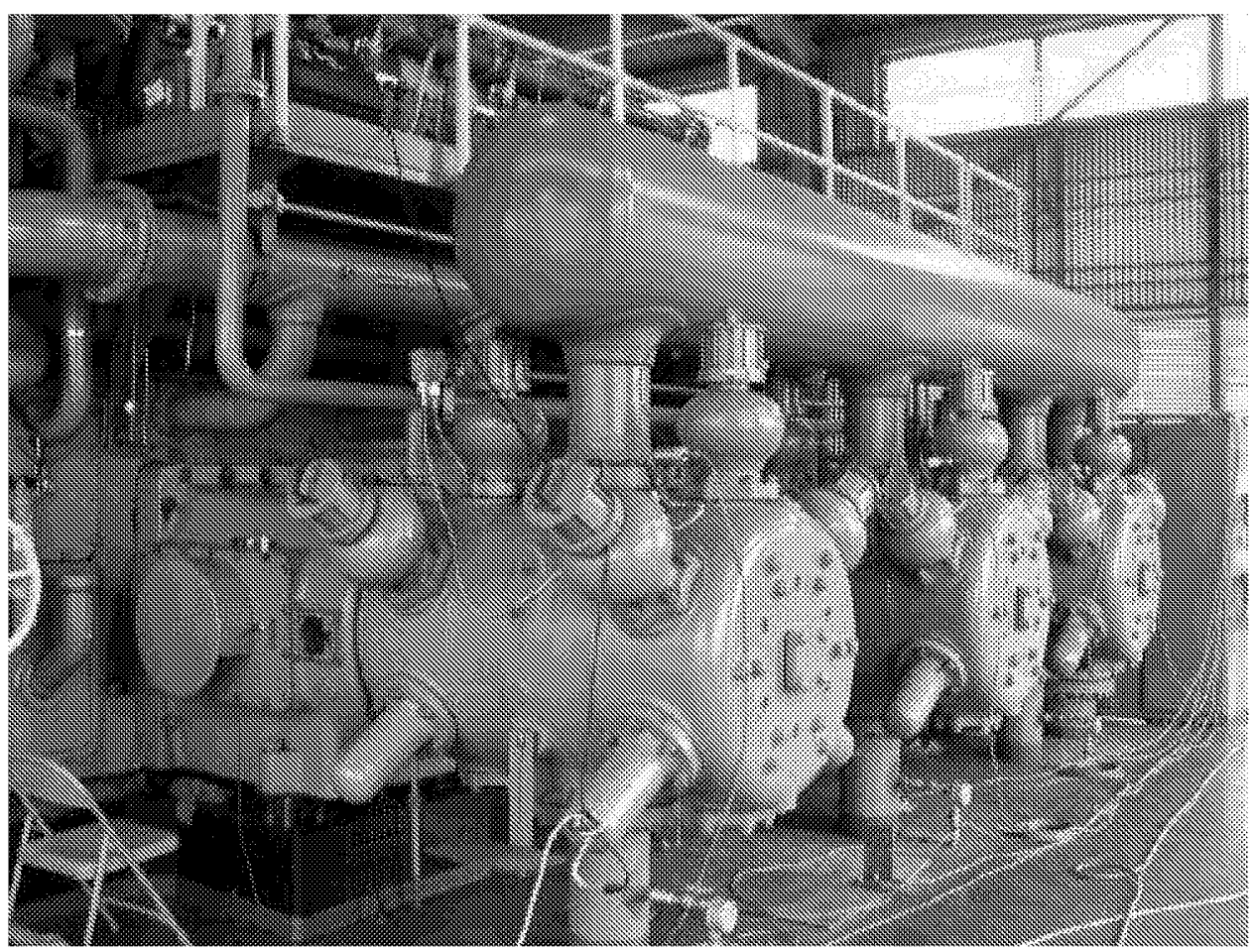

Figure 5-1. Williams Sour Lake Station; Unit 6; August 2003 


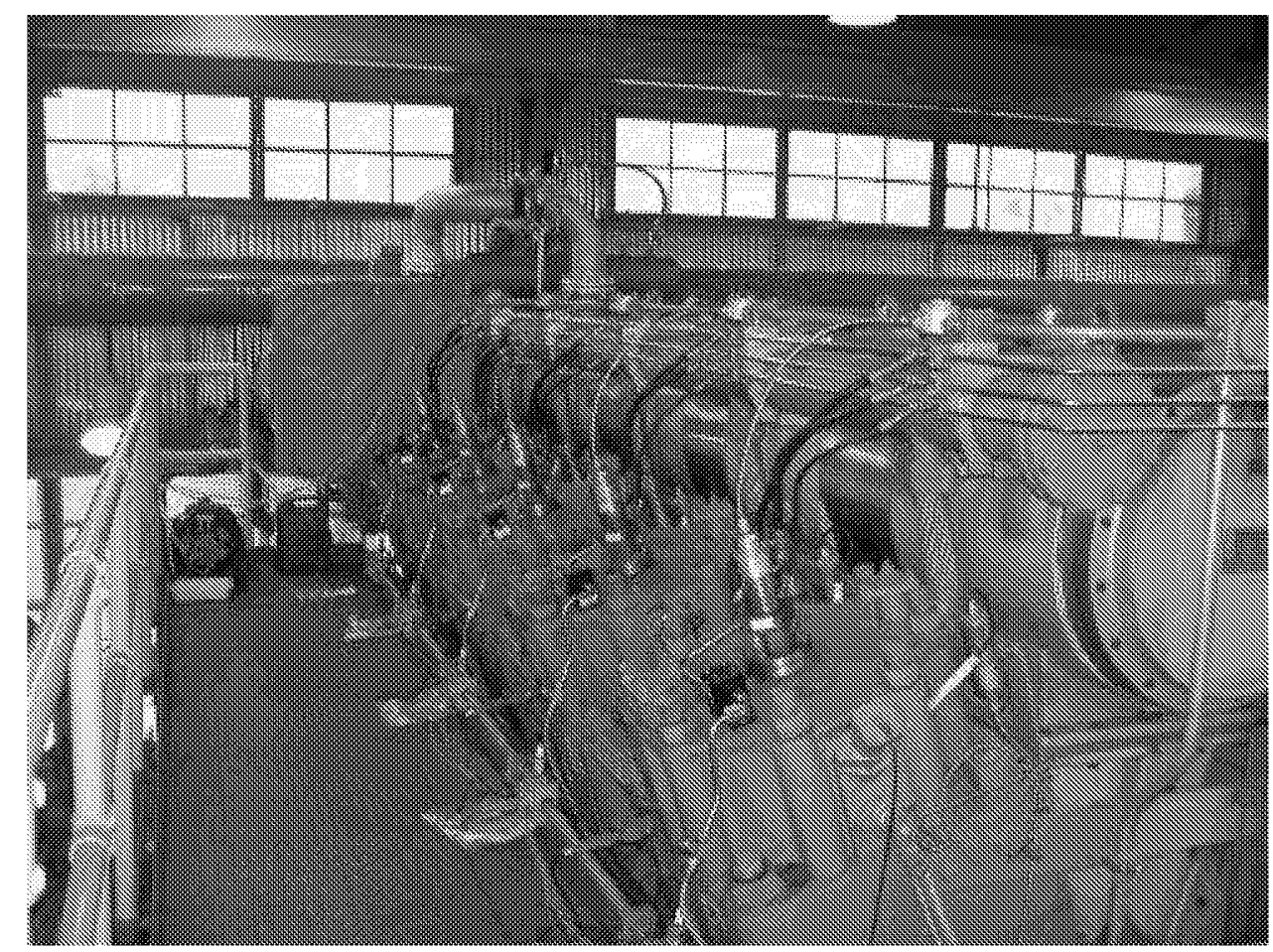

Figure 5-2. Power Cylinder, Left Bank; (Williams Station 40 (Sour Lake); August 2004)

Figure 5-3 presents the tabular screen used to display snapshot information relating to both the compressor and engine cylinders. For the ten power cylinders, the top half of the screen shows in columns the instantaneous peak-firing pressure, the instantaneous angular location (after TDC), the pressure at 20 degrees before TDC ("compression pressure"), the average peak-firing pressure, the standard deviation in peak-firing pressure, the indicated horsepower, the instantaneous indicated mean effective pressure (IMEP), the average HP, the standard deviation in horsepower, and the compression pressure ratio (CPR) - defined as the instantaneous ratio of peak-firing pressure to compression pressure. The averages in Figure 5-3 are rolling averages (FIFO).

It is noted that the standard deviation in peak-firing pressure varies from 46.3 to 66.1 PSI - a 20-PSI difference in standard deviation between cylinders. Standard deviations are about $13 \%$ of the average peak-firing pressure.

Below, the cylinder data columns are various averages, totals, and spreads from this typical snapshot:

- The Instantaneous Spread (211.06)

- The Average Instantaneous Spread (169.6)

- The Standard Deviation in Peak-Firing Pressure Instantaneous Spread (36.85)

- The Spread in Average Peak-Firing Pressure (16.99)

- The Total Average Horsepower (2253.82)

- The Average CPR (1.839)

Topical Report

DOE Award No. DE-FC26-02NT41646 - SwRI Project 18.06223 


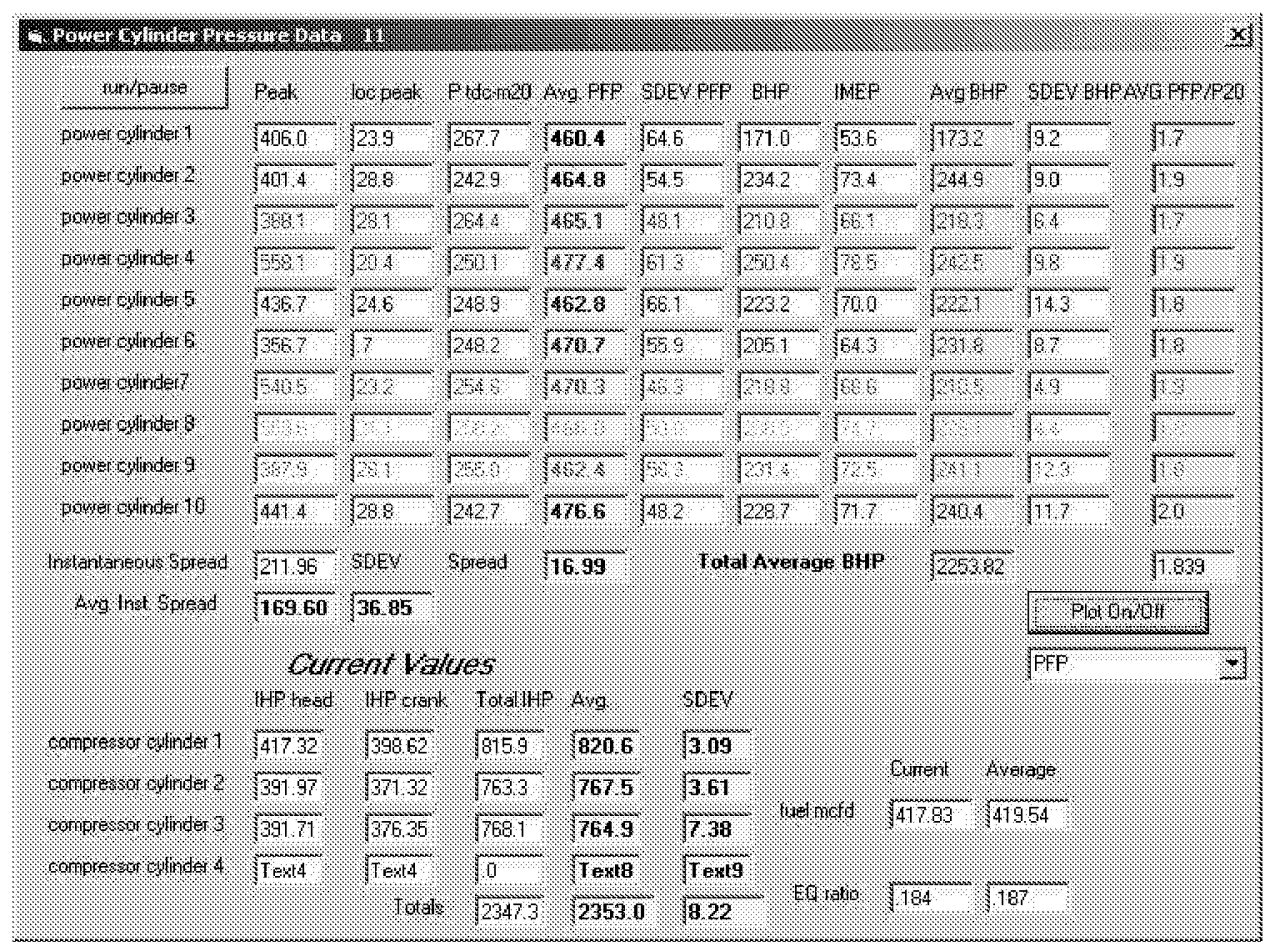

Figure 5-3. Snapshot of On-Site Real-Time Calculations; (Williams Station 40 (Sour Lake); August 2004)

Under the data for the ten power cylinders are the indicated horsepowers for the two ends of each of the three compressor cylinders, together with the total of the two ends for each cylinder. These instantaneous value columns are followed by the average and the standard deviation of the cylinder's horsepower $(2353,8.22)$.

The exceptionally low (17 PSI) spread in average PFP in this snapshot is attributable to the automated balancing system installed as part of HPFI $^{\mathrm{TM}}$. This system is designed to constantly adjust the bias in pulse width on individual fuel injectors in order to minimize the spread in cycle averaged peak-firing pressure. Although disabled during the tests, the biases from prior automated balancing clearly remained close enough during the test program to keep this spread very low.

The total instantaneous indicated horsepower for the compressor cylinders (2347) and the average total indicated horsepower are also shown (2353), with the total standard deviation in horsepower across all the cylinders (8.22). Also on this screen are the current and rolling average values for fuel flow (417.83/419.54) and global equivalence ratio $(0.184 / 0.187)$. This is a low global equivalence ratio. The influence of the air and injection system appears to be to allow operation acceptably close to the lean limit at a low equivalence ratio.

It may be observed that the power for the power cylinders is measured as about $100 \mathrm{HP}$ below the compressor cylinders. This, of course, is not realistic. The sensors are well calibrated, but the required power cylinder sensor installation shown in Figure 3-4 is 
undoubtedly a factor in reducing the apparent horsepower. Because the required piggybacking separates the SwRI transducers from the cylinder chamber by an additional length, the channel distortion is exaggerated. The filtering induced by the flow passage geometry attenuates the higher frequency dynamic variation, and thereby lowers the observed horsepower. The channel attenuation phenomenon has been well documented $[6,7]$. The similarity of installation for the 10 transducers and the similarity in form of the power cylinder traces makes it strongly arguable that the distortion induced in each cylinder is the same for each cylinder and, therefore, that trends observed in horsepower and peak pressure are valid. The very low spread observed by both the SwRI instruments and the $\mathrm{HPFI}^{\mathrm{TM}}$ system makes it very likely that the cylinder pressure measurements are consistent with those of the $\mathrm{HPFI}^{\mathrm{TM}}$ system (upon which they are piggy-backed).

Figure 5-4 shows typical averaged pressure traces for the 10 power cylinders. These include a numerical value for the current average spread in average peak-firing pressure of about 60 PSI for this condition. This higher spread (and higher peak pressures) probably corresponds to a test condition (e.g., increase in timing advance), which caused both PFP and spread to increase. The similarity of the traces is notable, and even 60 PSI is a relatively low spread in average peak pressure - not above about 12 or $13 \%$ of PFP.

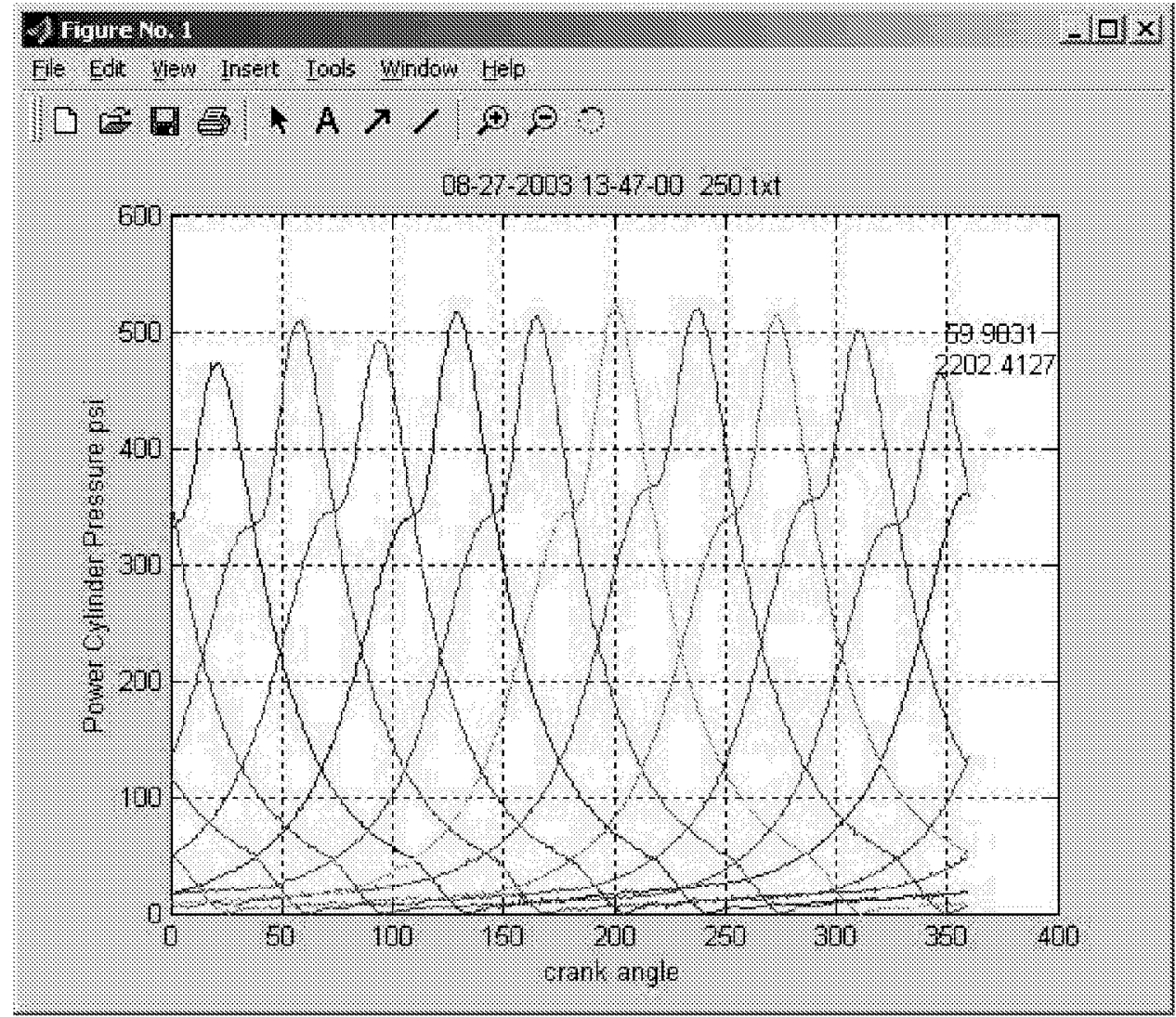

Figure 5-4. Typical Power Cylinder Pressure Data; (Williams Station 40 (Sour Lake); August 2004) 
Figure 5-5 shows the corresponding compressor cylinder pressure traces. The header pressures are superimposed. The pulsations in the cylinder pressure, which reflect dynamic response to cylinder/valve dynamics in the attached piping, are apparent in the cylinder traces. The piping normally includes pulsation control features, which filter out pulsations above a relatively low cut-off frequency with minimum flow resistance. However, the reflections of lower order pulsations in the cylinder pressure traces and the small, but non-zero flow resistance associated with pulsation control filters and choke tubes can influence the unproductive horsepower in the compressor cylinders, and thereby can influence cylinder thermal efficiency.

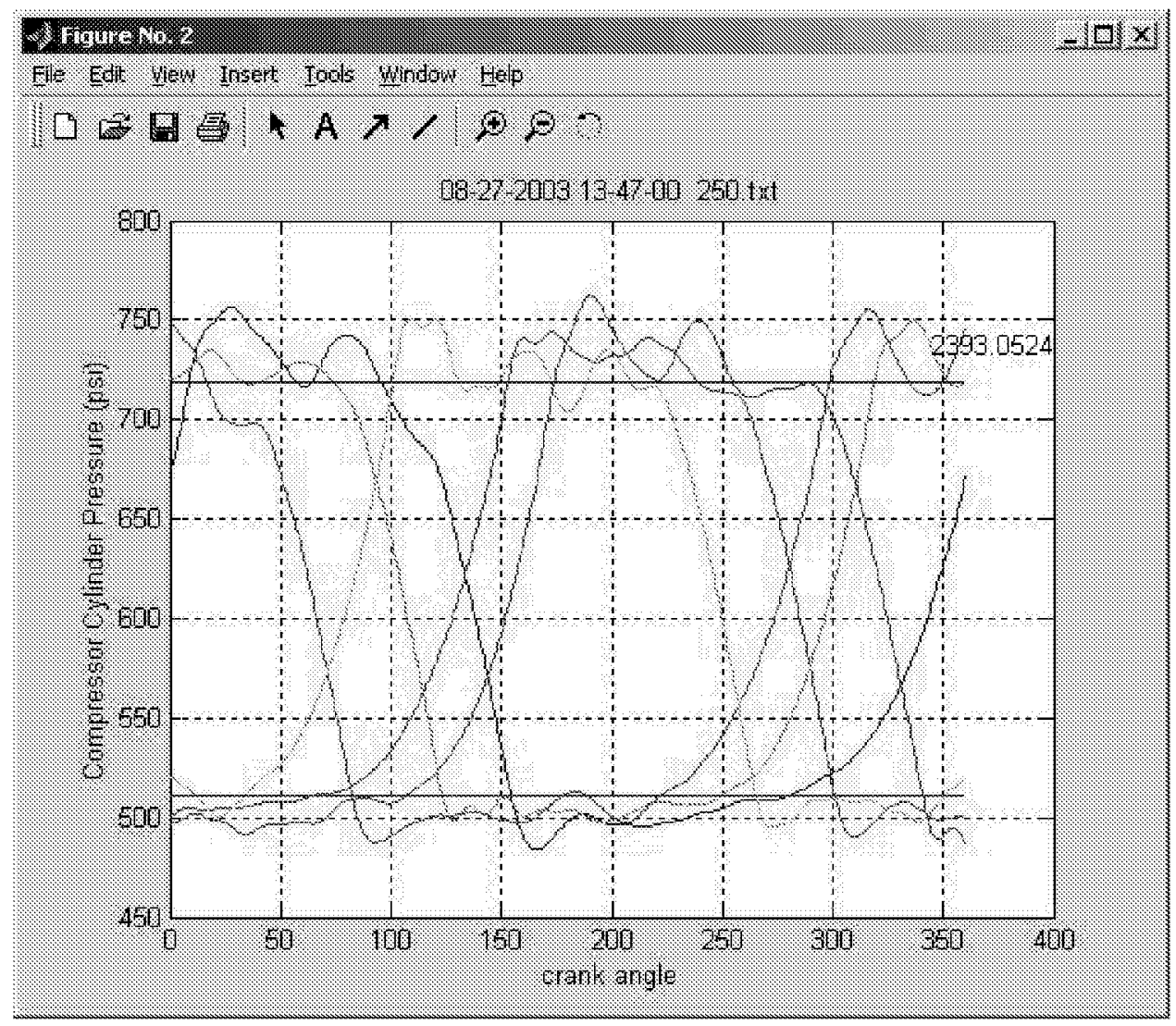

Figure 5-5. Typical Compressor Cylinder Pressure Data; (Williams Station 40 (Sour Lake); August 2004)

Figure 5-6 shows the dynamic variation in inlet air manifold pressure at the location of measurement. The top trace presents the pressure as a function of crank angle over one engine cycle (360 degrees). The lower trace shows the result of transforming the upper trace to the frequency domain, presenting zero-to-peak pressure variation as a function of orders of rotational speed. The upper trace indicates a range from about 4.6 to 5.7 PSIA; i.e., close to $20 \%$ of the average, with a series of reversals in the trace within one revolution. The lower frame of Figure 5-6 shows that there are peaks at about $3^{\text {rd }}, 10^{\text {th }}$, $16^{\text {th, }}$ and $25^{\text {th }}$ orders, and action to the $40^{\text {th }}$ order. 


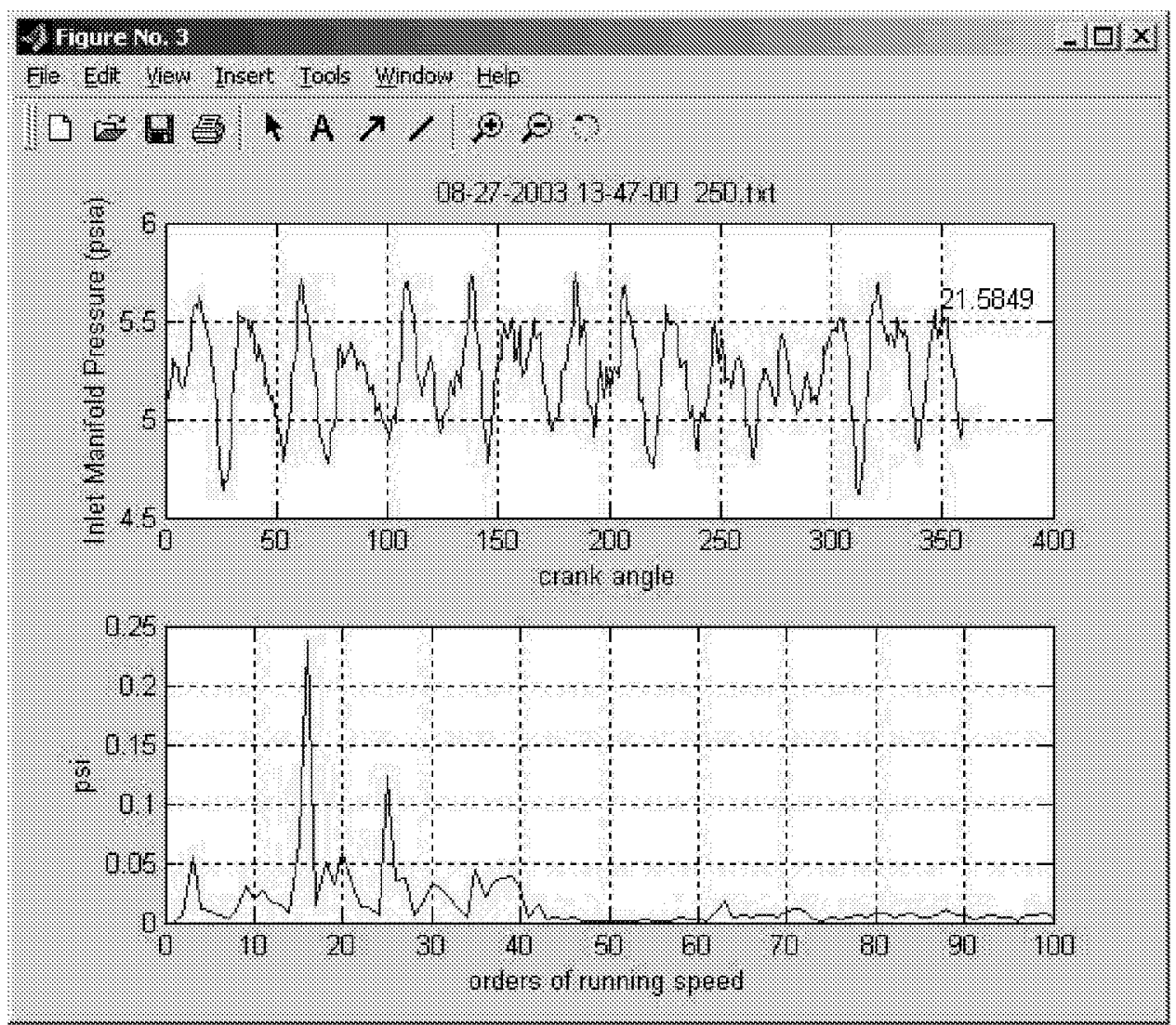

Figure 5-6. Typical Inlet Manifold Pressure Trace and Order Spectrum; (Williams Station 40 (Sour Lake); August 2004)

Figure 5-7 makes a similar presentation to Figure 5-6 for exhaust manifold pressure. The range shown in the upper trace is from 3 PSI to 4.9 PSI; i.e., close to $50 \%$ of the average. The lower trace shows peaks at the $4^{\text {th }}, 9^{\text {th }}, 11^{\text {th }}$, and $22^{\text {nd }}$ orders of running speed. 


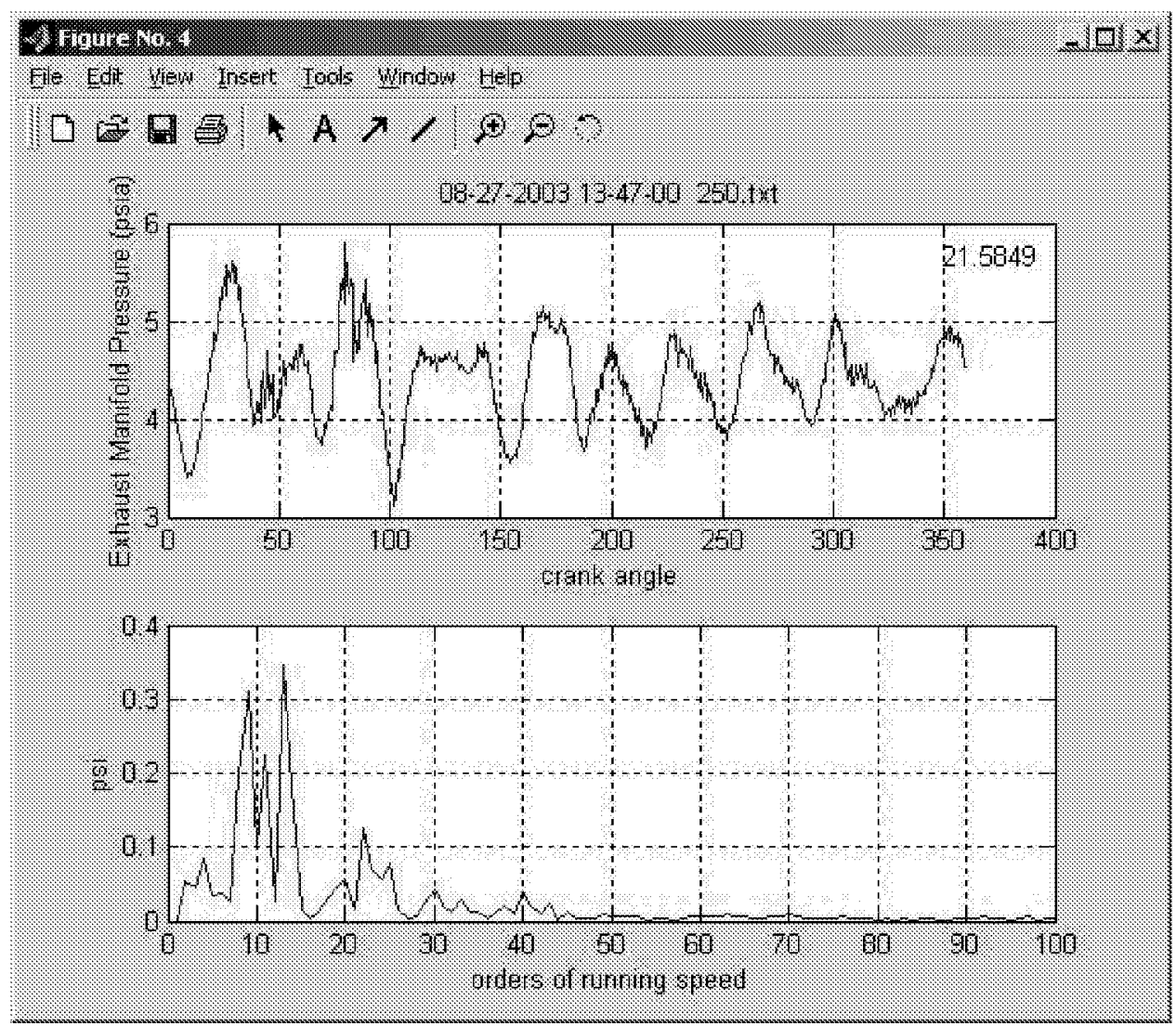

Figure 5-7. Exhaust Manifold Pressure Trace and Order Spectrum; (Williams Station 40 (Sour Lake); August 2004)

Figure 5-8 summarizes the range of variation - typical in the manifold pressures throughout a day of testing. In general, the inlet air manifold dynamic range lies just below $20 \%$ of its average, although a few points exceed $20 \%$. The exhaust manifold dynamic range lies generally just over $50 \%$, ranging from 45 to $70 \%$. These are cycleaveraged pressures indicating both time variation and variation along the manifolds. Since flow into and out of the cylinder is directly influenced by these pressures, the trapped air would be expected to vary from cylinder-to-cylinder as a result of the time/space variation, as previously discussed with respect to data from El Paso Station 823. 


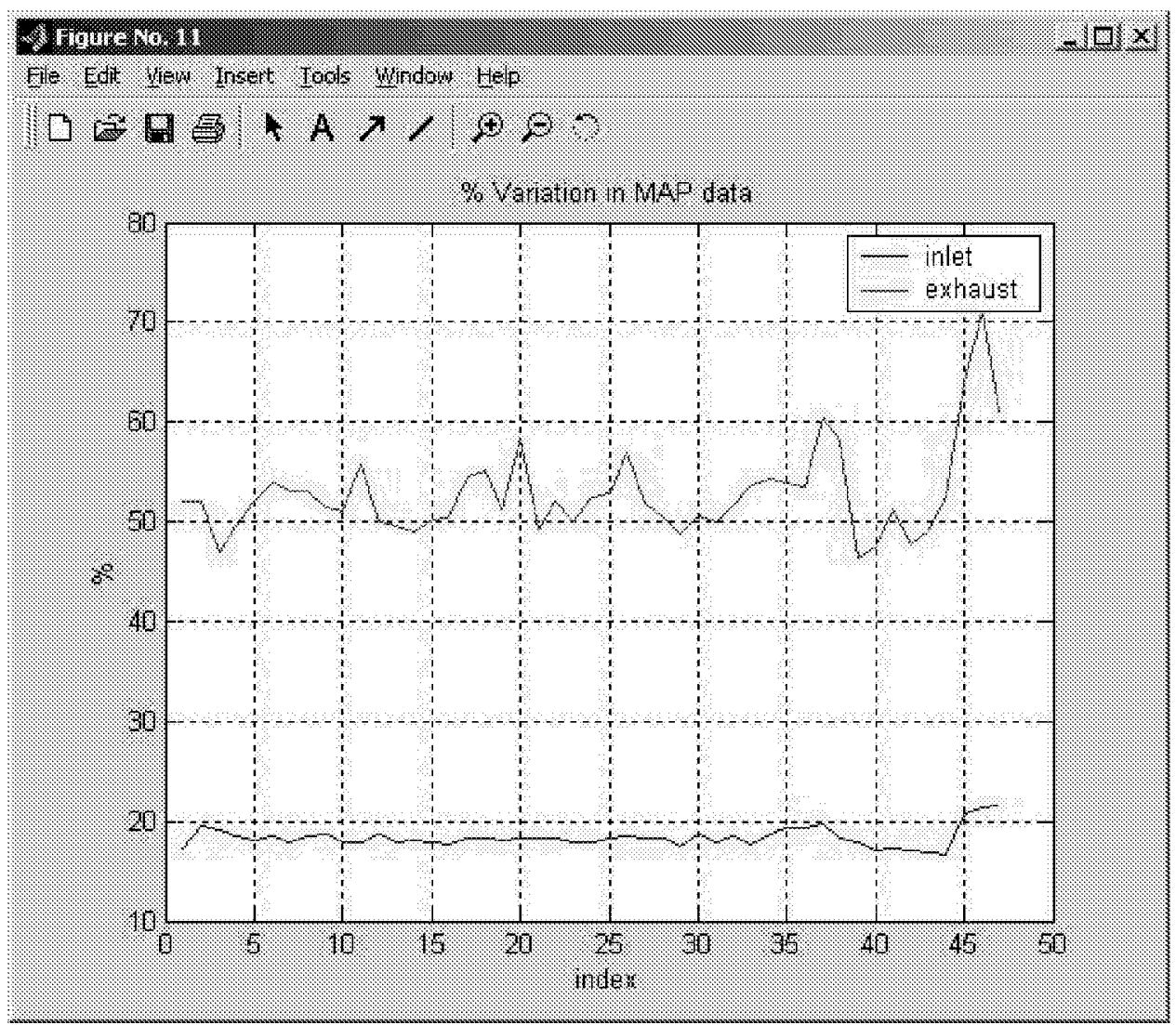

Figure 5-8. Variation in Inlet and Exhaust Pressures at Point of Measurement; (Williams Station 40 (Sour Lake); August 2004)

Figure 5-9 shows the cycle-averaged output of the rod load sensor in the format of rod load versus crank angle over a single revolution (360 degrees). The inferred rod load ranges from $-47,000 \mathrm{lb}$. to $+55,000 \mathrm{lb}$. - a total range of $102,000 \mathrm{lb}$. The variation reflects the difference between head-end pressure force and crank-end pressure force, together with the inertia force resulting from acceleration and deceleration of the piston. Further analysis in conjunction with piston kinematic analysis will yield horsepower data from the rod load measurement.

Figure 5-10 shows the variation of compressor and engine horsepower indicated by the cylinder pressure transducers as a function of test record number (index). It will be seen that the indicated compressor power remains rather constant over the day's testing at an average of about $2375 \mathrm{HP}$, with a scatter range of about $50 \mathrm{HP}$ about this average value. The indicated engine power appears to drop gradually during the day from an initial average around $2275 \mathrm{HP}$ to about $2225 \mathrm{HP}$. There is, again, a range of about $50 \mathrm{HP}$ about the average, but the reducing trend in engine power, by 2 to $2.5 \%$ over the day, is clear. The measured engine power lying below compressor power on this engine reflects a long measurement channel attenuating fast changing signals. 


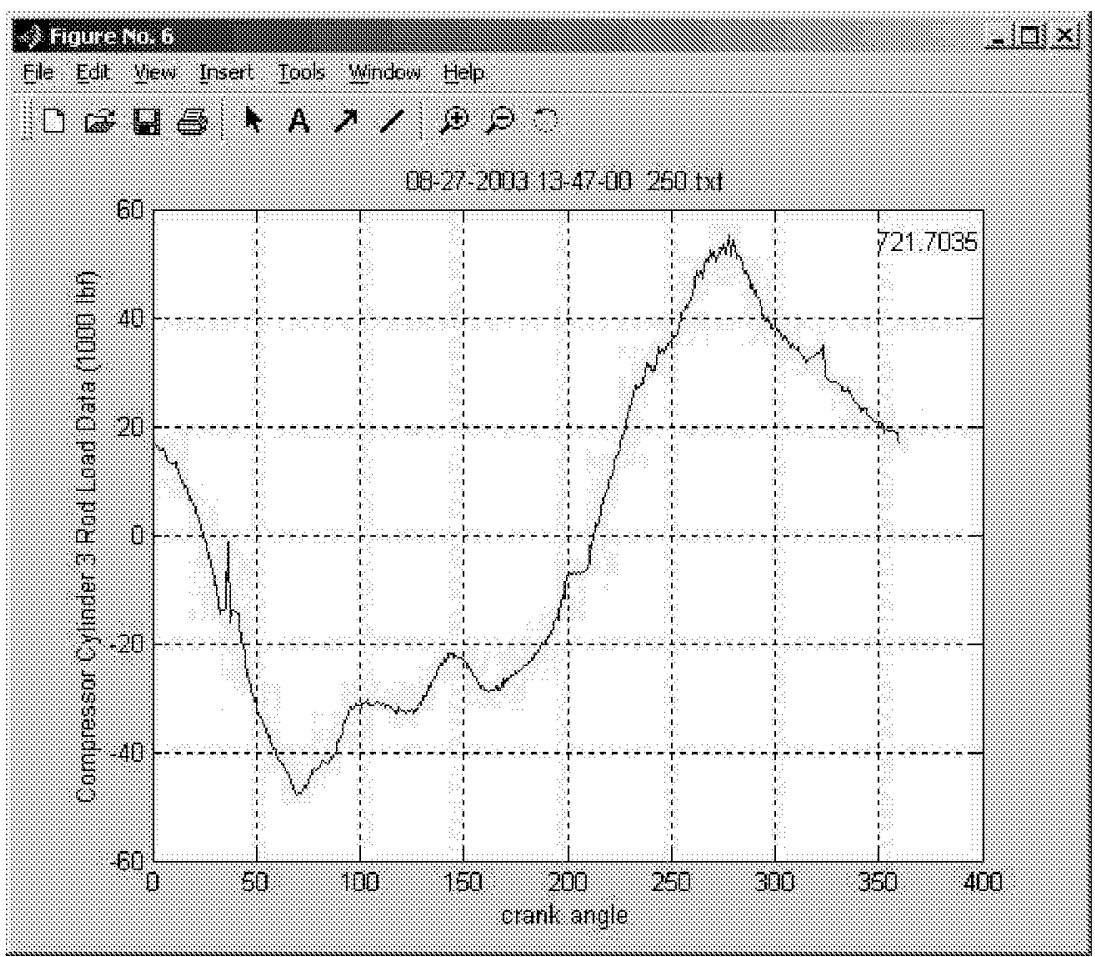

Figure 5-9. Typical Rod Load Variation over One Revolution; (Williams Station 40 (Sour Lake); August 2004)

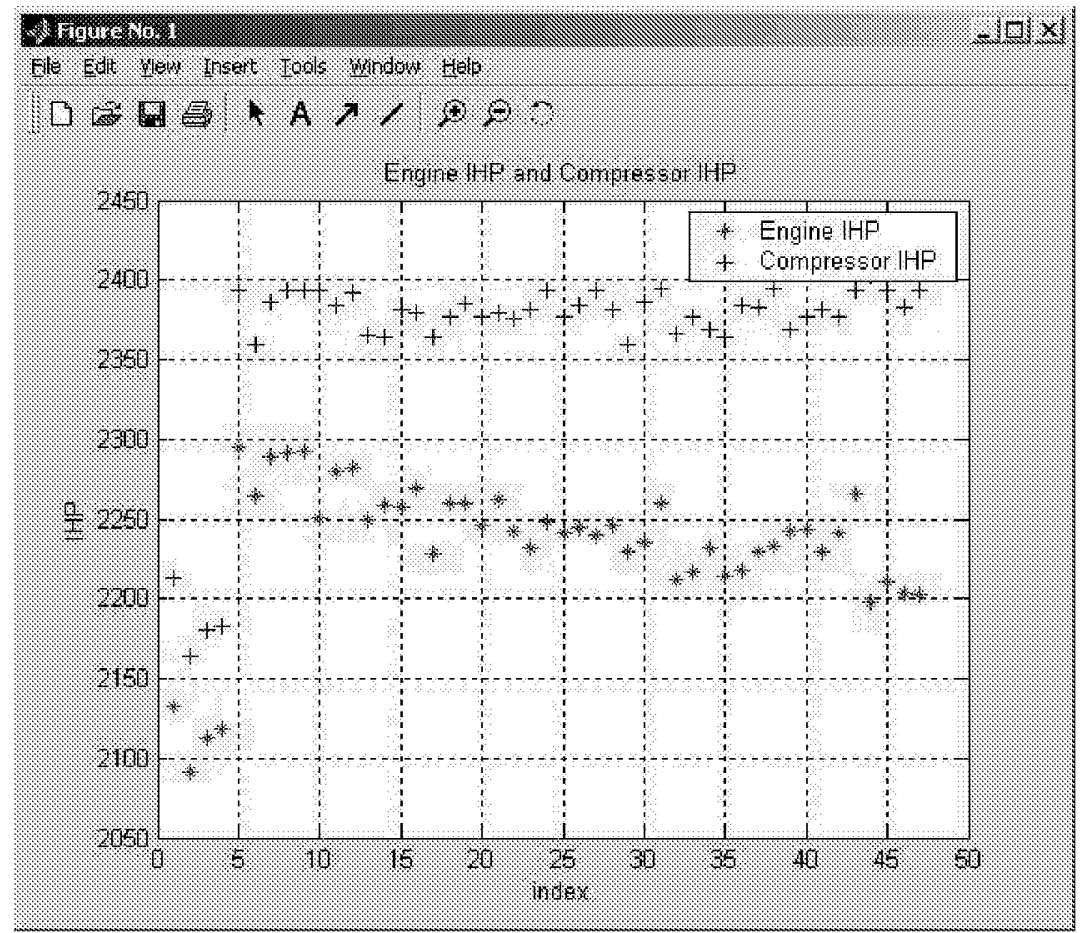

Figure 5-10. Indicated HP Over Test Day; (Williams Station 40 (Sour Lake); August 2004) 
A similar trend was seen in the data at the first test site (which will be discussed further below) - an apparent reduction in the losses between engine and compressor pistons over a 5- to 6-hour period following the start of the day's tests.

The first four data sets in Figure 5-10 show much lower power for both compressor and engine - reflecting the transients immediately following start-up.

Figure 5-11 shows how the ratio of indicated compressor power to indicated engine power varies over 47 test data sets. Discounting the first four part load conditions, the ratio runs from 104.1 to about 106.5 for test series 5 through 43 . Test series 44 through 47 reflect some substantial changes in engine conditions (timing and air manifold pressure), and indicate a higher ratio of compressor to engine power (108 to 109\%). Thus, the main body of data indicates an increase in the ratio of compressor to engine power - consistent with the reduction in engine power discussed with reference to Figure 5-10. The artifact of higher compressor power than engine power has been discussed and explained previously.

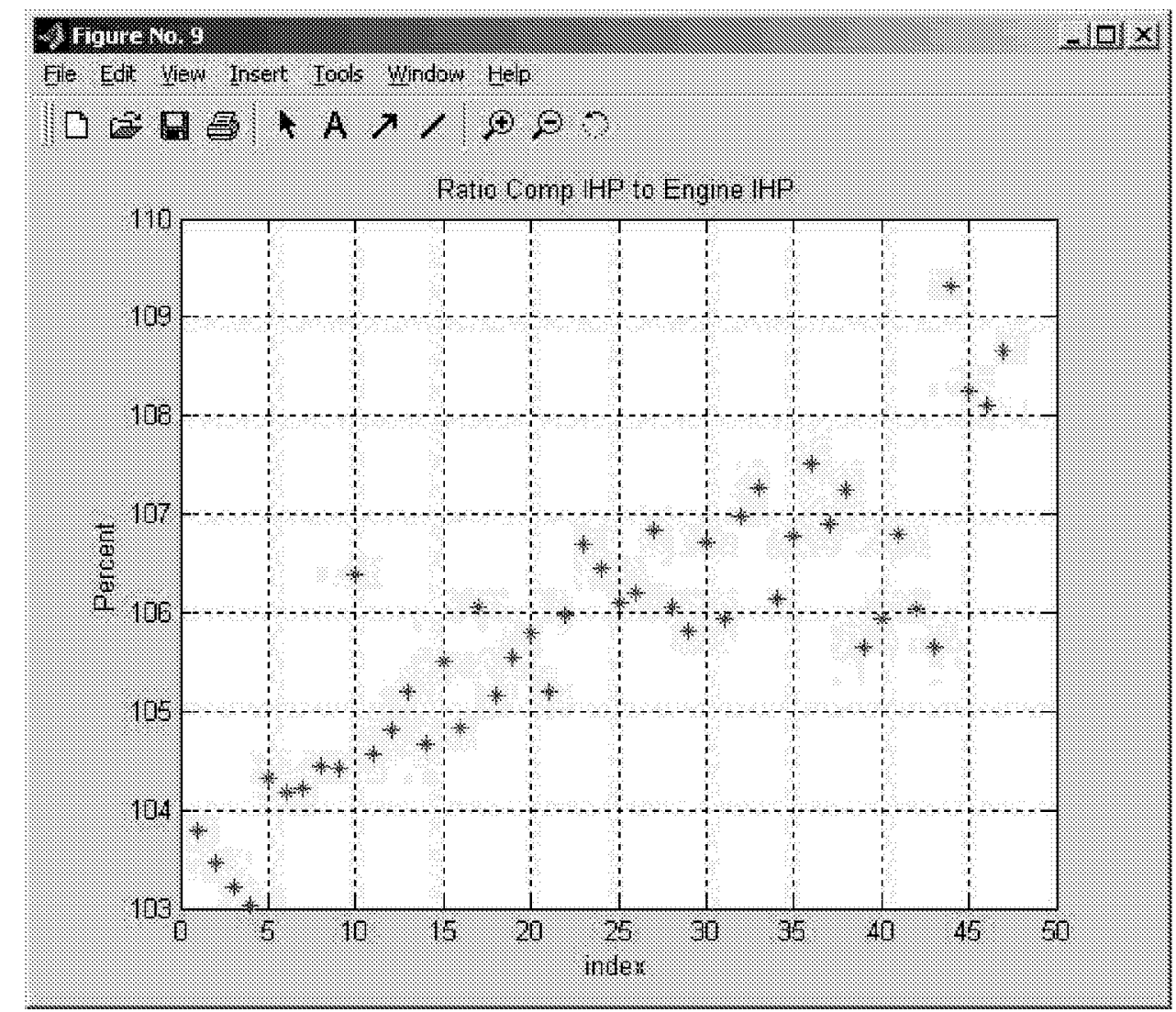

Figure 5-11. Ratio of Indicated Compressor HP to Engine HP during Test Day; (Williams Station 40 (Sour Lake); August 2004) 
Figure 5-12 shows how compression pressure in the power cylinder (defined for these data sets as the pressure 20 degrees before top dead center) varies over the test data series. The spread in compression pressure reflects a potential difference in trapped air mass in the different cylinders, and over the test series, the profile of compression pressure across the ten cylinders has a clear and repeatable pattern. With minor qualification, when one cylinder's compression pressure goes up or down, the compression pressure for all cylinders goes up or down by a similar amount. A reasonable interpretation is that trapped air in each cylinder remains linked to the other cylinders through the air and exhaust manifold flow dynamics, even when global behavior of the engine cylinders changes. This suggests the importance of these manifold flow dynamics in determining engine behavior as influenced by air balance across the cylinders.

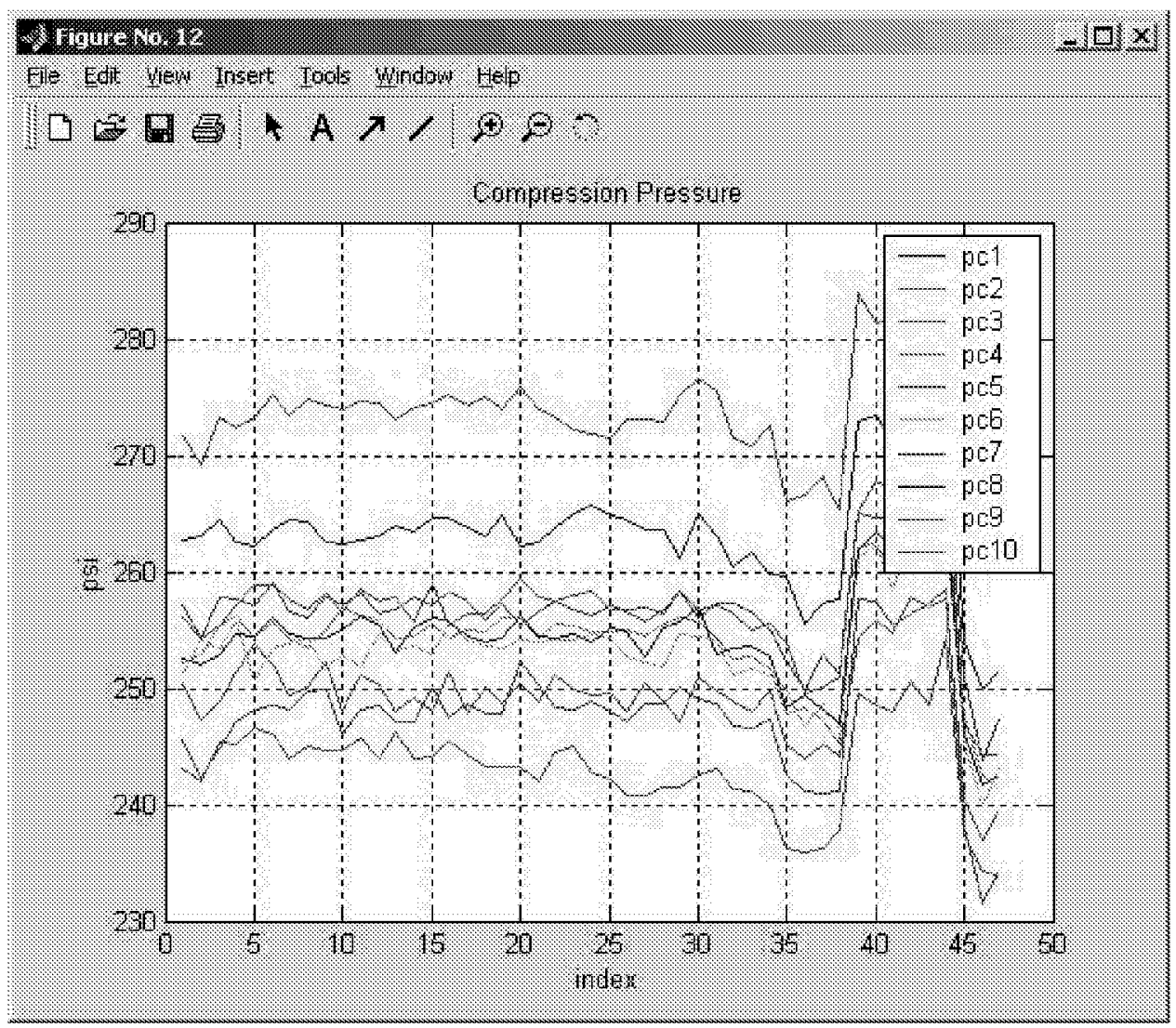

Figure 5-12. Power Cylinder Compression Pressure; (Williams Station 40 (Sour Lake); August 2004)

Figure 5-13 shows how compressor thermal efficiency varies during the test series. Even including the first four part load data sets, the efficiency covers a rather small range from 85 to $86.8 \%$. With these first four points removed, the thermal efficiency for the complete compressor has a range of one point from 85 to $86 \%$. This is a very consistent data set, reflecting in part the consistency of conditions under which the compressor was operating. Consistency can also be seen between efficiencies calculated using differential 
indicated power based on the toes of the PV card, and the thermal efficiencies based on header conditions. In general, the header-based thermal efficiency is slightly lower than the cylinder pressure based efficiency, but only by typically 0.2 percentage points. As discussed relative to earlier figures, the first four data sets in this chart reflect start-up transients.

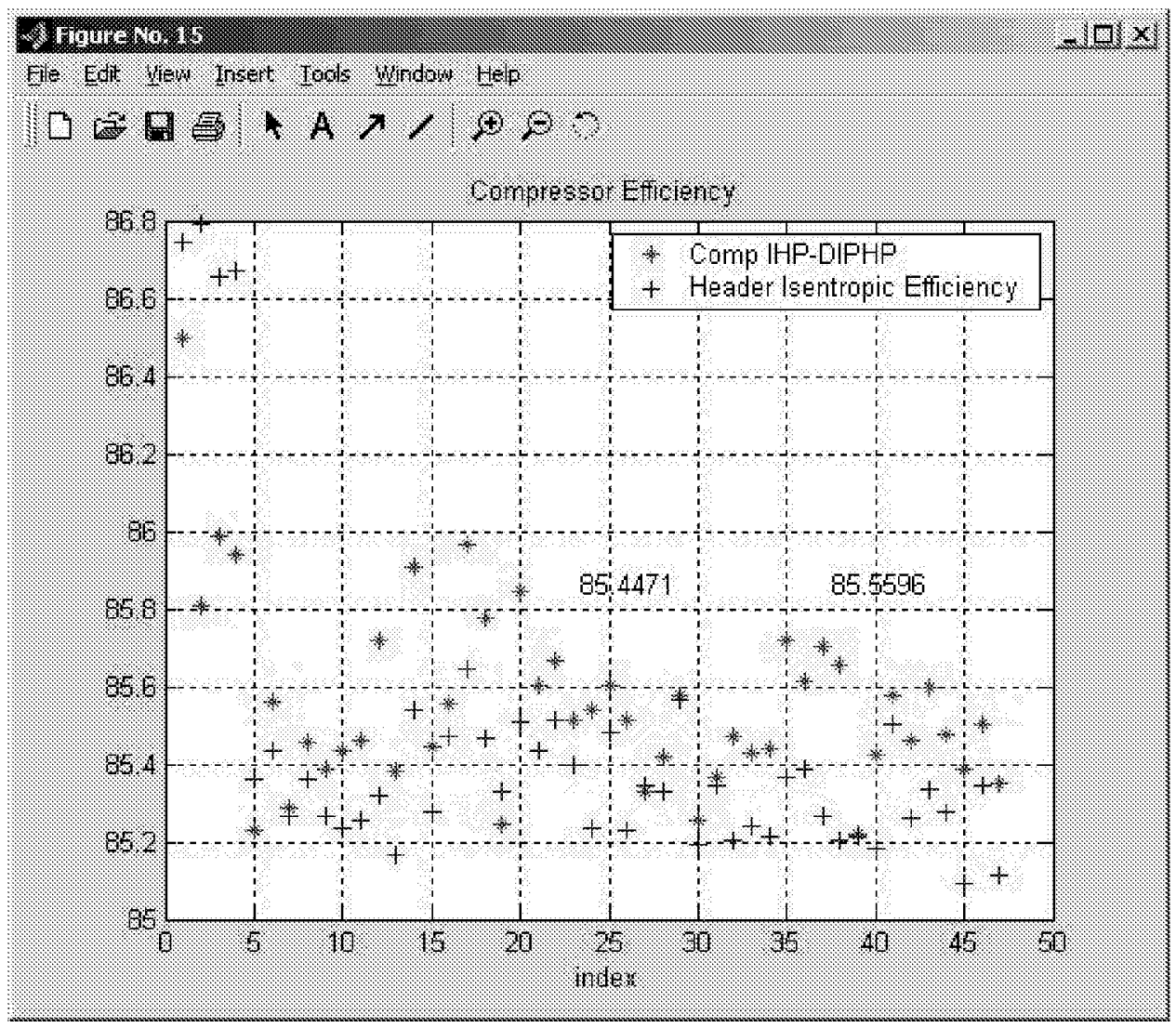

Figure 5-13. Compressor Efficiency; (Williams Station 40 (Sour Lake); August 2004)

Figure 5-14 shows the waveform from the strain data capture module (SDCM) over eight engine revolutions. There is some variation from one revolution to the next, which could well correspond to the variation from cycle-to-cycle in combustion, as reflected in peakfiring pressure variations from cycle-to-cycle. 


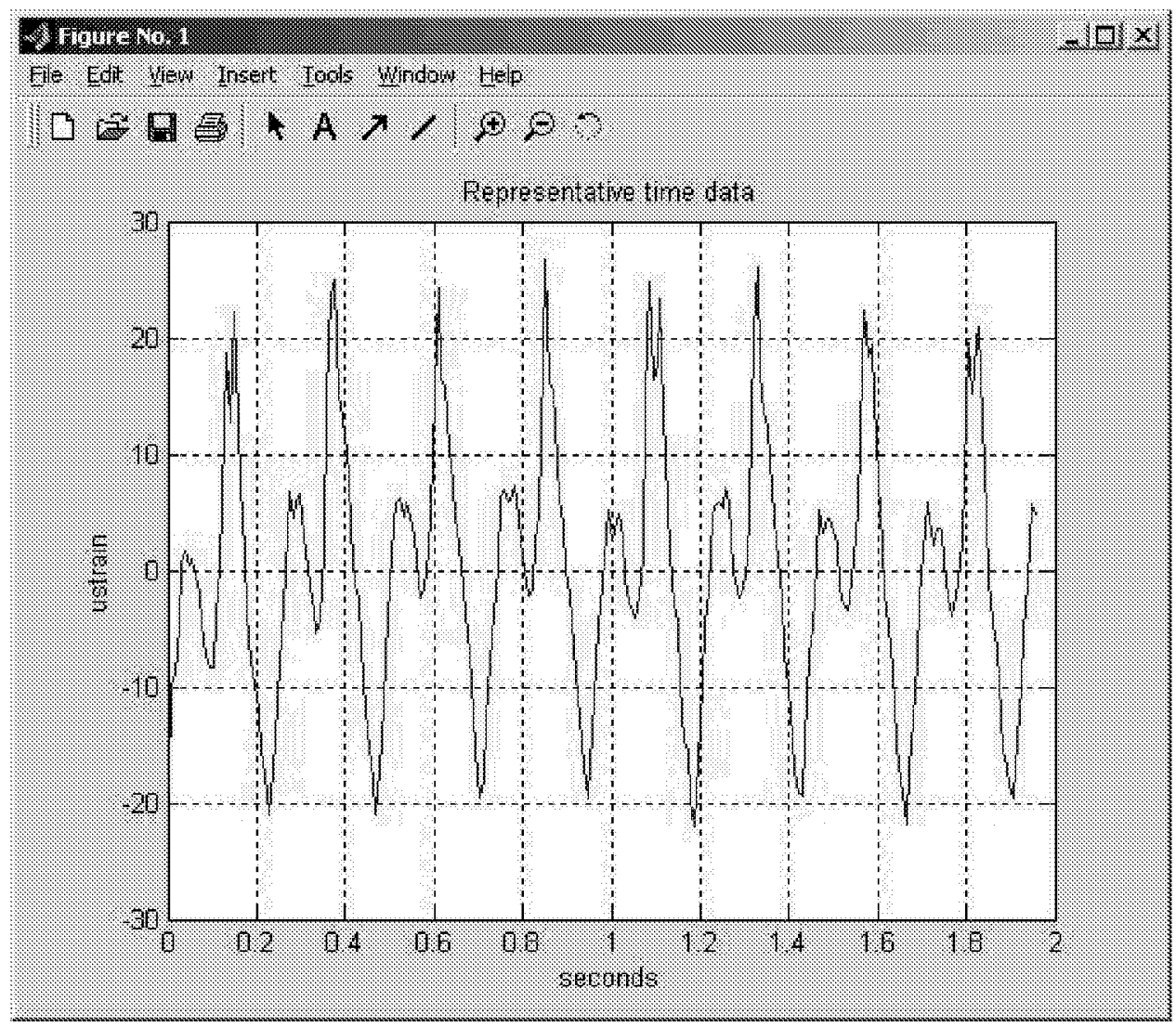

Figure 5-14. Typical Waveform (PC34); (Williams Station 40 (Sour Lake); August 2004)

Figure 5-15 shows the variation of strain data capture module output (expressed as peakto-peak microstrain) throughout the approximately 7-hour test series. The start of the unit can be identified by sharp continuous increase from below 10 microstrain to above 50 microstrain at about 50 minutes, and the stop is identifiable by a drop with similar range at about 415 minutes. The SDCM is installed and starts recording data every five minutes. Then, the covers are installed and preparations are made to start the unit, which occurred in this case after about 50 minutes. The short-term variation after start-up shows a gradual increase from about 50 to 57 microstrain - probably reflecting the final speed increase and loading of the unit after start-up, which covered about 30 minutes. The level of microstrain generally decreased from 57 microstrain to about 50 over the next 250 minutes (4 hours) - matching the trend in steadily reducing engine load over this similar period, as reflected in Figure 5-10. In the last two hours of testing, some short-term timing and air manifold pressure changes were included in the testing, which may have resulted in the short-term increase in peak-to-peak microstrain seen at about 345 minutes in Figure 5-15. Data indicating how timing advance can increase crankshaft strain will be discussed again with reference to the second test on a GMW10 later in this report. 


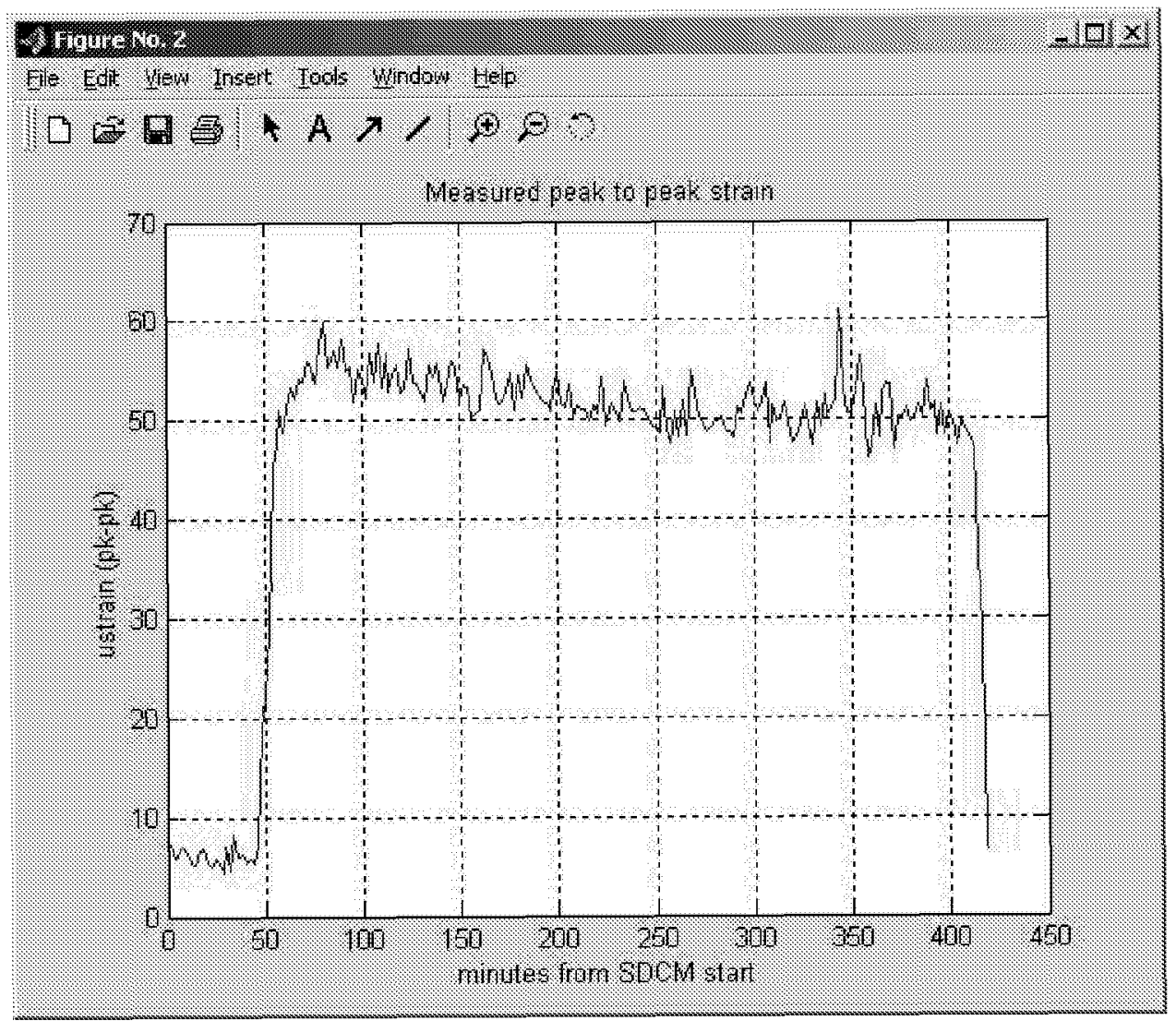

Figure 5-15. Peak-to-Peak Variation in Crankshaft Web Bending Stream (PC34); (Williams Station 40 (Sour Lake); August 2004)

The cycle-to-cycle variation is illustrated in 20 cycles of continuous pressure recording from power cylinder \#2, presented in Figure 5-16. Clearly, this sort of cycle-to-cycle variation in power cylinder load could be the cause of the cycle-to-cycle variation in SDCM data, shown in Figure 5-14.

Figure 5-17 shows the power cylinder standard deviation throughout the day's testing, averaged across cylinders. Its nominal value is 58 PSI. 


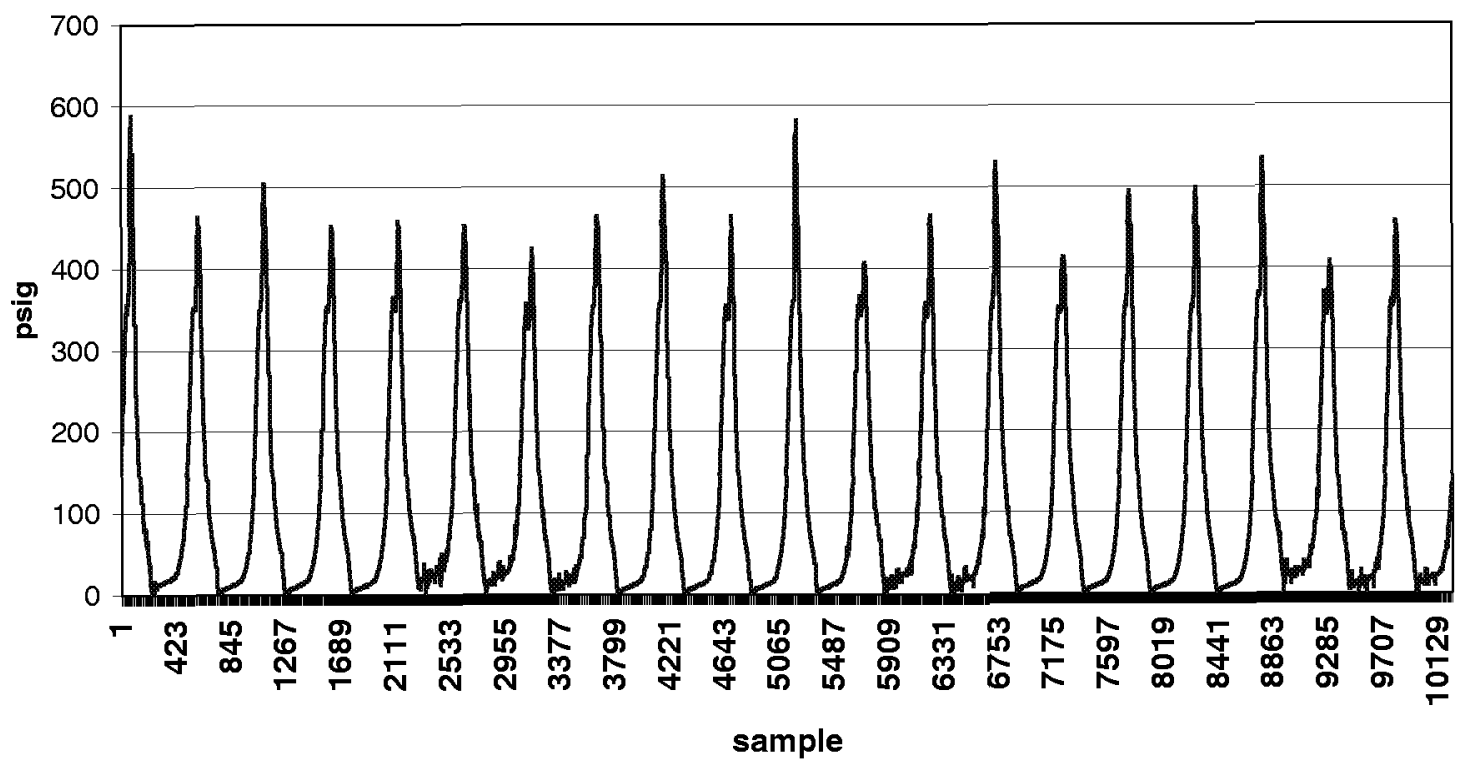

Figure 5-16. Typical 20 Successive Cycles - Power Cylinder \#2; (Williams Station 40 (Sour Lake); August 2004)

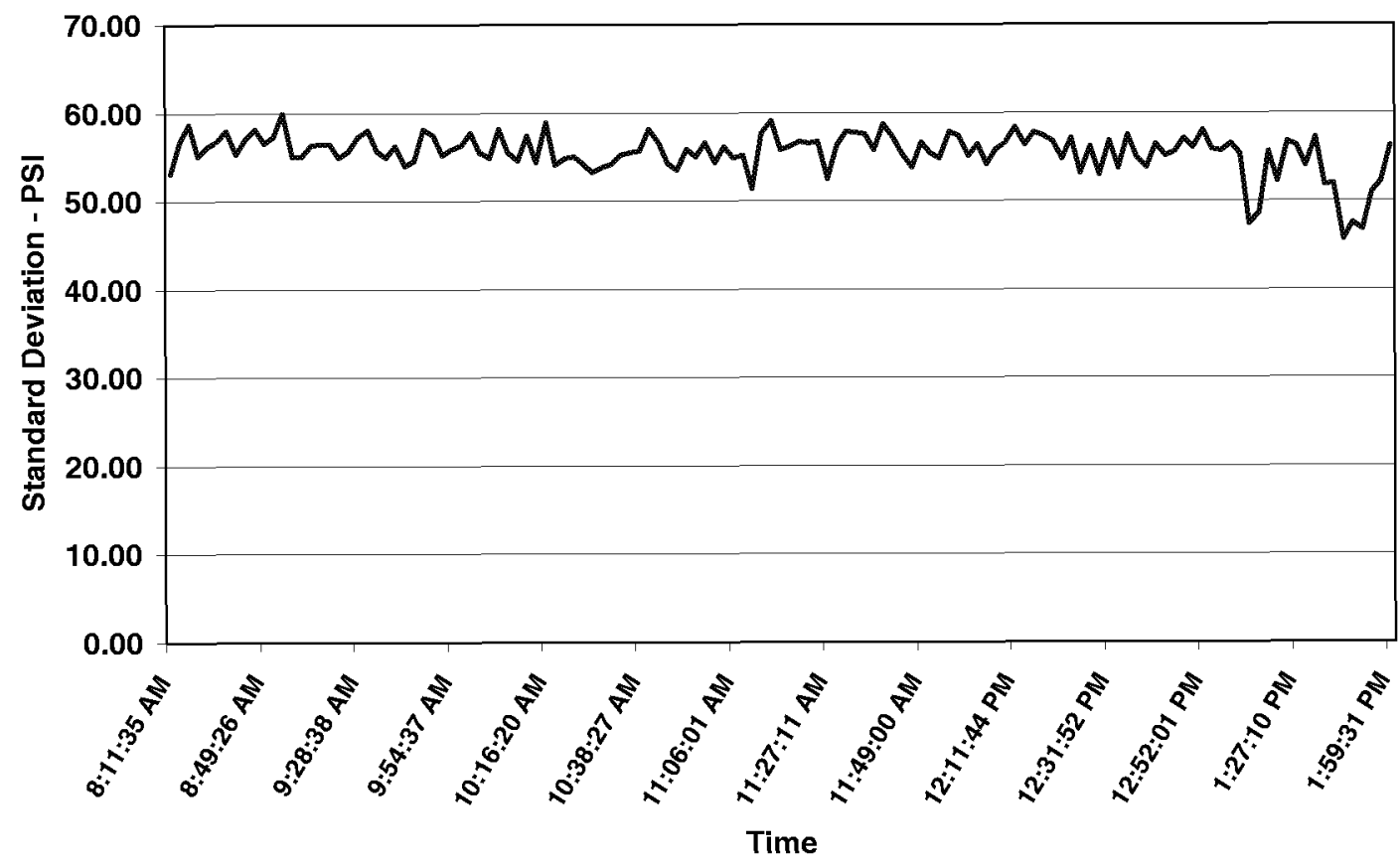

Figure 5-17. Average Standard Deviation in Peak-Firing Pressure over Time; (Williams Station 40 (Sour Lake); August 2004) 
Figure 5-18 shows the variation of fuel flow over about 7 hours of testing. The fuel flow reduces in a manner qualitatively consistent with the reduction in engine horsepower over time during the tests. The magnitude of the reduction is from about 427 MMSCFD to 420 MMSCFD. This is slightly less than $2 \%$. A potential reason for this reduction in fuel flow being lower than the 2 to $2.5 \%$ reduction in engine power is that engine brake thermal efficiency typically decreases with decreasing load on the engine. The sharp dip in fuel flow from 420 to 404 MMSCFD at about 1:00 PM corresponds to an advance in timing from 8.5 to 11 degrees at that time, and the spike up to 441 MMSCFD corresponds to a reduced timing value of 6 degrees.

\section{Fuel Flow}

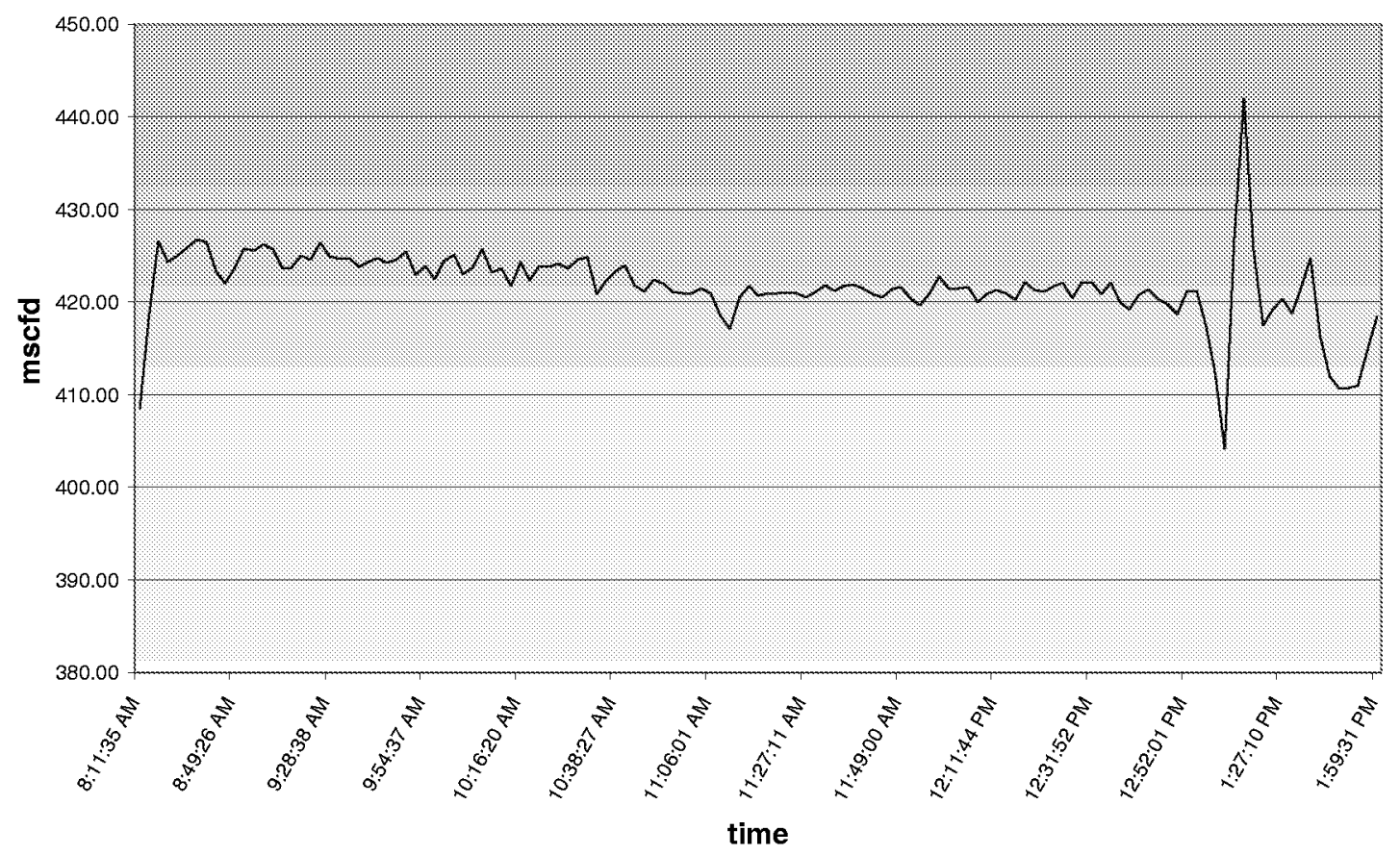

Figure 5-18. Engine Fuel Flow; (Williams Station 40 (Sour Lake); August 2004)

Figure 5-19 shows how normalized NOx concentration and equivalence ratio vary with time throughout the testing. There is no significant change for several hours once the unit has started up. The NOx concentration values have all been normalized (not as brake specific NOx). The spike before start-up, of course, has no relevance. After that, for most of the test, the NOx remained close to constant until about 1:00 PM when some timing change and air manifold pressure changes were made. These changes had a noticeable influence on NOx, and the NOx changes tracked the equivalence ratio changes. 


\section{NOx and EQ ratio}

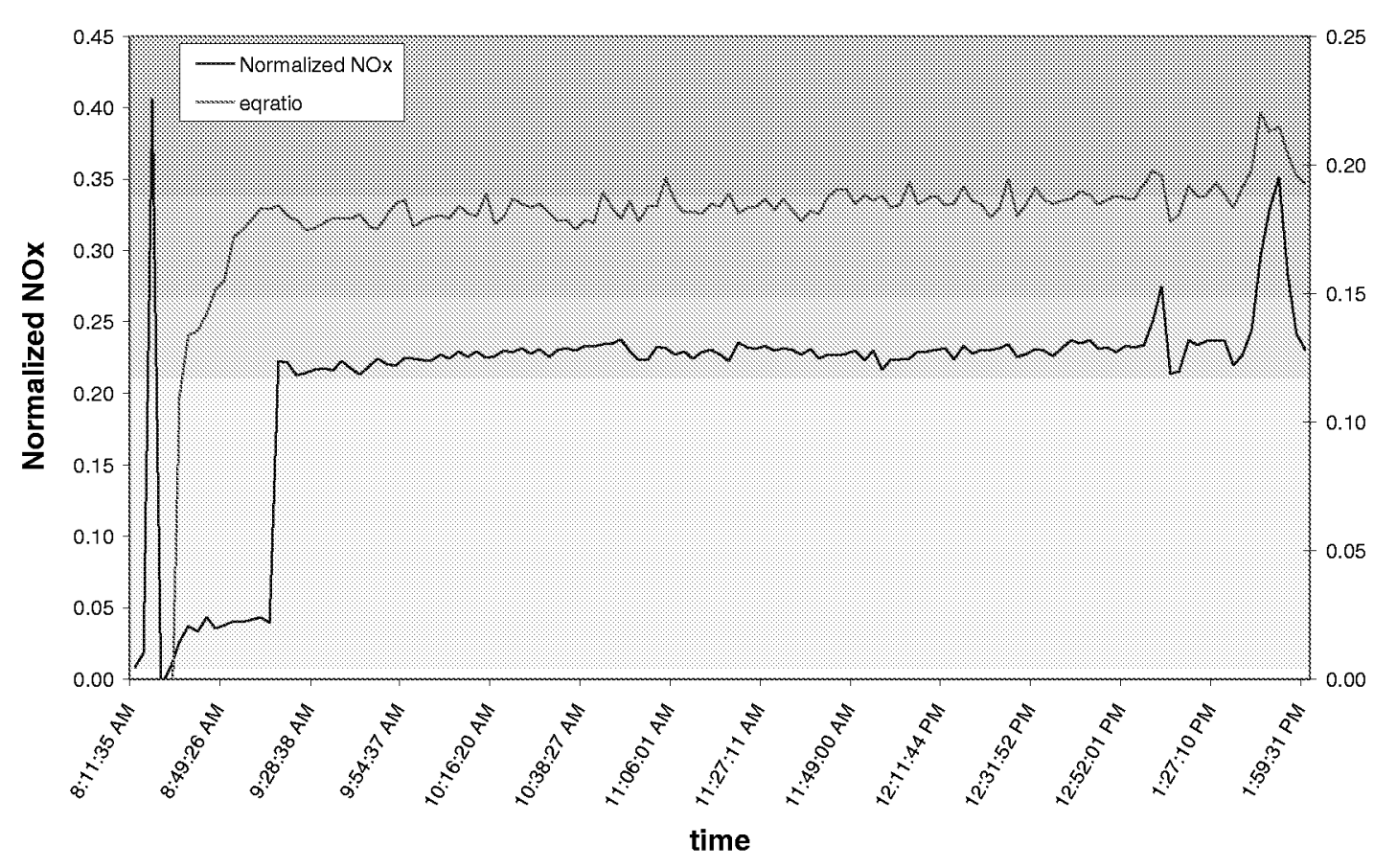

Figure 5-19. Normalized NOx Concentration and Equivalence Ratio; (Williams Station 40 (Sour Lake); August 2004)

Figure 5-20 shows the variation in instantaneous spread in PFP across the ten cylinders and the spread in average PFP across the cylinders over a days testing. The instantaneous spread does not change much, except late in the day when timing and air manifold pressure changes were investigated. The high and consistent level of instantaneous spread directly reflects the cycle-to-cycle variability.

The spread in average PFP is typically around 30 PSI. It increases as a result of two changes in conditions. First, the engine was intentionally unbalanced around 10:00 AM, and returned to its previous balanced condition around 11:00 AM. Then, around 11:30 $\mathrm{AM}$, the unit was balanced using CPR balancing (which seeks to equalize the ratio of PFP to compression pressure - termed the combustion pressure ratio, or CPR). The result of CPR balancing is to raise the spread in peak-firing pressure, because there is imbalance in compression pressure. However, the anticipated benefit of CPR balancing is to approach more closely a condition of equal air fuel ratio across the cylinders. It is further expected that this will have some benefit in reducing the tendency to detonate. 


\section{Engine Spread}

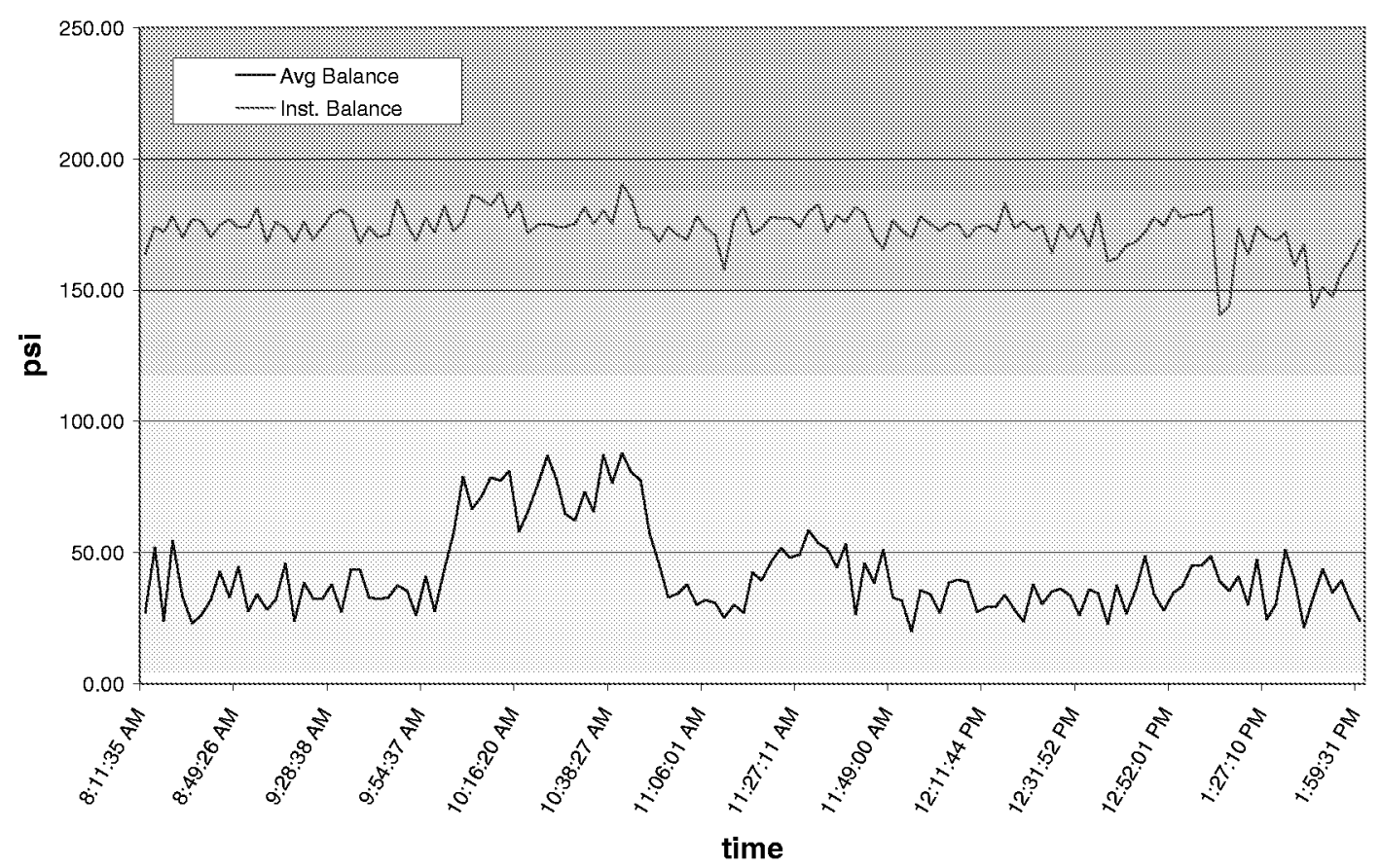

Figure 5-20. Engine PFP Spread; (Williams Station 40 (Sour Lake); August 2004)

Figure 5-21 presents the evidence of accomplishment of CPR balancing. It shows how for all ten cylinders, the ratio of peak-firing pressure to compression pressure is effectively equal. The actual maximum tolerance on these CPR values is $+/-2.5 \%$, when they display as equal, as a result of the precision to which they are graphed.

Figure 5-22 shows how average combustion pressure ratio (CPR) varies over the test series, and also how the standard deviation in CPR divided by average CPR falls under the condition when the engine is CPR balanced. There appears to be a small but consistent increase in CPR over the test from about 1.81 at 8:30 AM to about 1.84 at 12:50 PM. The Sdev (CPR)/avg CPR exhibits noticeable modulation, sample-to-sample, about a $4 \%$ average for most of the test. This is the COV of CPR across the cylinders. During CPR balancing, this quantity drops to under $2 \%$, as would be expected, since bringing all CPR values close to the average CPR is the accomplished objective of CPR balancing! 


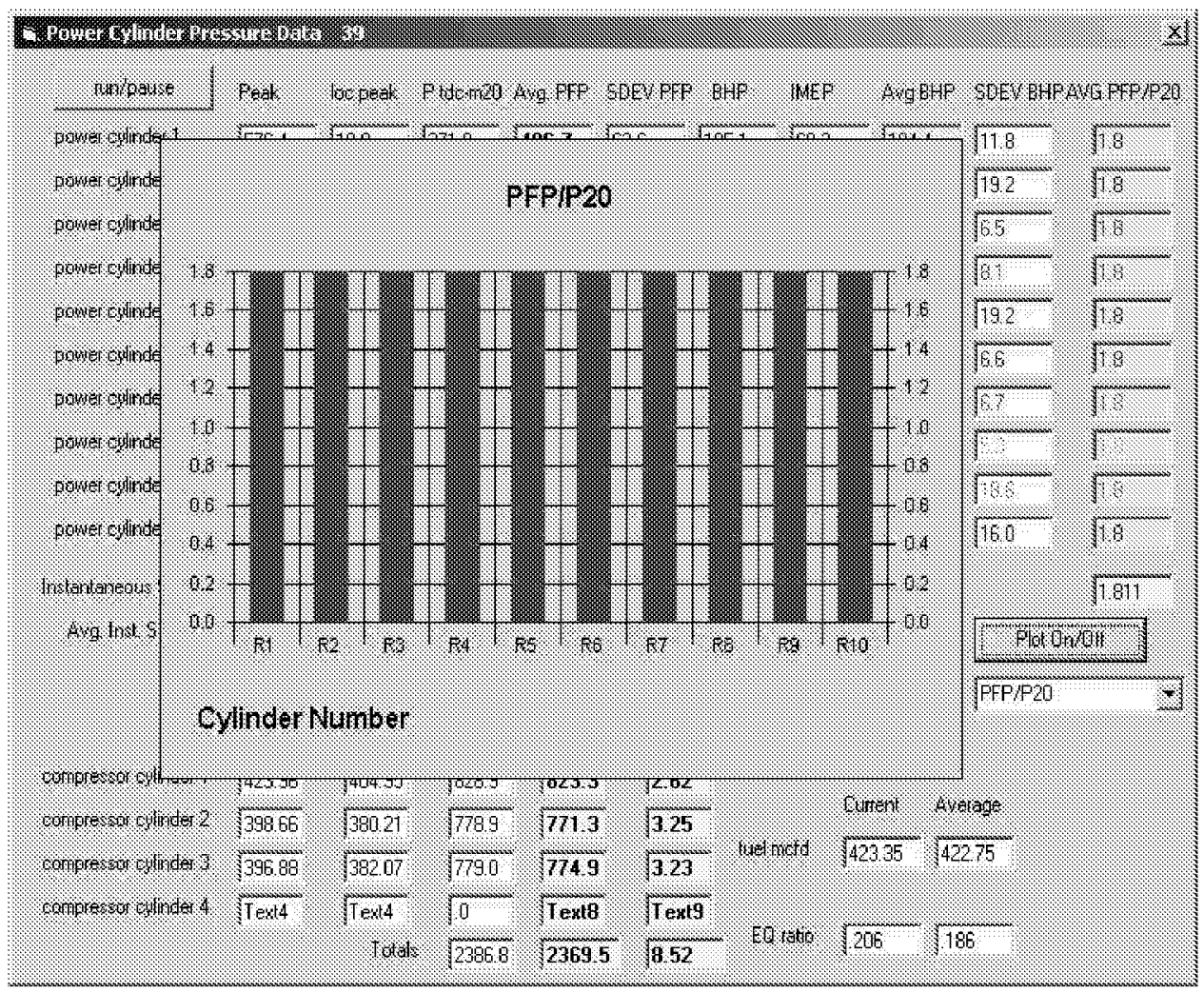

Figure 5-21. CPR Balancing Feasibility Demonstration; (Williams Station 40 (Sour Lake); August 2004)

Figure 5-23 shows how the heat rate of the engine (BTU/BHP-hr.) varies, where BHP-hr. represents the indicated cylinder energy. It also shows how the overall system efficiency (conversion of LHV fuel energy to useful compression energy) varies over the test. The heat rate is low for this recently converted engine, lying in the range 6900 to 7000 BTU/BHP-hr. for most of the test. The overall system efficiency is about $30.0 \%$, once the mechanical efficiency has reached its asymptotic condition. With the timing advance towards the end of the test, the heat rate drops to $6620 \mathrm{BTU} / \mathrm{HP}-\mathrm{hr}$., and the overall system efficiency increases to almost $31.4 \%$, a high number for an integral engine compressor. These numbers of 30.0 to $31.4 \%$ overall system efficiency set a challenging benchmark for the industry. (It will be noted some of these numbers have changed from an earlier quarterly report. The earlier calculations did not include the effect of compressor mechanical efficiency in calculating HP for use in the heat rate.) For reference purposes, overall system efficiency is the product of engine brake thermal efficiency, compressor mechanical efficiency, and compressor thermal efficiency. 


\section{CPR versus Time}

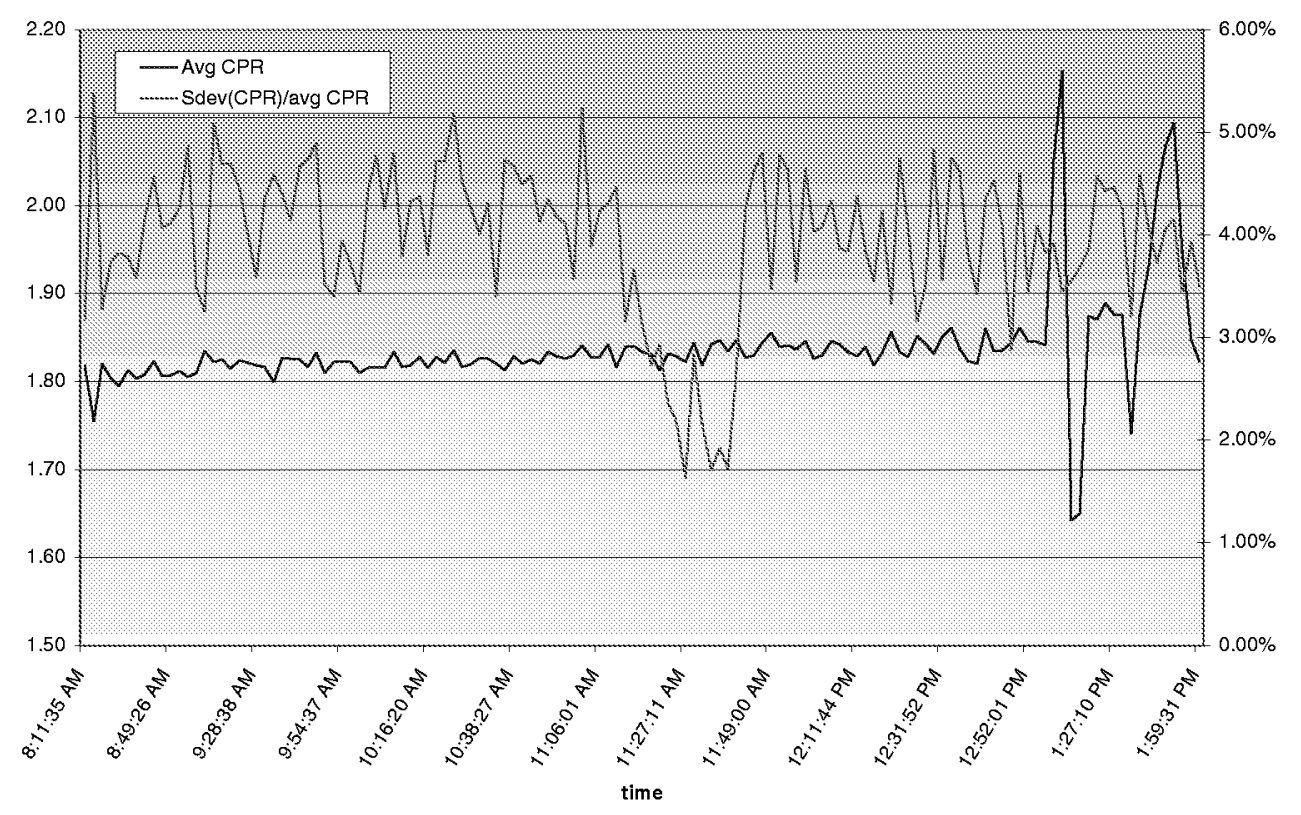

Figure 5-22. Ratio of PFP to Compression Pressure - Average and COV; (Williams Station 40 (Sour Lake); August 2004)

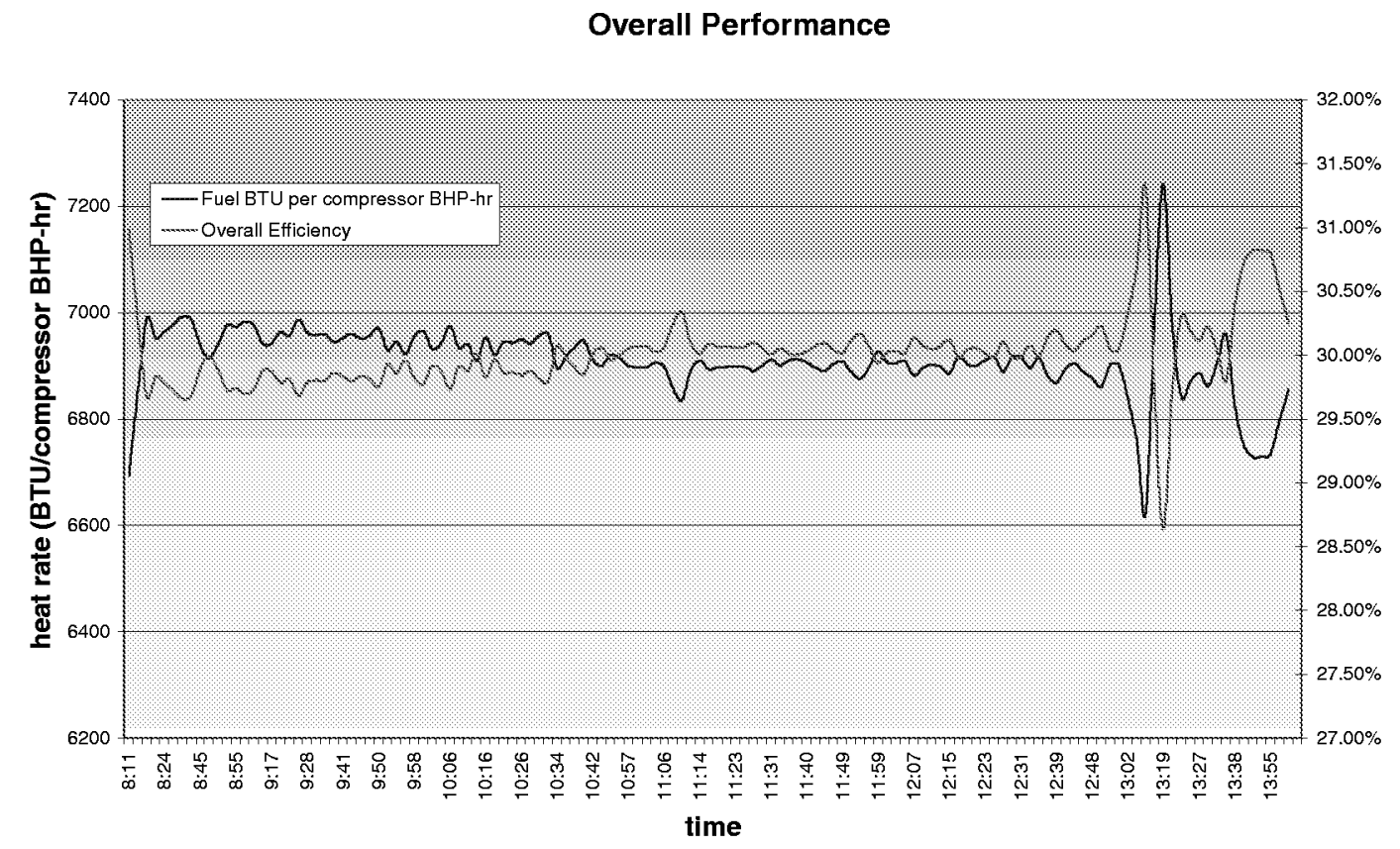

Figure 5-23. System Performance;

(Williams Station 40 (Sour Lake); August 2004) 


\subsection{SUPPLEMENTARY ANALYSIS OF DATA FROM GMW10 TEST 1}

Table 5-1 summarizes the data obtained during the GMW10 Test 1 at Sour Lake (Williams-Transco, Station 40). The following addresses some additional items of data analysis from these tests.

Table 5-1. Summary of Sour Lake Data Analysis Results

\begin{tabular}{|c|c|}
\hline Dynamic Variation Range for Air Manifold Pressure & 17 to $22 \%$ of Average \\
\hline $\begin{array}{l}\text { Dynamic Variation Range for Exhaust Manifold } \\
\text { Pressure }\end{array}$ & 48 to $70 \%$ \\
\hline Rod Load Range & $-47,000 \mathrm{lb}$. to $+55,000 \mathrm{lb}$. \\
\hline Typical Compression Power during Tests & $2375 \mathrm{HP}$ \\
\hline Compressor Thermal Efficiency & $85 \%$ to $86 \%$ \\
\hline Engine Heat Rate & 6900 to 7000 \\
\hline $\begin{array}{l}\text { Increase in Ratio of Compressor to Engine Power } \\
\text { during } 5 \text { Hours of Tests - As an Apparent Increase in } \\
\text { System Mechanical Efficiency as Oil Heats Up }\end{array}$ & 2 to $2.5 \%$ \\
\hline Corresponding Decrease in Fuel Flow & $1.5 \%$ \\
\hline Corresponding Decrease in Heat Rate & $1.25 \%$ \\
\hline $\begin{array}{l}\text { Heat Rate Reduction by Advancing Timing from } 8.5 \\
\text { to } 11 \text { Degrees BTDC }\end{array}$ & Reduction from 6900 to $6620 \mathrm{BTU} / \mathrm{HP}-\mathrm{Hr}$. \\
\hline System Thermal Efficiency with "As Found" Timing & $30 \%$ \\
\hline System Thermal Efficiency with 11 Degrees Timing & $31.3 \%$ \\
\hline $\begin{array}{l}\text { Typical Range of Peak-Firing Pressure in } 20 \\
\text { Successive Cycles }\end{array}$ & 401 Minimum to 588 Maximum (PC2) \\
\hline Range of Crankshaft Dynamic Strain during Tests & Between 50 and 60 Microstrain Peak-to-Peak \\
\hline $\begin{array}{l}\text { Typical Spread in Power Cylinder Compression } \\
\text { Pressure Over } 10 \text { Cylinders }\end{array}$ & From 244 to $275 \mathrm{PSI}$ \\
\hline $\begin{array}{l}\text { Typical Spread in Average Peak-Firing Pressure } \\
\text { Across } 10 \text { Power Cylinders }\end{array}$ & $35 \mathrm{PSI}$ \\
\hline Typical Instantaneous Spread & $175 \mathrm{PSI}$ \\
\hline
\end{tabular}

\subsubsection{Relating Heat Rate, Efficiency, and NOx Emissions to Timing and Air Manifold Pressure}

Figure 5-24 and Figure 5-25 show how timing and air manifold pressure (AMP) influence heat rate and system thermal efficiency. The points at $8.5^{\circ}$ before top dead center (BTDC) for timing and at 12.5 inches of Mercury $(\mathrm{Hg})$ for AMP represent the nominal condition (resulting in $7250 \mathrm{BTU} / \mathrm{HP}-\mathrm{hr}$. and $29.8 \%$ efficiency). The points at higher and lower timing ( $\left.6^{\circ} \mathrm{BTDC}, 11^{\circ} \mathrm{BTDC}\right)$ and at higher and lower AMP (10 inches, 14 inches $\mathrm{Hg}$ ) represent independent perturbations in timing and AMP about this nominal condition. They quantify how heat rate falls as timing is increased and how heat rate 
rises as AMP is increased (making the combustion leaner). Figure 5-26 and Figure 5-27 quantify how NOx follows opposite trends to the heat rate. This opposing trend is sometimes referred to as the NOx-heat rate trade-off. Figure 5-28 presents a plot of heat rate as a function of NOx with all the data from Figure 5-23, Figure 5-24, Figure 5-25, and Figure 5-26 on it. Figure 5-28 shows, for example, that heat rate can be substantially reduced from 7250 to 6950 , with a $20 \%$ NOx increase, by an increase in timing to $11^{\circ}$ BTDC.

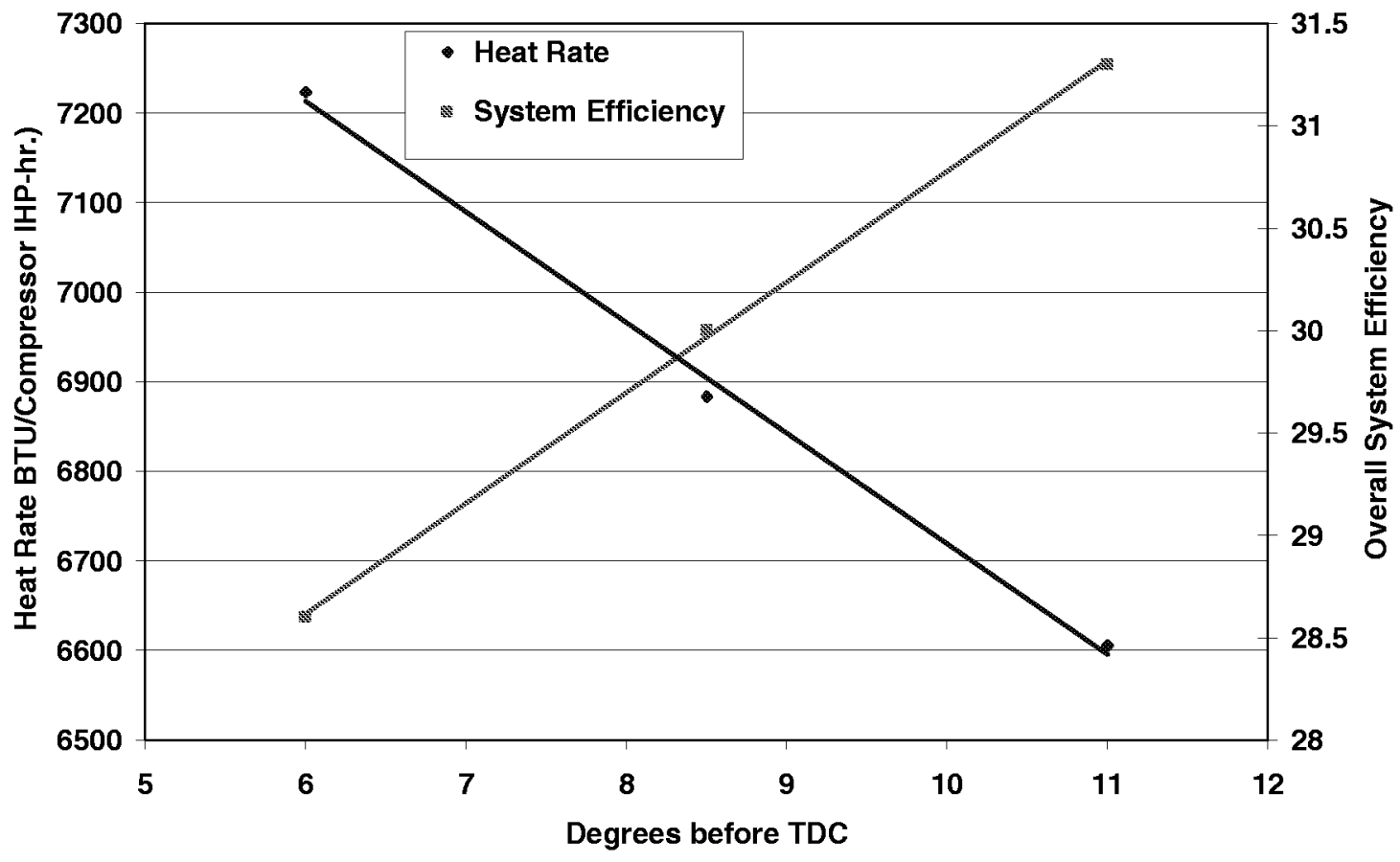

Figure 5-24. Heat Rate and System Efficiency as a Function of Timing (use for Relative Analysis Only); (Williams Station 40 (Sour Lake); August 2004)

It is noted that the result of air manifold pressure changes is to change equivalence ratio, and that other changes in conditions such as ambient temperature may cause equivalence ratio to change. For this reason, there are benefits to be expected from implementing equivalence ratio control. This would need to be coupled with timing control in response to detonation detection. Plans for implementing these controls using an equivalence ratio sensor and detonation detection will be discussed subsequently. 


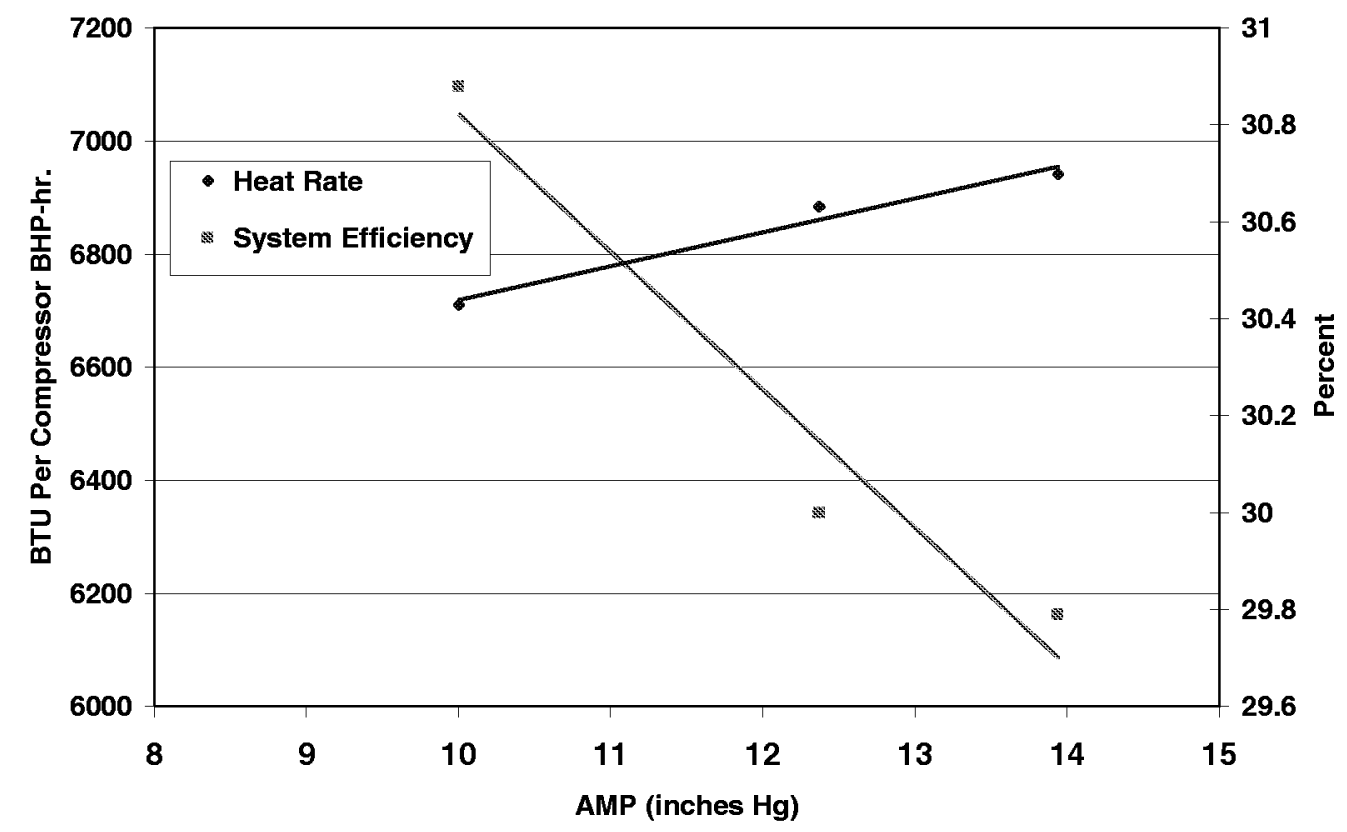

Figure 5-25. Heat Rate and System Efficiency as a Function of Air Manifold Pressure; (Williams Station 40 (Sour Lake); August 2004)

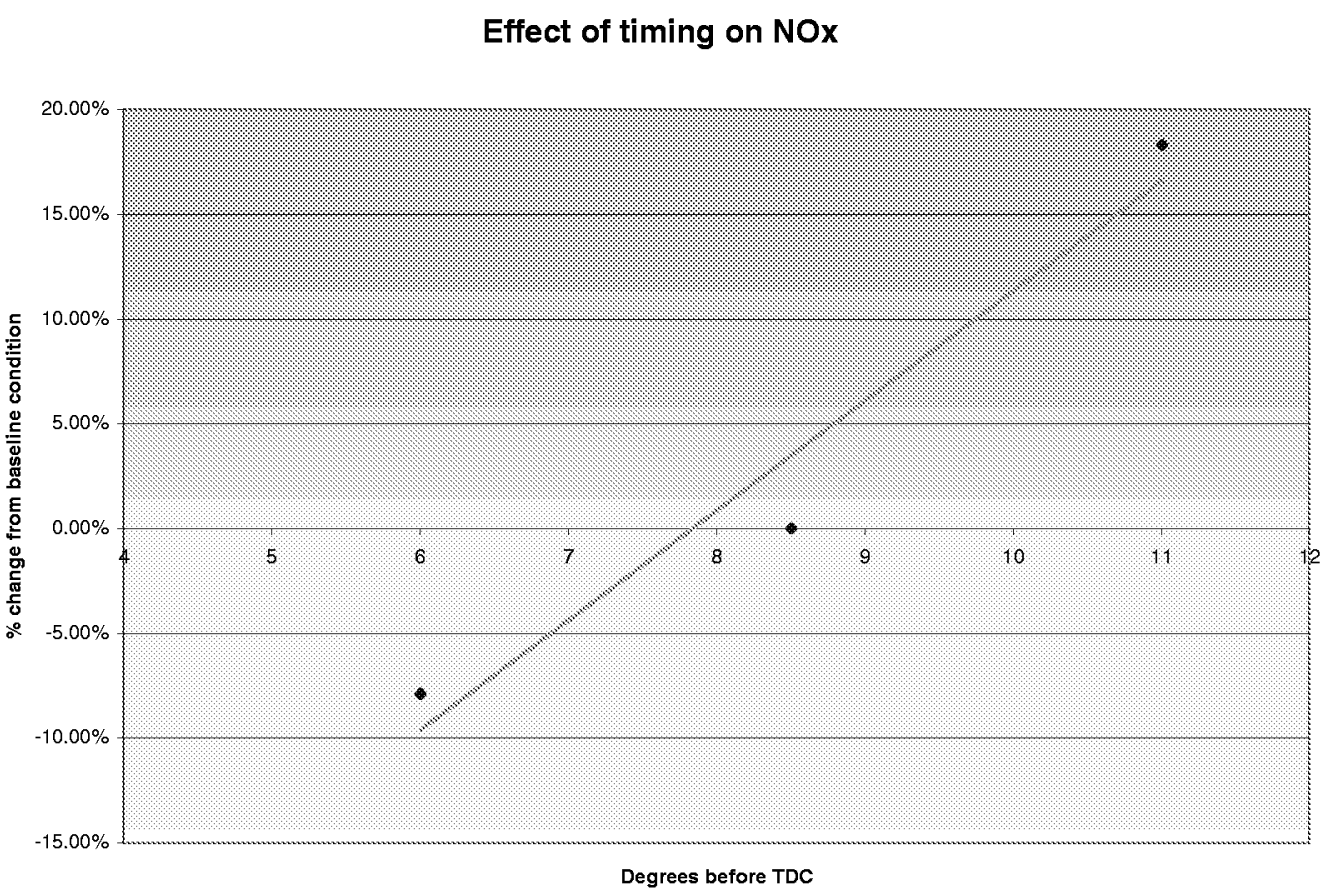

Figure 5-26. Change in NOx as a Function of Timing;

(Williams Station 40 (Sour Lake); August 2004) 


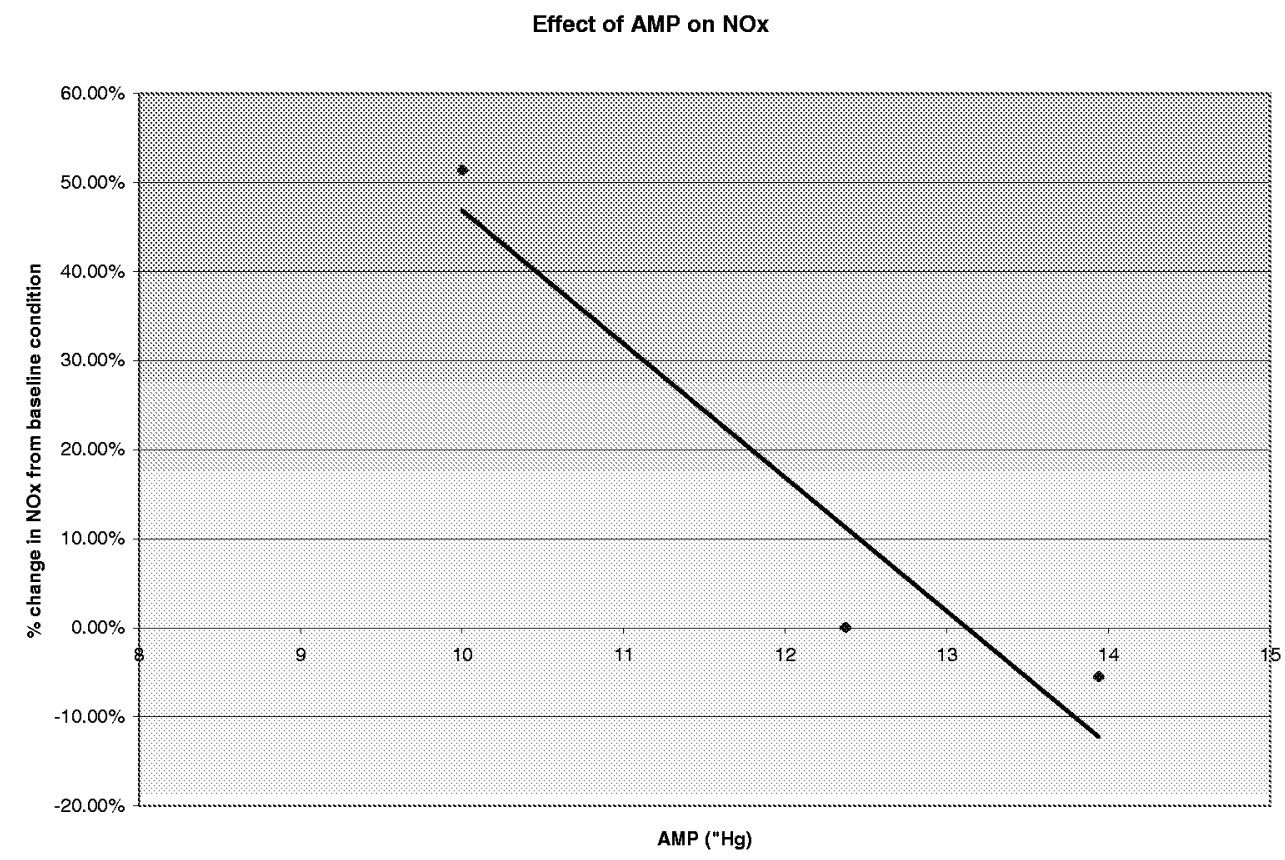

Figure 5-27. Change in NOx as a Function of Air Manifold Pressure; (Williams Station 40 (Sour Lake); August 2004)

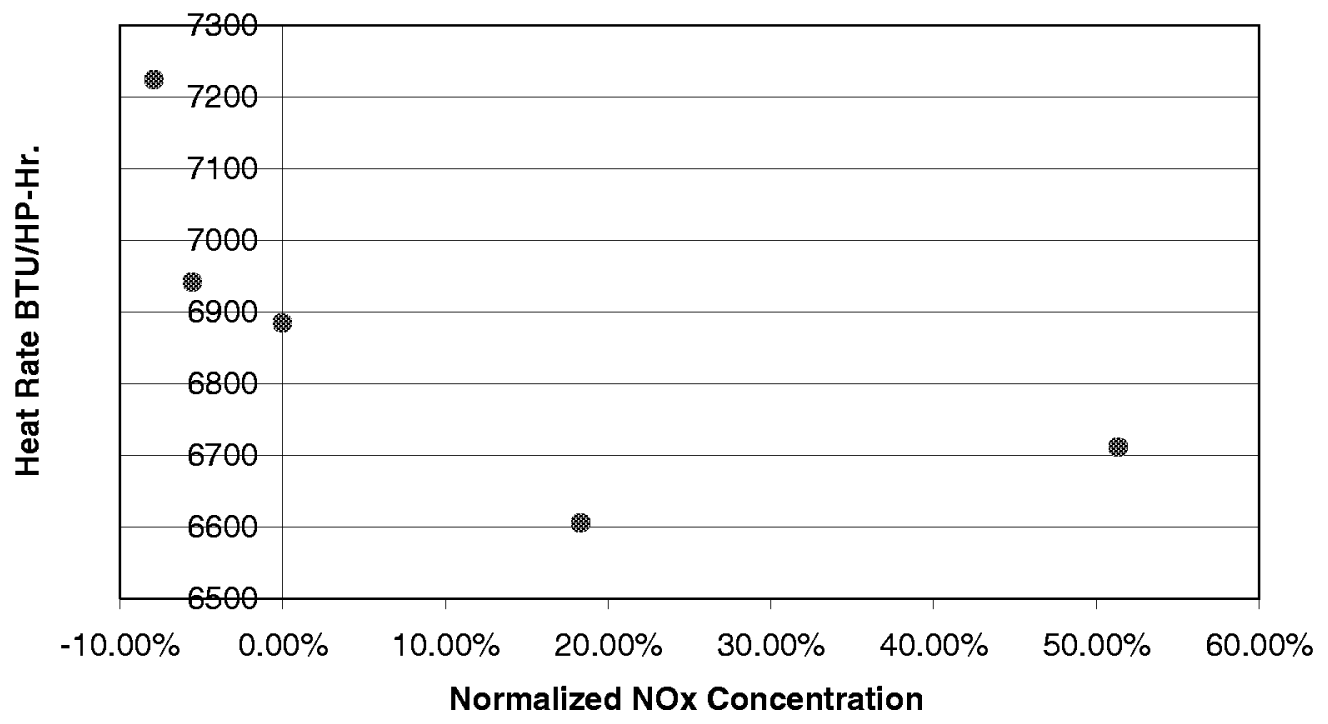

Figure 5-28. Trade-off between Head Rate and NOx (Relative Analysis Only); (Williams Station 40 (Sour Lake); August 2004) 


\subsubsection{Relating Rod Load Monitor Output to Cylinder-Indicated Power}

During the Sour Lake tests, data was obtained on compressor cylinder \#3 with cylinder pressure and with the rod load monitor (RLM). However, when compared, the ratio between cylinder-pressure-indicated horsepower and the horsepower determined from the RLM varied strongly during the day. The sensitivity of the RLM appeared to be changing during the day, and since it has already been observed that there is an increase in oil temperature over the day, a temperature effect was suspected. Tests in the laboratory following the Sour Lake tests confirmed a distinct increase in the ratio of volts per 1000 microstrain with temperature, as shown in Figure 5-29. Based on this, an effort was made to correct the data. Figure 5-30 presents the variation of oil inlet and outlet temperature during the test day, and the increase in outlet temperature is clear. As the best information available on temperature variation, the outlet temperature data of Figure 5-30 has been combined with the sensitivity correction of Figure 5-29, as expressed in the equation on the chart $(y=0.0016 \mathrm{x}+0.8571$, where $y$ is volts $/ 1000$ microstrain and $x$ is temperature), to come up with a corrected horsepower based on the RLM. The correction is not perfect, because the oil temperature would not be expected to provide a precise measurement of rod temperature.

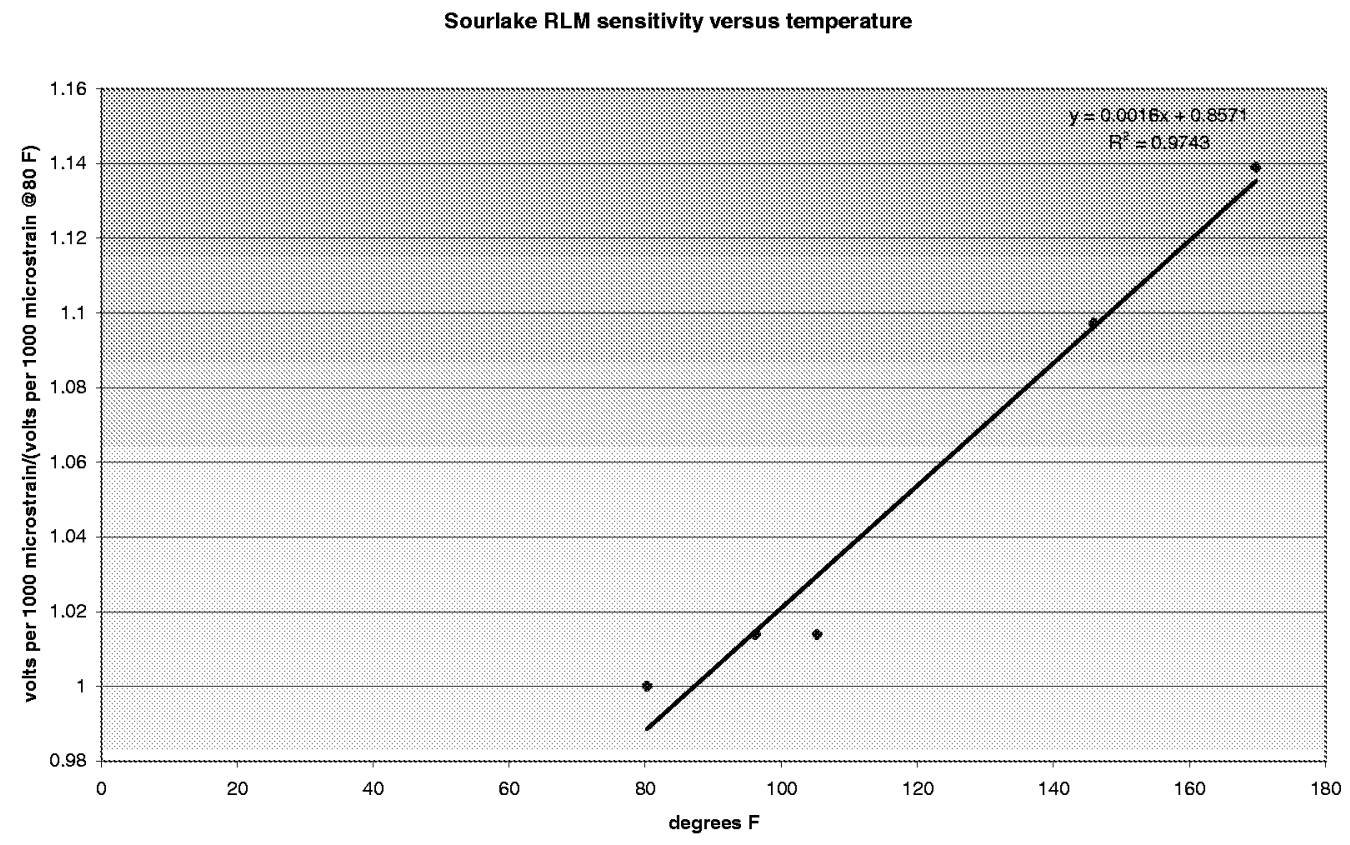

Figure 5-29. Post Test RLM Temperature Sensitivity Measurements with Subsequently Replaced Component 
The result is shown two ways. Figure 5-31 presents the horsepower determined from cylinder pressure (compressor IHP) and from the RLM (corrected), as they varied during the day. Figure 5-32 presents the ratio of the two horsepowers. Clearly, the correction is imperfect, and is not a long-term satisfactory way to determine horsepower from the rod load measurement. Based on these results, the component in question in the RLM was replaced and the sensitivity now does not vary with temperature. The refined RLM was retested on the return to El Paso Station 823, as reported in Section 6 of this report.

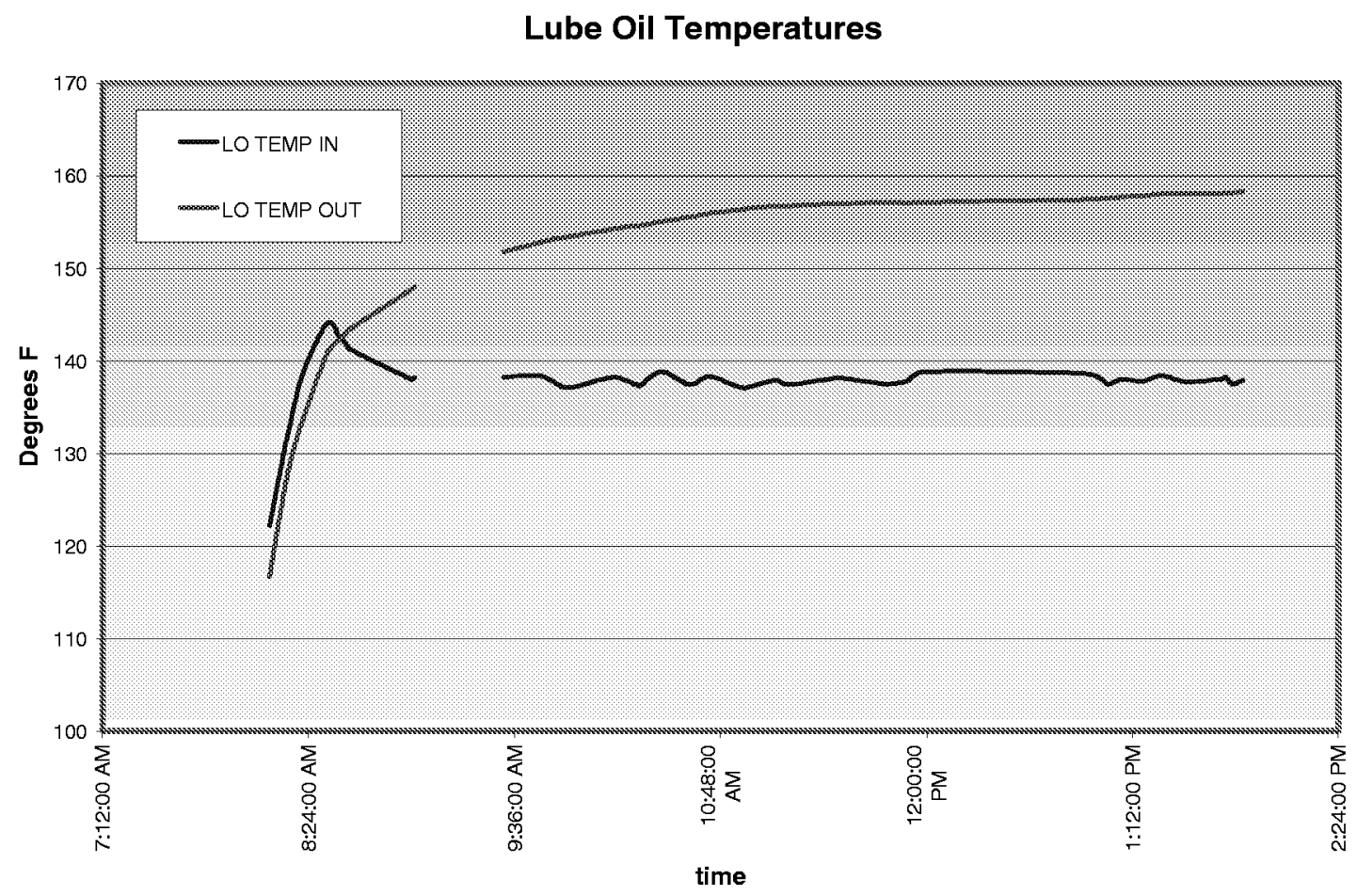

Figure 5-30. Variation of Oil Inlet and Outlet Temperatures; (Williams Station 40 (Sour Lake); August 2004) 


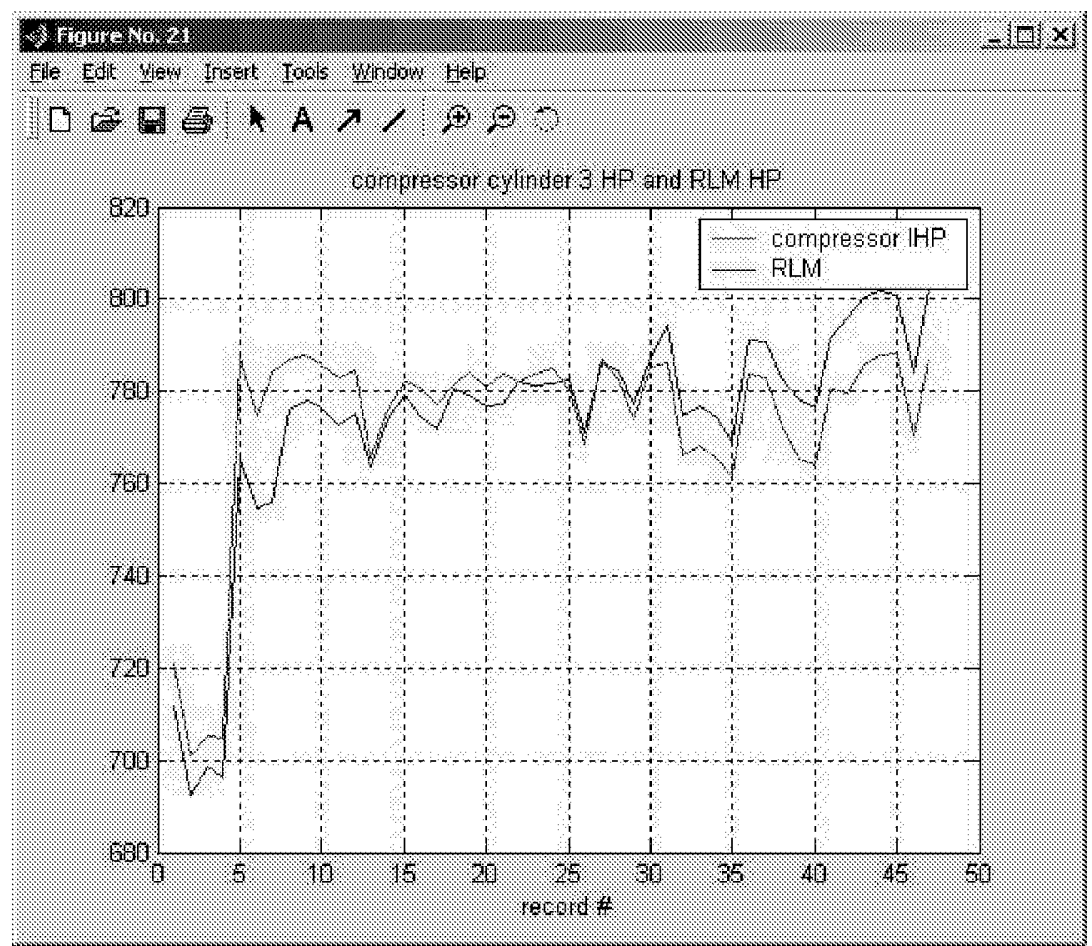

Figure 5-31. Compressor IHP and RLM HP; (Williams Station 40 (Sour Lake); August 2004)

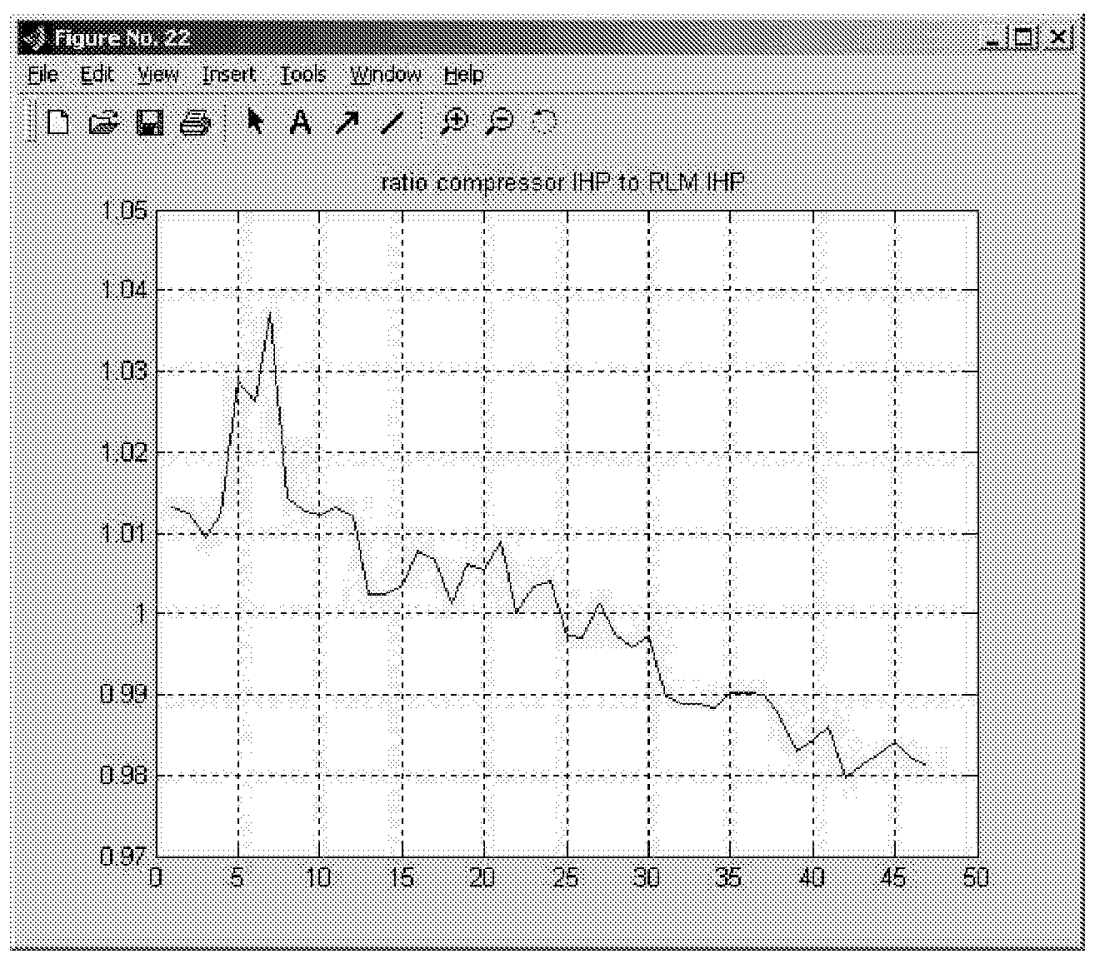

Figure 5-32. Residual Ratio Compressor IHP to RLM HP; (Williams Station 40 (Sour Lake); August 2004) 


\subsubsection{Influence of Load and Load Step (Williams Station 40)}

During a second day's testing, the influence of load step was investigated. The first objective was to investigate how load step might influence brake thermal efficiency or heat rate when the unit was otherwise operating at the same horsepower. Some test results on a preceding GMRC/PRCI project had suggested that the way the compressor cylinder load is distributed along the shaft might influence the power cylinder behavior to a small extent under part load. A second objective was to investigate how load on the engine might influence compression pressure and rod load data.

These objectives encountered mixed success. By combining a change in load step with pinching the suction line to increase ratio, it should, in principle, be possible to achieve the same horsepower with a different load step. However, the efforts to readjust the horsepower back to the value before the load step change were not successful - a series of operational problems and unit trips showed that this was not readily attainable - at least under the prevailing pipeline conditions. Thus, the first objective could not be met during these tests.

The change in load step prior to efforts to change suction pressure did however accomplish a change in horsepower, as would be expected, and data was obtained on how compressor load influences compression pressure in the power cylinder and the relationship of rod load monitor to indicated horsepower. Figure 5-33 shows the variation of horsepower during the tests. Approximately 20\% increase in compressor power was obtained over the test range. Figure 5-34 shows the corresponding variation in compression pressure in the ten power cylinders. They all track each other and appear to maintain a similar separation. Figure 5-35 confirms this by plotting the difference from cylinder \#1 compression pressure for all the other cylinders. In spite of substantial absolute variation in compression pressure (over 30 PSI) the difference of all cylinders from cylinder \#1 shows at most a 5 to 6 PSI variation. This is further indication of a consistent cylinder-to-cylinder variation in the trapped mass of air, which is a basis for a separately proposed air balance investigation.

Figure 5-36 shows the change in indicated cylinder \#3 horsepower and the corresponding ratio of indicated horsepower to RLM horsepower (this time without temperature correction). The qualitative ability of the RLM to track horsepower is clearly demonstrated. However, the need for temperature correction is re-emphasized by this data. The uncorrected data in Figure 5-36 shows much wider variation of the horsepower ratio than the corrected data for the previous day in Figure 5-32. As Section 6 of this report will show, the drift in the relationship between RLM power and cylinder indicated power has been eliminated following refinements indicated by these Sour Lake tests. Section 5 of this report will document the need for refinement in self-powering design process (which defines requirements for stationary magnet arrange length and clearance between moving coils and magnets). 


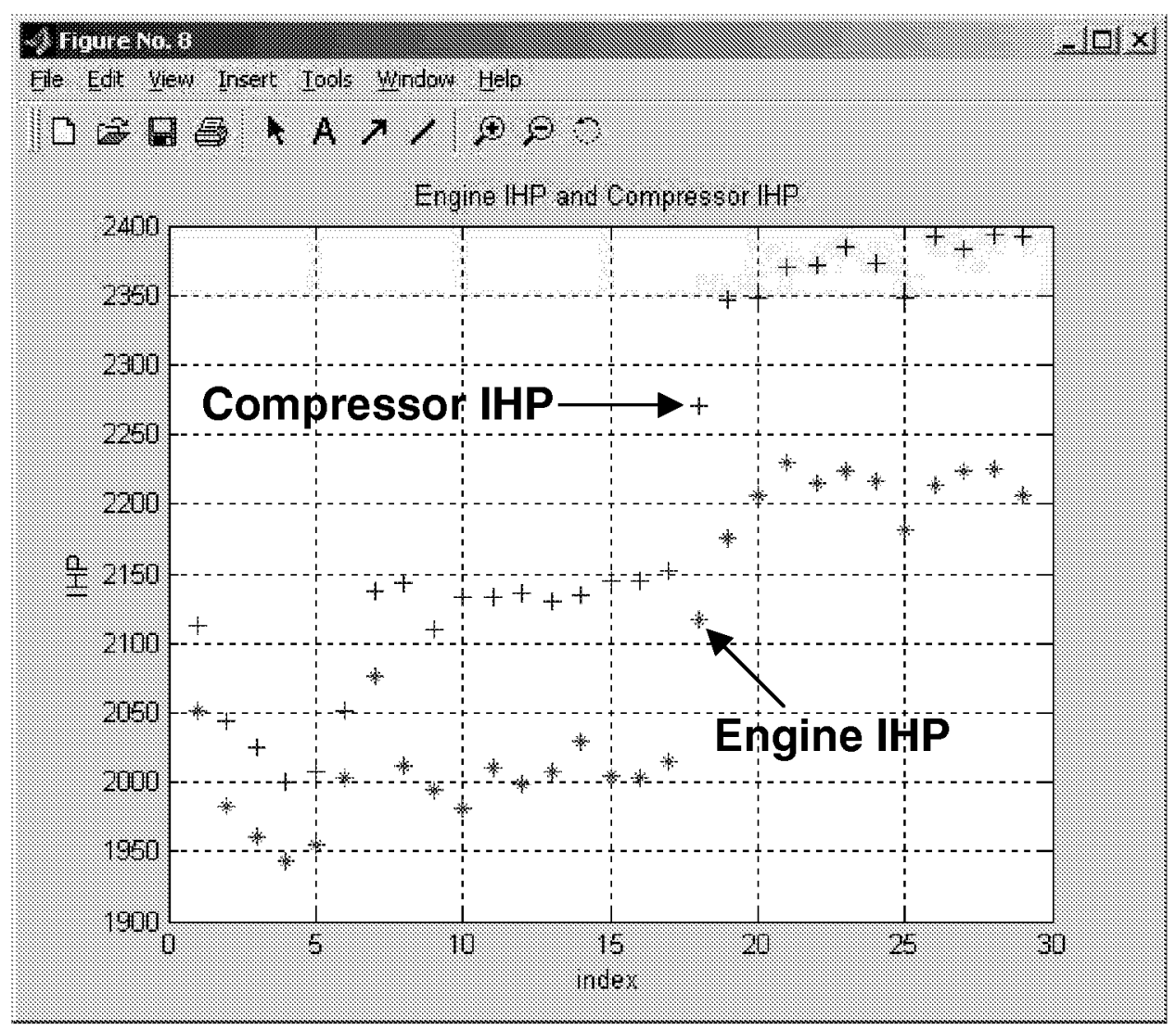

Figure 5-33. Variation in Power during Second Day's Testing; (Williams Station 40 (Sour Lake); August 2004) 


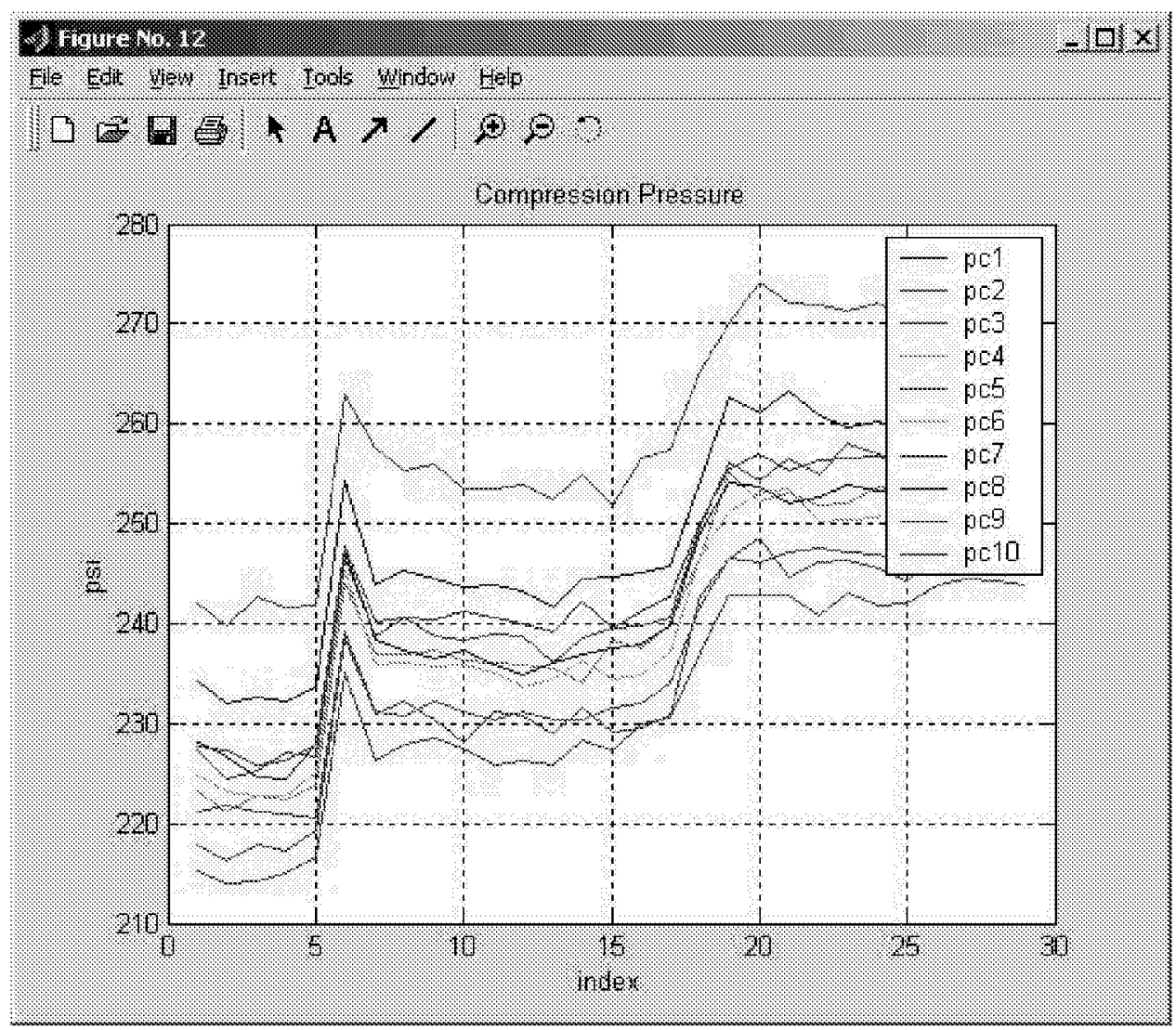

Figure 5-34. Compression Pressure for 10 Power Cylinders during Second Day's Testing; (Williams Station 40 (Sour Lake); August 2004) 


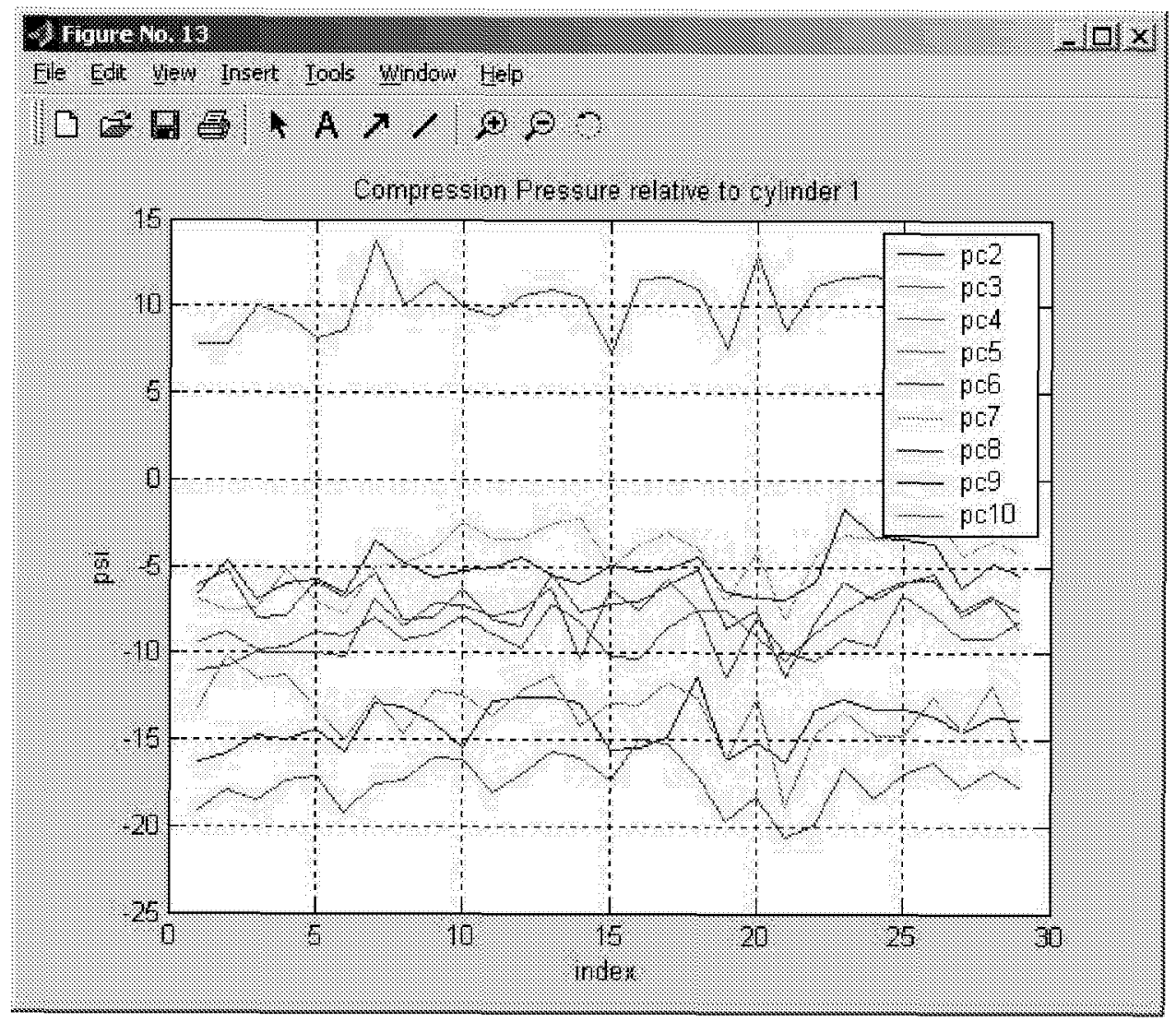

Figure 5-35. Compression Pressure Relative to Cylinder \#1 for Second Day's Testing; (Williams Station 40 (Sour Lake); August 2004) 


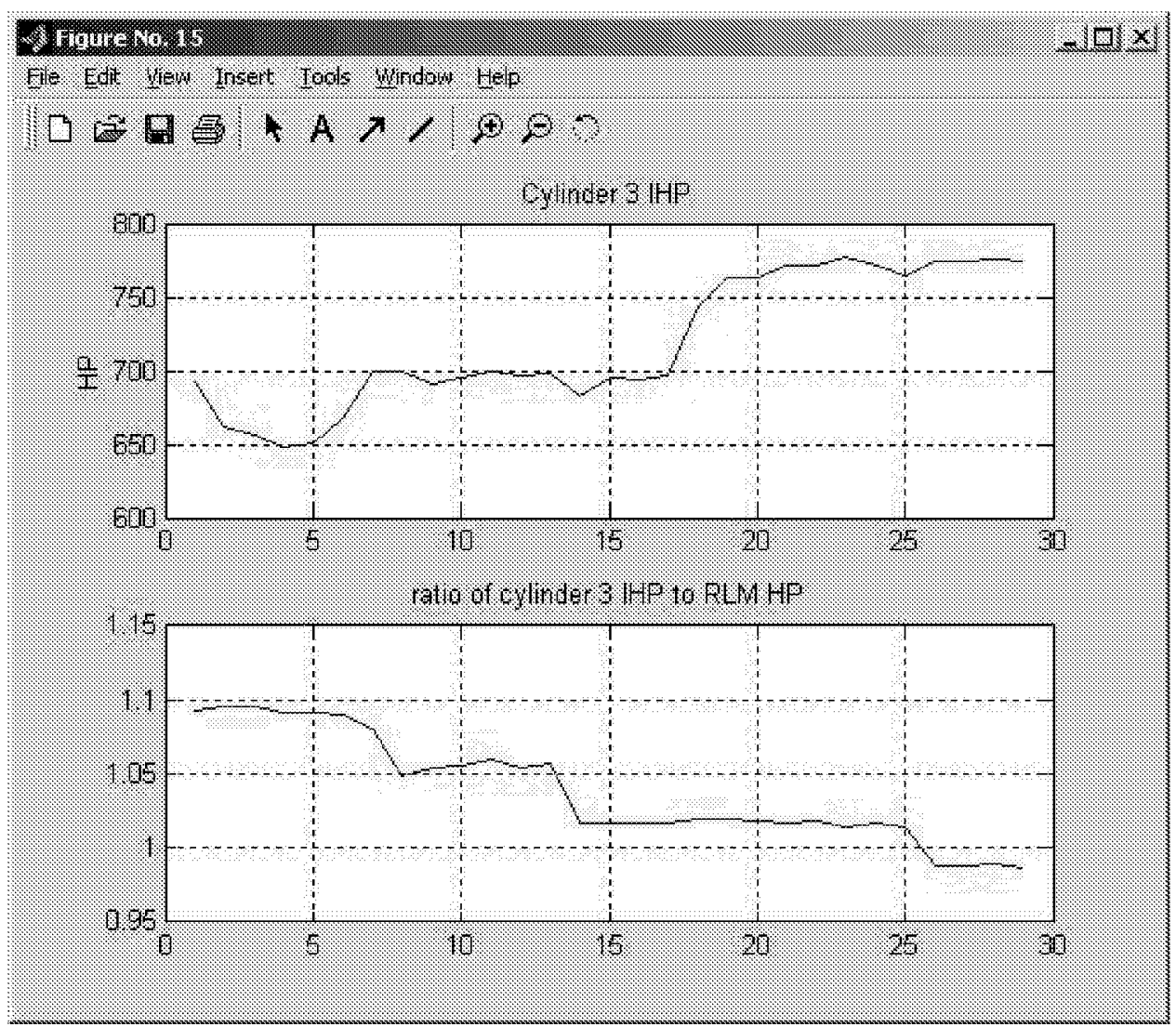

Figure 5-36. Cylinder Indicated HP and Ratio of IHP to Rod Load HP (without Temperature Correction); (Williams Station 40 (Sour Lake); August 2004) 


\section{RESULTS AND DISCUSSION: SECOND TEST ON A GMW10}

\subsection{OVERVIEW}

During the week of February 23-26, 2004, a test series was completed on a GMW10 at Williams Station 60 located in St. Francisville, near Jackson, Louisiana. Figure 6-1, Figure 6-2, and Figure 6-3 show the unit tested and the installation of transducers for compressor cylinder pressure, power cylinder pressure, and crankshaft strain. The station is scheduled for installation of retrofit technology designed to improve performance and reduce NOx later this year on all but one of the GMW10 engines. These engines currently have no turbocharger and a small amount of inlet air boost (about 1.5 PSIG) is achieved with Cooper's flapper valve driven by the crankshaft. The main theme of the tests recently completed is to provide baseline data for comparison with similar data obtained after the retrofit technology is installed. The planned modifications are the installation of a turbocharger, installation of a high-pressure fuel injection system (Enginuity's $\mathrm{HPFI}^{\mathrm{TM}}$ ), installation of cylinder pressure sensors on compressor and engine, and addition of automatic balancing as part of the high-pressure fuel injection system.

A similar suite of instruments was installed as for the preceding tests described in this report, with the exception of the exhaust manifold sensor. All instruments worked well with the exception of the rod load monitor. This was installed with self-powering for the first time on this test program, and the self-powering provided insufficient power. This power problem has since been tracked down to nonlinearities in the relationship between gap and power generated. Following this experience, predictive software to define stationary magnet array length and clearance between moving coils and magnets was refined and calibrated with a rotary rig. The rotary rig did not reproduce the intermittent nature of coil excitation resulting from reciprocating motion, but defined relationships sufficiently closely to allow effective correction for intermittent excitation. 


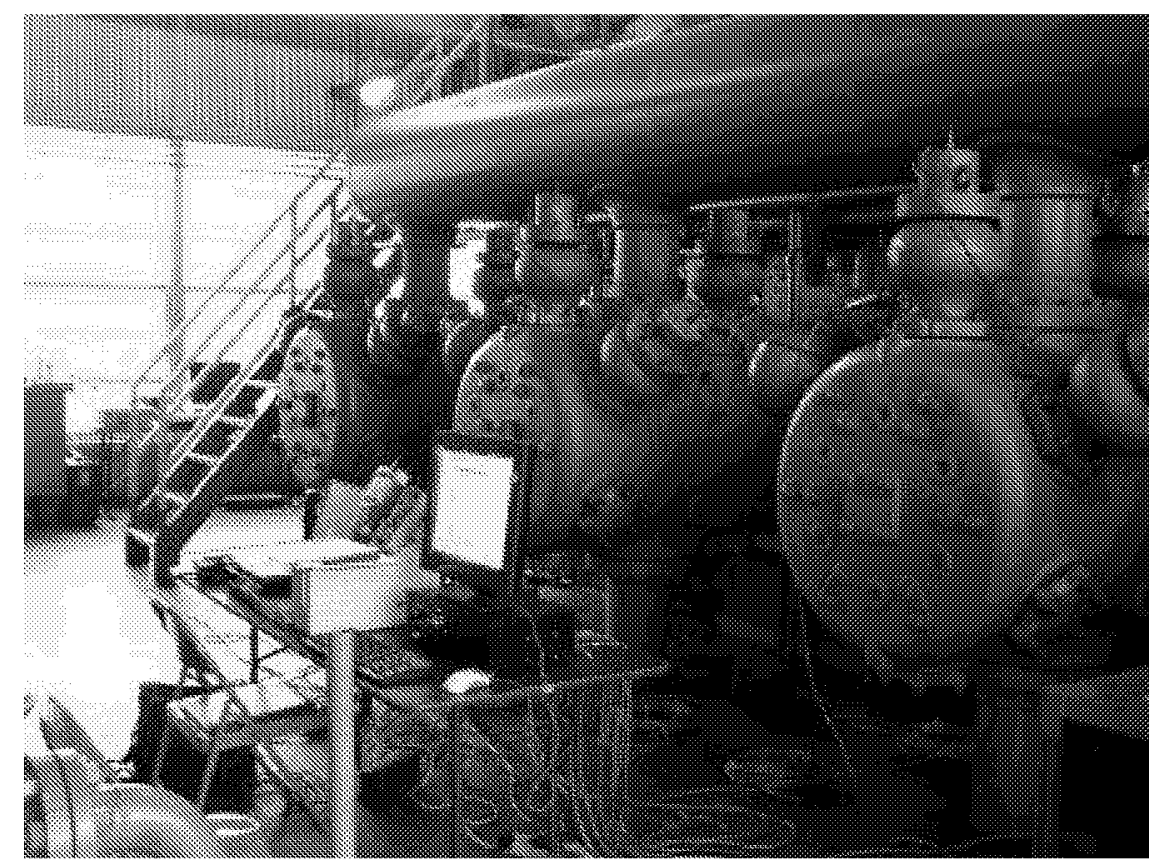

Figure 6-1. GMW10 Compressor Cylinders with Pressure Transducer Installed (Williams Station 60; February 2004)

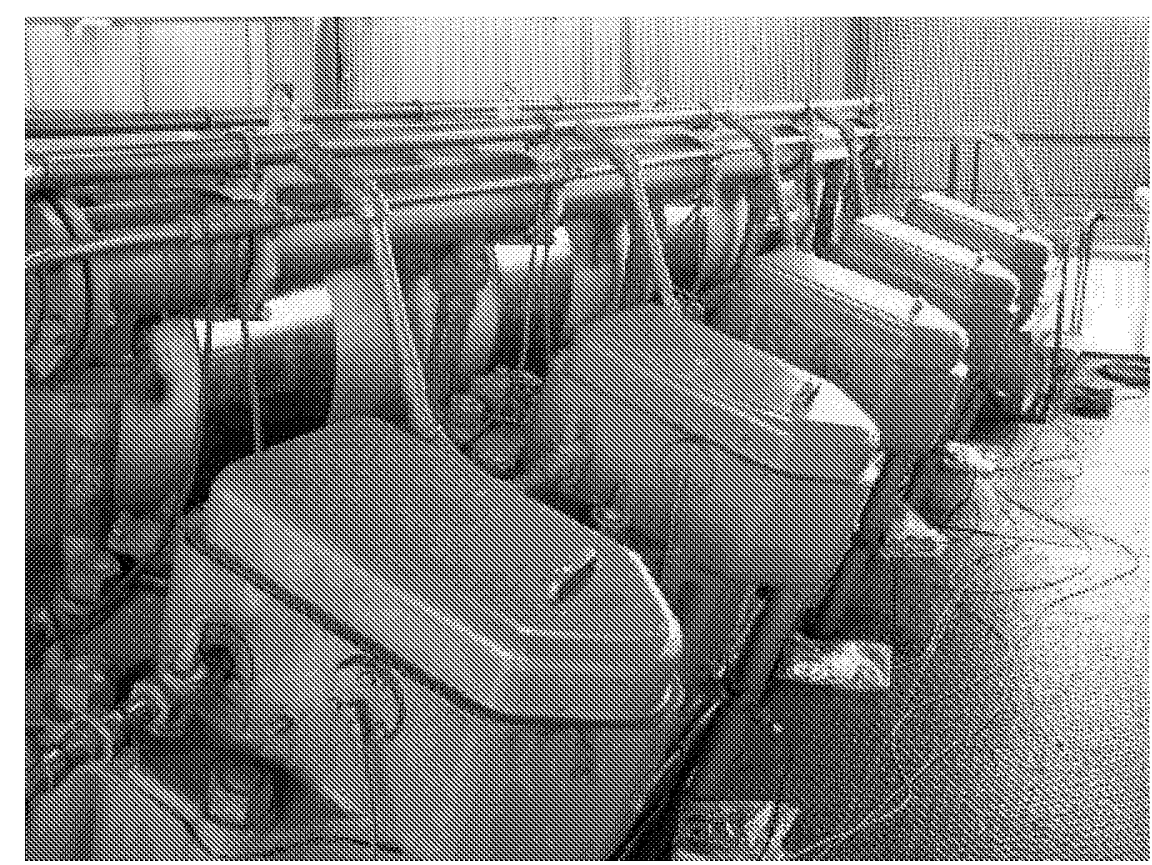

Figure 6-2. GMW10 Power Cylinder with Pressure Transducers Installed (Williams Station 60; February 2004) 


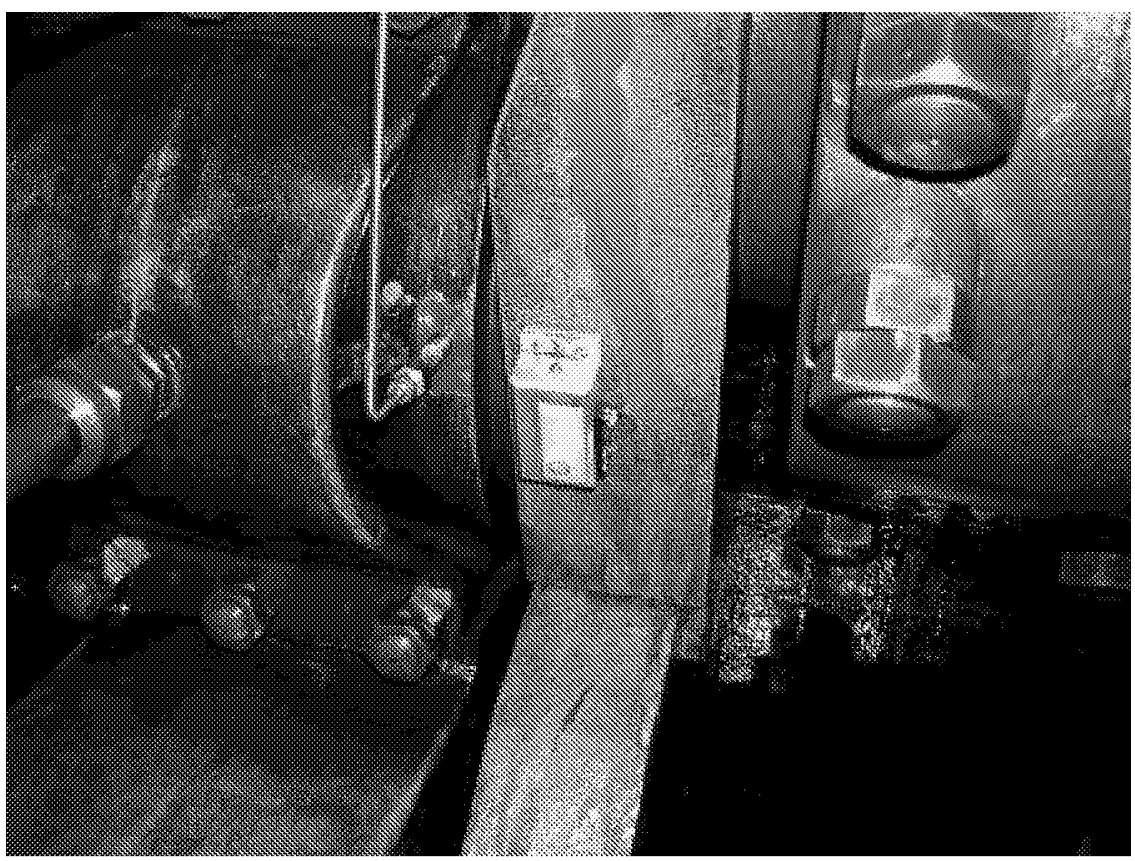

Figure 6-3. Strain Data Capture Module and Combined Power and Compressor Throw (Williams Station 60; February 2004)

In addition to the instruments used in past tests, several knock detection sensors (loaned by Metrix) were used during the tests. The primary purpose was to gain experience with these sensors before using them at a subsequently planned test to evaluate the use of knock protection during timing advance tests. The instruments provide a voltage proportional to the count of events causing shock vibration above a specified threshold in the sample period.

\subsection{DAY \#1 TeSTs - UnMOdified GMW10}

After the instruments were installed and checked out on February 23 and 24, two days of testing followed. Figure 6-4 shows speed variation during the first day. For the first hour of testing to 11.21, speed was at 245 RPM. At 11.21, speed was increased to 250 RPM, where it remained for most of the test. Between 1.42 and 1.57, problems with the encoder caused a loss of speed signal, but not a change in speed. The sharp changes in plotted speed at this time should be ignored. 


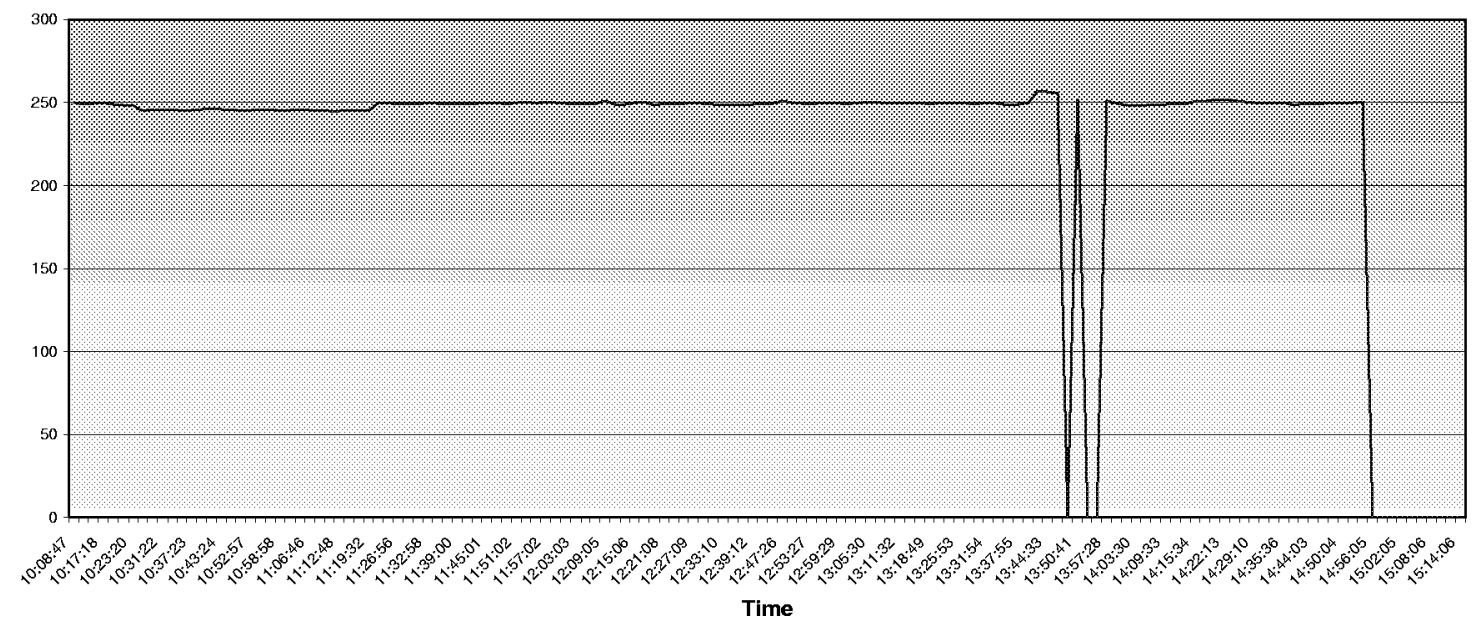

Figure 6-4. Speed in RPM Throughout Test Program from 10.08 Through 15.14, February 25, 2004; Day 1; Williams Station 60 (Loss in speed signal from 1.42 through 1.57 should be ignored.)

In addition to the SwRI instruments, Williams' personnel recorded a number of channels from the installed station instruments. Some of these channels provide a convenient profile of conditions during the test. The torque was maintained close to the range 100 to $101 \%$ during the day's testing, as shown in Figure 6-5, except towards the end of the day when an increase to about $103.5 \%$ occurred, which was then reduced back to $102 \%$ by load step adjustment. Figure 6-6 shows suction and discharge pressure during the day, with values very nearly constant at 573 and 774 PSIG, giving a ratio (shown in Figure 6-7) of about 1.34 until about 1:30 PM. Between 1:30 and 2:00 PM, suction pressure fell to 505 PSI and discharge pressure rose to 781 with a resultant increase in ratio to about 1.37. This increase is part of the reason for the increase in torque towards the end of the day, though adjustments in load step, which went from Step 10 to Step 14, as shown in Figure 6-8, help maintain the torque close to $100 \%$.

A number of temperatures relevant to operation, control, and protection are shown in Figure 6-9. Specifically, gas suction temperature remains around $58^{\circ} \mathrm{F}$. Cylinder discharge temperature remains at around $101^{\circ} \mathrm{F}$ for most of the day, and increases to $104^{\circ} \mathrm{F}$ when the discharge pressure and ratio of compression increase (only cylinder \#1 is shown, but the others have the same discharge temperature within $1{ }^{\circ} \mathrm{F}$; cylinders \#2 and \#3 tended to be about 1 degree lower in discharge temperature). Air manifold temperature is between $102^{\circ} \mathrm{F}$ and $105^{\circ} \mathrm{F}$. Lubricating oil-cooling water remains very steady at $120^{\circ} \mathrm{F}$; lubricating oil outlet temperature maintains itself at 143 to $144^{\circ} \mathrm{F}$. Jacket water inlet and outlet are at $150^{\circ} \mathrm{F}$ and $160^{\circ} \mathrm{F}$, respectively. $1^{\circ} \mathrm{F}$ difference out of a nominal $43^{\circ} \mathrm{F}$ temperature rise indicates losses for all cylinders are within less than $2.5 \%$ of each other, and that no significant valve leaks are occurring. 


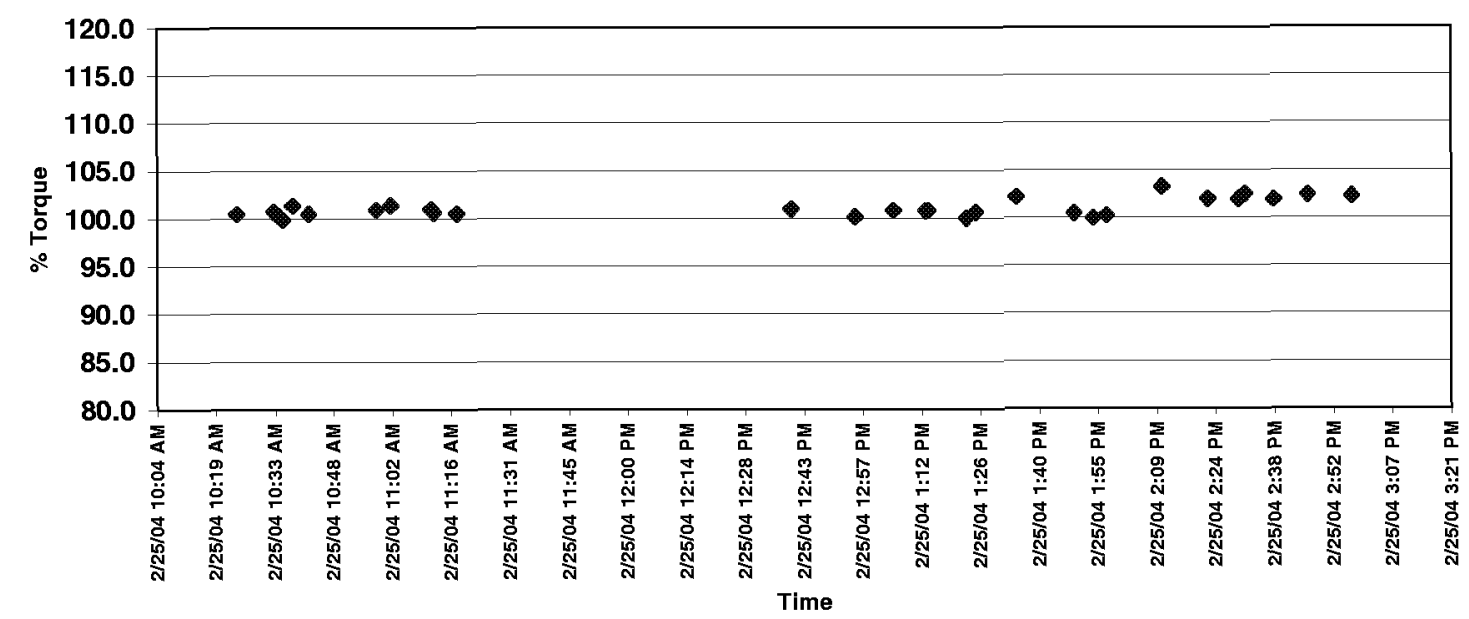

Figure 6-5. Torque, Percent from 10.04 through 15.21, Day 1; Williams Station 60

To summarize Figure 6-9, the unit operating temperatures appeared quite stable during the day. It had been running immediately prior to the tests, so no significant warm-up occurred during the early hours of the tests.

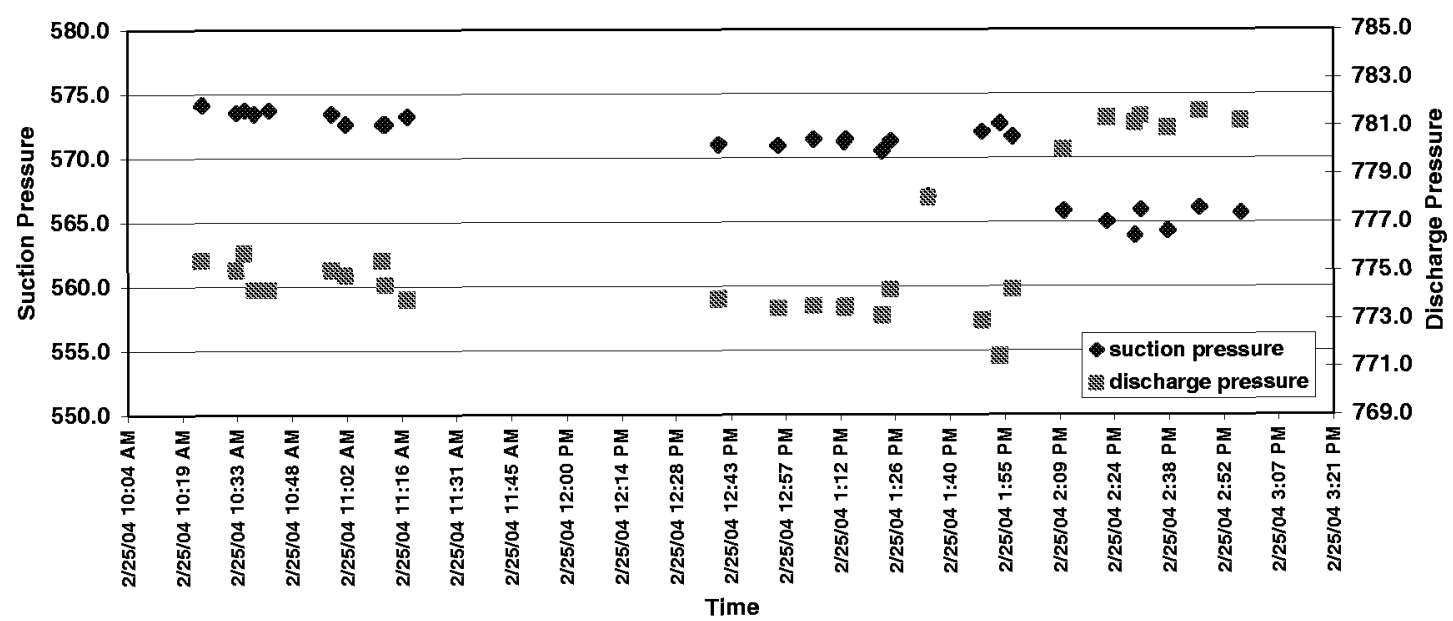

Figure 6-6. Suction and Discharge Pressure from 10.04 through 15.21; Day 1; Williams Station 60 


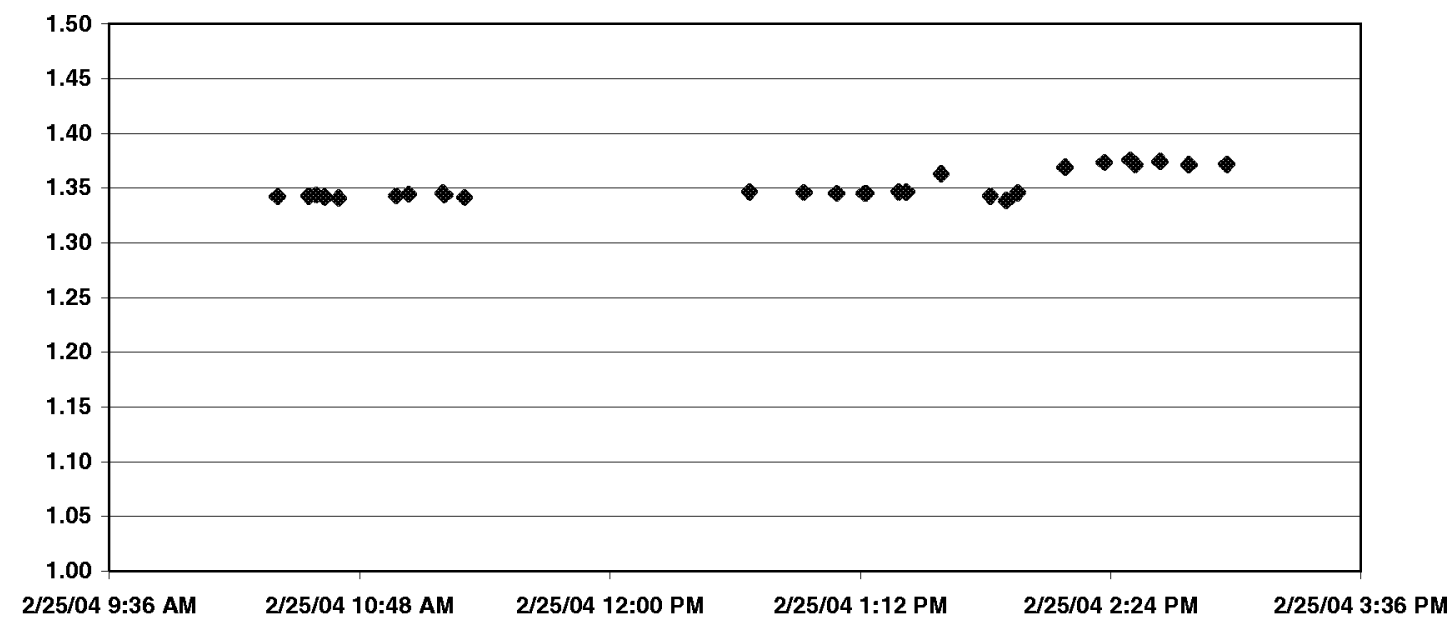

Figure 6-7. Ratio of Compression during Day 1; Williams Station 60

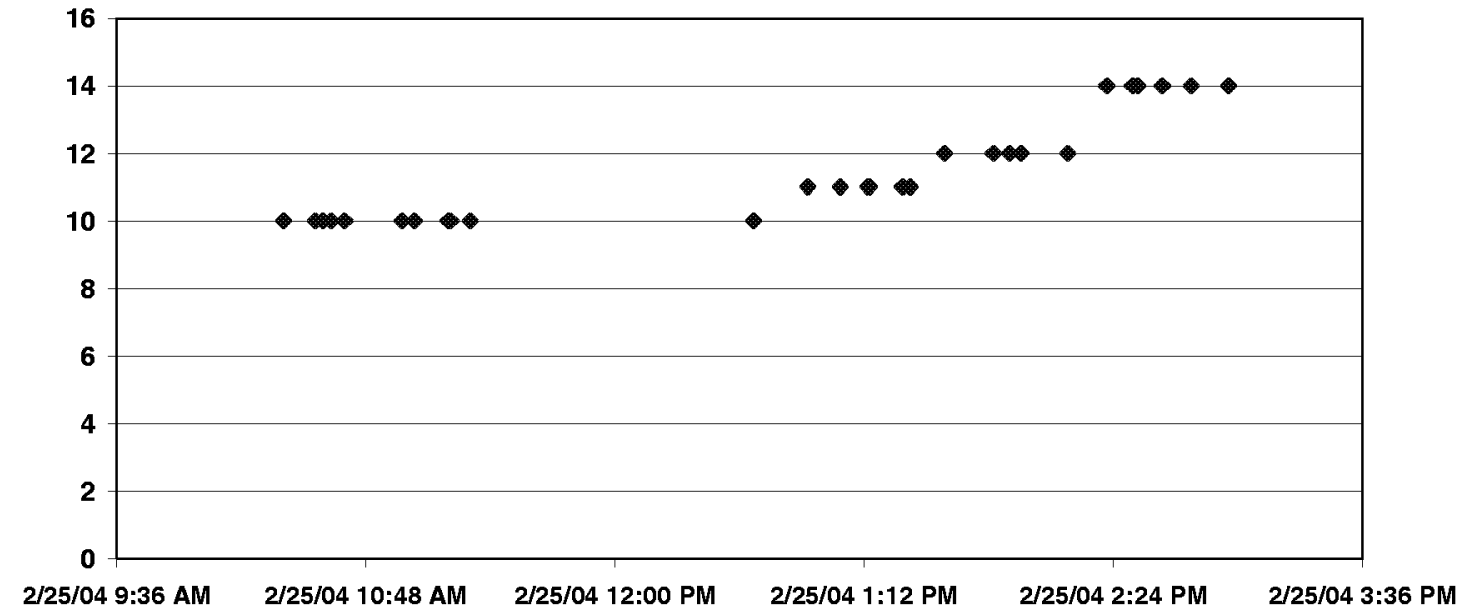

Figure 6-8. Load Step during Day 1; Williams Station 60 


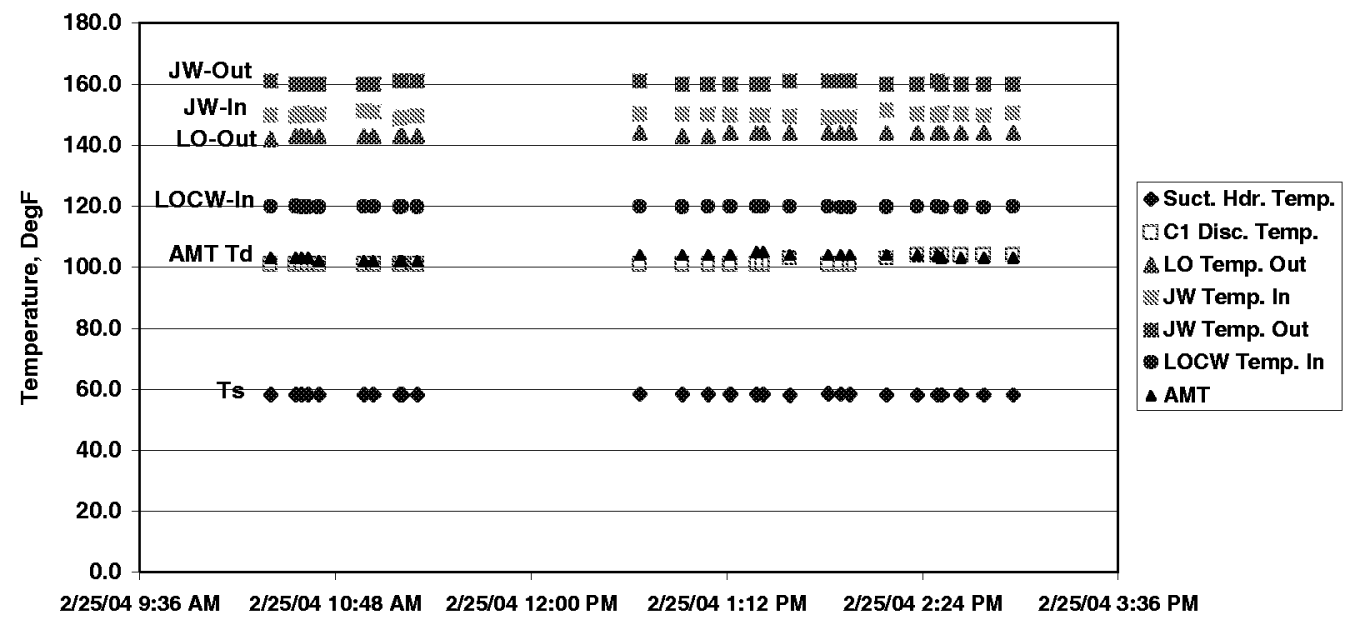

Figure 6-9. Temperatures during Day 1 for Suction Gas, Discharge Gas, Air Manifold, Lube Oil Cooling Water Inlet, Lube Oil Outlet, Jacket Water Inlet, and Jacket Water Outlet; Williams Station 60

Figure 6-10 provides an overview of test conditions during the day superimposed on a plot of peak-firing pressure normalized spread (expressed as a percentage of peak-firing pressure) during day 1. Day 1 was designed to provide a set of baseline data, including the effects of timing for the unmodified GMW10, to investigate balancing options, and to evaluate the influence of balance on performance.

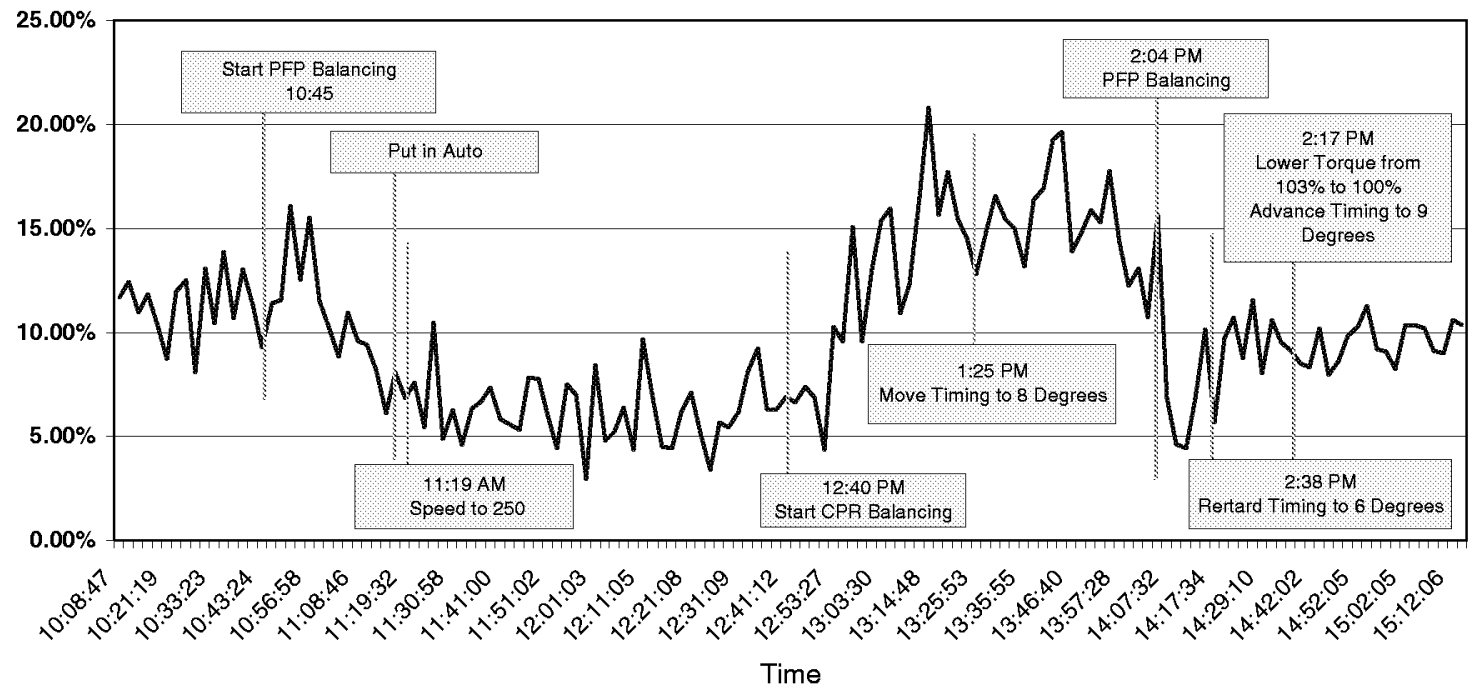

Figure 6-10. Test Conditions Overview Superimposed on Spread in Peak-Firing Pressure as Percent; Day 1; Williams Station 60; February 2004 
Thus, the log shows the unit was started soon after 10:00. At 10.45, peak-firing pressure (PFP) balancing was started, and the PFP spread was reduced from over $10 \%$ to about $6 \%$. The unit speed was adjusted to 250 RPM at 11:21, then the unit was left to run for an hour or so, with automated load step control activated. At 12:40, CPR balancing was started. Although this appears to increase the spread in peak-firing pressure to almost $15 \%$, this is to be expected, since CPR seeks to equalize the ratio of peak-firing pressure to compression pressure. Compression pressure is defined for this test as P20, the pressure 20 degrees before top dead center (TDC). The implicit goal of CPR balancing is to equalize air fuel ratio across the cylinders, accounting for the differences in trapped air mass between cylinders.

Figure 6-11 and Figure 6-12 present bar graphs of CPR for all cylinders. Clearly, Figure 6-12 has almost exactly equal height bars, indicating a CPR-balanced condition, whereas Figure 6-11 shows much more spread between the bars. These are two representative conditions: one indicating good CPR balance, and one showing cylinder-to-cylinder deviation in CPR.

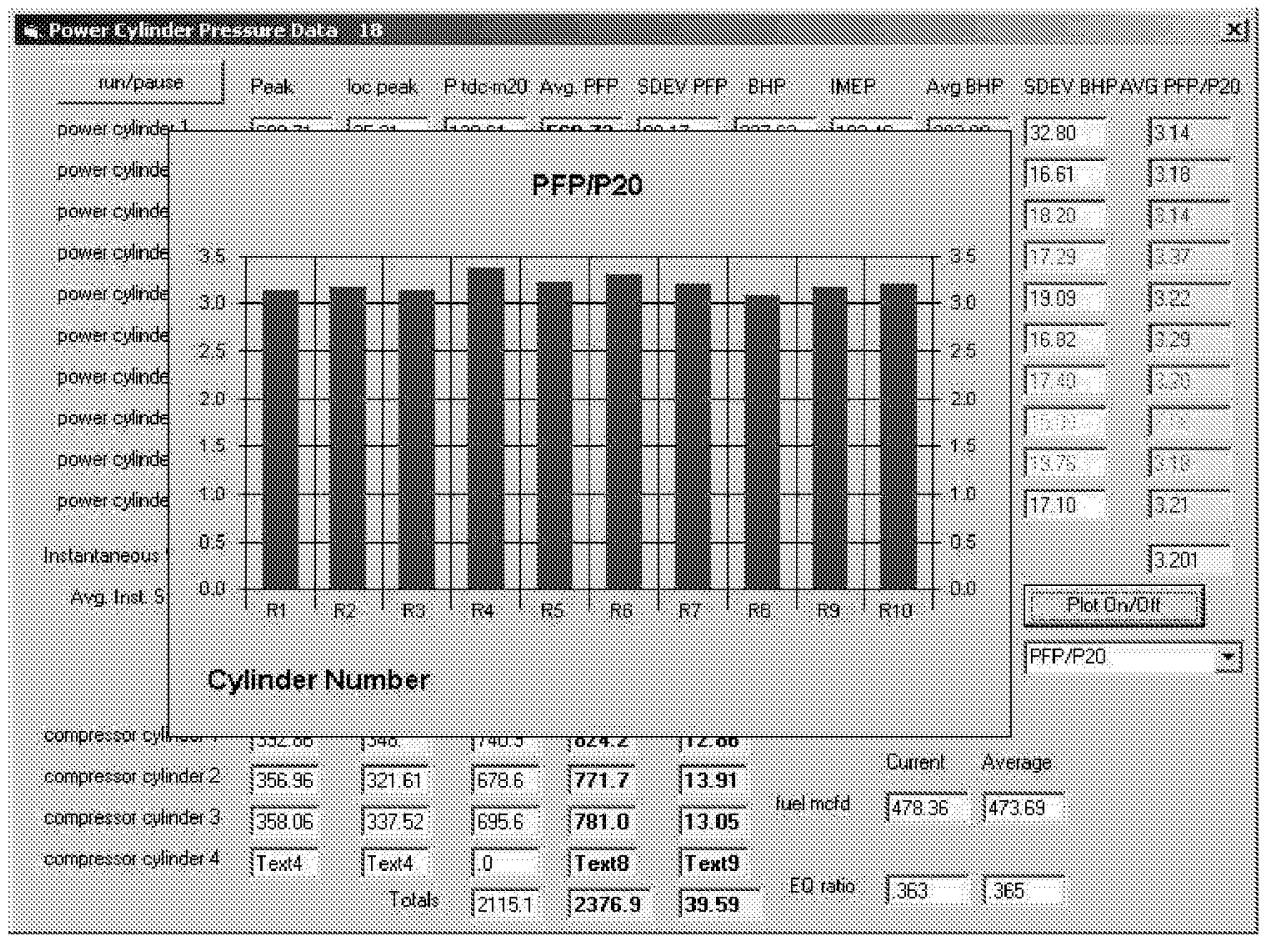

Figure 6-11. Cylinder-to-Cylinder Variation in Combustion Pressure Ratio (CPR); Day 1; Williams Station 60; February 2004

Returning to Figure $6-10$, the log shows that at 1.25 , ignition timing was advanced 2 degrees from 6 to 8 degrees before TDC. Then at 2.04 PM, peak-firing pressure balancing was initiated again, bringing the normalized spread in PFP momentarily down 
below 5\%. Just as PFP balancing was being performed, station control instrumentation indicated torque had increased on the unit to over 103\%, and at about 2.15 load step was increased from 12 to 14 in an attempt top reduce torque. Figure 6-5 has shown that this change succeeded in reducing torque, based on station instruments, to about $102 \%$.

Timing was further advanced to 9 degrees at 2:17 PM, and then retarded back to 6 degrees at 2:38 PM. Testing ceased about 30 minutes after this final retarding.

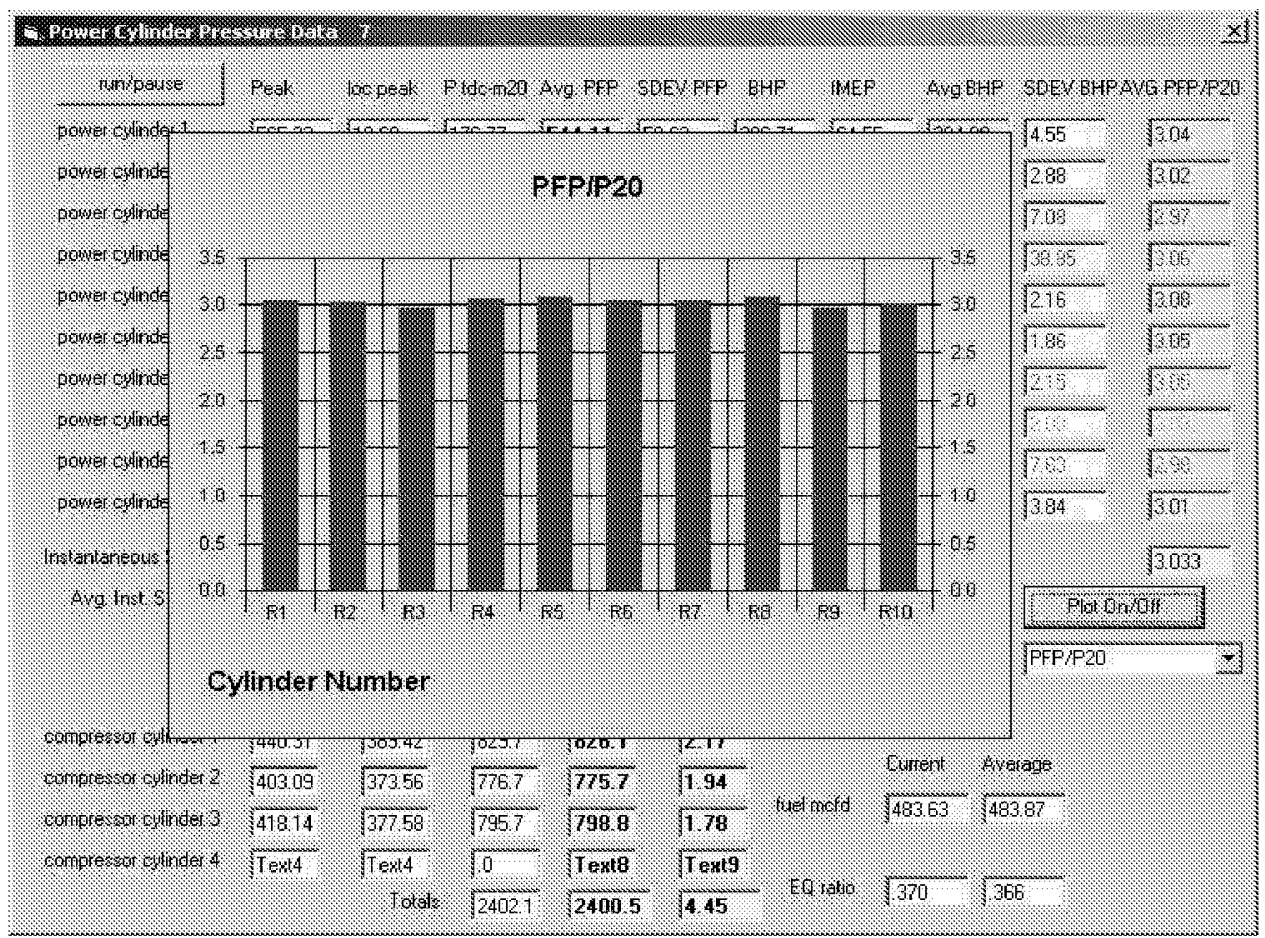

Figure 6-12. Cylinder-to-Cylinder Variation in Combustion Pressure Ratio after CPR Balancing; Williams Station 60; February 2004

Figure 6-13 shows the variation in fuel flow during day 1 testing. Up to about 10.30 , the variation can be attributed to start-up transients, prior to any organized testing. Between the start of PFP balancing and the end, there is no obvious reduction in fuel flow. However, there is a distinct response of fuel flow to the increase in speed from 245 to 250 RPM - this $2 \%$ increase in speed at constant torque would cause about $2 \%$ increase in power and, hence, the fuel flow increases also by about 2\%. Then just before 2:00 PM, a minimum in fuel flow rate occurs as a result of the timing advance to $8-$ a reduction almost immediately offset by the increase in torque on the engine from the compressor, which causes an increase in fuel flow to keep the speed set point of the governor under increased load. The combination of load step adjustment and timing advance to 9 degrees brings fuel flow down, and then the return to 6 degrees timing causes fuel flow to go up again. 


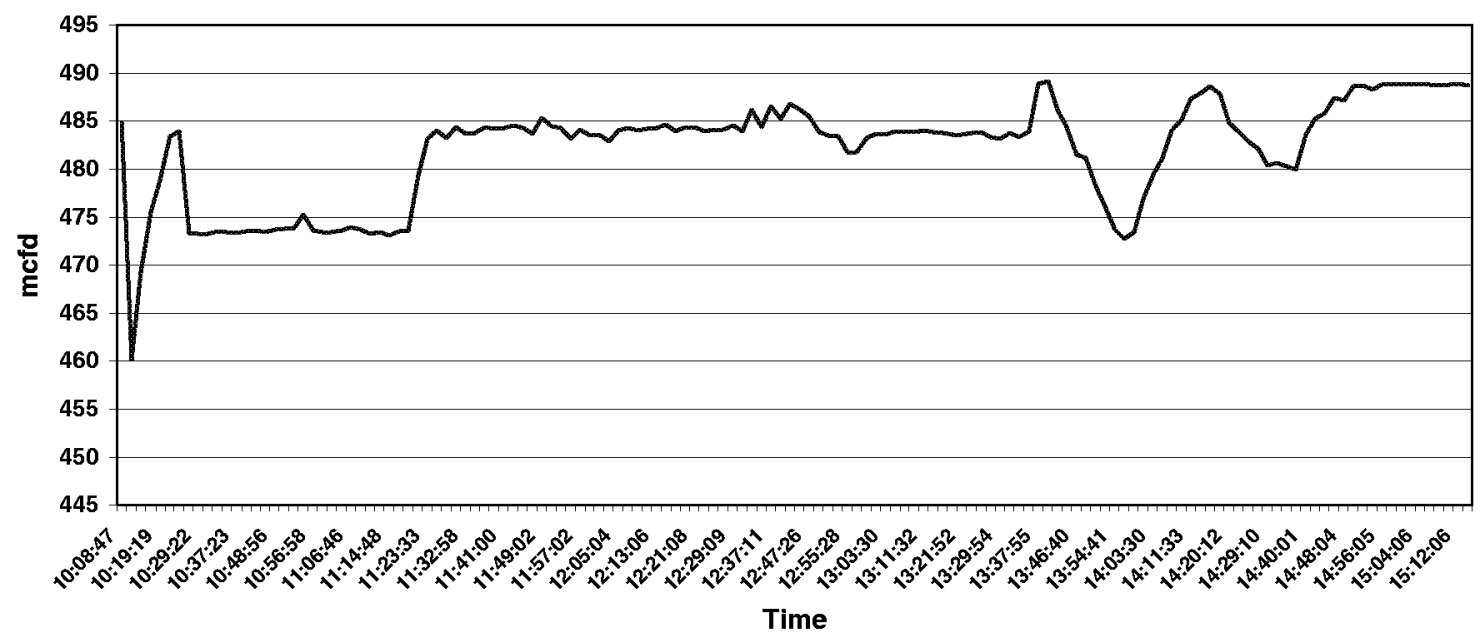

Figure 6-13. Engine Fuel Flow in MCFD during Day 1 Testing; Williams Station 60; February 2004

There does not appear to be any notable relationship between fuel flow and state of balance - at least in the ranges of spread covered in the first day's testing.

In Figure 6-14, the fuel flow has been partially normalized in a plot of heat rate versus time - heat rate is the ratio of fuel energy consumed to energy provided by the engine to the compressor. Its units, by widely used convention, are BTU/HP-hr., using lower heating value as the fuel energy input (actually BTU/HP-hr. can be related to thermal efficiency by the relationship efficiency $=2545 /(\mathrm{BTU} / \mathrm{HP}-\mathrm{hr}$.$) ).$

The first item of note from Figure 6-14 is that the average level of heat rate at 6 degrees timing is around (7500 BTU/HP-hr.). This is distinctly higher than the value obtained at Williams Station 40 on a GMW10 similar to these, which already had been modified for high-pressure fuel injection conversion. The nominal value measured at Station 40 was 6900 BTU/HP-hr. at 8.5 degrees timing. A direct comparison will be made against data from the same unit at Station 60 after it has had the same conversion.

A second item of note is that the heat rate appears to respond directly to timing changes. The advance in timing from 6 to 8 degrees at 1.25 is followed in the next 19 minutes by a reduction in heat rate from 7500 to $7250 \mathrm{BTU} / \mathrm{HP}-\mathrm{hr}$. (a 3.3\% reduction). The advance from 8 to 9 degrees at 2.17 is followed by a reduction in heat rate from 7410 to 7360 in the next 18 minutes (a $0.7 \%$ reduction). The retardation in timing from 9 to 6 degrees is followed by an increase in heat rate over the next 18 minutes from about 7360 to 7560 . The 18- or 19-minute delay in response to timing changes appears quite consistent. 


\section{Heat Rate (LHV)}

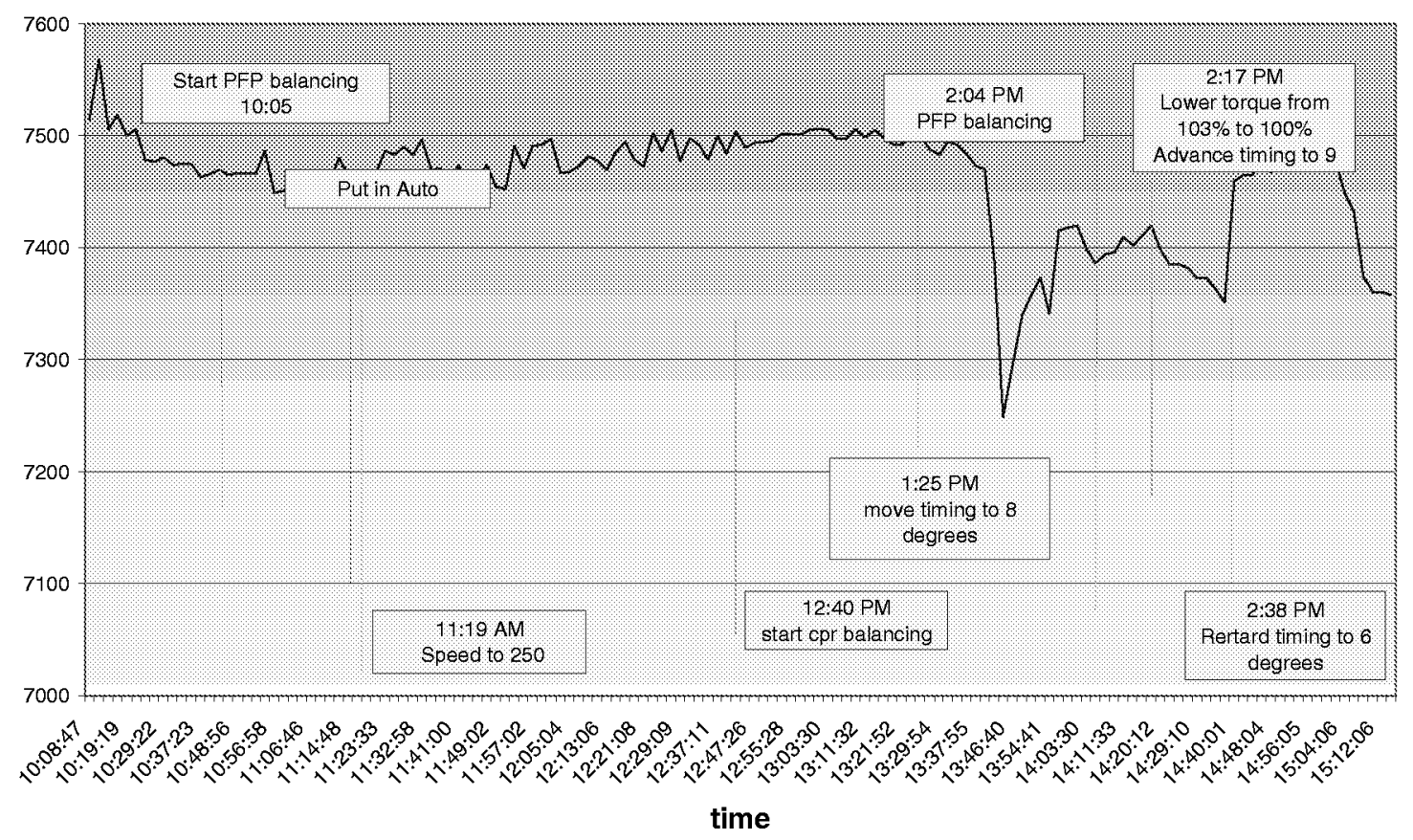

Figure 6-14. Heat Rate during Day 1 Tests; Williams Station 60; February 2004

Clear documentation of the factory specified nominal timing for these GMW units has not been obtained, but it is believed to be 8 degrees.

There is an increase in heat rate between the lowest value following the advance to 8 degrees, and the advance to 9 degrees. There was a load step change from step 12 to 14 , between 2.10 and 2.21 , in an effort to reduce torque from $103 \%$, which may have influenced some of the observed changes in heat rate.

A third item of note in Figure 6-14 is the lack of a distinct response of heat rate to balancing changes - either by peak-firing pressure balancing, or by CPR balancing. No obvious change occurs in heat rate following the 10.45 start of PFP balancing or the 12.40 start of CPR balancing. It should be noted that the unbalance expressed as percentage spread prior to any balancing was only about $12 \%$, so the unit was already moderately well balanced at the start of the day. On day 2, the effects of a bigger spread were investigated, as will be shown, also with little consistent influence of balancing.

Figure 6-15 presents the variation of compressor efficiency over the day's testing. The compressor isentropic efficiency is the quantity identified as "comp IHP-DIP HP". It varies over a range of about $1.8 \%$ from 83.3 to 85 over the day. The header isentropic efficiency tracks quite closely in the range 84 to 85 with one low outlier. 


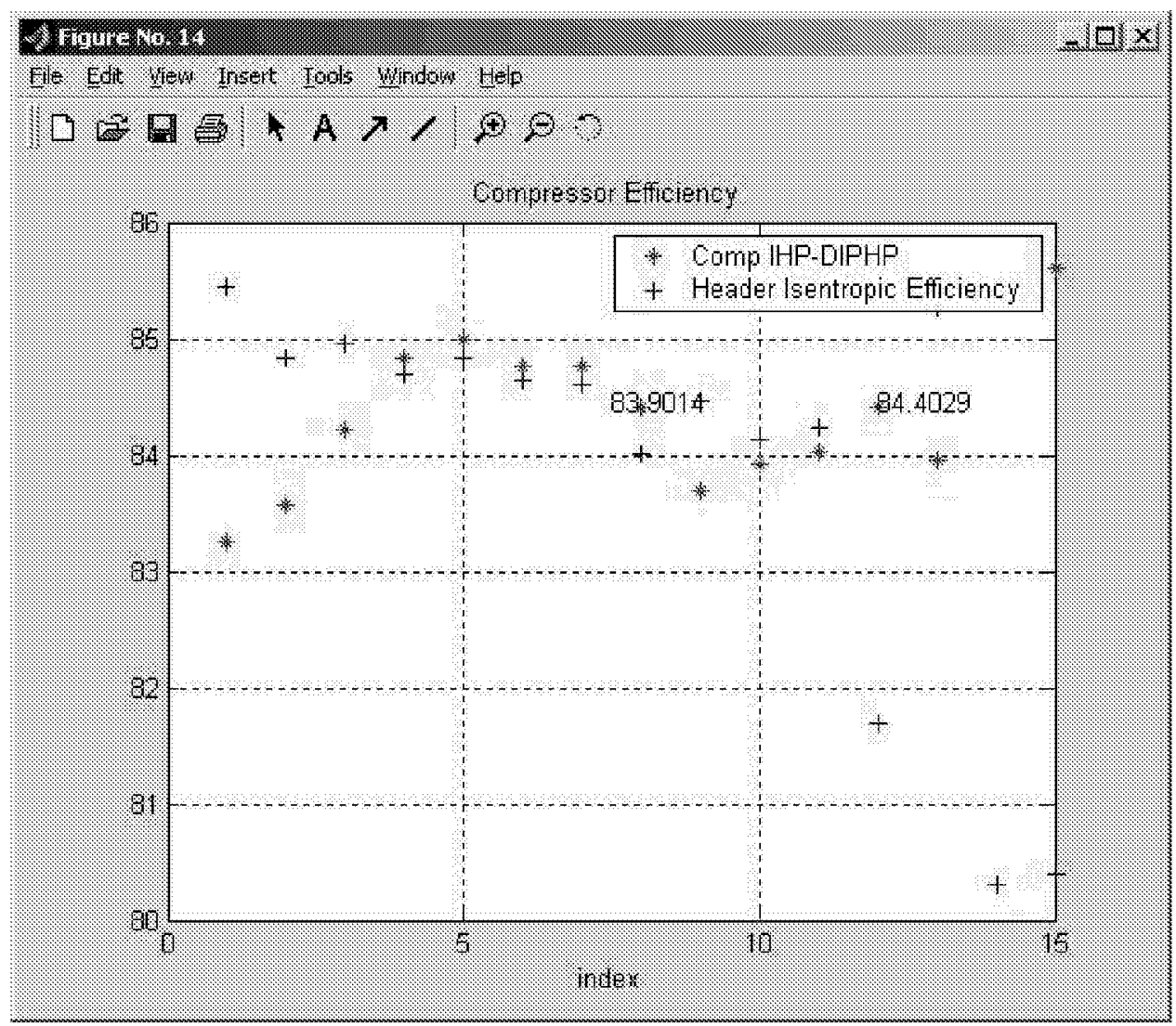

Figure 6-15. Compressor Efficiency; Williams Station 60; Day 1; February 2004

Figure 6-16 presents the overall system efficiency. The nominal value is $27.4 \%$. It ranges between 27.3 and 27.5 over the first 3-1/2 hours of testing, and then generally increases as a result of timing changes. This overall efficiency combines three important components: 1) the engine thermal efficiency; 2) the mechanical efficiency of power transmission from power cylinders to compressor cylinders; and 3) the thermal efficiency of the compressor. Unfortunately, the component efficiencies cannot be precisely isolated, but the overall efficiency is directly calculated as the ideal rate of doing work in compressing the gas from suction to discharge conditions divided by the energy input rate (calculated from the measured flow rate and fuel's lower heating value). Improving any of these efficiencies provides an equal opportunity to improve the overall system efficiency, which measures the conversion of fuel gas burned to useful compression work on the transported gas. Use of this quantity helps with the meaningful evaluation of any compressor package - integral or separable. 


\section{Overall System Efficiency}

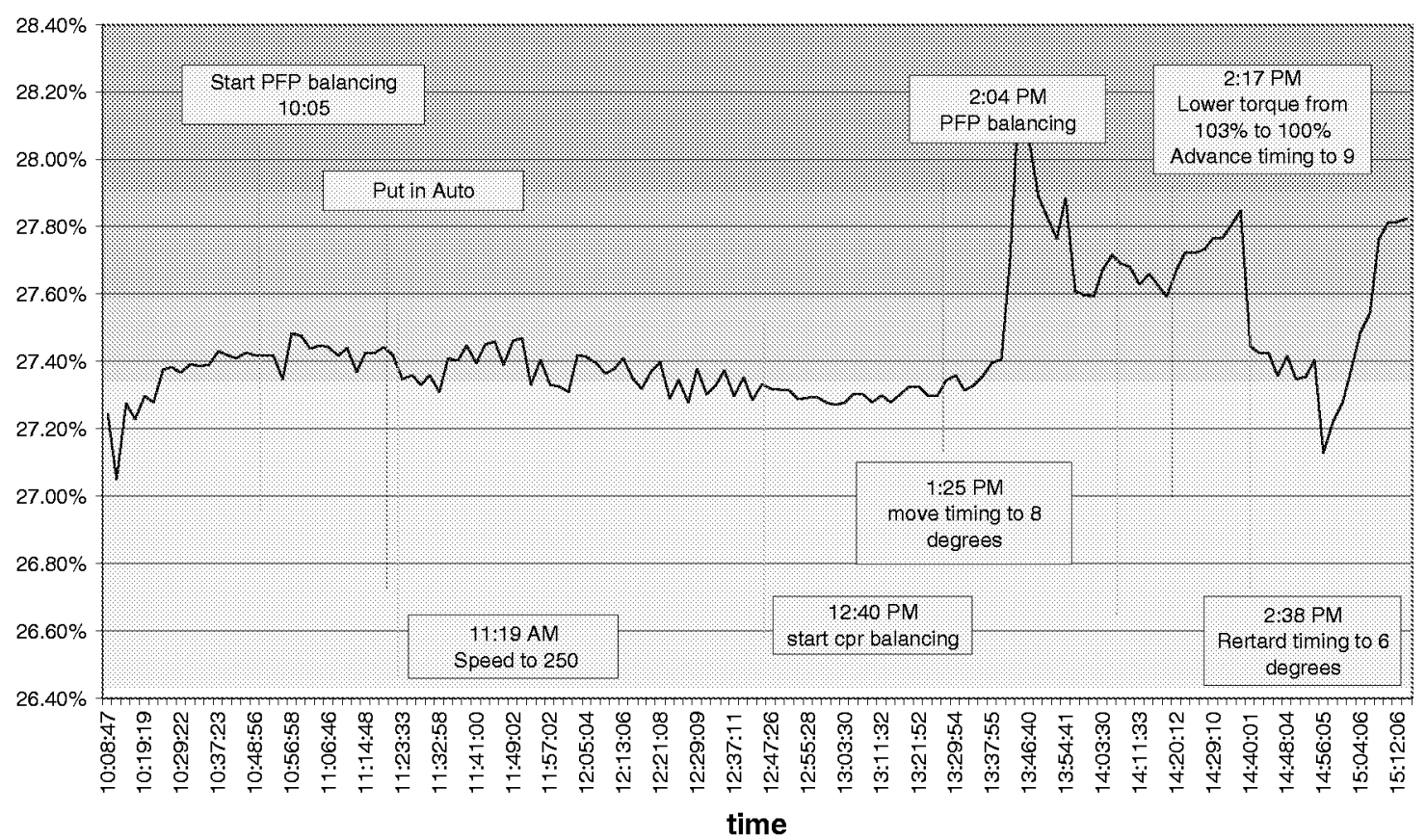

Figure 6-16. Overall Engine-Compressor System Efficiency; Williams Station 60; Day 1; February 2004

The unit tested at Williams Station 40 demonstrated an overall system efficiency of $30 \%$, rising to $31.4 \%$ when timing was advanced. The benefits of the HPFI ${ }^{\mathrm{TM}}$ package modifications to the Station 40 units in improved overall efficiency are apparent. The benefits of similar modifications to the Station 60 units will be quantified following the planned tests later this year.

Figure 6-17 shows the ratio of engine to compressor power. This figure suggests a slight drop over most of the day, but it is not very pronounced. The excursion near the end of the day's testing is unexplained, but may have been a temporary response to a timing change from 8 to 6 degrees.

Figure 6-18 shows average values of peak-firing pressure and of P20 as they varied through the day. These are averaged over 50 cycles, and then averaged across the cylinders. The values of PFP and P20 are approximately 600 and 200 PSIG, respectively, for reference purposes with some variation in peak-firing pressure during the day, from a minimum of 568 to a maximum 679 . The compression pressure, P20, varies hardly at all during the day - its extremes are a low of 189.6 and a high of 203.1, but the majority of variation is much less. 


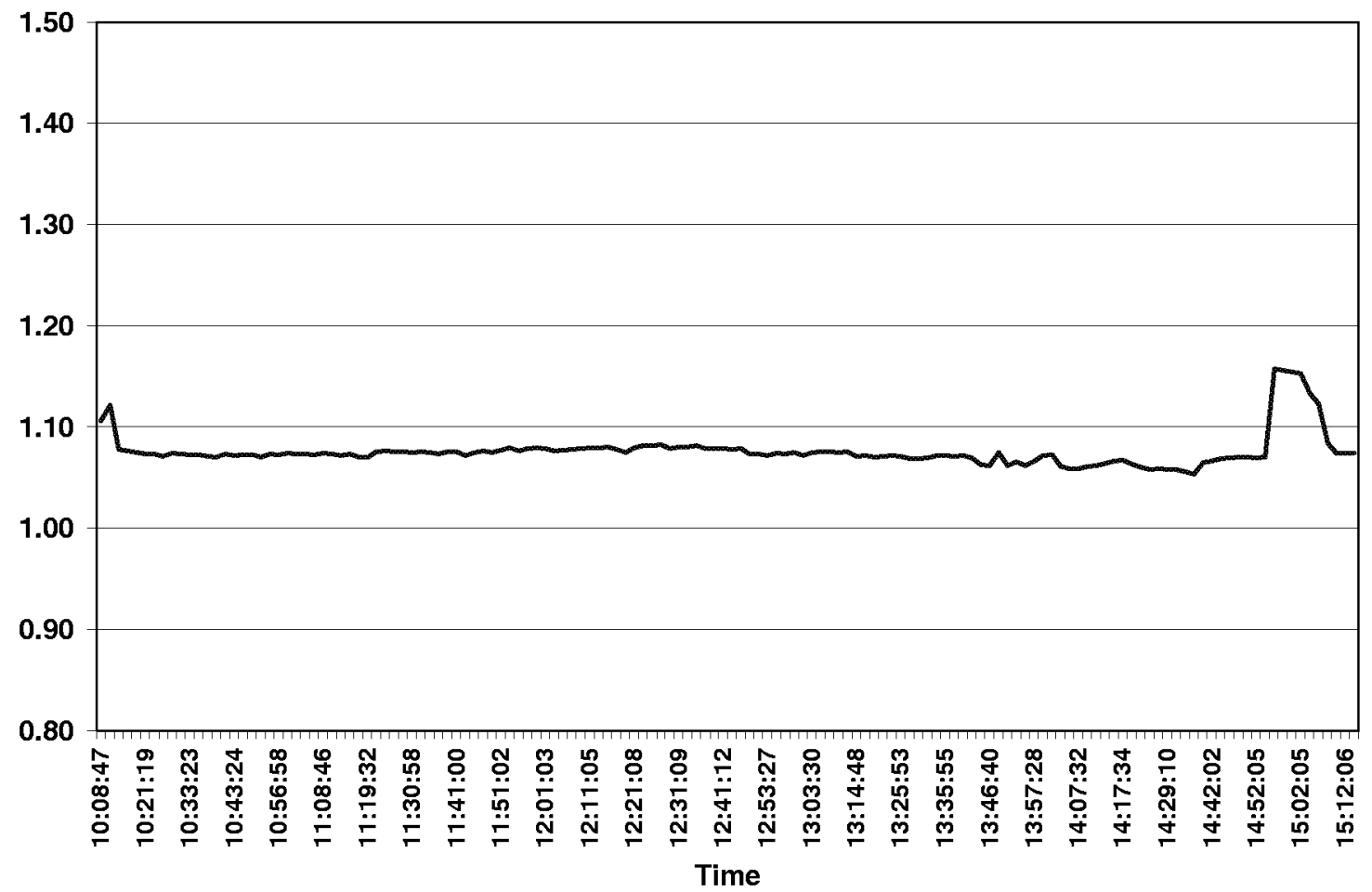

Figure 6-17. Ratio of Engine to Compressor Indicated Power; Williams Station 60; Day 1; February 2004

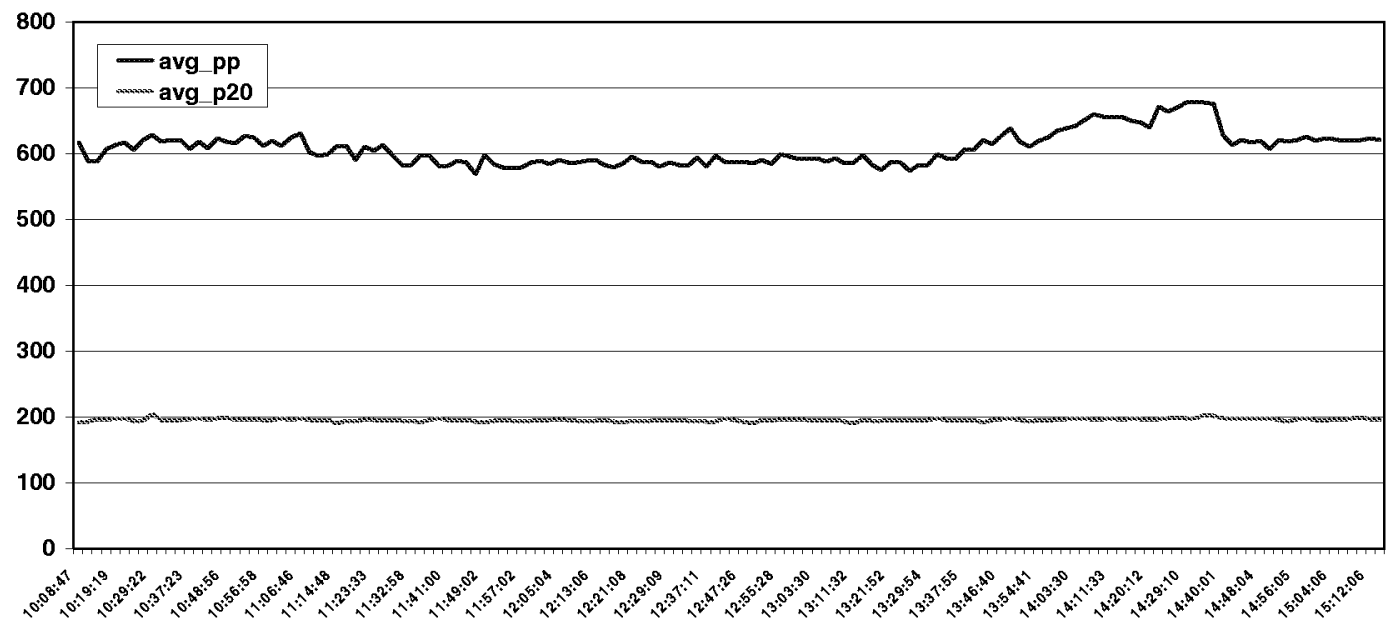

Figure 6-18. Peak-Firing Pressure and Compression Pressure $\left(20^{\circ} \mathrm{BTDC}\right)$; Day 1; Williams Station 60; February 2004 
As might be expected, the mean value for peak-firing pressure appears to drop as a result of PFP balancing in the period 10:45 to $11: 15$ from about 620 to 600 . There is a further drop in PFP to about 585 after 11:15. Speed is increased to 250 RPM at about this time, although with no change in torque, there is no obvious speed related effect on pressure to be expected; the load step stays at 10 until 12:55 PM, so small further drop in PFP may be the continued result of PFP balancing at 10:45 to 11:15.

Figure 6-19 presents the cycle-to-cycle standard deviation in peak-firing pressure, averaged over all cylinders. This quantity has a nominal value of 40 during the day, though it can vary from a low of 25 to a high of 55. The nominal value of 40 is actually lower than the values recorded and calculated at Station 40 , which were about 58 . Of course, the goal at Station 40 is to run as lean as is possible with minimum misfiring.

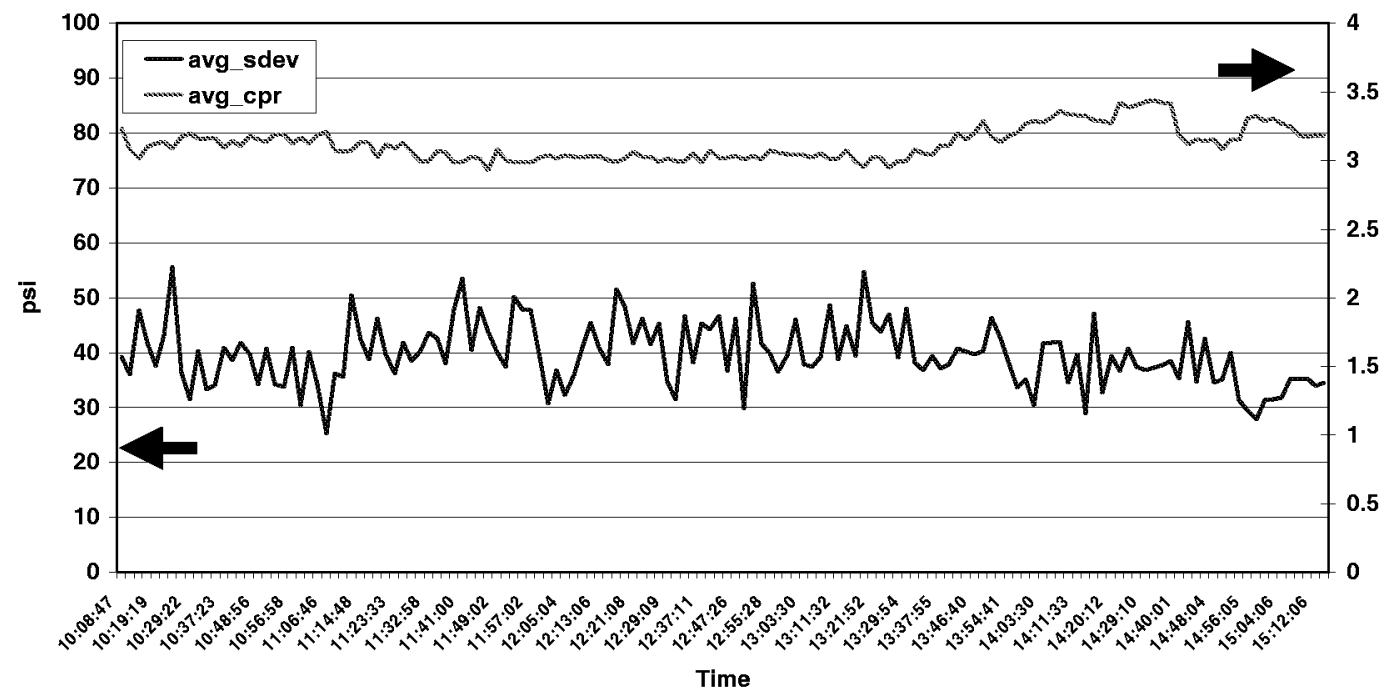

Figure 6-19. Engine Average Cycle-to-Cycle Standard Deviation Estimate; Ratio of Peak-Firing Pressure to Compression Pressure (CPR); Day 1; Williams Station 60; February 2004

Figure 6-19 also includes the average value for combustion pressure ratio (CPR) - that is the ratio of peak-firing pressure to $\mathrm{P} 20$, the compression pressure. This, of course, follows a variation identical to the peak-firing pressure (discussed previously with respect to Figure 6-18). Its value runs from a low of just under 3 (2.92) to a high of 3.44. The highest values correspond to the most advanced timing. It is noteworthy that the CPR value for the GMW10 tested with high-pressure fuel injection, and turbo was in the range 1.8 to 1.85 - much lower than this unmodified unit. Part of this difference is attributable to higher compression pressure on the turbocharged unit (255 versus 196 - a 
factor of 1.3), and part is attributable to lower peak-firing pressure to achieve the same power output.

Figure 6-20 shows the cylinder-to-cylinder variation of P20 and its cycle-to-cycle standard deviation estimate based on 50 cycles averaged over the day. P20 varies from cylinder-to-cylinder by about 20 PSI and its cycle-to-cycle standard deviation ranges from 2.8 to 4.4. Thus, P20 exhibits about a factor of 10 less short-term variance than PFP. Looking forward, it is interesting that the following days data produced identical statistics for all the individual cylinder values of P20 and standard deviation in P20.

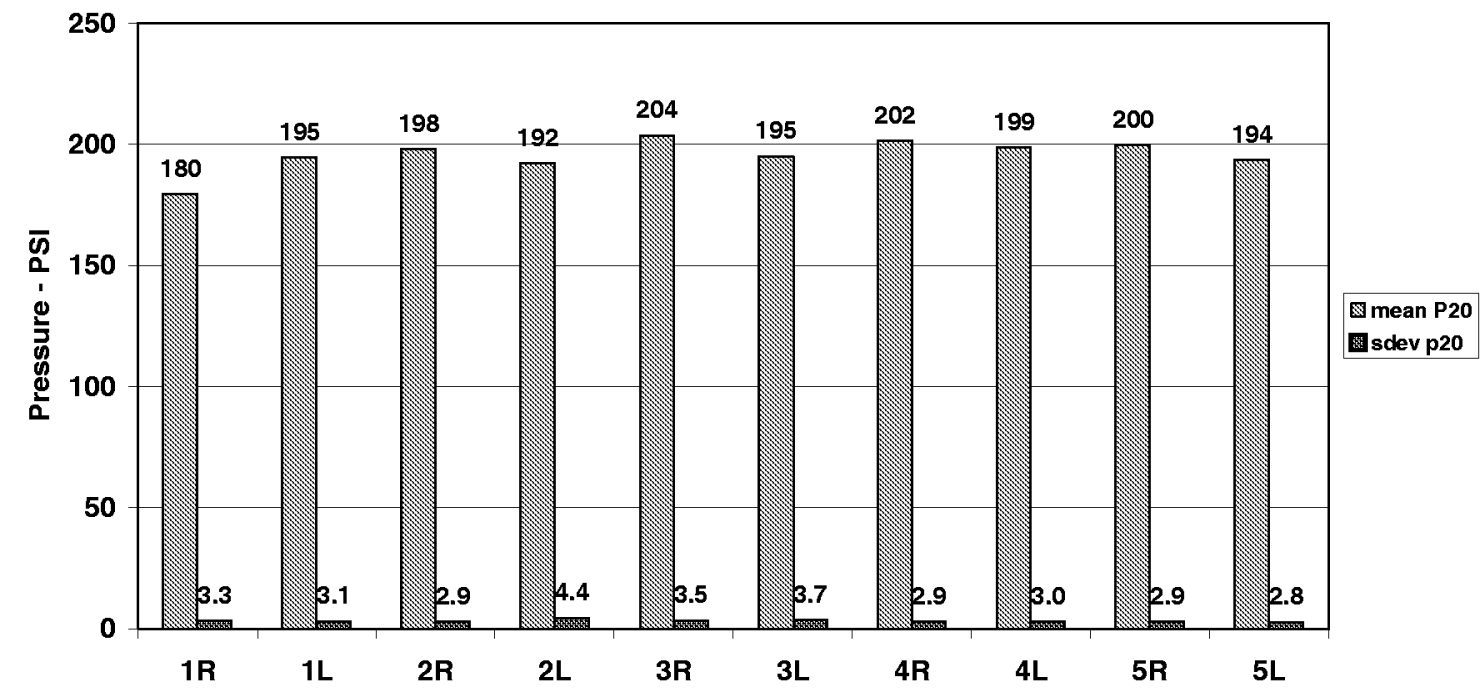

Figure 6-20. Mean and Standard Deviation for P20 (Pressure 20 DBTDC) as a Function of Cylinder; Day 1; Williams Station 60; February 2004

Figure 6-21 shows the average and instantaneous cylinder-to-cylinder spread for peakfiring pressure. The average spread is the difference between maximum and minimum peak-firing pressure for all 10 cylinders, after the individual cylinder values have been averaged over 50 cycles. The instantaneous spread is the difference between maximum and minimum peak-firing pressure for all 10 cylinders obtained for each successive cycle, and then averaged over 50 cycles.

The result of PFP balancing is clearly apparent in the average spread - since this quantity is what PFP balancing seeks to reduce, the success in cutting this quantity from about 70 PSI to about 35 PSI is apparent. This is a 50\% (factor of 2) reduction. However, the impact of balancing on instantaneous spread is much less - it reduces from about 175 to 160 , which is by less than $10 \%$. If balance were to reduce fuel consumption, it would tend to be as a result of reducing the extremity of outliers in the population of combustion events. Spread, particularly instantaneous spread, reflects the extremity of outliers, so this limited influence of balancing on fuel flow and heat rate is probably a result of this 
limited influence on instantaneous spread. Of course, the quantity spread does not directly measure the frequency of occurrence of the outliers, so there may be a yet more definitive cause if the outlier frequency statistics were reviewed; on the basis of this result, individual and population outlier statistics will be recorded and analyzed in future tests. As a result of CPR balancing, the instantaneous spread approaches 200.

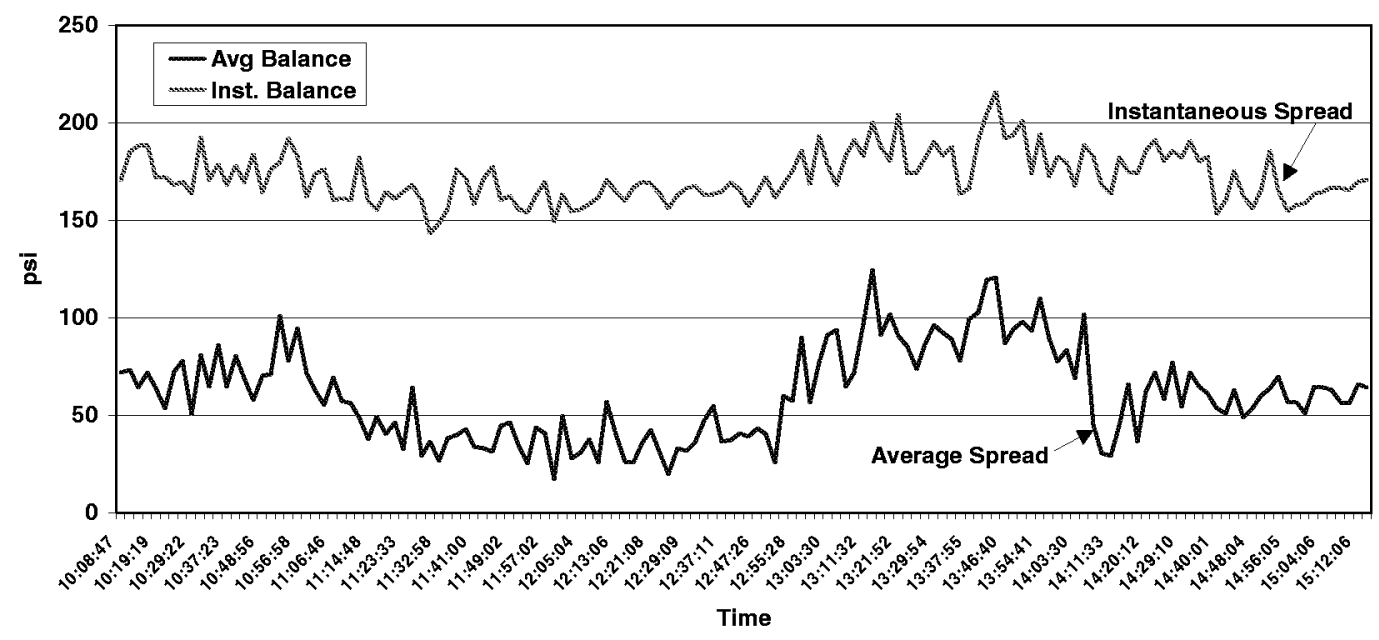

Figure 6-21. Average and Instantaneous Spread in Peak-Firing Pressure; Day 1; Williams Station 60; February 2004

Figure 6-22 shows the standard deviation estimate for variation across the cylinders of CPR, divided by the mean CPR value. This is the cylinder-to-cylinder coefficient of variation (COV) for CPR. It starts at about 4 and drops slightly as an immediate result of PFP balancing from 10:45 to 11:15. It drops further to about 3 over the next hour when no changes to the engine occurred, and then as a result of CPR balancing starting at 12:40, it drops to 2 , with a minimum recorded value of 1.41. As a result of PFP balancing, starting at 2.04, the COV of CPR increased from 2 to about 3.5 .

The consistency of P20 is further emphasized by Figure 6-23, which presents the individual cylinder values as they varied during the day. It is noted that the pressure transducer for cylinder \#1 was still giving trouble in this test series. The solution to this problem was discovered shortly after the tests at Williams Station 60. The lowest trace on Figure 6-23 should be higher. 


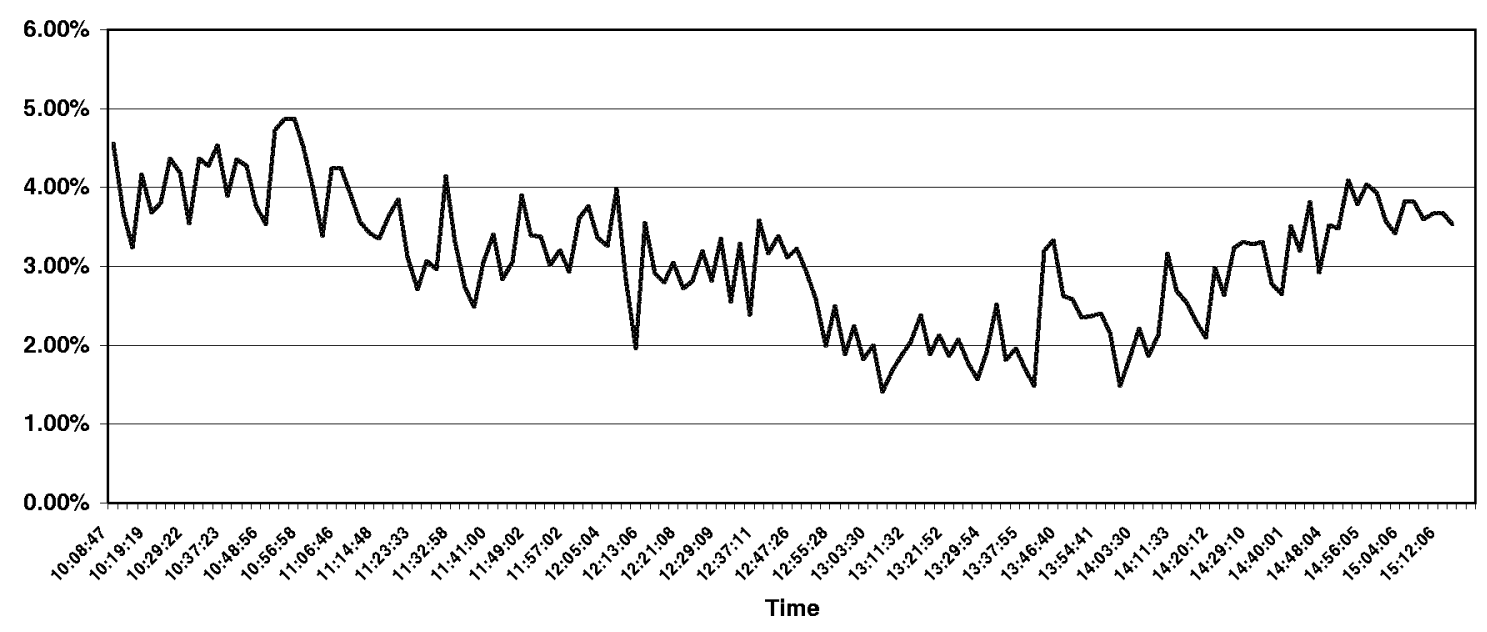

Figure 6-22. Coefficient of Variation for CPR (Standard Deviation/Mean); Day 1; Williams Station 60; February 2004

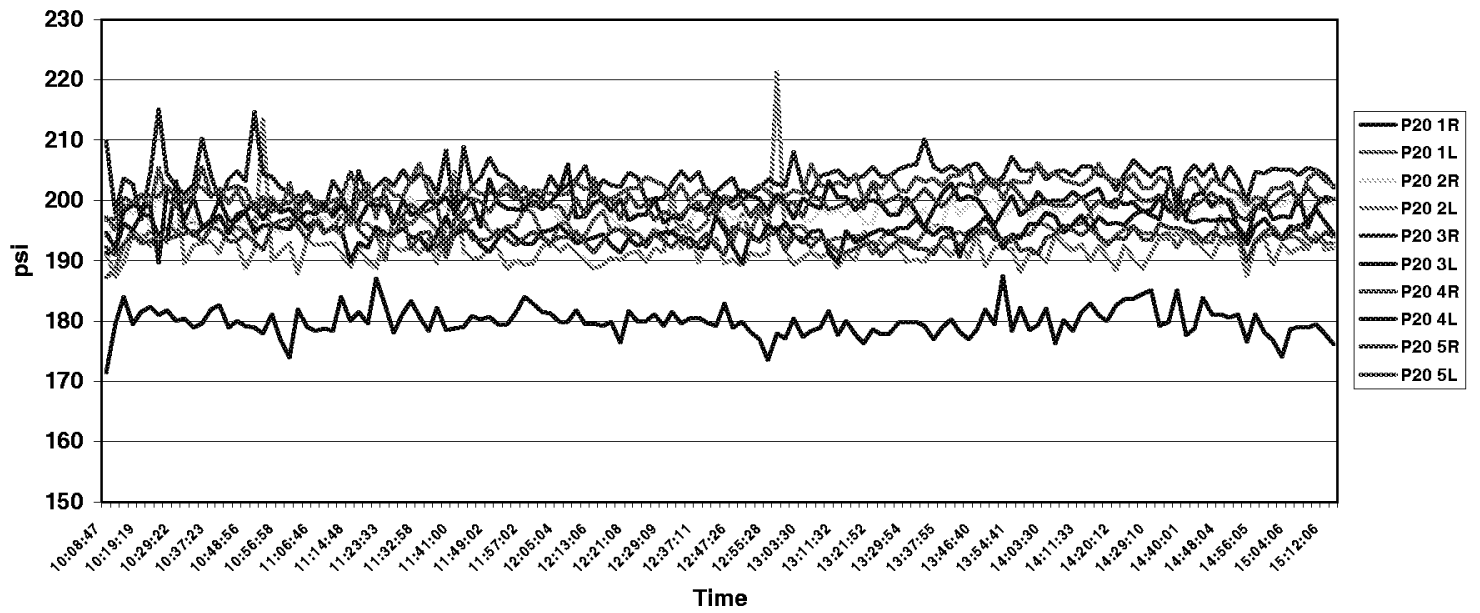

Figure 6-23. Variation of Compression Pressure (P20) for all 10 Cylinders; Day 1; Williams Station 60; February 2004

Figure 6-24 shows the average location of peak-firing pressure (in degrees after top dead center). This quantity exhibits surprisingly wide swings with a minimum value during the day of 11.25 and a maximum of 28.125 degrees. Although the effect appears delayed and the wide variance makes trends hard to discern, this location of peak-firing pressure 
seems to respond most strongly to the timing changes, reaching its lowest value of 11.25 soon after timing is advanced to 9 degrees at 2.17 .

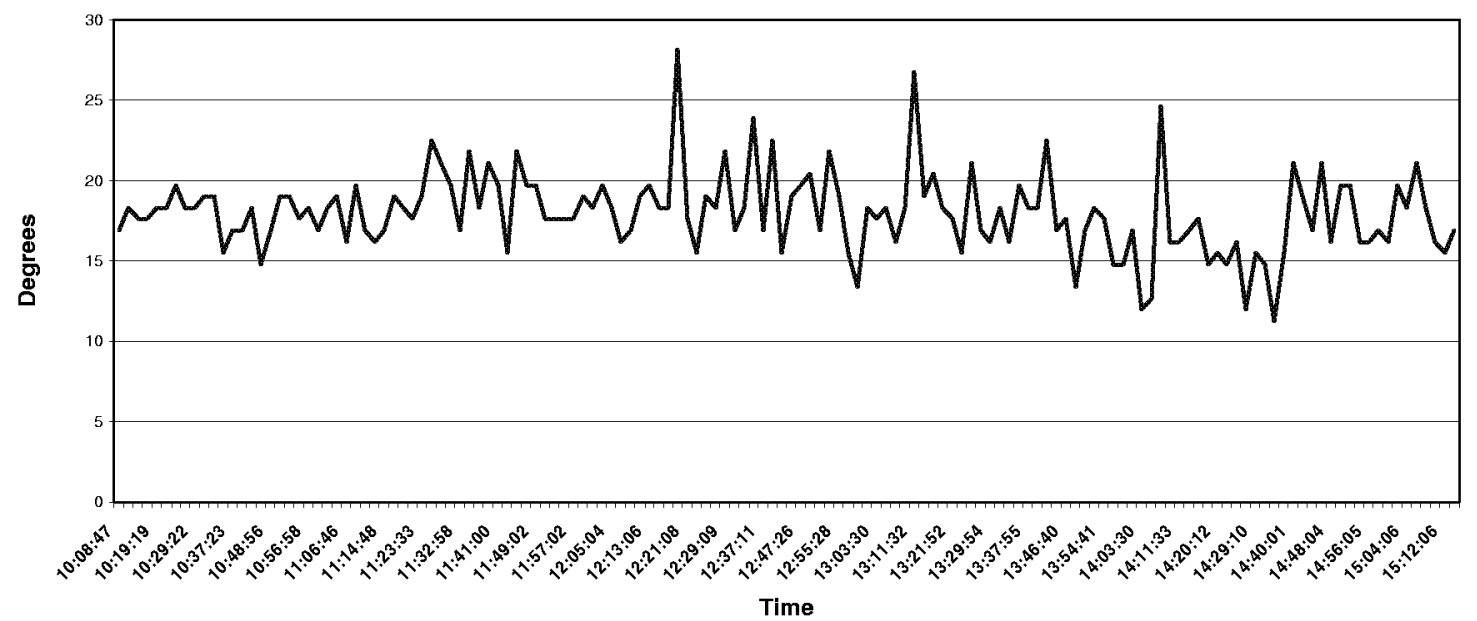

Figure 6-24. Average Location of Peak-Firing Pressure in Degrees after TDC; Day 1; Williams Station 60; February 2004

Figure 6-25 shows the peak-to-peak vibration in inches per second at two locations on the frame and its variation during the day. The highest vibration averages over 0.9 inch per second peak-to-peak, and has maximum excursions to over 1.6 inches per second. This appears to be relatively high for frame vibration on a slow-speed unit. However, as a measure of how cycle-to-cycle and cylinder-to-cylinder variation in combustion might be influencing integrity, this vibration does not appear to provide a discernible trend.

Figure 6-26 presents a waterfall plot of the vibration, showing a very dominant first order vibration, with magnitude of this order very similar to the peak-to-peak vibration. Based on this dominant frequency, an estimate can be made of the frame vibration in linear units. The result is a value of 30 mils or more (750 microns), and suggests a need to inspect the foundation, and a possible need for maintenance of the foundation and mounting of the unit.

The last three figures from the first day address crankshaft strain from the strain data capture module - the general characteristics of its output, and its relationship as a measure of integrity to the variation in test conditions during the day. 


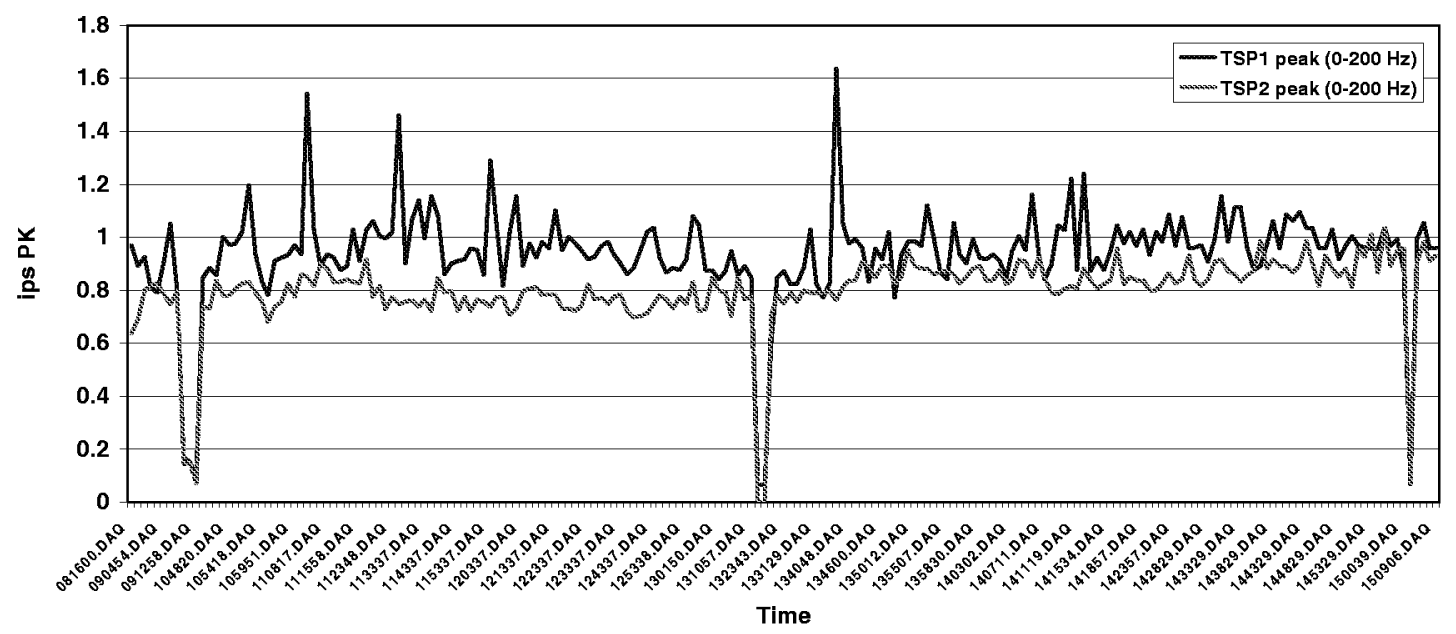

Figure 6-25. Vibration at Two Locations on Frame; Inches Per Second; Peak-to-Peak; Day 1; Williams Station 60; February 2004

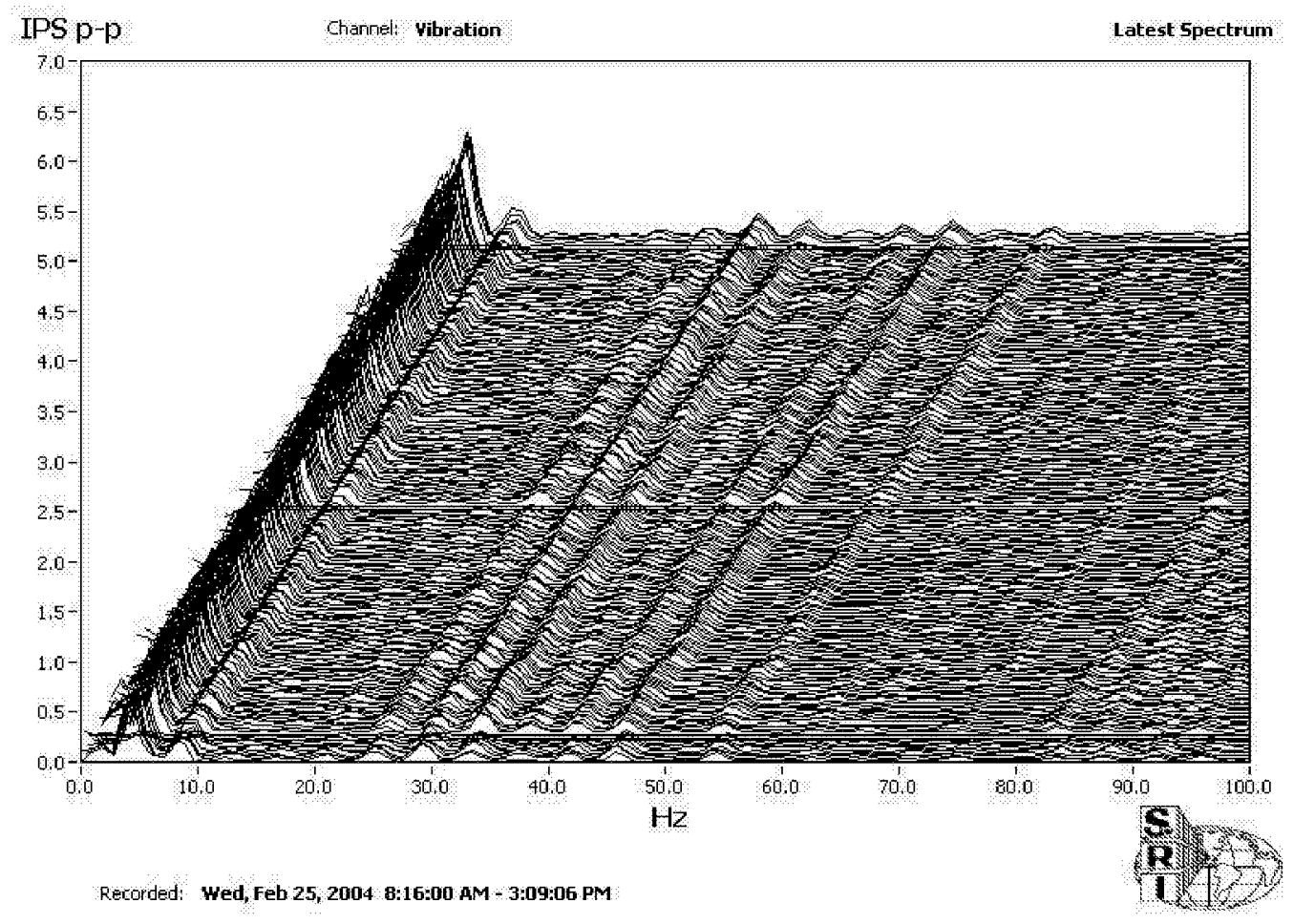

Figure 6-26. Vibration Waterfall Plot; Day 1; Williams Station 60; February 2004 
Figure 6-27 shows a typical series of waveforms over a 2-second snapshot (this is how the SDCM captures its data). The shape reflects the sharp variation in load on the crank throw over each revolution. It exhibits a narrow negative-going peak, often with two individual spikes, and a broader single positive going peak. The peak-to-peak amplitude in this snapshot is about 115 microstrains.

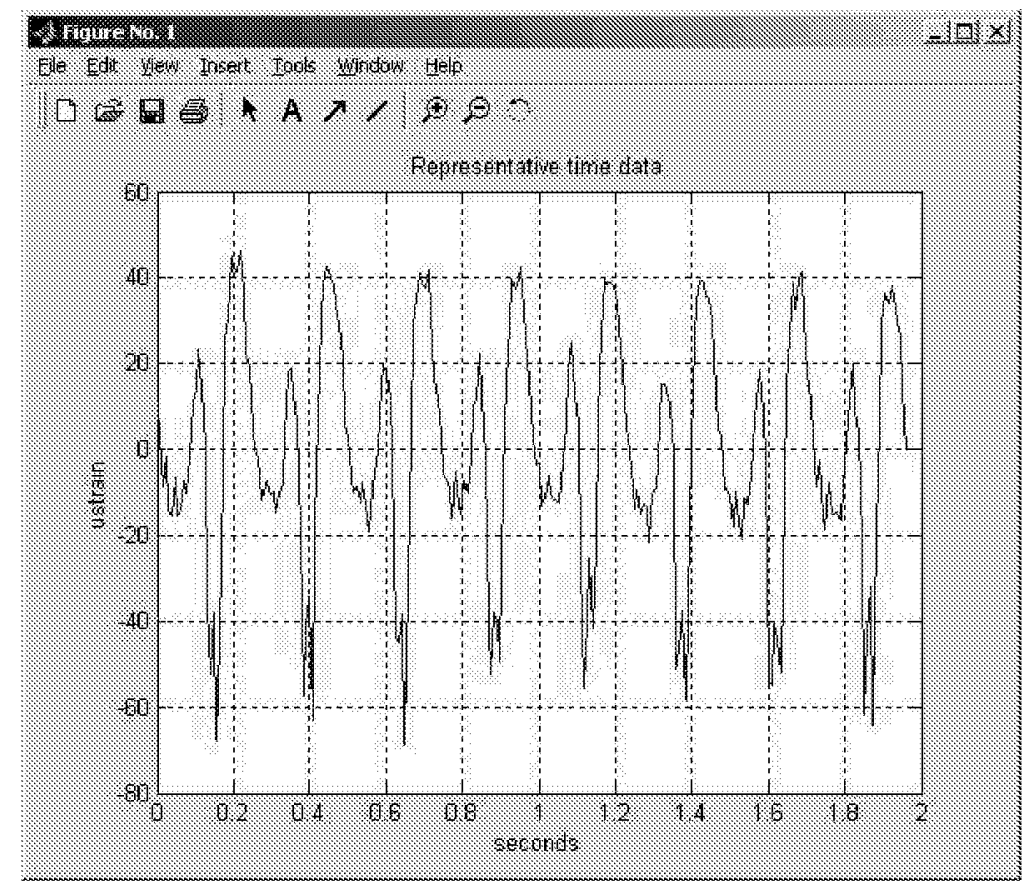

Figure 6-27. Typical Waveform for Crankshaft Strain Variation; Day 1; Williams Station 60; February 2004

Figure 6-28 shows the spectral content as a waterfall plot over the day. The crankshaft strain shows noticeable amplitude at the first four orders, with the second order dominating (about 26 microstrains zero-peak). The second order is a strong component, because the compressor is double-acting and the SDCM strain gage rotates with the crankshaft, putting it in position to respond similarly to the applied load from either cylinder end. First order is also high at about 21 microstrains zero-peak, and third order is about 16 microstrains zero-peak. The fourth order is about 10 microstrains zero-peak. 


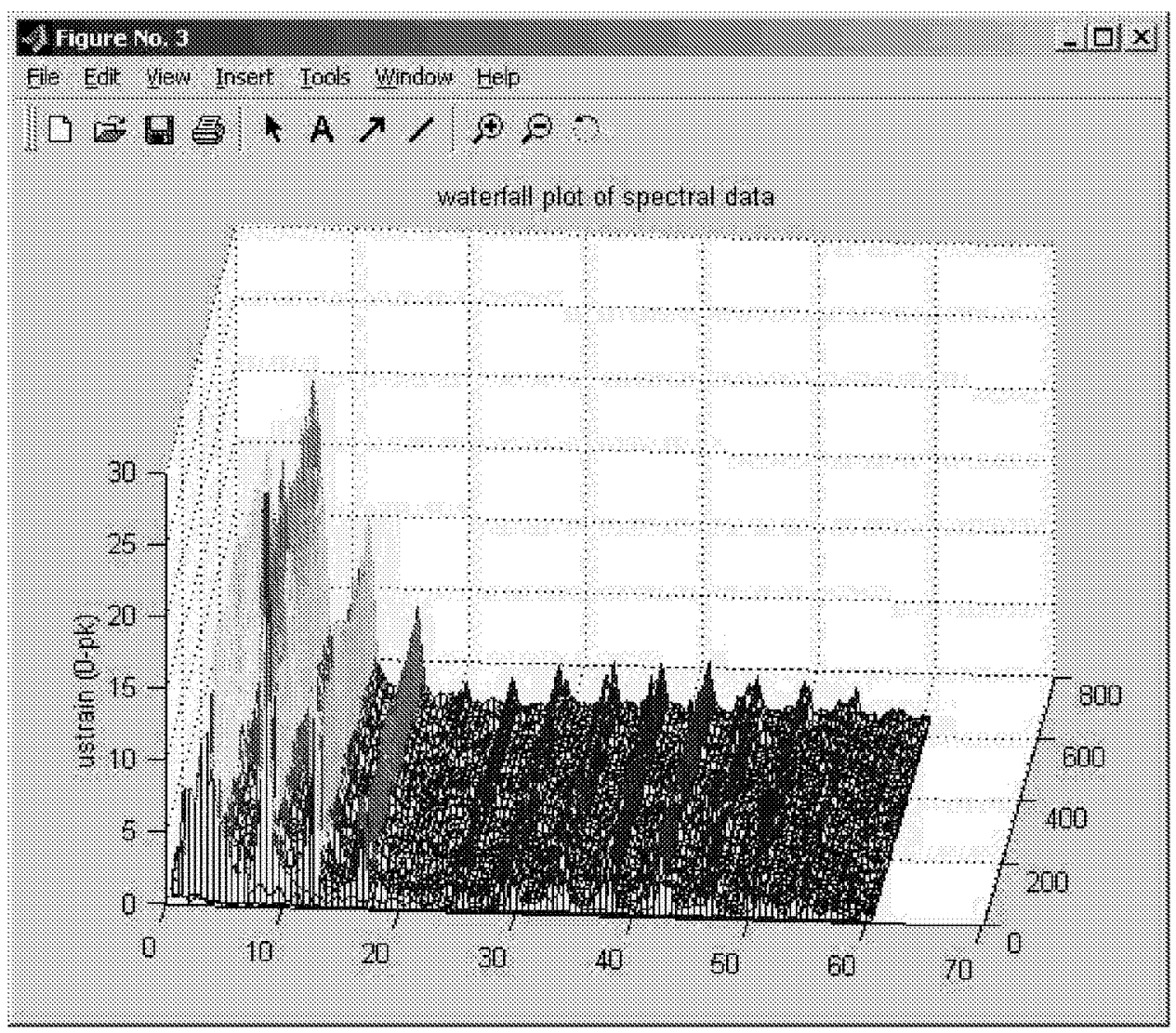

Figure 6-28. Waterfall Plot for Crankshaft Strain; Day 1; Williams Station 60; February 2004

Figure 6-29 shows the variation in the peak-to-peak amplitude, extracted from each snapshot over the entire first day's testing, as a function of time in minutes from when the SDCM was installed and started for the day. The level stays quite steady at about 115 microstrains peak-to-peak until 220 minutes when a trend to increase starts, which corresponds directly to the advances in timing, first to 8 degrees, and then further to 9 degrees - going up to an average of about 135 microstrains, and a maximum value approaching 145 microstrains. Thus, the $17 \%$ increase in crankshaft microstrains accompanies the approximately $12 \%$ increase in peak-firing pressure observed when timing is advanced and discussed with respect to Figure 6-18. This is a factor to be considered in conjunction with any performance benefits from timing advance.

It is also to be noted that crankshaft strains on the unmodified GMW10 are about 115 microstrains compared to a maximum of about 60 on the Station 40 unit with highpressure fuel. 


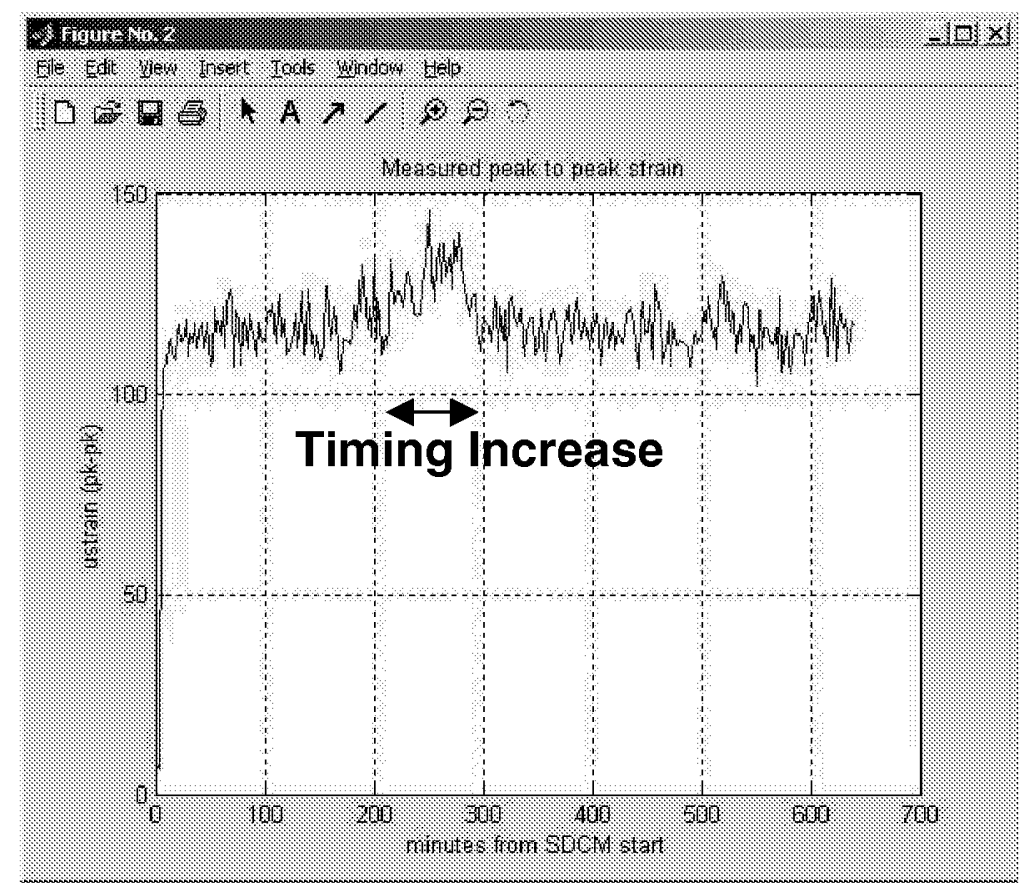

Figure 6-29. Variation in Peak-to-Peak Crankshaft Strain; Williams Station 60; February 2004; Day 1

Figure 6-6 through Figure 6-29 conclude the data presentation and preliminary analysis for day 1's testing of the GMW10 at Williams Station 60.

\subsection{DAY 2 TESTS - UNMODIFIED GMW10}

The data from the second day of testing is presented in similar format to day 1 , with a similar set of charts.

Figure 6-30 shows speed in RPM during the second day's testing - it was maintained close to 250 RPM from the start of testing, apart from three very brief and momentary excursions down by a few RPM.

Figure 6-31 shows the torque during the day 2 testing from the station instruments and data system. It was maintained near $101 \%$, except near the end of the test day when it was intentionally reduced to $96 \%$, by an increase in load step to 19 . 


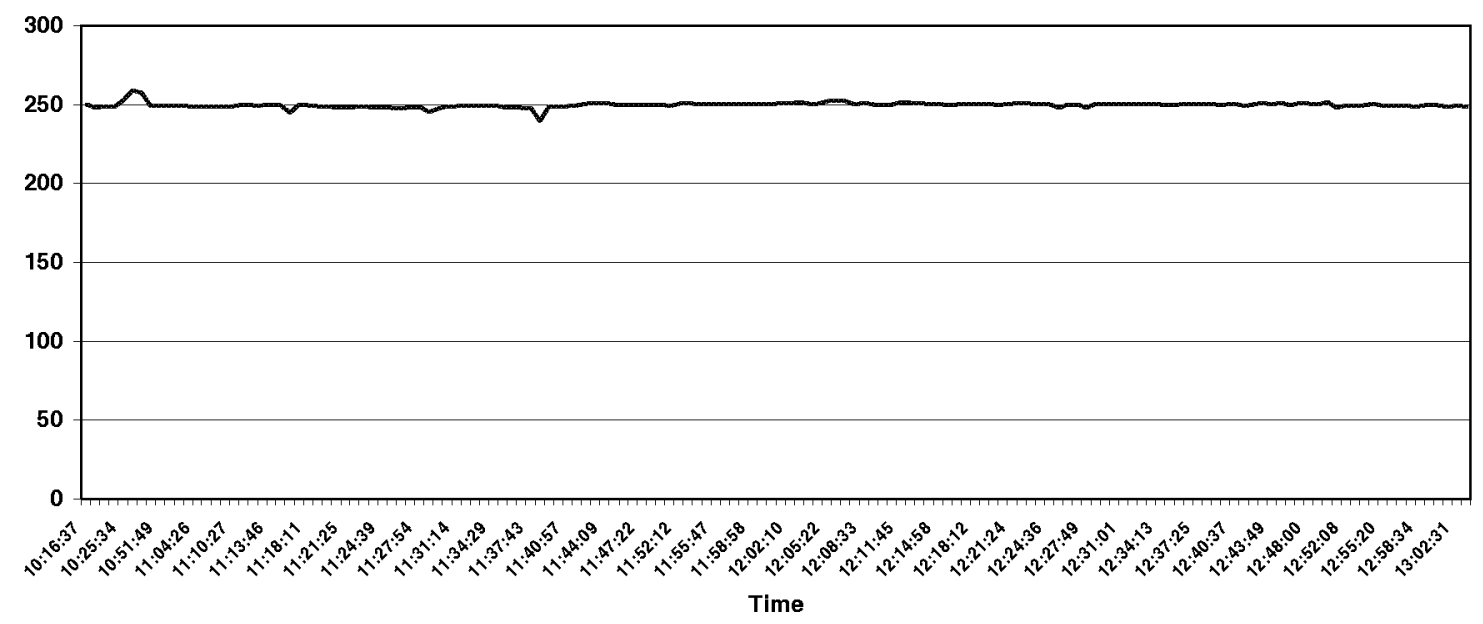

Figure 6-30. Speed Variation; Day 2; Williams Station 60; February 2004

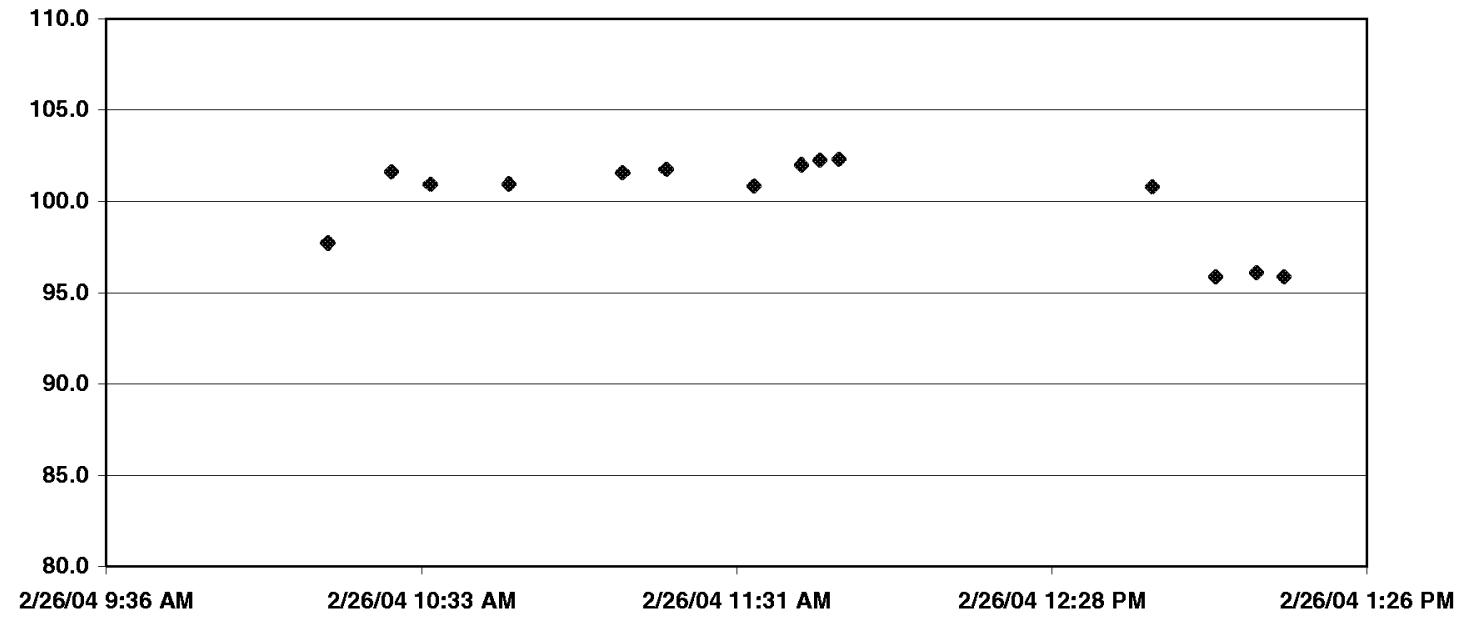

Figure 6-31. Torque from Station Data; Day 2; Williams Station 60; February 2004

Figure 6-32 presents suction and discharge pressure. Suction pressure stayed very nearly constant around 530 PSIG, with a minimum of 527.1, and a maximum of 531. Discharge pressure started at 735.2, and ended the day close to 747, an increase of about 12 PSI. The corresponding ratio of compression is shown in Figure 6-33, increasing from 1.38 to about 1.4 in the middle of the day's testing, and then staying very close to 1.4 for the remainder of testing. 


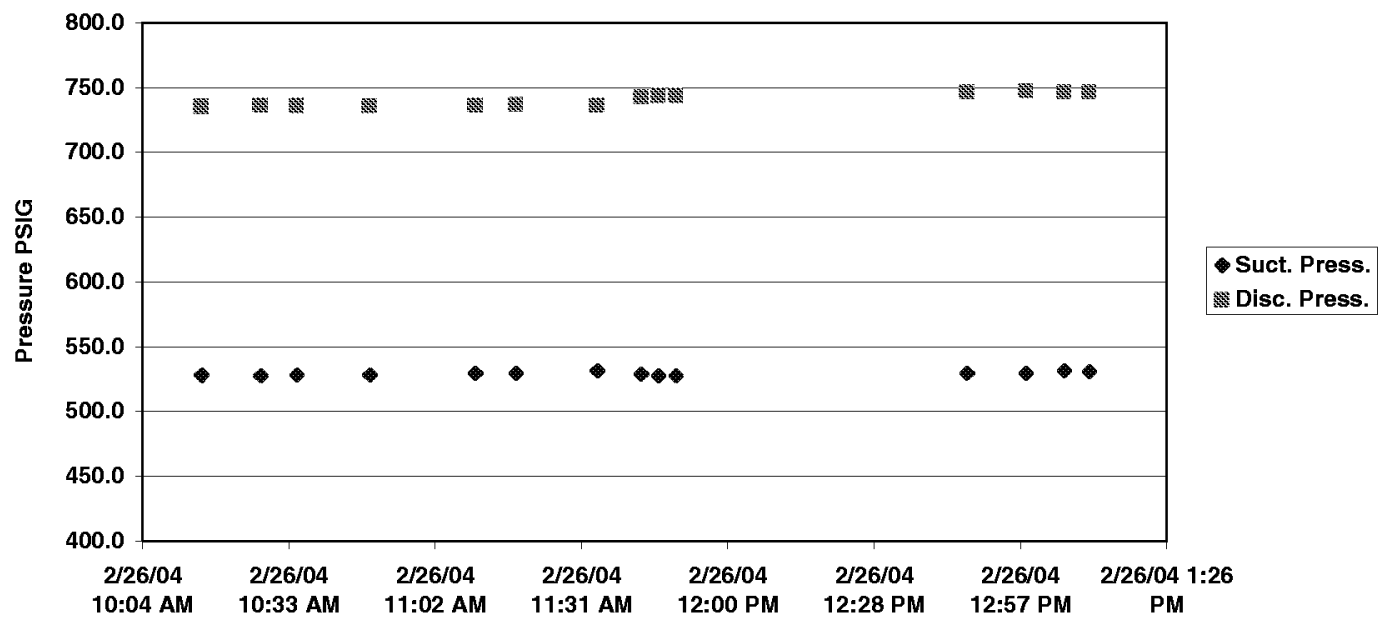

Figure 6-32. Suction and Discharge Pressure; Day 2; Williams Station 60; February 2004

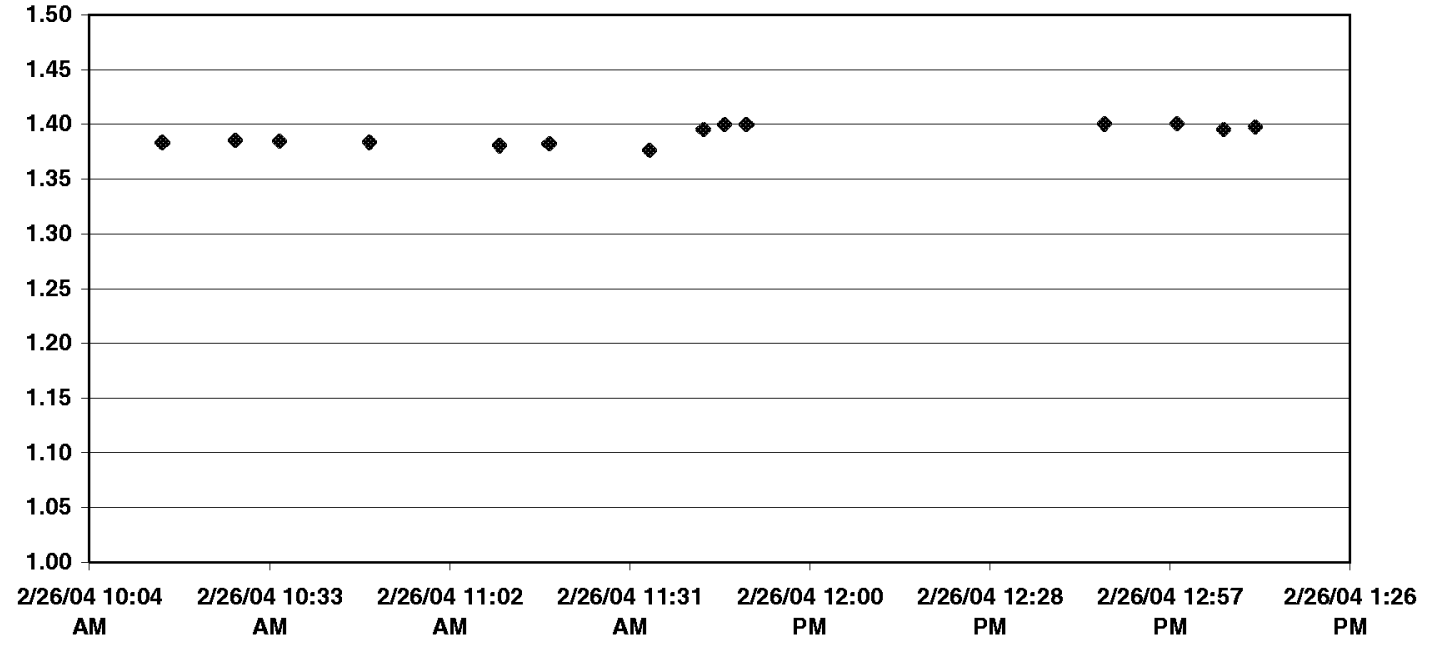

Figure 6-33. Ratio of Compression; Day 2; Williams Station 60; February 2004

Figure 6-34 shows the load step. After starting and a momentary value of 12, load step stays at 8 for the early part of testing, and then increases to 9. To achieve the desired torque reduction, load step was increased to 19 for the last half hour. 


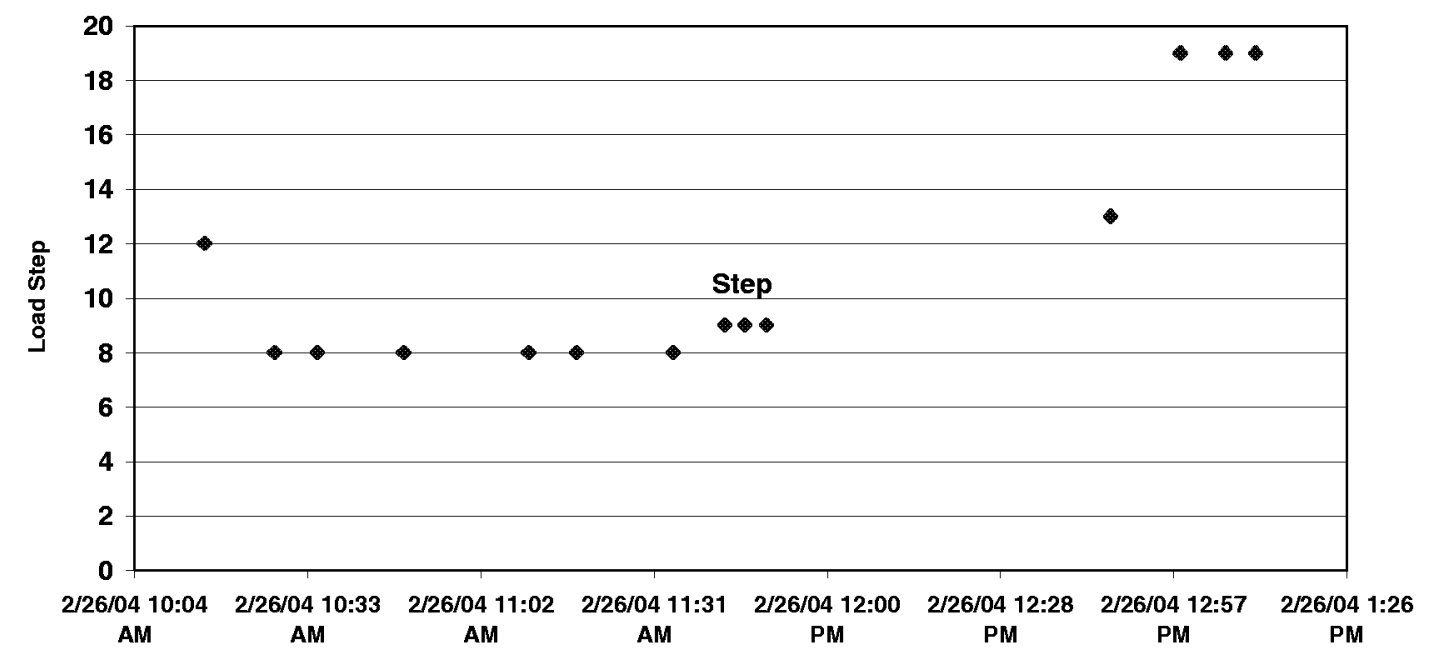

Figure 6-34. Load Step; Day 2; Williams Station 60; February 2004

Figure 6-35 shows key temperatures of oil, water, air, and gas. Gas suction temperature stays very close to $58^{\circ} \mathrm{F}$. Air manifold temperature stays close to $95^{\circ} \mathrm{F}$ (compared to $102^{\circ} \mathrm{F}$ on day 1). Cylinder \#1 discharge pressure starts the day at $105^{\circ} \mathrm{F}$, and ends the day at $106^{\circ} \mathrm{F}$. The higher temperature rise of 47 to $48^{\circ} \mathrm{F}$, compared to $43^{\circ}$ to $44^{\circ} \mathrm{F}$ on day 1 , reflects the higher ratio on day 2 (1.38 to 1.4), compared to between 1.34 and 1.37 on day 1. Lube oil cooling water stays close to $120^{\circ} \mathrm{F}$, with excursions down to $118^{\circ} \mathrm{F}$, and up to $122^{\circ} \mathrm{F}$. Lube oil outlet temperature stays around $142^{\circ} \mathrm{F}$, but starts lower at around $138^{\circ} \mathrm{F}$ and has excursions up to $144^{\circ} \mathrm{F}$. Jacket water temperature in stays around $149^{\circ} \mathrm{F}$ and jacket water temperature out is between $185^{\circ} \mathrm{F}$ and $161^{\circ} \mathrm{F}$.

On day 2 , in an attempt to discern a stronger influence of engine spread on measured fuel flow and heat rate, the fuel flow valves in all cylinders were opened wide. Figure 6-36 shows the subsequent normalized spread and a log of events. The fuel valves were opened at 10:25 AM. The spread rapidly jumped to over $25 \%$. At 11:10, ignition timing was advanced from 6 to 8 degrees. Balancing started at 11.15 and spread reduced from about $17 \%$ to $12 \%$ over the next half hour. At 11:49, timing was retarded from 8 to 6 degrees. At 12:45, the torque was reduced. The spread remained at around $15 \%$, and the COV of CPR remained around 4. 


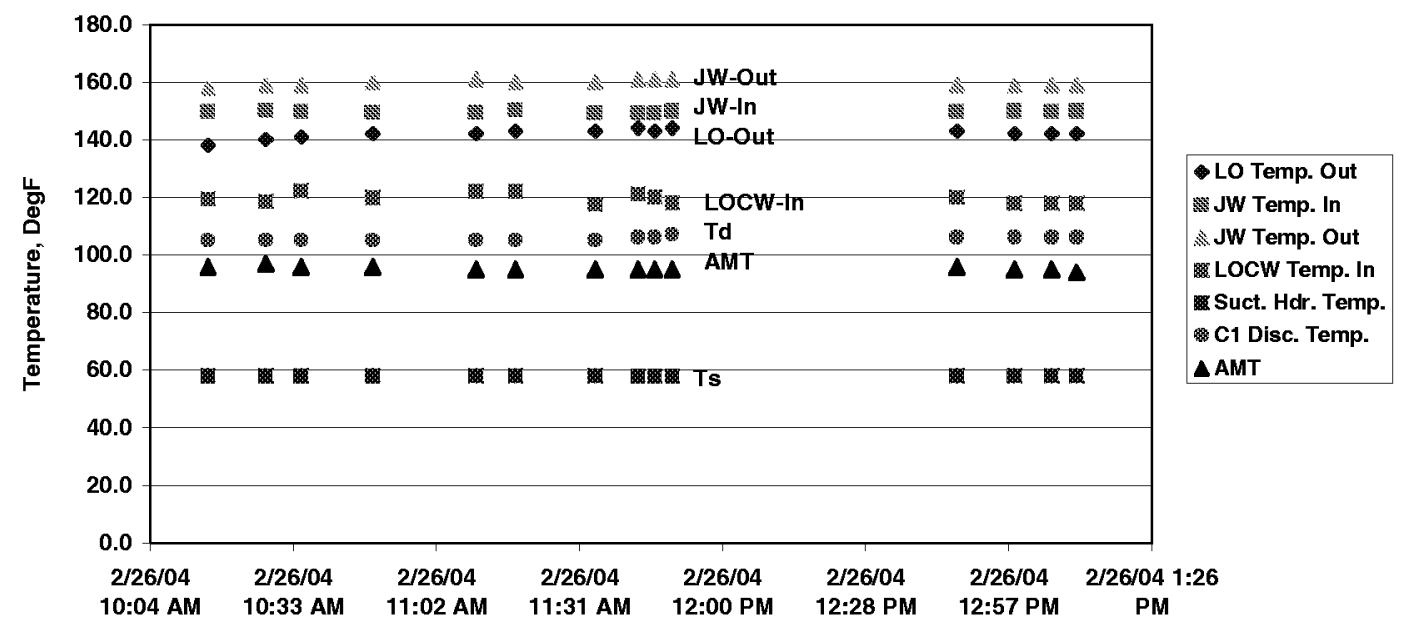

Figure 6-35. Temperatures during Day 2 for Suction Gas, Discharge Gas, Air Manifold, Lube Oil Cooling Water Inlet, Lube Oil Outlet, Jacket Water Inlet, and Jacket Water Outlet; Williams Station 60; February 2004

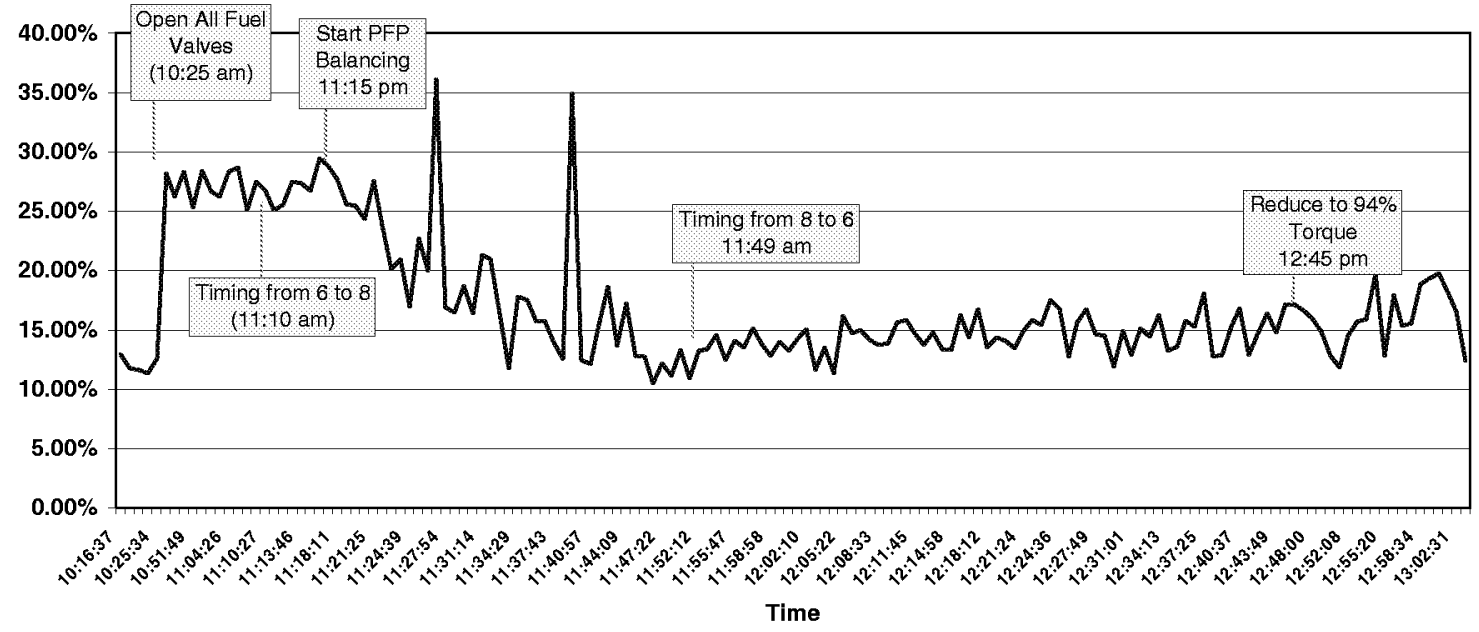

Figure 6-36. Spread in Peak-Firing Pressure as a Percentage with Timing of Test Conditions; Williams Station 60; February 2004; Day 2

Figure 6-37 shows the variation of fuel flow on day 2. This is presented for the purpose of documentation, and appears to respond distinctly to some changes, particularly timing changes. However, the next figure (Figure 6-38), presenting heat rate, provides a more 
consistent basis for assessing how balancing and timing changes affect engine performance.

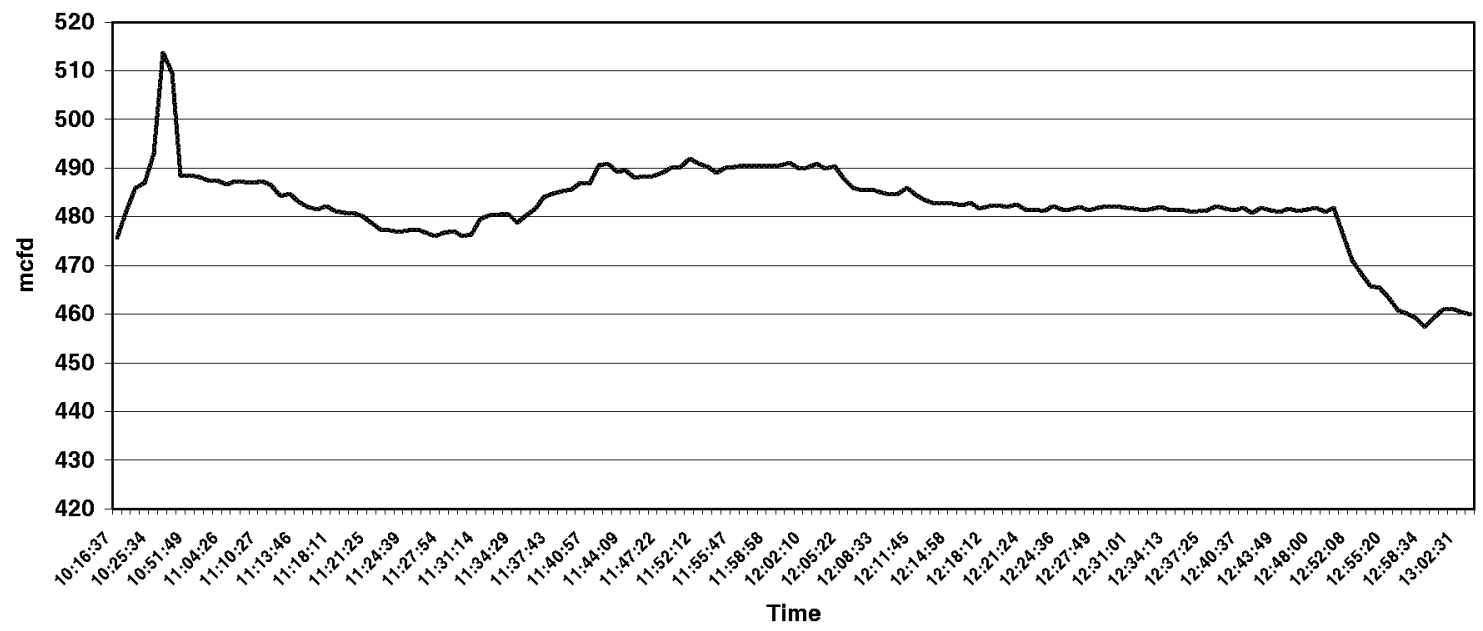

Figure 6-37. Engine Fuel Flow; Day 2; Williams Station 60; February 2004

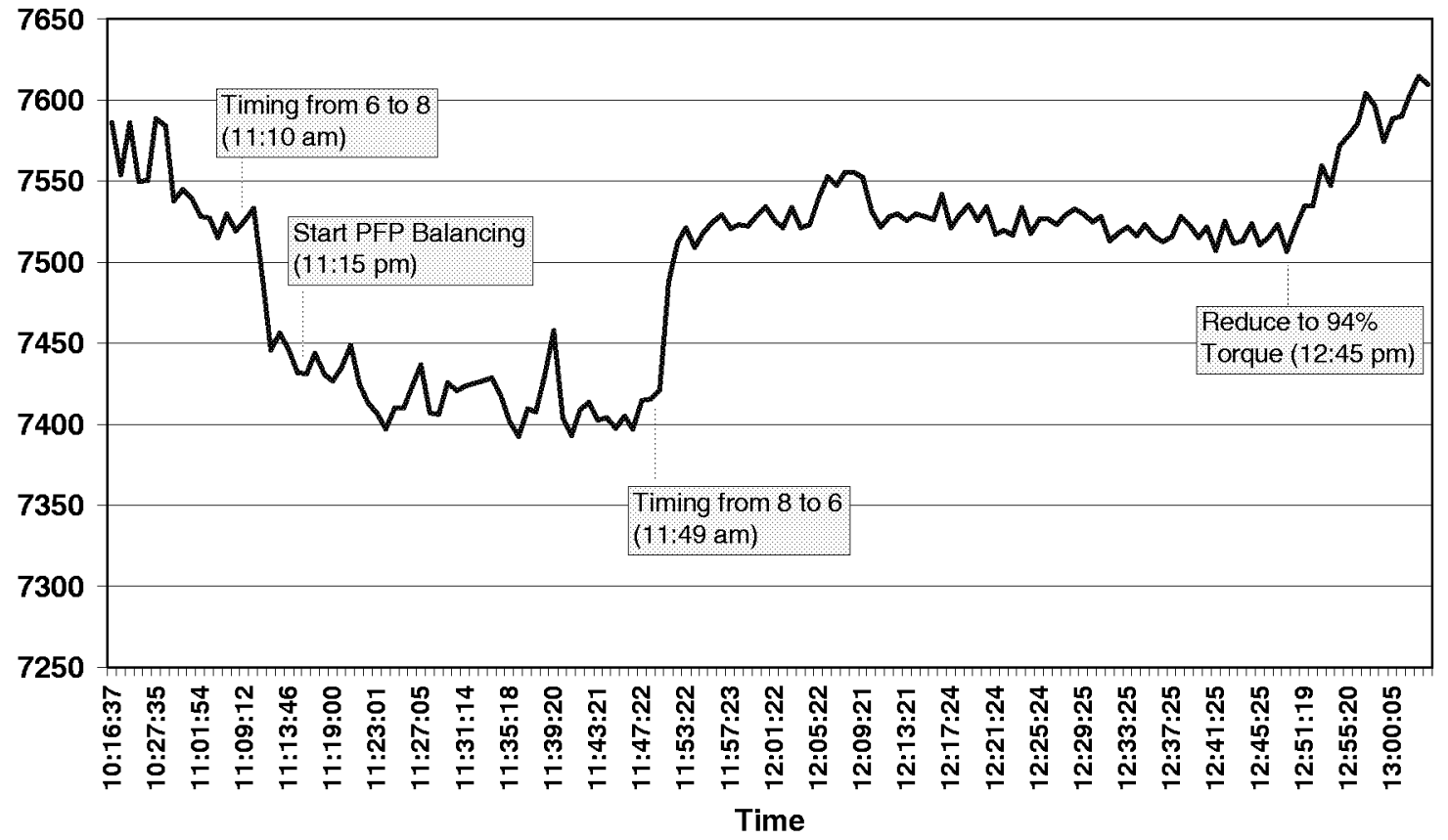

Figure 6-38. Heat Rate; Day 2; Williams Station 60; February 2004 
Prior to timing changes or balancing, the heat rate with fuel valves wide open and a spread of $27 \%$ is $7550 \mathrm{BTU} / \mathrm{HP}-\mathrm{hr}$. . The previous day, prior to any timing or balancing changes with a spread of about $12 \%$, the heat rate was about 7485 . This might indicate that reducing the spread from 27 to $12 \%$ leads to a small reduction in heat rate, but the reduction is small - about $0.85 \%$ for a substantial reduction in spread. The heat rate on day 2 clearly responds to the advance in ignition timing at 11:10 AM, with an immediate reduction in heat rate of $90 \mathrm{BTU} / \mathrm{HP}-\mathrm{hr}$. PFP balancing, which reduces the spread from $27 \%$ to $15 \%$, appears to be followed by a small reduction in heat rate, from 7460 to 7435 . However, this small effect may also have been the continuation of heat rate reduction associated with timing advance, since the elapsed time for this influence is about 19 minutes. The torques on the two days at this point in the two tests were remarkably similar at about 101\%; thus, any influence of torque level on heat rate can be discounted.

The retardation of timing back to 6 degrees was followed by an immediate increase in heat rate. After this, there were no significant changes, and the heat remained close to 7550 BTU/HP-hr., with the unit at $15 \%$ spread and timing of 6 degrees. Thus, there is no evidence from this data that on day 2 , that balancing had any documentable effect on heat rate. Both with a spread of $27 \%$ and with a spread of $15 \%$, the heat rate is 7550 BTU/HP-hr.

When the torque is reduced to $96 \%$, there is a clear and immediate increase in heat rate from 7550 to about 7620 BTU/HP-hr. - almost $1 \%$.

Figure 6-39 presents the overall system efficiency; after the balancing and timing changes, this settles to $27.13 \%$ for a timing value of 6 degrees - very similar to day 1 . The values obtained at Williams Station 40 were $28.6 \%$ for 6 degrees timing, $30 \%$ for 8.5 degrees timing, and $31.3 \%$ for 11 degrees timing. Thus, for the same timing of 6 degrees, we should compare $27.1 \%$ without the HPFI modification to $28.6 \%$ with it. The comparison will be more directly valid when made against data obtained on the identical unit - when tested later this year. With 8 degrees timing, the overall thermal efficiency on the Station 60 unit is $27.5 \%$, and extrapolating approximately for 8.5 degrees $(27.6 \%)$. This would be compared to $30 \%$ for the same timing ( 8.5 degrees).

Figure 6-40 presents the ratio of engine to compressor power. At approximately 1.11 to 1.13 , it is clear this ratio has increased from the approximately 1.08 of the first day's testing. The start-up temperature of the oil was a few degrees lower than on day 1 , but this is unlikely to account for this much difference in this ratio. In addition, this ratio appears to take a small jump up near the mid-point of the day's testing. 


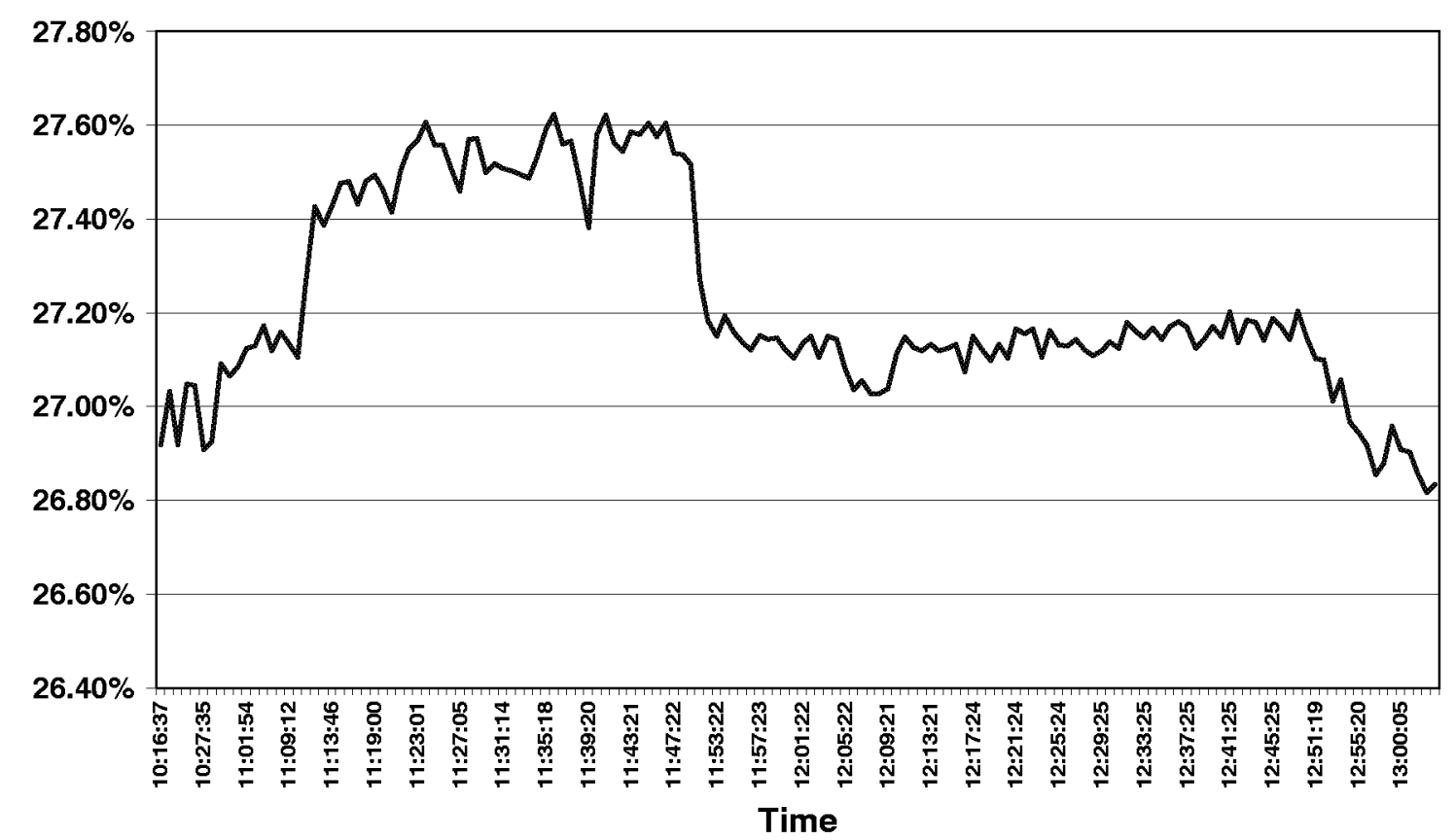

Figure 6-39. Overall System Efficiency; Day 2; Williams Station 60; February 2004

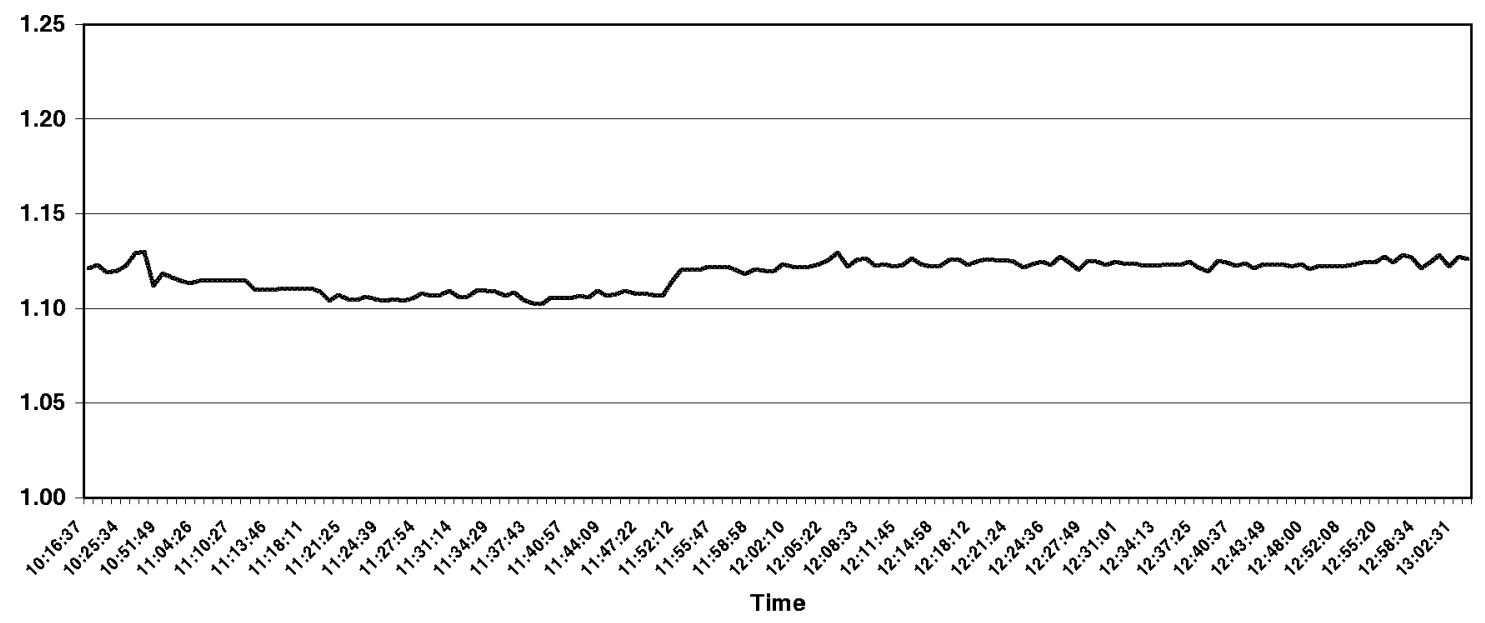

Figure 6-40. Ratio of Engine to Compressor Power; Williams Station 60; February 2004; Day 2 
Figure 6-41 presents the peak-firing pressure and P20 during day 2 (averaged across the cylinders). As before, the P20 is right around 200 PSI. The peak-firing pressure is right around 600 PSI for the 6-degree timing, but increases to almost 700 PSIG with timing of 8 degrees.

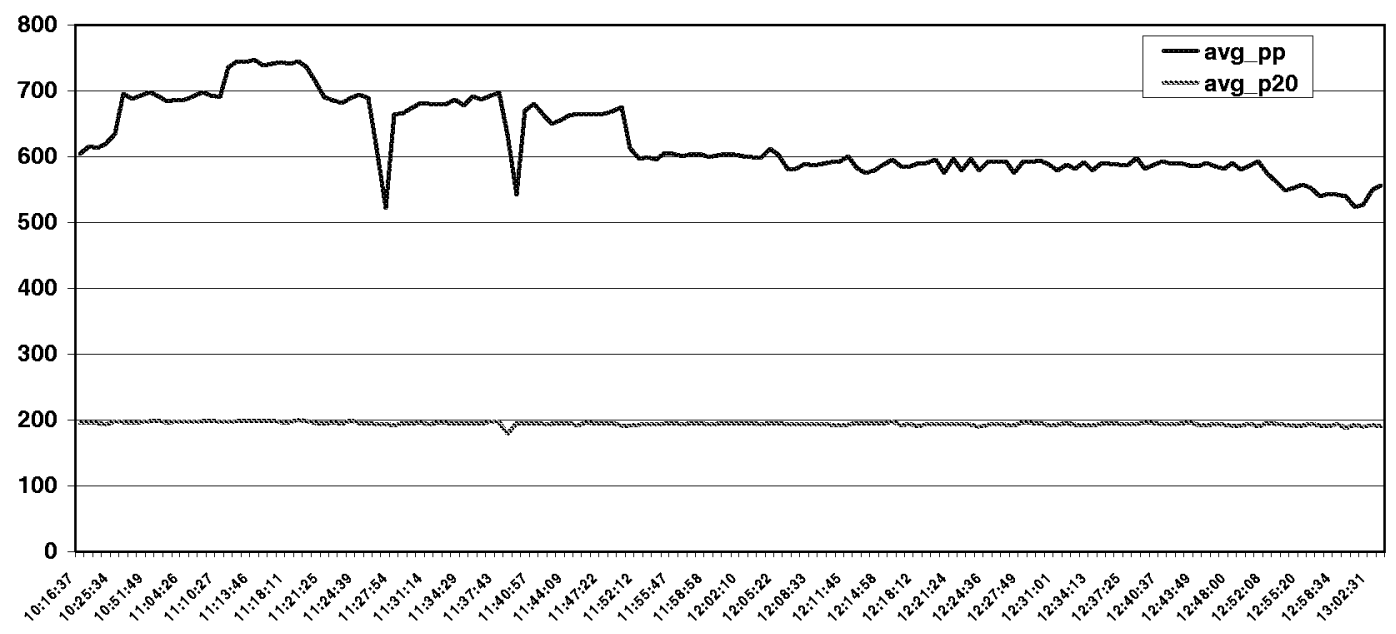

Figure 6-41. Peak-Firing Pressure and Compression Pressure (20 ${ }^{\circ}$ BTDC); Day 2; Williams Station 60; February 2004

Figure 6-42 shows the variation of P20 for individual cylinders; the consistency of individual P20's, and their spread is apparent.

Figure 6-43 presents average standard deviation for cycle-to-cycle variation in peakfiring pressure, together with CPR (ratio of peak-firing pressure to P20). The peak-firing pressure standard deviation starts day 2 in the range 30 to 40 PSI, but increases to lie in the range 40 to 50 PSI for the second half of the test day, when the conditions were mainly steady running with 6 degrees timing. Based on Station 40 results, this standard deviation is expected to increase to 50 or 60 , after the conversion to high-pressure fuel injection. 


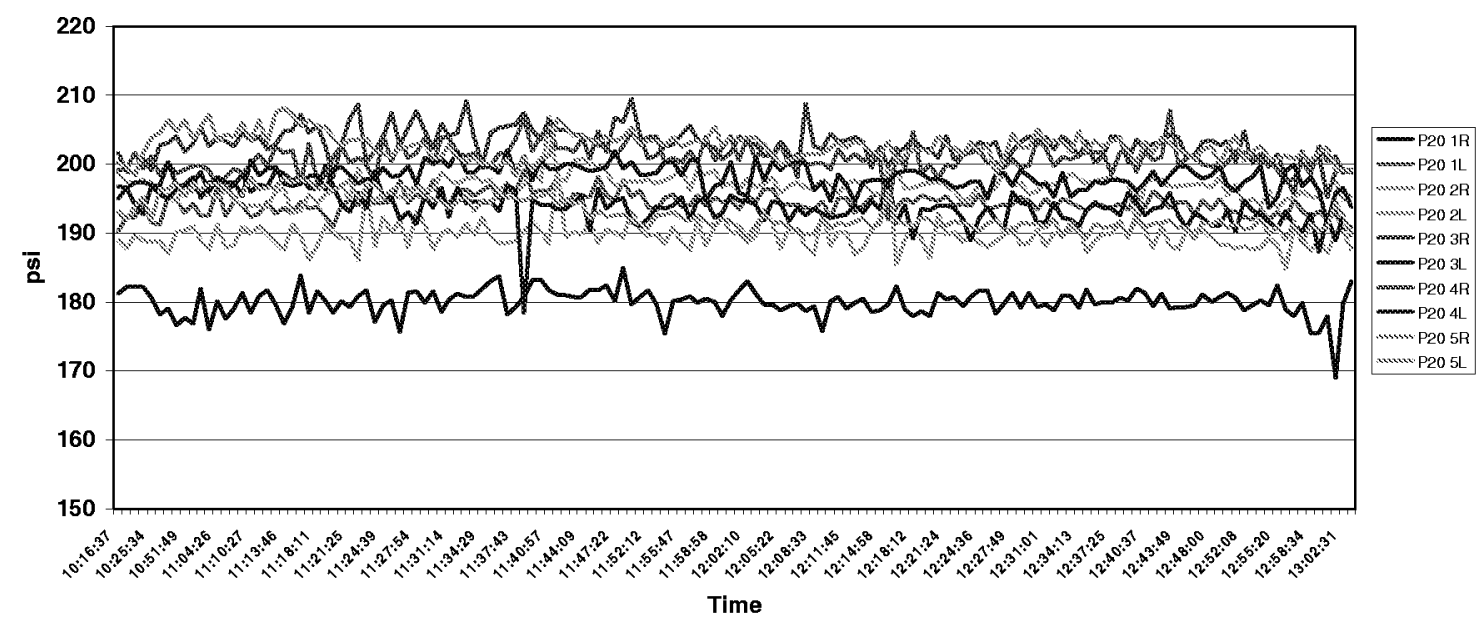

Figure 6-42. Individual Cylinder Compression Pressure; Day 2; Williams Station 60; February 2004

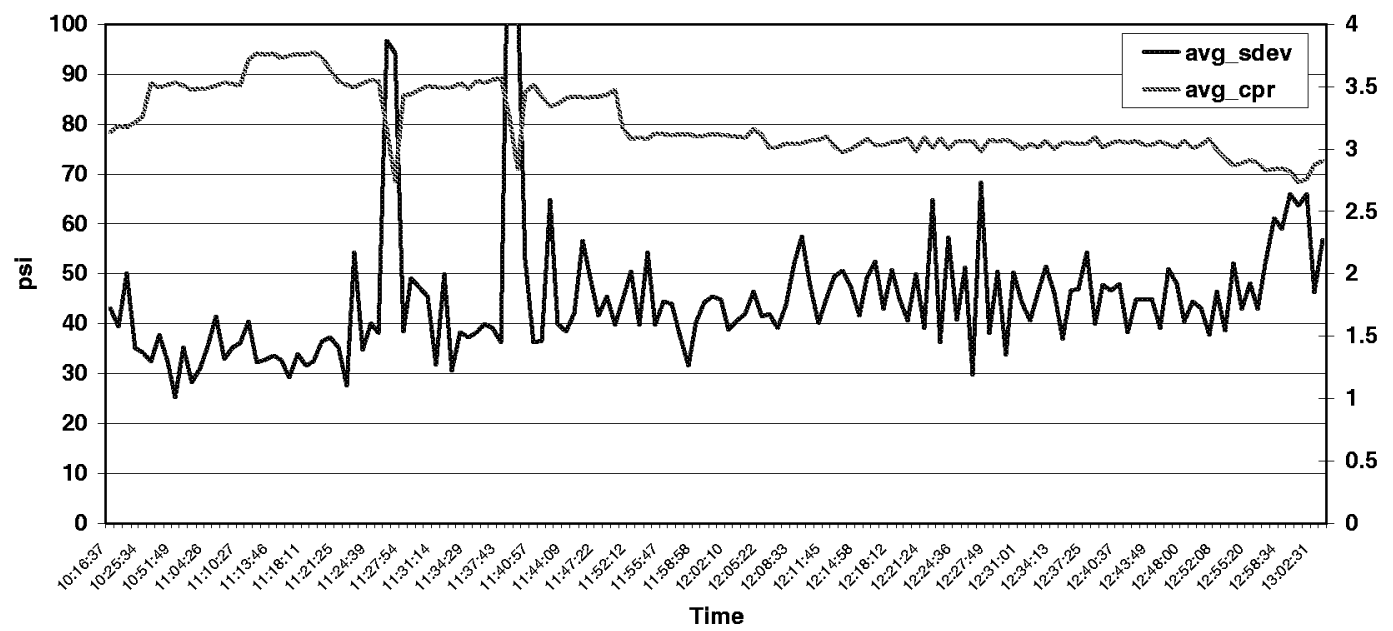

Figure 6-43. Engine Average Cycle-to-Cycle Standard Deviation Estimate; Ratio of PeakFiring Pressure to Compression Pressure (CPR); Day 2; Williams Station 60; February 2004

With the timing advances early in the day, combustion pressure ratio, CPR starts off at about 3.8, but once timing is back at 6 degrees, the CPR remains steady at just about 3 , just as for the previous day. 
Figure 6-44 shows the mean value and standard deviation for compression pressure (P20) in each of the 10 cylinders. The values obtained for these quantities, when averaged over the day, were exactly the same for every cylinder on day 2 , as for the same cylinders on day 1 (see Figure 6-20). This is remarkable consistency for compression pressure.

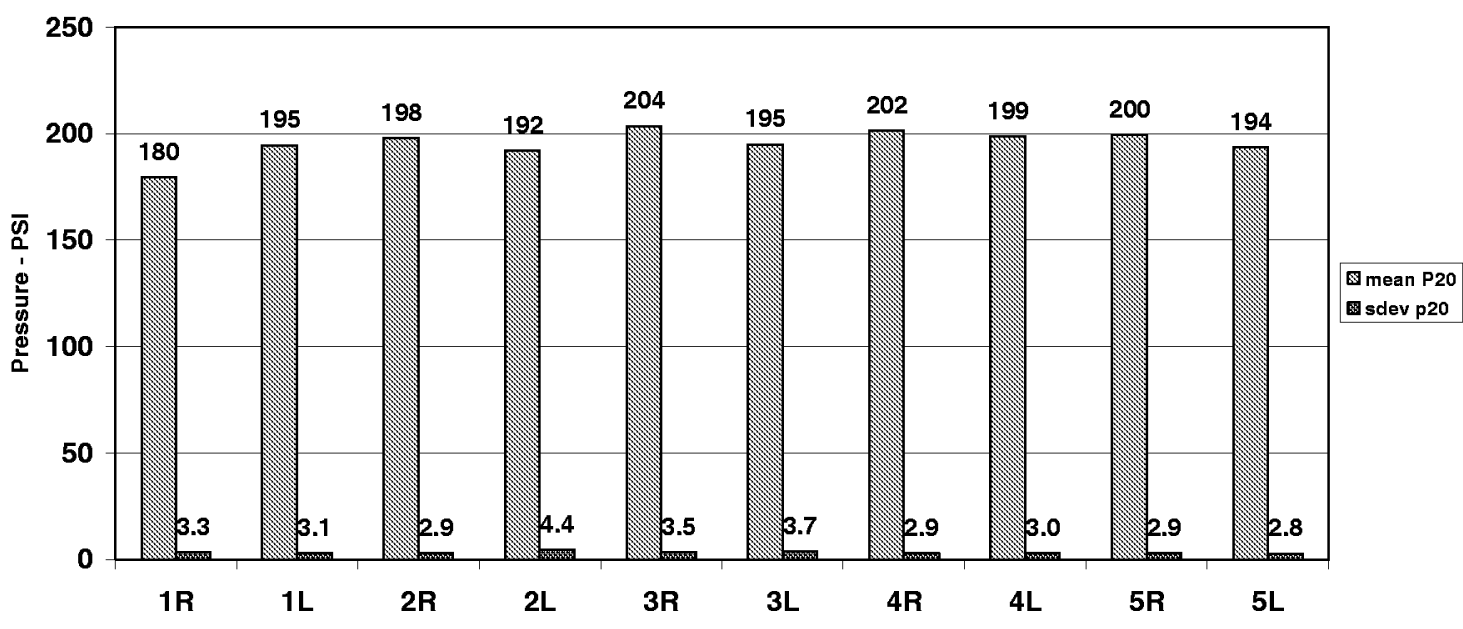

Figure 6-44. Mean and Standard Deviation for P20 (Pressure 20 DBTDC) as a Function of Cylinder; Williams Station 60; February 2004; Day 2

Figure 6-45 shows the average and instantaneous spread in PSI for day 2. As already discussed, these values start higher for day 2 than for day 1 . The average spread starts at 200 PSI and drops to 80 PSI after balancing, a $60 \%$ reduction. The instantaneous spread starts at 280 PSI and drops to about 200 after balancing - a $28 \%$ reduction. This instantaneous spread after balancing is not much different from the instantaneous spread of the previous day.

Figure 6-46 shows the estimate for COV of CPR variation across the cylinders. This drops from almost $9 \%$ prior to any balancing to about $3.7 \%$, and maintains this level quite closely during the second half of the day's testing. This is also approximately a $60 \%$ reduction.

Figure 6-47 shows the variation in location of peak-firing pressure through the day. It varies from average values of 15 to 20 degrees after TDC as timing is changed. It exhibits extremes from 11.25 degrees to 29.5 degrees, indicating wide variance in this quantity. The low of 11.25 degrees does correspond to the time soon after timing was advanced from 6 to 8 degrees. 


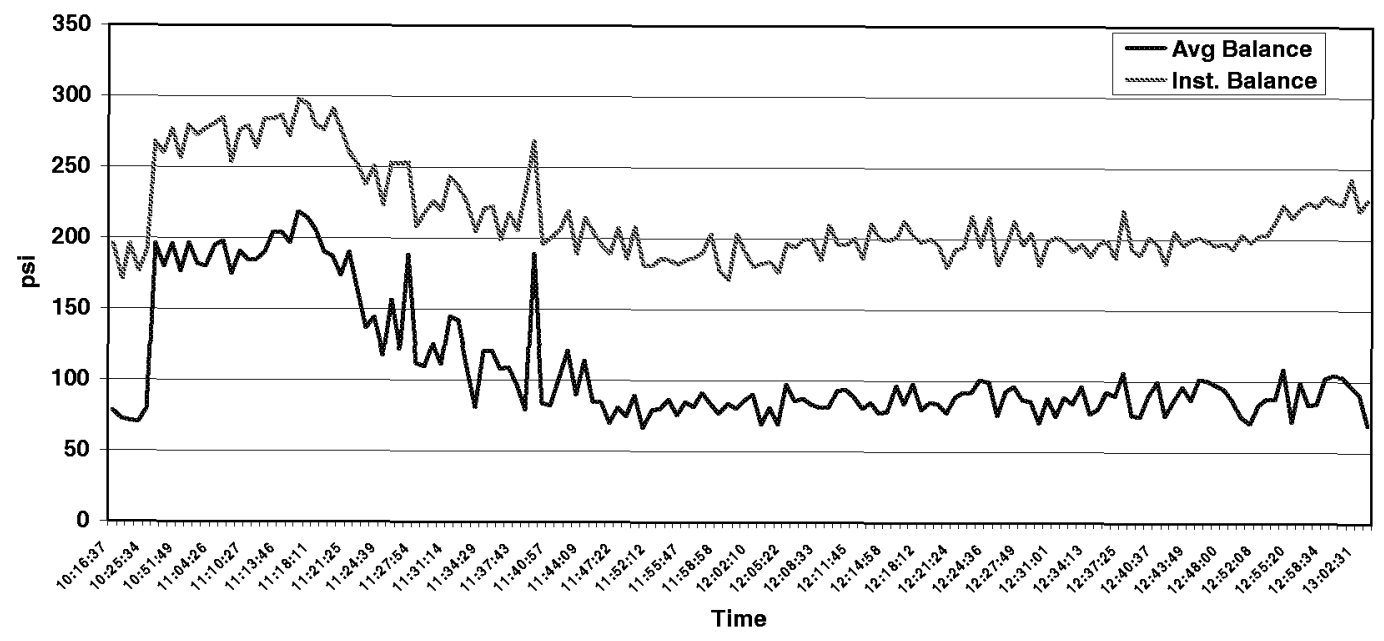

Figure 6-45. Average and Instantaneous Spread in Peak-Firing Pressure; Day 2; Williams Station 60; February 2004

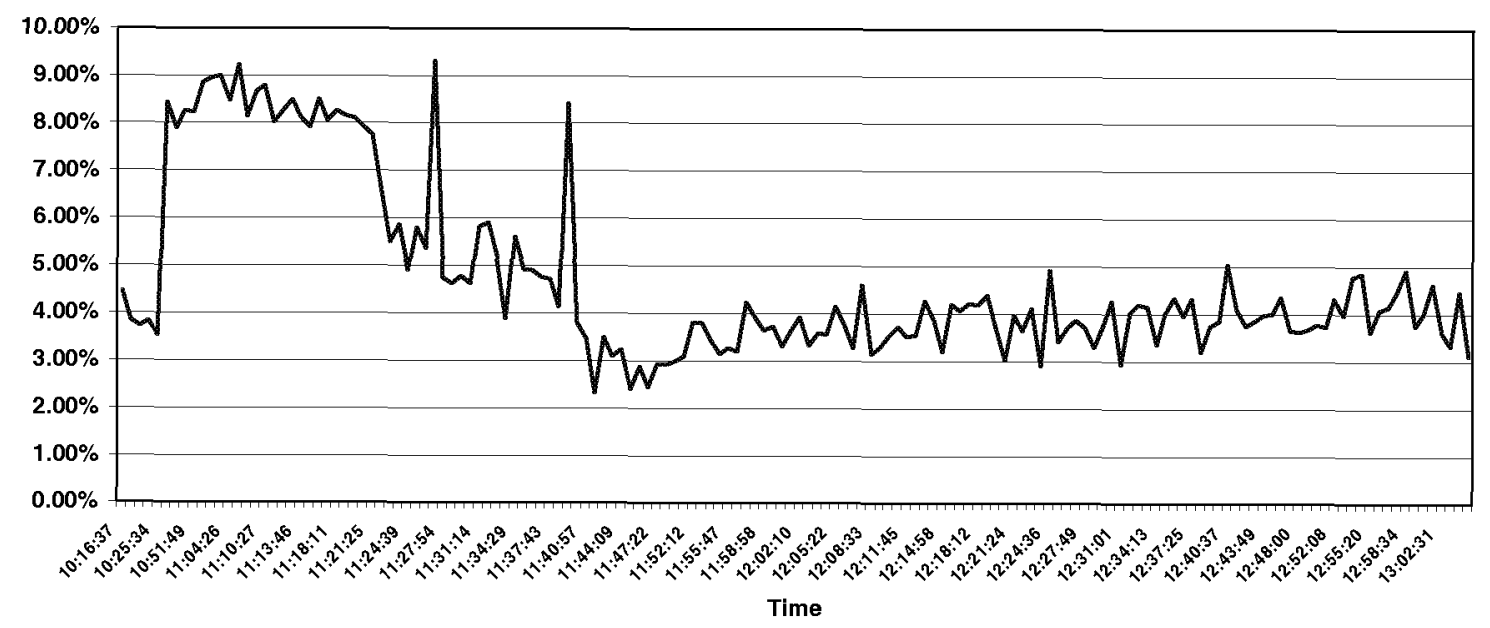

Figure 6-46. Estimate for Coefficient of Variation in CPR; Day 2; Williams Station 60; February 2004 


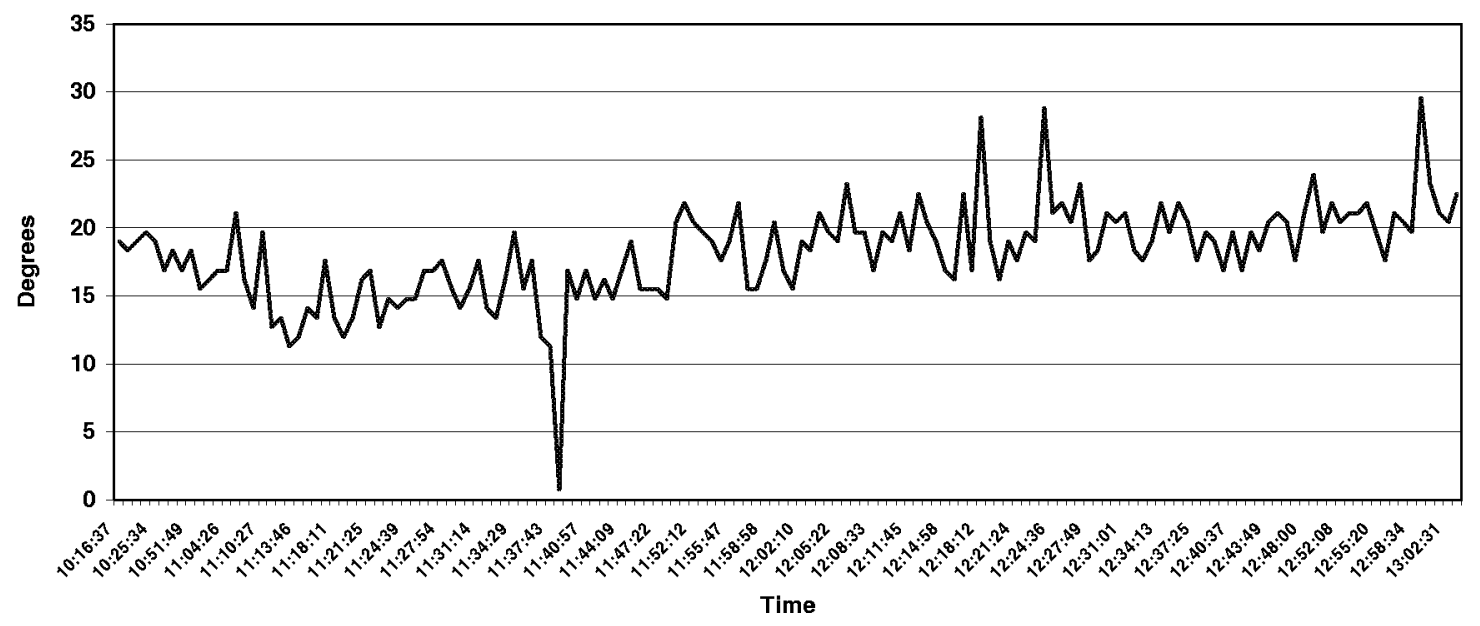

Figure 6-47. Average Location of Peak-Firing Pressure in Degrees after TDC; Day 2; Williams Station 60; February 2004

Vibration data for day 2 is similar to day 1 , and is not replotted.

Figure 6-48 shows a waterfall plot; as on day 1 , the first four orders are noticeably higher than the remainder, with the second order dominating.

Figure 6-49 shows that on day 2 once the unit starts, the strains rapidly set in at 118 microstrain as an average. When the timing is advanced to 8 degrees about 50 minutes after the start, the peak-to-peak microstrains increase to about 140 as a maximum, then start to fall rapidly back to 118 microstrain, after the timing is set back to 6 degrees. Reducing the torque to $94 \%$ is followed by a further reduction in peak-to-peak microstrain to about 110 microstrain. Thus, the impact of timing advance, in addition to its influence on reducing heat rate, is to increase the dynamic load on the crankshaft with possible increase in damage accumulation rate. Again, this unmodified unit is showing higher crankshaft strains than the modified unit tested at Station 40. 


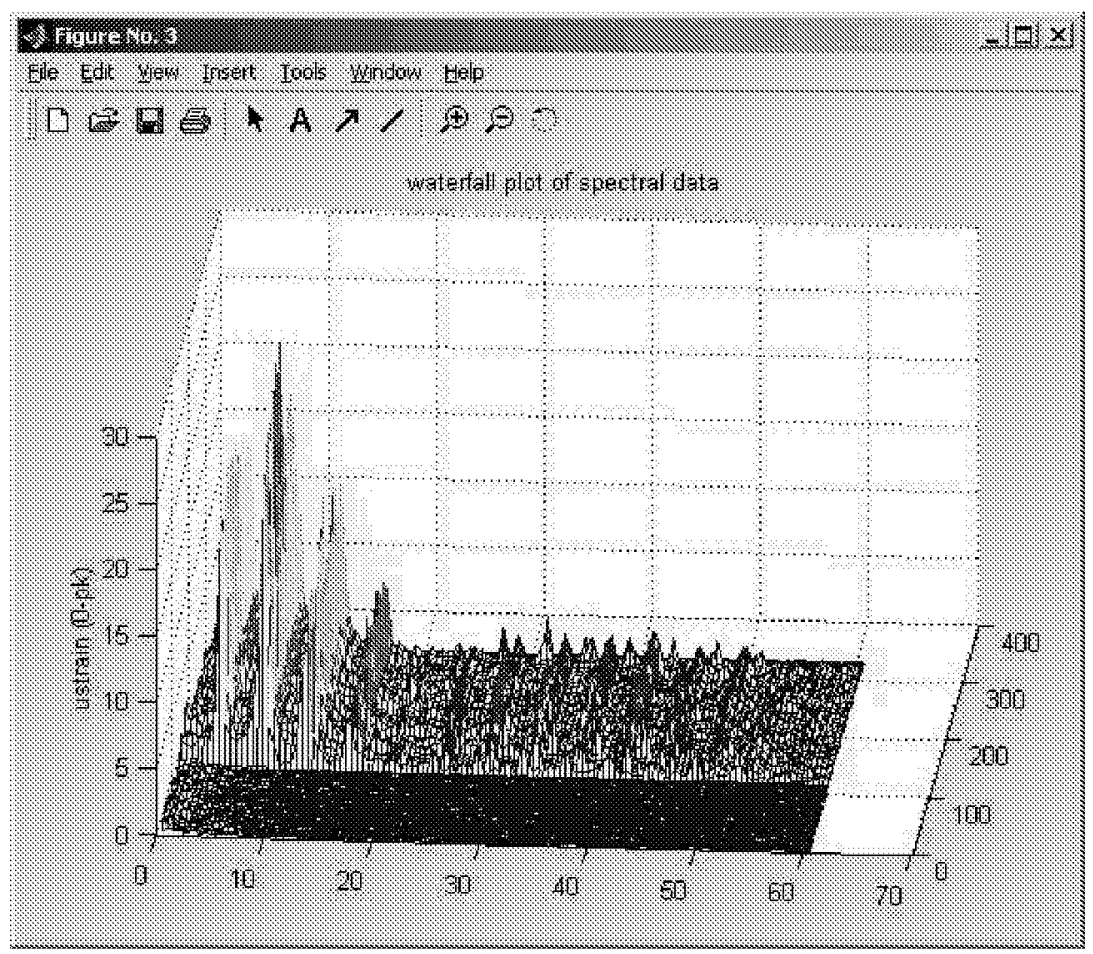

Figure 6-48. Waterfall Plot of Crankshaft Strain; Williams Station 60; February 2004; Day 2

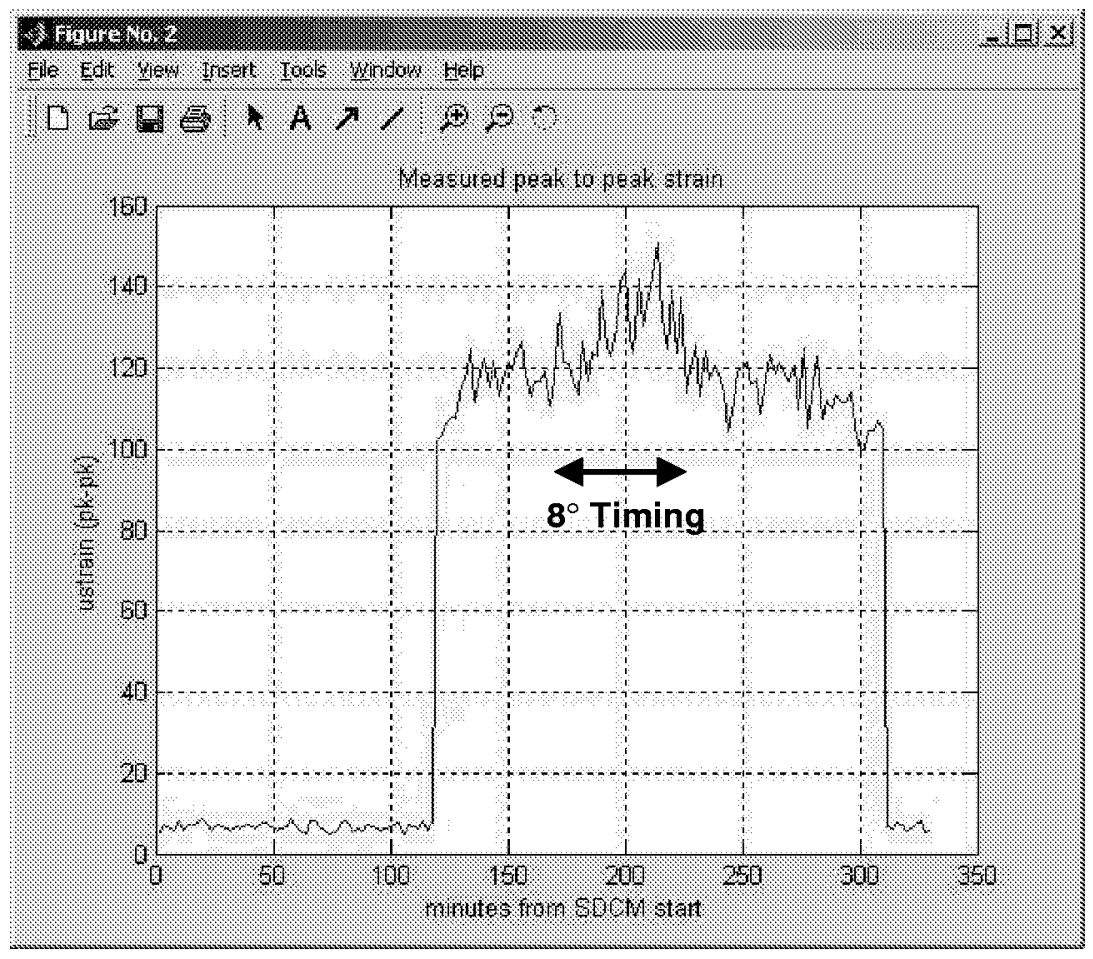

Figure 6-49. Crankshaft Peak-to-Peak Strain; Day 2; Williams Station 60; February 2004

Topical Report

(Reporting Period 01/01/04 - 06/30/04)

DOE Award No. DE-FC26-02NT41646 - SwRI Project 18.06223 


\subsection{SUPPLEMENTARY DATA}

\subsubsection{Emission Equivalence Ratio and Normalized NOx Concentration}

Figure 6-50 and Figure 6-51 present normalized NOx concentration and global equivalence ratio. (Note: This normalized NOx is not brake specific NOx.) In Figure $6-50$, the equivalence ratio stays around 0.375 , with small changes. It appears to respond to timing changes. The day 1 normalized NOx is in the range of 1.85; it follows some of the equivalence ratio change. Figure 6-51 for day 2 shows a lower equivalence ratio of about 0.36 . The normalized NOx generally runs between 1.6 and 1.8 , and follows the changes in equivalence ratio. Both equivalence ratio and NOx drop at the end of the day when torque was cut to $96 \%$.

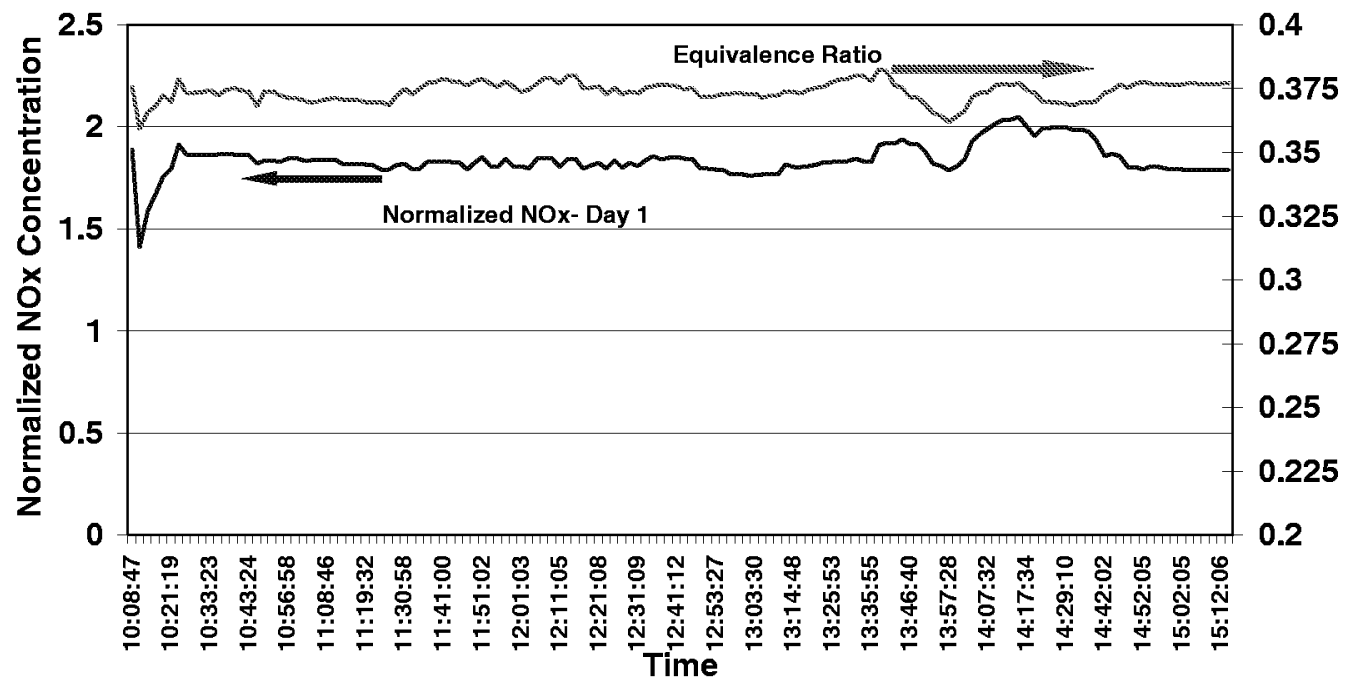

Figure 6-50. Normalized NOx Concentration and Equivalence Ratio; Day 1; Williams Station 60; February 2004 


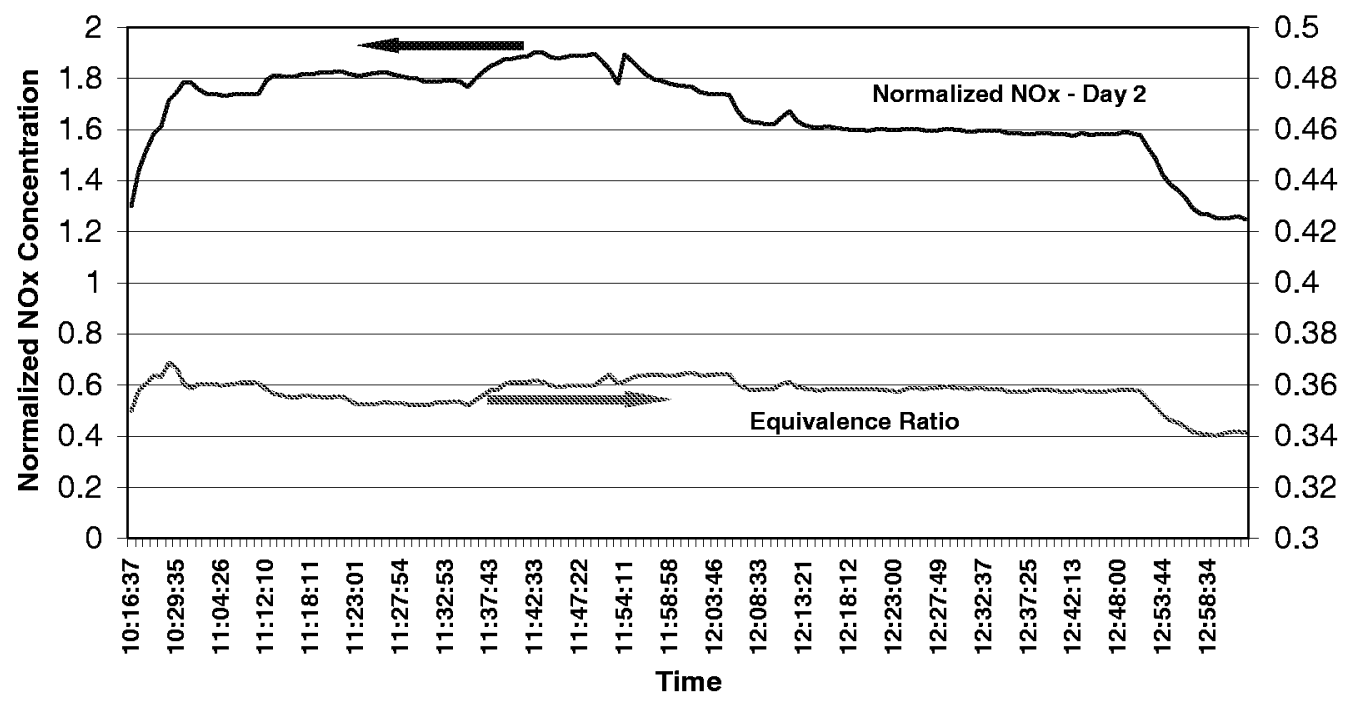

Figure 6-51. Normalized NOx Concentration and Equivalence Ratio; Day 2; Williams Station 60; February 2004

\subsubsection{Air Manifold Pressure}

Figure 6-52 presents the typical variation of air manifold pressure with crank angle. The peak-to-peak variation by almost 2 PSI is clearly higher than the average of about 1.5 . The specific analysis in the lower part of the figure shows "action" to at least 67 orders. 


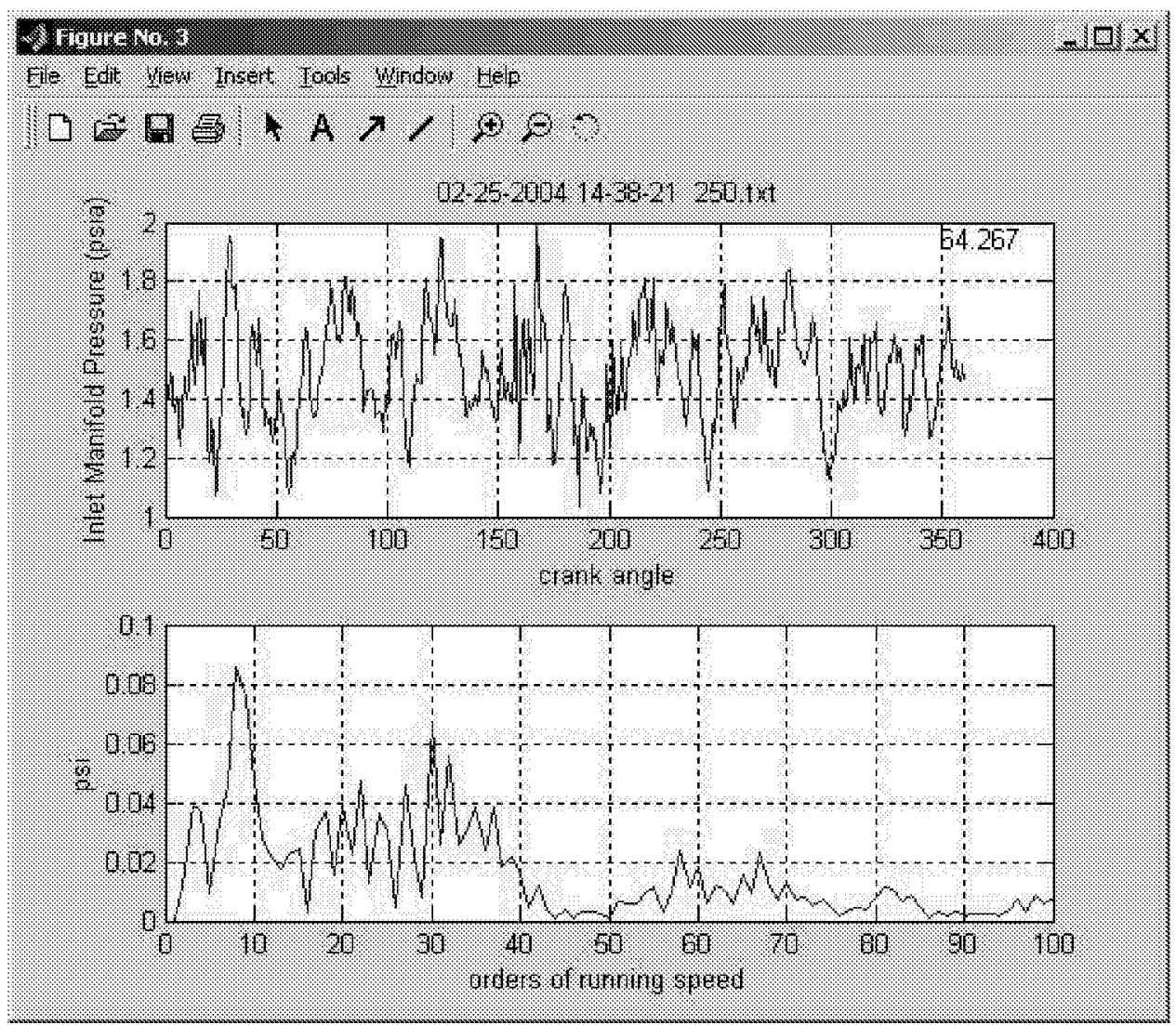

Figure 6-52. Inlet Manifold Pressure; Time Wave and Order Spectrum; Williams Station 60; February 2004; Day 2

\subsubsection{Knock Detection}

Figure 6-53 presents results from the knock detector on day 2, after the knock detector had been moved to power cylinder \#4L. The output increased substantially after timing was advanced to detonation. Both the audible and detected detonation went away after timing was retarded again to 6 degrees. 


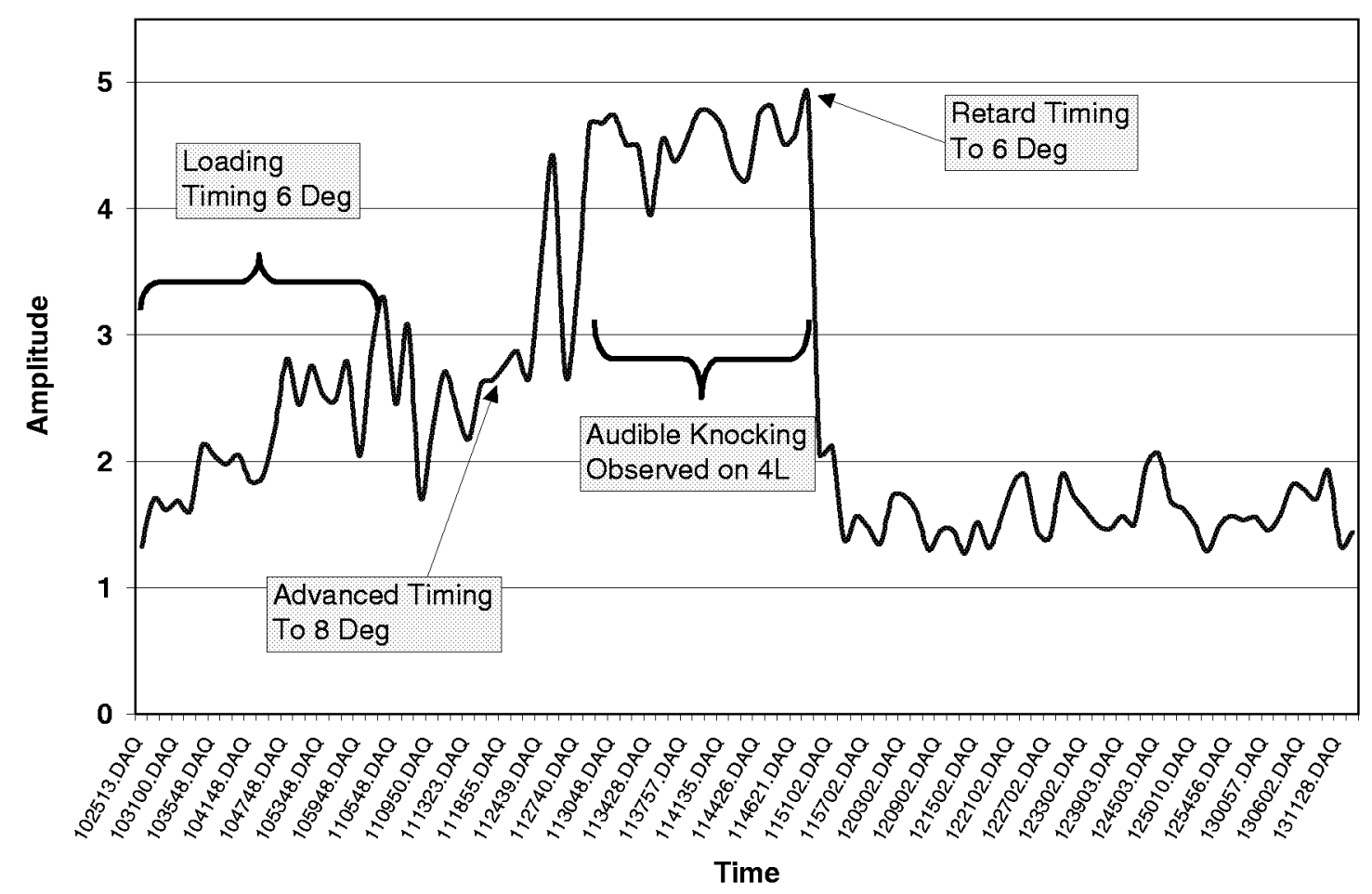

Figure 6-53. Knock Detector Output on Cylinder \#4L; Williams Station 60; February 2004; Day 2

\subsubsection{Comparison of Indicated Power and Station Power}

Figure 6-54 compares the indicated power for the unit based on cylinder pressure measurements with the corresponding values logged from the permanently installed station data system. Clearly, the two data sets compare very closely for most of the day, with occasional small divergence. It is understood that such good comparison is the result of very extensive mapping of the compressor performance over a range of operating conditions. However, such mapping is clearly costly and would have to be repeated if some changes to upgrade the compressor valves or load step controls were implemented. It also will not respond to changes not covered by the mapping process, such as the development of a valve leak. The value of a permanently installed power measurement, such as would be obtained with the rod load monitor in this case, would be to avoid the need for mapping the compressor, and to ensure accurate power and torque numbers even when unmapped changes in condition occurs. 


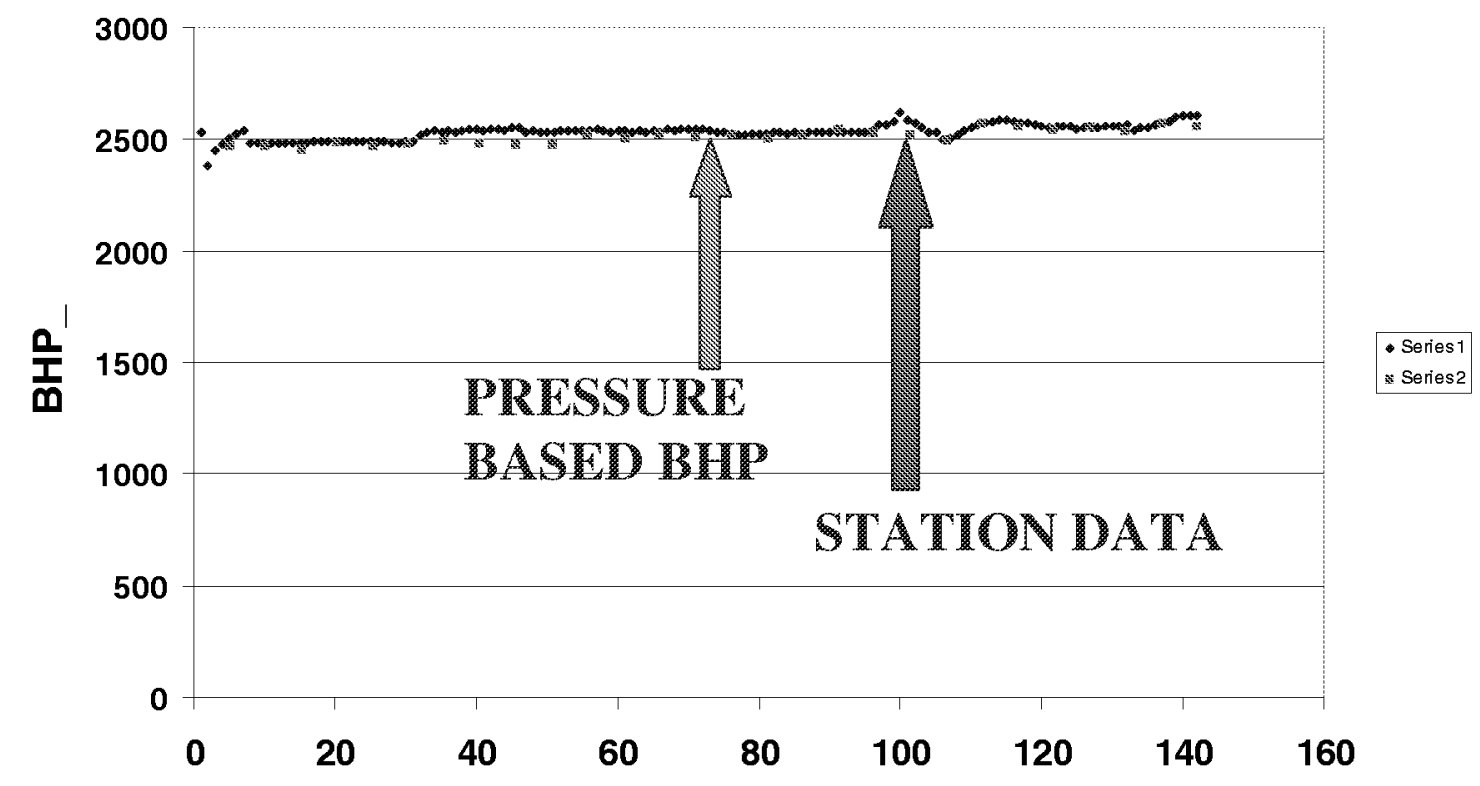

Figure 6-54. Pressure-Based BHP versus Station Data - Williams Station 60

\subsubsection{Performance Summary}

Table 6-1 summarizes the heat rate, normalized NOx, and system thermal efficiency for the unmodified GMW10 tested at Williams' Station 60. Figure 6-55 compares these results from Station 60 with similar results for the modified GMW10 at Williams' Station 40. If tests on the Station 60 unit (after modifications) are similar to Station 40, Figure 6-55 suggests there will be a substantial decrease in heat rate, normalized NOx and equivalence ratio, and a significant increase in system thermal efficiency.

Table 6-1. Summary of Baseline Data; GMW10 - Unmodified

\begin{tabular}{|c|c|c|c|c|c|c|c|c|}
\hline $\begin{array}{c}\text { Day } \\
\text { RPM }\end{array}$ & $\begin{array}{c}\text { Speed, } \\
\text { \% }\end{array}$ & & Timing & AMP & AMT & $\begin{array}{c}\text { Heat Rate } \\
\text { BTU/HP- } \\
\text { Hr. }\end{array}$ & $\begin{array}{c}\text { Normalized } \\
\text { NOx }\end{array}$ & $\begin{array}{c}\text { System } \\
\text { Thermal } \\
\text { Efficiency, \% }\end{array}$ \\
\hline 1 & 250 & $102 \%$ & $6^{\circ}$ & $3.5^{\prime \prime} \mathrm{Hg}$ & $102^{\circ} \mathrm{F}$ & $7477 \pm 14$ & $1.818 \pm 0.019$ & $27.31 \pm 0.0005$ \\
\hline 2 & 250 & $102 \%$ & $6^{\circ}$ & $3.5^{\prime \prime} \mathrm{Hg}$ & $96^{\circ} \mathrm{F}$ & $7526 \pm 11$ & $1.660 \pm 0.091$ & $27.11 \pm 0.04$ \\
\hline 2 & 250 & $101 \%$ & $8^{\circ}$ & $3.5^{\prime \prime} \mathrm{Hg}$ & $96^{\circ} \mathrm{F}$ & $7418 \pm 16$ & $1.825 \pm 0.036$ & $27.53 \pm 0.06$ \\
\hline 2 & 250 & $96 \%$ & $6^{\circ}$ & $3.5^{\prime} \mathrm{Hg}$ & $95^{\circ} \mathrm{F}$ & $7566 \pm 35$ & $1.395 \pm 0.140$ & $26.99 \pm 0.13$ \\
\hline
\end{tabular}




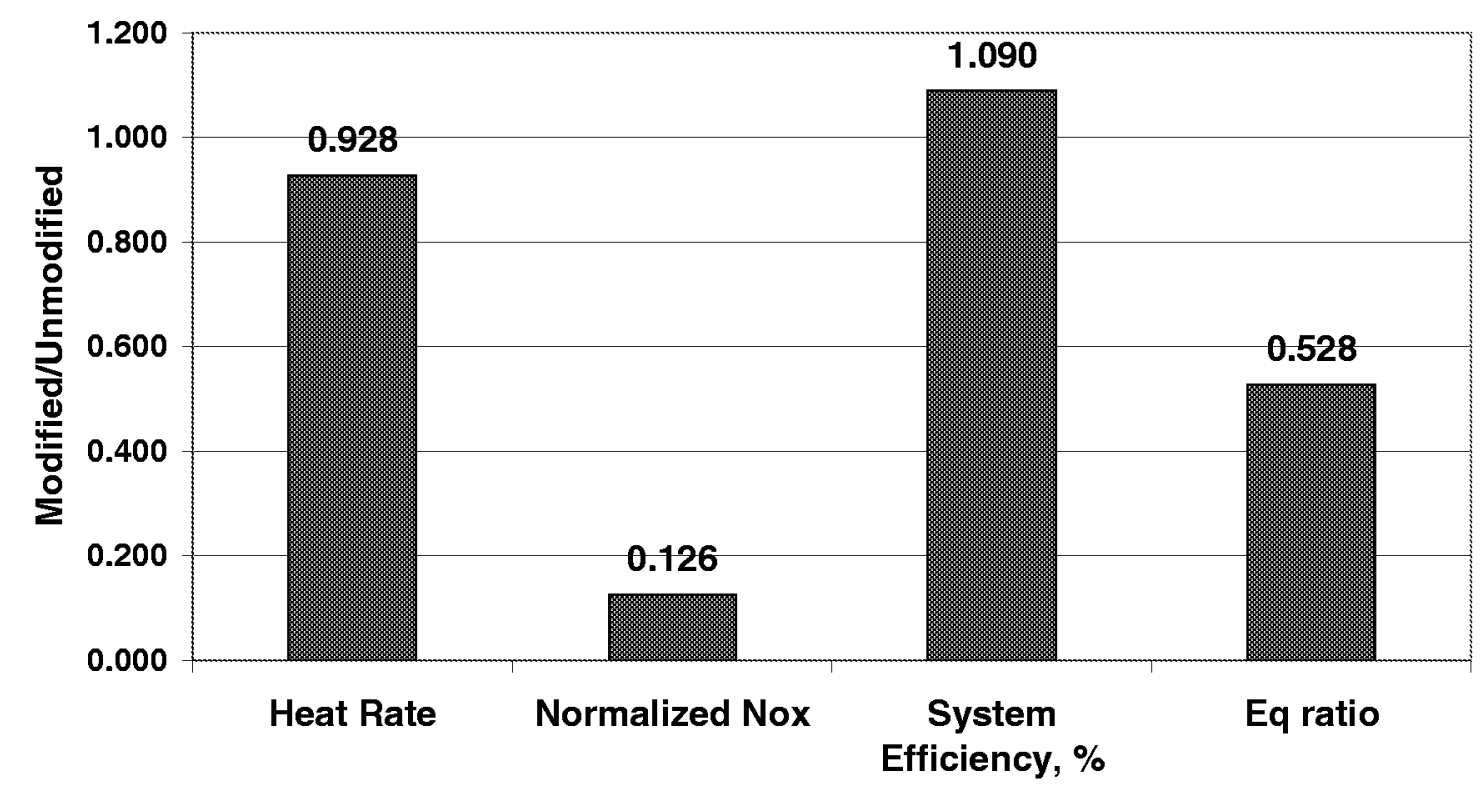

Figure 6-55. Ratio of Performance for Modified GMW10 (Turbo + High-Pressure Fuel) to Another Unmodified GMW10; 8 BTDC Timing

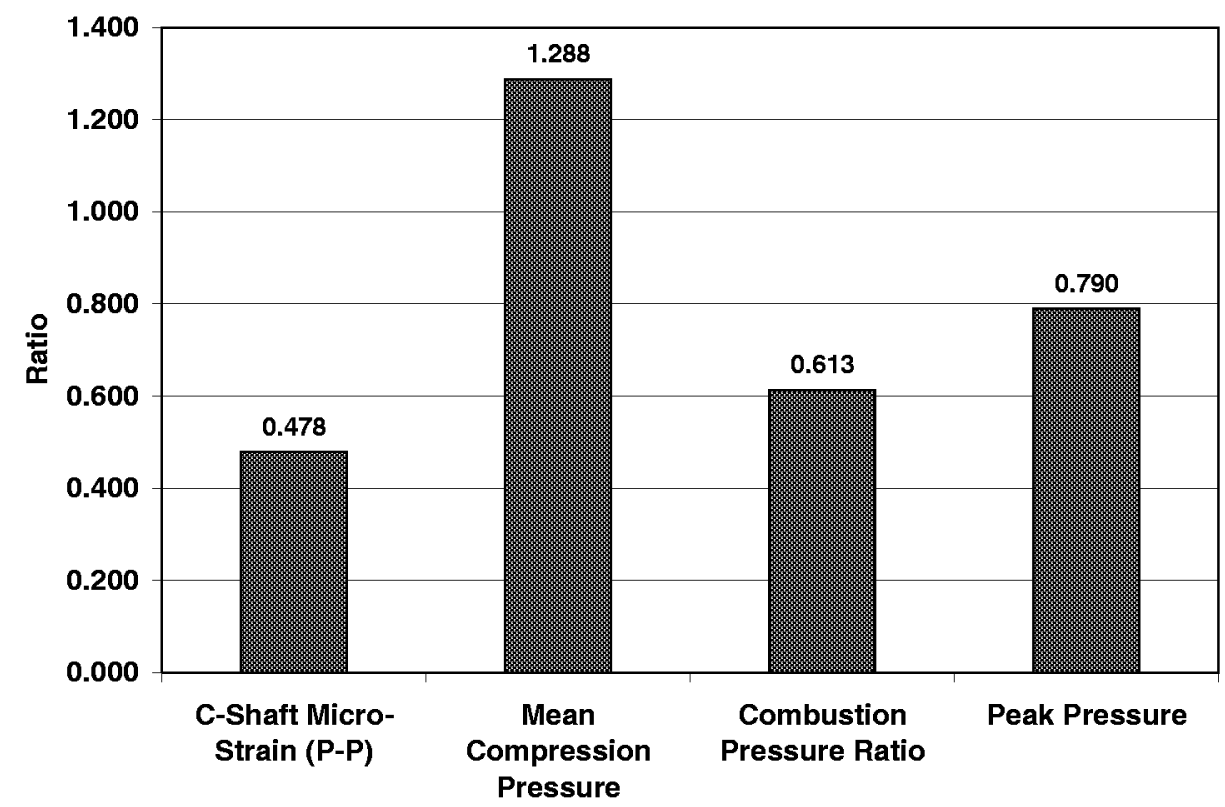

Figure 6-56. Crankshaft Strain, Mean Compression Pressure, Combustion Pressure Ratio, and Peak Pressure; Ratio of Typical Values for GMW10 Modified for High-Pressure Fuel + Turbocharger Compared to Unmodified GMW10 


\subsubsection{Comparison of Pressures and Strains}

Table 6-2 presents some supplementary comparisons of data from the modified GMW10 at Station 40, with the unmodified unit at Station 60. It shows typical or average values for crankshaft strain, compression pressure (pressure 20 degrees BTDC), combustion pressure ratio $(\mathrm{CPR}=\mathrm{PFP} / \mathrm{P} 20)$, and peak-firing pressure (PFP calculated from the CPR and compression pressure values in the table). The data is not precise since it involves averaging and the crankshaft strain locations may not be exactly the same on the two units. However, the trend directions are correct.

Table 6-2. Stations 60 and 40: Additional Data Comparisons for Crankshaft Strain, Compression Pressure, Combustion Pressure Ratio, and Peak Pressure

\begin{tabular}{|c|c|c|c|c|c|}
\hline & & $\begin{array}{l}\text { Crankshaff } \\
\text { Microstrain }(\mathrm{P}-\mathrm{P})\end{array}$ & $\begin{array}{l}\text { Mean compression } \\
\text { Pressure }\end{array}$ & $\begin{array}{l}\text { Combustion Pressure } \\
\text { Ratio }\end{array}$ & Peak Pressure \\
\hline Station 40 & High Pressure + Turbo (Station 40) & 55 & 255 & 1.84 & 469 \\
\hline \multirow[t]{2}{*}{ Station 60} & Unmodified (Station 60) & 115 & 198 & 3 & 594 \\
\hline & Ratio: Modified to Unmodified & 0.478 & 1.288 & 0.613 & 0.790 \\
\hline
\end{tabular}

Table 6-2 shows that the modifications substantially reduced crankshaft peak-to-peak strain on these two units; the turbocharger increased compression pressure by over $20 \%$; the combustion pressure ratio was substantially lower on the modified unit, both because the peak-firing pressure is lower, and because the compression pressure is higher; the peak-firing pressure was lower on the modified unit by about $20 \%$.

The ratios between the data values for the modified unit and the unmodified unit are presented in Figure 6-56. These show crankshaft strain and peak-firing pressure on the modified unit at $48 \%$ and $79 \%$ of the corresponding values from the unmodified unit, respectively. Although these comparisons are on different units at different stations, similar benefits are expected when the unit at Station 60 is tested after modifications. 


\section{RESULTS AND DISCUSSION: SECOND TEST OF HBA-6T}

This section of the report presents results from the second series of tests performed on an HBA-6T at El Paso's Kinder Station 823. Test objectives included:

- Feasibility Analysis for Wastegate/Global Equivalence Ratio Control

- Evaluation of Timing Advance

- Evaluation of a Detonation Detection in Conjunction with Timing Advance

- Refinement and Evaluation of Combustion Pressure Ratio Balancing

- Further Testing of the Rod Load Monitor

- Documenting the Need for a Rod Load Monitor

The following sub-sections present installation photographs; data obtained with permanently installed station instruments; data obtained with instrumentation installed temporarily for the tests; strain data capture module data; heat rate summaries; analysis of heat rate as a function of load; rod load monitor evaluation; knock detection; potential integrity indicators based on instantaneous rotational velocity; display of system and component thermal efficiencies; demonstration and refinement of combustion pressure ratio balancing; and comparison of station $\mathrm{BHP}$ to $\mathrm{BHP}$ from cylinder pressure.

\subsection{INSTALLATION PHOTOGRAPHS}

Figure 7-1 shows the four compressor cylinders with suction manifold bottle above them and cabling to the cylinder pressure sensors apparent. Close inspection shows the temperature sensors in the discharge nozzles below the cylinders. Figure 7-2 shows the power cylinders. Close inspection shows the pressure sensors installed. Figure 7-3 is a back view of the unit. It shows a full bed grout - some units at the station including the one previously tested have been regrouted on chock mounts.

Figure 7-4 shows pressure transducers installed on one compressor cylinder - head and crank ends. Figure 7-5 shows a power cylinder pressure sensor. Figure 7-6 shows the air manifold and the air manifold pressure sensor installed at one end.

Figure 7-7 is a composite of four photographs showing the elements of the wastegate control to maintain a global equivalence ratio set point. The sensor is a $\mathrm{NGK}_{2}$ sensor in the stack. The PID controller is from Honeywell (a UDC 3000 Universal Digital Controller). The 4 to $20 \mathrm{~mA}$ output is connected to a current-to-pressure converter with feedback from the $\mathrm{O}_{2}$ sensor. The pressure signal actuates the wastegate through the existing station pneumatic control system. The controller has both manual and automatic modes. For permanent installation, the controller would likely be a Woodward 723, which is already used in compressor stations and could be programmed with safeties, start-up/shutdown procedures, and a default fuel air curve - if the NGK signal is lost. 


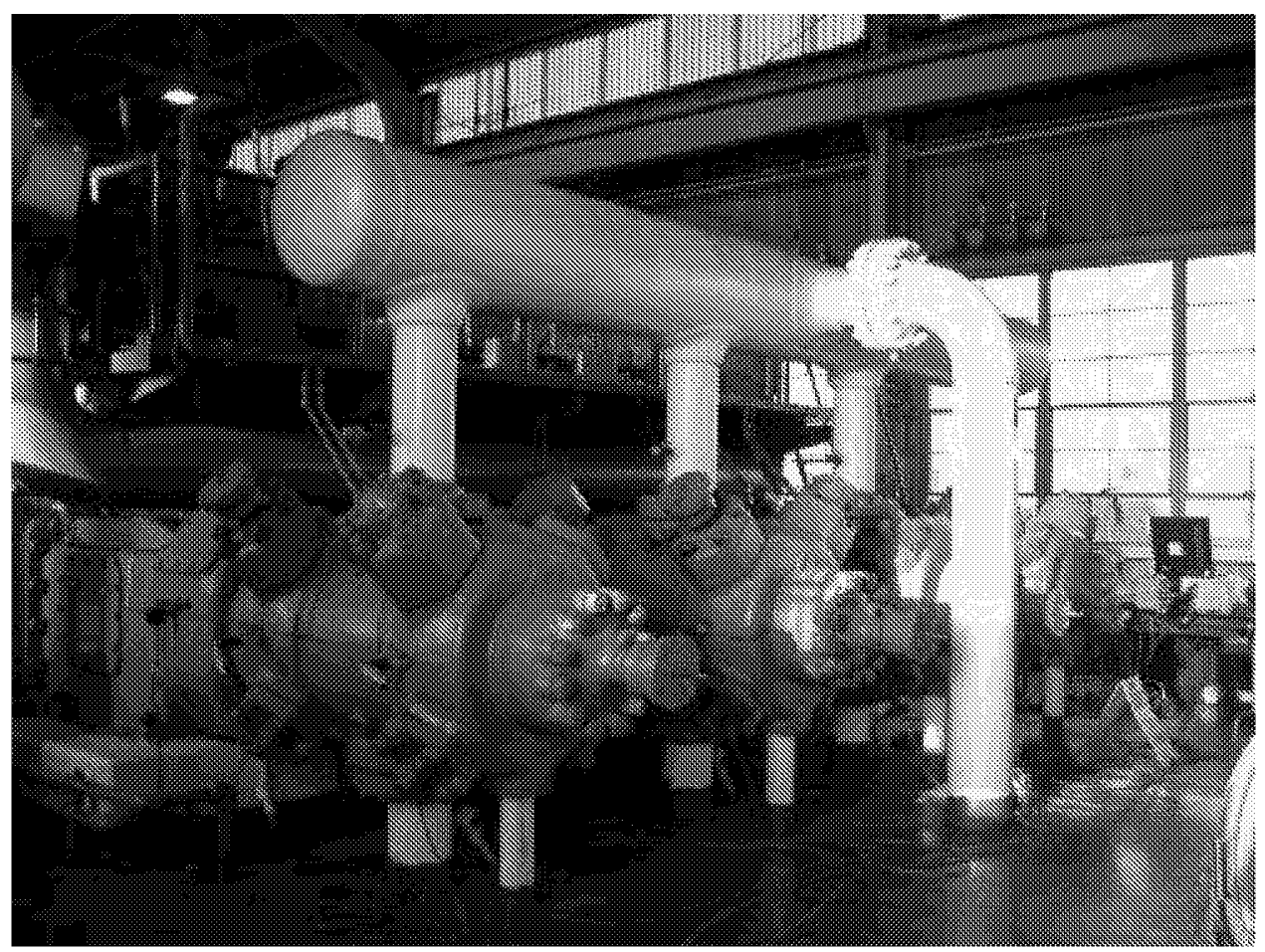

Figure 7-1. Compressor Cylinders; HBA-6T at El Paso Station 823; April 2004

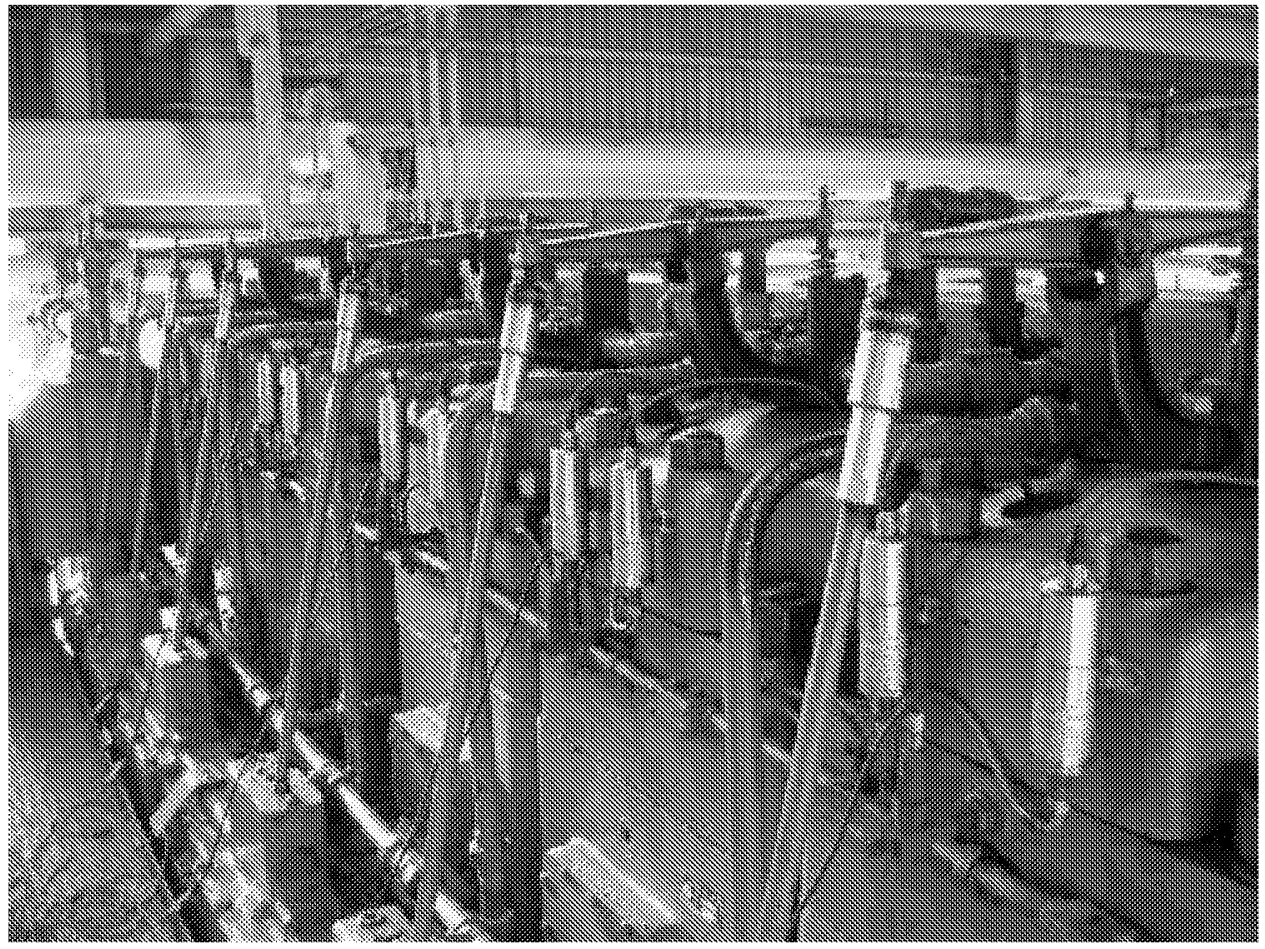

Figure 7-2. Power Cylinders; HBA-6T at EI Paso Station 823; April 2004 


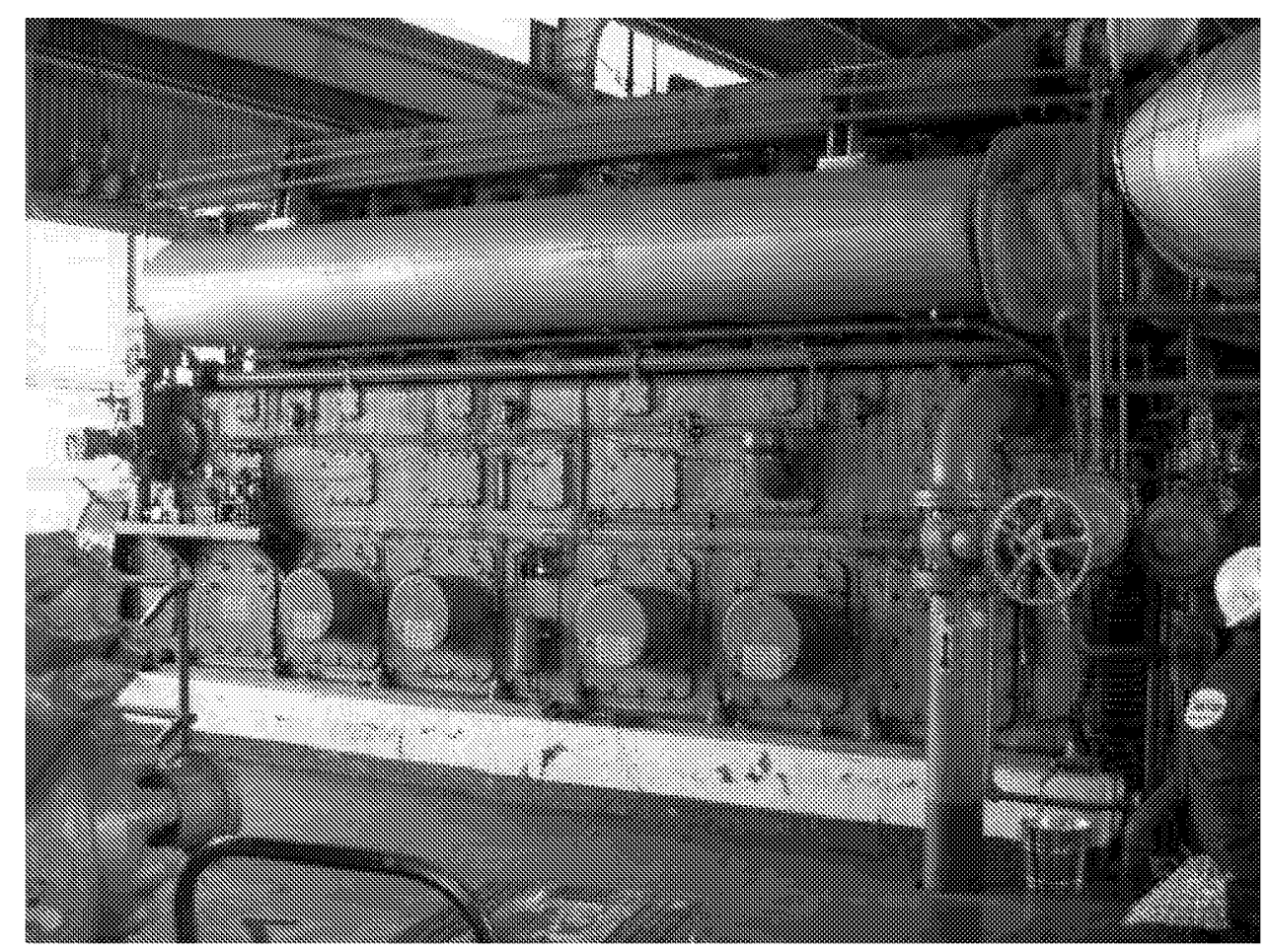

Figure 7-3. Back View of Engine; HBA-6T at EI Paso's Station 823; April 2004

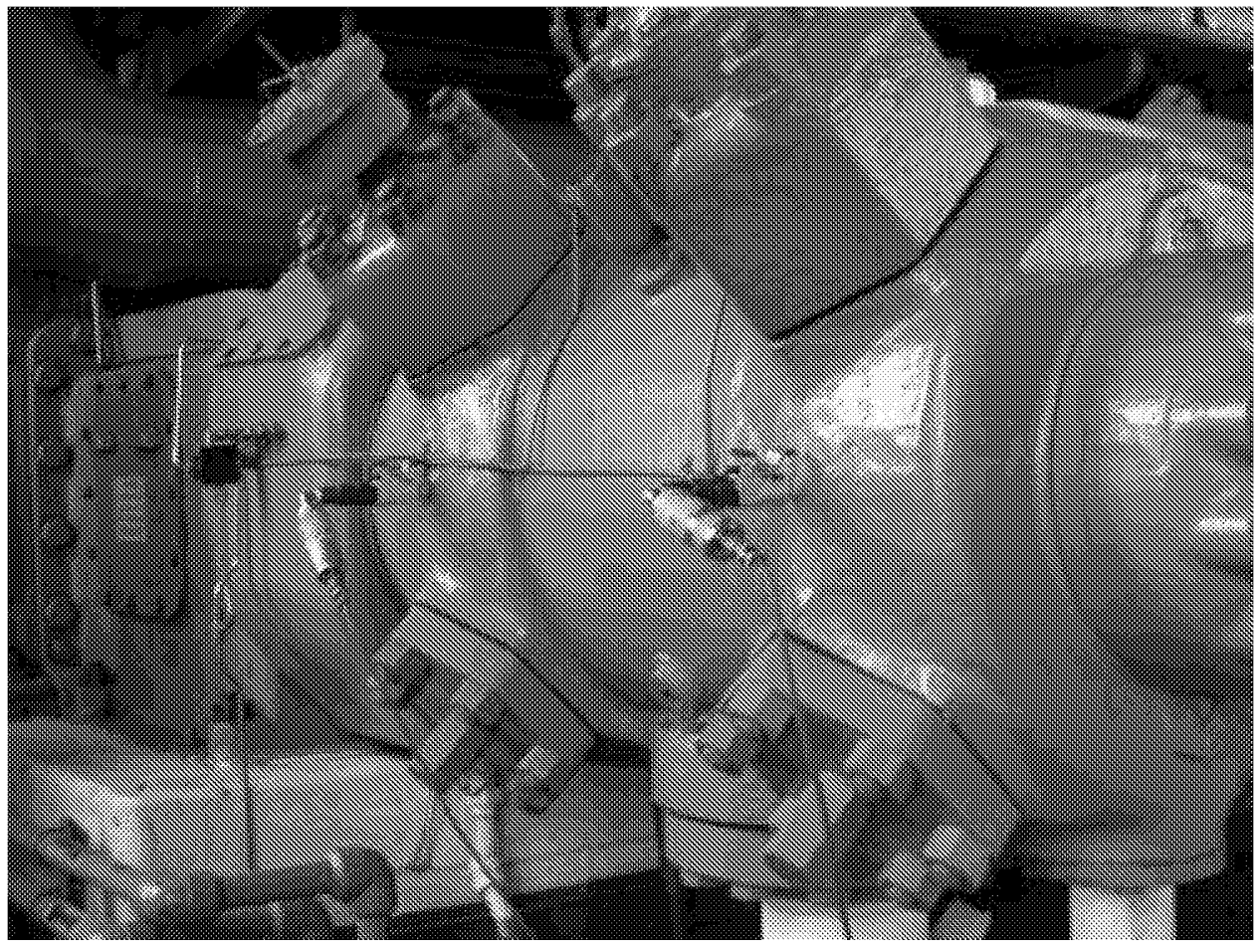

Figure 7-4. Compressor Cylinder with Pressure Transducers Installed on Head and Crank Ends; HBA-6T at El Paso's Station 823; April 2004 


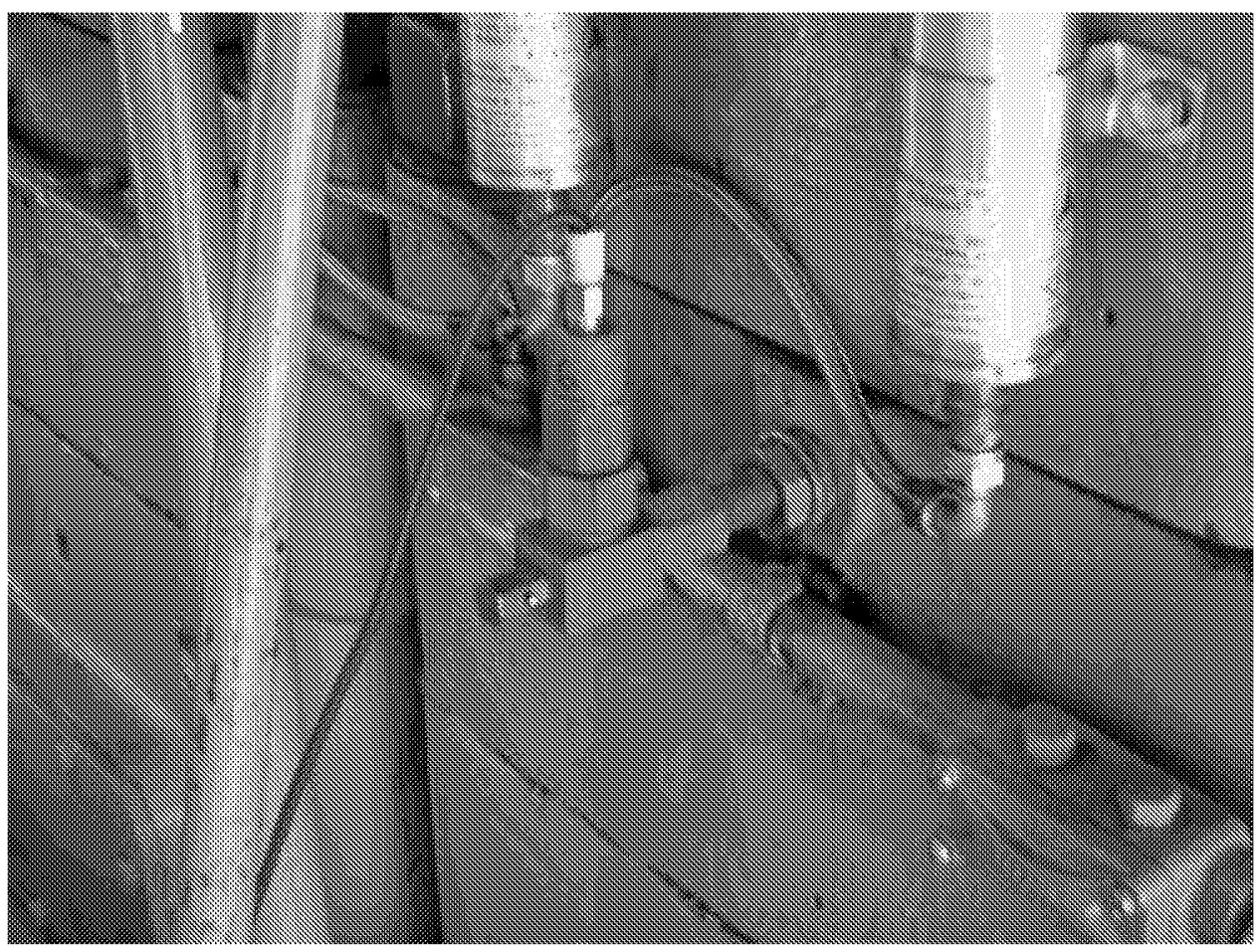

Figure 7-5. Power Cylinder Pressure Transducer; HBA-6T at El Paso's Station 823; April 2004

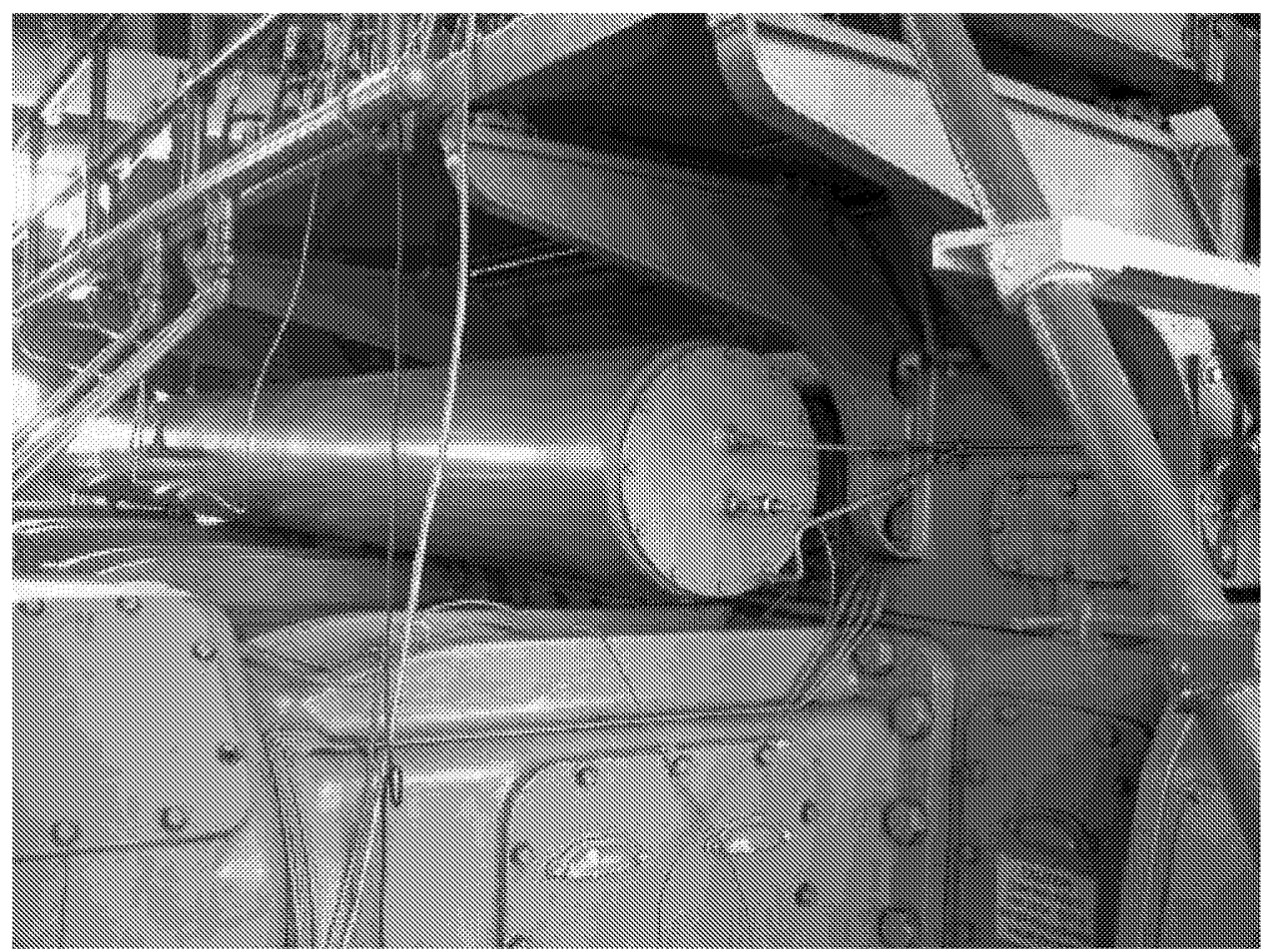

Figure 7-6. Air Manifold Pressure Transducer; HBA-6T at EI Paso's Station 823; April 2004 

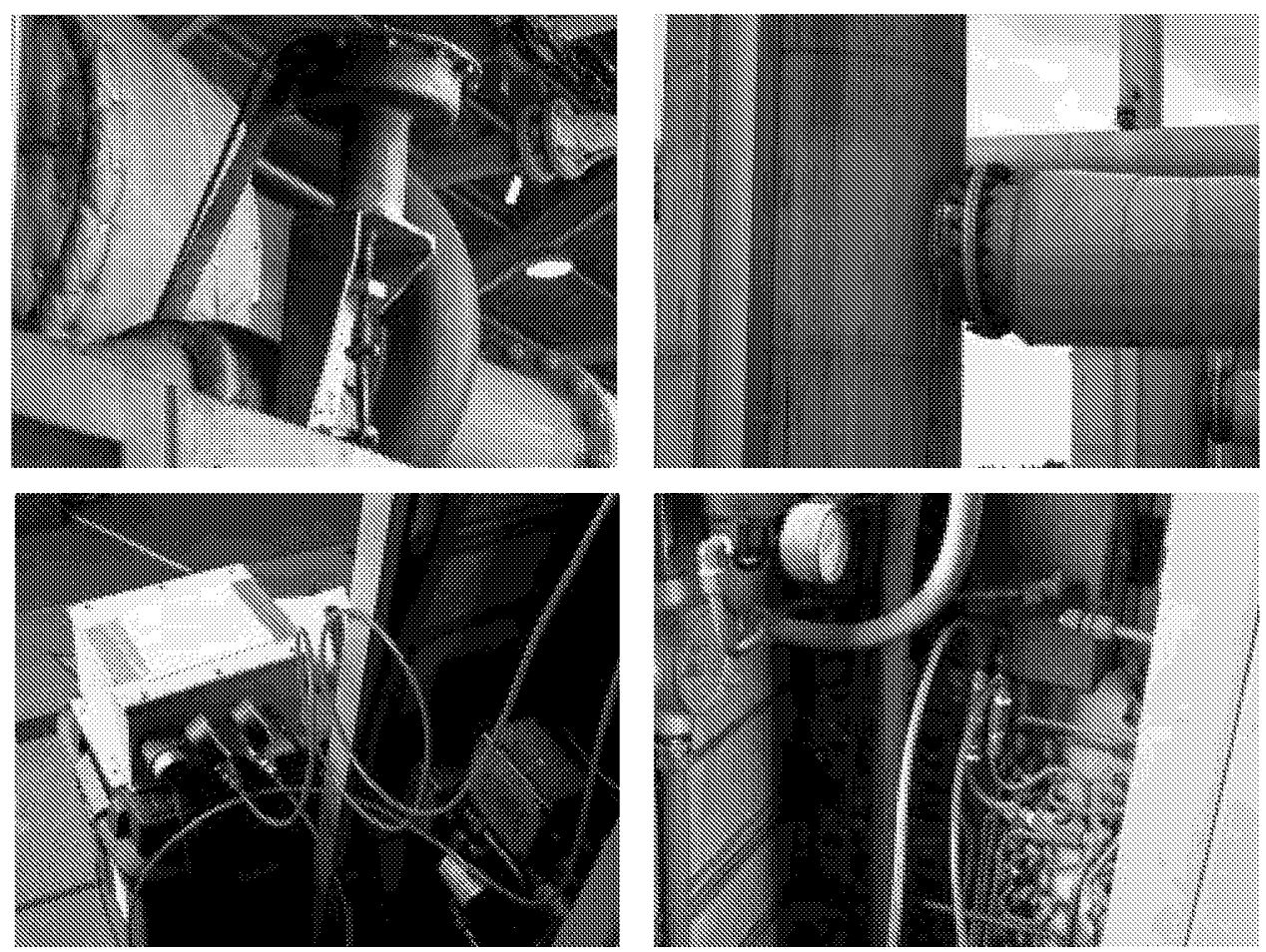

Figure 7-7. Element of Wastegate Control for Equivalence Ratio; HBA-6T at EI Paso's Station 823; April 2004

The wastegate/equivalence ratio controller will need a supplementary system to detect knock. This will allow timing to be advanced back to OEM specifications, and yet prevent knock by temporary retardation in the event knock is detected as a result of changing ambient conditions or insufficient boost capacity. Option for knock detection will be evaluated in later subsections of this report.

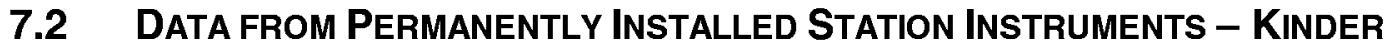 SECOND TEST}

After installation and checkout of instrumentation, two productive days of testing were performed. Much of the data will be presented as pairs of plots as a function of time for day 1 and day 2 . Following this, some supplementary analyses will be presented.

Data from most temporarily installed instruments was recorded as usual with the project data acquisition system. In addition, data from the detonation detector and from the rod load monitor was separately recorded. The crank strain data capture module has its own data acquisition system installed on the crankshaft, and this data has been separately analyzed.

Data from the station instruments was manually logged and entered into a spreadsheet. This data will first be presented and discussed below. 
Figure 7-8 and Figure 7-9 show the variation of several station temperatures - lube oil outlet temperature, air manifold temperature, gas suction header and gas discharge header temperatures. On both days, the lube oil outlet temperature rises by about 20 degrees to between 155 and $160^{\circ} \mathrm{F}$ over the first 1-2 hours as the sump heats up. Once the initial rise is over, this temperature stays relatively constant over the day. On day 1 , the other temperatures are remarkably constant. On day 2, the air manifold temperature rises by about 8 degrees during the middle of the day; also, the discharge temperature drops because the ratio across the machine drops between 12:30 and 1:00 PM, as will be seen in subsequent figures.

Figure 7-10 and Figure 7-11 show the variation of suction and discharge pressures for the unit, together with their ratio and unit speed. The suction and discharge pressures vary by small amounts during the day, and this shows up as noticeable changes in compression ratio across the unit. On day 2 , the pressure changes are more pronounced. At around 1:00 PM, the ratio drops, and then between 2:30 and 4:00, it steadily rises again.

Close examination of the speed plots shows the speed changes implemented as part of the test plan. These speed changes will be presented on an expanded scale based on revolution timing by SwRI's data acquisition system in subsequent plots.

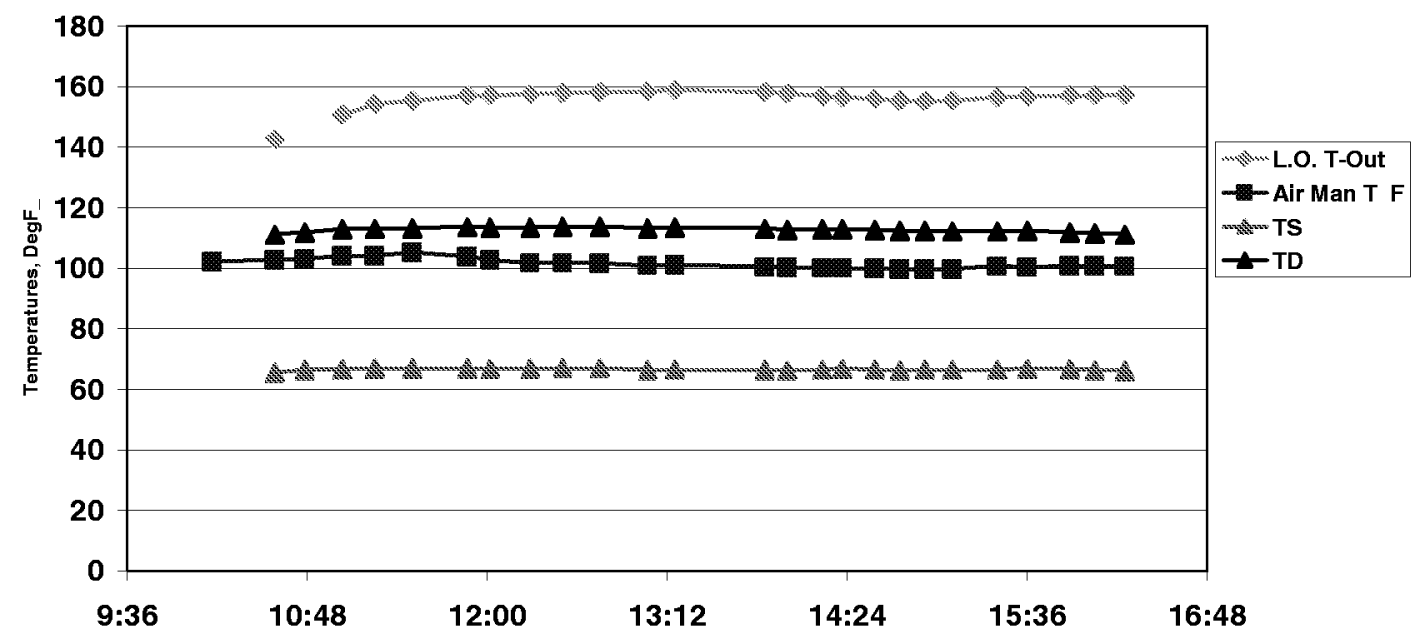

Figure 7-8. Station Data Temperatures; Kinder Test 2; Day 1 (April 21, 2004) 


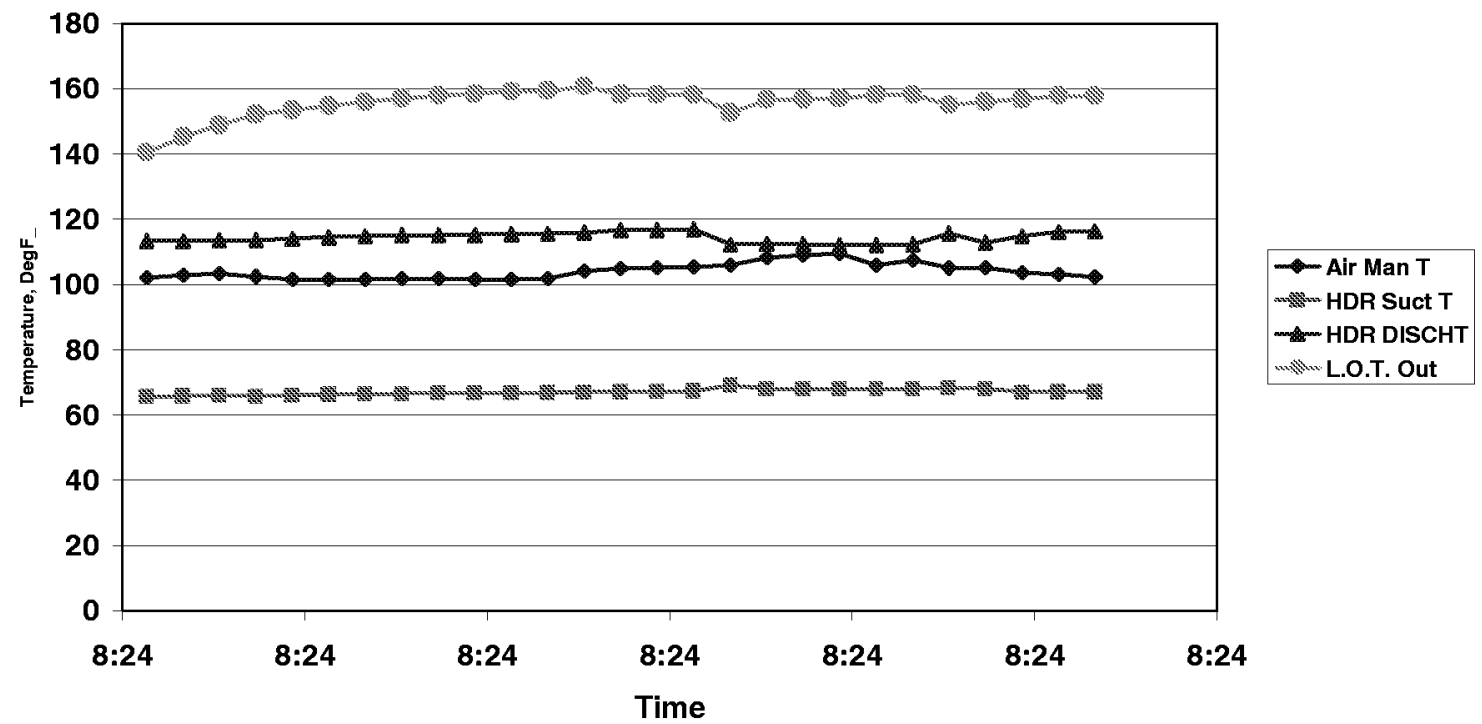

Figure 7-9. Temperature Deg. F; Day 2; Kinder Tests; April 22, 2004

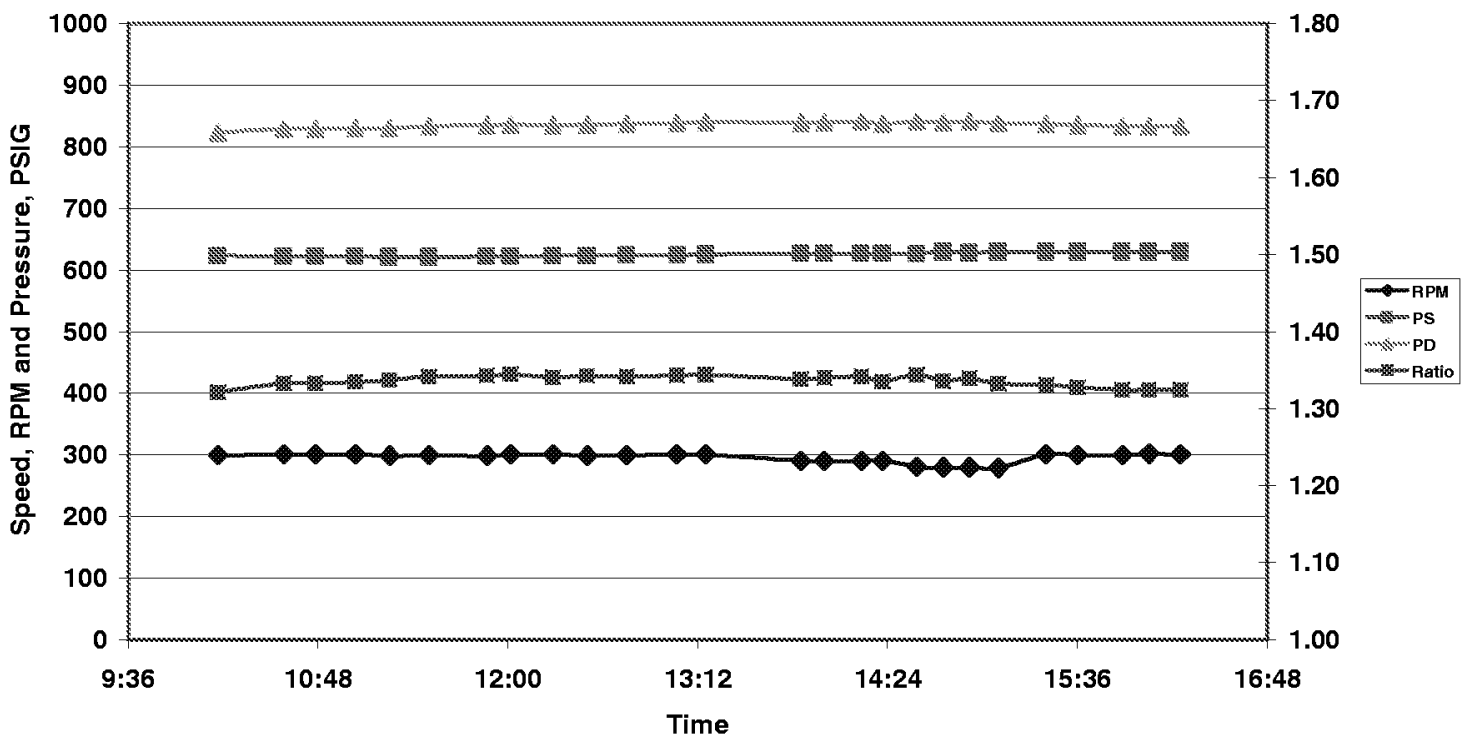

Figure 7-10. Suction Pressure, Discharge Pressure, Speed during Day 1 Test (April 21, 2004); Kinder Tests 


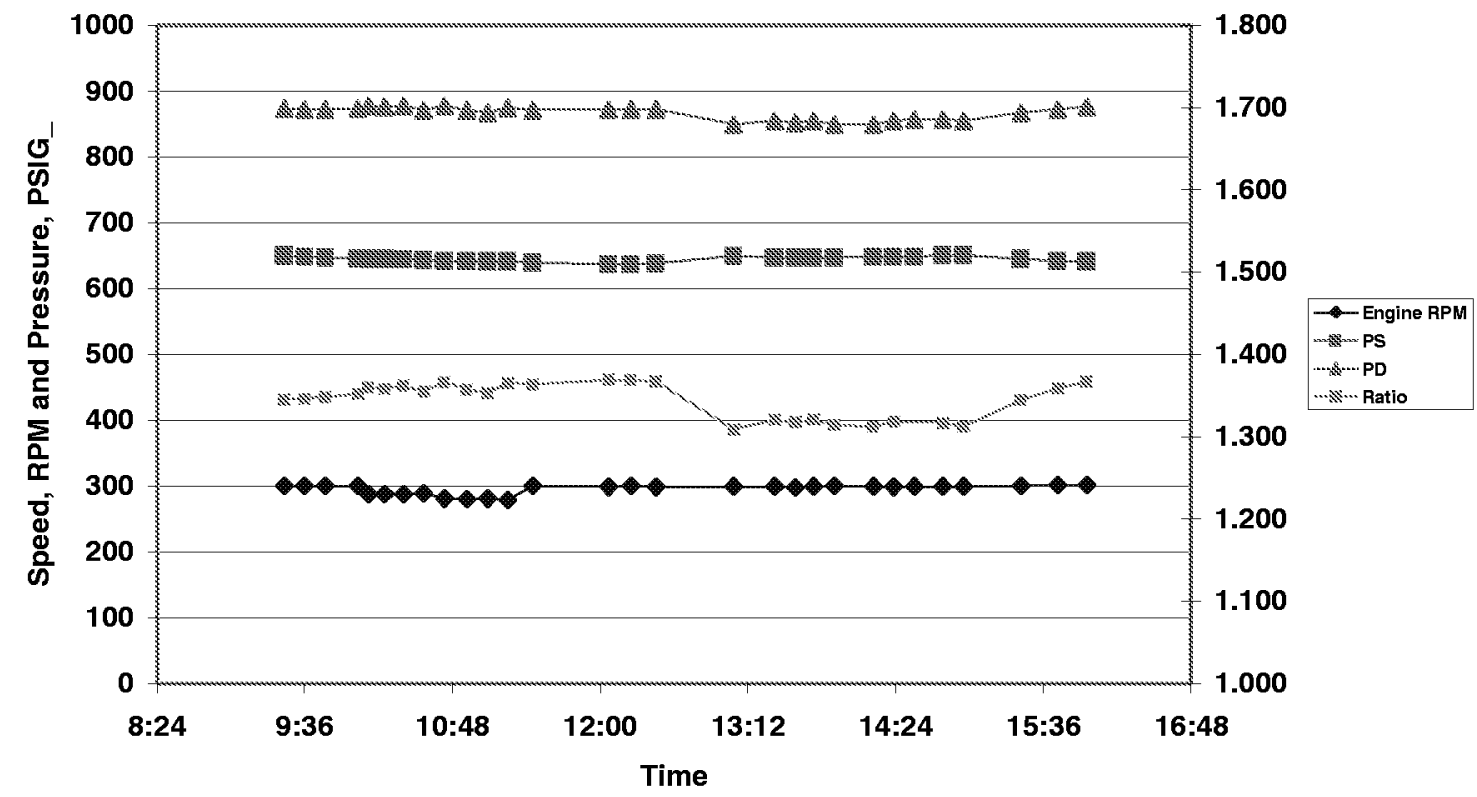

Figure 7-11. Suction Pressure, Discharge Pressure, Speed, and Ratio during Day 2 Test; April 22, 2004; Kinder Tests

Figure 7-12 and Figure 7-13 show the variation of compressor BHP and "fuel curve" (often referred to as load step). The compressor BHP from the station data is the result of a calculation using the suction and discharge conditions and an ideal model corrected for losses. This it is approximate. The load step is adjusted to keep the unit loaded at $100 \%$ torque or close thereto. It tends to respond closely to ratio changes and suction temperature; thus, reasonably close correspondence between load step and ratio can be seen by comparing Figure 7-10 to Figure 7-12 and Figure 7-11 to Figure 7-13.

The station BHP wanders a little at fixed speed. It also drops as speed drops around 1:15 and 2 on day 1 , and at about 10 and 11 on day 2 . 


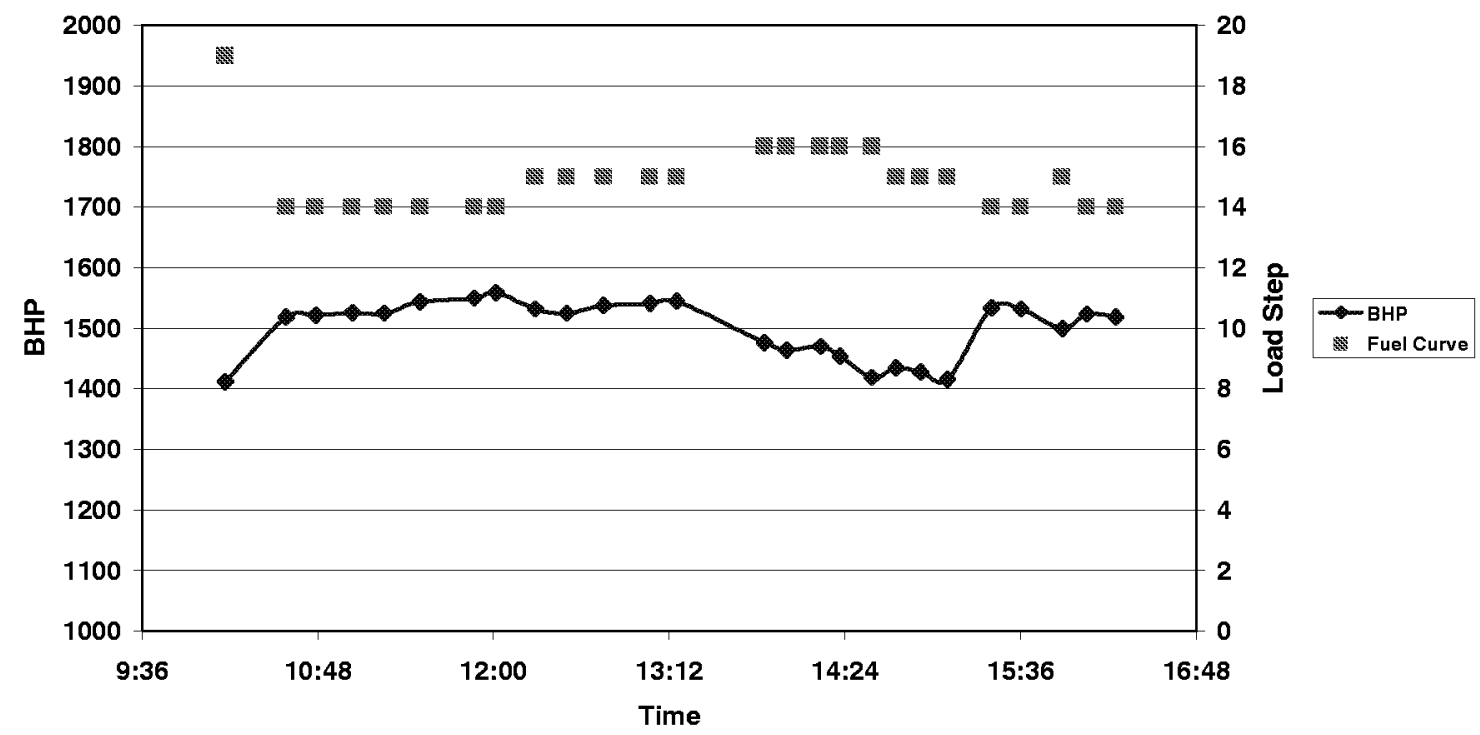

Figure 7-12. Station Data for Brake HP and Load Step ("Fuel Curve"); Day 1, April 21, 2004; Kinder Station

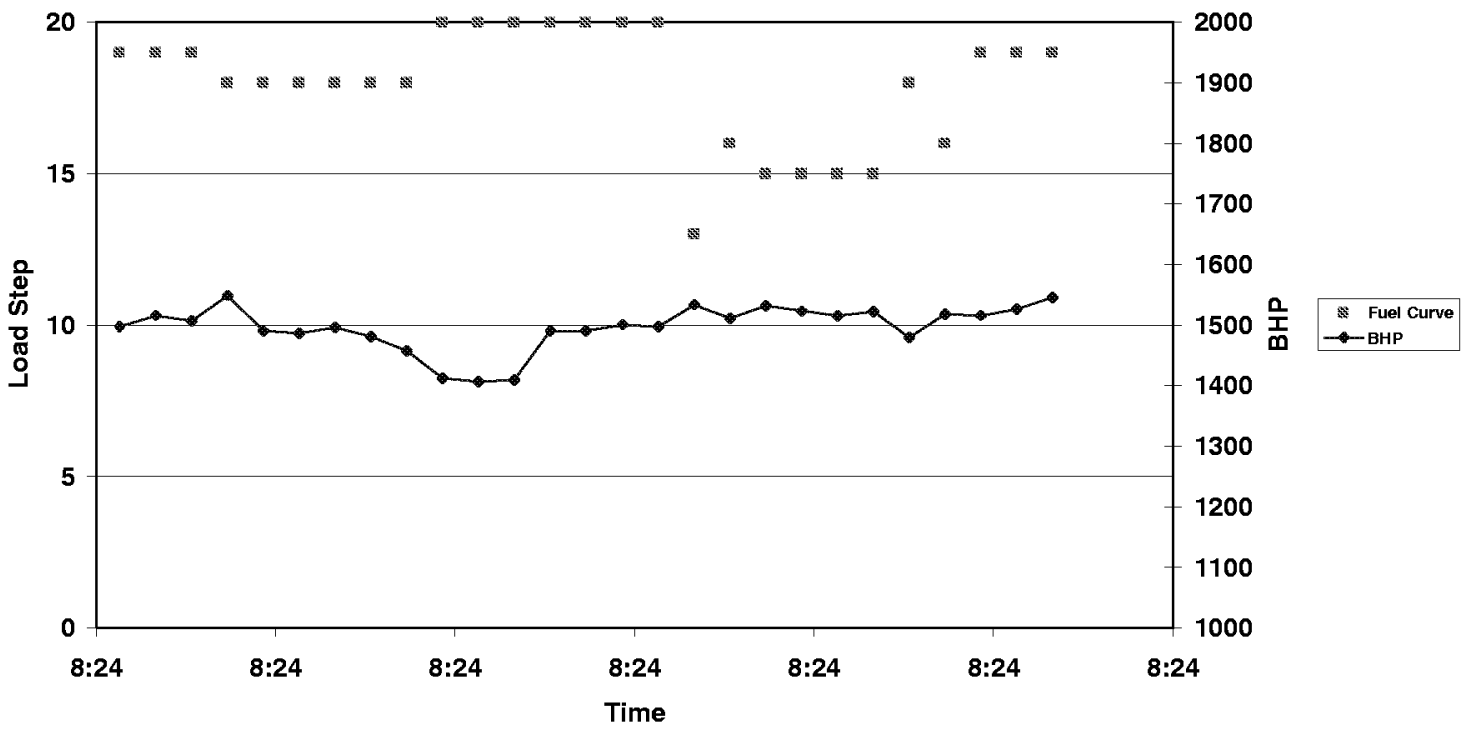

Figure 7-13. Station Data for Brake HP and Load Step ("Fuel Curve"); Day 2; April 22, 2004; Kinder Station

Figure 7-14 and Figure 7-15 present the compressor cylinder discharge temperature values from the station data. A characteristic common to both days is that the highest temperature rise at any time is 3 to 4 degrees higher than the lowest temperature rise. Compressor cylinder temperature rise when accurately measured is a very meaningful indicator of compressor efficiency - the higher the temperature rise for a given pressure 
rise, the less efficient the compressor cylinder. Even when the temperatures change with time, they remain in a very similar relationship to each other. The percentage difference between the highest and the lowest is a measure of the added losses in the inefficient cylinder - the indication is that cylinders 2 and 3 incurs about $8 \%$ higher losses than cylinder 4 . The most common contributors to losses are valves which leak when closed, and monitoring cylinder temperature rise is an effective way of identifying when a valve replacement would save energy (and increase capacity). To take full advantage of the information, there is a need for appropriate statistical analysis of the data, and for quantification of the benefits which will result from reducing the implied inefficiency. These benefits can then be compared to the labor, materials, and downtime cost of the maintenance action to replace the valve. For example, $8 \%$ on two cylinders out of four on a nominal 1550 BHP compressor add up to a possible fuel energy penalty of about 12 MCF per day. An alternative way to look at the possible penalty is that the unit has potentially $4 \%$ more capacity available when torque limited, since that amount of the torque presently has to overcome losses.

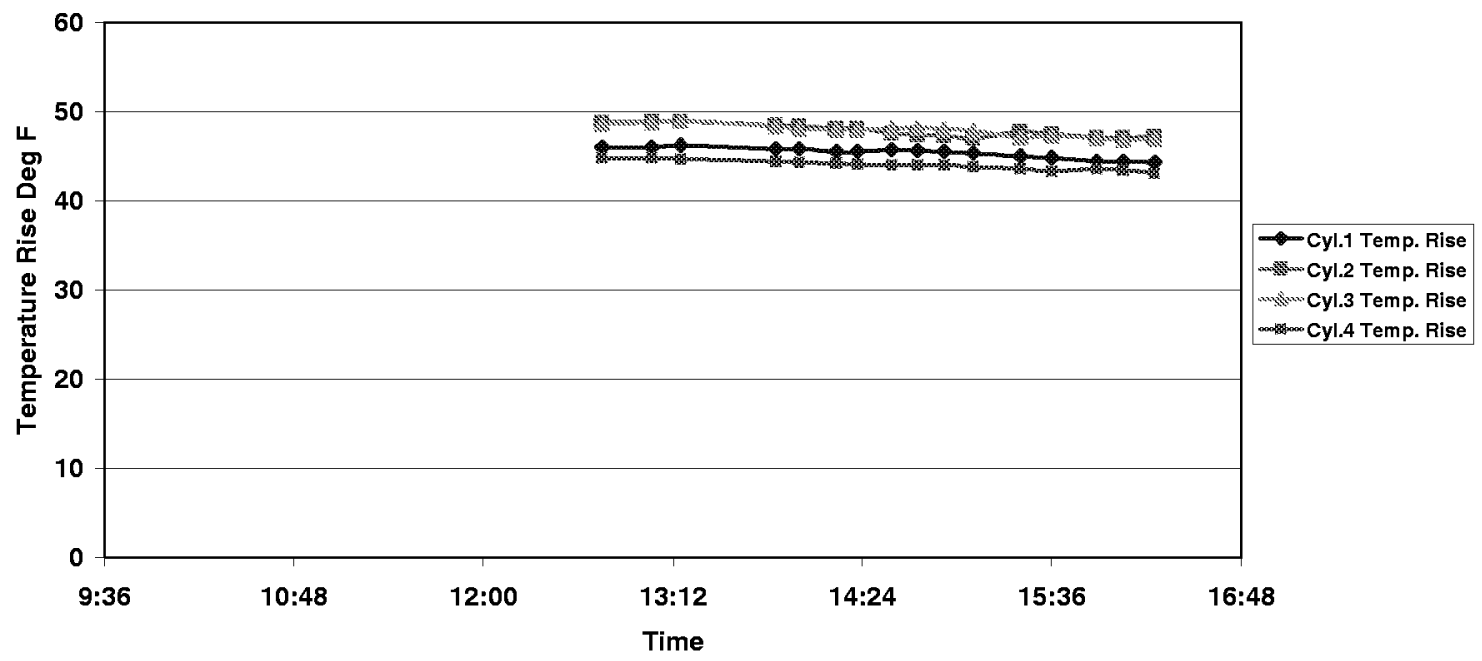

Figure 7-14. Compressor Cylinder Temperature Rise in Deg. F; Day 1; April 21, 2004; Kinder Tests 


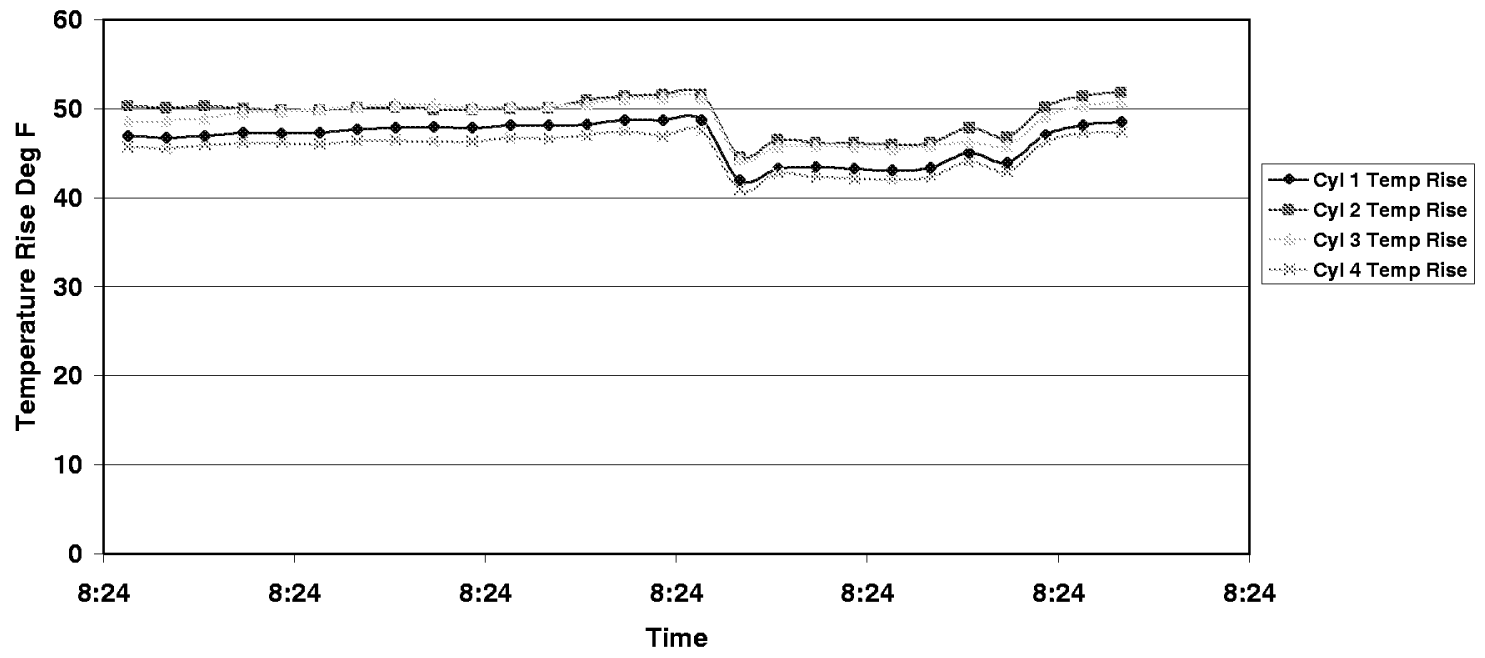

Figure 7-15. Compressor Cylinder Temperature Rise in Deg. F; Day 2; April 22, 2004; Kinder Tests

The hour-by-hour variation seems very consistent in these figures - all temperatures move together. The driving force behind changes in temperature rise is the change in compression ratio ( $\mathrm{Pd} / \mathrm{Ps}$ ). Thus, Figure 7-16 and Figure 7-17 have been prepared; these present temperature rise as a function of compression ratio, and show consistent linear relationships over the ratio range covered. These relationships could be used as part of a condition monitoring process to detect statistically and economically significant deviations from good condition. The reference from which deterioration can be identified, established as a regression model with all valves in good condition would then be used to detect repeated deviations which are more than (say) three standard deviations from the regression model. Deviations from individual valve regression models can be supplemented by quantification of the range of temperature rise in nominally identical cylinders such as Figure 7-14 and Figure 7-15 show. 


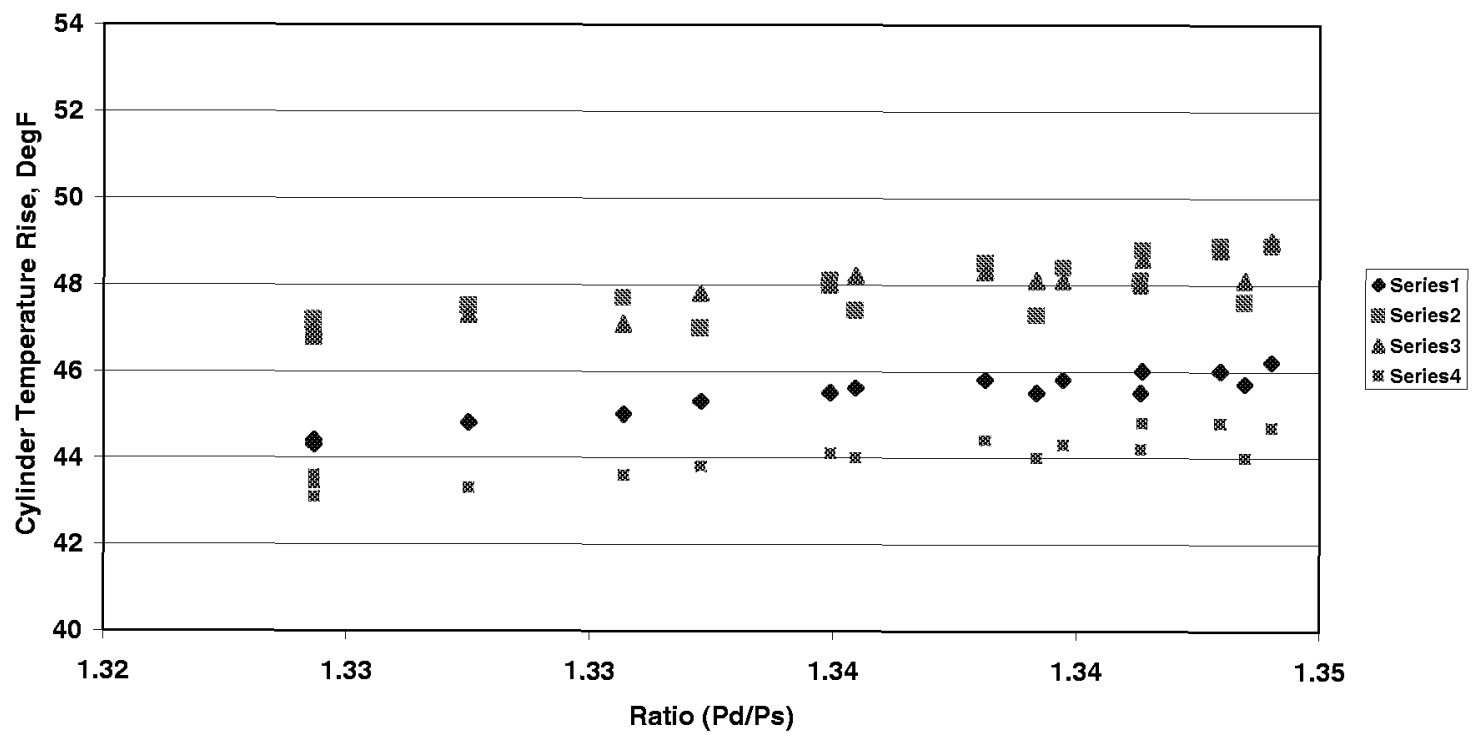

Figure 7-16. Cylinder Temperature Rise as a Function of Ratio (Series Number = Cylinder Number); Kinder Tests; Day 1; April 21, 2004

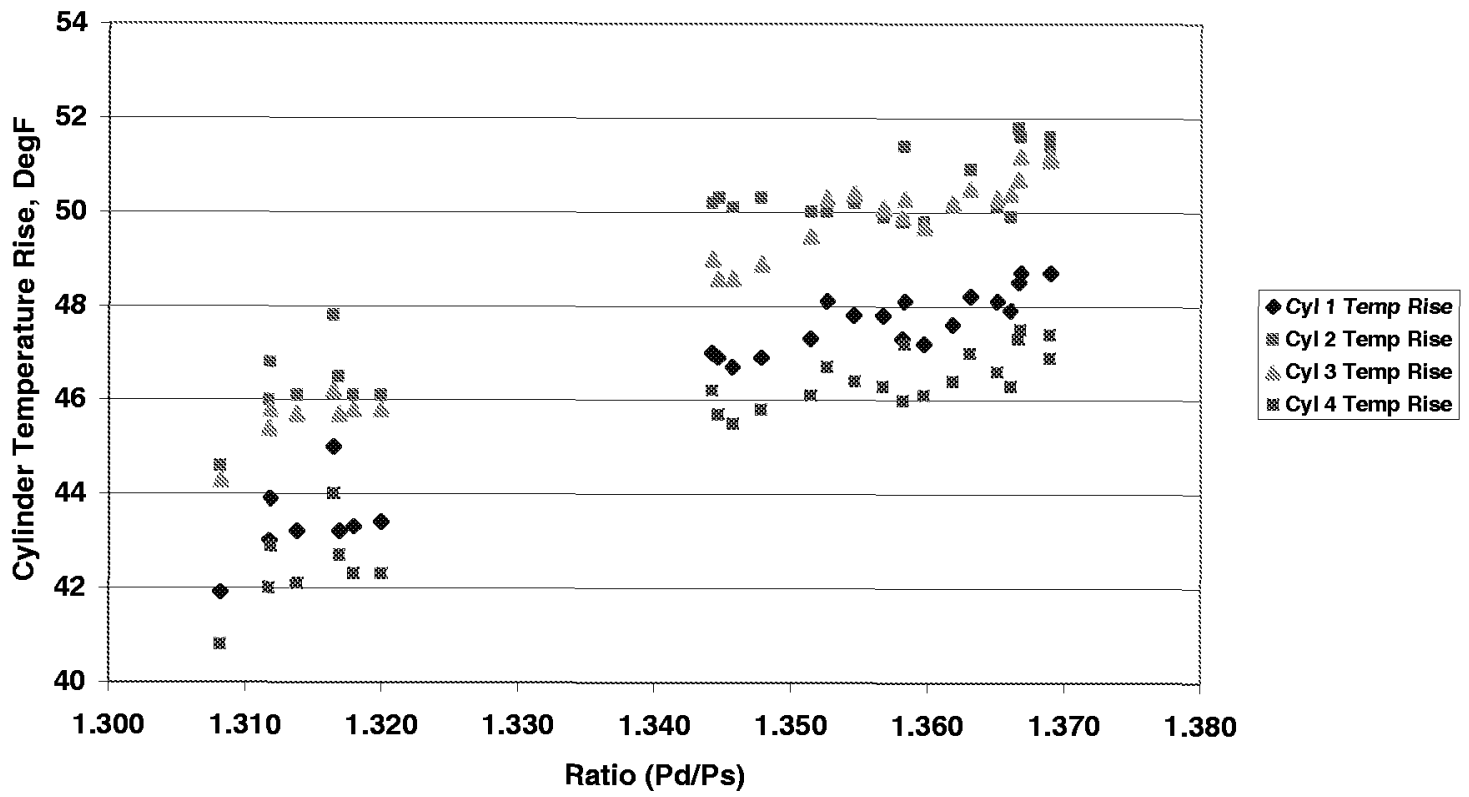

Figure 7-17. Cylinder Temperature Rise as a Function of Ratio (Series Number = Cylinder Number); Kinder Tests; Day 2; April 22, 2004 
Figure 7-18 plots average cylinder discharge temperature against discharge header temperature. With the one obvious outlier neglected, the two track very closely with normal small scatter. Thus, little heat (at most fractions of a degree) is lost between cylinders and header. If flow could be measured accurately, the temperature rise and pressure rise from suction to discharge would give enthalpy rise, and provide, with flow, an alternative basis for assessment of system performance, giving added redundancy to system performance evaluation.

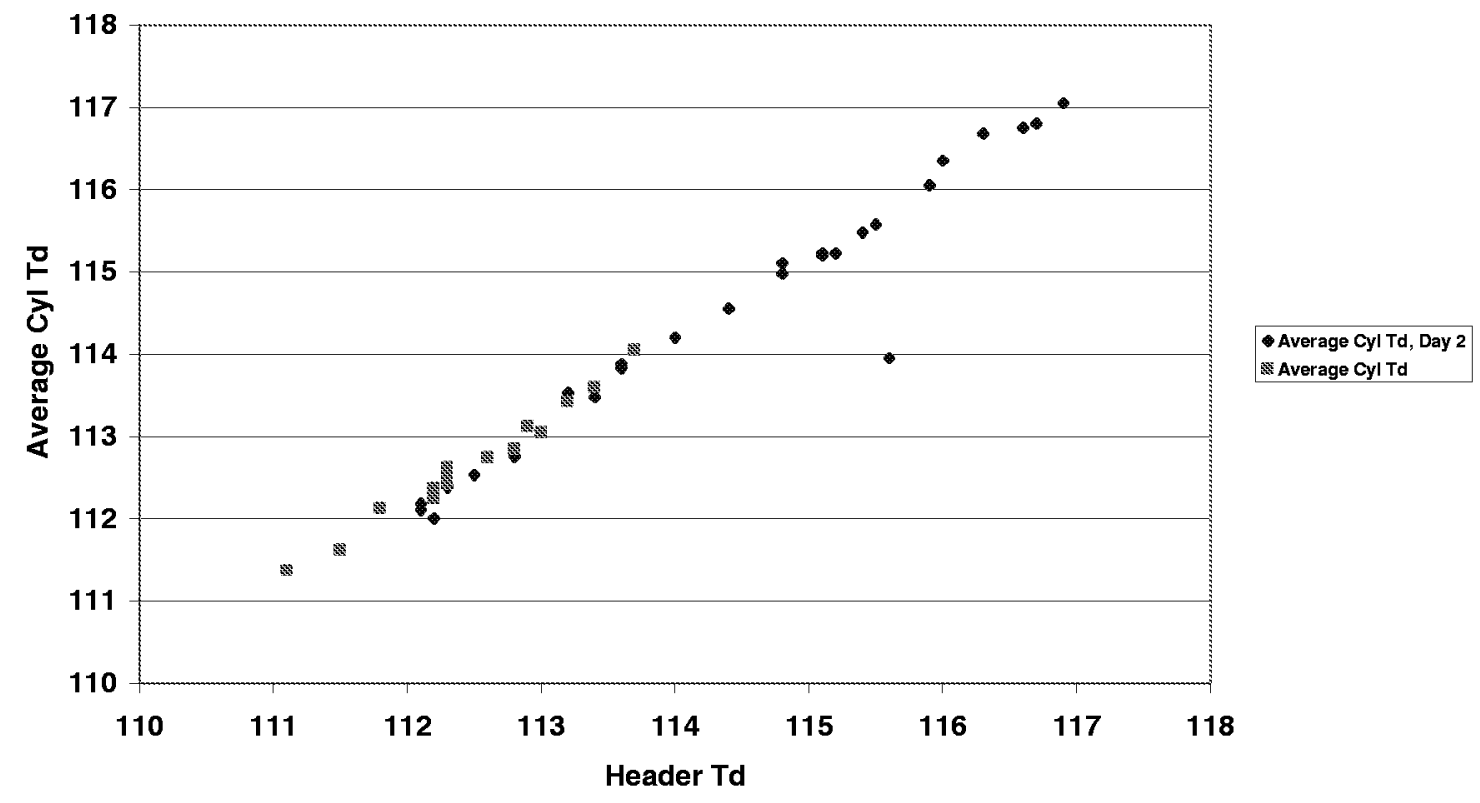

Figure 7-18. Average Cylinder Td versus Header Td; Days 1 and 2

Figure 7-19 and Figure 7-20 show power cylinder exhaust temperatures. These show a substantial spread of about 170 degrees F. The high $(4,6)$ and low cylinders $(3)$ seem to stay reasonably consistent, but the total spread on the second day rises to about 240 degrees towards the end. This is when the fuel valves were opened wide. 


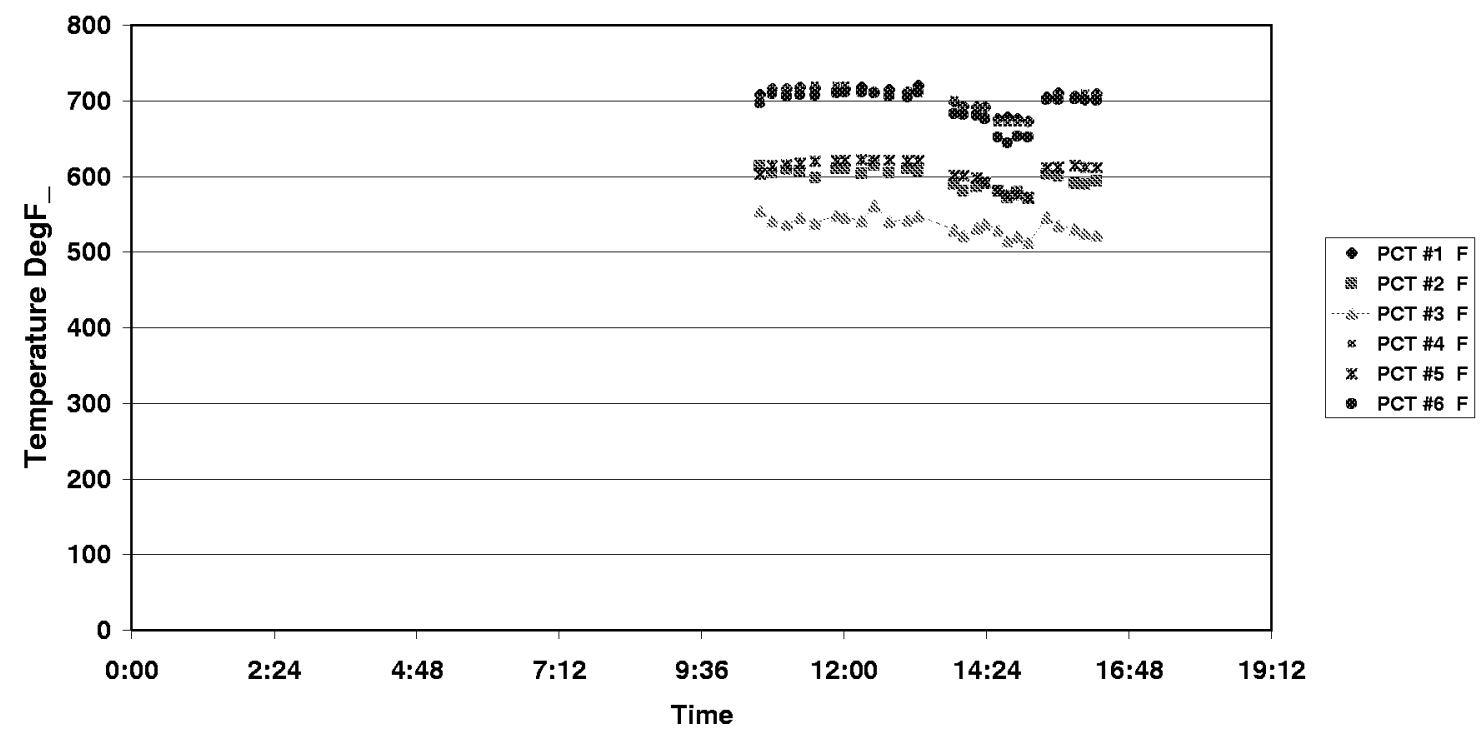

Figure 7-19. Power Cylinder Exhaust Temperatures; Kinder Tests; Day 1; April 24, 2004

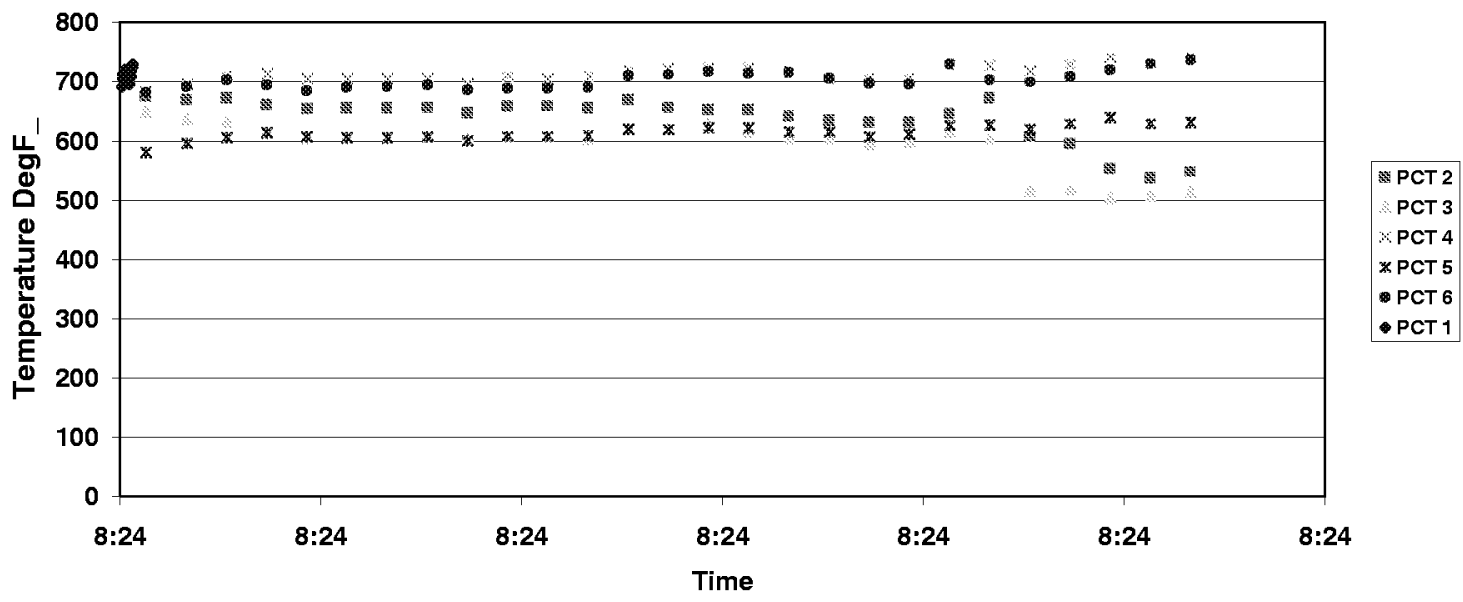

Figure 7-20. Power Cylinder Exhaust Temperatures; Kinder Tests; Day 2; April 22, 2004 


\subsection{DATA FROM TEMPORARILY INSTALLED TEST INSTRUMENTATION - KINDER SECOND TEST}

Figure 7-21 and Figure 7-22 show the speed history for the two days, based on SwRI revolution timing. The speed generally stays close to 300 RPM, except in the periods when it was cut to 290 and 280 to test the wastegate controllability for maintaining global equivalence ratio.

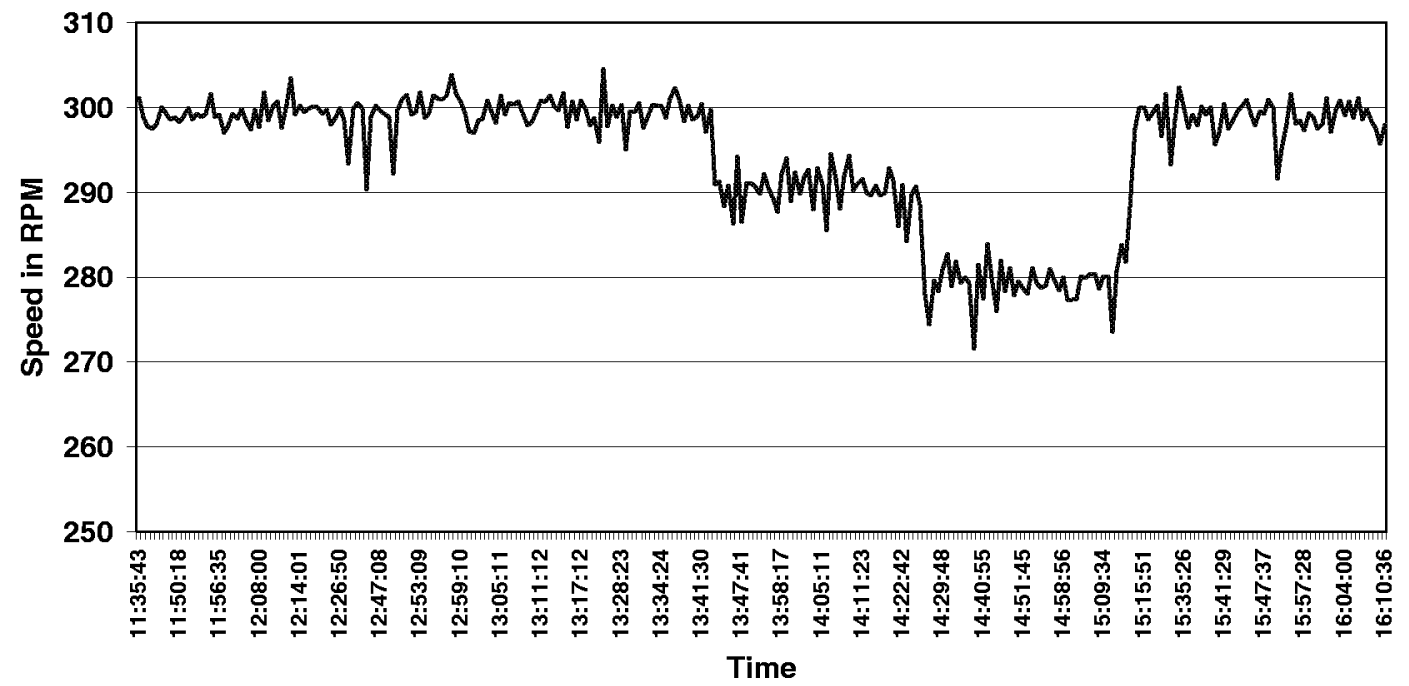

Figure 7-21. Unit Speed; Kinder Second Test; Day 1; April 21, 2004

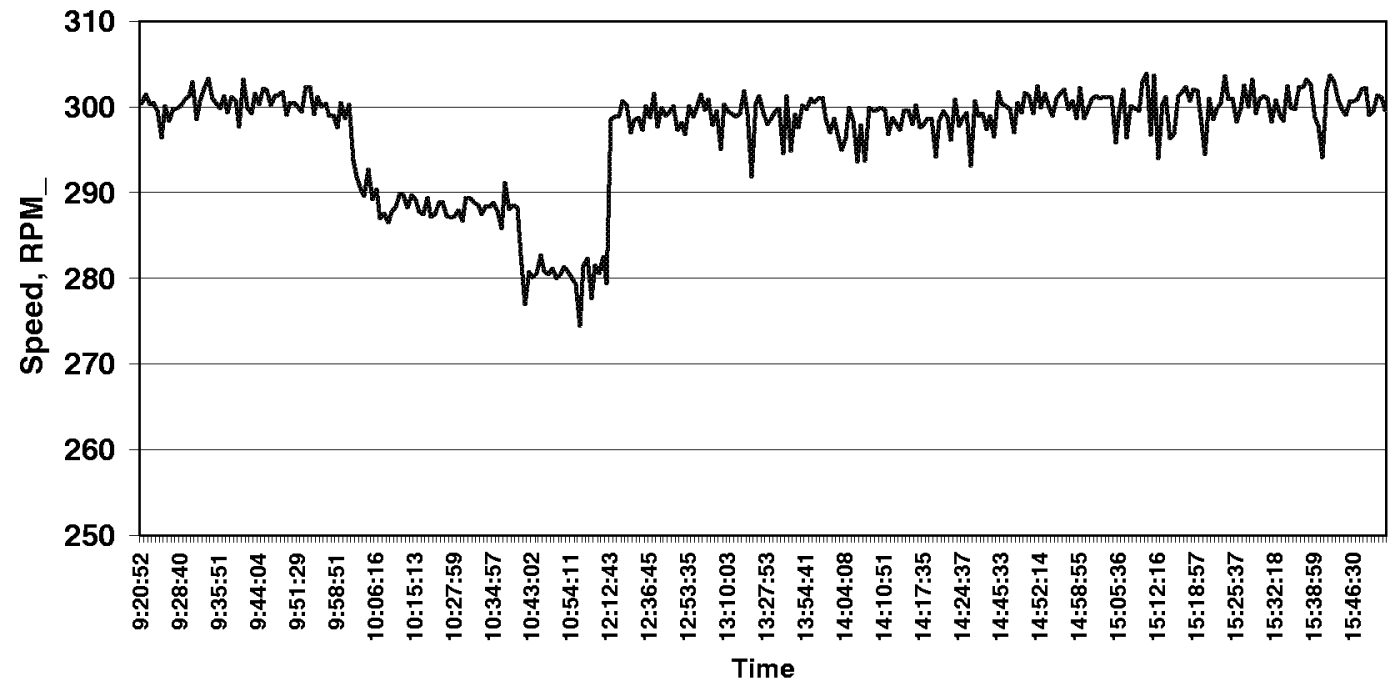

Figure 7-22. Unit Speed; Kinder Second Test; Day 2; April 22, 2004 
Figure 7-23 and Figure 7-24 show the global equivalence ratio and normalized NOx concentration for the two days. On day 1 , the equivalence ratio drops from about 0.428 to about 0.403 when speed is reduced to 280 RPM. This is because the global equivalence ratio was on open-loop control - though maintaining air manifold pressure constant. On day 2 , the wastegate position was under closed-loop control to keep the global equivalence ratio at a set point. The equivalence ratio was measured by the NGK Universal Exhaust Gas Oxygen Sensor (UEGO) installed in the stack. Matching up Figure 7-22 and Figure 7-24 shows that when speed is changed with global equivalence ratio controlled to a set point, the equivalence ratio stays at its set point. The changes in global equivalence ratio from its set point between 2:00 and 3:00 PM occurred when deliberate efforts were made to over-ride the controller and richen the fuel air mixture to the cylinders during tests of the detonation detector.

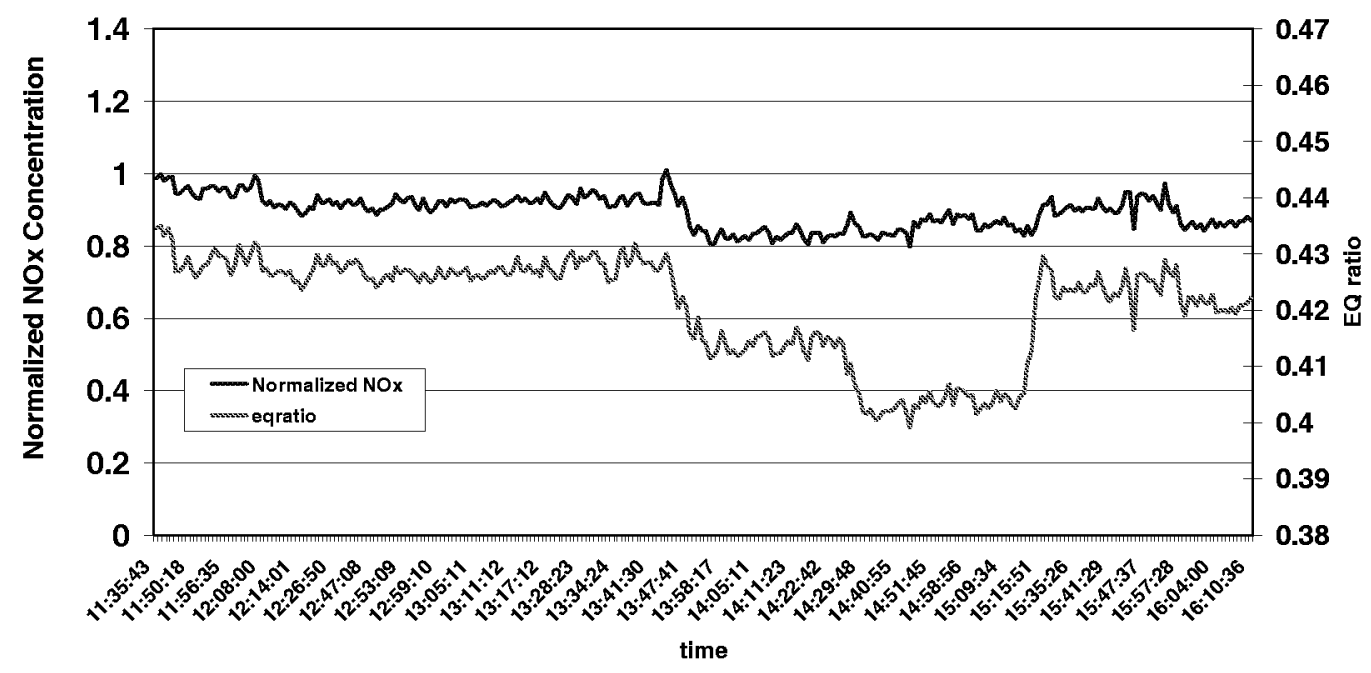

Figure 7-23. Global Equivalence Ratio and Normalized NOx Concentration; Kinder Second Test; Day 1; April 21, 2004

The elements of this control system have been shown in Figure 7-7, including the stack sensor, the wastegate, and actuator arm, the pneumatic controller, and the connections to the station control system. The comparison of Figure 7-23 and Figure 7-24 provide clear evidence of the feasibility of this closed loop control - it is very simple and effective. 


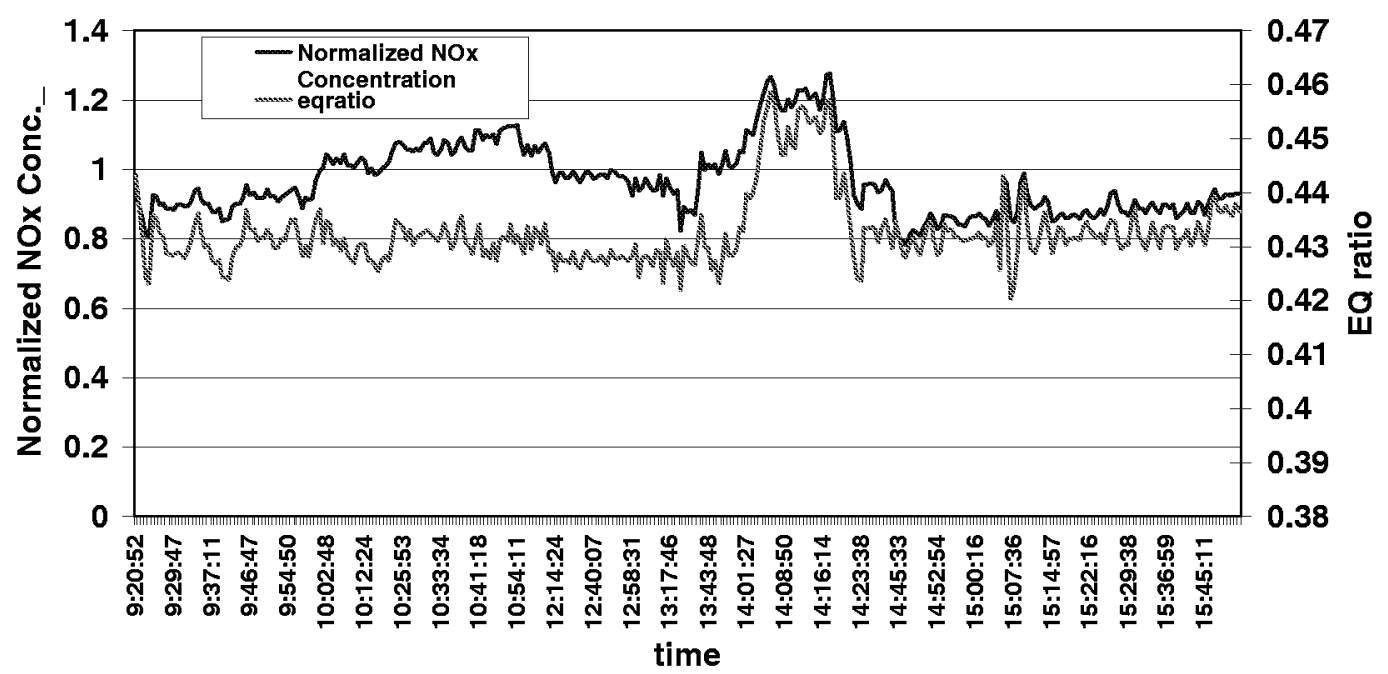

Figure 7-24. Global Equivalence Ratio and Normalized NOx Concentration; Kinder Second Test; Day 2; April 22, 2004

Figure 7-25 and Figure 7-26 show fuel flow variation during the two days. This clearly reflects the speed changes, but assessment of fuel flow relative to other parameters will be addressed more closely when discussing the heat rate, and how heat rate varies with load.

Figure 7-27 and Figure 7-28 show the variation of engine and compressor indicated horsepower during the two days, together with the ratio of engine to compressor power. Since test data acquisition did not start until some time after the unit started, this data is not available for the starting transient of day 1 . However, on day 2 , there is an indication of a drop in the ratio of engine to compressor power over the first hour of operation. A similar drop for a more complete cold start was previously observed for another unit at this station - hypothesized at the time as a result of increasing oil temperature. 


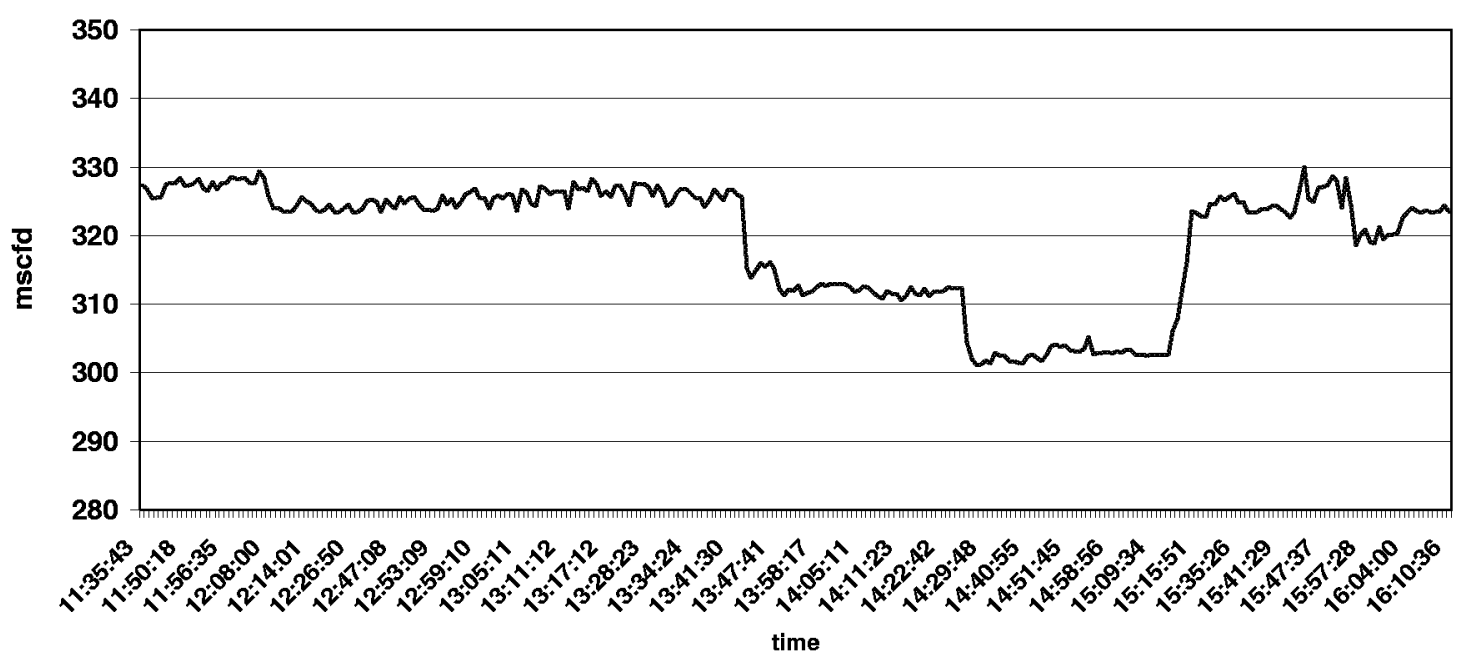

Figure 7-25. Fuel Flow; Kinder Second Test; Day 1; April 21, 2004

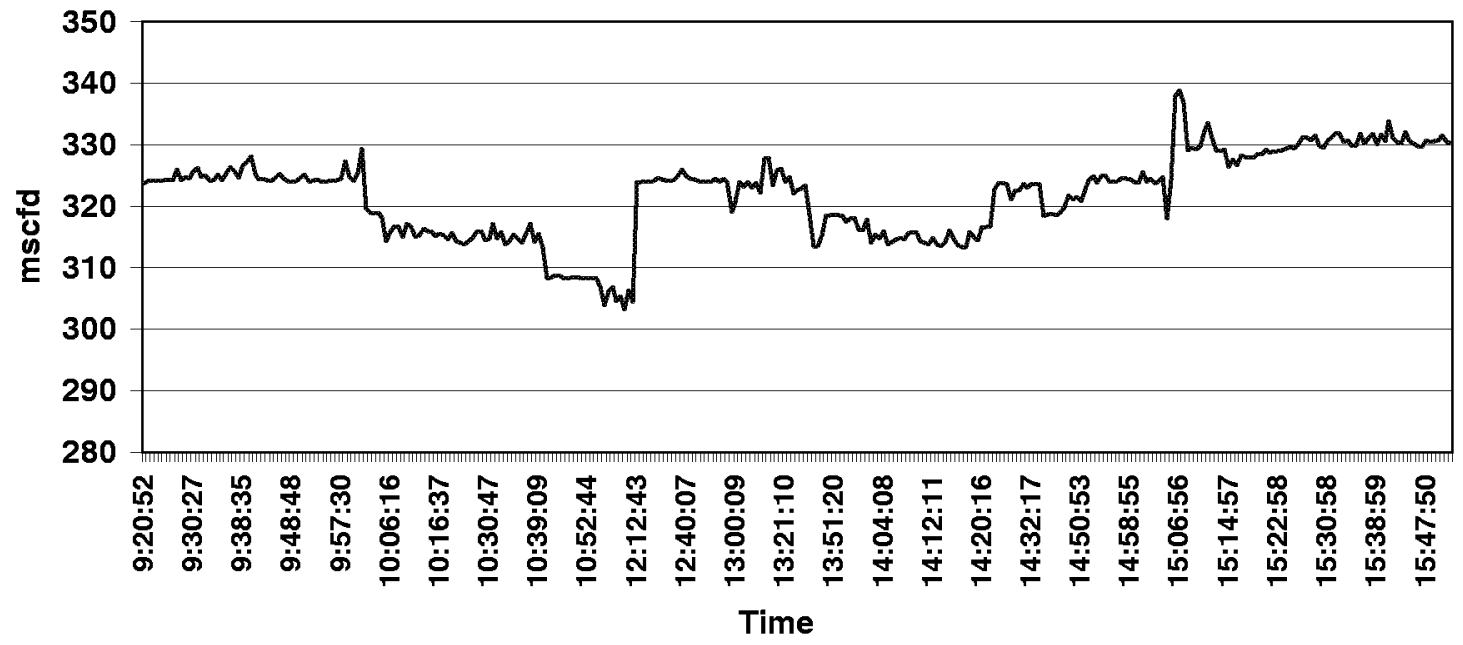

Figure 7-26. Fuel Flow; Kinder Second Test; Day 2; April 22, 2004 


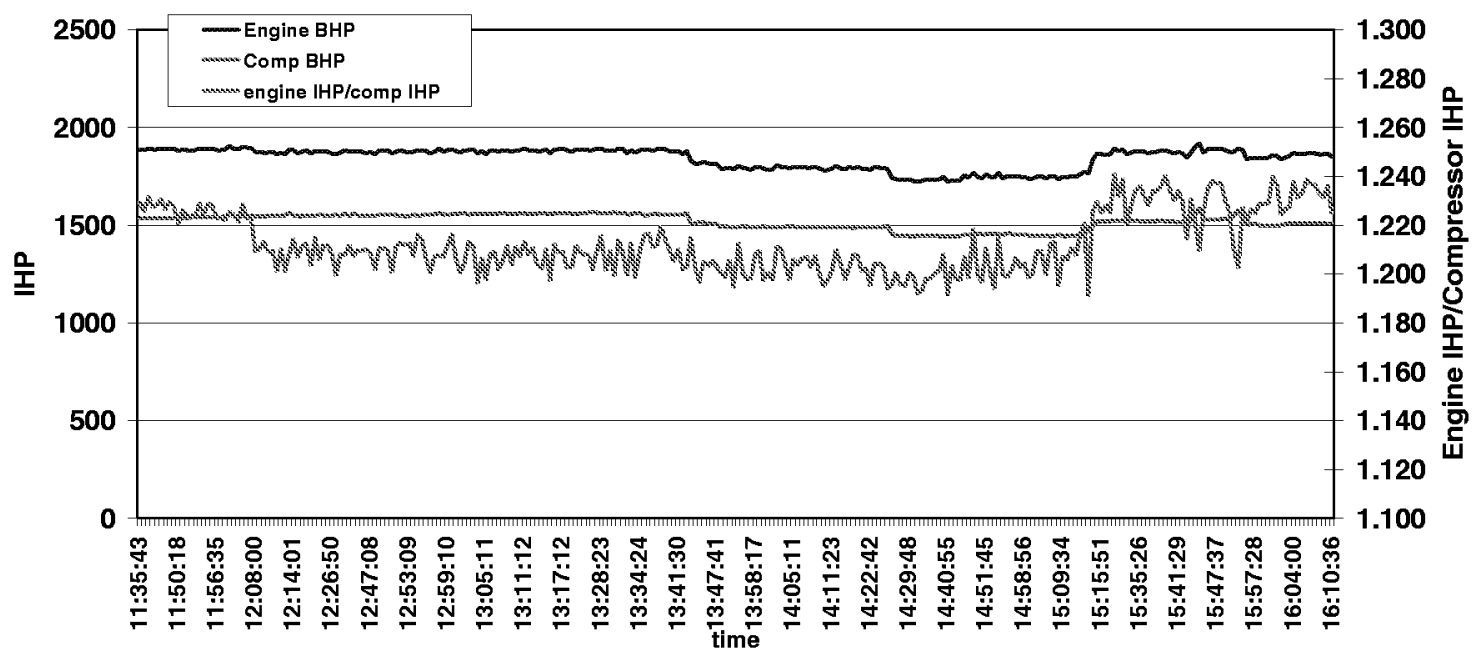

Figure 7-27. Measured IHP for Engine and Compressor and their Ratio; Kinder Second Test; Day 1; April 21, 2004

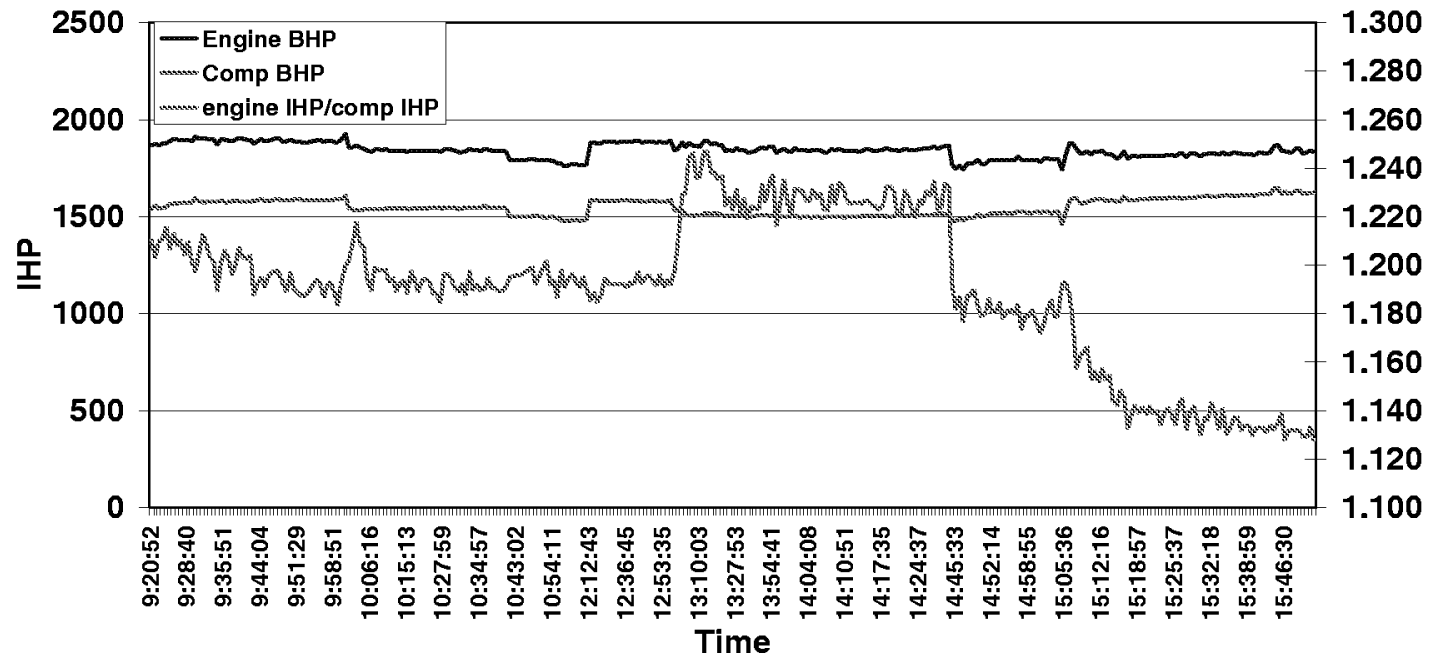

Figure 7-28. Measured IHP for Engine, Compressor, and their Ratio; Kinder Second Test; Day 2; April 22, 2004 
On both days, there are some changes in power on compressor or engine, which are attributable to test condition changes, and some that appear to be the result of other causes. On day 1 after about 12:30, the changes are directly attributable to speed changes. On day 2, after the speed variation tests were completed (about 12:00), there is a reduction in compressor power about 1:00 PM, which is not directly matched by a reduction in engine power, and so the ratio of engine to compressor power jumps. The reduction in compressor power seems to correspond to a reduction in ratio across the compressor. Later in the day about 2:35, the engine power drops with only a slight matching drop in compressor power. This is approximately when the fuel valves were opened wide on all power cylinders. Soon after 3:00 PM, the compressor power increased - apparently coinciding with an increase in ratio. This time there is not a matching increase in engine power, and so the ratio of engine power to compressor power drops to its lowest of the test series - about 1.14 or below. There is an indication that the mechanical efficiency of power transmission from power cylinders to compressor cylinders changes with conditions, but the reasons are not clear at this time.

The heat rate for days 1 and 2 is shown in Figure 7-29 and Figure 7-30. On day 1, the heat rate stays quite constant through the speed variation tests at $7950 \mathrm{BTU} / \mathrm{HP}-\mathrm{hr}$. Late in the day, efforts were made with the help of a station operator to reduce load on the unit at 300 RPM by adjustments to load step, and investigate heat rate effects, but this was only slightly successful as registered by the station values for percentage torque. The indicated compressor horsepower numbers in Figure 7-27 show there was very little change in horsepower load, and yet the heat rate went up as high as 8100 BTU/HP-hr. during this period, with short spikes downwards. Fortunately, the day 2 results will show a much wider range in load (which occurred without intentional effort) whose influence on heat rate will be discussed subsequently.

The day 2 heat rates were distinctly lower - at 7800 for a good part of the testing, as opposed to 7950. The wastegate control was active from the start of the days testing, and the setting led to a slightly higher equivalence ratio than on the early part of day 1 . This might explain the lower heat rate. The 7800 heat rate does not change much during the speed changes with equivalence ratio control. 


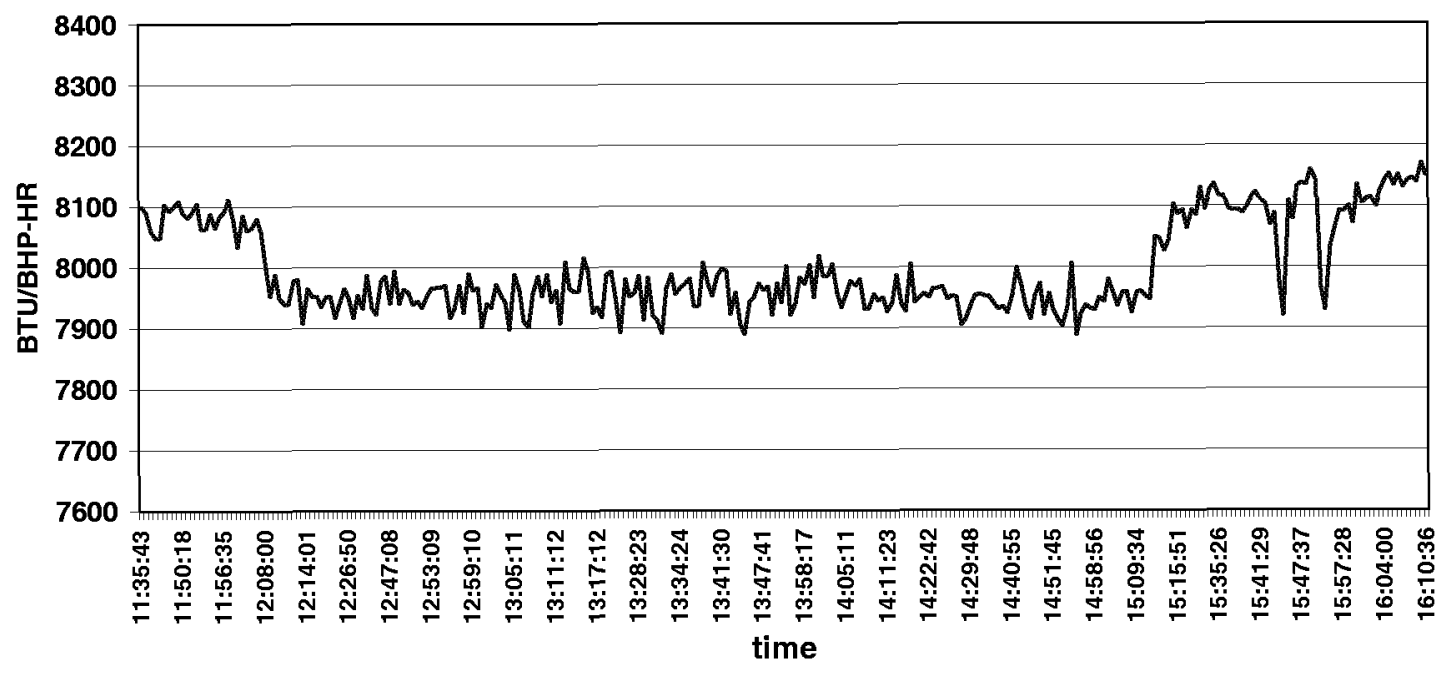

Figure 7-29. Heat Rate (LHV); Kinder Second Test; Day 1; April 21, 2004

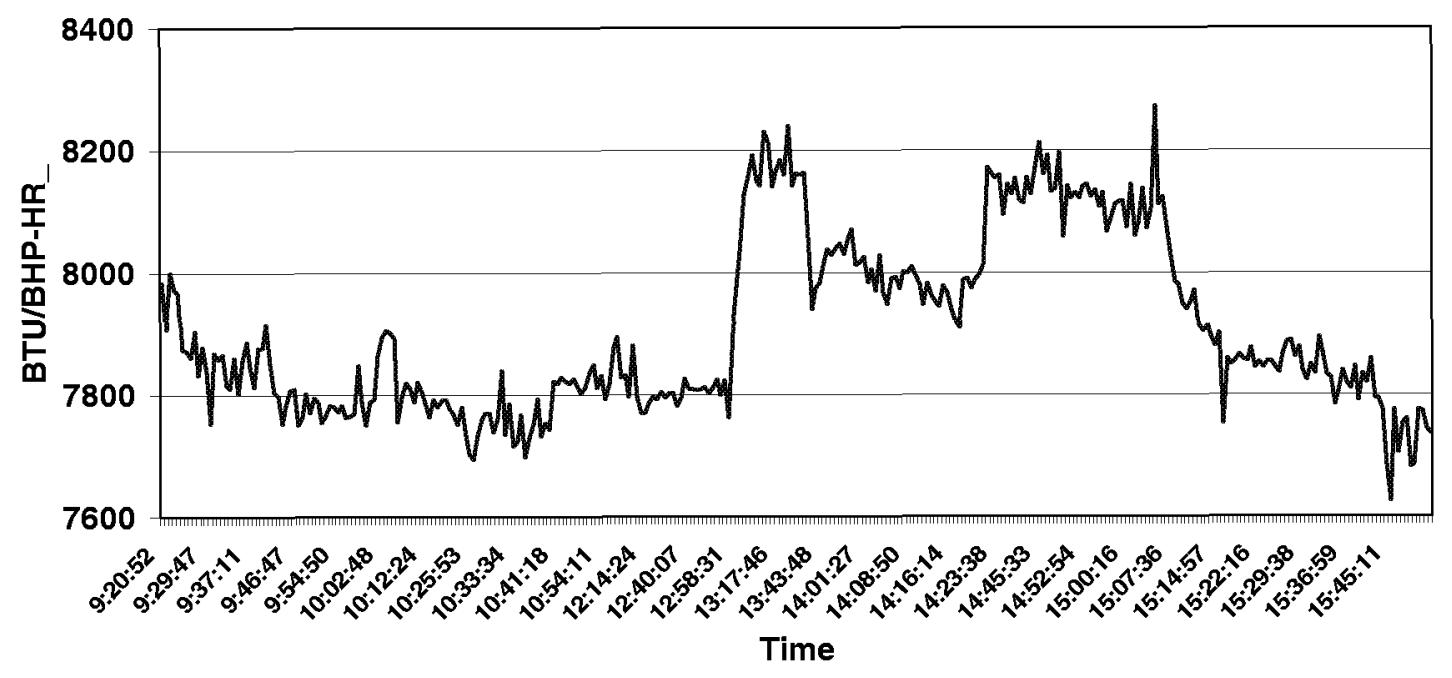

Figure 7-30. Heat Rate (LHV); Kinder Second Test; Day 2; April 22, 2004

Soon after 1:00 on day 2, the heat rate went up, which corresponds to a decrease in compressor power and brings up the point that studying heat rate in isolation of load for this unit is incomplete and can be misleading.

The effect on normalized NOx of the wastegate control was to raise it by 10 to $15 \%$ relative the day 1 testing with air manifold pressure control, as previously shown in Figures 5-24 and 5-25. Thus, an explicit advantage of maintaining low NOx is not yet 
demonstrated by the approach. Rather, the feasibility has been shown, and so the low cost ability to control of a global equivalence ratio set point for a particular objective exists. Such an objective could be to maintain lower NOx concentration.

One benefit of the particular equivalence ratio setting is that the combustion stability does not deteriorate when speed is reduced. Figure 7-31 and Figure 7-32 illustrate this - they show standard deviation for the time variation of peak-firing pressure (averaged over the six power cylinders), together with combustion pressure ratio. When speed is dropped in day 1, standard deviation increases from an average value of 60 with spikes to 68 , reaching about 67 or 68 on average, with spikes to 78 PSI. On day 2, with global equivalence ratio maintained at a set point, when the speed is dropped (between 10.02 and 12:14), the standard deviation appears to drop slightly from its average value right around 60 to about 57 spiking to 62 .

The average ratio of peak-firing pressure to compression pressure (at 20 degrees Before Top Dead Center (BTDC)) is also presented in Figure 7-31 and Figure 7-32. This quantity (CPR) stays between 2.4 and 2.6 on day 1 . On day 2 , it shows more variation with a low of 2.25 , and a high of 2.85 . The day 2 highs result from advancing timing, which occurred between $13: 43$ and 14:23. It also goes up from 2.5 to 2.65 during the speed decrease on day 2, whereas very little change in CPR is seen on day 1 when speed is changed.

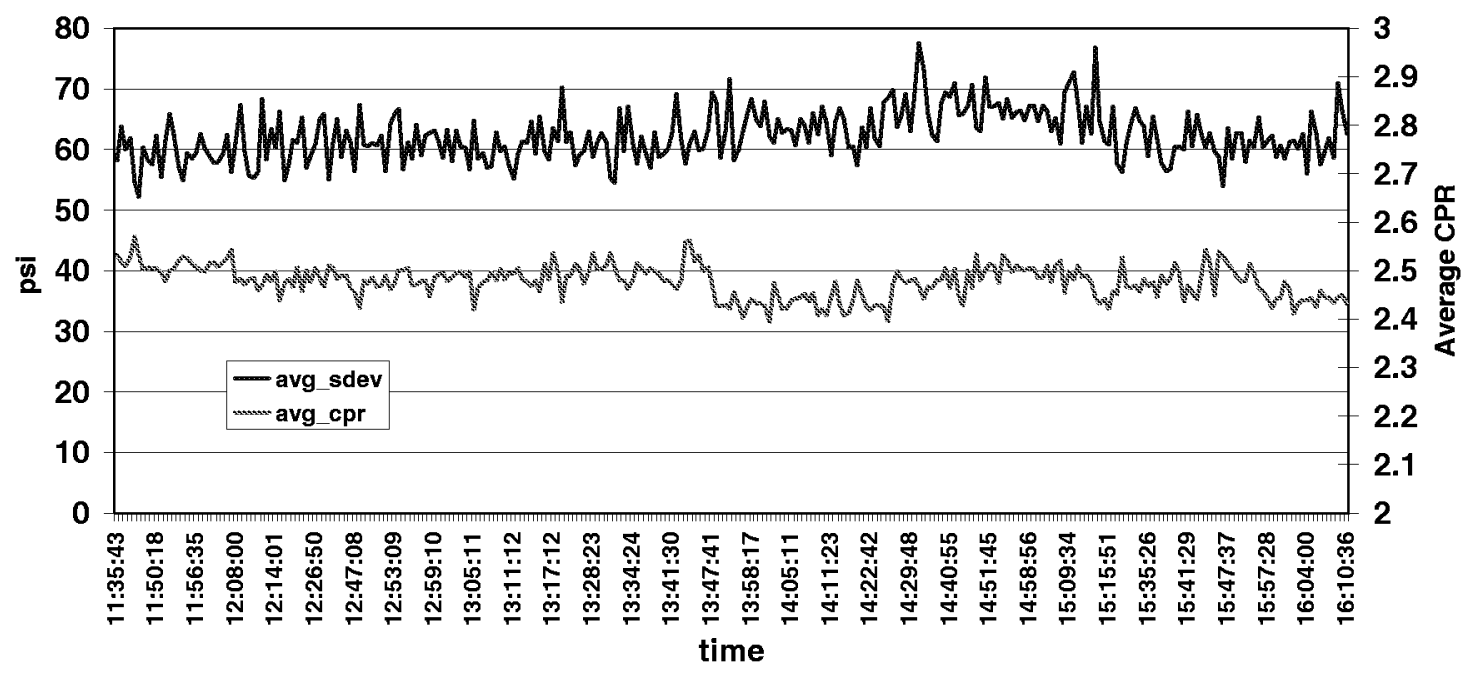

Figure 7-31. CPR and Standard Deviation for Peak-Firing Pressure; Averaged across the Six Power Cylinders; Kinder Second Test; Day 1; April 21, 2004 


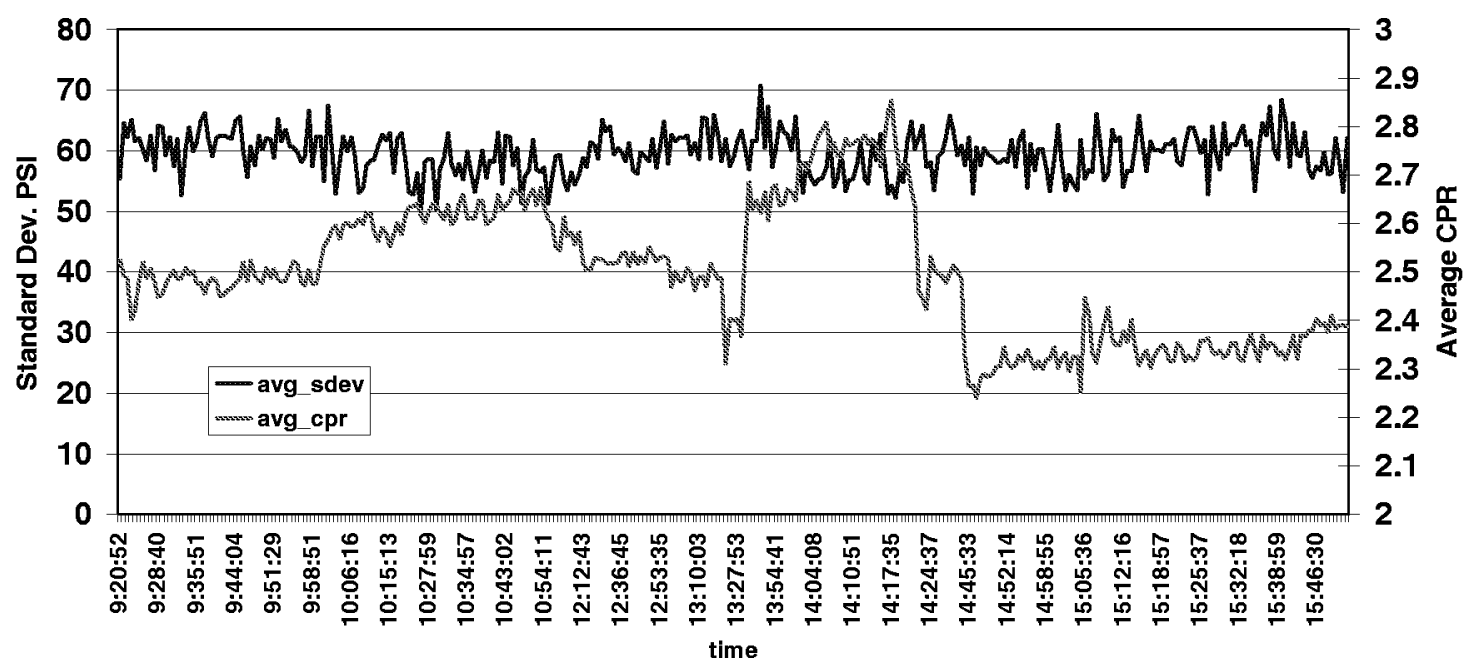

Figure 7-32. CPR and Standard Deviation for Peak-Firing Pressure; Averaged across the Six Power Cylinders; Kinder Second Test; Day 2; April 22, 2004

Figure 7-33 and Figure 7-34 show the average and instantaneous spread in peak-firing pressure across the power cylinders for days 1 and 2 . On day 1, the average spread stays around 50 to 55 PSI. The instantaneous spread starts around 155 PSI, and appears to rise slightly when speed is decreased, to about 175 PSI at 280 RPM. On day 2, the average spread again starts around 50 PSI, and the instantaneous spread is about 155 PSI. These spreads are essentially unchanged when speed changes on day 2 with equivalence ratio control. The effect of CPR balancing between 12:40 and 13:20 is to create a clear reduction in average spread to about 40 PSI, but no obvious reduction in instantaneous spread. At 2:30, when all fuel valves were opened, average spread jumps to almost 100 PSI, then drops back to between 40 and 50 as CPR balancing was repeated towards the end of testing. 


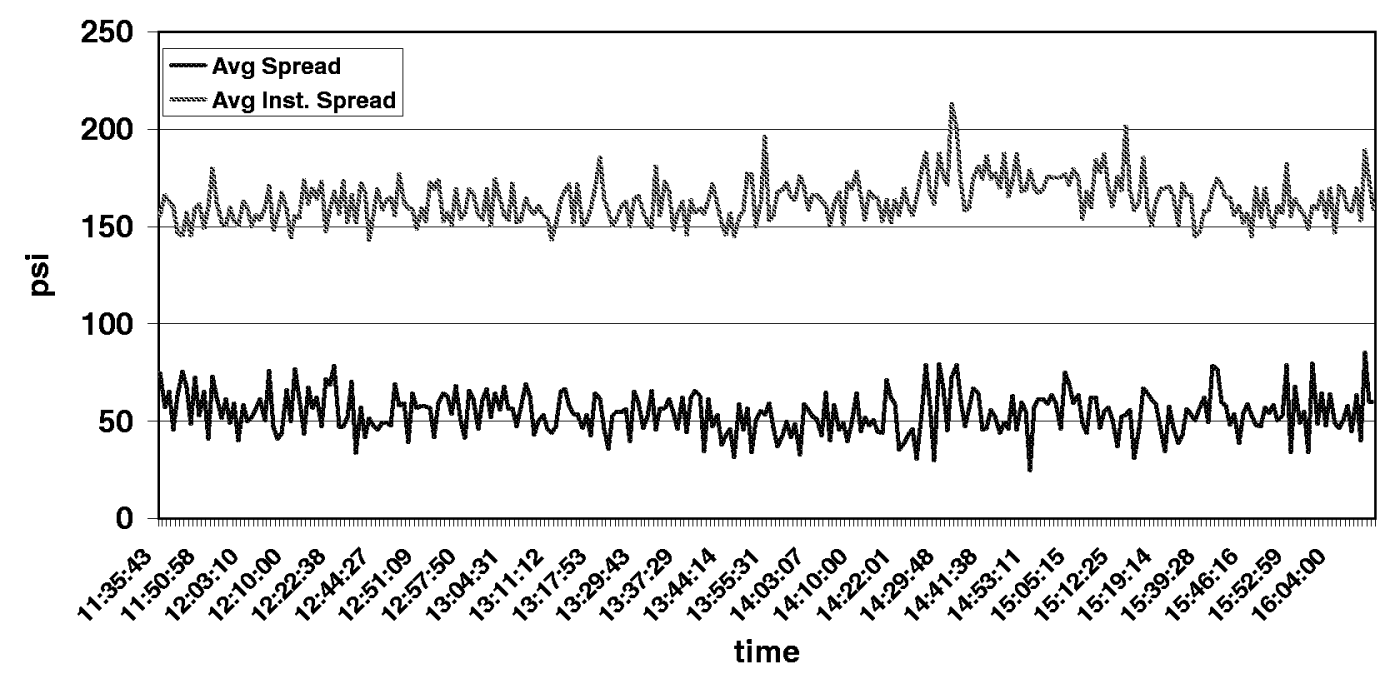

Figure 7-33. Average and Instantaneous Spread; Kinder Second Test; Day 1; April 21, 2004

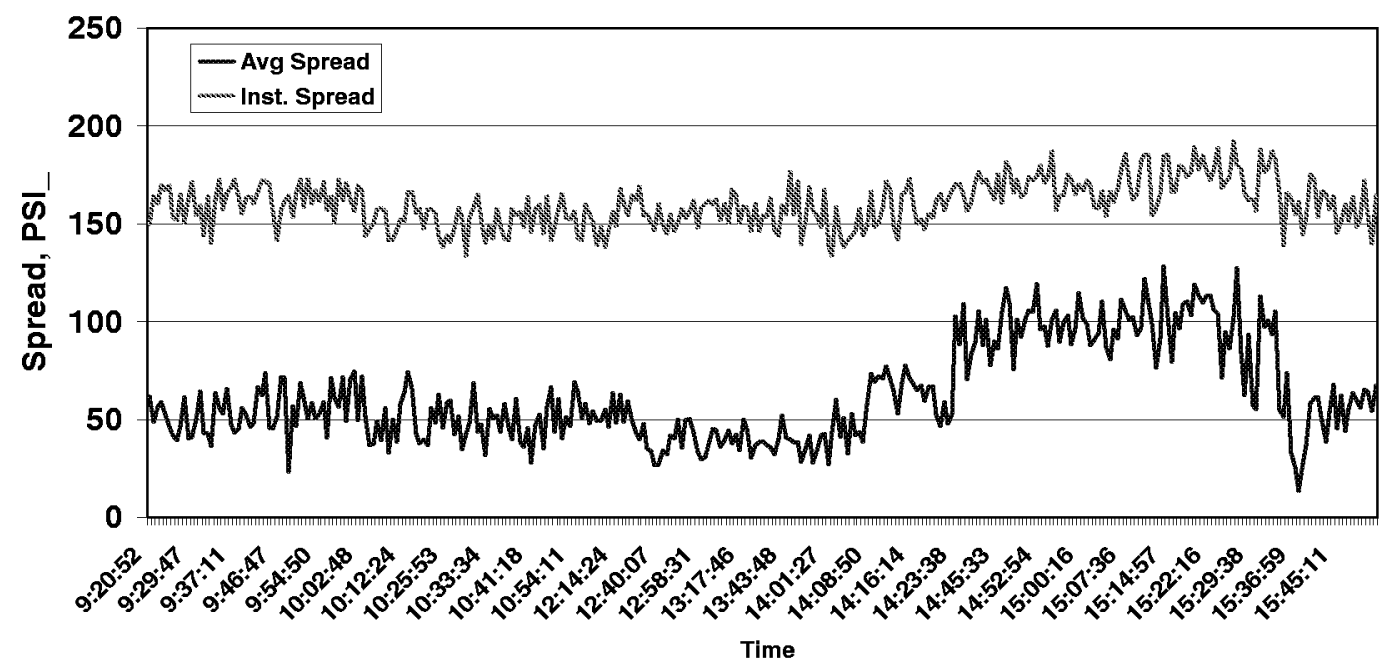

Figure 7-34. Instantaneous and Average Spread; Kinder Second Test; Day 2; April 22, 2004

In Figure 7-35 and Figure 7-36, peak-firing pressure (averaged across the six power cylinders) and average spread normalized with respect to average peak-firing pressure are presented. The peak-firing pressure on day 1 starts around 520 PSI, then during the speed reduction tests (down to 280 RPM) falls slightly to as low as 505 PSI, then returns 
to 520 when speed is returned to $300 \mathrm{RPM}$, with slight variation, again, as efforts were made to vary load with changes in load step.

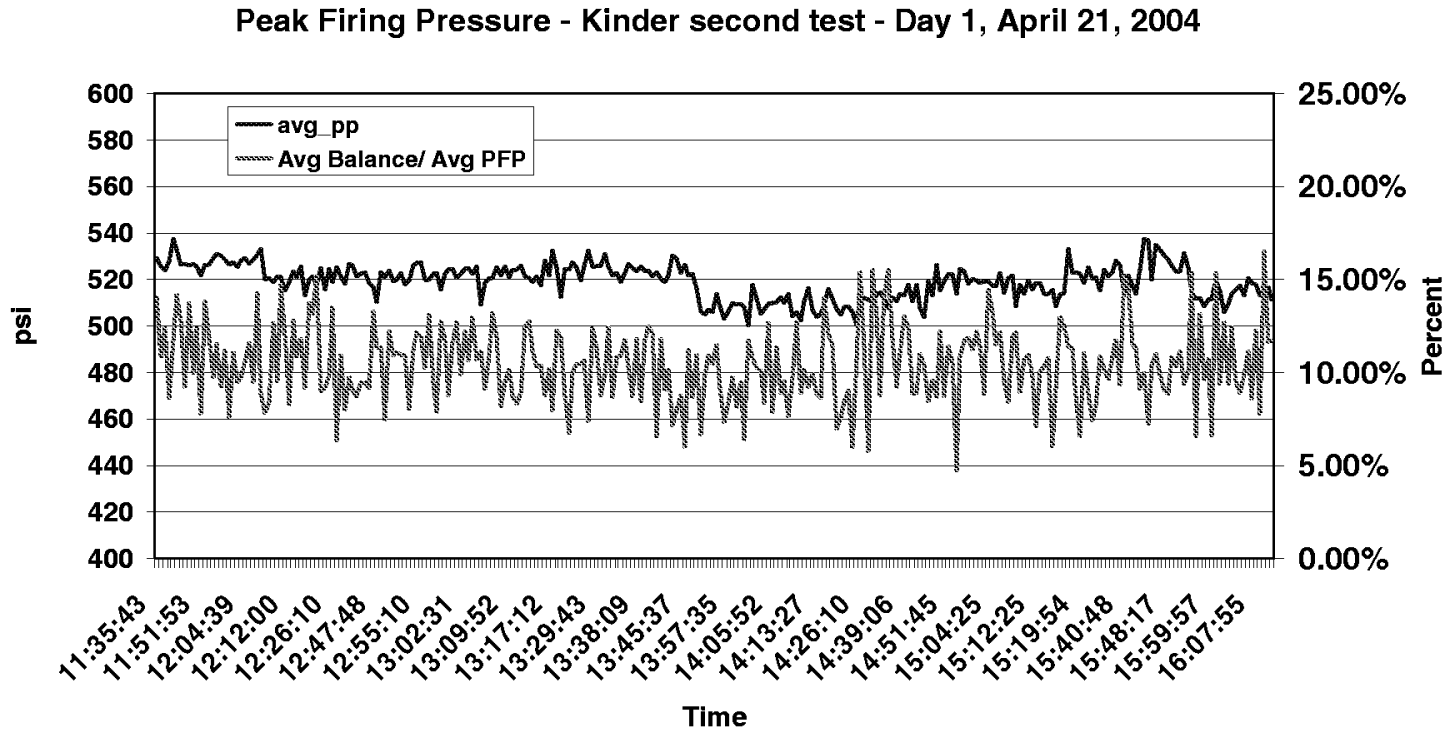

Figure 7-35. Peak-Firing Pressure and Average Spread Normalized by Peak-Firing Pressure; Kinder Second Test; Day 1; April 21, 2004

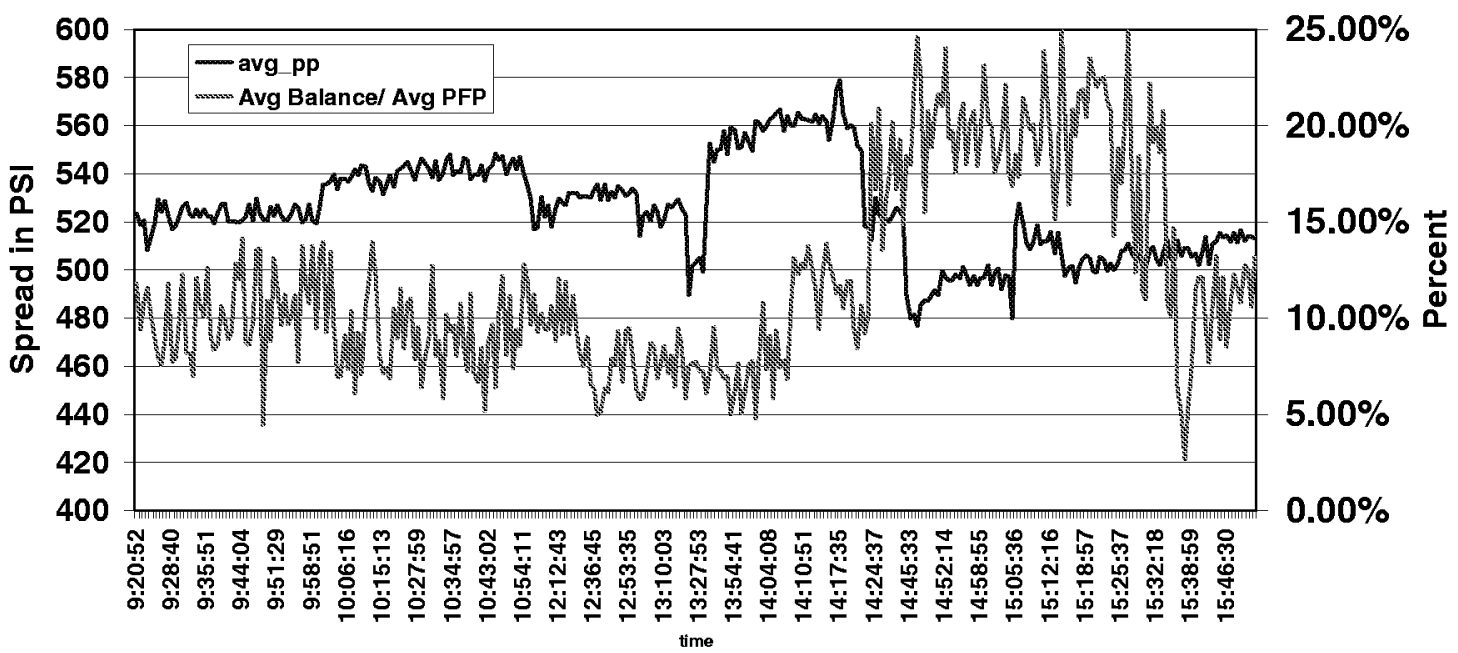

Figure 7-36. Peak-Firing Pressure and Average Spread Normalized by Peak-Firing Pressure; Kinder Second Test; Day 2, April 22, 2004 
On day 2, Figure 7-36 shows that peak-firing pressure increases noticeably when speed is decreased (between 10:00 and 12:00) under equivalence ratio control. The peak-firing pressure clearly rises again at 13:50 as timing is advanced, then drops to around 500 PSI when the fuel valves are all opened wide. The normalized average spread on day 1 is generally 10 to $12 \%$. On day 2 , it starts at a similar level, but CPR balancing around 12.40 reduces the normalized average speed to about $7.5 \%$.

Figure 7-37 and Figure 7-38 show the variation of compression pressure (pressure 20 degrees before TDC) and the angle of peak-firing pressure. During the tests on day 1, both stay rather constant. Compression pressure is around 210 with a range from 204 to 215 (5\% variation). There is a slight reduction of 2 or 3 PSI in compression pressure when speed is reduced to 290 and 280 RPM. Peak angle averages about $22^{\circ}$ with extremes from about $17.5^{\circ}$ to $26^{\circ}$. On day 2, Figure 7-38 shows more variation in compression pressure, which lies between 200 and 223 PSI, although its average stays around 210 PSI. The difference between days 1 and 2 is that the air manifold pressure was held as constant as possible on day 1, whereas it was allowed to vary more widely in order to maintain a global equivalence ratio set point on day 2. Varying boost pressure affects the mass of air trapped in the cylinder and, therefore, affects compression pressure. Thus, on day 2 when speed is reduced, compression pressure falls by between 5 and 10 PSI, compared to the 2 or 3 PSI on day 1 . There is also a reduction in compression pressure when timing is advanced at about 13:43. The matching drop in peak angle and compression pressure is clear in Figure 7-38. This is likely a result of changes in boost pressure to maintain equivalence ratio as timing is changed. The high values of compression pressure towards the end of day 2 are likely a result of opening up all the fuel valves and efforts to richen the mixture during detonation tests - the amount of air required to maintain equivalence ratio under these conditions also goes up - hence, a higher compression pressure.

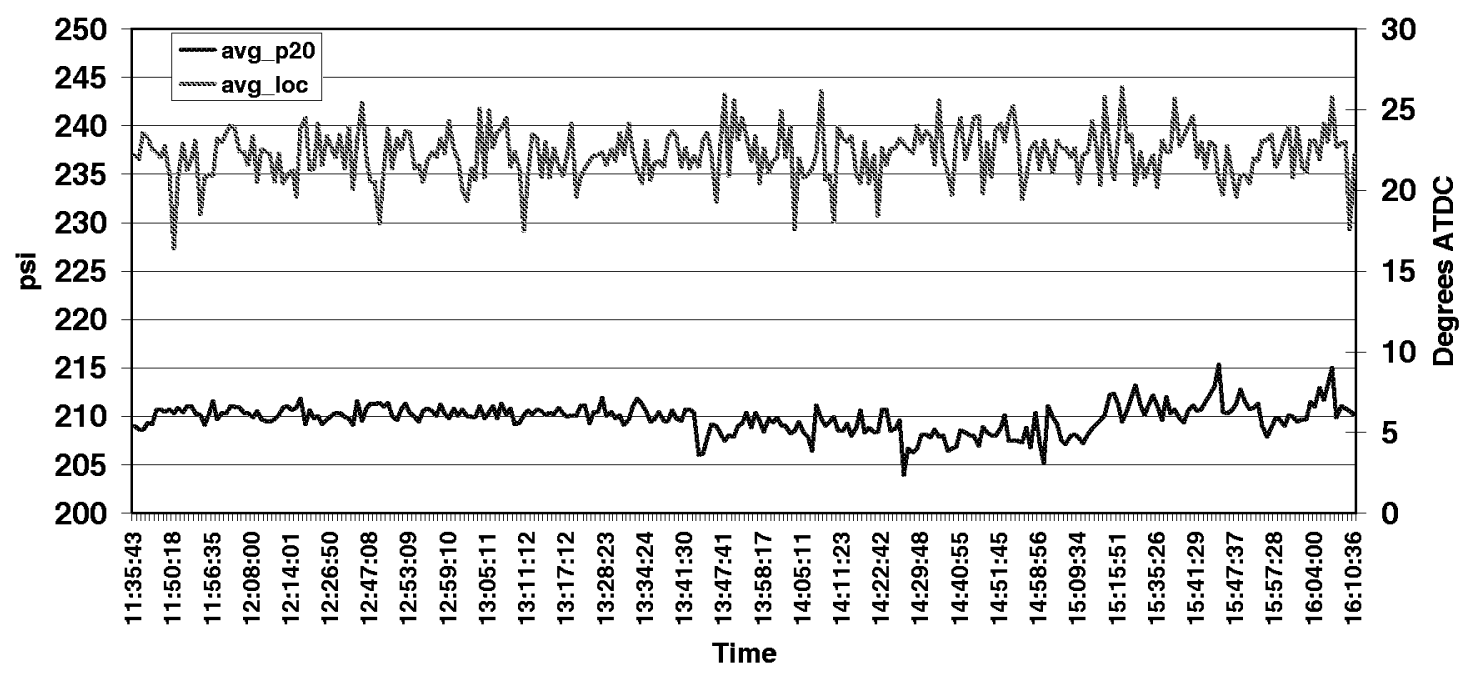

Figure 7-37. Power Cylinder Pressure 20 Degrees BTDC and Angle of Peak-Firing Pressure; Kinder Second Test; Day 1; April 21, 2004 


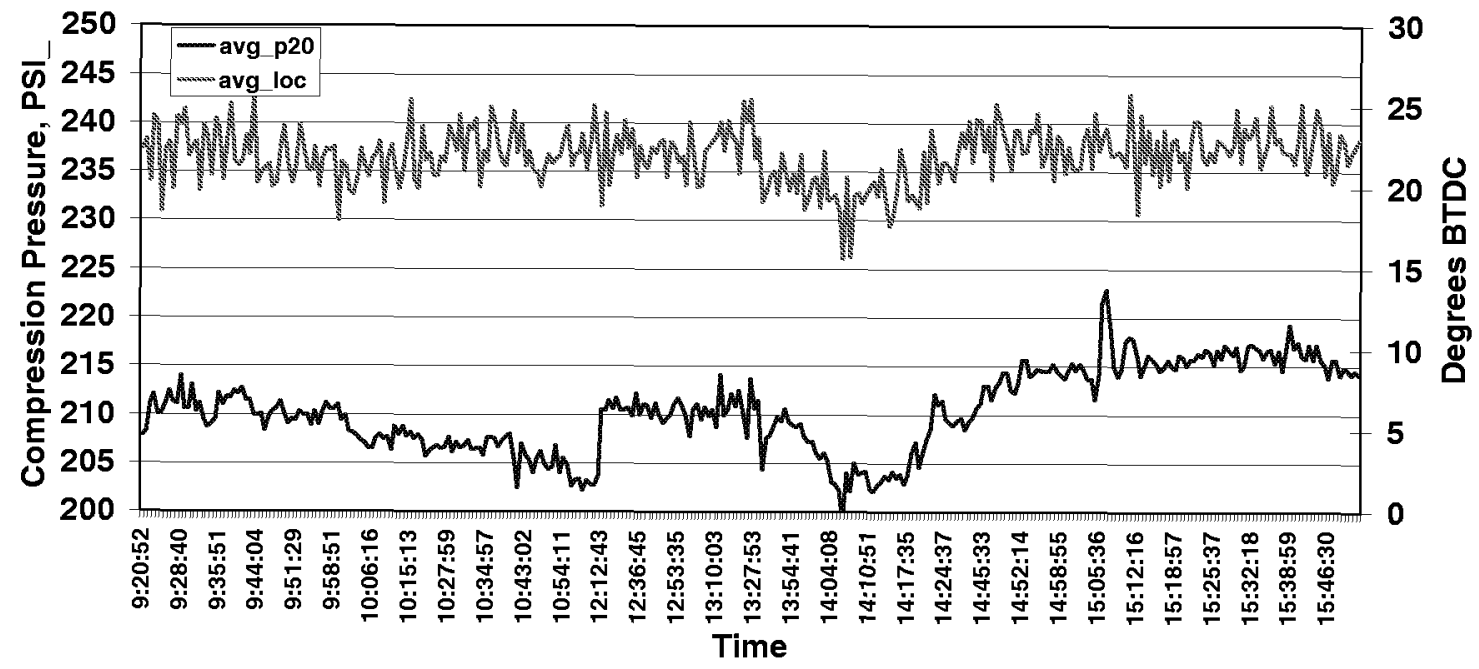

Figure 7-38. Power Cylinder Pressure 20 Degrees BTDC and Angle of Peak-Firing Pressure; Kinder Second Test.; Day 2; April 22, 2004

Figure 7-39 and Figure 7-40 present and compare the maximum standard deviation with time for days 1 and 2. The levels of standard deviation during much of each day are similar at around 70 PSI. Some difference is seen in the speed variation tests. On day 1 with no equivalence ratio control, the maximum standard deviation goes up to about 78 or 80 PSI - starting around 14:00 with the reduction to 290 RPM, and more strongly at 280 RPM from 14:28 to $15: 09$.

On day 2, Figure 7-40 shows maximum standard deviation staying very constant under equivalence ratio control, with a slight reduction below 70 PSI during the speed reduction tests 10:00 to 11:00. Comparison with Figure 7-31 and Figure 7-32 for day 1 and day 2, temporal standard deviation averaged across the cylinders. The maximum standard deviation is typically 10 to 15 PSI higher than the average. 


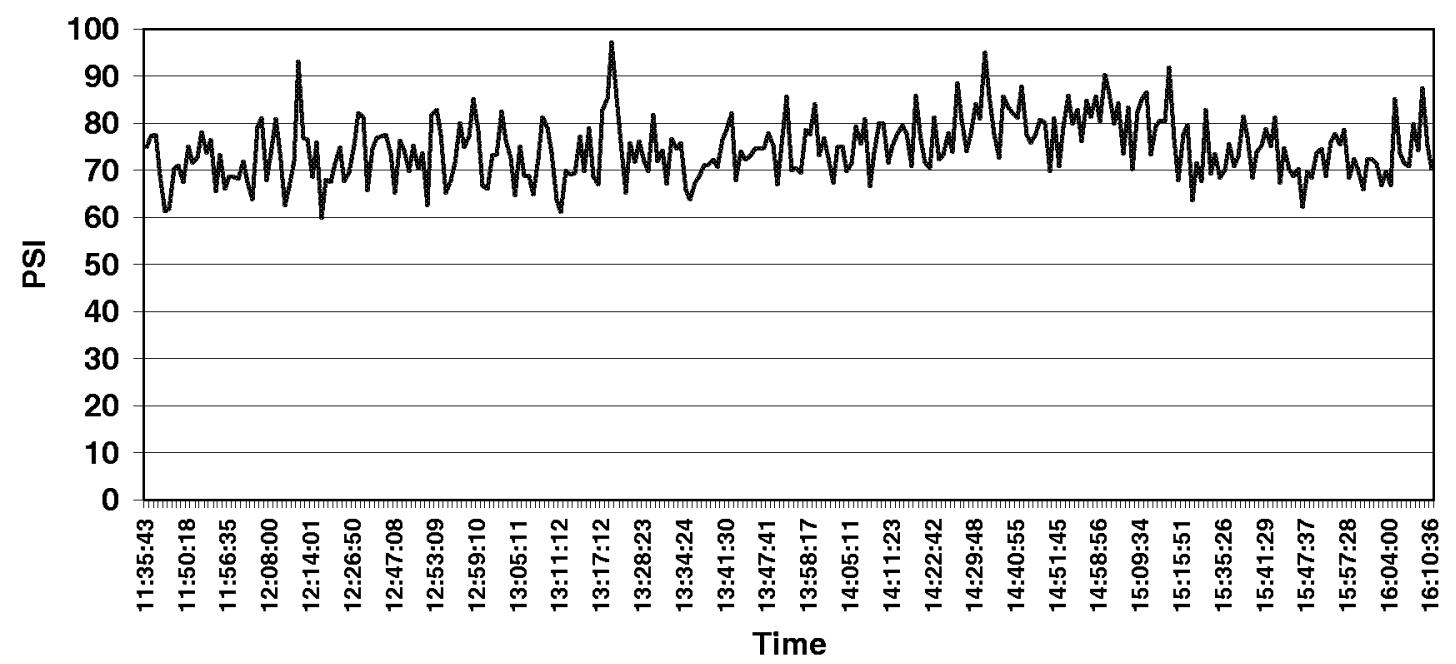

Figure 7-39. Maximum Standard Deviation from All Power Cylinders; Kinder Second Test; Day 1; April 21, 2004

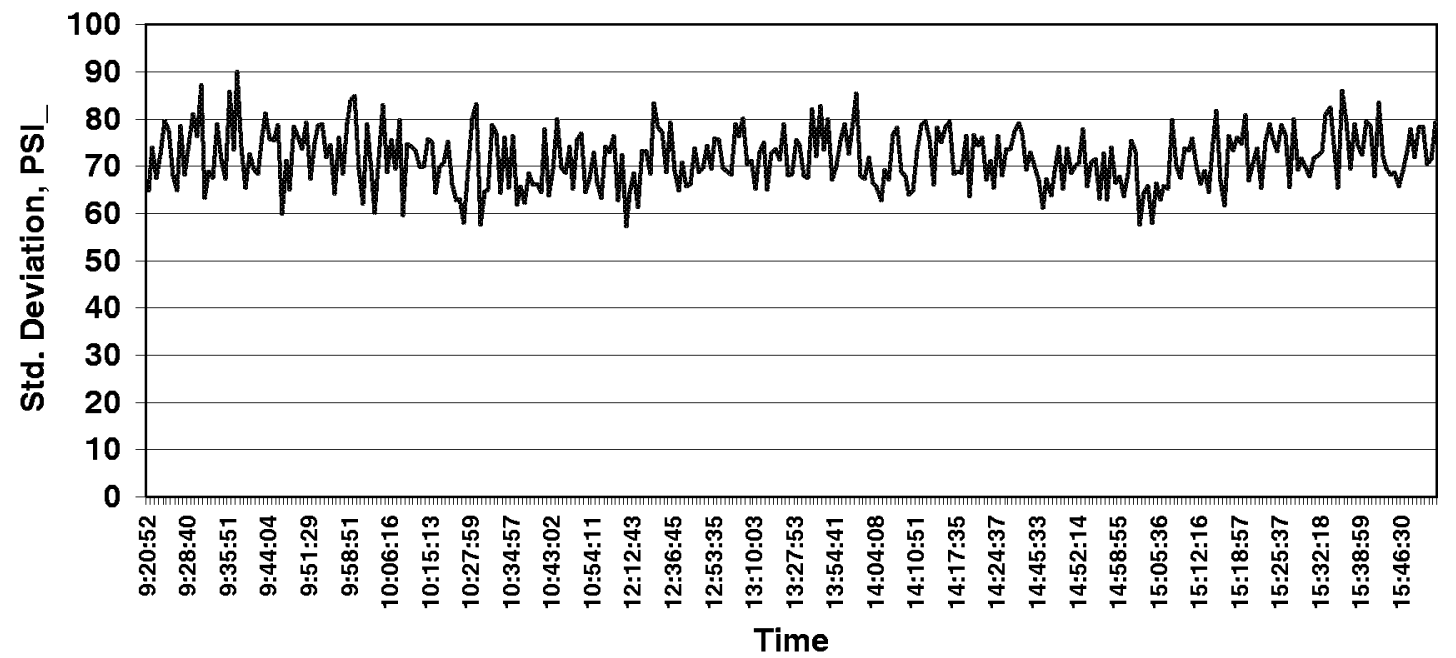

Figure 7-40. Maximum Standard Deviation from All Power Cylinders; Kinder Second Test; Day 2; April 22, 2004 
Figure 7-41 and Figure 7-42 show the normalized standard deviation of Combustion Pressure Ratio (CPR) across all cylinders. This is actually the coefficient of variance obtained by dividing the standard deviation in CPR by the average CPR. On day 1 , this starts around 0.09 to 0.1 , with a wide range in local values from 0.04 to 0.14 . During the speed reduction tests, this normalized deviation goes up quite clearly to 0.14 , then returns to 0.1 when speed returns to 300 .

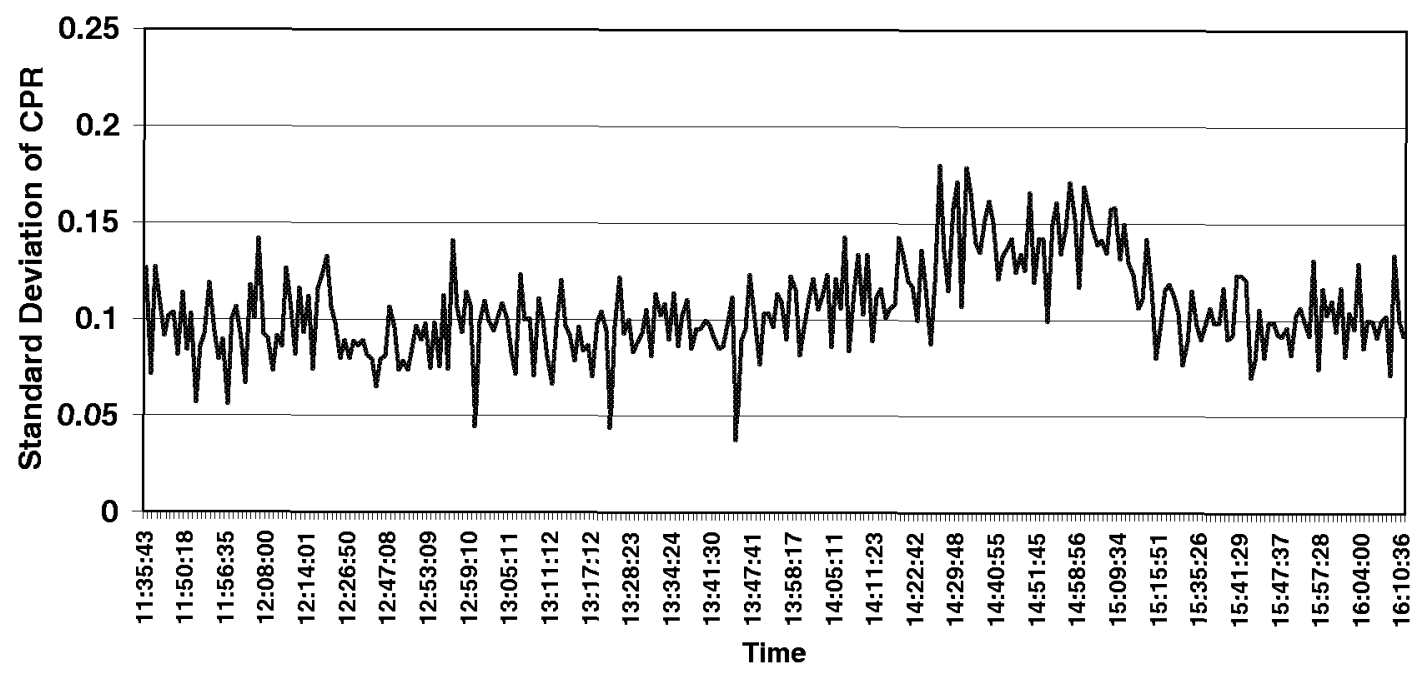

Figure 7-41. Normalized Standard Deviation of Combustion Pressure Ratio across All Power Cylinders; Kinder Second Test; Day 1; April 21, 2004

On day 2, this COV of CPR starts at a similar level to day 1 and is unaffected by speed changes. Of course, it drops sharply as a result of CPR balancing to 0.025 - indicating first how precise a balance condition can be obtained with CPR balancing. It goes up to about 0.08 with timing increase, then to 0.15 or 0.16 when all fuel valves were opened.

Finally, with rebalancing towards the end of the day, the COV of CPR drops to 0.05 or 0.06 . 


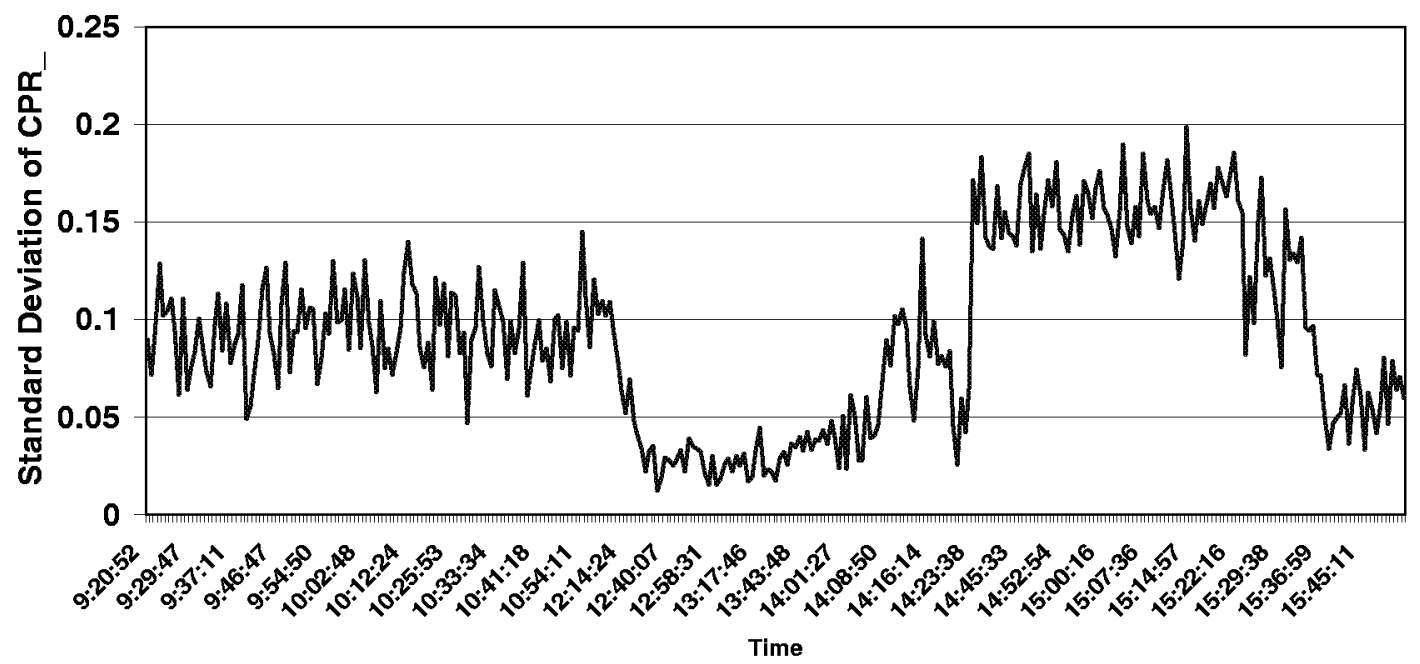

Figure 7-42. Normalized Standard Deviation of Combustion Pressure Ratio Across all Power Cylinders; Kinder Second Test; Day 2; April 22, 2004

Figure 7-43 and Figure 7-44 present overall system thermal efficiency. Most of day 1, this overall efficiency is around $27.3 \%$. On day 2 with the equivalence ratio control system, thermal efficiency is close to $28 \%$ - right through the speed variation tests. It increases slightly during the reduced speed tests - as might be expected with lower losses, then drops to $27.8 \%$ after the speed is returned to 300 RPM. After CPR balancing, there is a very slight increase, and then a significant drop to about $26.6 \%$, then a smaller increase. Review of earlier figures, particularly for compressor load, shows a sudden small drop in compressor load at 13:09 exactly when this drop in efficiency occurs. This drop in load is 4 to $5 \%$, which does not appear large, but as subsequent analysis will show, engine efficiency, heat rate and, therefore, system efficiency are extremely sensitive to load. Thus, it can be misleading to try and assess how other factors appear to influence heat rate when changes in load may be a major contributor. 


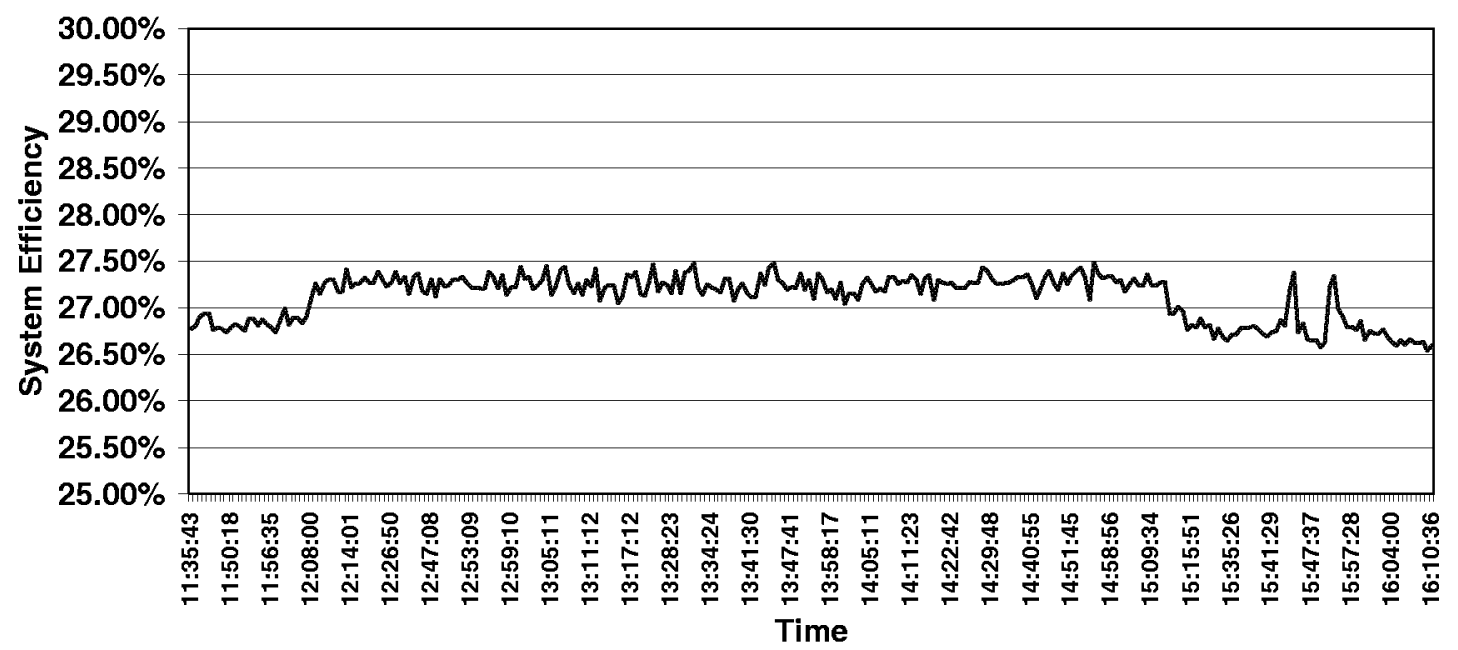

Figure 7-43. Overall System Efficiency; Kinder Second Test; Day 1; April 21, 2004

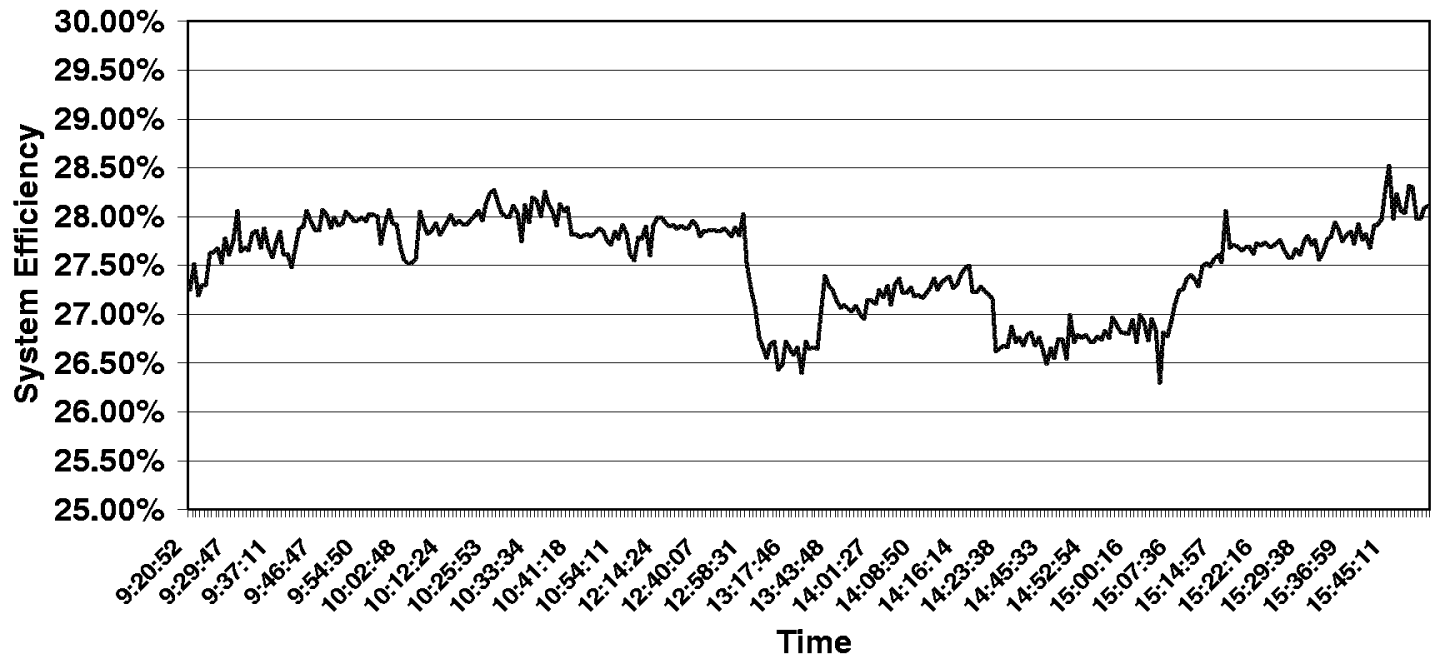

Figure 7-44. Overall System Efficiency; Kinder Second Test; Day 2; April 22, 2004 


\subsection{Data from the Strain Data Capture Module (SDCM) - Kinder Second TEST}

Figure 7-45 presents output in microstrain from the Strain Data Capture Module (SDCM) during the first day as a function of minutes from when the SDCM started taking data. The figure shows about 130 minutes of "inactivity" since after the SDCM starts to take data, the crank case cover has to be re-installed, and an operator has to take the time to initiate and follow a start-up procedure and reach steady operation. The start occurs at about 130 minutes and initial strain reaches about 88 microstrain before dropping to about 71 in the first five minutes of operation. Strain rises very slightly during the next 3.5 to 4 hours at which point the speed reduction runs start. Crankshaft strain then drops rapidly as speed is reduced. Figure 7-46, Figure 7-47, and Figure 7-48 present three typical 10-revolution snapshots for 300, 290, and 280 RPM. Each presents the variation of strain over about 2 seconds - showing the presence of both first and second order variation in waveform of the approximately ten revolutions. The peak-to-peak variation in each snapshot reduces from over 70 at 300 RPM to 68 at 290 to 62 at 280 RPM. This result is summarized in Table 7-1, giving peak-to-peak microstrain and percentage reduction as a function of speed. The reduction with speed is dramatic, reaching $17 \%$, and must be strongly related to the reduction in inertia forces, since the nominal torque does not change significantly with speed. Inertia forces are proportional to the second power of speed, so with appropriate phasing of the response to inertia forces and gas forces, the peak-to-peak force could be very strongly influenced by a speed squared reduction in one of its components. Of course, there is sometimes some influence of near resonant torsional vibration in the variation of crankshaft strain with speed, which might also influence these observations of reduction in peak-to-peak strain. However, the torsional vibration normally shows up in higher orders, since the first crankshaft torsional natural frequency is usually at or above the seventh order. 


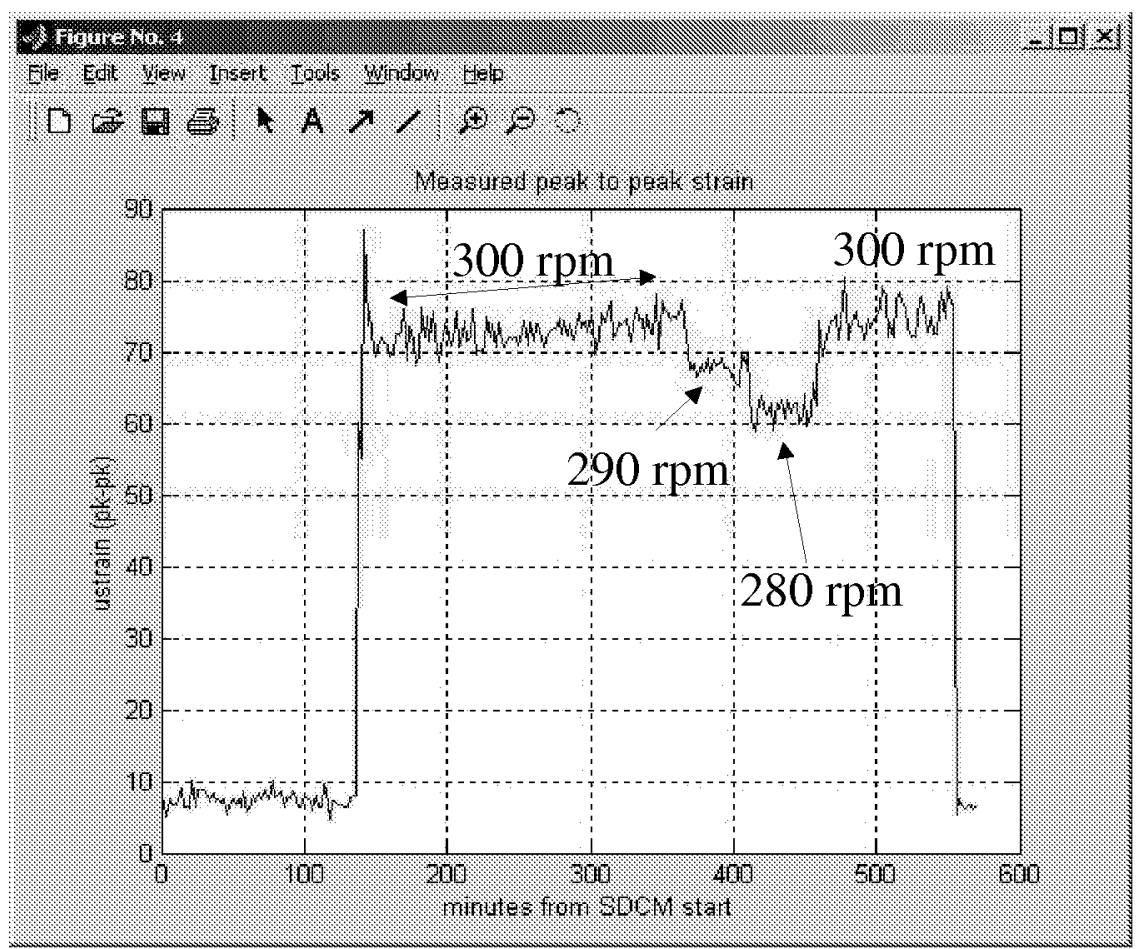

Figure 7-45. Crankshaft shown as a Function of Time from Start of SDCM Data Acquisition; Kinder Second Test; Day 1; April 1, 2004

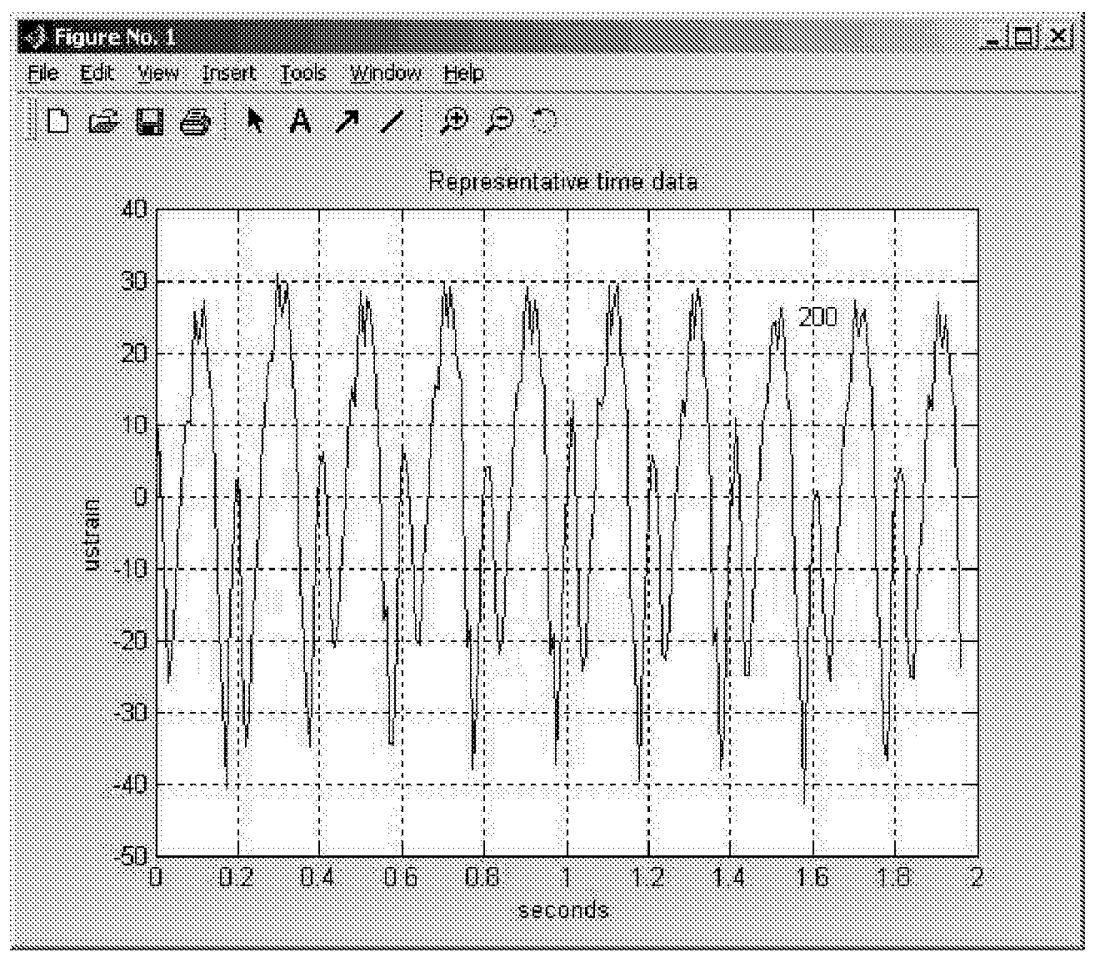

Figure 7-46. Crankshaft Strain Snapshot; 300 RPM; Kinder Test 2; Day 1; April 21, 2004 


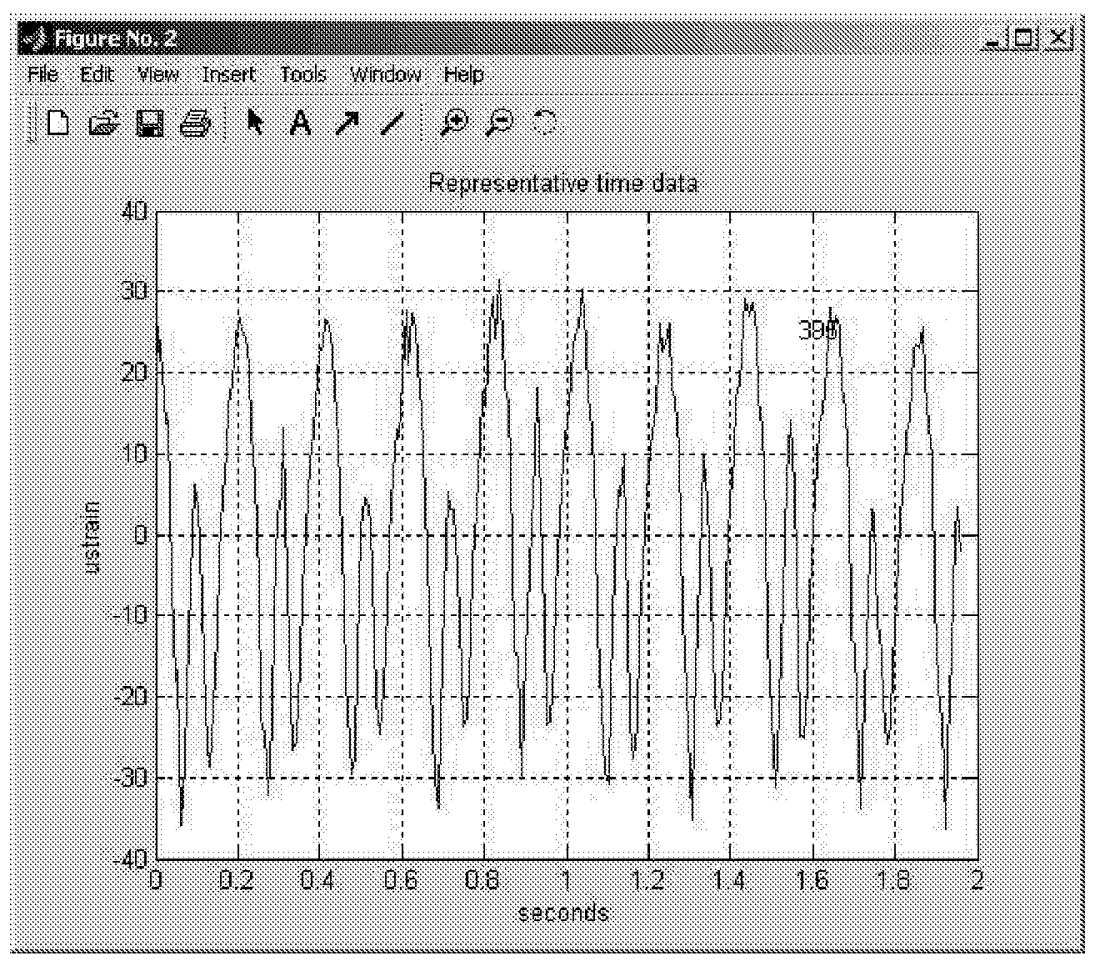

Figure 7-47. Crankshaft Strain Snapshot; 290 RPM; Kinder Test 2; Day 1; April 21, 2004

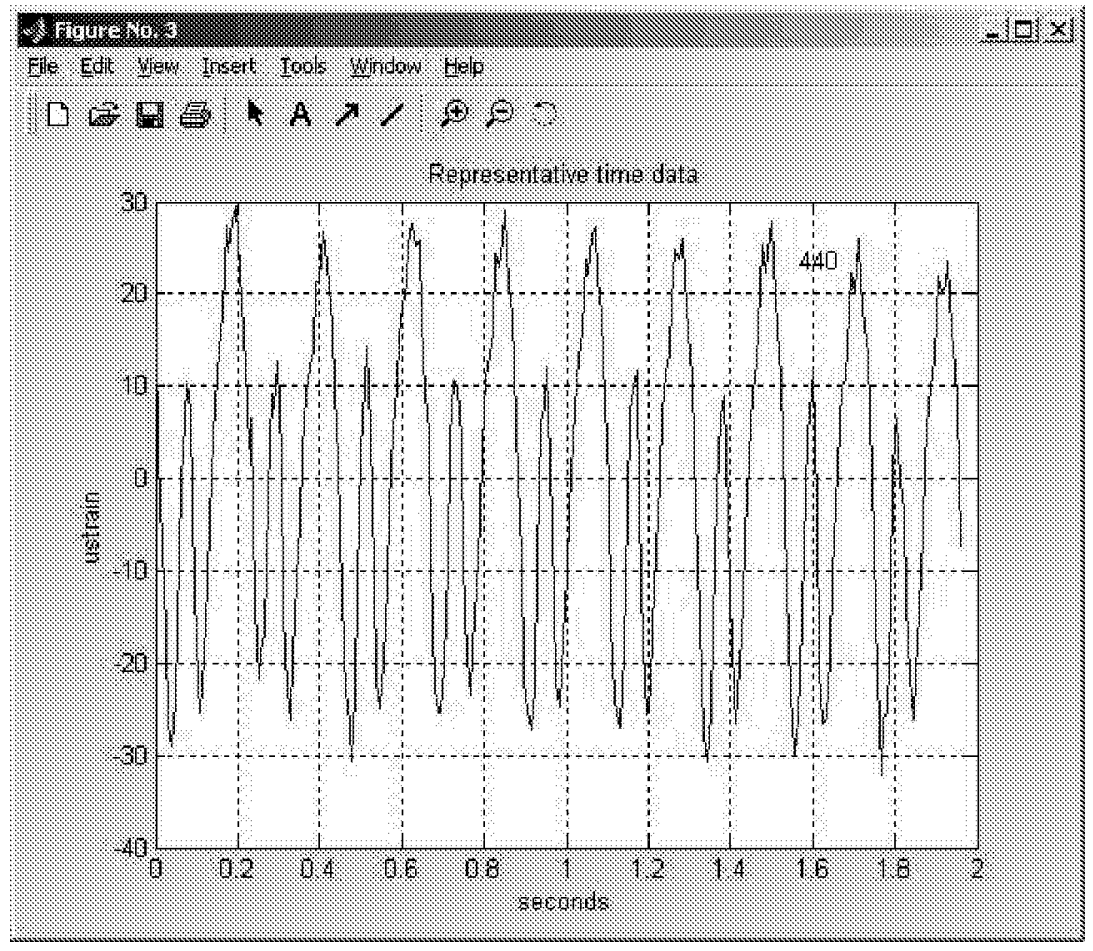

Figure 7-48. Crankshaft Strain Snapshot; 280 RPM; Kinder Test 2; Day 1; April 21, 2004 
Table 7-1. Crankshaft Strain Summary Table; Kinder Test 2; Day 1

\begin{tabular}{|c|c|c|}
\hline RPM & $\begin{array}{c}\mu \text { STRAIN } \\
\text { (PEAK-PEAK) }\end{array}$ & \\
\hline 300 & 75 & REDUCTION \\
\hline 290 & 68 & $9.3 \%$ \\
\hline 280 & 62 & $17.3 \%$ \\
\hline
\end{tabular}

Figure 7-49 presents similar output from the SDCM for day 2, as a function of minutes from the start of data acquisition. On day 2, the unit started within 30 minutes of starting the SDCM. The same overshoot is seen in the initial start-up with SDCM output then settling down at 70 microstrain - slightly lower than on day 1 . During the speed reduction test, the peak-to-peak strain levels reduced again. Figure 7-50, Figure 7-51, and Figure 7-52 show several representative 2-second strain snapshots for 300 RPM, 290 RPM, and 280 RPM operation with global equivalence ratio control. Table 7-2 shows the levels at 290 and 280 RPM were close to the previous days levels, but the value at 300 RPM was somewhat lower (70 versus 75 microstrains). Thus, the percentage reduction with speed is lower (11.4\% reduction from 300 to 280 RPM, but clearly more than linearly proportional to the speed reduction). Table 7-2 also shows strain values for several test conditions matching up with notations in Figure 7-49. As previously documented at Williams' Station 60, the advance in timing from $10^{\circ}$ to $12^{\circ}$ led to higher crankshaft strain. The highest strain occurs with the fuel valves open -78 microstrains balancing subsequently coincides with a reduction to 75 microstrain.

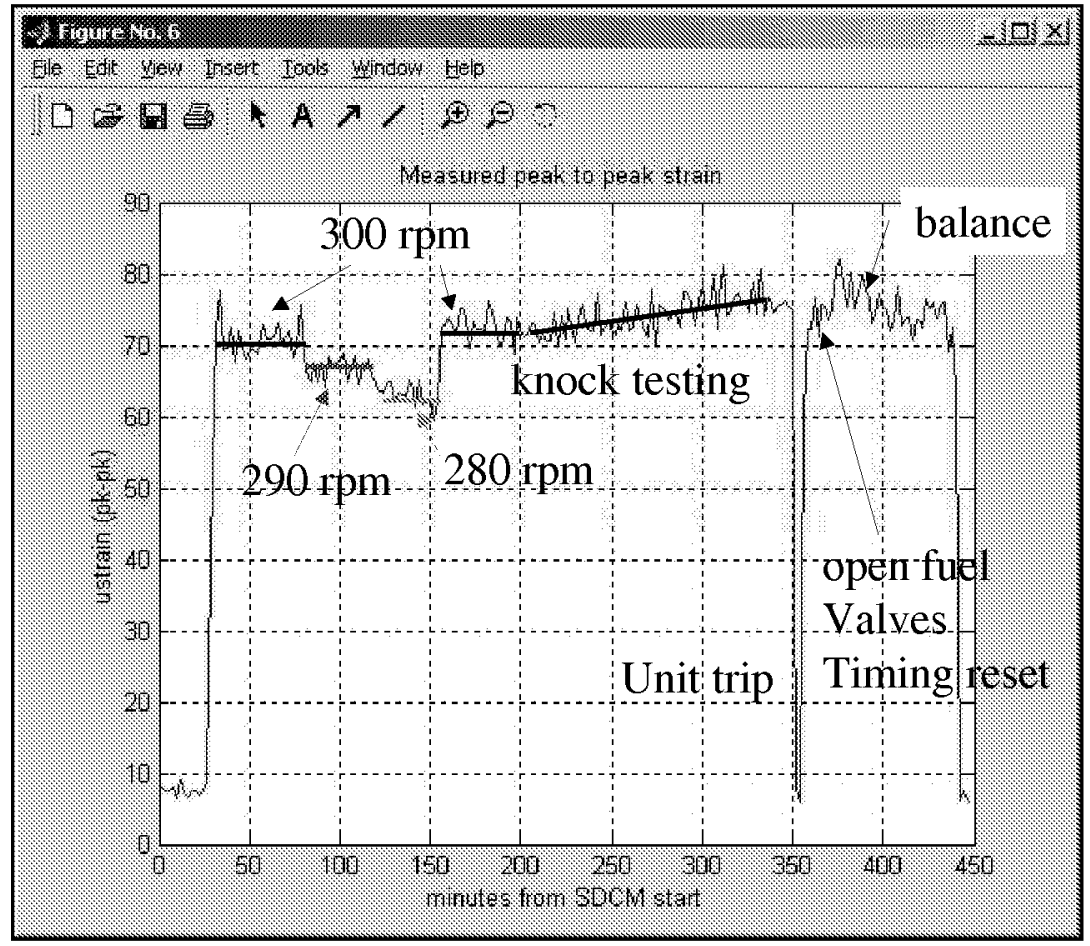

Figure 7-49. Crankshaft Strain as a Function of Time from Start of SDCM Data Acquisition; Kinder Second Test; Day 2; April 22, 2004 


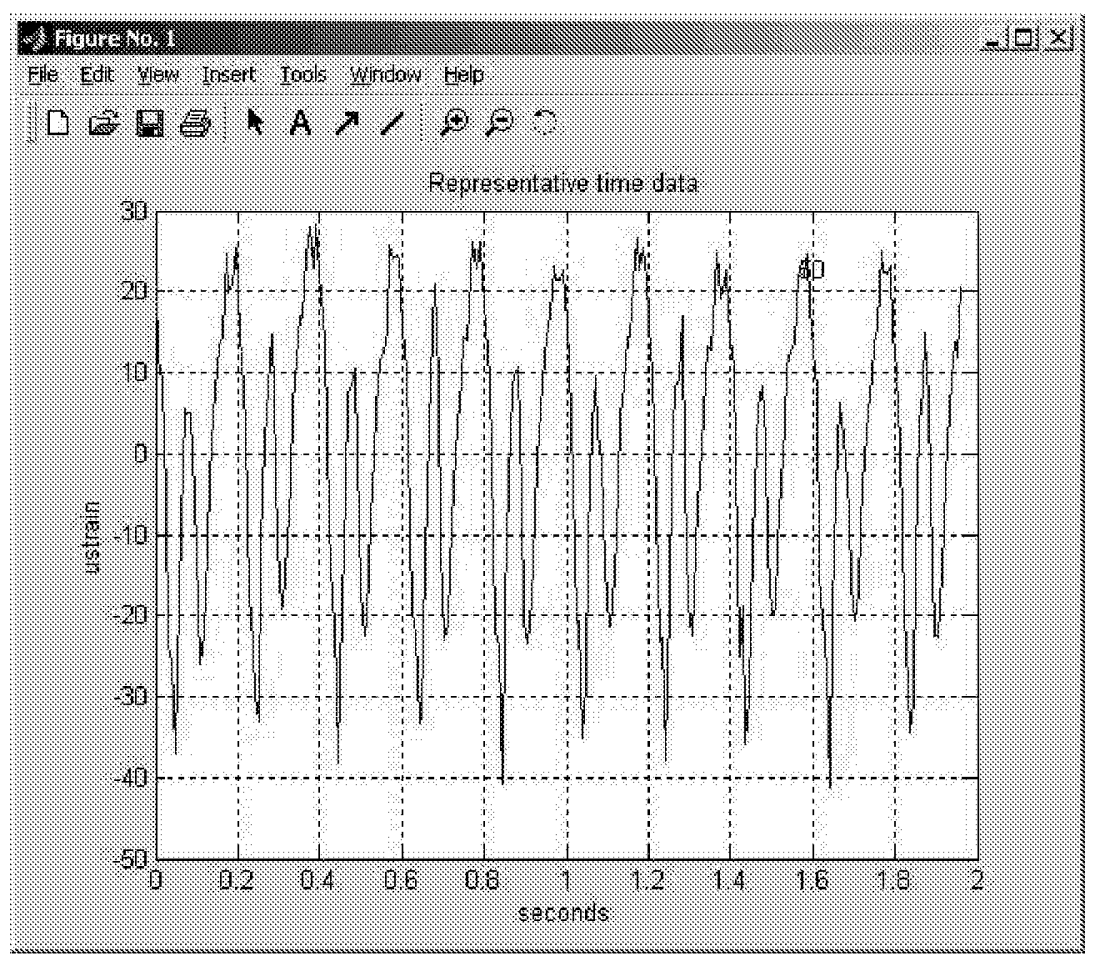

Figure 7-50. Crankshaft Strain Snapshot; 300 RPM; Kinder Test 2; Day 2; April 22, 2004

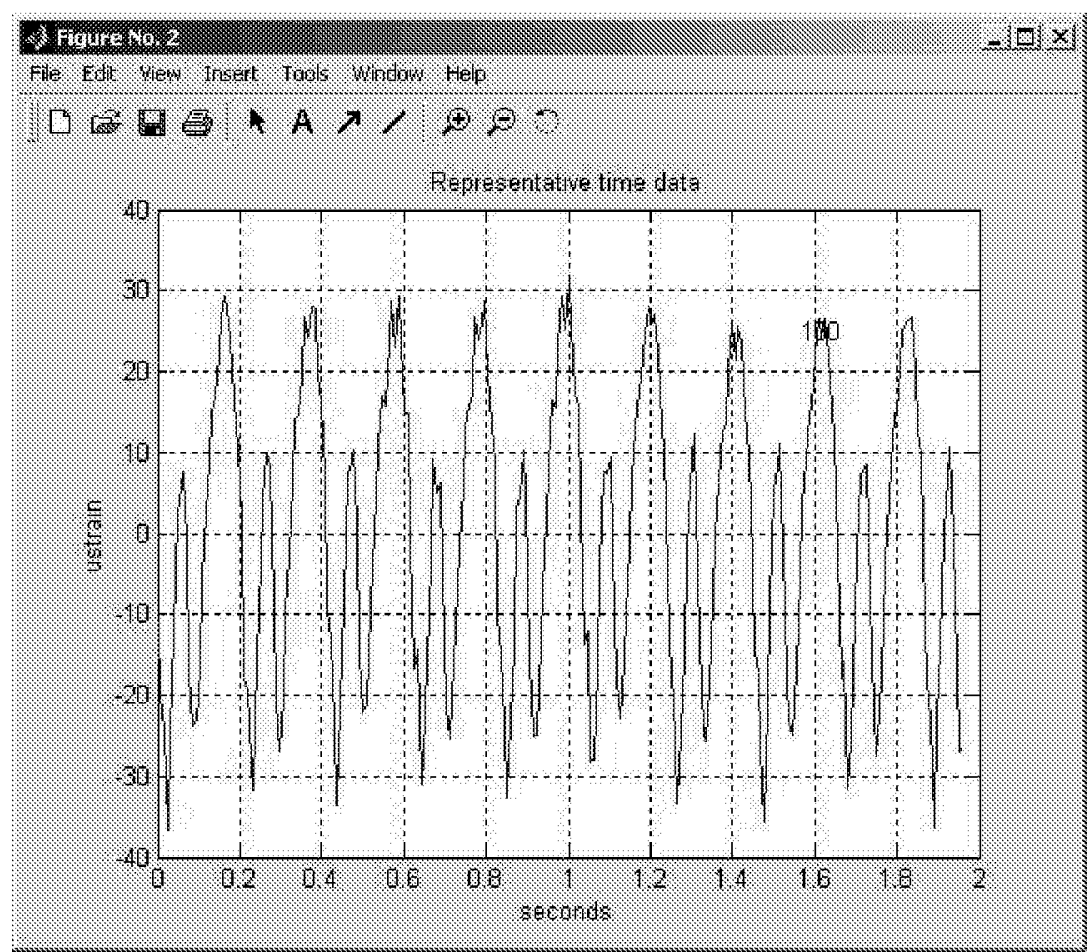

Figure 7-51. Crankshaft Strain Snapshot; 290 RPM; Kinder Test 2; Day 2; April 22, 2004 


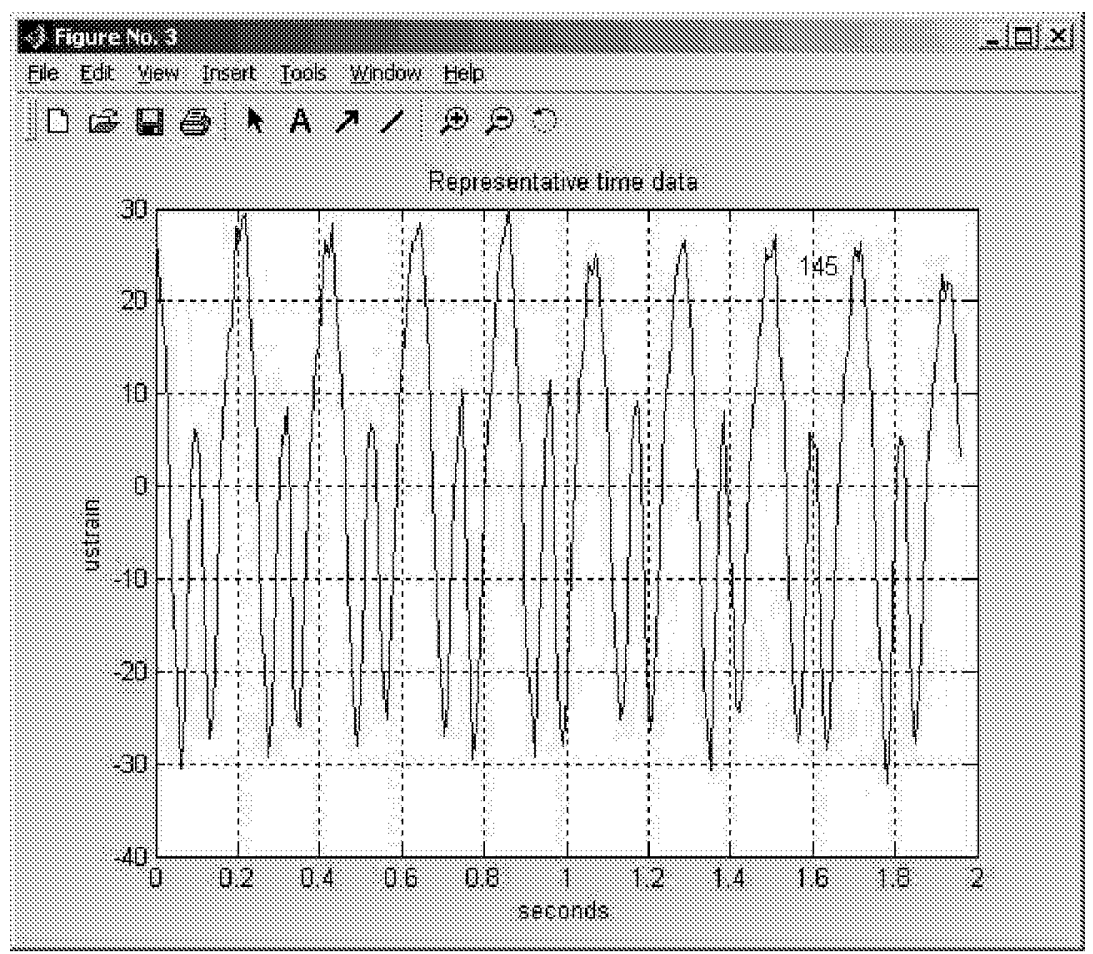

Figure 7-52. Crankshaft Strain Snapshot; 280 RPM; Kinder Test 2; Day 2; April 22, 2004

Table 7-2. Crankshaft Strain Summary Table; Kinder Test 2; Day 2

\begin{tabular}{|c|c|c|}
\hline RPM & $\begin{array}{c}\text { HSTRAIN } \\
\text { (PEAK-PEAK) }\end{array}$ & REDUCTION \\
\hline 300 & 70 & $-5.7 \%$ \\
\hline 290 & 66 & $-11.4 \%$ \\
\hline 280 & 62 & $+6.6 \%$ \\
$\begin{array}{c}\text { (Timing - 12 } \\
\text { Degrees, Rich Fuel) }\end{array}$ & 75 & \\
\hline $\begin{array}{c}\text { Fuel Valve Open, } \\
\text { Baseline Timing }\end{array}$ & 78 & \\
\hline $\begin{array}{c}\text { Balanced, Spread } \\
\text { Change }=40 \text { PSI }\end{array}$ & 75 & $-3.8 \%$ \\
\hline
\end{tabular}




\subsection{Heat Rate Summaries - Kinder Second Test}

Figure 7-53 and Figure 7-54 superimpose averaged values for fuel flow and compressor IHP on their variations for day 1 . Table 7-3 summarizes the heat rates from the day 1 data set. It shows very little change in heat rate between 300 and 290 RPM - a $0.42 \%$ reduction in heat rate between 300 and 280 RPM, then $1.4 \%$ increases in heat rate from the first 300-RPM data set to the second 300-RPM data set. Close examination of the two 300 RPM data points also shows the IHP was lower by $27 \mathrm{HP}$ for the second data set compared to the first. This seems a small difference, but the smallness of the IHP change may mask a very strong sensitivity of heat rate to load. In fact, this data implies that for a $1.7 \%$ decrease in power, there is a $1.4 \%$ increase in heat rate; i.e., a negative 0.83 nondimensional rate of change of heat rate with load. Clearly, these are just two data points and a larger statistical survey would be appropriate, but this value suggests the sensitivity of heat rate to load should be investigated further.

fuel flow

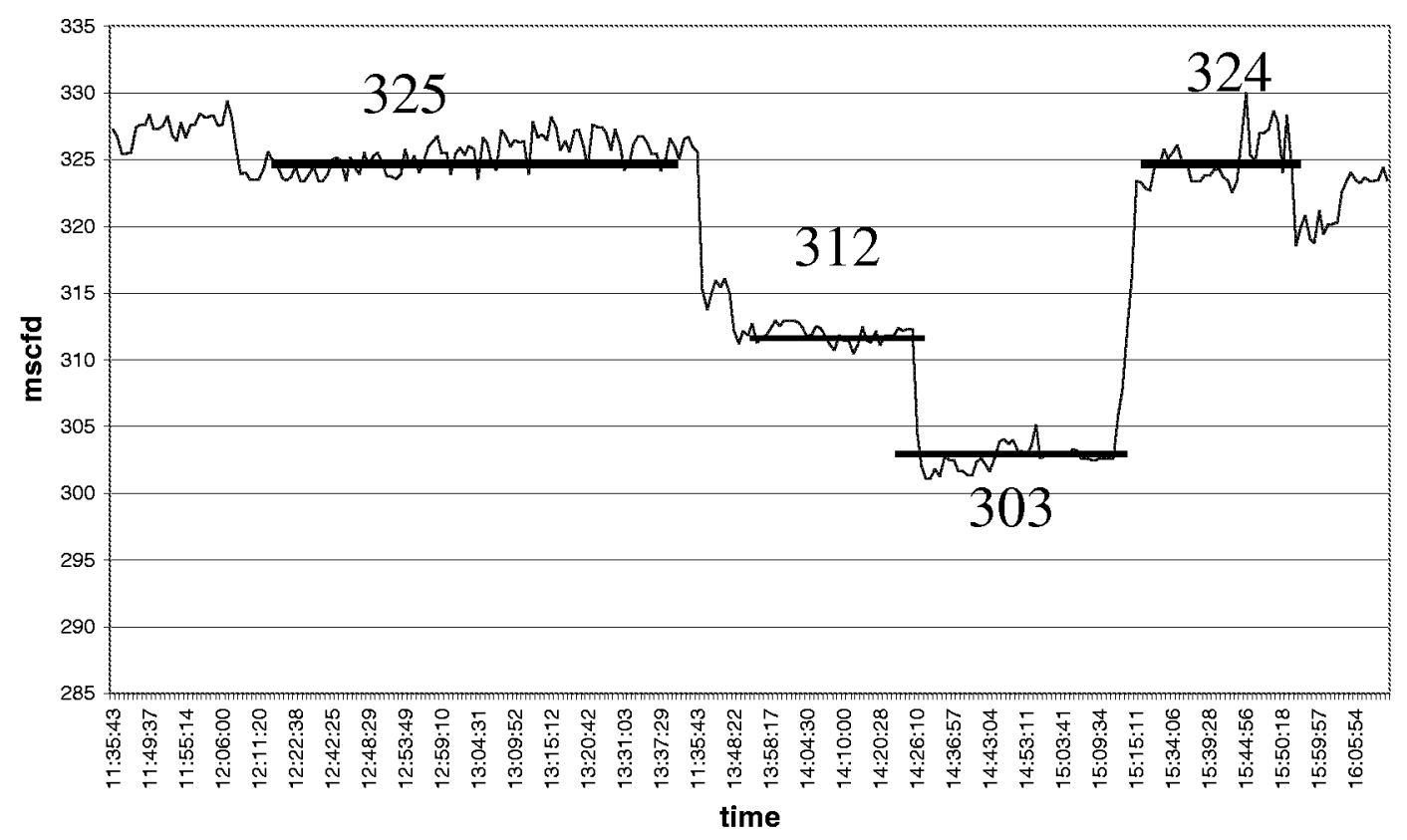

Figure 7-53. Kinder 2; Day 1; Fuel Flow History 


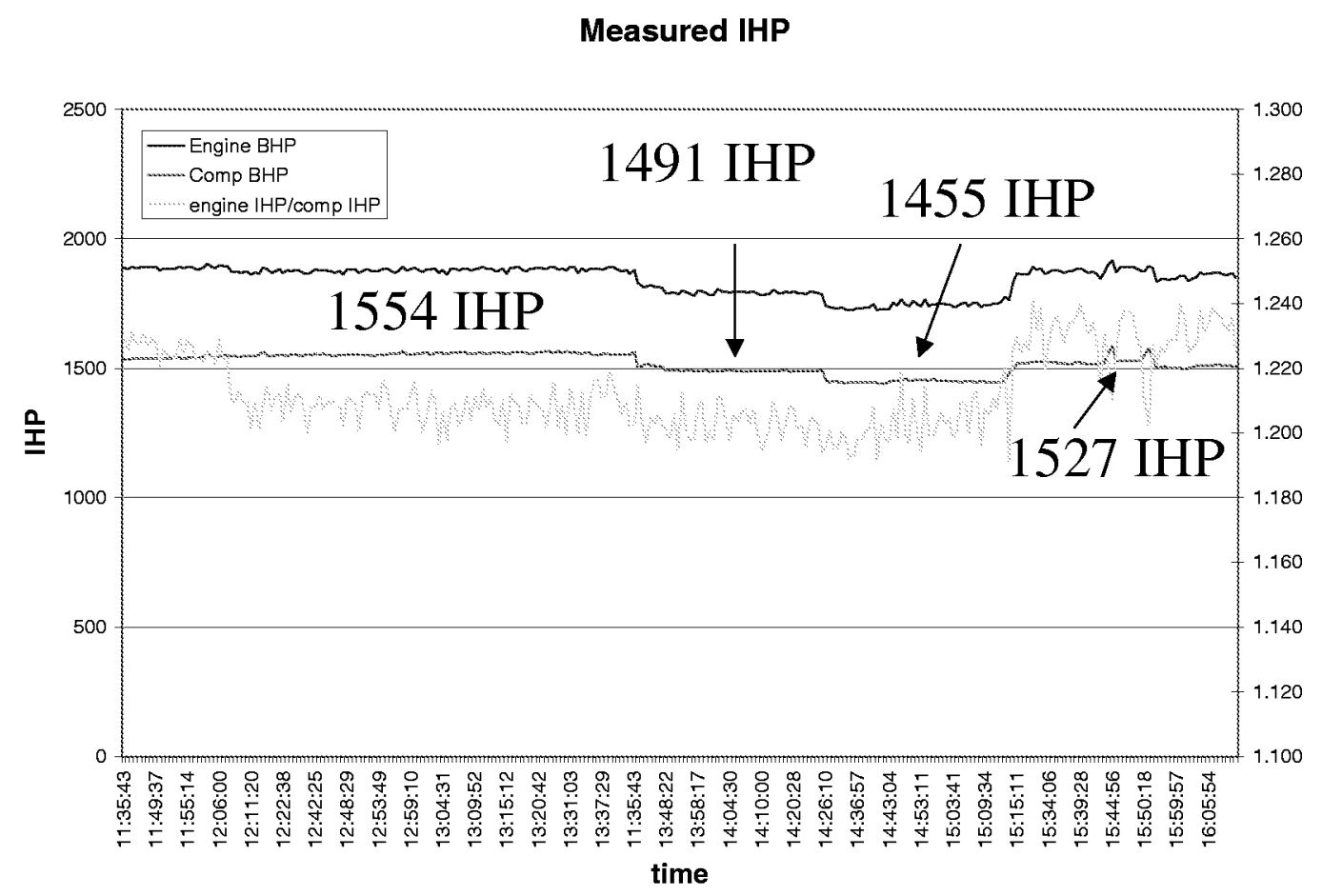

Figure 7-54. Kinder 2; Day 1; IHP History

Table 7-3. Heat Rate Calculations; Kinder 2; Day 1

\begin{tabular}{|c|c|c|c|c|}
\hline RPM & FUEL & IHP & HR & CHANGE \\
\hline 300 & 325 & 1554 & 7947 & \\
\hline 290 & 312 & 1491 & 7951 & $0.05 \%$ \\
\hline 280 & 303 & 1455 & 7913 & $-0.42 \%$ \\
\hline 300 & 324 & 1527 & 8062 & $1.4 \%$ \\
\hline $\mathrm{HR}=0.95^{\star}\left(1000^{\star} \mathrm{FF}^{\star} 960 / 24\right) / \mathrm{IHP}$ & \multicolumn{3}{l}{} \\
\hline
\end{tabular}

Figure 7-55 superimposes averaged values on the day 2 fuel flow chart. Figure 7-56 shows indicated power, and Figure 7-57 shows heat rate values for various test conditions of day 2. Table 7-4 summarizes heat rate calculations based on day 2 tests. The heat rate does not appear to change in this table as speed changes, but there are changes in heat rate as timing is changed. The 2-degree timing change from 10 to 12 degrees corresponds to a $2.2 \%$ reduction in heat rate, and the subsequent change of timing back to 10 degrees corresponds to a $2.2 \%$ increase in heat rate. Opening the fuel valves appears to correspond to a reduction in heat rate to 7810 , and the result of rebalancing corresponds to a further $0.38 \%$ reduction in heat rate. 


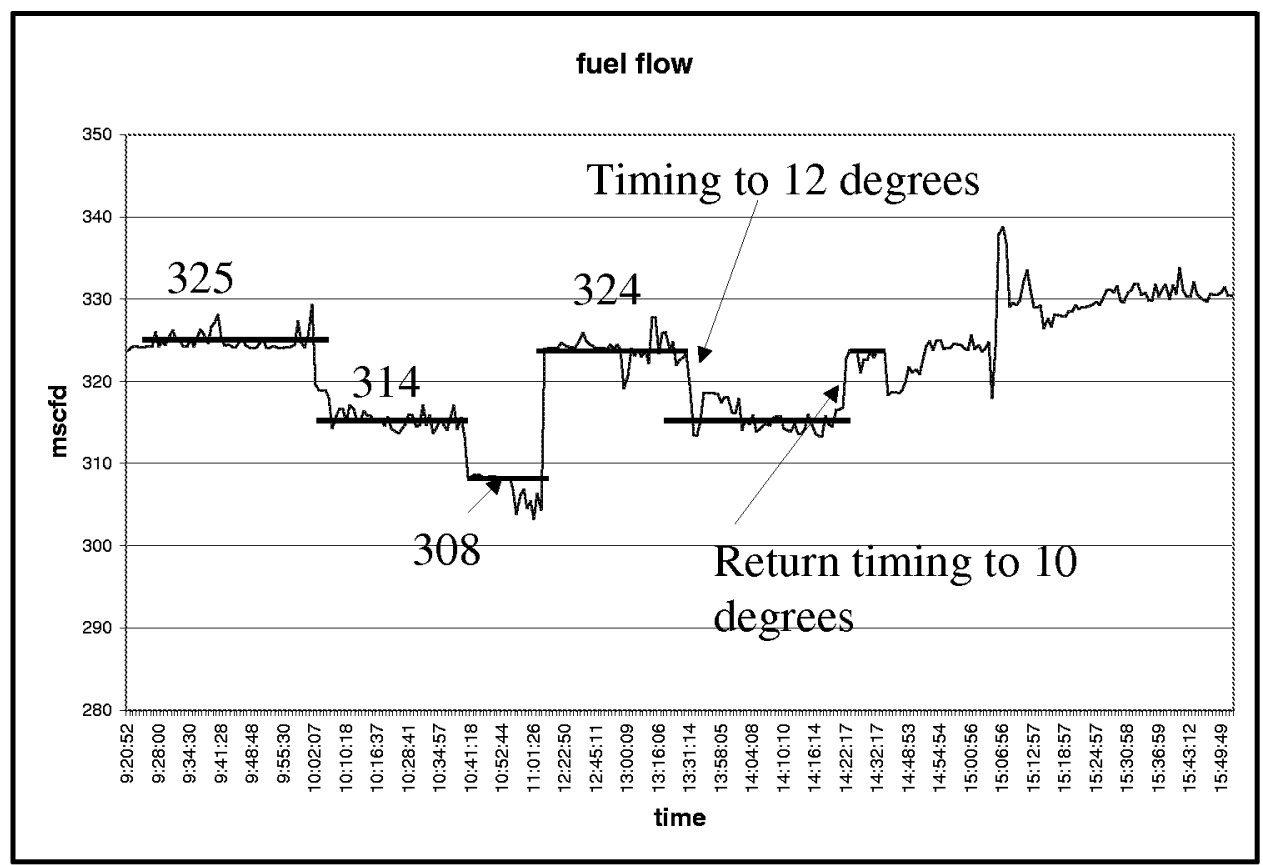

Figure 7-55. Kinder 2; Day 2; Fuel Flow History

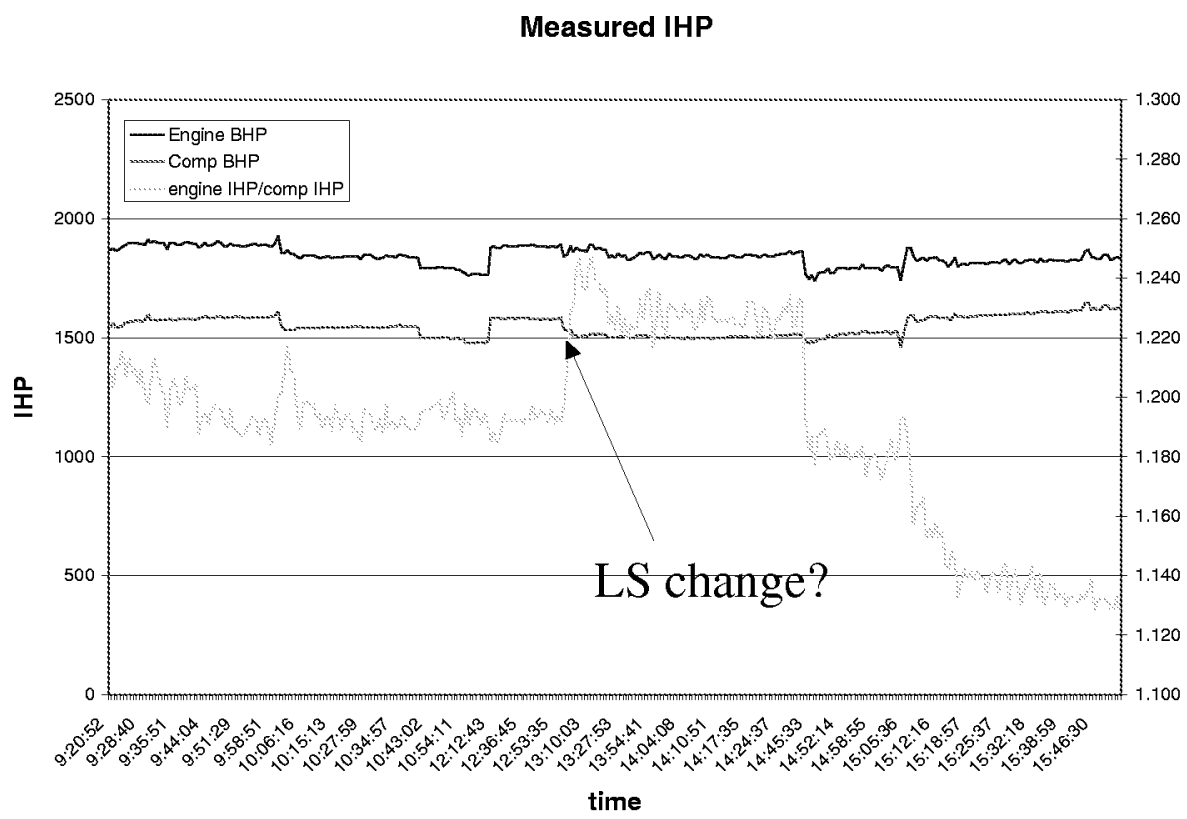

Figure 7-56. Kinder 2; Day 2; IHP History 
Heat Rate (LHV)

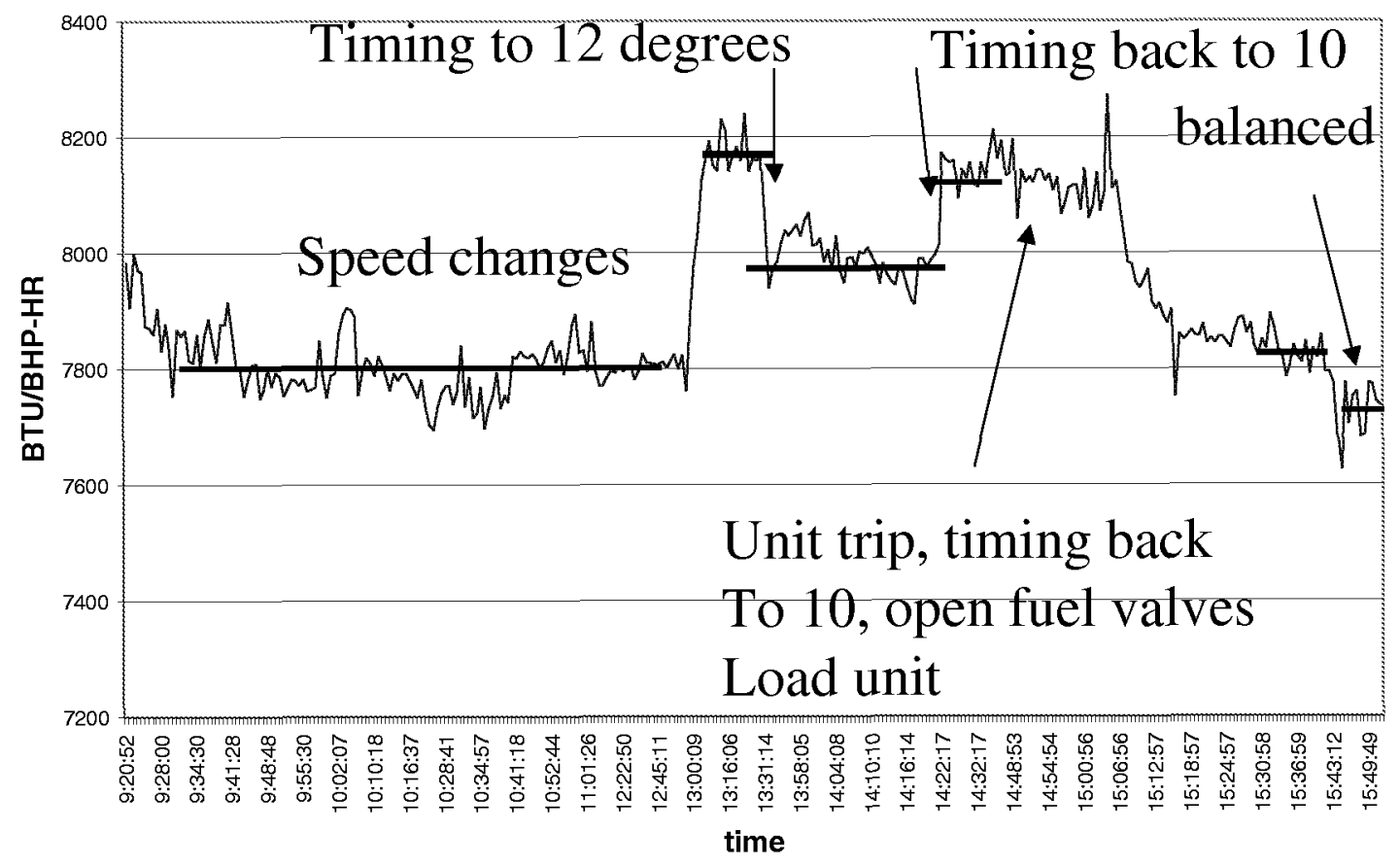

Figure 7-57. Hear Rate Calculations; Kinder 2; Day 2

Table 7-4. Heat Rate Summaries; Kinder 2; Day 2

\begin{tabular}{|c|c|c|}
\hline $\begin{array}{c}\text { CONDITION } \\
\text { Change }\end{array}$ & HR & CHANGE \\
\hline $\begin{array}{c}\text { Just Before Timing } \\
\text { Advance }\end{array}$ & 8800 & $\begin{array}{c}\text { No Significant } \\
\text { Change in HR }\end{array}$ \\
\hline Timing to 12 Degrees & 7980 & $-2.2 \%$ \\
\hline $\begin{array}{c}\text { Timing Back to 10 } \\
\text { Degrees }\end{array}$ & 8160 & $+2.2 \%$ \\
\hline $\begin{array}{c}\text { Fuel Valve Open, 40 } \\
\text { Increase in } \\
\text { Spread }\end{array}$ & 7810 & \\
\hline Balanced & 7780 & $-0.38 \%$ \\
\hline
\end{tabular}




\subsection{Analysis of Heat Rate as a Function of Load - Kinder Second Test}

Figure 7-48 presents an alternate way of looking at the heat rate data - with load as an independent variable. There was quite a substantial variation in load during day 2 , and Figure 7-58 shows how heat rate varies during the day when presented as a function of the corresponding load. The figure suggests a fairly consistent and near linear relationship between heat rate and load (with negative slope).

The non-dimensional rate of change of heat rate with load is defined as:

$$
\left[\frac{\text { Load }}{\text { Heat Rate }}\right]\left[\frac{d(\text { Heat Rate })}{d(\text { Load })}\right]
$$

The values for the derivative in the right-hand parenthesis are calculated from the trend line shown on Figure 7-58. The values for load and heat rate in the left-hand parentheses are obtained as approximate averages of the extremes in the difference calculation; i.e., 1550 for HP and 8000 for heat rate.

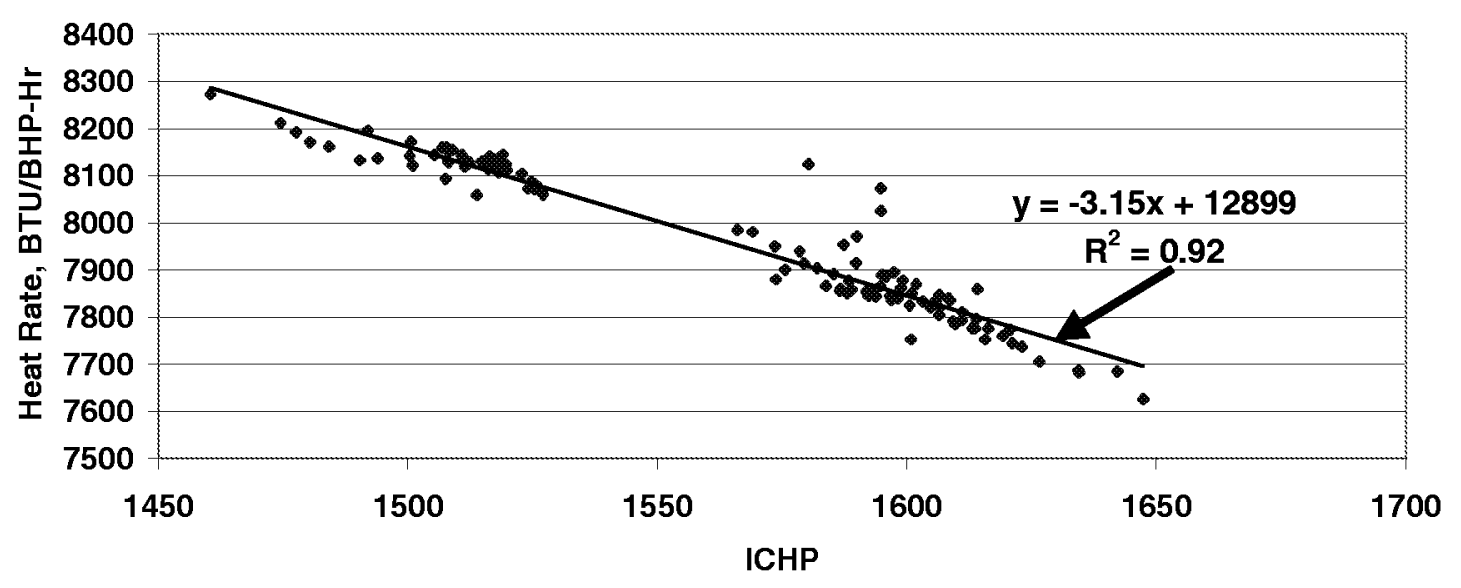

Figure 7-58. Heat Rate for Day 2 versus ICHP without CPR or Timing Tests or Speed Tests

The result is 0.61 - this means for every percentage reduction in load, the heat rate goes up by $0.61 \%$, indicating extreme sensitivity and one reason why such effort is made to keep these units $100 \%$ loaded.

Figure 7-59 adds the day 1 to the day 2 trends - the added data is reasonably consistent with the day 2 trends. 


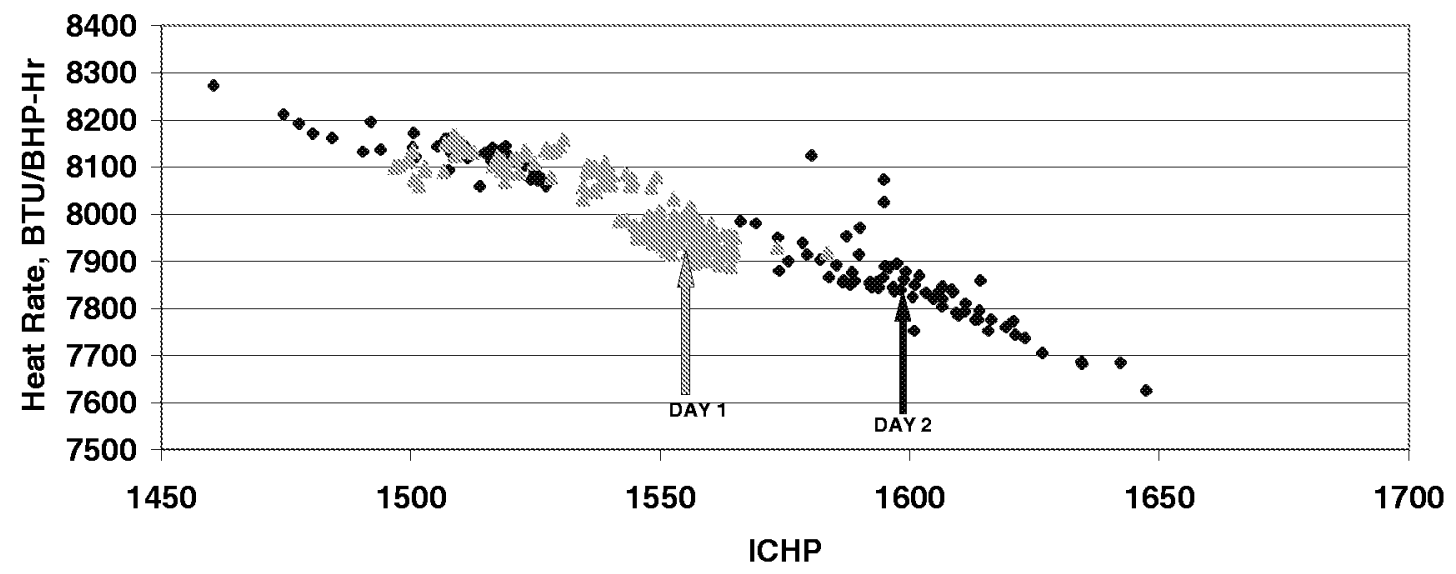

Figure 7-59. Heat Rate for Days 1 and 2 versus ICHP without CPR or Timing Tests or Speed Tests

Figure 7-60 presents the day 1 heat rate versus load chart with advanced timing tests and CPR balancing data added. This presentation provides a much clearer basis for evaluating the benefits of tests such as this on a unit with high sensitivity of heat rate to load. At least during the more highly loaded tests, there is indication of benefit to CPR balancing of about $100 \mathrm{BTU} / \mathrm{HP}-\mathrm{hr}$. - that is about $1.25 \%$. As compressor load suddenly dropped after the CPR balancing, there is a less distinctive difference between the CPR balancing data and the rest of the data set.

Figure 7-61 presents heat rate versus load during the reduced speed tests for days 1 and 2 . It shows that the heat rate versus load line is lowered by reducing speed. This is primarily because the torque for a given horsepower is increased by reducing speed and implicit in the observed reduction of heat rate with increasing load is a reduction with increasing torque. However, using trend lines for the 300, 290, and 280 RPM data, the heat rates at $100 \%$ torque $(1550,1498.3,1496.7 \mathrm{HP}$, respectively) are 8016,7934 , and 7949 BTU/BHP-hr., also indicating that reducing speed does reduce heat rate by a small amount for a given torque; one reason may be that friction losses are reduced by reducing speed. This figure shows that the heat rate ranges for the tests with equivalence ratio control were lower, but also that the corresponding loads were higher - thus, the benefits of reduced heat rate are not so clear, since a contributor to lower heat rate was clearly increased load. 


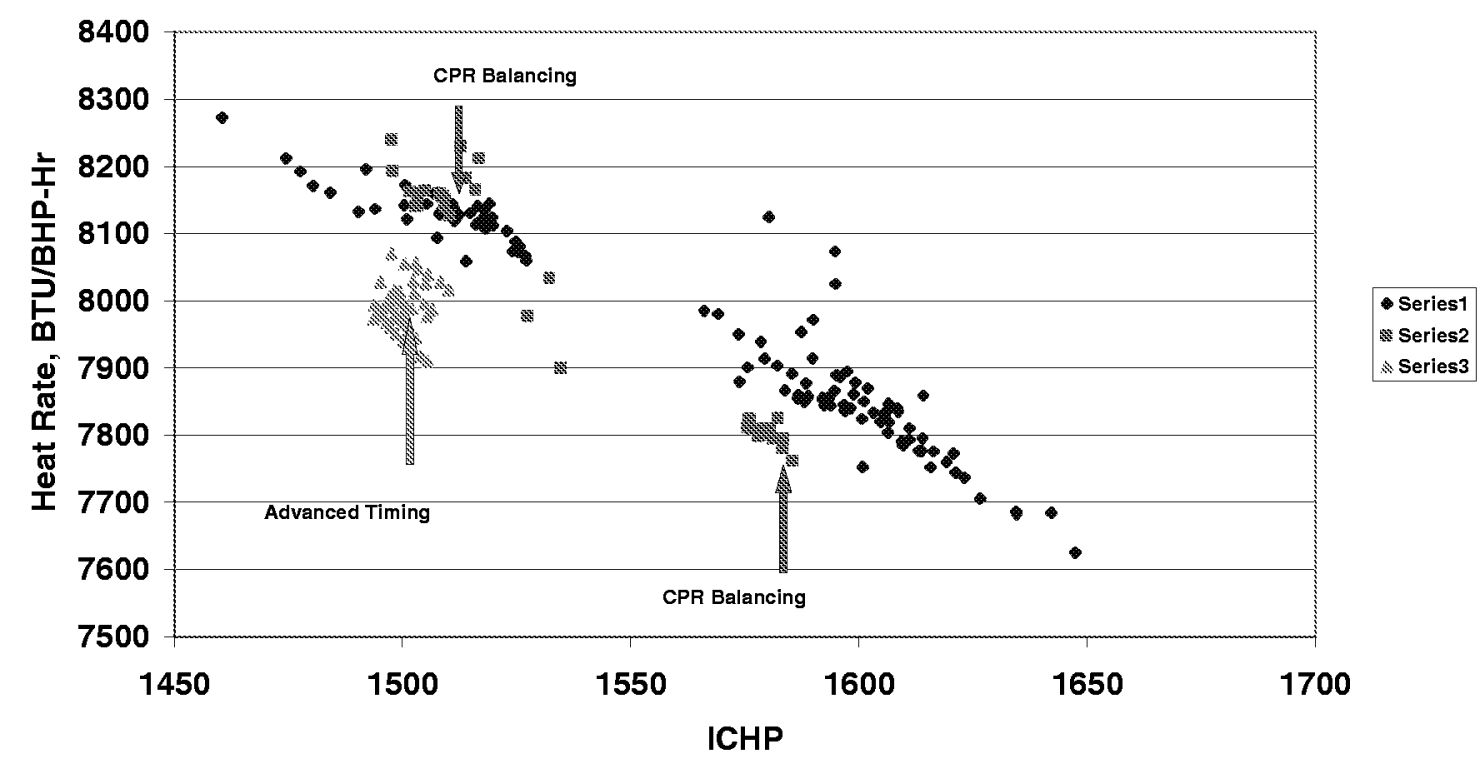

Figure 7-60. Heat Rate versus ICHP; Series 2 Adds in the CPR Balancing Data, and Series 3 Adds in the Advanced Timing Data; Kinder Second Test; Day 2; April 22, 2004

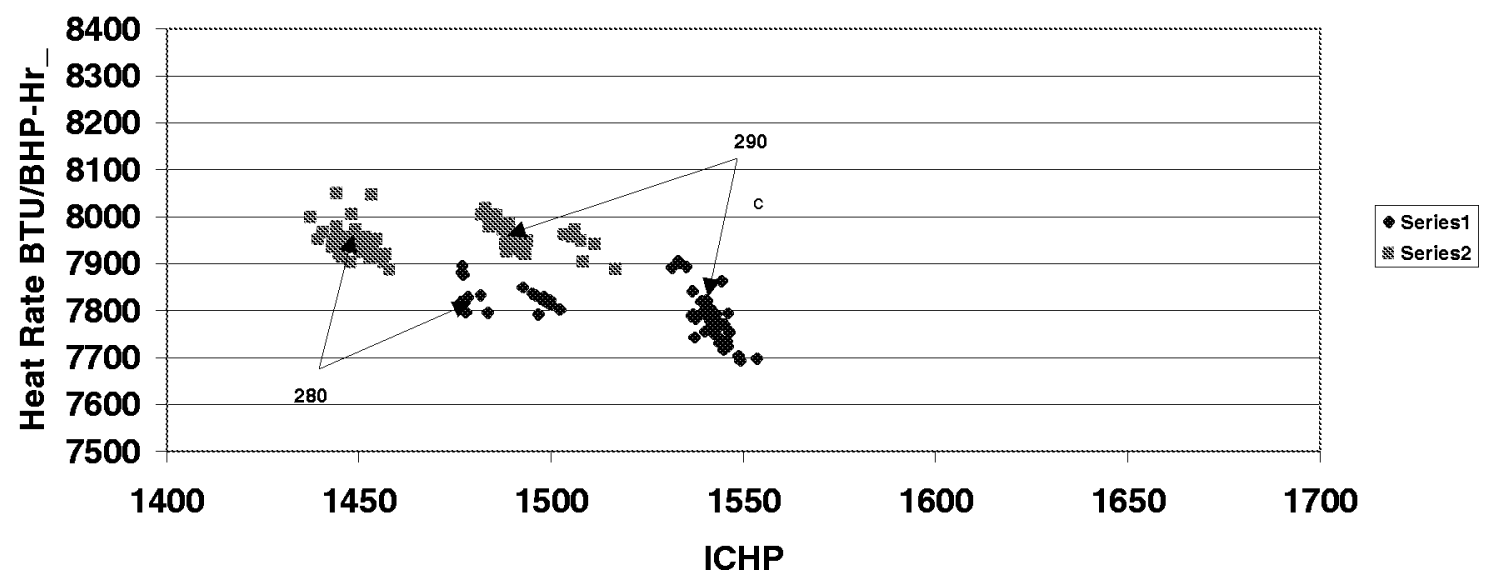

Figure 7-61. Heat Rate for 280 and 290 RPM as a Function of Load;

Day 2 and Day 1 (= Series 1 and Series 2) 


\subsection{COMPRESSOR EfFICIENCY}

Compressor efficiency is currently analyzed in a different set of codes than the charts previously presented as a function of time. Thus, the independent variable is a surrogate for time, referred to as index. Figure 7-62 shows compressor thermal efficiency for day 1 as a function of this index. It shows that under the normal test conditions, efficiency is around $90.2 \%$ - very close to that previously measured on another unit at this station. Then, under conditions which turn out to be reduced speed, the thermal efficiency goes down to $89 \%$ at 290 RPM and $87.8 \%$ at 280 RPM. The first candidate reason to consider for an efficiency change would be an increase in resistance, but the reduced flow which inevitably accompanies reduced speed should reduce the square law resistance. Another candidate reason is that pulsations increase. This is not easily pinned down as a cause, because pulsations are a nozzle and piping feature and we only have pressure measurement in the cylinder. However, close review of Figure 7-63 and Figure 7-64 reveal differences in the pressure modulation in the discharge cylinder traces. These are likely to indicate nozzle pulsations, which would add to the dynamic flow losses in the nozzles, and thereby reduce efficiency. Thus, the benefits of reduced speed in reducing heat rate previously observed on this unit and shown in Figure 7-61 are offset by the reduced compressor efficiency, which also results from reduced speed.

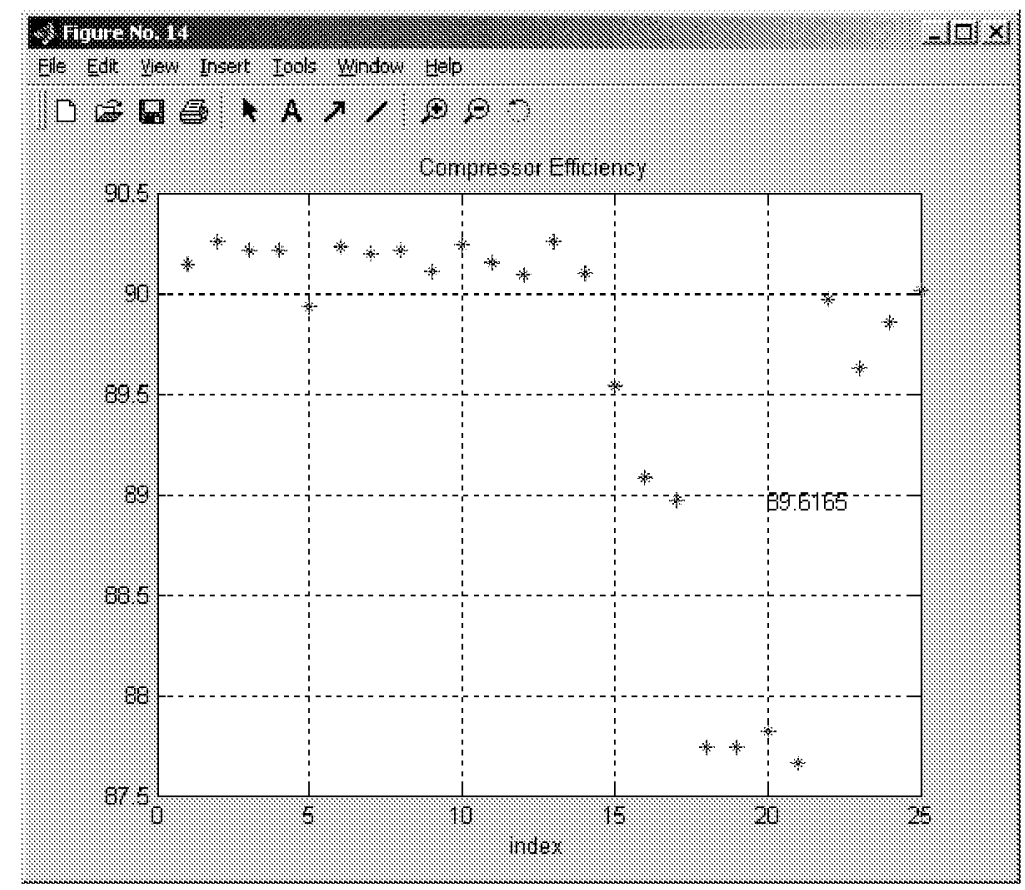

Figure 7-62. Compressor Efficiency During Day 1 Testing 


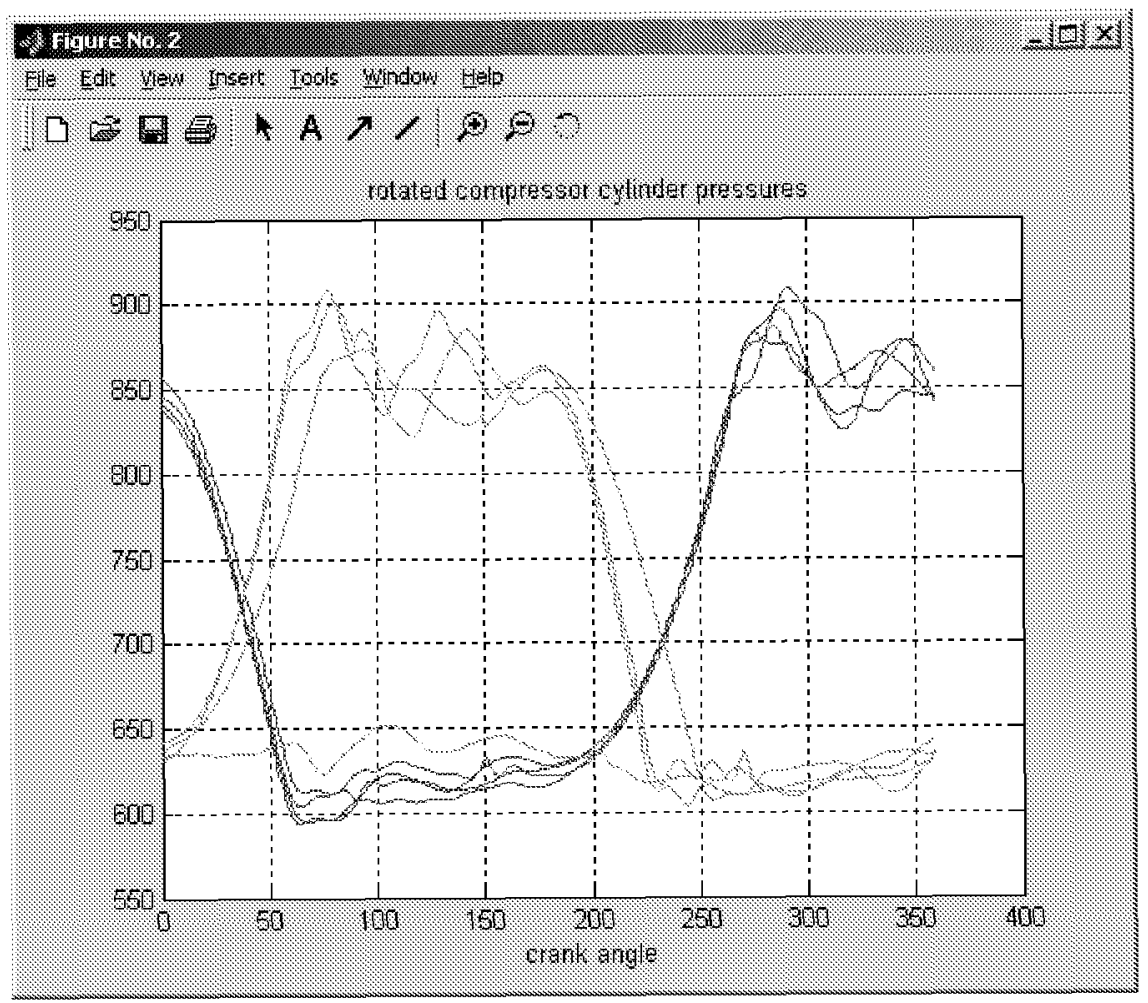

Figure 7-63. Pressure Trace for 302 RPM

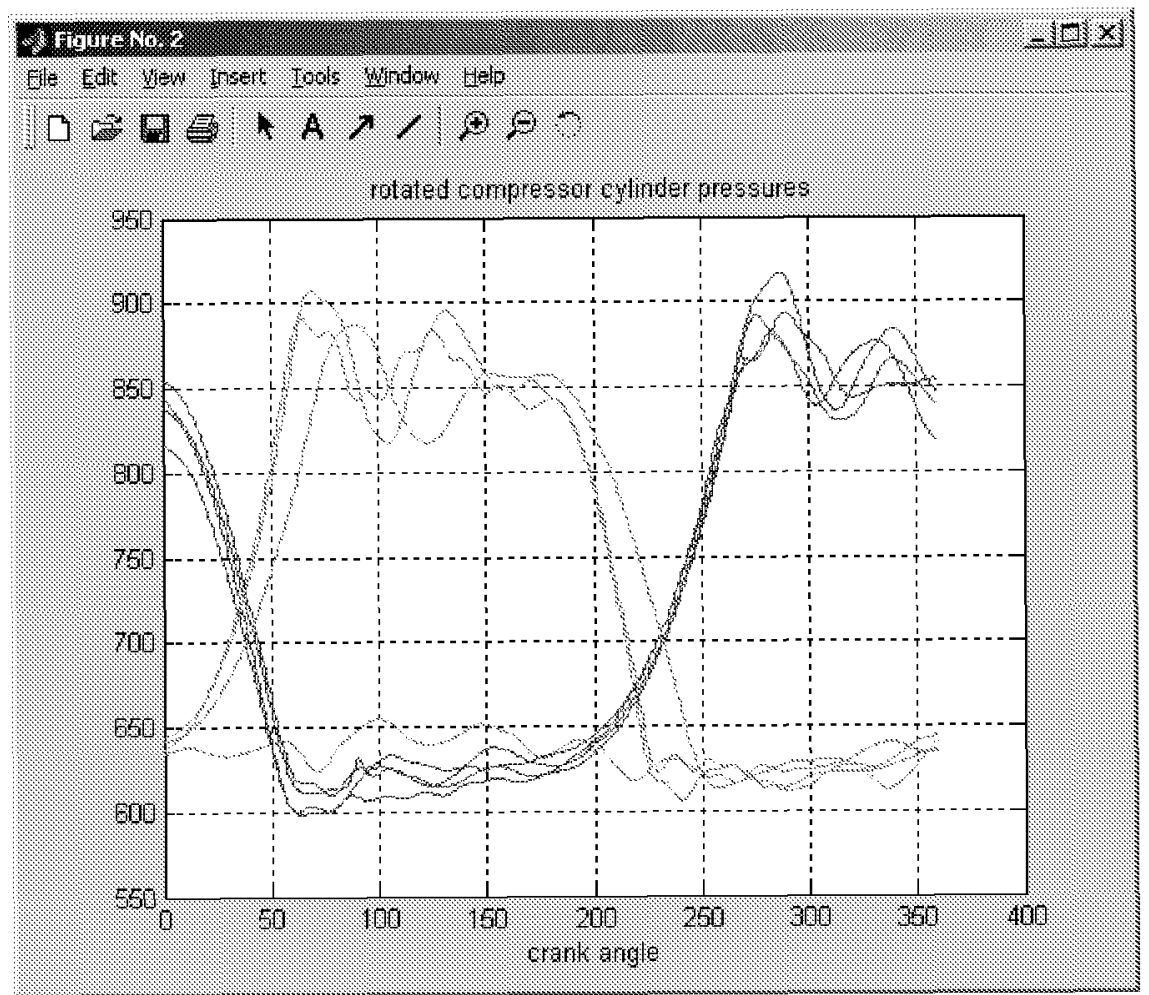

Figure 7-64. Pressure Trace for 278 RPM 
Table 7-5 combines these changes in compressor efficiency with previously observed changes in heat rate as a function of speed to assess the impact of speed on system thermal efficiency. Under test conditions, these calculations show system thermal efficiency reduces slightly with speed; it is emphasized that compressor mechanical efficiency was held constant in these calculations, and that reduction in friction losses with reduced speed is more likely, but we have no data on how speed influences mechanical efficiency, so a standard $95 \%$ assumption was made.

Table 7-5. Approximate System Thermal Efficiency Variation with Speed

\begin{tabular}{|c|c|c|c|c|c|c|c|}
\hline $\begin{array}{l}\text { Speed } \\
\text { RPM }\end{array}$ & $\begin{array}{l}\text { Horsepower } \\
\text { tor } 100 \% \text { Torque }\end{array}$ & $\begin{array}{l}\text { Fit } \\
\text { Constant } \\
\text { BTU/BHP-Hr. }\end{array}$ & $\begin{array}{l}\text { Fit } \\
\text { Slope }\end{array}$ & $\begin{array}{l}\text { Heat Rate at } \\
100 \% \text { T orque } \\
\text { from Fit }\end{array}$ & $\begin{array}{l}\text { Compressor: } \\
\text { Efficiency }\end{array}$ & $\begin{array}{l}\text { Assumed } \\
\text { Mechanical } \\
\text { Efficiency }\end{array}$ & $\begin{array}{l}\text { System } \\
\text { Thermal } \\
\text { Efficiency }\end{array}$ \\
\hline 300 RPM & 1550.00 & 12899 & -3.15 & 8016.50 & $90.20 \%$ & $95 \%$ & $27.20 \%$ \\
\hline 290 RPM & 1498.33 & 13406 & -3.65 & 7933.79 & $89 \%$ & $95 \%$ & $27.12 \%$ \\
\hline 280 RPM & 1446.67 & 11726 & -2.61 & 7948.61 & $87.60 \%$ & $95 \%$ & $26.65 \%$ \\
\hline
\end{tabular}

It is hoped that in future tests, comparing rod load waveforms with cylinder pressure force waveforms during speed/load changes would yield guidance on losses in rider bands and piston rings.

As a further observation, if unit gas flow could be measured, combining it with ideal and actual measured temperature rise data would yield information on the useful compression work done, associated compressor losses, and an alternative assessment of overall system efficiency which does not require an assumption of mechanical efficiency.

These two observations emphasize the future potential value of rod load measurements and the need for unit gas flow measurement technologies. The rod load measurement capability is evolving rapidly, helped by tests under this project. Two options for unit gas flow measurement are the tracer gas method pioneered by PRCI more than ten years ago, and ultrasonic gas flow measurement with high frequency data acquisition and analysis, pioneered for unit flow assessment by Tenneco gas more than ten years ago. Both are assessed for unit flow measurement in Reference [8].

\subsection{Rod Load Monitor Evaluation - Kinder Second Test}

The Rod Load Monitor (RLM) installation for these tests was shown in Section 2. This was the first successful operation of the RLM with both telemetry of data and selfpowering on a low speed engine/compressor. It employed a much longer magnet array for generating power in the moving coils. Previous versions did not cover enough of the stroke (17 inches on this unit) and had too much clearance between the moving coils and the stationary magnets. A rotational test rig at SwRI has been used to calibrate software for predicting power as a function of speed. This software has to correct for the timevarying velocity of relative motion in reciprocating motion. The software was used to size the magnet array and the clearance, and to predict the speed at which the RLM would switch on and self power; this occurred at just over 200 RPM, as predicted. 
Figure 7-65 shows the RLM inferred power values in comparison to power values from the compressor cylinders. These show clearly a significant difference - about $12 \%$. This difference is a calibration issue, which needs to be addressed, since the determination of power from the RLM involves an assumed value for Young's modulus of the material.

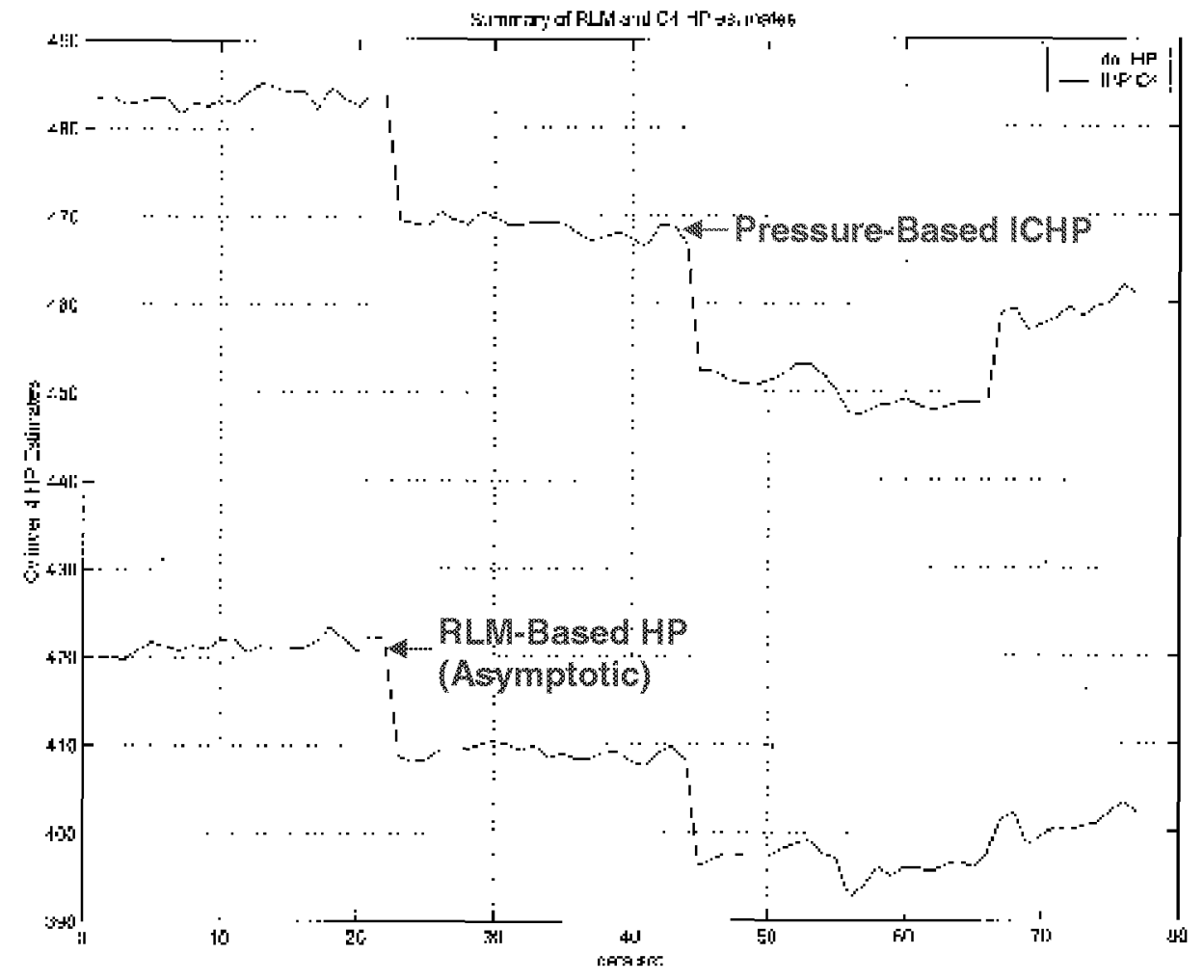

Figure 7-65. Raw Data (Kinder 2) Comparison; Cylinder 4; Rod Load and Pressure-Based HP

A straightforward approach to calibration is to use a calibrated pressure transducer to determine cylinder power, then to adjust the RLM calibration factor to best equate the two. This would need to be done only at one or two conditions, and then would yield a reliable power and torque measurement system.

Figure 7-66 shows the results of calibration based on average power from RLM and cylinder pressure measurement. Clearly, the relationship between RLM and cylinder power remains consistent over the speed range, within 1 to 4 HP (less than $1 \%$ ). 


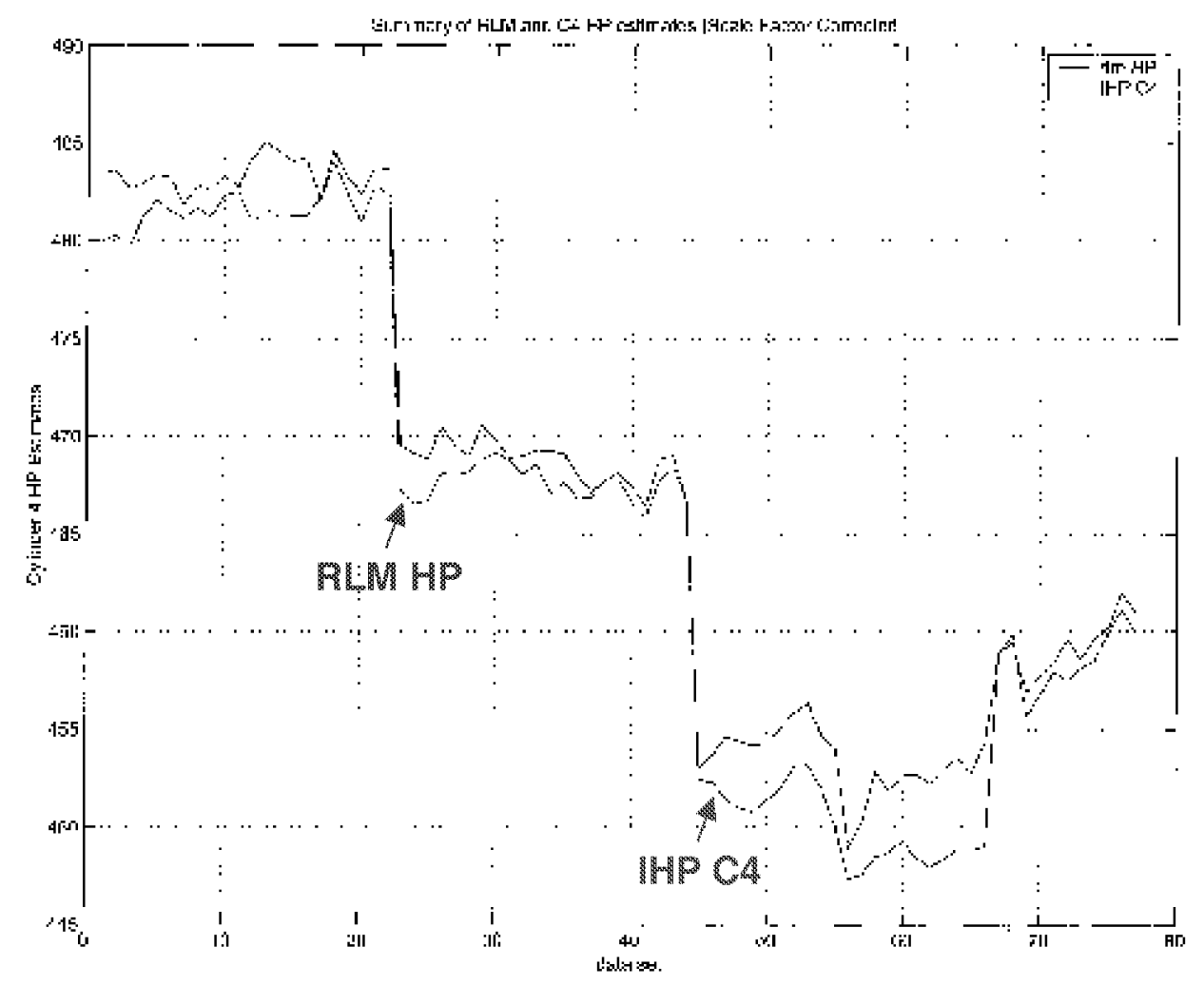

Figure 7-66. “Scale Factor” Adjusted Comparison; ICHP versus RLM (Test 4)

We have learned from the Industry Advisory Committee (IAC) for this project that some companies have devoted substantial effort to horsepower determination over a range of conditions for each unit they operate. The result is an accurate basis for interpolating power based on operating conditions, but the mapping effort is extensive. The calibration of the RLM for a few points greatly reduces this effort and yields a device which will cover any conditions including valve leaks.

The value of an RLM system will be several fold - the previous section of this report has emphasized how strongly heat rate depends on load, which makes clear how important it is to know load accurately. As regulators require increased documentation of emissions, and their dependence on load, it becomes increasingly important to be able to state the load with confidence. In addition, measuring system efficiency and isolating the contributors to efficiency losses will become more important to support pipeline economics and performance improvement. The RLM will be a contributor to all these evaluations. Work remains to decide specifically how the RLM signal should be used to adjust load step and maintain $100 \%$ torque. Since RLM measures power and torque on the rod, it would differ from indicated power because there are friction losses in rings and rider bands, which would change the appropriate mechanical efficiency to be applied. This needs to be addressed. 


\subsection{Equivalence Ratio Control Evaluation}

This sub-section of the report presents data previously plotted as a function of time in a way to further emphasize the feasibility and characteristics of closed-loop control of the wastegate to maintain an equivalence ratio set point. In Figure 7-67, a composite comparison is made of how equivalence ratio varies with speed in open-loop (day 1) and in closed-loop (day 2). Speed was chosen as the independent variable for these tests, because it is easy to control, and provided certainty of having an effect, and of showing differences in behavior. Even in open-loop, the controller was connected, but in its manual setting adjustments were continually made by hand to keep air manifold pressure as close to 7.1 PSIG as possible. For the day 2 closed-loop testing, the equivalence ratio set point was simply chosen to correspond approximately to this air manifold pressure, based on day 1 data. No effort was made to optimize performance in this selection simply to choose a value known to function satisfactorily. The difference in behavior is clear - as speed was varied on day 1 equivalence ratio varied, and on day 2 as speed was varied, equivalence ratio stayed constant. It was noted that in closed-loop, the combustion stability tended to improve as speed was reduced. However, in open-loop, combustion stability deteriorated as speed was reduced.

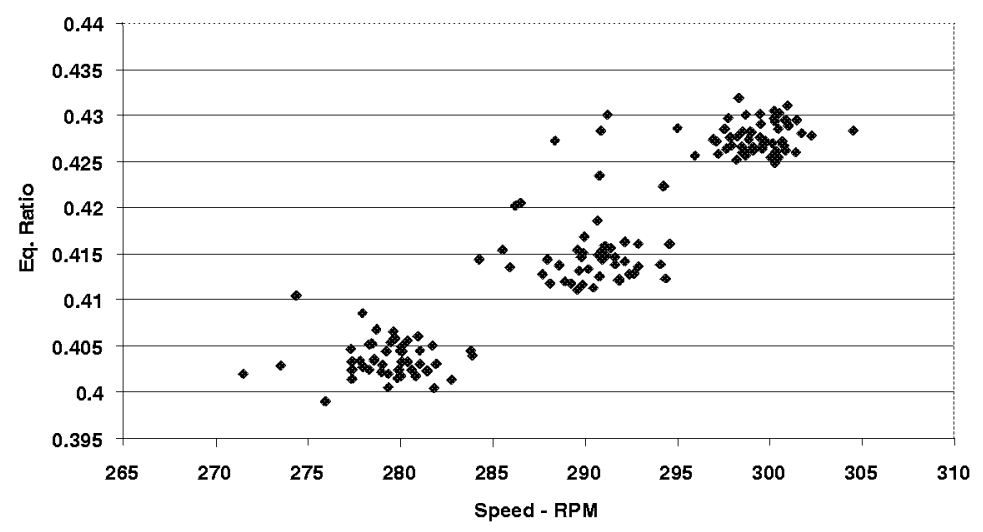

\section{OPEN-LOOP}

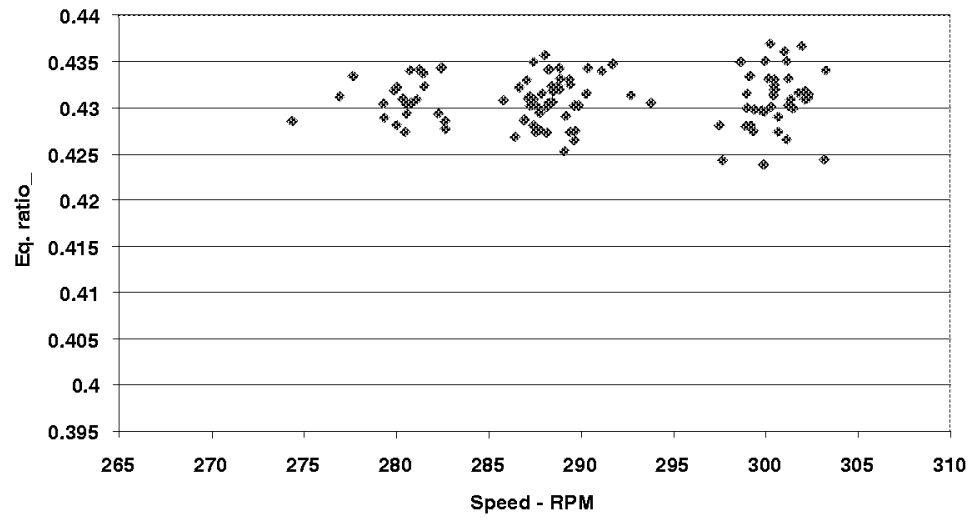

CLOSED-LOOP

Figure 7-67. Equivalence Ratio versus Speed; Comparison of Open-Loop and ClosedLoop Control; Kinder Test 2 
Figure 7-68 makes this clear; it shows a reduction in standard deviation with reducing speed, whereas the standard deviation increased with reduced speed under open-loop conditions.

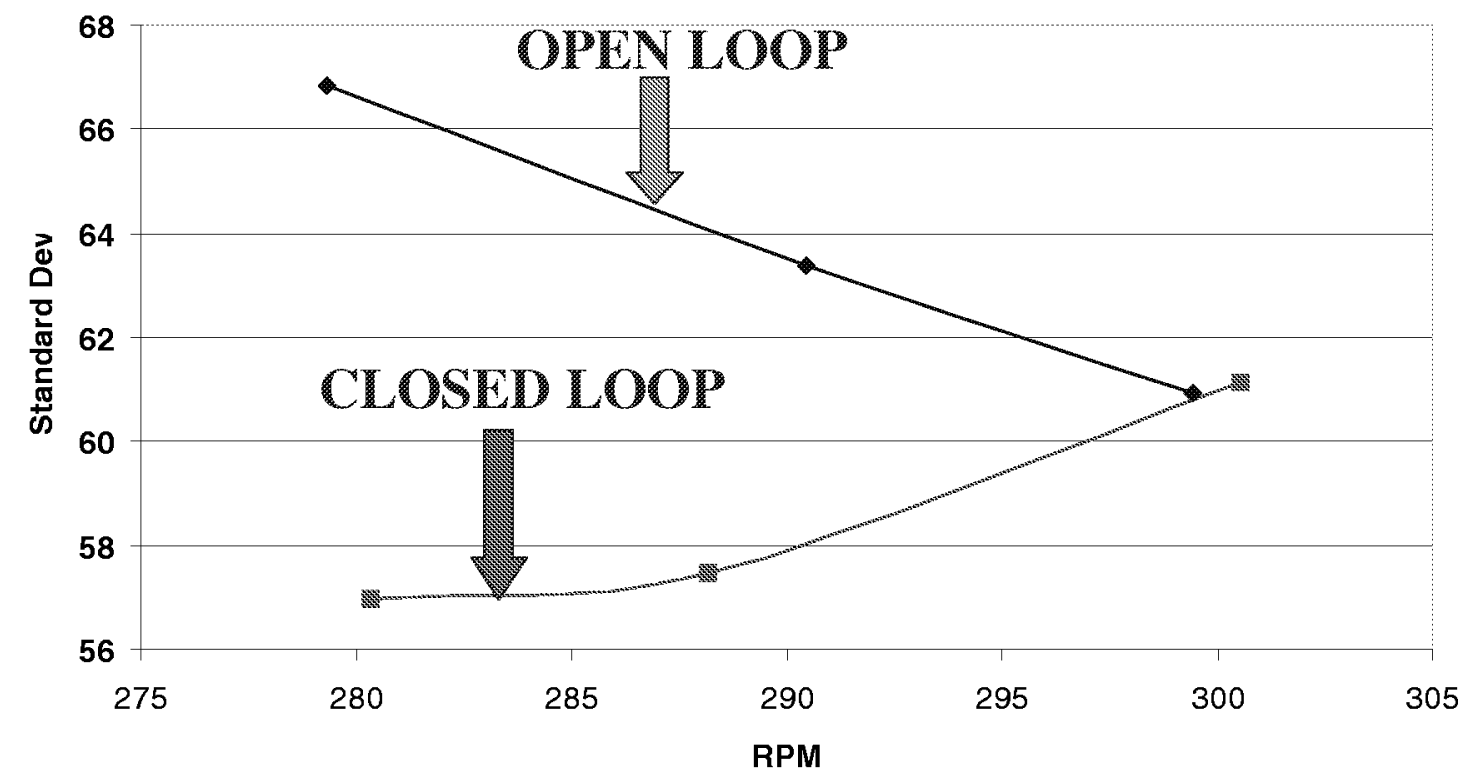

Figure 7-68. Mean Cylinder Cycle-to-Cycle Standard Deviation versus Speed; Comparison of Open-Loop and Closed-Loop Control of Wastegate; Kinder Test 2

Figure 7-69 shows that not all parameters benefited from the test conditions on day 2; the normalized NOx tended to go up with decreased speed on day 2, and to go down under open-loop control. This does not, of course, indicate that this is a general feature of closed-loop control, just that closed-loop control will influence NOx emissions. This influence appropriately applied can be made to achieve different or opposite characteristics. If appropriate, the equivalence ratio set point can be made to change with some conditions. Further testing of closed-loop equivalence ratio control can address the set point decisions with different operational goals. 


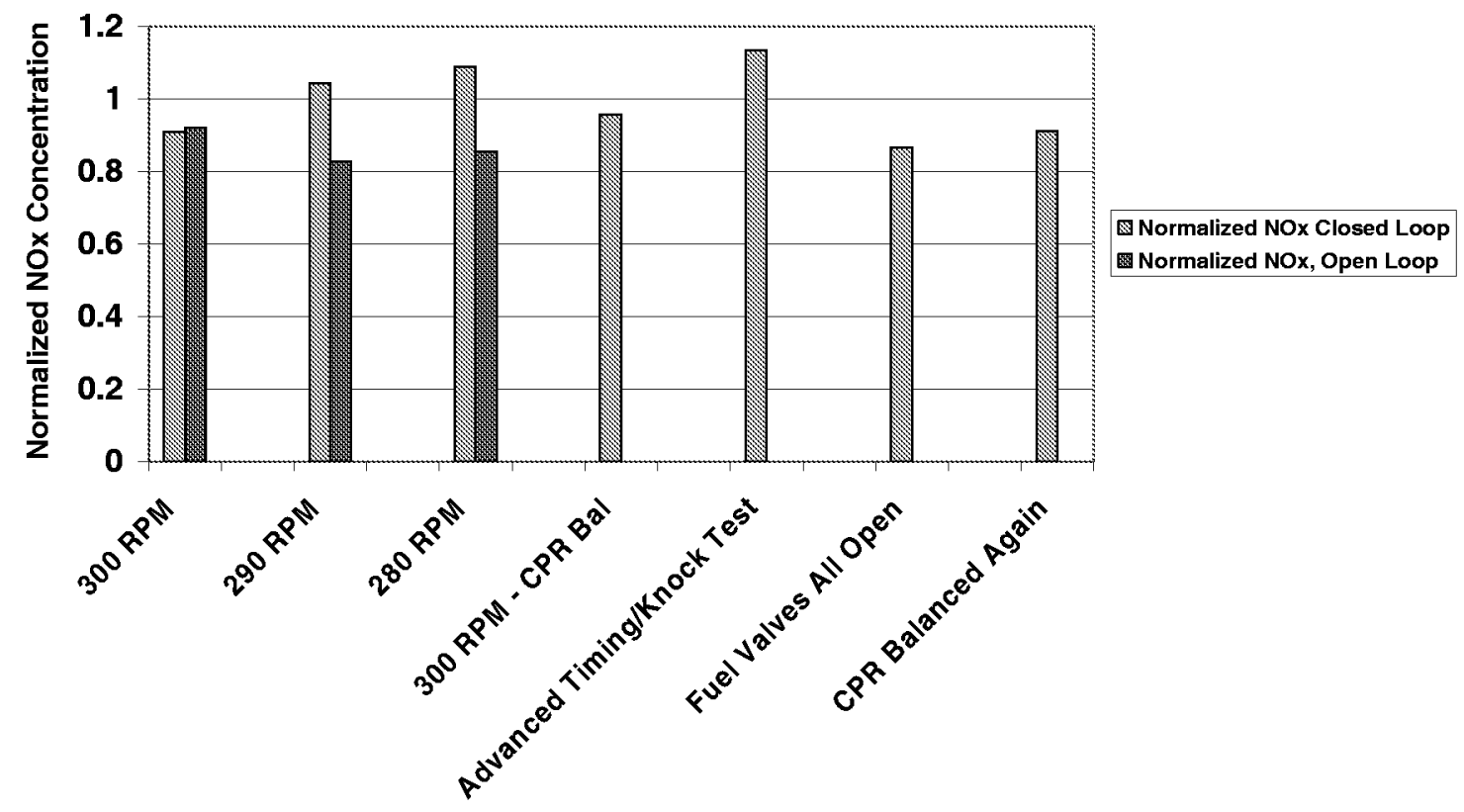

Figure 7-69. Test Results; Kinder Test Series 2; Open- and Closed-Loop Equivalence Ratio Control; Influence on Normalized NOx Concentration

\subsection{Knock Detection - Kinder Second Test}

During this test series at Kinder, a knock detection sensor was evaluated. This sensor was on loan to SwRI from Metrix, who manufactures it as a product. It had previously been evaluated for the first time on this project on a GMW10 at Williams' Station 60. In that case, the sensor successfully responded to a condition under which audible detonation occurred. The sensor voltage increased from about 2 volts to 5 volts under this condition. For reference purposes, Figure 7-70 reproduces the figure from Section 5.

For this series of tests, a more refined evaluation was made of the sensor output as conditions likely to lead to knock were aggravated, but before audible knock occurred. Specifically, timing was advanced and the equivalence ratio control was over-ridden to yield a richer mixture to all cylinders of the engine, and then the fuel valve for the single cylinder with the knock detector was opened to further richen the mixture locally. Severe audible knock did not occur - though there was an occasional knock observed. Figure 7-71 shows the sensor output gradually increased during this test - reaching just short of 3 volts output - suggesting that a threshold somewhere between 3 and 5 volts would probably be appropriate for use in a protective system coupled with timing advance to enhance fuel efficiency. 


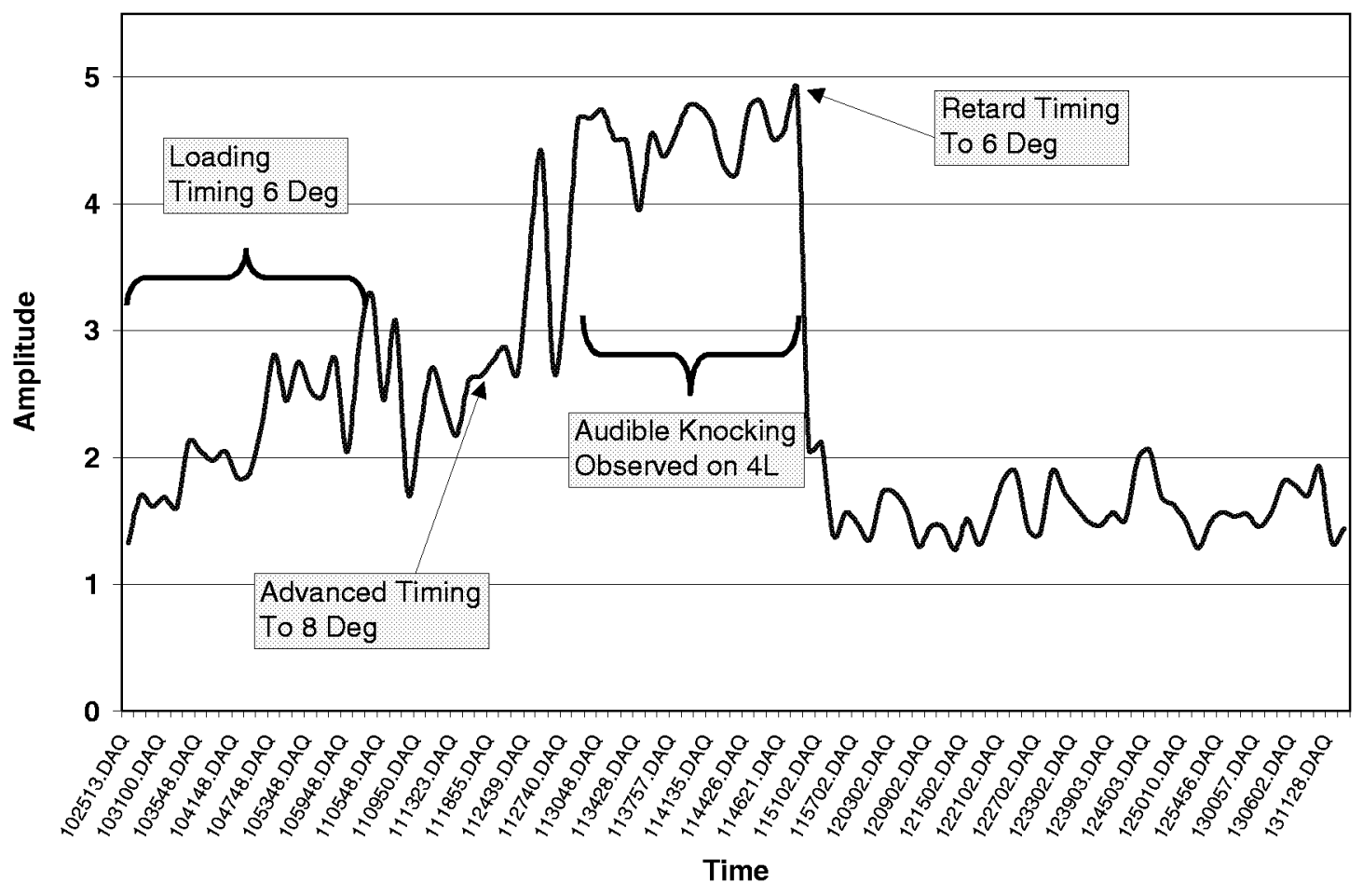

Figure 7-70. Knock Detector Output; Williams Station 60

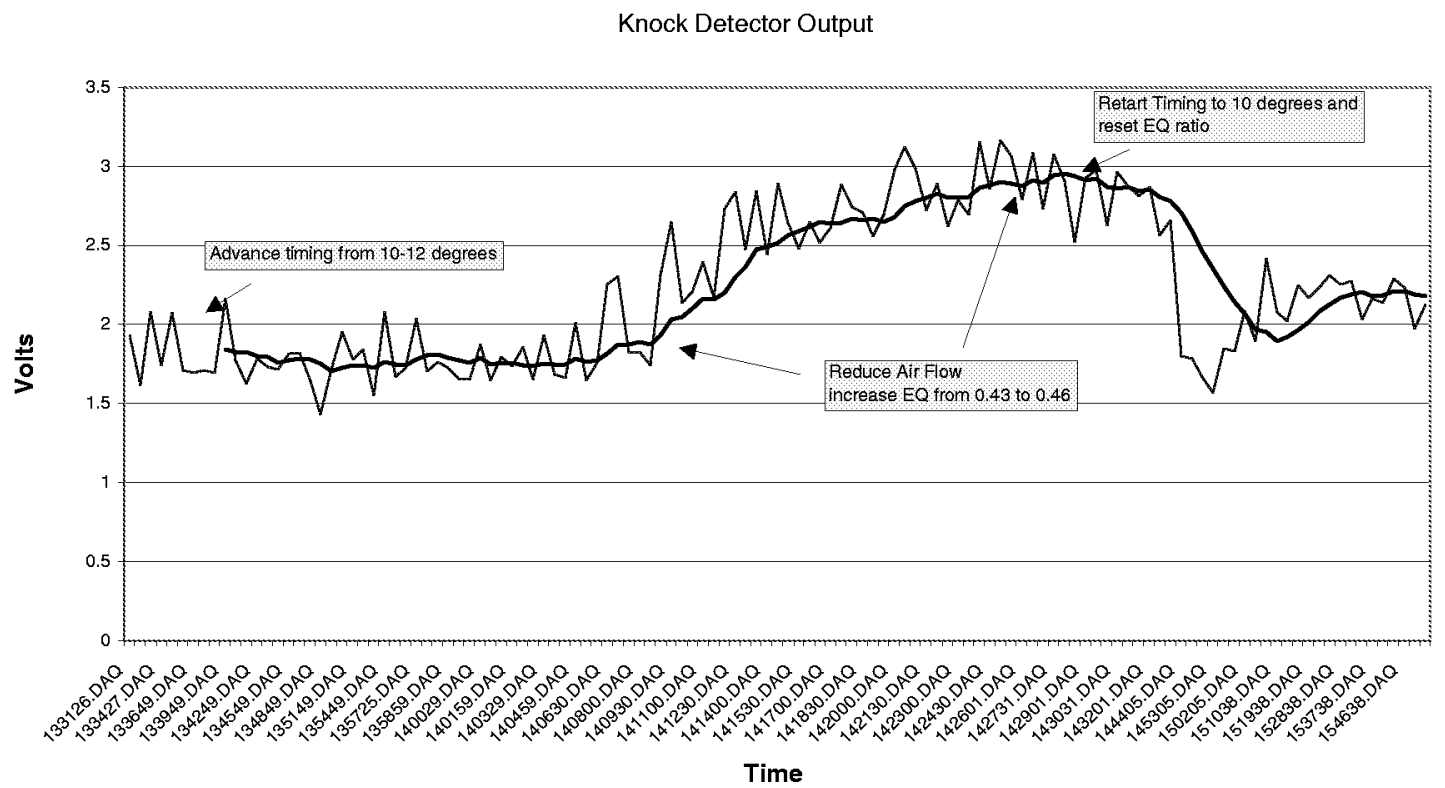

Figure 7-71. Knock Detector Output; EI Paso Station 823 


\subsection{POTENTIAL INTEGRITY INDICATORS BASED ON INSTANTANEOUS ROTATIONAL VeLocity - Kinder SECOND TEST}

During the data analysis, an effort was made to relate combustion events to characteristics of the Instantaneous Rotational Velocity (IRV). A series of "long records" were captured during the second Kinder test - providing a complete history of all measured parameters over 20 revolutions. Figure 7-72 shows power from the six cylinders over 20 successive revolutions, with a clear misfire event in revolution 4 , for cylinder 4. Figure 7-73 shows power for the compressor cylinders over the corresponding 20 revolutions. Figure 7-74 compares the total engine power and compressor power over the same 20 - the drop in total power from the misfire is clear. Figure 7-75 shows the crankshaft instantaneous rotational velocity over the same 20 revolutions. IRV on the fourth revolution clearly has a totally different characteristic from the other revolutions, with a substantial momentary slow down. This result provides encouraging evidence that pronounced, momentary, loss in power and torque from the engine would be detectable from the behavior of the crankshaft angular velocity as measured at the encoder. Figure 7-76 shows how crest factor (ratio of maximum to mean) for engine power and for IRV over the second long record correlate with each other. The difference in crest factor between records is not as pronounced as the IRV variation, but if it provides enough discrimination, calculating crest factor involves less intensive data analysis in an integrity monitoring method than tracking the characteristics of individual revolutions.

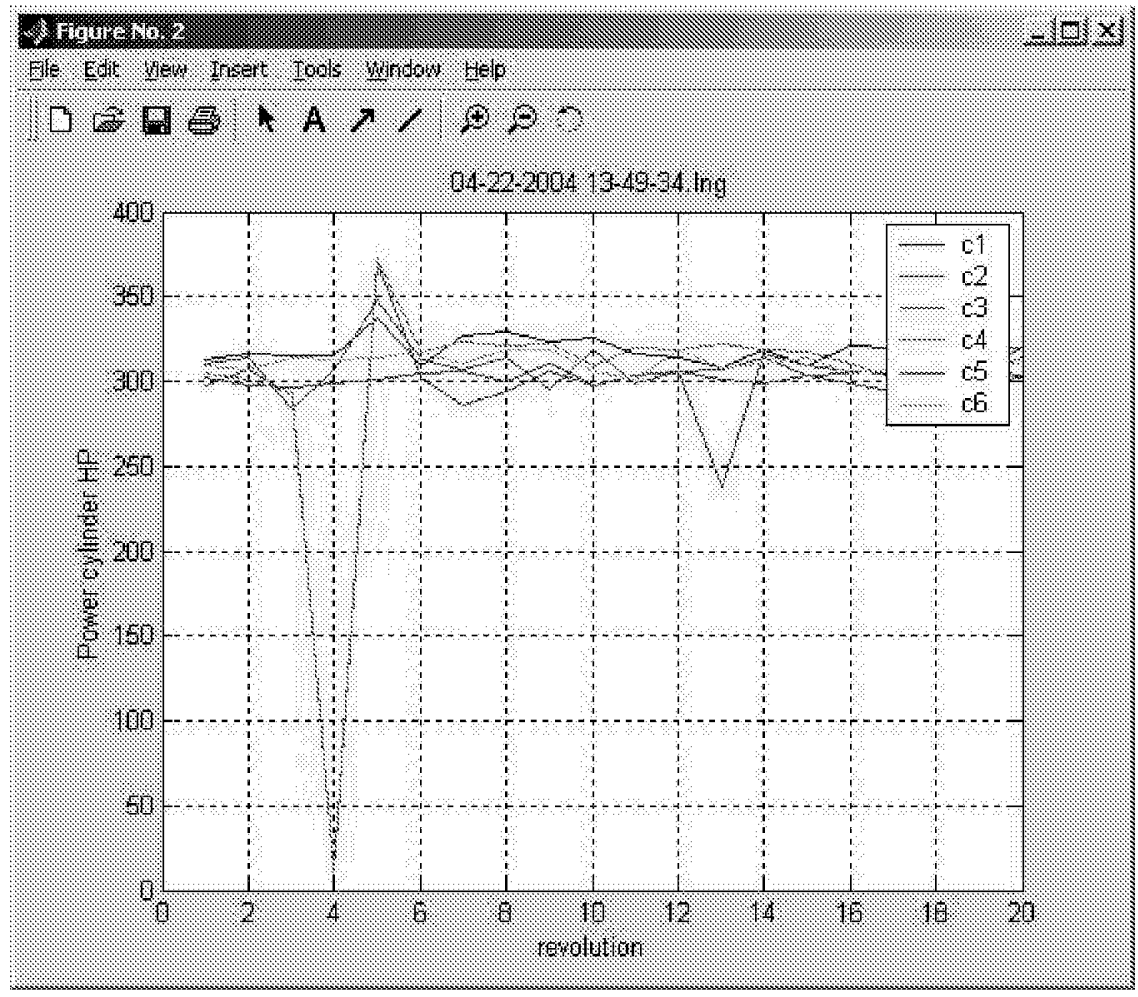

Figure 7-72. Engine Cylinder Power Over 20 Revolutions 


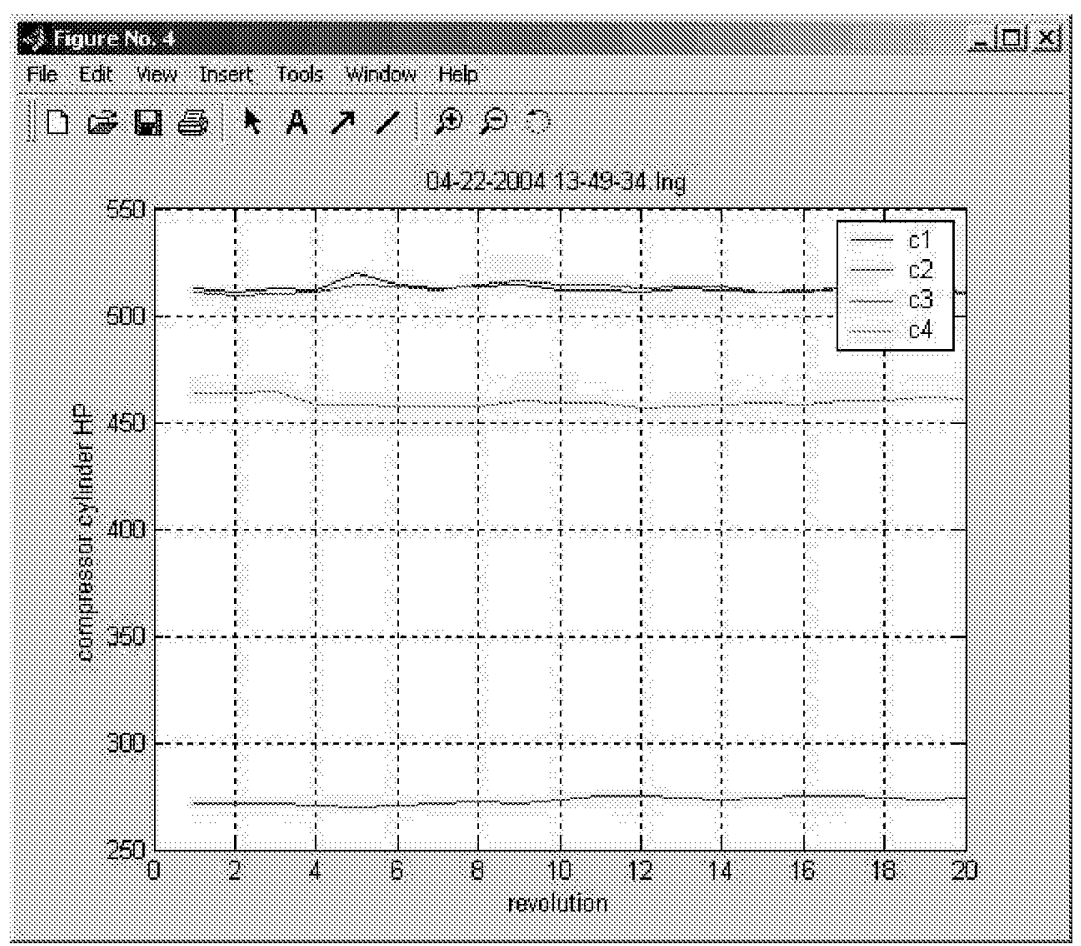

Figure 7-73. Compressor Cylinder Power Over 20 Revolutions

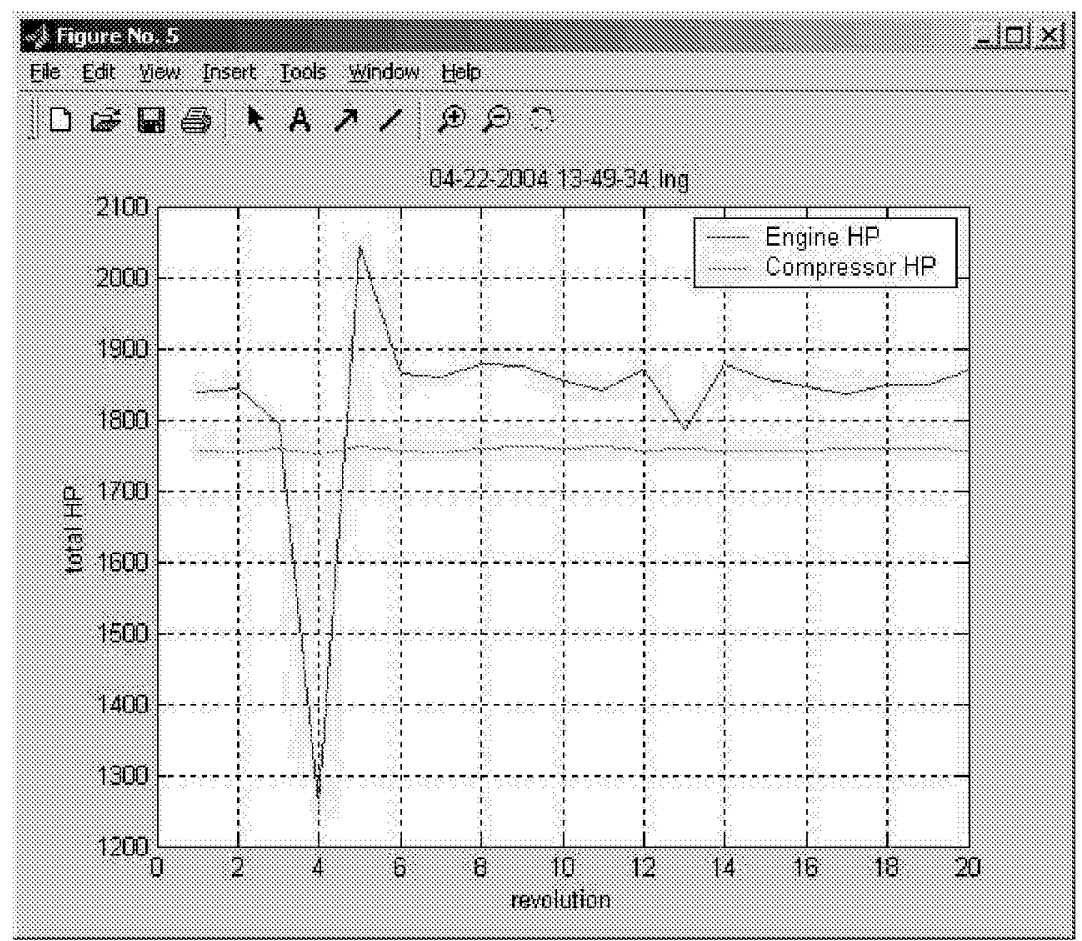

Figure 7-74. Combined, Total Engine, and Compressor Power Over 20 Revolutions 


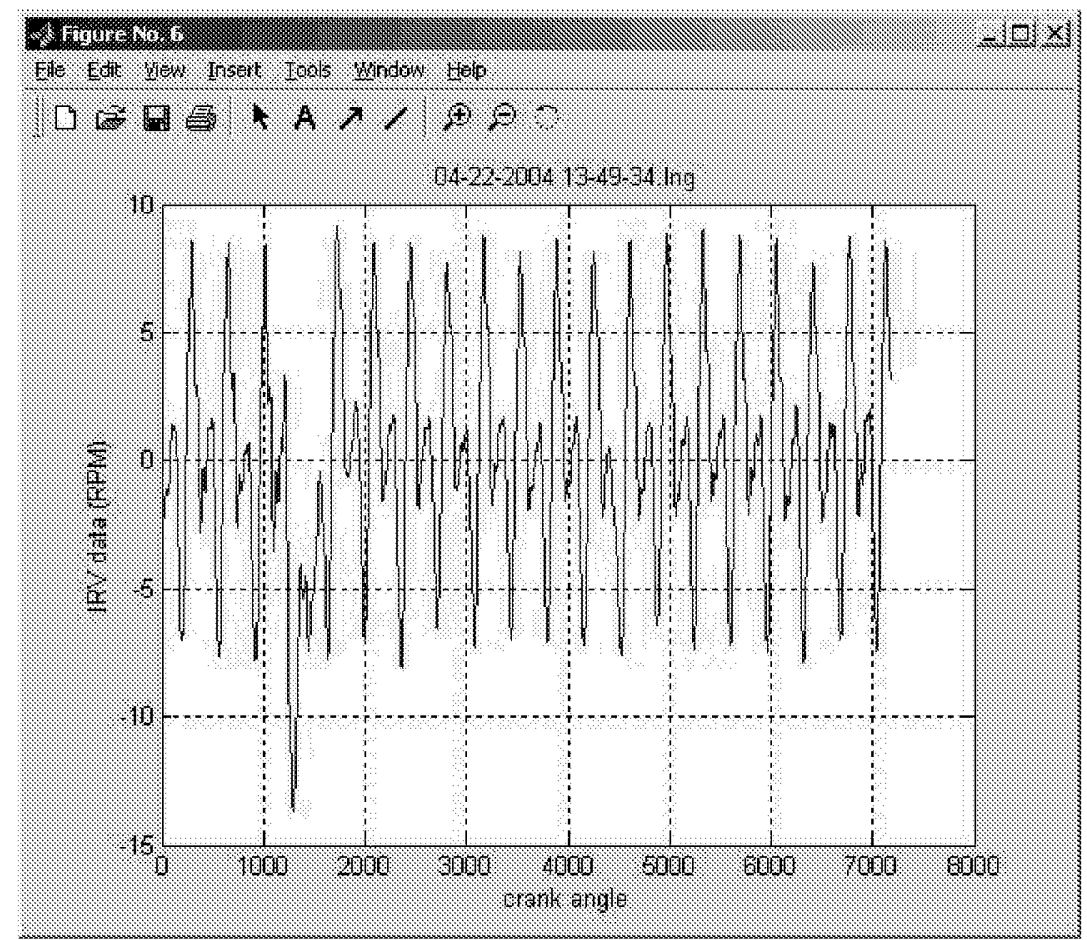

Figure 7-75. Instantaneous Rotational Velocity, as a Function of Crank Angle Over 20 Revolutions

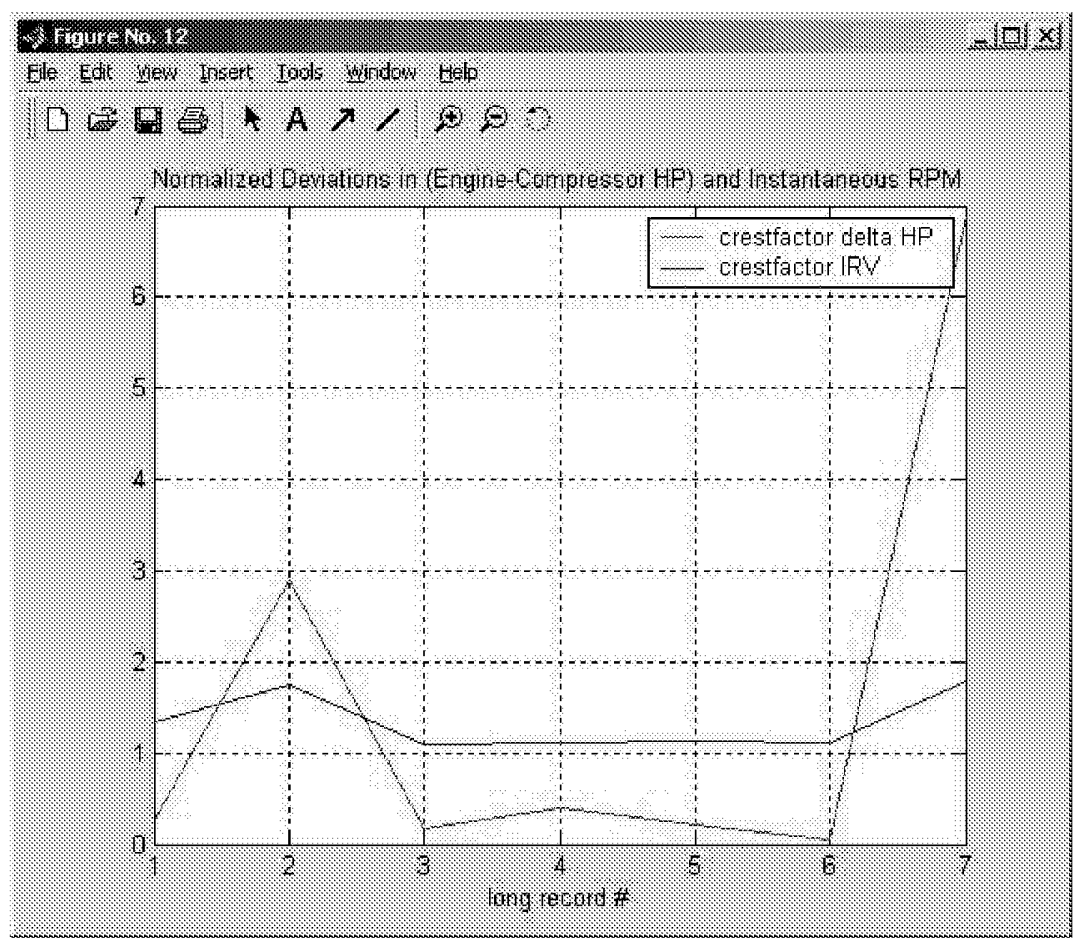

Figure 7-76. Deviations in HP and IRV for Seven Records of 20 Revolutions Each 


\subsection{System And Component Thermal Efficiency Display - Kinder Second TEST}

Figure 7-77, Figure 7-78, and Figure 7-79 present comparisons of system and component thermal efficiencies for this tested HBA-6T with values for two other others tested under this program, an unmodified GMW10, and a GMW10 with added high-pressure fuel injection and a turbocharger. These figures seek to place each of these component and system efficiencies on a scale ranging from typical low to typical high limits.

This represents the results of further review and illustrative analysis of benchmarks. At present, the variable efficiencies considered are limited to engine heat rate, compressor efficiency, and overall system thermal efficiency, which ranges from 27.54 for the HBA$6 \mathrm{~T}$ to 30.35 for the modified GMW10. The ranges indicate the potential ranges for improvement of individual components, and the values on these charts are single values nominally representative of the test data for each engine tested. It will be noted that the measured compressor thermal efficiency is a nominal $90 \%$ for the tests documented in this report section.

\section{Components of Overall System Efficiency}

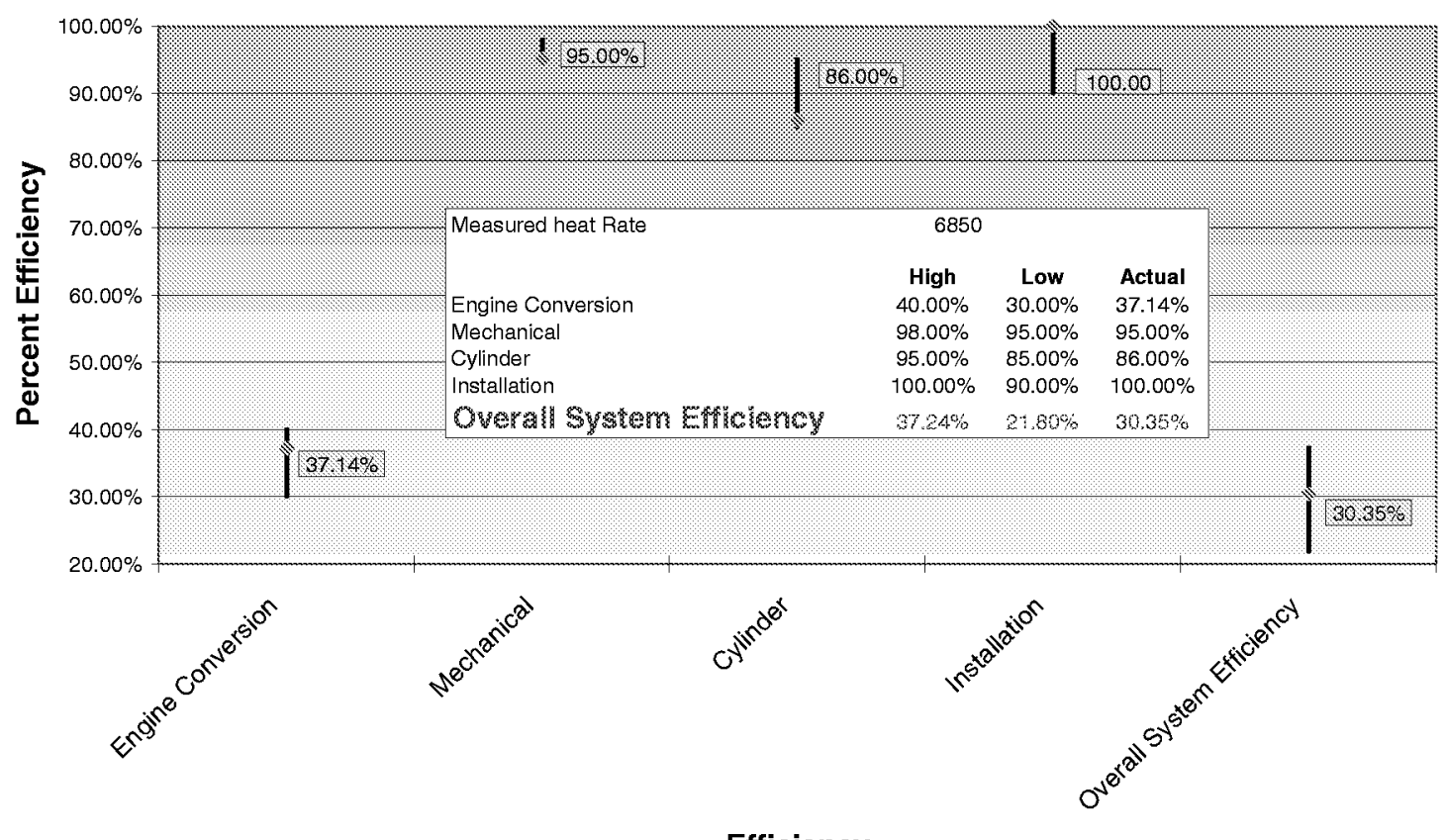

Figure 7-77. System and Component Thermal Efficiency Comparison; GMW10 with High-Pressure Fuel Injection and Turbocharger 
Components of Overall System Efficiency

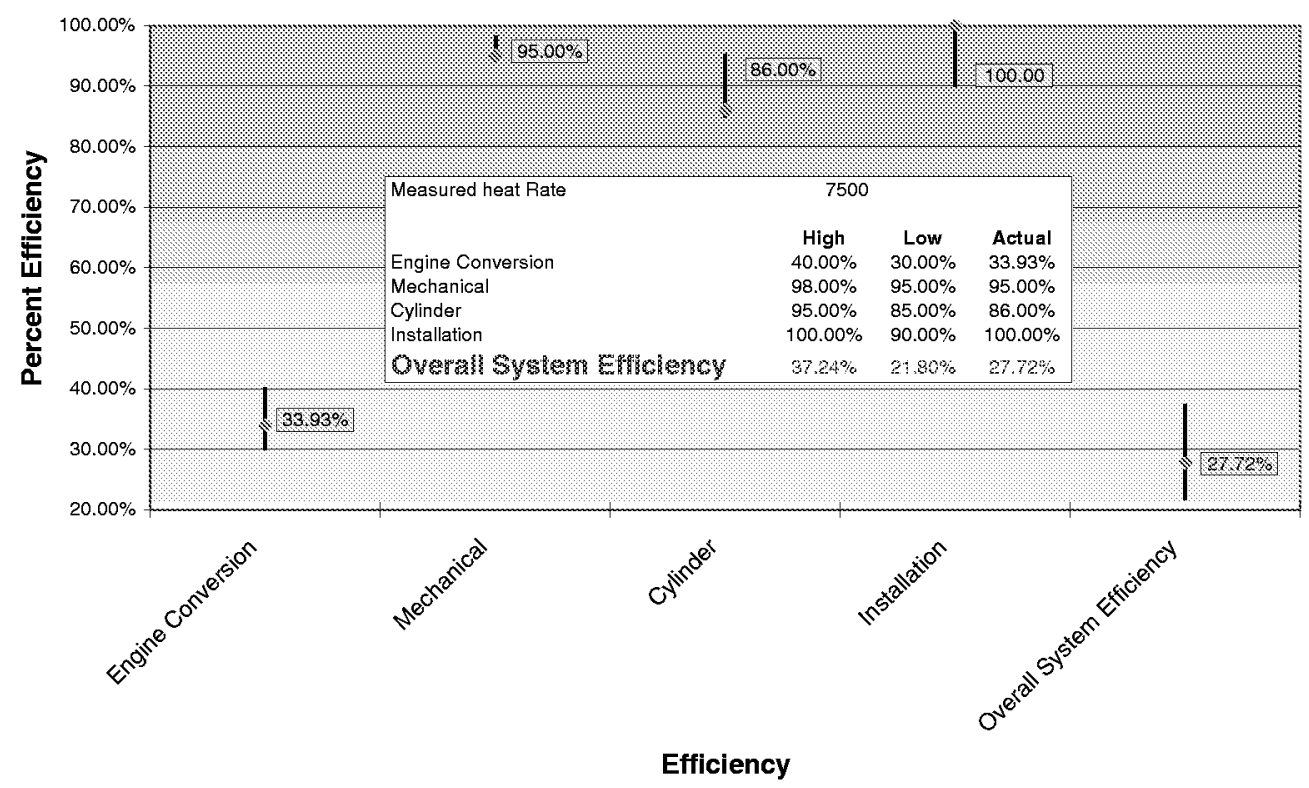

Figure 7-78. System and Component Thermal Efficiency Comparison; Unmodified GMW10

\section{Components of Overall System Efficiency}

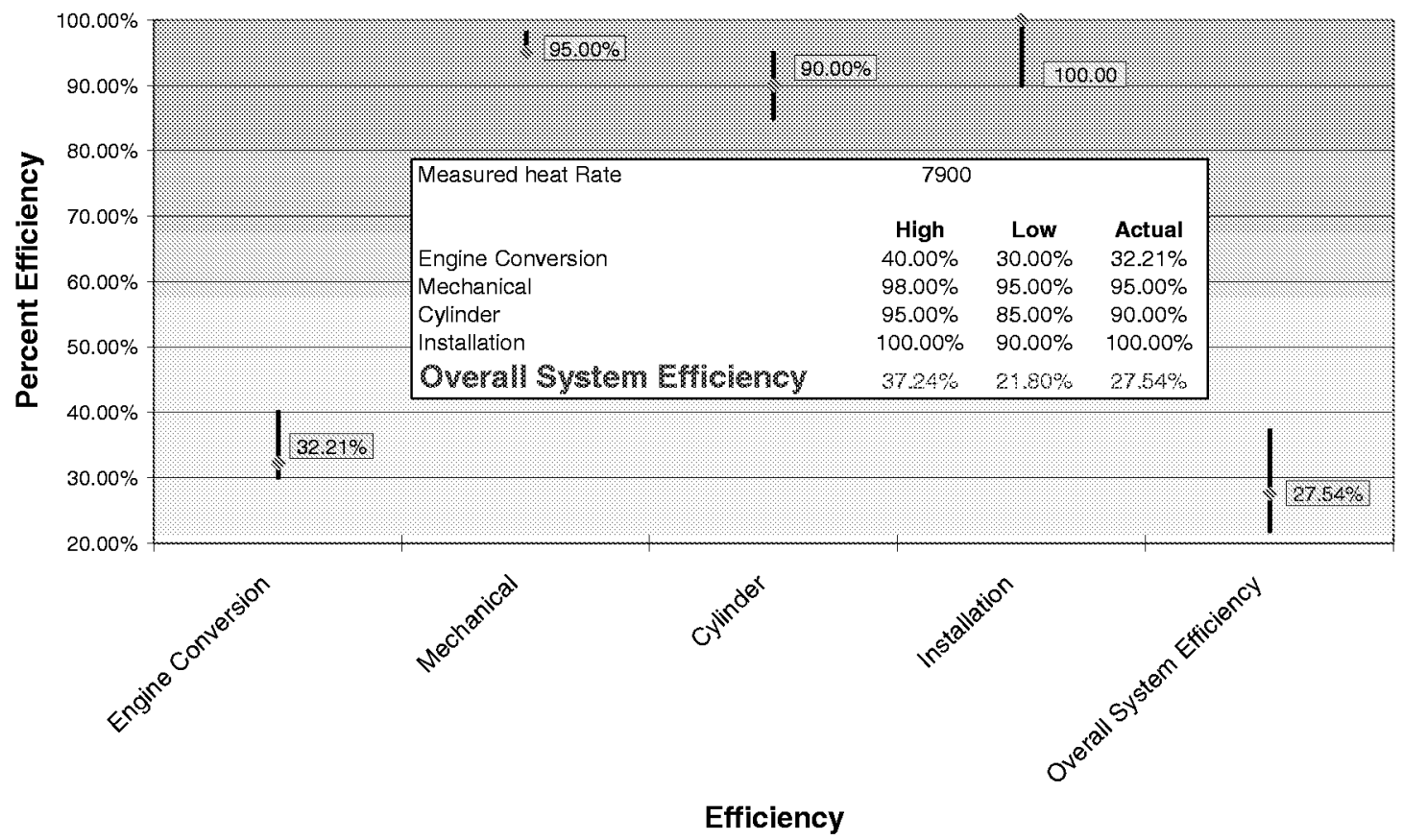

Figure 7-79. System and Component Thermal Efficiency Comparison; HBA-6T with Low-Pressure Fuel 


\subsection{Refinement and Demonstration of Combustion Pressure Ratio BALANCING - KINDER SECOND TEST}

This is the third test at which CPR balancing (Utility Patent applied for) has been performed. All tests so far have been manual, guided by data acquired, and displayed by computer. The method depends on having power cylinder pressure acquired digitally as a function of crank angle, so that the maximum value for each cylinder (peak-firing pressure) can be normalized with reference to the compression pressure for that cylinder to yield combustion pressure ratio. The compression pressure is defined for this purpose as the pressure value at some fixed angle before top dead center for the cylinder.

As implemented in tests so far, the combustion pressure ratio for each cylinder is calculated each revolution and averaged over a finite, specified, number of revolutions. After the averaging process is complete, a bar graph is displayed with averaged CPR for each cylinder side-by-side. A decision is then made to adjust fuel supply down for the cylinder with the highest CPR, and once this change has been made, the averaging process is then repeated. The process is repeated until all cylinders indicate acceptably similar values for CPR.

During the present tests, adjustments were made to the number of cycles for averaging, and 100 cycles was determined to provide a reasonable balance between consistency of data and speed of implementation; previously 50 revolutions had been used as the basis for averaging.

Figure 7-80 shows the CPR for six cylinders averaged in this way at the start of the CPR balancing process and at the end of the process. In this case, as Figure 7-42 has shown, the standard deviation across the cylinders of CPR was reduced from about $10 \%$ to about 2.5\% (a factor of four reduction) in approximately 20 minutes. Heat rate benefits have been discussed, and the data in Figure 7-60, plotting heat rate as a function of load, suggests that as much as 100 BTU/HP-hr. may have been gained by CPR balancing, although completion of the CPR balancing process was followed very shortly by a drop in power of several percent, which increased the heat rate and made the benefits less clearly defined. 


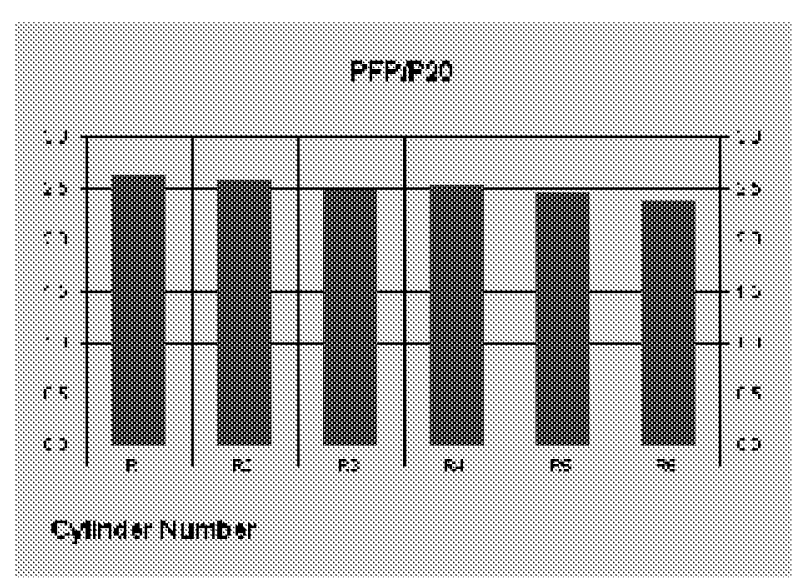

BEFORE

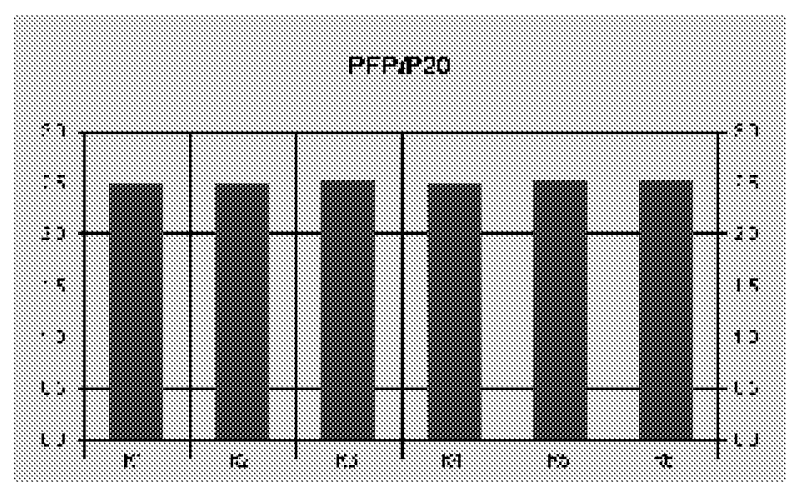

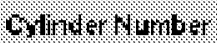

Figure 7-80. Combustion Pressure Ratio “Before and After" CPR Balancing (at Kinder Second Test)

\subsection{Comparison of Station BHP to BHP from Cylinder Pressure - Kinder SECOND TEST}

Figure 7-81 and Figure 7-82 compare brake horsepower taken from the station data to brake horsepower calculated from cylinder pressure for days 1 and 2 .

The station data is inferred from suction and discharge conditions. It comes from an ideal calculation of cylinder power based on suction and discharge pressure and an assumed expansion coefficient for the gas. The ideal calculation is corrected for non-ideal horsepower losses and adjusted from cylinder power to brake power through a mechanical efficiency (understood to be 0.95 ).

The brake horsepower from cylinder pressure comes from integrating incremental work done (pressure $\mathrm{x}$ area $\mathrm{x}$ incremental displacement) around the cycle to give work done per cycle. This work done is multiplied by speed to give cylinder power and adjusted from cylinder power to brake power by a mechanical efficiency (set to 0.95 ). 


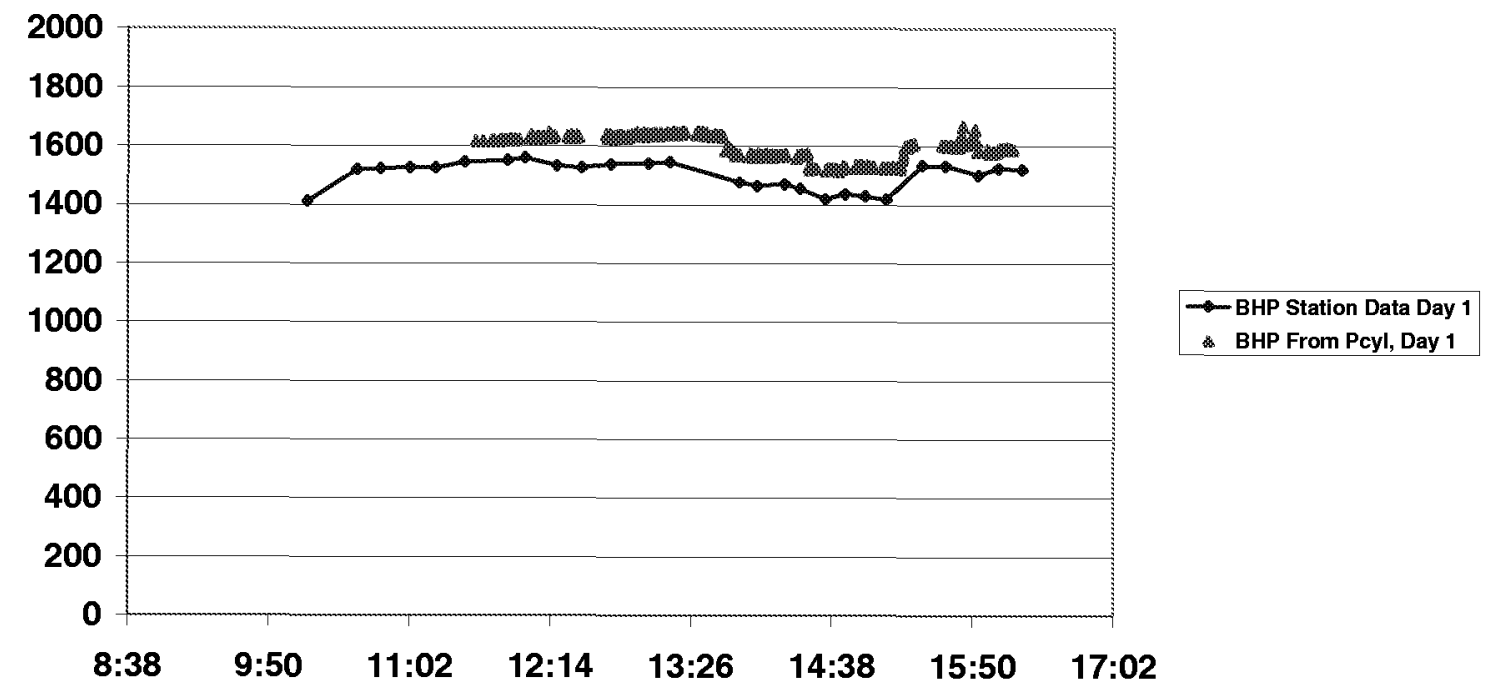

Figure 7-81. Comparison of Station BHP to BHP from Cylinder Pressure (using 0.95 Mechanical Efficiency); Kinder Test 2; Day 1

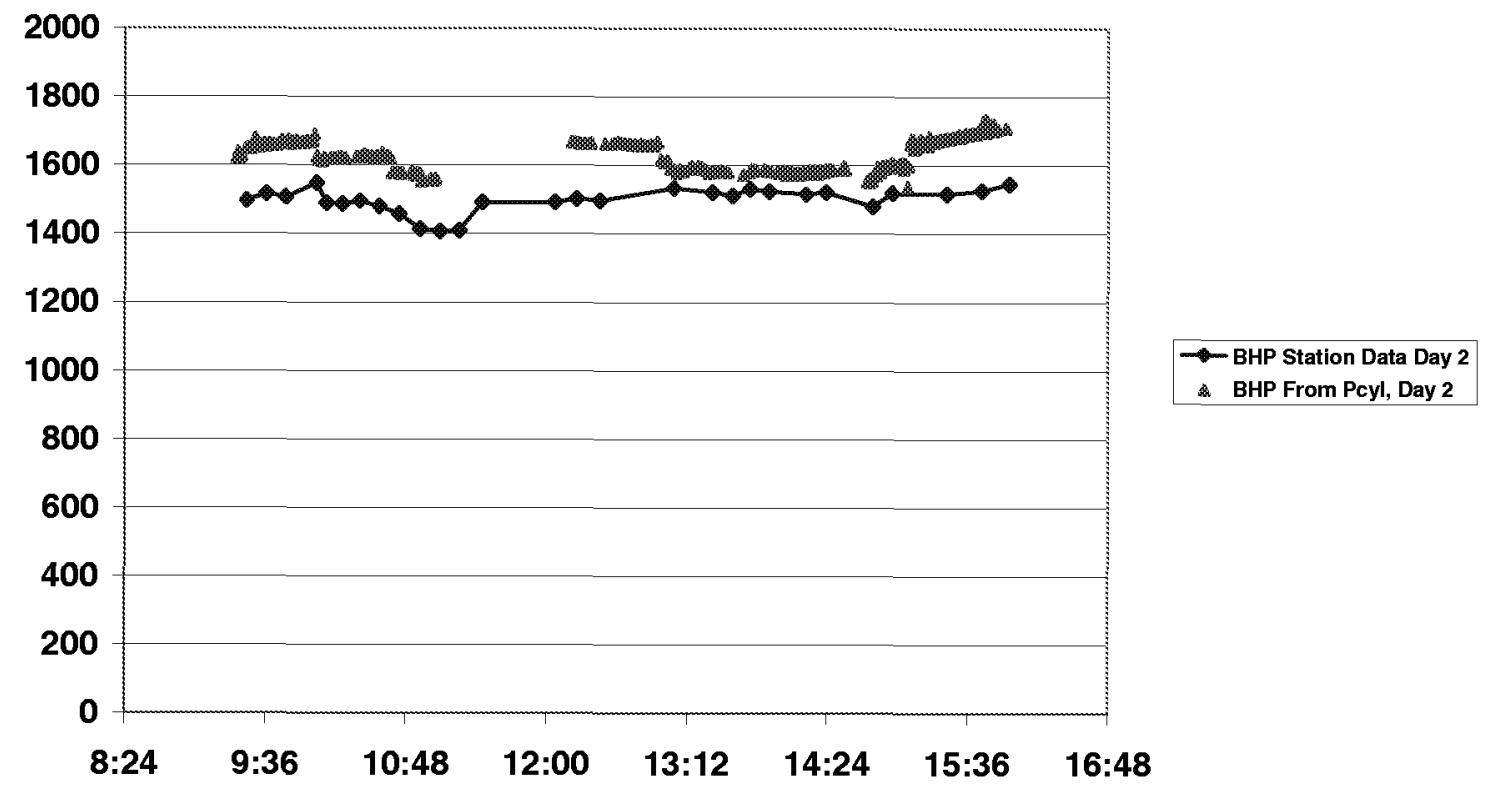

Figure 7-82. Comparison of Station BHP to BHP from Cylinder Pressure (using 0.95 Mechanical Efficiency); Kinder Test 2; Day 2 
The difference between the station data and the horsepower from pressure is apparent from Figure 7-81 and Figure 7-82. In general, the pressure-based power is higher than the station power by 50 to $100 \mathrm{HP}$ ( 3 to $6 \%$ ), and sometimes by more. This implies a risk of overload, but since heat rate reduces with load, it would increase the brake thermal efficiency for the engine relative to what would result from $100 \%$ load based on cylinder pressure. The apparent power difference in this case and the implied system-wide potential for inaccurate power based on inferential methods re-emphasize the need to enhance consistency in the engine load used for operational decisions. The rod load monitor, when deployed, should achieve this. 


\section{CONCLUSIONS}

The following items provide a comprehensive summary and set of conclusions from the project results so far.

1. Instrument Suite: A powerful suite of instruments for testing and characterizing integral engine compressor performance and integrity has been assembled (Section 2.1), with a powerful data acquisition system (Figure 3-1 and Figure 3-2). Associated data reduction, analysis, and display software has been adapted to the needs of this project, and refined to assist definition of key parameters. In addition to providing data for this project, this system will be commercially available for other service and research projects, where comparable information is needed to support programs of the gas industry in diagnostics, system and process development, and problem solving.

2. Cylinder-to-Cylinder Combustion Variability: Because of variations in air and fuel supplied, the trapped fuel to air ratio varies from cylinder to cylinder, resulting in combustion inequality, characterized most obviously by variations in peak-firing pressure across the cylinders (see Figure 4-17).

3. Balancing: Some form of combustion balancing is universally practiced on these engines. Most commonly, equal peak-firing pressures are sought by adjusting fuel to each cylinder. However, analysis has shown that with cylinder-to-cylinder variations in trapped air, equal peak pressures mean unequal trapped air fuel ratio and, hence, cylinder-to-cylinder inequality in combustion (see Figure 4-21).

4. Cycle-to-Cycle Combustion Variability: A dominant and complicating characteristic of the two-stroke engines tested is high cycle-to-cycle variability in combustion events for any cylinder. Average cycle-to-cycle standard deviations in peak-firing pressure of 45, 58, and 65 PSI have been observed on three engines (see Figure 5-17, Figure 6-19, and Figure 7-31). This standard deviation varies between cylinders - comparing Figure 7-32 and Figure 7-40 show a maximum standard deviation of 75 PSI and an average of 60 PSI for the HBA-6T tested April 2004.

5. Standard Deviation Balancing: One alternative to peak-firing pressure balancing is to equalize each cylinder's standard deviation in peak-firing pressure over time. This method derives from the reasonable assumption that the standard deviation over time is a direct function of air fuel ratio (richer combustion - within limits - is more stable). Reducing fuel to low standard deviation cylinders (or increasing it to high standard deviation cylinders) should equalize air fuel ratio. Limited testing of this method indicated it helped control high excursions in crankshaft strain (Figure 4-13). 
6. CPR Balancing: An alternative balancing method has been developed on the project (Figure 4-24). CPR balancing adjusts individual cylinder fuel to equalize Combustion Pressure Ratio (CPR) across all cylinders. Its feasibility has been proven (Figure 5-21, Figure 6-12, and Figure 7-80). CPR is the ratio of peakfiring pressure to compression pressure, calculated for each cylinder. Compression pressure is the pressure at a fixed angle ahead of top dead center for that cylinder. The method's implicit goal, just as with standard deviation balancing, is to equalize air fuel ratio. A utility patent for CPR balancing has been applied for.

7. Practice, Significance, and Benefits of CPR Balancing: As practiced in a computer-assisted manual form on three engines, the quantity CPR is calculated each cycle, then averaged over multiple cycles for all the cylinders. Evaluation has shown that averaging over 100 cycles provides a set of CPR values repeatable enough for balancing decisions. "Tweaking" down the fuel valve on the cylinder with the highest CPR leads to a readjustment and leveling of the CPR distribution. The method is significant because cylinder-to-cylinder variation in compression pressure between 6 and $12 \%$ has consistently been observed on the engines tested (Figure 4-17, Figure 5-12, and Figure 6-23). Standard balancing on peak-firing pressure works against this intrinsic and characteristic variation, while CPR balancing recognizes and works with it.

8. Limitations Imposed by Cycle-to-Cycle Variability: Cycle-to-cycle variability imposes a limit on the benefits to be obtained by any type of combustion balancing. Figure 6-21 shows that while average spread in peak-firing pressure can be cut in half (from 70 to 35 ) by peak-firing pressure balancing, the instantaneous spread only drops by about $10 \%$ (from 175 to 160 ).

9. Cylinder-to-Cylinder Air Imbalance: Significant imbalance in compression pressure is a consistent feature of slow-speed two-stroke engines. The compression pressures are much more consistent over time than combustion pressures; Figure 6-20 and Figure 6-44 show how compression pressures standard deviation over time are smaller than the standard deviations in peak-firing pressure by a factor of ten. They also show identical average values for two successive days. Compression pressure imbalance can contribute to variability in equivalence ratio.

10. Cylinder-to-Cylinder Air Imbalance: Data measured on the project shows that $25 \%$ to $50 \%$ dynamic variability in exhaust and air manifold pressure is typical and by inference is a major contributor to compression pressure imbalance (e.g., Figure 5-8). A separate set of tasks has been defined and is now being executed which will characterize the relationship between manifold dynamics and air imbalance in a 6-cylinder GMVH, and seek manifold designs to optimize dynamic flow characteristics to reduce air imbalance. 
11. Longer Term Variability in Equivalence Ratio Data: Longer term variability in equivalence ratio data has shown how equivalence ratio (fuel to air ratio normalized by Stoichiometric) can vary over time (Figure 5-33) - probably as a result of conditions changing, though random variation and hysteresis may contribute; performance of engines is highly sensitive to equivalence ratio and a need exists for a low-cost means to control equivalence ratio as conditions change. This capability would allow more direct tuning to meet a particular goal; for example: in combustion stability, heat rate, or emissions.

12. Closed-Loop Wastegate Control: The feasibility of a low-cost closed-loop control of wastegate setting, which will maintain an equivalence ratio set point in turbocharged engines, has been demonstrated (Figure 7-67). At this stage, the demonstration has simply shown the feasibility of the control method. Application of the capability to meet a particular operational objective is a planned next step.

13. Influence of Load on Heat Rate: The project has documented the strong dependence of heat rate on load - the HBA-6T recently tested show $0.6 \%$ increase in heat rate for every $1 \%$ reduction in load (Figure 7-58).

14. Need for Accurate Power and Torque Measurement: There is a strong need for convenient, accurate, and reliable measurement of actual brake power delivered to the compressor by the engine. Inferential methods evaluated under this project show variable accuracy, with as much as 10 or more percent discrepancy from indicated power (Figure 7-81). The achievement of high accuracy in inferential methods is possible (Figure 6-54), but requires extensive and costly mapping of each compressor in good condition, and errors can still result when malfunctions such as a valve or ring leak occur.

15. Problems with Inaccurate Torque and Power: The heat rate implications of not knowing torque accurately are clear. Overload can also result.

16. $\quad$ Rod Load Monitor (RLM): The GMRC Rod Load Monitor (RLM) promises to provide a means to measure power and torque directly, helping to optimize heat rate while avoiding overload.

17. $\quad$ Rod Load Monitor (RLM) Functionality: Evolving versions of the GMRC Rod Load Monitor (RLM) have been evaluated under this program and results have guided refinements. A self-powered RLM with digital telemetry has been demonstrated for the first time on a 300-RPM slow-speed integral HBA-6T (Figure 3-16), and the demonstration validated the software used to select magnet array length and clearance between magnets and moving coil, so that selfpowering with the particular engine is achieved above an acceptably low speed. 
18. Rod Load Monitor (RLM) Calibration: There is a need to calibrate the RLM power output. Use of indicated horsepower based on cylinder pressure is a viable approach and, in an initial evaluation of this approach, the resulting power remained consistent with indicated power over a range of speeds and load variations (see Figure 7-66).

19. Rod Load Monitor (RLM) Application: The need also exists to define and demonstrate how the RLM will be used to select load step. Since it determines torque at a different point in the power transmission chain (upstream of frictional losses from rings and rider bands), refinement is needed to the mechanical efficiency used to translate measured power from the RLM into engine brake torque for set point comparison which indicates load step selection.

20. Crankshaft Strain: The crankshaft Strain Data Capture Module (SDCM) has been used with success on all tests so far. It has shown sensitivity to changes in operating conditions and how they influence crankshaft bending strain, including: how standard deviation-based balancing reduced the frequency of high strain excursions during the first HBA-6T test; how timing advance directly increased crankshaft dynamic strain; how reducing speed directly reduced crankshaft dynamic strain; and how high-pressure fuel injection reduced crankshaft strain.

21. Assessing How Operational Changes Influence Heat Rate: In recognition of the high sensitivity of heat rate to load, direct use of heat rate values in comparing operational conditions is subject to uncertainty when even small changes in load occur. However, the use of the heat rate versus load chart, as a reference for evaluating how changes influence heat rate, has shown promise on data from the most recent HBA-6T tested (Figure 7-60).

22. Influence of CPR Balancing on Heat Rate: While not conclusive, tests on an HBA-6T showed a distinct reduction in heat rate after CPR balancing, by about 100 BTU/HP-hr., when compared to the baseline heat rate versus load chart (Figure 7-60).

23. Influence of Timing on Heat Rate: Comparison to the baseline heat rate versus load chart showed distinct heat rate reduction by about $100 \mathrm{BTU} / \mathrm{HP}-\mathrm{hr}$. for the HBA-6T tested when timing was advanced by 2 degrees. Immediate changes in heat rate after timing changes on GMW10 tests also showed that advancing timing reduces heat rate, and that retarding timing increases heat rate by several hundred BTU/HP-hr. (Figure 7-60).

24. High-Pressure Fuel Benefits: Comparison between two different GMW10s, one with high-pressure fuel and turbocharger and one unmodified, showed that the high-pressure fuel allowed much leaner operation (by almost a factor of two); reduced heat rate (by 7\%); and reduced normalized NOx concentration (by 87\%). The modified GMW10 also showed lower crankshaft peak-to-peak strains than the unmodified GMW10, and lower peak-firing pressure (Figure 6-55 and Figure 6-56). The first half of a direct comparison between performance before and after 
modification on the same engine has been completed, but until the second half of this comparison is complete, the data from the first half must be compared against this already converted unit.

25. System Thermal Efficiencies: System thermal efficiencies in the range 26.5 to $30 \%$ have been observed with "as found" timing. A high value of $31 \%$ has been observed with an advance to 11 degree timing on a GMW10 with high-pressure fuel and turbocharger (Figure 5-23). System thermal efficiency provides an effective way to assess a complete compressor package - usable for integral or separable compressor installations. The use of system thermal efficiency showed, for example, that the effect of reduced speed in reducing compressor efficiency may have overwhelmed the benefits of lower heat rate with reduced speed, although assumptions about mechanical efficiency keep some uncertainty in this observation.

26. Compressor Thermal Efficiencies: Compressor thermal efficiencies in the range 84 to $91 \%$ have been observed (Figure 4-24, Figure 5-13, and Figure 6-15); compressor thermal efficiency is an important benchmark for two reasons: first, because increasing thermal efficiency reduces fuel consumption for a given amount of useful compression work; and secondly, it increases capacity because it allows more of the available engine power to provide useful compression work. Pulsations have been observed as a major contributor to increased losses which can result from speed changes.

27. Mechanical Efficiency: Attempts to assess the influence of speed on system thermal efficiency have emphasized the need for enhanced information on compressor mechanical efficiency. They have also shown the need for a method of assessing system thermal efficiency, which does not depend on an assumed mechanical efficiency. In the near-term, the rod load measurement may reveal information about mechanical losses if waveforms for rod force and for piston pressure force are compared as speed and load are varied. Measuring fuel flow, unit gas flow, and temperature rise across the compressor would lead to a system thermal efficiency method which is independent of mechanical efficiency assumptions; and promising options for unit flow measurement exist. These are tracer gas measurement (good for short-term tests) and ultrasonic flow measurement with high frequency data acquisition and analysis, which could be permanently installed. Both methods have been prototyped for this purpose in the past.

28. Cylinder Discharge Temperature as an Indicator of Compressor Cylinder Condition: Many pipeline compressors have temperature measurement on each discharge nozzle. Temperature rise across each cylinder directly indicates the increase in enthalpy. Any losses in the cylinder increase the enthalpy rise above the ideal for the net pressure rise. Project results have confirmed cylinder discharge temperature rise for a particular cylinder is a direct and consistent function of compression ratio (Figure 7-16), and that consistent differences in discharge temperature can be observed between cylinders (Figure 7-14), which 
with well-calibrated instrumentation and appropriate detection logic, can be used to detect a difference in efficiency from compressor cylinder to compressor cylinder. With appropriate statistical analysis, the deviations between a cylinder's temperature rise and its expected value based on ratio provide a basis for assessing the condition of the cylinder.

29. Knock Detection: One observed reason why timing is not advanced as much as it might be to reduce heat rate is the potential for detonation on hot days with advanced timing. If detonation could be detected, it would allow active control to reduce timing immediately when detonation occurs.

30. Knock Detector Evaluation: A knock detector on loan from Metrix has been evaluated on an unmodified GMW10, and on an HBA-6T. The first test showed it could clearly detect audible detonation whenever it occurred. A second test on the HBA-6T showed that when timing was advanced, air manifold pressure reduced, and fuel supply to a cylinder increased; the detonation detector mounted on that cylinder responded with a steady increase in output even though no audible detonation was observed. The highest output from the sensor in this second test was well below that with audible detonation ( 3 volts rather than 5 ), indicating that a threshold could be defined between 3 and 5 volts on which to base timing retard decisions (Figure 7-70 and Figure 7-71).

31. Influence of Time from Cold Start on Power Transmission: The first tests on an HBA-6T and a GMW10 each showed a reduction in the ratio of indicated engine power to indicated compressor power over several hours of testing following start-up (Figure 4-25 and Figure 5-10). Further circumstantial evidence indicates this could be a result of the sump oil heating and its viscosity and shear reducing. The need remains to show a more direct cause and effect relationship between oil temperature and this power transmission efficiency, and this has not yet been accomplished.

32. Frame Vibration: Frame lateral vibration has not shown itself as a sensitive indicator of loading severity. However, it should be used as an indicator of condition of an integral engine compressor's mounting system integrity, and when high can be used to guide regrout decisions.

33. Instantaneous Rotational Velocity: When studied for obvious changes, the IRV data does not provide a direct indication of loading severity. However, detailed processing of IRV data has been shown to reveal characteristics which respond directly to a misfire (Figure 7-74 and Figure 7-75).

34. Future Testing: So far, Cooper and Clark two-strokes have been tested - in addition to completing the before and after test on the converted GMW10. Future tests should spread the base to include a Worthington, and a four-stroke. Further consideration should be given to either adding a newer technology engine to the base, or to adding another widely deployed older engine (e.g., a TLA). To the extent possible, the tests should include: 
- Application of the equivalence ratio control to a selected operational optimum.

- Identification of causes of variability in compressor thermal efficiency.

- Evaluation of calibration of the RLM.

- Development of a control approach for maintaining engine load at $100 \%$.

- Further evaluation of balancing alternatives.

- Testing timing advance with detonation detection.

- Completion of GMW10 testing to evaluate performance and integrity after modification. 


\section{REFERENCES}

[1] Harris, R.E., Edlund, C.E., Smalley, A.J., and Weilbacher, G., (2000) "Dynamic Crank Web Strain Measurements for Reciprocating Compressors," presented at the GMRC Gas Machinery Conference (GMC), Colorado Springs, Colorado.

[2] Wood, C.D. and Kubesh, J.K., (1995) "Evaluation of Emissions Control Technology for Reciprocating Integral Engine-Compressor Units," SwRI Report for Tenneco Gas Environmental and Technology Department.

[3] Smalley, A.J. "Topical Report: Misalignment and Temperature Measurements on a Fully Grouted Reciprocating Compressor," prepared for the Pipeline Research Committee of the American Gas Association, Project PR15-174, SwRI Project 04-7564, May 1985.

[4] Transmission, Book T-2: Compressor Station Operations, GEOP - Gas Engineering and Operating Practices, The American Gas Association Operating Section, Vol. II, A.G.A. Catalog No. XY0185.

[5] Smalley, A.J., Mauney, D.A., and Ash, D.I., (1997) Final Report PR-15-9529, "Compressor Station Maintenance Cost Analysis," prepared for the Compressor Research Supervisory Committee of PRC International, SwRI Project No. 047424.

[6] Harris, R.E. and Beeson, C.M. (1990) "Channel Resonance Correction for Improved Cylinder Performance and Diagnostic Analyses," Proceedings, PCRC Fifth Annual Reciprocating Machinery Conference, Nashville, Tennessee.

[7] Harris, R.E. and Edlund, C.E. (1998) "Performance Measurement of High Speed/High Ratio Reciprocating Compressors," presented at the GMRC Gas Machinery Conference (GMC), Denver, Colorado.

[8] Smalley, A. J., "Compressor Diagnostic Software: Development, Test, and Evaluation," GRI Report No. GRI 95/0448. 


\section{LIST OF ACRONYMS AND ABBREVIATIONS}

$\begin{array}{ll}\text { A/F } & \text { Air/Fuel Ratio } \\ \text { AGA } & \text { American Gas Association } \\ \text { AMP } & \text { Air Manifold Pressure } \\ \text { BEI } & \text { Manufacturer's Trade Name } \\ \text { BHP } & \text { Brake Horsepower } \\ \text { BTDC } & \text { Before Top Dead Center } \\ \text { BTU } & \text { British Thermal Unit } \\ \text { CES } & \text { Cooper Energy Services } \\ \text { COV } & \text { Coefficient of Variance } \\ \text { CPR } & \text { Compression Pressure Ratio } \\ \text { DAS } & \text { Data Acquisition System } \\ \text { DOE } & \text { U.S. Department of Energy } \\ \text { EQ } & \text { Equivalence Ratio } \\ \text { FHP } & \text { Fuel Header Pressure } \\ \text { FIFO } & \text { First In, First Out } \\ \text { GMC } & \text { Gas Machinery Conference } \\ \text { GMRC } & \text { Gas Machinery Research Council } \\ \text { GMVH } & \text { Cooper Engine Model } \\ \text { GMVH-6 } & \text { Cooper Engine Model } \\ \text { GMW10 } & \text { Cooper Engine Model } \\ \text { HBA-6 } & \text { Clark Engine Model } \\ \text { HBA-6T } & \text { Clark Engine Model } \\ \text { HBA8 } & \text { Clark Engine Model } \\ \text { HP } & \text { Horsepower } \\ \text { HPFI }{ }^{\text {TM }} & \text { Enginuity's High Pressure Fuel Injection System } \\ \text { I/P } & \text { Current-to-Pressure Converter } \\ \text { IAC } & \text { Industry Advisory Committee } \\ \text { IMEP } & \text { Indicated Mean Effective Pressure } \\ \text { IRV } & \text { Instantaneous Rotational Velocity } \\ \text { LBSI } & \text { Lean-Burn Spark-Ignited } \\ \text { LHV } & \text { Lower Heating Value } \\ \text { mAmp } & \text { Milliamp } \\ \text { MMSCFD } & \text { Million of Standard Cubic Feet Per Day } \\ \text { MW } & \text { Megawatts } \\ \text { NGK } & \text { Manufacturer's Trade Name } \\ \text { NOx } & \text { Oxides of Nitrogen } \\ \text { O } & \text { Oxygen Molecule } \\ \text { OEM } & \text { Original Equipment Manufacturer } \\ & \end{array}$




\section{LIST OF ACRONYMS AND ABBREVIATIONS (CONT'D)}

$\begin{array}{ll}\text { PCB } & \text { Manufacturer's Trade Name } \\ \text { PFP } & \text { Peak-Firing Pressure } \\ \text { PID } & \text { Proportional-Integral-Differential } \\ \text { PPM } & \text { Parts Per Million } \\ \text { PSI } & \text { Pounds Per Square Inch } \\ \text { PSIA } & \text { Lb./Sq. Inch Absolute } \\ \text { PV } & \text { Pressure-Volume } \\ \text { RLM } & \text { Rod Load Monitor } \\ \text { RPM } & \text { Revolutions Per Minute } \\ \text { SCF } & \text { Standard Cubic Feet } \\ \text { SDCM } & \text { Strain Data Capture Module } \\ \text { Sdev } & \text { Standard Deviation } \\ \text { SwRI }{ }^{\circledR} & \text { Southwest Research Institute } \\ \text { TDC } & \text { Top Dead Center } \\ \text { TGP } & \text { Tennessee Gas Pipeline } \\ \text { UEGO } & \text { Universal Exhaust Gas Oxygen }\end{array}$

